HOHENHEIMER VOLKSWIRTSCHAFTLICHE SCHRIFTEN

Carsten H. Wander

\title{
Logistik und Wettbewerb
}




\section{Carsten H. Wander}

\section{Logistik und Wettbewerb}

In dieser Untersuchung werden mit der Logistik und dem wirtschaftlichen Wettbewerb zwei Themenfelder miteinander verknüpft, welche innerhalb der ökonomischen Theorie bislang isoliert voneinander betrachtet wurden und noch immer werden. Hauptzielsetzung der Arbeit ist es zu zeigen, dass Logistik und wirtschaftlicher Wettbewerb, welche prima facie verschiedene Ausschnitte der Ökonomik beleuchten und voneinander unabhängig $\mathrm{zu}$ sein scheinen, bei näherer Betrachtung dennoch konzeptionelle Parallelen und vielfältige Wirkungsinterdependenzen aufweisen. Diese werden aufgedeckt, systematisiert und bezüglich ihrer Ausgestaltungsform sowie ihrer Wirkungsrichtung konkretisiert.

Carsten H. Wander, geboren 1973 in Leutkirch, studierte Wirtschaftswissenschaften an der Universität Hohenheim, wo er im Anschluss auch promovierte. Während seines Promotionsvorhabens war er dort am Institut für Volkswirtschaftslehre sowie bei einem Logistikunternehmen in Neu-Ulm beschäftigt. 
Logistik und Wettbewerb 


\section{Hohenheimer Volkswirtschaftliche Schriften}

Herausgegeben von

Prof. Dr. Michael Ahlheim, Prof. Dr. Thomas Beißinger, Prof. Dr. Ansgar Belke, Prof. Dr. Rolf Caesar, Prof. Dr. Harald Hagemann, Prof. Dr. Klaus Herdzina, Prof. Dr. Walter Piesch, Prof. Dr. Ingo schmidt, Prof. Dr. Ulrich Schwalbe, Prof. Dr. Peter Spahn, Prof. Dr. Jochen Streb, Prof. Dr. Gerhard Wagenhals,

\section{Band 61}

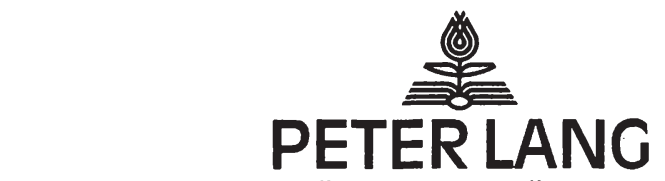

Frankfurt am Main · Berlin · Bern · Bruxelles - New York · Oxford · Wien 


\title{
Carsten H. Wander
}

\author{
Logistik \\ und Wettbewerb \\ Zur Rolle logistischer \\ (Re-)Organisation in einer \\ wettbewerbsbasierten \\ Marktwirtschaft
}

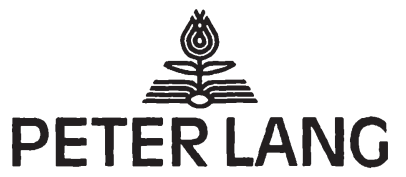

Frankfurt am Main · Berlin - Bern · Bruxelles - New York - Oxford - Wien 
Bibliografische Information der Deutschen Nationalbibliothek Die Deutsche Nationalbibliothek verzeichnet diese Publikation in der Deutschen Nationalbibliografie; detaillierte bibliografische Daten sind im Internet über <http://www.d-nb.de> abrufbar.

Open Access: The online version of this publication is published on www.peterlang.com and www.econstor.eu under the international Creative Commons License CC-BY 4.0. Learn more on how you can use and share this work: http://creativecommons.org/licenses/ by/4.0.

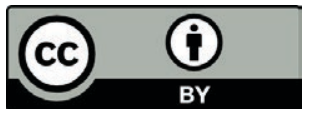

This book is available Open Access thanks to the kind support of ZBW - Leibniz-Informationszentrum Wirtschaft.

Zugl.: Hohenheim, Univ., Diss., 2008

Gedruckt auf alterungsbeständigem, säurefreiem Papier.

\author{
D 100 \\ ISSN 0721-3085 \\ ISBN 978-3-631-59000-3 \\ ISBN 978-3-631-75390-3 (eBook) \\ (c) Peter Lang GmbH \\ Internationaler Verlag der Wissenschaften \\ Frankfurt am Main 2009 \\ Alle Rechte vorbehalten.
}

Das Werk einschließlich aller seiner Teile ist urheberrechtlich geschützt. Jede Verwertung außerhalb der engen Grenzen des

Urheberrechtsgesetzes ist ohne Zustimmung des Verlages unzulässig und strafbar. Das gilt insbesondere für

Vervielfältigungen, Übersetzungen, Mikroverfilmungen und die Einspeicherung und Verarbeitung in elektronischen Systemen.

Printed in Germany 123457

www.peterlang.de 


\section{Vorwort}

Die vorliegende Arbeit wurde von der Fakultät Wirtschafts- und Sozialwissenschaften der Universität Hohenheim im Wintersemester 2008/09 als Dissertation angenommen. Sie entstand während meiner Tätigkeit als wissenschaftlicher Mitarbeiter am Institut für Volkswirtschaftslehre der Universität Hohenheim sowie während meiner Zeit bei der Honold Logistik Gruppe in Neu-Ulm.

Besonderen Dank schulde ich meinem Doktorvater Prof. Dr. Klaus Herdzina. Er gewährte mir nicht nur ein Höchstmaß an wissenschaftlichem Freiraum bei der Erstellung dieser Arbeit und förderte in vielfältiger Weise meinen akademischen „Reifeprozess", sondern war und ist auch in vielerlei anderer Hinsicht Lehrer und Vorbild für mich. Bei Prof. Dr. Harald Hagemann möchte ich mich für die Übernahme des Zweitgutachtens bedanken. Ebenso danke ich Prof. Dr. Thomas Beißinger für seine Mitwirkung am Promotionsverfahren.

Bei meinen ehemaligen Kolleginnen und Kollegen am Institut für Volkswirtschaftslehre möchte ich mich für eine stets angenehme Arbeitsatmosphäre, für anregende Diskussionen und für zahlreiche gemeinsame außeruniversitäre Aktivitäten bedanken, welche den allgegenwärtigen Promotionsstress auf einem erträglichen Level gehalten haben: Frank Baumgärtner, Rainer Berger, Dr. Andreas Findeis, Stephanie Fleischmann, Kai Geisslreither, Dr. Guntram Hepperle, Dr. Jürgen Schechler und Martin Würthner.

Auch außerhalb der Universität gibt es eine Reihe von Personen, welche einen erheblichen Anteil am Gelingen meines Promotionsvorhabens haben. Hier sind zunächst meine Eltern zu nennen, deren emotionale Präsenz und finanzielle Unterstützung mich während meines gesamten akademischen Werdeganges begleitet haben und auf welche ich mich stets verlassen konnte und noch immer verlassen kann. Dafür sei ihnen herzlich gedankt. Meiner lieben Frau Sabine danke ich dafür, dass sie mir den Rücken in jeder erdenklichen Form freigehalten und mich für die gesamte Zeitdauer meines Dissertationsprojektes geduldig ertragen hat. Ihr Anteil am erfolgreichen Abschluss des Promotionsvorhabens kann nicht hoch genug bewertet werden. Meine Tochter Leonie, die in der "heißen Phase“ meines Dissertationsprojektes zur Welt kam, kann natürlich noch gar nicht begreifen, wie viel sie mir allein mit ihrer Anwesenheit geholfen hat. Gerade deshalb werde ich alles dafür tun, mich auch bei ihr angemessen dankbar zu zeigen. 
Schließlich möchte ich meinem ehemaligen Arbeitgeber, Herrn Heiner Matthias Honold, Geschäftsführender Gesellschafter der Honold Logistik Gruppe in Neu-Ulm,

\section{HONOL"}

für sein großes Entgegenkommen sowie für den sehr großzügigen Druckkostenzuschuss danken, mit dem er Fertigstellung und Veröffentlichung dieser Arbeit gefördert hat.

Kornwestheim im Februar 2009

Carsten H. Wander 


\section{Inhaltsverzeichnis}

Abbildungsverzeichnis ..................................................................................... XV

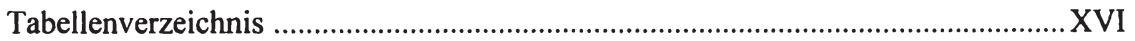

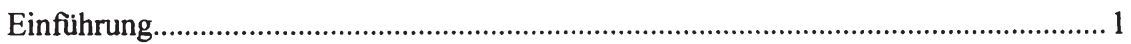

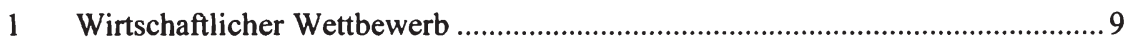

1.1 Grundlegende Bemerkungen ......................................................................

1.1.1 Zum Verhältnis von Wettbewerbstheorie und

Wettbewerbspolitik ............................................................................ 9

1.1.2 Zur Problematik des Wettbewerbsbegriffes...................................... 13

1.1.3 Schlussfolgerungen ......................................................................... 17

1.2 Entwicklungslinien der Wettbewerbstheorie ............................................... 19

1.2.1 Der wettbewerbstheoretische Ansatz in der klassischen

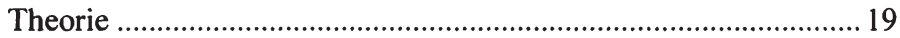

1.2.1.1 Wettbewerbswirkungen und Wettbewerbsprozess .............. 19

1.2.1.2 Wettbewerbsdeterminanten................................................... 23

1.2.2 Der Ansatz der neoklassischen Preistheorie und deren wettbewerbstheoretische Implikationen ............................................26

1.2.2.1 Wettbewerbswirkungen und Wettbewerbsprozess ...............26

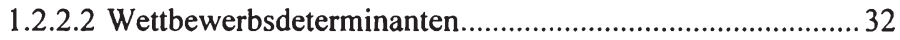

1.2.2.2.1 Grundhypothese .................................................... 32

1.2.2.2.2 Alternative Marktstrukturhypothesen .................... 35

1.2.3 Die Ansätze des Workable Competition und der

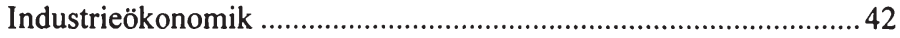

1.2.3.1 Workable Competition .......................................................... 42

1.2.3.1.1 Die Grundlegung des WorkableCompetition-Ansatzes ............................................. 42

1.2.3.1.2 Der konzeptionelle Kern des WorkableCompetition-Ansatzes ............................................. 45

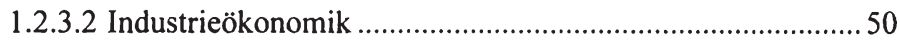

1.2.3.2.1 Die Grundlegung der Industrieökonomik ............. 50

1.2.3.2.2 Der konzeptionelle Kern der

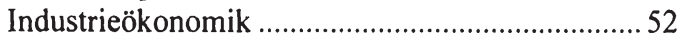

1.2.3.2.3 Wettbewerbsdeterminanten....................................... 61 
1.2.3.3 Gegenüberstellung und Positionierung der beiden Theorien

1.2.4 Die Theorie der Marktentwicklungsphasen und deren wettbewerbstheoretische Implikationen

1.2.4.1 Die Grundlegung der Theorie der

Marktentwicklungsphasen

1.2.4.2 Charakterisierung der Marktphasen nach HEUß ................... 68

1.2.5 Der systemtheoretische Ansatz der neuklassischen

Wettbewerbstheorie .71

1.2.5.1 Wettbewerbswirkungen und Wettbewerbsprozess ................ 72

1.2.5.2 Wettbewerbsdeterminanten.

1.3 Ansatz zu einer systematischen Integration einzelner wettbewerbstheoretischer Ansätze zu einer umfassenderen Wettbewerbskonzeption .77

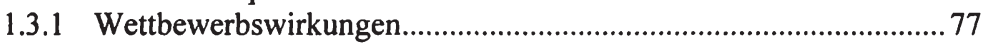

1.3.1.1 Ökonomische Wirkungen des Wettbewerbs .......................... 78

1.3.1.2 Wirtschaftliche Freiheit und Wettbewerb ............................. 81

1.3.1.3 Systematik der Wettbewerbswirkungen ................................ 84

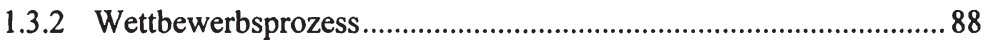

1.3.2.1 Charakterisierung des Wettbewerbsprozesses ....................... 88

1.3.2.2 Wettbewerbliches und nichtwettbewerbliches Marktverhalten ................................................................ 90

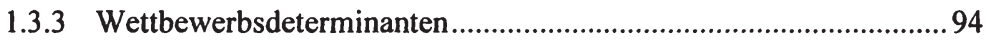

1.3.3.1 Unmittelbare Wettbewerbsdeterminanten ............................. 94

1.3.3.2 Mittelbare Wettbewerbsdeterminanten...............................96

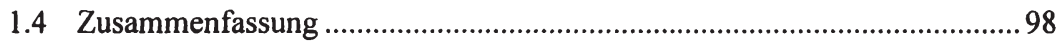

2 Logistische Reorganisation ........................................................................... 101

2.1 Methodische und theoretische Vorbemerkungen ..................................... 101

2.1.1 Der industrieökonomische Ansatz als geeignete

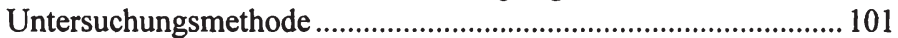

2.1.2 Der Markt als Gegenstand ökonomischer Analysen......................106

2.1.2.1 Der Begriff des Marktes..................................................... 106

2.1.2.2 Markt, Wettbewerb und Kooperation .................................. 109

2.1.3 Transaktionskostentheoretische Grundlagen ................................. 113

2.1.3.1 Koordination, Transaktionen und Transaktionskosten ....... 113

2.1.3.2 Einflussgrößen auf die Transaktionskosten ........................ 117

2.1.3.2.1 Verhaltensannahmen ........................................... 118

2.1.3.2.2 Eigenschaften von Transaktionen ......................... 118 
2.1.3.3 Charakteristika alternativer

Koordinationsmechanismen............................................. 122

2.1.3.3.1 Koordination über den Markt.............................. 122

2.1.3.3.2 Koordination über Hierarchie ............................... 124

2.1.3.3.3 Koordination über Kooperation ........................... 125

2.1.4 Zusammenfassung und Schlussfolgerungen .................................. 130

2.2 Ökonomische Grundlagen der Logistik und der Logistikleistung ............ 134

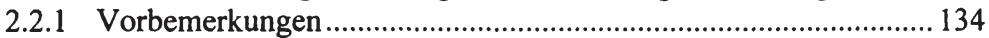

2.2.2 Grundlegung der Logistikkonzeption ............................................ 135

2.2.2.1 Logistiksysteme im Kontext der Gütertransformation ...... 135

2.2.2.2 Begriffsabgrenzungen: Transport, Verkehr, Logistik........ 140

2.2.2.2.1 Transport ............................................................ 140

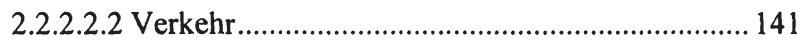

2.2.2.2.3 Logistik .............................................................. 142

2.2.2.2.4 Verknüpfung von Transport, Verkehr und Logistik ........................................................... 151

2.2.2.3 Systeme der Logistik......................................................... 152

2.2.2.3.1 Systemtheoretische Grundlagen der Logistik ........................................................... 152

2.2.2.3.2 Institutionelle Gliederung von

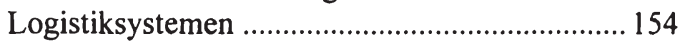

2.2.2.4 Ökonomische Bedeutung der Logistik ............................ 159

2.2.2.4.1 Gesamtwirtschaftliche Bedeutung der Logistik ............................................................. 159

2.2.2.4.2 Einzelwirtschaftliche Bedeutung der Logistik ............................................................. 161

2.2.3 Ökonomische Charakteristika der Logistikleistung ...................... 165

2.2.3.1 Wesen und Umfang der Logistikleistung .......................... 165

2.2.3.1.1 Der Dienstleistungscharakter der

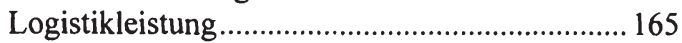

2.2.3.1.2 Strukturierung von Logistikleistungen ............... 167

2.2.3.2 Der abgeleitete Charakter der Nachfrage nach

Logistikleistungen ............................................................. 171

2.2.3.3 Besonderheiten bei der Produktion ausgewählter

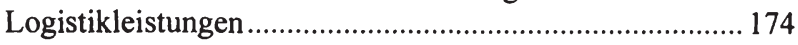

2.2.3.3.1 Transportleistung als organisatorisches

Kuppelprodukt ................................................... 174

2.2.3.3.2 Differenzierte Produktionsverfahren ................... 176

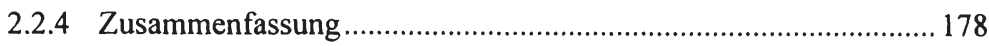


2.3 Zentrale Rahmenbedingungen des Logistikmarktes .................................. 181

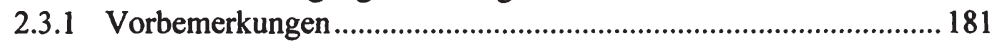

2.3.2 Verkehrspolitik.......................................................................... 181

2.3.2.1 Begründungen für verkehrspolitischen

Handlungsbedarf ................................................................. 181

2.3.2.1.1 Normativ- theoretischer Ansatz .......................... 182

2.3.2.1.2 Positiv-theoretischer Ansatz ............................. 184

2.3.2.2 Erscheinungsformen, Verlauf und Wirkungen verkehrspolitischer Marktintervention auf den deutschen Verkehrsmärkten............................................. 185

2.3.2.2.1 Deutsche Verkehrspolitik bis zum Zweiten Weltkrieg............................................................. 185

2.3.2.2.2 Deutsche Verkehrspolitik in der Zeit nach dem Zweiten Weltkrieg bis in die 1960er Jahre .................................................................... 188

2.3.2.2.3 Wirkungen der Verkehrsmarktregulierung ......... 190

2.3.2.3 Reform- und Deregulierungsprozesse in der deutschen Verkehrspolitik .................................................... 193

2.3.2.4 Grundzüge der europäischen Verkehrspolitik ................... 196

2.3.2.4.1 Verkehrspolitische Regelungen im EWGVertrag................................................................. 196

2.3.2.4.2 Das Untätigkeitsurteil von 1985 ......................... 197

2.3.2.4.3 Liberalisierungsprozesse in der europäischen Verkehrspolitik

2.3.2.4.4 Auswirkungen der europäischen Verkehrspolitik auf die deutsche Verkehrspolitik...................................................... 199

2.3.2.5 Wirkungen der Deregulierung .........................................201

2.3.3 Ökonomische Rahmenbedingungen .............................................203

2.3.3.1 Netzwerkökonomik ............................................................ 203

2.3.3.1.1 Zu Begriff und Charakteristika der Netzwerkökonomik .............................................203

2.3.3.1.2 Business-to-business-Netzwerke ....................... 212

2.3.3.1.3 Business-to-consumer-Netzwerke .......................2 215

2.3.3.1.4 Netzwerkökonomik und Logistik bzw. Logistikleistung..................................................216

2.3.3.2 Gesamtwirtschaftlicher Strukturwandel ............................. 230

2.3.3.2.1 $\mathrm{Zu}$ den Begriffen der Struktur und des Strukturwandels 230 
2.3.3.2.2 Logistikrelevante Arten des

Strukturwandels .232

2.3.3.2.3 Ausprägung und Entwicklung

logistikrelevanter Strukturen...............................2235

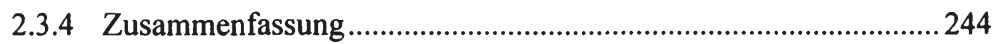

2.4 Angebot und Nachfrage nach Logistikleistungen ...................................251

2.4.1 Vorbemerkungen..........................................................................251

2.4.2 Der relevante Markt für Logistikleistungen ...................................251

2.4.2.1 Abgrenzung des sachlich relevanten Marktes .................... 252

2.4.2.2 Abgrenzung des räumlich relevanten Marktes ................... 257

2.4.3 Das Logistik-Marktvolumen ......................................................... 267

2.4.3.1 Operationalisierung des Logistikbegriffes zur

Bestimmung des Marktvolumens ...................................... 267

2.4.3.2 Ermittlung und Aufteilung des Logistik-

Marktvolumens nach KLAUS und MÜLLER-

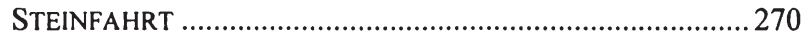

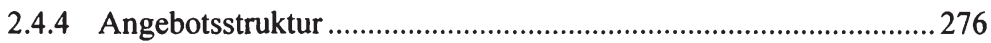

2.4.4.1 Begriff und Wettbewerbswirkungen der

ökonomischen Konzentration .............................................278

2.4.4.2 Das Ausmaß der Anbieterkonzentration im Gesamt-

Logistikmarkt und in den Logistikteilmärkten ................... 282

2.4.4.2.1 Horizontale Konzentration .................................2282

2.4.4.2.2 Vertikale und diagonale Konzentration ............... 289

2.4.5 Typen von Marktakteuren und deren Marktstrategien.................... 293

2.4.5.1 Basisformen von Marktakteuren......................................... 295

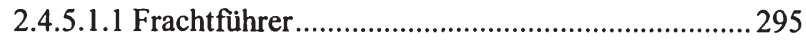

2.4.5.1.2 Lager-, Umschlags- und

Verpackungsunternehmen...................................296

2.4.5.1.3 Speditionen und Vermittler ................................... 297

2.4.5.2 Mischformen von Marktakteuren ...................................... 301

2.4.5.2.1 Kurier-, Express- und Paketdienstleister.............. 302

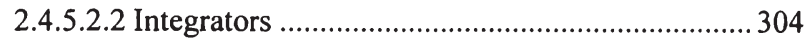

2.4.5.2.3 Kontraktlogistikdienstleister ................................. 305

2.4.5.2.4 Third-Party-Logistics-Provider und Fourth-

Party-Logistics-Provider ........................................305

2.4.5.3 Systematisierung von

Logistikdienstleistungsunternehmen .................................. 308

2.4.5.4 Strategische Stoßrichtungen und Trends .......................... 310

2.4.5.4.1 Prinzipielle Überlegungen.................................. 310 
2.4.5.4.2 Standardisierung und Automatisierung von netzwerkbasierten

Logistikleistungskomponenten .............................316

2.4.5.4.3 Individualisierung des Leistungsangebotes .........325

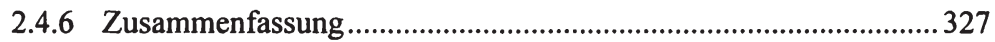

2.5 Koordination von Angebot und Nachfrage nach Logistikleistungen .........333

2.5.1 Vorbemerkungen ................................................................................. 333

2.5.2 Eigenerstellung oder Fremdbezug von Logistikleistungen als Grundfragestellung.............................................................................. 333

2.5.3 Ausprägungsformen institutioneller Koordination im

Logistikmarkt

2.5.3.1 Zur Systematisierung der Darstellung

2.5.3.2 „Normale“ Geschäftsbeziehungen: Elemente reinmarktlicher Koordination im Logistikmarkt.

2.5.3.3 Kooperative Arrangements: Elemente hybrider Koordination im Logistikmarkt

2.5.3.3.1 Beziehungsebenen und

Beziehungsrichtungen von Kooperationen

2.5.3.3.2 Horizontale kooperative Arrangements im Logistikmarkt, dargestellt am Beispiel der System-Kooperationen im nationalen allgemeinen Stückgutmarkt.

2.5.3.3.3 Vertikale kooperative Arrangements im Logistikmarkt, dargestellt am Beispiel des Konzeptes des Supply-Chain-Managements .......366

2.5.3.4 Konzentrative Arrangements: Elemente hierarchischer Koordination im Logistikmarkt.

2.5.3.4.1 Ausprägungsformen und Beziehungsrichtungen unternehmerischer Konzentrationsstrategien

2.5.3.4.2 Motive für die Bildung konzentrativer Arrangements im Logistikmarkt 379

2.5.3.4.3 Konzentrative Arrangements im Logistikmarkt, dargestellt am Beispiel der akquisitionsgetriebenen Expansionsstrategien von Konzernlogistikunternehmen 
3 Berührungspunkte zwischen den Konzeptionen des Wettbewerbs und der Logistik

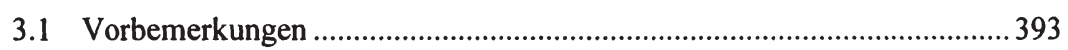

3.2 Ausgangspunkt: Zusammenfassende Standortbestimmung der

Konzeptionen des Wettbewerbs und der Logistik 395

3.2.1 Der Wettbewerb als Ordnungsprinzip innerhalb eines marktwirtschaftlich organisierten Wirtschaftssystems ...................395

3.2.2 Logistik als Koordinationsprinzip im Systemverbund der gesamtwirtschaftlichen Gütertransformation

3.3 Integration der Logistikkonzeption in die Wettbewerbskonzeption 403

3.3.1 Logistische Reorganisation und die Wettbewerbsdeterminanten 403

3.3.1.1 Logistische Reorganisation und die mittelbaren

Wettbewerbsdeterminanten 403

3.3.1.1.1 Logistische Reorganisation und interne Unternehmensstruktur 403

3.3.1.1.2 Logistische Reorganisation und die gesamtwirtschaftliche Produktivitätsstruktur

3.3.1.1.3 Logistische Reorganisation und Marktwachstum 409

3.3.1.2 Logistische Reorganisation und die unmittelbaren

Wettbewerbsdeterminanten.

3.3.2 Logistische Reorganisation und Marktverhalten

3.3.2.1 Logistische Reorganisation und wettbewerbliches

(kreatives/adaptives) Marktverhalten

3.3.2.2 Logistische Reorganisation und kollektives

Marktverhalten

3.3.2.2.1 Zur Kompatibilität von logistikbezogenen kooperativen Beziehungsgefügen und wettbewerblichem Marktverhalten

3.3.2.2.2 Wirkungspotenziale logistikbezogener kooperativer Beziehungsgefüge

3.3.3 Logistische Reorganisation und Wettbewerbswirkungen 422

3.3.3.1 Logistische Reorganisation und die ökonomischen

Wettbewerbsfunktionen

3.3.3.1.1 Logistische Reorganisation und die Anpassungs- bzw. Allokationsfunktion des Wettbewerbs. 
3.3.3.1.2 Logistische Reorganisation und die Entdeckungs- bzw. Fortschrittsfunktion des Wettbewerbs.

3.3.3.1.3 Logistische Reorganisation und die

Verteilungsfunktion des Wettbewerbs....

3.3.3.2 Logistische Reorganisation und die Freiheitsfunktion des Wettbewerbs

3.3.3.2.1 Freiheitsfunktion des Wettbewerbs, Beschränkungen des Handlungsspielraumes und Wettbewerbsbeschränkungen

3.3.3.2.2 Logistische Reorganisation und Beschränkungen der Handlungsspielräume

3.4 Zusammenfassung der wesentlichen Ergebnisse

Schlussbetrachtungen 459

Literaturverzeichnis 461 


\section{Abbildungsverzeichnis}

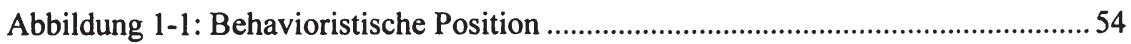

Abbildung 1-2: Strukturalistische Position .................................................................5

Abbildung 1-3: Paradigma der zirkularen Verknüpfung ............................................5

Abbildung 2-1: Integrationsbedarf der Logistikforschung ....................................... 102

Abbildung 2-2: Alternative Koordinationsmechanismen ........................................... 117

Abbildung 2-3: Einflussgrößen auf die Transaktionskosten....................................... 121

Abbildung 2-4: Auswirkung der Spezifität auf die Wahl des geeigneten

Koordinationsmechanismus......................................................... 129

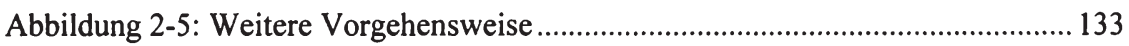

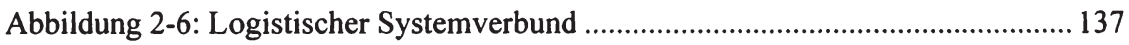

Abbildung 2-7: Bestimmungsfaktoren der Logistik .................................................. 139

Abbildung 2-8: Tatsächlicher und gewünschter Entwicklungsstand der

Logistik in deutschen Unternehmen .................................................. 146

Abbildung 2-9: Logische Verknüpfung der Problembereiche

Transport/Verkehr/Logistik ...........................................................151

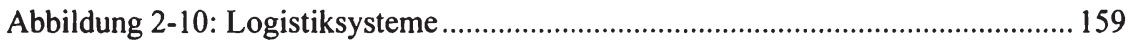

Abbildung 2-11: Funktionen von Logistikunternehmen......................................... 170

Abbildung 2-12: Organisatorisches Kuppelprodukt bei der Produktion von

Transportleistungen ......................................................................... 175

Abbildung 2-13: Mögliche Netzwerkbeziehungen zwischen Stakeholdern im

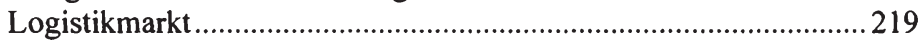

Abbildung 2-14: Stilisierte Darstellung von Launhardtschen Trichtern ..................... 262

Abbildung 2-15: Märkte ohne Überlappung mit unversorgten Gebieten .................... 263

Abbildung 2-16: Märkte mit Überlappung ohne unversorgte Gebiete ........................ 264

Abbildung 2-17: Schematische Darstellung der einzelnen Logistik(teil)märkte........ 265

Abbildung 2-18: Systematisierung von Logistikunternehmen .................................... 310

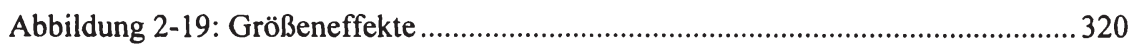

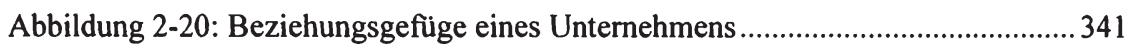

Abbildung 2-21: Richtungen kooperativer interorganisatorischer Beziehungen ........ 357

Abbildung 2-22: Logik von Motiven für konzentrative Arrangements im

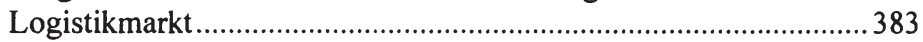

Abbildung 3-1: Optimierungspotenzial metalogistischer Systeme ............................ 426

Abbildung 3-2: Beschränkungen des Handlungsspielraumes und Wettbewerbsbeschränkungen ..... 


\section{XVI}

\section{Tabellenverzeichnis}

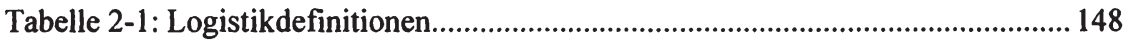

Tabelle 2-2: Vergleich der nationalen Bruttowertschöpfung in jeweiligen

Preisen nach Wirtschaftszweigen in den Jahren 1999-2004 ...........236

Tabelle 2-3: Güterverkehrsaufkommen der Binnenverkehrsträger in 1000t nach Güterabteilungen im Jahr 2006 .............................................2239

Tabelle 2-4: Das deutsche Logistik-Marktvolumen in den Jahren 1996 - 2002 ........ 271

Tabelle 2-5: Das deutsche Logistik-Marktvolumen nach Marktsegmenten in den Jahren 2002 und 2004

Tabelle 2-6: Horizontale Anbieterkonzentration im Gesamt-Logistikmarkt in den Jahren 1998, 2002 und 2004

Tabelle 2-7: Horizontale Anbieterkonzentration ( $\mathrm{CR}_{10}$-Wert) getrennt nach Marktsegmenten in den Jahren 2002 und 2004

Tabelle 2-8: Betriebsgrößen nach Zahl der Beschäftigten im Jahr 2000..................... 287

Tabelle 2-9: Die „TOP 20“ des Gesamt-Logistikmarktes und deren

Teilmarktaktivitäten im Jahr 2004 292

Tabelle 2-10: Akquisitionstätigkeit der Deutsche Post World Net in den Jahren 1999 - 2007 386

Tabelle 3-1: Abgrenzung von Marktwirtschaft und Zentralplanwirtschaft 397 


\section{Einführung}

Untersuchungsgegenstand der folgenden Abhandlung sind mit der logistischen Reorganisation wirtschaftlicher Aktivität und dem wirtschaftlichen Wettbewerb zwei ökonomische Prozessphänomene, welche innerhalb der ökonomischen Theorie bislang isoliert voneinander betrachtet wurden und noch immer werden:

Bei der Logistik handelt es sich um eine Erscheinung, welche sich heute als ganzheitliches, prozess- und kundenorientiertes betriebswirtschaftliches Managementkonzept und Führungsinstrument versteht ${ }^{1}$, welches der Optimierung des unternehmensinternen und unternehmensübergreifenden Material- und Warenflusses dient ${ }^{2}$. Die ausdrücklich unternehmensübergreifende Ausrichtung des in der logistischen Organisation verankerten Optimierungsansatzes impliziert dabei, dass sich Nachfrager und Anbieter von logistischen Leistungen aktiv und mit besonderer Aufmerksamkeit mit den Veränderungen ihrer logistischen Unternehmensumwelt auseinanderzusetzen haben und - darauf aufbauend - dass ihr logistisches Nachfrage- und Angebotsverhalten eng an die jeweils vorherrschenden Bedingungen gekoppelt ist, welche von dieser logistischen Unternehmensumwelt geschaffen werden. Die Entwicklungsdynamik dieser Bedingungen sowie die dadurch erforderlichen Maßnahmen der Unternehmen zur (Neu-)Ausrichtung ihrer Logistiksysteme begründen den Prozess der logistischen Reorganisation. ${ }^{3}$ Dieser vollzieht sich mit großer Beständigkeit und Macht, weil kaum eine andere für die Unternehmen relevante Umwelt durch Veränderungen von ähnlicher Tragweite gekennzeichnet ist wie die logistische ${ }^{4}$. Der Prozess der logistischen Reorganisation umfasst die Gesamtheit der Aktivitäten der Unternehmen, welche zur aktiven Gestaltung und zur Anpassung von Logistiksystemen unter Berücksichtigung der Möglichkeiten und Grenzen des jeweiligen logistischen Bedingungsrahmens erforderlich sind. Die Vorsilbe „Re-“ im Wort Reorganisation soll dabei auf die Dynamik und Wandelbarkeit der ,güterwirtschaftlichen UnternehmenUmwelt-Beziehungen "s verweisen, deren inhaltliche Ausgestaltung und institutionelle Verankerung den zentralen Gegenstandsbereich der Logistik darstellt. Der Wettbewerb hingegen wird als systembegründendes Steuerungsprinzip eines marktwirtschaftlichen Systems ${ }^{6}$ bzw. als jenes Ordnungsprinzip, welchem im volkswirtschaftlichen Ord-

\footnotetext{
Vgl. Baumgarten (2001), S. 9.

Vgl. Stabenau (2000), S. 127.

Vgl. ähnlich Drechsler (1988), S. 35.

Vgl. Ihde (2001), S. 242.

Ihde (2001), S. 242.

Vgl. Hoppmann (1972), S. 9.
} 
nungssystem „Marktwirtschaft“ die Steuerung und Kontrolle der mikroökonomischen Prozesse übertragen worden ist ${ }^{7}$, begriffen.

Die beiden Phänomene scheinen somit auf den ersten Blick grundverschiedene Problembereiche zu behandeln und Fragestellungen abzudecken, welche dementsprechend in völlig unterschiedlichen Teilbereichen und zudem auf verschiedenen Betrachtungsebenen innerhalb des Gesamtgebäudes der Wirtschaftswissenschaften verortet werden:

- Die Logistikwissenschaft beschäftigt sich mit Fragestellungen hinsichtlich der Analyse der, sowie Entscheidungsfindung zur Gestaltung und Koordination von Güter- und Informationsströmen in und zwischen Unternehmungen. Sie stellt insofern eine Querschnittsfunktion der Unternehmung dar und ist somit, zumindest im Grundsatz, der Betriebswirtschaftlehre zuzuordnen. ${ }^{8}$

- Die Wettbewerbstheorie hingegen beschäftigt sich mit Fragestellungen hinsichtlich der Analyse des Wettbewerbsprozesses, dessen Determinanten und Wirkungen innerhalb eines marktwirtschaftlichen Systems. Sie ist somit der Volkswirtschaftlehre zuzuordnen.

Die vorliegende Arbeit nun befasst sich mit der Rolle der logistischen Reorganisation wirtschaftlicher Aktivität innerhalb eines wettbewerbsbasierten, marktwirtschaftlichen Systems. Gegenstand und Hauptziel der Untersuchung ist es zu zeigen, dass die beiden ökonomischen Phänomene, welche prima facie verschiedene Ausschnitte der Ökonomik beleuchten und voneinander unabhängig zu sein scheinen, bei näherer Betrachtung dennoch konzeptionelle Parallelen und vielfältige Wirkungsinterdependenzen aufweisen. Einen frühen Anhaltspunkt für die Reflexion derartiger konzeptioneller Parallelen zwischen Wettbewerb und Logistik lieferte möglicherweise bereits der ordo-liberale Nationalökonom Walter EUCKEN, welcher jenes Wirtschaftssystem,

8 Teilaspekte der Logistik werden jedoch durchaus auch in anderen Fachdisziplinen als der Betriebswirtschaftslehre untersucht. Vornehmlich ordnungs- und regulierungsökonomische Fragestellungen des logistischen Teilbereichs des Verkehrs sowie der Verkehrsinfrastruktur sind bspw. Gegenstand der volkswirtschaftlichen Analyse im Rahmen der Verkehrswissenschaften und der Verkehrspolitik. Technische Fragestellungen hinsichtlich der Konzipierung, Gestaltung, Anwendung und Nutzung von Verkehrsinfrastrukturen sowie technische Fragestellungen der Verkehrstelematik oder logistischer Verwaltungs- bzw. Durchführungssysteme wiederum werden im Rahmen der Informatik und Wirtschaftsinformatik behandelt. 
welches üblicherweise unter „Marktwirtschaft“ firmiert, zunächst mit dem Begriff der „Verkehrswirtschaft“ beschrieben hat. ${ }^{9}$ Zwar füllte er den Gedanken, wettbewerbliche, auf dezentralen Planungskompetenzen der einzelnen Wirtschaftsakteure fußende Marktkoordination aus einer verkehrs- geschweige denn logistikbasierten Perspektive heraus zu erklären, inhaltlich leider nicht weiter aus. Dennoch liegt der von EUCKEN gewählten terminologischen Etikettierung offensichtlich die Auffassung zugrunde, dass die verkehrliche Perspektive einen zweckdienlichen Blickwinkel darstellt, ein wettbewerbsbasiertes marktwirtschaftliches System adäquat zu charakterisieren. Die EUCKENsche Sprachregelung ist damit sicherlich ein - wenngleich lediglich terminologisches - Indiz, welches die These des Vorliegens von Wirkungsinterdependenzen zwischen der Wettbewerbs- und der Logistikkonzeption stützt. Diese Wirkungsinterdependenzen sollen im Rahmen der vorliegenden Arbeit aufgespürt, analysiert und systematisch als Ursache-Wirkungs-Zusammenhänge dargestellt werden, was insofern auch als ein Beitrag dazu gedeutet werden kann, den „Blick für das Zusammenspiel der ökonomischen Kräfte ${ }^{\text {“10 }}$ zu schärfen. Denn gerade der Aufdeckung und Analyse von Ursache-Wirkungs-Zusammenhängen zwischen ökonomischen Variablen kommt in den Wirtschaftswissenschaften eine grundlegende Bedeutung zu: Wissen über Ursache-Wirkungs-Zusammenhänge versetzt den Ökonomen in die Lage, reales Wirtschaftsgeschehen zu erklären und bildet damit die notwendige Voraussetzung, dessen mögliche Entwicklung zu prognostizieren und die Entscheidungsträger hinsichtlich der Gestaltung des Wirtschaftsgeschehens angemessen zu beraten. ${ }^{11}$

Zentrales Anliegen ist es in diesem Zusammenhang insbesondere auch, die gesamtwirtschaftliche Dimension des Prozesses der logistischen Reorganisation herauszuarbeiten und hervorzuheben. Diese gesamtwirtschaftliche Dimension sei an dieser Stelle - in Vorgriff auf eine spätere, genauere Darstellung - noch etwas unscharf als Ausdruck der Tatsache umrissen, dass der Prozess der logistischen Reorganisation, welcher sich auf Unternehmensebene zunächst zwar auf der Grundlage einzelwirtschaftlicher (betriebswirtschaftlicher) Überlegungen zur Optimierung von Material-, Güter- und Informationsströmen und zur Neugestaltung von Wertschöpfungsketten vollzieht, zumindest perspektivisch auch im gesamtwirtschaftlichen Kontext dazu beiträgt, Raum und Zeit unter zunehmend komplexen Umfeldbedingungen ökonomisch zu beherrschen. ${ }^{12}$ Damit ist die zentrale ökonomische Fragestellung nach

\footnotetext{
Vgl. Eucken (1959).

Herdzina (1981), S. 17.

Vgl. Baßeler, Heinrich, Utecht (2006), S. 3.

Vgl. Hesse (1998), S. 125.
} 
Bestimmungsgründen und Ablaufmechanismen der ökonomischen Leistungskoordination angesprochen, welche im Rahmen der Wettbewerbstheorie (auf gesamtwirtschaftlicher Ebene) und auch in der Logistik (unmittelbar in disaggregierter Form auf einzelwirtschaftlicher und mittelbar auf gesamtwirtschaftlicher Ebene) zum Forschungsgegenstand gemacht wird und welche somit offensichtlich die beiden Konzepte der Logistik und des Wettbewerbs miteinander zu verbinden scheint. Welche koordinierende Funktion der Logistik dabei im Kontext des gesamtwirtschaftlichen Gütertransformationsprozesses zukommt, wird an entsprechender Stelle vertieft dargestellt. An dieser Stelle mag es genügen darauf hinzuweisen, dass es der Verweis auf die gesamtwirtschaftliche Dimension des Prozesses der logistischen Reorganisation gestattet, Logistik und Wettbewerb - wenngleich originär auf unterschiedlichen Betrachtungsebenen ökonomischer Analyse beheimatet - dennoch „auf gleicher Augenhöhe" vergleichend zu untersuchen.

Um Abhängigkeiten zwischen ökonomischen Phänomenen ergründen zu können, ist es zunächst notwendig, diese Phänomene in geeigneter Art und Weise dergestalt greifbzw. handhabbar zu machen, dass sie einer vergleichenden Analyse zugänglich sind. Dies gilt insbesondere dann, wenn es sich bei den in Rede stehenden Phänomenen - wie in diesem Fall zutreffend - um komplexe Konstrukte handelt, über deren fundamentale Wesensmerkmale sowie bezüglich der daraus abzuleitenden Schlussfolgerungen und Konsequenzen innerhalb der jeweiligen Forschungsgemeinde zudem bislang kein abschließender Konsens gefunden werden konnte. ${ }^{13}$

Zum Zwecke der Operationalisierung der beiden Phänomene ist es vielleicht zunächst hilfreich, sich zu vergegenwärtigen, dass die ökonomische Realität durch die permanente Veränderung von Bedingungskonstellationen und durch Entwicklungsdynamik gekennzeichnet ist. ${ }^{14}$ Die Untersuchung dieser Veränderungen oder Entwicklungen im Zeitablauf ist Aufgabenbereich der Prozessanalyse. ${ }^{15} \mathrm{Da}$ es sich auch bei den beiden hier in Rede stehenden ökonomischen Phänomenen um prozessuale Phänomene handelt, welche sich durch kontinuierlichen Wandel und fortwährende Entwicklungsvorgänge auszeichnen, erscheint die Prozessanalyse hier als dienliches Analyseinstrument. Die Prozesstheorie nun ist das wissenschaftstheoretische Fundament der Prozessanalyse. Sie hat zur Aufgabe, mögliche Ursache-Wirkungs-Zusammenhänge

13 Vgl. dazu für den Bereich der Wettbewerbstheorie bspw. Herdzina (1981), S. 215; für den Bereich der Logistik bspw. Stabenau (2000), S. 127.

14 Vgl. dazu für die Wettbewerbstheorie bspw. Kantzenbach (1967), S. 32.; für den Bereich der Logistik bspw. Baumgarten (2001), S. 9.

15 Dazu und grundsätzlich zum Begriff der Prozessanalyse vgl. Arndt (1976), S. 6. 
zwischen den Veränderungen ökonomischer Variablen zum Zwecke der Untersuchung und Erklärung von Prozessphänomenen zu ergründen.

Ökonomische Prozesse können nun einerseits

(1) als Anpassungsreaktionen auf gestörte Gleichgewichtszustände interpretiert werden. ${ }^{16}$ Gestörte Gleichgewichtszustände sind das Resultat von Änderungen von Daten oder Verhaltensweisen, welche den ursprünglichen Gleichgewichtszustand determiniert haben. Andererseits können derartige Prozesse

(2) sichtbares Zeichen einer unaufhörlichen, sich nie vollendenden Anpassung sein, da es aufgrund ständig wiederkehrender Datenänderungen oder bedingt durch das menschliche Verhalten niemals zu einem Gleichgewichtszustand kam und kommen kann. ${ }^{17}$

Daraus erhellt: Will man nun einzelne derart gekennzeichnete ökonomische Prozessphänomene untersuchen und darüber hinaus mögliche Interdependenzen zwischen ihnen ergründen, so muss man sich folglich mit

- den diesen Prozess bedingenden Daten und Bedingungskonstellationen, d. h. den Determinanten bzw. Voraussetzungen dieser Prozesse,

- dem Ablauf der Prozesse sowie mit

- den Wirkungen bzw. Ergebnissen dieser Prozesse

auseinandersetzen. Dieser Befund lässt sich in Form folgender Argumentationssequenz wiedergeben: Die Prozessdeterminanten bedingen den Prozessablauf; der Prozessablauf zeitigt bestimmte Wirkungen. Diese kausale Beziehung „Determinanten - Prozessablauf - Wirkungen“ spannt den analytischen Bogen für die Untersuchung der beiden in Rede stehenden ökonomischen Prozessphänomene sowie für die Untersuchung der Interdependenzen zwischen ihnen.

Was dabei den Umgang mit der gegenständlichen Komplexität und thematische Breite der beiden Phänomene betrifft, so ist es zunächst sicherlich angezeigt, beides zu vermindern und die Phänomene auf den - bezogen auf die weiter oben entwickelte Argumentationssequenz - relevanten Kern zu reduzieren, m. a. W. die jeweiligen 
unterschiedlichen Perspektiven zusammenzuführen und ihre gemeinsame „Essenz“ zu extrahieren. Dazu allerdings ist es unabdingbar, zunächst eine ausreichend breite Ausgangsbasis zu wählen, um bei diesem Extraktionsprozess möglichst alle relevanten Fakten zu berücksichtigen und möglichst wenige Informationen zu verlieren. Für den Bereich des Wettbewerbs existieren umfassende, lohnende Ansätze ${ }^{18}$, welche auf eine hier verwertbare Form der Extraktion des Phänomens abzielen und deren Befunde daher bei dieser Untersuchung als Systematisierungsgrundlage und Orientierungsrahmen dienen können. Entsprechend verwertbare Ansätze existieren im Bereich des vergleichsweise jungen Feldes der Logistik jedoch (noch) nicht. Zwar sind auch hier erste Versuche erkennbar, einzelne auseinander gedriftete Themenblöcke wieder zusammenzuführen, allerdings befindet sich die logistische Forschungsgemeinde hier eher noch auf dem Weg in die entgegengesetzte Richtung, nämlich die gesamte thematische Breite des Feldes auszuloten, Themenblöcke auszudifferenzieren und neue Perspektiven zu fixieren. Infolgedessen präsentiert sich die ökonomische Logistikliteratur genauso fragmentiert und weitläufig wie die Logistikmaterie selbst.

Deshalb muss für die Untersuchung der logistischen Reorganisation hinsichtlich der Untersuchungsmethode ein gangbarer Mittelweg zwischen einer (aus Gründen des Anspruches an die Analysequalität gebotenen) Breite sowie einer (aus Zweckmäßigkeitsüberlegungen gebotenen) Einengung der Analysebasis durch eine Vorselektion von Analysekriterien gefunden werden. Die Grundsatzentscheidung bezüglich dieser Vorselektion, welche für den Fall der vorliegenden Untersuchung getroffen werden musste, dokumentiert sich in deren prinzipieller Ausrichtung bzw. Fokussierung auf die institutionelle Perspektive der logistischen Reorganisation, eingebettet in die Systematik einer Marktanalyse des Logistikmarktes. Doch selbst die Konzentration der Analyse auf institutionelle Aspekte im weitesten Sinne belässt den Analyseansatz angesichts der hohen gegenständlichen Komplexität der Logistik noch ausreichend breit, so dass die Analysequalität und mithin die Aussagekraft der Analyse nicht leidet und die damit vollzogene Einschränkung insofern nicht zu beanstanden ist. Präzisierende Ausführungen zur Wahl der geeigneten Untersuchungsmethode für den Prozess der logistischen Reorganisation folgen in Unterabschnitt 2.1.1. Damit ist auch der Gang der Untersuchung skizziert:

Im ersten Kapitel der Arbeit wird das Phänomen des wirtschaftlichen Wettbewerbs analysiert. Nach einigen grundlegenden Bemerkungen begrifflicher Natur (Abschnitt 1.1) folgt eine ausführliche Erörterung verschiedener wettbewerbstheoretischer 
Ansätze mit besonderem Augenmerk auf deren jeweilige Implikationen hinsichtlich der Wettbewerbsdeterminanten, des Prozessverlaufes sowie der Wirkungen des Wettbewerbs (Abschnitt 1.2). Anschließend wird der Versuch unternommen, die Aussagen der verschiedenen wettbewerbstheoretischen Ansätze zu einer umfassenderen Wettbewerbskonzeption zusammenzuführen, welche dann als wettbewerbstheoretischer Bezugsrahmen für die vergleichende Analyse im dritten Kapitel dienen soll (Abschnitt 1.3).

Das zweite Kapitel der Arbeit befasst sich mit dem Phänomen der logistischen Reorganisation wirtschaftlicher Aktivität. Nach theoretischen und methodischen Vorbemerkungen (Abschnitt 2.1) bildet die Marktanalyse des Logistikmarktes mit Fokus auf die institutionellen Aspekte der Logistik den „harten Kern“ des Kapitels mit der Zielsetzung, Wissen über den Prozess der logistischen Reorganisation, dessen Determinanten und dessen Wirkungen aufzubauen. Zunächst werden die ökonomischen Grundlagen der Logistik und der Logistikleistung gelegt (Abschnitt 2.2). Daran anschließend erfolgt eine Auseinandersetzung mit den zentralen verkehrspolitischen und ökonomischen Rahmenbedingungen, welche auf die Vorgänge auf dem Logistikmarkt einwirken (Abschnitt 2.3). Die nächste Komponente der Marktanalyse umfasst die Untersuchung von Angebot und Nachfrage nach Logistikleistungen (Abschnitt 2.4). Den Abschluss des Kapitels bildet die Analyse der Leistungskoordination auf dem Logistikmarkt (Abschnitt 2.5), wobei die faktische Ausgestaltung der Leistungskoordination als Ausdruck des Zusammen- und Wechselwirkens von Angebot und Nachfrage nach Logistikleistungen unter Zugrundelegung der vorherrschenden Rahmenbedingungen aufgefasst wird. Dementsprechend wird bei der Analyse der Marktkoordination in gewissem Umfang auch auf koordinationsrelevante Fakten zurückgegriffen, welche in den vorangehenden Komponenten der Marktanalyse zutage gefördert worden sind.

Im dritten Kapitel der Arbeit werden die Berührungspunkte zwischen den beiden Phänomenen dargestellt. Nach einführenden Vorbemerkungen (Abschnitt 3.1) folgt zunächst eine zusammenfassende Erörterung der Stellung des Wettbewerbs als Ordnungsprinzip in einem marktwirtschaftlich organisierten Wirtschaftssystem und der Stellung der Logistik bzw. des Logistiksystems im Systemverbund der Gütertransformation (Abschnitt 3.2). Daran schließt sich als inhaltlicher Schwerpunkt des dritten Kapitels die Integration der Logistikkonzeption in die Wettbewerbskonzeption an. Hierzu werden die im zweiten Kapitel gewonnenen Erkenntnisse um den Prozess der logistischen Reorganisation in den wettbewerbstheoretischen Bezugsrahmen eingearbeitet, welcher im ersten Kapitel in Gestalt der umfassenderen Wettbewerbskonzeption 
entwickelt worden ist (Abschnitt 3.3). Eine Zusammenfassung der wesentlichen Ergebnisse dieser konzeptionellen Integration beschließt das dritte Kapitel (Abschnitt 3.4). 


\section{Wirtschaftlicher Wettbewerb}

\subsection{Grundlegende Bemerkungen}

\subsubsection{Zum Verhältnis von Wettbewerbstheorie und Wettbewerbspolitik}

Die Wirtschaftswissenschaften beschäftigen sich mit der Beschreibung, der Erklärung und der Prognose des Wirtschaftsprozesses sowie der Beratung bei der Gestaltung des Wirtschaftsgeschehens.' Überragende Bedeutung kommt dabei der Erklärung des Wirtschaftsprozesses zu. ${ }^{2}$ Begründete Prognosen über die zukünftige Entwicklung ökonomischer Variabler können nur abgegeben, sinnvolle Beratung von Wirtschaftssubjekten kann nur praktiziert werden, wenn man in der Lage ist, Wirtschaftsprozesse zu erklären, $d$. $h$. dass man bestehende Ursache-Wirkungs-Zusammenhänge aufdeckt. Im Rahmen ökonomischer Theorien werden Hypothesengerüste entworfen, die eben diese Zusammenhänge thematisieren. Ökonomische Theorien haben demzufolge

- die Voraussetzungen ökonomischer Prozesse,

- den Ablauf dieser Prozesse sowie

- die Wirkungen bzw. Ergebnisse der Prozesse

zum Analysegegenstand. ${ }^{3}$

Nur auf der Basis begründeter theoretischer Erkenntnisse kann rationale Wirtschaftspolitik betrieben werden. Rationale Wirtschaftspolitik erfolgt üblicherweise in den drei Planphasen

- Zielfestlegung (Festlegung der gewünschten Soll-Ausprägung ökonomischer Variabler),

Vgl. Herdzina (2005), S. 36.

Vgl. Krüsselberg (1969), S. 41 ; Herdzina (1981), S.24.

Vgl. Herdzina (1999), S. 2. 
- Diagnose (Analyse des Ist-Zustandes, Analyse des Ausmaßes sowie der Ursachen von Soll-Ist-Abweichungen bzw. Zielverletzungen, Prognose der zukünftigen Entwicklung) und

- Therapie (Prüfung des Einsatzes wirtschaftspolitischer Instrumente). ${ }^{4}$

So folgt auch die Wettbewerbspolitik als zentraler Bereich der Wirtschaftpolitik in einer Marktwirtschaft diesen drei Planphasen. Jedoch gilt auch hier, dass wettbewerbspolitische Diagnose von Marktgeschehnissen und Therapie durch wettbewerbspolitischen Instrumenteneinsatz nur auf der Grundlage begründeter theoretischer Aussagen bezüglich der Voraussetzungen, des Ablaufes sowie der Ergebnisse von Wettbewerbsprozessen sinnvoll ist. ${ }^{5}$ Die Aussagekraft der wettbewerbspolitischen Analyse ist folglich durch die Güte der Erkenntnisse der Wettbewerbstheorie determiniert. TOLKSDORF führt dazu zustimmend aus: "Wenn eine Theorie Ursachen bestimmter Wettbewerbsprozesse erklärt, dann ist sie die Grundlage einer vernünftigen Politik, mit der Marktprozesse beeinflusst werden können: Die Kette von Ursache und Wirkung wird zu einem Zusammenhang von vorgegebenem wirtschaftlichem Ziel (die Wirkung der Politik) und dafür eingesetzten wettbewerbspolitischen Mitteln (den Ursachen der beobachteten Wirkung) ". ${ }^{6}$ BARTLING betont in diesem Zusammenhang besonders die Obliegenheit der Wettbewerbspolitik, die von der Theorie aufgedeckten Kausalzusammenhänge in geeignete Ziele und Diagnoseinstrumente zu überführen.' Er weist der theoretischen Wettbewerbspolitik ferner die Aufgabe zu, ..., über die allgemeine Erklärung von Wettbewerbsprozessen hinaus... die Wirkungszusammenhänge auf[zu]decken, die sich aus der Kombination von Zieloperationalisierung und geeigneter Instrumentenauswahl sowie Trägerinstitutionalisierung ergeben““ ${ }^{8}$

Vgl. Herdzina (1999), S. 2.

Vgl. Tolksdorf (1994), S. 33. Giesel identifiziert in diesem Zusammenhang mit den drei Grundfragestellungen „Was ist Wettbewerb? - Woraus entsteht Wettbewerb? - Was kann Wettbewerb bewirken?" diejenigen Grundfragestellungen, auf welche die Wettbewerbstheorie als eine erklärende Theorie in ausreichendem Umfang Antwort zu geben in der Lage sein müsste und bewegt sich dabei ebenfalls in Reichweite zu der Argumentationssequenz „Determinanten Prozessablauf - Wirkungen“, ohne jedoch explizit einen Kausalzusammenhang zwischen seinen drei Fragestellungen herzustellen. Vgl. Giesel (1975), S. 13.

Tolksdorf (1994), S. 34.

Vgl. Bartling (1997), S. 17.

Bartling (1997), S. 17. 
Bedauerlicherweise existieren in der Wettbewerbstheorie zahlreiche unterschiedliche Interpretationen des Wettbewerbsphänomens. ${ }^{9}$ Bezüglich der Voraussetzungen, unter denen sich Wettbewerb einstellt, bezüglich des wettbewerblichen Prozessverlaufes sowie bezüglich der Wirkungen, die der Wettbewerb zeitigt, bestehen erhebliche Meinungsverschiedenheiten, welche sich in $\mathrm{z}$. T. stark voneinander divergierenden theoretischen Positionen niederschlagen. ${ }^{10}$ Dies führt dazu, dass die wettbewerbstheoretische Fundierung wettbewerbspolitischer Konzeptionen " sowie infolgedessen die ordnungspolitische Ausgestaltung des Wettbewerbsprinzips ${ }^{12}$ mit erheblichen Schwierigkeiten behaftet ist.

Ferner wird das wie eingangs dargestellt an sich sachlogisch „trennscharfe“ Beziehungsverhältnis zwischen Wettbewerbstheorie und Wettbewerbspolitik zusätzlich dadurch verwässert, dass der Primat des Wettbewerbs als Steuerungsprinzip in einer marktwirtschaftlich orientierten Wirtschaftsordnung Ergebnis einer wirtschaftspolitischen Grundsatzentscheidung im Kontext einer gesellschaftspolitischen Gesamtkonzeption war und ist. ${ }^{13}$ Das wiederum bedeutet, dass eine Entscheidung pro Wettbewerb allein „aus Gründen der ökonomischen Rationalität“ nicht möglich ist. ${ }^{14}$ Für die Wettbewerbstheorie hatte dies zur Folge, dass die materielle Diskussion des Wettbewerbsphänomens wohl nie frei und unabhängig von normativen Überlegungen war bzw. sein konnte. ${ }^{15}$ Dieser Umstand stellt somit einen weiteren Anhaltspunkt für die Problematik der theoretischen Fundierung wettbewerbspolitischen Handelns dar. Auch MANTZAVINOS ist dieser Ansicht und betrachtet insbesondere die Gegebenheit, dass die verschiedenen Ansätze der Wettbewerbstheorie mit normativen Elementen

So kommt auch Haubrock zu dem Ergebnis, dass es eine allgemeingültige, alle Fragestellungen ausfüllende Wettbewerbstheorie nicht gibt. Vgl. dazu Haubrock (1994), S. 74. Der Mangel an Wissen um Wesen und Charakter des Wettbewerbsprozesses führt nach Ansicht von Kaufer zu dem unbefriedigenden Ergebnis, dass die Wettbewerbspolitik eine Politik ist, „die im Dunkel operiert". Kaufer (1980), S. VII.

Vgl. für eine Übersicht über die unterschiedlichen Positionen bspw. Kerber (2003), S. 302 ff.; Borchert, Grossekettler (1985), S. $132 \mathrm{ff}$.

11 Dieser Meinung ist auch Aberle. Ein Faktor, der die Anwendbarkeit wettbewerbstheoretischer Aussagen für die Wettbewerbspolitik zudem erschwert, ist seiner Ansicht nach die Tatsache, dass in der historischen Entwicklung stets unterschiedliche Fragestellungen in unterschiedlicher Intensität Gegenstand der wettbewerbstheoretischen Analyse waren und zudem die Analysen der Teilkomplexe mit normativen Überlegungen durchsetzt waren. Darüber hinaus sind die theoretischen Ansätze aufgrund der Komplexität des Wettbewerbsphänomens durch eine hohe „Formulierungskomplexität" gekennzeichnet. Vgl. dazu Aberle (1992), S. 75 f. Vgl. Poeche (1970), S. 9.

Vgl. Kantzenbach (1967), S. 12.

Kantzenbach (1967), S. 12.

I5 Vgl. dazu auch Hoppmann (1968b), S. 87. 
durchsetzt sind, welche sich zudem teilweise mit erfahrungswissenschaftlichen Aussagen vereinigt haben, als eine für die wettbewerbstheoretische Diskussion außerordentlich belastende und störende Tatsache. Die Ursache für die normative Durchdringung sieht er in dem Umstand, dass die Wettbewerbstheorien ursprünglich weniger als erfahrungswissenschaftliche Theorie, sondern als wettbewerbspolitische Konzeptionen mit paradigmatischem Leitbildcharakter geschaffen worden sind. ${ }^{16}$

Ergänzend und relativierend darf dem bislang Ausgeführten allerdings hinzugefügt werden, dass man augenfällig zwar von einer einheitlichen Theorie des Wettbewerbs weit entfernt zu sein scheint, jedoch bezüglich einiger wesentlicher Grundeigenschaften des Wettbewerbs offenkundig doch Einigkeit innerhalb der Forschungsgemeinde besteht. ${ }^{17}$ Zudem scheint auch „im Ergebnis“ dahingehend Konsens zu bestehen, dass „trotz gewisser Unterschiede in der Begründung“, welche von den unterschiedlichen wettbewerbstheoretischen Positionen herrühren, „die Postulate, die für eine wirksame, weil konsequente Politik gegen Wettbewerbsbeschränkungen unabdingbar sind, bereits seit geraumer Zeit prinzipiell kaum mehr umstritten sind“..$^{18}$

Aus diesen Erörterungen kann gefolgert werden, dass es unabdingbar notwendig ist, aus der Fülle divergierender wettbewerbstheoretischer Aussagen eine umfassendere Kernkonzeption zu isolieren bzw. zu erarbeiten, um

(1) das Phänomen des wirtschaftlichen Wettbewerbs für die Zwecke der hier beabsichtigten theoretischen Analyse möglichst praktikabel und angemessen zu erfassen und um

(2) eine möglichst aussagefähige Basis für eine theoriegeleitete wettbewerbspolitische Beurteilung von Marktvorgängen wie bspw. der logistischen Reorganisation wirtschaftlicher Aktivität zu schaffen. ${ }^{19}$

Vgl. Mantzavinos (1994a), S. 13. Zusammenfassend kann möglicherweise festgehalten werden, dass, so einwandfrei korrekt der Zusammenhang ,eine erklärungsfähige Wettbewerbstheorie ist die geeignete Grundlage einer vernünttigen Wettbewerbspolitik“ ist, so offenkundig falsch die Praxis ist, bei diesem Zusammenhang die Kausalrichtung zu ändern und ihn im Umkehrschluss zur Basis ökonomischer Überlegungen zu machen. Belange der praktizierten Wettbewerbspolitik können nie die geeignete Grundlage einer vernünftigen Wettbewerbstheorie sein. 
Ein solches Unterfangen indes ist angesichts eines gewissen Basiskonsenses, welcher trotz der augenfälligen Heterogenität der verschiedenen wettbewerbstheoretischen Ansätze zu herrschen scheint, wenigstens nicht schon von vornherein zum Scheitern verurteilt. Dies soll in den folgenden Unterabschnitten aufgezeigt werden.

\subsubsection{Zur Problematik des Wettbewerbsbegriffes}

Wie die Darlegungen im vorangehenden Unterabschnitt bereits vermuten lassen mussten, existiert keine allgemein akzeptierte Definition dessen, was unter Wettbewerb zu verstehen ist. ${ }^{20}$ Vielmehr führen die bereits zitierten erheblichen Unklarheiten hinsichtlich der Frage, welche Vorgänge als wettbewerbliche Vorgänge betrachtet werden können und welche nicht, zu divergierenden Definitionsansätzen. ${ }^{21}$ Dies ist insofern zunächst bemerkenswert, da die Bedeutung des Wettbewerbs als „systembegründendes Prinzip“،22, als „Leistungsstimulator“23 einer Marktwirtschaft im Allgemeinen übereinstimmend akzeptiert wird. HERDZINA identifiziert drei Ursachenkomplexe für die divergierenden Wettbewerbsdefinitionen: ${ }^{24}$

(1) Eng verbunden mit der Definition eines ökonomischen Vorgangs ist die Frage seiner Messbarkeit. Messvorhaben können sich dabei - analog der oben bereits eingefürten theoretischen Argumentationssequenz - auf die Wirkungen, die der Vorgang zeitigt, auf den Vorgang selbst, sowie auf die Voraussetzungen, die ihn maßgeblich bedingen, beziehen. Gemäß dieser Systematik können mindestens drei unterschiedliche Definitionsansätze für den Wettbewerb in folgendem Schema systematisiert werden: ${ }^{25}$

- Wirkungsdefinitionen (ein Marktgeschehen wird als wettbewerblich definiert, wenn es bestimmte Marktergebnisse zeitigt)

20 Vgl. auch Tolksdorf: „Immer wieder wird mit gutem Grund darauf verwiesen, dass der marktwirtschaftliche Wettbewerb ein wandelbares, vielgestaltiges, entwicklungsfähiges und widersprüchliches „Phänomen“ sei, das sich ungern in die Zwangsjacke einer abgesegneten Begriffsbestimmung einpressen lasse." Tolksdorf (1994), S. 10.

Vgl. Herdzina (1981), S. 215; Herdzina (1989), S. 3.

Hoppmann (1972), S. 9.

Herdzina (1975), S. 19.

Vgl. dafür und für das Folgende Herdzina (1981), S. 215 ff. und Herdzina (1999), S. 10 f.

Vgl. auch Herdzina (1999), S. $10 \mathrm{f}$. 
- Prozess- bzw. Verhaltensdefinitionen (ein Marktgeschehen wird als wettbewerblich definiert, wenn es sich durch bestimmte Prozessabläufe dokumentiert, bzw. durch ein bestimmtes Marktverhalten der Marktteilnehmer gekennzeichnet ist)

- Determinantendefinitionen (ein Marktgeschehen wird als wettbewerblich definiert, wenn die notwendigen und hinreichenden Wettbewerbsvoraussetzungen für das Eintreten gewünschter Prozesse oder Wirkungen vorliegen, wie bspw. bestimmte Marktstrukturen oder Wettbewerbsfreiheit)

(2) Als zweite Ursache für divergierende Wettbewerbsdefinitionen kann der Umstand betrachtet werden, dass kein Konsens darüber besteht, welche Funktionen dem Wettbewerb im einzelnen zu übertragen sind und ob der Wettbewerb alle ihm übertragenen Funktionen gleichzeitig erfüllen kann oder nicht (Dilemma- vs. Harmoniethese).

(3) Schließlich sind drittens divergierende Wettbewerbsdefinitionen das Ergebnis der methodologischen Debatte, ob Wettbewerb überhaupt hinsichtlich der Erreichung konkreter Ziele definiert werden kann, oder ob sich der Wettbewerbsprozess, verstanden als permanenter Such- und Entdeckungsprozess im HAYEKschen Sinne, als prinzipiell ergebnisoffener Prozess nicht gänzlich der Möglichkeit einer positiven wirkungs-, prozess- oder strukturorientierten Definition entzieht. Wenn Wettbewerb nämlich als offener Prozess betrachtet wird, dessen Wirkungen oder Prozessverläufe allenfalls als Mustervoraussagen, keinesfalls aber als Einzelaussagen prognostizierbar sind, so scheiden wirkungs-, prozess- oder strukturorientierte Definitionsansätze, d. h. Definitionsansätze, die das Vorliegen von Wettbewerb an bestimmten Ausprägungen von Wirkungs-, Prozess- oder Strukturvariablen festmachen, aus.

Würde man letztere der unter (3) präsentierten Sichtweisen präferieren, dann erschiene am ehesten noch eine Wettbewerbsdefinition im HOPPMANNschen Sinne, welche an der Wettbewerbsfreiheit als zentraler Determinante von Wettbewerbsprozessen anknüpft, als angemessen. Einer solchen Definition liegt die Vermutung zugrunde, 
dass das Vorliegen von Wettbewerbsfreiheit zu guten ökonomischen Ergebnissen führt, die jedoch im Einzelnen nicht vorhergesagt werden können. ${ }^{26}$

Insofern wäre möglicherweise aus der Fülle der möglichen Definitionsansätze folgender Ansatz zunächst hervorzuheben:

Das Phänomen Wettbewerb ist negativ zu definieren, und zwar als Situation der Abwesenheit von Wettbewerbsbeschränkungen. So sollen, im Sinne von HOPPMANN unter Wettbewerb all jene Marktprozesse zusammengefasst werden, ... "die sich entfalten unter der Bedingung „Abwesenheit von Beschränkungen der Wettbewerbsfreiheit "“.". 27

Würde man dem Wettbewerbsphänomen diesen freiheitsorientierten Definitionsansatz zugrunde legen, dann verböte es sich, spezifische Maße für die Wettbewerbsintensität zu entwickeln. Jegliche Forderung nach einem konkreten Ausmaß an Aktions- bzw. Freiheitsspielraum für die einzelnen Marktteilnehmer nämlich wäre unverträglich mit der Forderung nach Offenheit der Marktprozesse. ${ }^{28}$ Allerdings erscheint es dann trotzdem als unabdingbar notwendig festzulegen, wann der Freiheitsspielraum für den einzelnen Marktteilnehmer noch hinreichend groß ist, wenn man die Güte des Wettbewerbs auf einem Markt diagnostizieren möchte.

Doch auch der HoPPMANNschen Herangehensweise kann, wie allen anderen Definitionsvorhaben auch, kritisch entgegengehalten werden, dass der Wettbewerbstheorie als Erfahrungswissenschaft gar nicht die Aufgabe zukommt, nach dem „Wesen“, der „wesentlichen Beschaffenheit“ oder der „wahren Natur“ der Dinge zu fragen und dann dieses "Wesen" des Dinges (hier: des Wettbewerbs) in einer eindeutigen essentialistischen Definition zu formulieren, da es sich dabei um eine übergeordnete Fragestellung, d. h. ein metaphysisches Problem handelt. Das „Wesen“ des Dinges ist folglich

So spricht sich auch Hoppmann ausdrücklich für eine freiheitsorientierte Wettbewerbsdefinition aus, „weil Wettbewerbsfreiheit Voraussetzung ist für die Erfüllung der so genannten ökonomischen Wettbewerbsfunktionen (...). Im Rahmen einer marktwirtschaftlichen Ordnung sind Wettbewerbsfreiheit und ökonomische Vorteilhaftigkeit zwei Aspekte des wettbewerblichen Prozesses, sie sind zwei Seiten derselben Medaille oder anders formuliert: Wenn die Wettbewerbsfreiheit und somit der Wettbewerb beschränkt wird, ergibt sich eine Verminderung der ökonomischen Vorteilhaftigkeit." Hoppmann (1972), S. 18. Hoppmann (1972), S. 10. 
durch die Erfahrungswissenschaft selbst prinzipiell nicht überprüfbar, die Güte bzw. der Grad des absoluten Wahrheitsgehaltes einer Definition entzieht sich der Möglichkeit einer Bewertung im Rahmen einer erfahrungswissenschaftlichen Analyse.

Vielmehr habe sich die Wettbewerbstheorie mit der Frage auseinandersetzen, welche marktlichen Konstellationen, welche ökonomischen und nichtökonomischen Gegebenheiten als „Wettbewerb“ zu etikettieren sind. Der Begriff „Wettbewerb“ wird dann benutzt um, anstelle einer ausführlichen Auflistung sämtlicher für ihn relevanter Konstellationen und Gegebenheiten, diese Konstellationen und Gegebenheiten stellvertretend in Form einer Abkürzung erklärend zu „benennen“. Man habe also der Position des methodologischen Nominalismus zu folgen. ${ }^{29}$ Bezogen auf HOPPMANNs Wettbewerbsdefinition bedeutet dies nun, dass, wenngleich er von einer positiven Definition des Wettbewerbs Abstand nimmt, das methodologische Problem von der unzulässigen Frage „Was ist Wettbewerb“ auf die nicht minder problematische Frage „Was ist Wettbewerb nicht" verlagert wird. ${ }^{30} \mathrm{Da}$ nun für das Vorhaben, den Begriff der „Wettbewerbsbeschränkung“ zu definieren, genauso unüberwindlich zu sein scheint, wie die Definition des Wettbewerbsbegriffs selbst, so muss die HOPPMANNsche Definition als nominalistische Definition interpretiert werden.

Abschließend muss folglich das Fazit gezogen werden, dass es eine allgemein gültige, positive Definition dessen, was Wettbewerb ist oder nicht ist, nicht gibt und - methodologisch betrachtet - wohl auch nicht geben kann. Vielmehr existiert eine Vielzahl unterschiedlicher Wettbewerbsdefinitionen und -vorstellungen, welche sich ihrem Erkenntnisobjekt aus völlig unterschiedlichen Blickwinkeln und unter Berücksichtigung verschiedener Ansatzpunkte nähern, wobei sich die Definitionsvorhaben in der Sequenz „Determinanten - Prozess - Wirkungen“ systematisieren lassen. Den nachfolgenden Darlegungen kann daher, in Reflexion des materiellen Dissenses innerhalb der Forschungsgemeinde sowie der methodologischen Debatte, keine allgemein gültige und von allen akzeptierte Wettbewerbsdefinition vorangestellt werden.

29 Vgl. ausführlich zur methodologischen Debatte in der Wettbewerbstheorie bzw. in der wissenschaftlichen Wettbewerbspolitik sowie grundsätzlich zum methodologischen Essentialismus vs. methodologischen Nominalismus Schmidtchen (1978), insb. S. 35 ff. Vgl. zur Problematik der Wettbewerbsdefinition auch Herdzina (1999), S. 7 ff.

Vgl. Schmidtchen (1978), S. 44. 


\subsubsection{Schlussfolgerungen}

Sachdienlicher als das in der wettbewerbstheoretischen Disziplin bislang wenig erfolgreiche Unterfangen, den Wettbewerbsbegriff einheitlich und positiv zu definieren erscheint es indessen - wie im vorangehenden Unteratschnitt festgestellt - die verschiedenen wettbewerbstheoretischen Ansätze dahingehend zu untersuchen, inwieweit sie

(1) einen Beitrag zu leisten in der Lage sind, den wirtschaftlichen Wettbewerb zu erklären und

(2) darauf aufbauend helfen können, eine für die Zwecke der hier beabsichtigten theoretischen Analyse angemessene „umfassendere“ ${ }^{\text {(3) }}$ Wettbewerbskonzeption formulieren zu können.

Dabei ist insbesondere darauf zu achten, dass die wettbewerbstheoretisch verwertbaren erfahrungswissenschaftlichen Hypothesen der einschlägigen Theorien bezüglich der jeweils vorgeschlagenen Wettbewerbsdeterminanten, des sich vollziehenden Wettbewerbsprozesses sowie der daraus resultierenden Wettbewerbswirkungen möglichst isoliert von den normativen Elementen der Theorien vorgestellt und untersucht werden. An dieser Stelle wäre vielleicht der Rückgriff auf das HEUB zuzuschreibende Bild von „erratischen Blöcken“ zweckmäßig - von Bausteinen also, welche „ziemlich verloren auf dem Feld herumliegen “ ${ }^{32}$ Demnach verfugen die einzelnen wettbewerbstheoretischen Auffassungen über Stärken, welche es aus der Isolation heraus miteinander zu verbinden gilt, um dadurch möglicherweise zu einer umfassenderen Wettbewerbskonzeption zu gelangen.

Von einer nach solchem Muster angestrebten Zusammenführung einzelner Komponenten verschiedener wettbewerbstheoretischer Ansätze zu einer umfassenderen Wettbewerbskonzeption darf allerdings keine derartige Perfektion erwartet werden, wie sie andere Wettbewerbskonzepte zu besitzen vielleicht für sich in Anspruch nehmen. Vielmehr wird damit der Versuch unternommen, ein im Wesentlichen stringentes und in sich stimmiges Bild essentieller Ideen und Fakten zu zeichnen. Dies geschieht auf der Grundlage einer explikativ ausgerichteten theoretischen Untersuchung des Wettbewerbsphänomens, welche es gestattet, gegebenenfalls existente Kausalitäten 
nachvollziehbar zu begründen. Diese hier angedachte Entwicklung und Formulierung einer fur die hier beabsichtigte theoretische Analyse zweckdienlichen Wettbewerbskonzeption soll in den beiden folgenden Abschnitten 1.2 und 1.3 geleistet werden. Abschnitt 1.4 fasst die Ergebnisse des ersten Kapitels zusammen. 


\subsection{Entwicklungslinien der Wettbewerbstheorie}

In diesem Abschnitt soll untersucht werden, welchen Beitrag die einzelnen wettbewerbstheoretischen Ansätze dazu leisten können, den wirtschaftlichen Wettbewerb zu erklären. Speziell von Interesse sind dabei die jeweils herausgearbeiteten Wettbewerbsdeterminanten, die Vorstellungen bezüglich des Wettbewerbsprozesses sowie darauf aufbauend die erwarteten Wettbewerbswirkungen. Um dabei die Entwicklungslinien der Wettbewerbstheorie nachzuzeichnen, erscheint es zunächst einleuchtend, die wettbewerbstheoretischen Ansätze der einzelnen historischen Epochen chronologisch systematisiert zu untersuchen. Dies allerdings bereitet in der wettbewerbstheoretischen Disziplin erhebliche Schwierigkeiten. Jeglicher Versuch nämlich, die Entwicklung der Wettbewerbstheorie in zeitlich aufeinander folgende Phasen einzuteilen ist deshalb ein heikles Unterfangen, weil sich einzelne theoretische Entwicklungsabschnitte häufig nicht trennscharf voneinander abgrenzbar verorten lassen, sondern sich vielmehr über längere Perioden hinweg überlappen.' Zudem sind Einteilung sowie terminologische Etikettierung der einzelnen Entwicklungsphasen oftmals derart unglücklich gewählt, dass sie unter Umständen Inhalte oder Abgrenzungen vermuten lassen, welche „der Theorie resp. den sie vertretenden Theoretikern nicht immer gerecht werden". ${ }^{2}$ Phaseneinteilungen gleich welcher Art sind daher stets kritisch zu hinterfragen.

Die nachfolgend gewählte Systematik soll demgemäß nicht als historische Chronologie der wettbewerbstheoretischen Entwicklung missgedeutet werden. Darauf kann sie keinen Anspruch erheben. Vielmehr soll sie - mit aller gebotener Vorsicht - als didaktisch zweckmäßige Anordnung markanter theoretischer Beiträge bzw. Positionen interpretiert werden, welche den Zweck verfolgt, die bemerkenswerte methodologische Divergenz der wettbewerbstheoretischen Ansätze wiederzugeben.

\subsubsection{Der wettbewerbstheoretische Ansatz in der klassischen Theorie}

\subsubsection{Wettbewerbswirkungen und Wettbewerbsprozess}

Die ersten rudimentären Ansätze einer theoretischen Betrachtung des Wettbewerbsphänomens sind bereits auf das 5 . Jahrhundert v. Chr. zu datieren. ${ }^{3}$ Unbeschadet dessen und gleichsam unbeschadet der Tatsache, dass die theoretische Untersuchung

Vgl. Neumann (1982), S. 67.

Herdzina (1975), S. 16.

Vgl. Mantzavinos (1994a), S. 15. 
des Wettbewerbskonzepts bereits im vorklassischen Zeitalter Usus war ${ }^{4}$ und dem Wettbewerb schon in dieser Zeit, so bspw. von BoISGUILLEBERT (1646 - 1714), der Charakter eines Ordnungsprinzips zugeschrieben worden ist ${ }^{5}$, so gilt dennoch für viele der klassische Ökonom SMITH als die erste, alle anderen überragende, zentrale Gestalt inmitten der Wettbewerbstheoretiker. Eine solche Auffassung muss insofern zunächst überraschen, da zentrale prominente Thesen SMITHs, wie bspw. seine Etikettierung des Wettbewerbs als diejenige treibende Kraft, welche die Marktpreise an die natürlichen Preise angleicht, nachgewiesenermaßen nicht originär von ihm stammen, sondern eher aus der Tradition der ökonomischen Literatur seiner Zeit herrühren. ${ }^{6}$ Das eigentliche große Verdienst von SMITH ist deshalb weniger im, verglichen zur Leistung der anderen Nationalökonomen seiner Zeit, absoluten Neuigkeitsgrad i. S. eines analytischen Erkenntniszugewinns in der Wettbewerbsmaterie begründet. Vielmehr ist seine überragende Leistung darin zu sehen, dass er (1) die Beiträge seiner Vorgänger und Zeitgenossen umfassend systematisiert und aufgearbeitet hat und vor allem (2) den Wettbewerb zu einem allgemeinen sozialökonomischen Organisationsprinzip erhoben hat. SMITHs „Inquiry into the Nature and Causes of the Wealth of Nations" stellt insofern einen Meilenstein in der ökonomischen Literatur und gleichsam einen Wendepunkt im ökonomischen Denken dar, da SMITH mit diesem Werk die Arbeiten seiner Vorgänger dahingehend zu defragmentieren und kanalisieren vermochte, dass die in der damaligen Nationalökonomie bereits dominierende Neigung, die traditionell ethisch und politisch motivierte Preisbildung zugunsten der wettbewerbsbasierten Preisbildung aus dem Fokus der ökonomischen Analyse zu verdrängen, endgültig vollzogen werden konnte und im Zuge dessen das Wettbewerbskonzept von nun an zur „sine qua non“ ökonomischen Denkens avancierte. ${ }^{7}$ Insofern ist dem Urteil J. M. CLARKs wahrlich zuzustimmen, welcher SMITH als den "prophet of competition“ bezeichnet hat. ${ }^{8}$

SMITH begriff den Wettbewerb als das Organisationsprinzip einer auf die Freiheit der beteiligten Handlungsträger gründenden Gesellschaftsordnung. ${ }^{9}$ Dieses Prinzip manifestierte sich im wirtschaftlichen Bereich in Form eines freien Wettbewerbs ohne

Vgl. McNulty (1967), S. 395 ff.

Vgl. McNulty (1967, S. 395; Mantzavinos (1994a), S. 16.

Vgl. McNulty (1967), S. 396.

Vgl. McNulty (1967), S. 396 f.

J. M. Clark (1961), S. 24.

$\mathrm{Vgl}$. für die philosophische Grundposition Smiths sowie die damit verbundenen Denkkategorien der "natürliche Ordnung“ und der „Sympathie“, aus welcher heraus er seine wettbewerbstheoretische Konzeption entwickelte, Söllner (2001), S. 29 ff. 
staatliche Lenkung als ein „System nicht-autoritärer Kontrolle“10 und richtete sich somit als „ordnungspolitische Alternative“ ausdrücklich gegen den Absolutismus des 18. Jahrhunderts sowie gegen die feudal-merkantilistischen Fesseln der Wirtschaftsfreiheit ${ }^{1}$. Im freien Wettbewerb wirkt das Eigeninteresse, welches die Wirtschaftssubjekte verfolgen (dürfen), als Triebkraft. Doch während die Wirtschaftssubjekte eigennützig die ihnen zur Verfügung stehenden Ressourcen in die für sie beste Verwendung mit dem höchstmöglichen Gewinn bzw. Nutzen lenken, steigern sie damit die gesamtwirtschaftliche Wohlfahrt, ,as... led by an invisible hand “'12, ohne dies beabsichtigt zu haben ${ }^{13}$. Darüber hinaus sichert der freie Wettbewerb den am Wirtschaftsprozess beteiligten Parteien einen - allerdings begrenzten - Freiheitsspielraum. ${ }^{14} \mathrm{Da}$ insofern der Wettbewerb in klassischer Interpretation zusätzlich zu seiner ökonomischen Dimension gesellschaftliche bzw. politische Relevanz besitzt, ist der Ansatz der klassischen Theorie als politökonomisch einzustufen. ${ }^{15}$

In Anbetracht dieser enormen Bedeutung, welche dem Wettbewerb in der klassischen Theorie beigemessen wurde, muss es jedoch überraschen, dass eine analytische Präzisierung der Vorstellungen bezüglich des Wettbewerbskonzeptes weder von SMITH noch von den anderen klassischen Wettbewerbsökonomen geleistet wurde. ${ }^{16}$ Insbesondere wurde offen gelassen, unter welchen Bedingungen genau der Wettbewerbsprozess einen Ausgleich von Einzel- und Gesamtinteressen vollzieht bzw. ein optimales Marktergebnis produziert. ${ }^{17}$ Dennoch vermag die klassische Wettbewerbstheorie bedeutende Beiträge zur Erklärung des Wettbewerbs- bzw. des Marktprozesses zu leisten, wie die nachstehenden Folgerungen belegen.

Vgl. Hoppmann (1968b), S. 81; Giesel (1975), S. 16.

Vgl. Knieps (2001), S. 67; Herdzina (1981), S. 221.

Smith (1852), S. 184.

$\mathrm{Vgl}$. Starbatty (1986), S. 82. Poeche spricht in diesem Zusammenhang von einem "unbegrenzten Vertrauen”, welches die Klassiker in eine „Harmonievorstellung“ gesetzt haben, welche „die gegenläufigen Gruppenegoismen im Interesse der gesellschaftlichen Wohlfahrt ausgleicht“. Poeche (1970), S. 11.

14 Vgl. Schmidt (1999), S. 2.

15 Vgl. Söllner (2001), S. 29; Herdzina (1981), S. 222.

16 J. M. Clark über A. Smith: „As a prophet of competition, one of the notable things about him was that he said unfinished things about it." J. M. Clark (1961), S. 24.

17 Vgl. Knieps (2001), S. 68. Diesen Umstand schreiben heutzutage die einen der Unfähigkeit der klassischen Ökonomen zu (so bspw. Kaufer (1967), S. 95), die anderen betrachten es als ein Pflichtversäumnis - eine Unterlassungssünde also (so bspw. Schmidt (1999), S. 4). Tolksdorf stellt hingegen die Frage, ob die Optimalität des wettbewerblichen Marktergebnisses überhaupt im Bereich des Erkenntnisinteresses der Klassiker war, oder ob die Sichtweise der klassischen Theorie eine Entscheidung zwischen mehreren Ergebnisnormen zur Auswahl der optimalen überhaupt nicht vorsah. Vgl. Tolksdorf (1994), S. 40. 
Der Wettbewerb ist ein dynamischer Marktprozess, welcher gekennzeichnet ist durch unabhängige Verhaltenweisen der Marktteilnehmer. ${ }^{18}$ Dieser dynamische Marktprozess vollzieht sich zum einen in vorstoßenden und nachahmenden Wettbewerbshandlungen unter den konkurrierenden Anbietern eines Gutes (Freiheit zum Wettbewerb unter Konkurrenten), und dokumentiert sich zum anderen in der Wahlfreiheit der Konsumenten, aus den angebotenen Alternativen auszuwählen. ${ }^{19}$ Beide Freiheiten stehen in einem wechselseitigen Bedingungsverhältnis zueinander, wobei sie sich im Rahmen eines wettbewerblichen Prozesses konkretisieren und dabei gleichermaßen dessen Bedingung und Wirkung darstellen. ${ }^{20}$ Der Wettbewerb überwindet dabei das aufkommende Spannungsverhältnis zwischen dem natürlichen Preis, d. h. demjenigen Preis ,the commodity...precisely...is worth, or what it really costs the person who brings it to market... ${ }^{، 21}$ und dem Marktpreis, d. h. ,...the actual price at which any commodity is commonly sold,...,22. Letzterer "...is regulated by the proportion between the quantity which is actually brought to the market and the demand of those who are willing to pay the natural price of the commodity..."23 Bei Nachfrageüberschuss werden einige Nachfrager "be willing to give more. A competition will immediately begin among them, and the market price will rise more or less above the natural price, according as either the greatness of the deficiency, or the wealth and wanton luxury of the competitors, happen to animate more or less the eagerness of the competition" ${ }^{24}$. Entsprechend muss bei Angebotsüberhang "some part ....be sold to those who are willing to pay less,... The market price will sink more or less below the natural price, according as the greatness of the excess increases more or less the competition of the sellers, or according as it happens to be more or less important to them to get immediately rid of the commodity"25. Werden in einem Markt durch hohe Preise übermäßige Gewinne realisiert, so lockt dies neue Anbieter an, was Preise und Gewinne reduziert ${ }^{26}$, ein Marktaustritt von Anbietern wiederum reduziert den Wettbewerbsdruck. Der Wettbewerbsprozess koordiniert die Interessen der Anbieter und der Nachfrager und bewirkt hierbei, dass sich über Preiszugeständnisse der einen, unter Druck stehenden Marktseite an die jeweils andere, sich in der komfortableren

\footnotetext{
Vgl. Mantzavinos (1994a), S. 18; Herdzina (1981), S. 222.

Vgl. Hoppmann (1968b), S. 81; Schmidt (1999), S. 2.

Vgl. Hoppmann (1968b), S. 81.

Smith (1852), S. 23.

Smith (1852), S. 23.

Smith (1852), S. 23.

Smith (1852), S. 23.

Smith (1852), S. 24.

Vgl. Smith (1852), S. 25.
} 
Position befindlichen Marktgegenseite die Angebots- und Nachfragemengen angleichen und sich damit der Marktpreis dem natürlichen Preis annähert. ${ }^{27}$

Ferner erörtert SMITH die positiven Wirkungen wettbewerblichen Verhaltens auf die Realisierung nachfrageinduzierten Fortschritts: „The increase of demand, besides, though in the beginning it may sometimes raise the price of goods, never fails to lower it in the long-run. It encourages production, and thereby increases the competition of the producers, who, in order to undersell one another, have recourse to new divisions of labour and new improvements of art, which might never otherwise have been thought of ${ }^{28}$. Dem Wettbewerb wird hierbei der Charakter eines Entdeckungsverfahrens mit ungewissem Ausgang zugeschrieben. ${ }^{29}$

Aus heutiger Sicht kann die klassische Wettbewerbstheorie als „evolutorische Theorie“ etikettiert werden, welche die Erklärung prozessualer Vorgänge zum Gegenstand hat. ${ }^{30}$ Als „Entwicklungstheorie“ setzt sie sich mit der Evolution der ökonomischen Systeme auseinander, der Frage also, wie der dynamische Prozess der Entfaltung ökonomischer Systeme aus „dem Zustand feudalistischer Verharrung“ vonstatten ging. ${ }^{31}$

\subsubsection{Wettbewerbsdeterminanten}

Obwohl SMITH keine präzisen Aussagen bezüglich der Bedingungen gemacht hat, unter welchen sich seiner Meinung nach der skizzierte Wettbewerbsprozess einstellt, so identifiziert er doch diverse den Wettbewerb hemmende Umstände, welche dazu führen, dass der Marktpreis für eine längere Zeit über dem natürlichen Preis liegen kann. Der Wettbewerbsprozess ist also kein Automatismus. Es sind dies $:^{32}$

(1) Natürliche Hemmnisse: „...particular accidents, sometimes natural causes...",

(2) Das Bestreben der am Markt anbietenden Unternehmer, die übermäBige Höhe ihrer Gewinne vor anderen geheim zu halten, wobei allerdings ,Secrets of this kind, however,..., can seldom be long kept“. Nach Bekanntwerden der effektiven Gewinnsituation des Anbieters

Vgl. Smith (1852), S. 24.

Smith (1852), S. 314.

Vgl. Herdzina (1981), S. 222.

Vgl. Tolksdorf (1994), S. 39.

Tolksdorf (1994), S. 39.

Vgl. Smith (1852), S. 25, S. 54. 
werden dann durch Marktzutritt neuer Anbieter die Marktpreise sinken und die Gewinne erodiert.

(3) Durch staatliche Maßnahmen ${ }^{33}$ initiierte, überdauernde Monopolstellungen bzw. Privilegien (,exclusive privileges“) einzelner Anbieter: „A monopoly granted either to an individual or to a trading company, has the same effects as a secret in trade or manufactures."

(4) Gemeinsame Preisabsprachen zwischen Unternehmern derselben Branche: „People of the same trade seldom meet together, even for merriment or diversion, but the conversation end in a conspiracy against the public, or in some contrivance to raise prices." Dabei sind Preisabsprachen umso einfacher zu treffen, je weniger Marktteilnehmer vorhanden sind, wohingegen die Wettbewerbsintensität mit steigender Anbieterzahl zunimmt: „If this capital is divided between two different grocers, their competition will tend to make both of them sell cheaper than if it were in the hands of one only; and if it were divided among twenty, their competition would be just so much the greater, and the chance of their combining together, in order to raise the price, just so much the less. ${ }^{634}$

Insbesondere bei (3) und (4) kommt gemäß SMITH dem Staat die Aufgabe zu, derartige Umtriebe, welche den Wettbewerb hemmen, zu unterbinden - bzw. solche wenigstens nicht zu begünstigen. Allerdings forderte er, obwohl er die Gefahr, welche von Preisabsprachen auf den Wettbewerb ausgeht, erkannte, kein Kartellverbot. ${ }^{35}$

Bezüglich der Anzahl der Marktteilnehmer als Wettbewerbsdeterminante trifft SMITH - abgesehen von dem unter (4) angeführten Zitat keine eindeutigen Aussagen. ${ }^{36}$ So nimmt zwar die Wettbewerbsintensität mit steigender Anbieterzahl zu, jedoch wird auch in jeder anderen Marktform, selbst im Dyopol, gegenseitige Preisunterbietung als das entscheidende Wettbewerbsinstrument praktiziert. ${ }^{37}$ Viel wichtiger als die aktuelle Anzahl der Konkurrenten hingegen scheint SMITH die Möglichkeit zum freien

Vgl. auch Tolksdorf (1994), S. 38.

Smith (1852), S. 148.

Vgl. Smith (1852), S. 54.

Vgl. Stigler (1957), S. 2.

Vgl. McNulty (1967), S. 399. 
Marktein- und -austritt zu sein, die Disziplinierungswirkung potentieller Konkurrenz also. $^{38}$

Zusammengefasst waren für SMITH offenkundig folgende Wettbewerbsdeterminanten relevant: ${ }^{39}$

- Markttransparenz (MT): Die aktuellen und potentiellen Marktteilnehmer müssen über ausreichendes Wissen hinsichtlich der Marktdaten und -verhältnisse verfügen, um ihre Entscheidungen über die Lenkung ihrer Ressourcen auf bestmögliche Informationen zu gründen.

- Eigeninteresse (E): Die aktuellen und potentiellen Marktteilnehmer müssen notwendigerweise eine auf Eigeninteresse gründende Wirtschaftsmentalität zeigen. Das Streben nach persönlichem Erfolg begründet bei ihnen die ökonomische Beweglichkeit hin in Aktivitätsbereiche mit überdurchschnittlichen Gewinn- und Lohnaussichten.

- Staatliche Rahmenordnung (R): Um sicherzustellen, dass gut informierte und auf den eigenen Vorteil bedachte aktuelle und potentielle Marktteilnehmer nicht abgesprochene, unabhängige Verhaltensweisen praktizieren, muss der Staat eine entsprechende Rahmenordnung gewährleisten. Eine solche Rahmenordnung, welche die Gleichheit und Freiheit aller Bürger sichern und aufrechterhalten soll $^{40}$, muss sich vornehmlich gegen Monopolstellungen und Privilegien wenden und Gewerbefreiheit resp. die Möglichkeit zu freiem Marktzu- und -austritt schaffen. In einer solchen marktlichen Konstellation, welche gekennzeichnet ist durch eigennützig agierende, mit ausreichend Kenntnis über existierende Marktchancen versehene Wirtschaftssubjekte, wird die Anzahl der Marktteilnehmer normalerweise so hoch sein, dass die Möglichkeiten zu wettbewerbsbeschränkenden Absprachen äußerst gering sein werden.

Es gilt also bezüglich der Wettbewerbsintensität W:

$$
\mathrm{W}=\mathrm{W}(\mathrm{MT}, \mathrm{E}, \mathrm{R})
$$




\subsubsection{Der Ansatz der neoklassischen Preistheorie und deren wettbewerbstheore- tische Implikationen}

\subsubsection{Wettbewerbswirkungen und Wettbewerbsprozess}

Nachdem die modernen Marktwirtschaften die feudal-merkantilistischen Wirtschaftsordnungen erfolgreich niedergerungen haben, wandelte sich zwangsläufig das Erkenntnisinteresse in der wettbewerbstheoretischen Forschung. Beiträge nämlich, welche intendierten, den freien Wettbewerbsprozess traditionell im Sinne einer „Entwicklungstheorie" als überlegen gegenüber einer feudal-merkantilistischen Wirtschaftsordnung hervorzuheben,..., rannte[n] immer öfter offene Türen ein" ${ }^{41}$ Im Vordergrund stand nunmehr nicht mehr die Diskussion um die grundsätzliche Überlegenheit des Wettbewerbs als Marktprozess - das schien die Historie der ökonomischen Entwicklung soweit geklärt zu haben -, sondern die Frage, welche der zahlreichen möglichen Ausprägungsformen eines wettbewerblichen Marktprozesses bezüglich der Wettbewerbsintensität die beste ist. ${ }^{42}$ Das zentrale Erkenntnisinteresse der SMITH und den anderen Klassikern nachfolgenden Wettbewerbstheoretiker bestand nunmehr darin, die klassische Vorstellung bezüglich Ausgestaltung und Wirkungen des wettbewerblichen Preisbildungsprozesses zu präzisieren, sowie die Voraussetzungen, unter denen Wettbewerb den maximalen Wohlstand hervorzubringen in der Lage ist, also „vollkommen“ oder „vollständig“ ist, möglichst exakt zu erarbeiten. ${ }^{43}$ Die wettbewerbspolitischen Entscheidungsträger sollten nun mit konkreten Handlungsanweisungen versorgt werden, wie sie sich zu verhalten haben, um ein vorher zu definierendes Ziel bestmöglich zu erreichen. Wettbewerbstheorie bekam somit den Charakter einer Handlungs- bzw. Entscheidungstheorie. ${ }^{44}$ Diese angestrebte Exaktheit der Analyse wollte die sog. "mathematische Schule“ leisten. ${ }^{45}$ COURNOT analysierte die Preisbildung im Falle des Wettbewerbs und im Monopol und unternahm als erster den Versuch, den Wettbewerb mit mathematischer Genauigkeit zu definieren. ${ }^{46}$ JEVONS untersuchte die Bedingungen für einen wie er es nannte „vollständigen Markt“ und konstatierte für den Fall des Vorliegens vollständig unabhängigen Wettbewerbs-

40 Das Ordnungsprinzip, welches sich hinter dieser Forderung verbirgt, wurde als „Rule of Law“ bezeichnet. Vgl. Hoppmann (1968b), S. 83.

41 Tolksdorf(1994), S. 40.

42 Vgl. Tolksdorf (1994), S. 40.

$43 \mathrm{Vgl}$. Mantzavinos (1994a), S. 19

44 Vgl. Tolksdorf (1994), S. 42.

45 Vgl. Stigler (1957), S. 5 ff.

46 Vgl. Cournot (1924). 
verhaltens, dass auf demselben Markt zu einem Zeitpunkt nicht zwei Preise für dasselbe Gut existieren können (,law of indifference“). ${ }^{47}$ Eine vollständige formalisierte Abfassung der Modellbedingungen der vollkommenen Konkurrenz leisteten, nach Vorarbeiten von EDGEWORTH ${ }^{48}$, letzten Endes J. B. CLARK und insbesondere $\mathrm{KNIGHT}^{49} .{ }^{50}$

Mit dem Bestreben jedoch, den Wettbewerb mit mathematischer Exaktheit zu erfassen, ging eine fundamentale Neuausrichtung der wettbewerbstheoretischen Forschung einher. ${ }^{51}$ Diese manifestierte sich in radikalen Umdenk- bzw. Umgewichtungsprozessen, welche Anlass zur Kritik geben sollten, sowohl was die sachlogische Adäquanz des methodisch-konzeptionellen Betrachtungshorizontes als auch was die instrumentelle Adäquanz der „handwerklichen“ Umsetzung der Konzeption anbelangt.

Eine erste wesentliche Ausprägung dieser Umgewichtungsprozesse liegt in der durch das Bedürfnis nach quantifizierbaren Aussagen hinsichtlich Güte und Optimalität des Wettbewerbs hervorgerufenen rigorosen Mathematisierung der Wettbewerbstheorie selbst begründet. ${ }^{52}$ Die Mathematisierung nämlich veranlasst systembedingt zur Durchdringung der Wettbewerbsmaterie auf der Basis der theoretischen Deduktion und widmet die überwiegende Aufmerksamkeit dem quantitativen Ausdruck. Gleichzeitig bewirkt sie das weitgehende Loslösen von eigener Deduktion, um welche sich die Klassiker noch auf der Basis des Abgleichs von eigenen Annahmen über das Wettbewerbsphänomen mit empirischen Beobachtungen bemüht haben. In Konsequenz führt diese neue Herangehensweise jedoch dazu, dass der Wettbewerbstheoretiker nun offenbar geneigt ist, zugunsten des Strebens nach „ein für allemal festgelegten Ausgangsaxiomen" eigene Grundannahmen und -begriffe nicht mehr an der empirischen Realität zu überprüfen bzw. sie zu hinterfragen und gegebenenfalls zu revidieren. Somit ist wohl NEUMANNs Urteil beizupflichten: "Obwohl dadurch die Deduktion zunehmend an logischer Konsistenz und ästhetischer Eleganz gewinnt, wird die

Vgl. Jevons (1888), IV.22 ff. Jevons war es also, der als erster die beiden Konzepte des Wettbewerbs und des Marktes miteinander vermischt hat. Diese Vorgehensweise, welche von seinen Nachfolgern weitgehend übernommen worden ist, ist jedoch unsachgemäß. Beide Konzepte sollten vielmehr getrennt voneinander untersucht werden, der Grad der „Vollkommenheit“ eines Marktes bzw. der in ihm ablaufenden Prozesse sollte unabhängig von der Frage, ob oder inwieweit er wettbewerblich ist oder nicht, beurteilt werden. Vgl. Stigler (1957), S. 7.

Vgl. Edgeworth (1881).

Vgl. Knight (1921).

Für eine Übersichtsdarstellung der Bedingungen des Modells der vollständigen Konkurrenz vgl. bspw. Schmidt (1999), S. 5 f.

51 Tolksdorf spricht in diesem Zusammenhang sogar von einem „Paradigmenwechsel“. Vgl. Tolksdorf (1994), S. 40. 
Wissenschaftlichkeit der daraus abgeleiteten Aussagen hinsichtlich ihrer Aktualität bzw. ihres Erklärungsanspruchs über Wirklichkeitszusammenhänge in Frage gestellt, da wegen der wirklichkeitsfremden Ausgangsannahmen eine Falsifikation unmöglich ist. “53 In dieselbe Richtung argumentiert auch HOPPMANN, der der Gleichgewichtstheorie abspricht, Erklärungen über reale Ursache-Wirkungszusammenhänge zu geben. Die Ergebnisse („Preis/Mengen-Strukturen“) der Gleichgewichtanalyse seien Resultat eines logischen Kalküls aus den jeweils gemachten Annahmen; „die Antwort ist in den Annahmen bereits vollständig enthalten " ${ }^{54}$ In diesen Aussagen HOPPMANNs sind also gleich zwei Kritikpunkte enthalten: zum einen sei die Theorie des totalen Gleichgewichts tautologisch, zum anderen eine Übung in reiner Logik ohne empirischen Bezug. ${ }^{55}$

Eine zweite essentielle Ausprägung dieser Umgewichtungsprozesse war das scheinbare Verschwinden des dynamischen bzw. evolutorischen Charakters des wettbewerblichen Marktprozesses aus der Analyse - einer weiteren Kategorie also, welche in der klassischen Theorie als zentrales Wesensmerkmal des Wettbewerbs hervorgehoben worden war. ${ }^{56}$ Zentrales theoretisches Werkzeug der neoklassischen Preistheorie, ihre Erkenntnisse bezüglich der Bedingungen für die Optimalität des wettbewerblichen Marktprozesses zu untermauern, war hingegen die Gleichgewichtsanalyse. Diese Gleichgewichtsanalyse allerdings drängte den zu erklärenden Prozess in „das Prokrustesbett der stationären Wirtschaft der vollständigen Konkurrenz... in der nahezu alle Variablen, die dem Einfluss der unternehmerischen Entscheidung unterliegen, als Daten fixiert sind“. ${ }^{57}$ Das Wettbewerbskonzept wandelte sich somit implizit von der Dominanz der dynamischen Verhaltenkategorie hin zum Primat der statischen Ergebniskategorie mit rein ökonomischem Fokus. ${ }^{58}$ Diese Entwicklung muss natürlich als unsachgemä $\beta$ und unangemessen zurückgewiesen werden..$^{59}$ Allerdings wurde einer solchen Entwicklung möglicherweise von SMITH selbst Vorschub geleistet, indem er die ökonomischen Wirkungen des Wettbewerbs und hier insbesondere seine Allokationswirkung hervorgehoben hat und seine Ausführungen diesbezüglich den Fehlschluss

Vgl. dazu und für den folgenden Gedankengang Neumann (1982), S. 69 f.

Neumann (1982), S. 70.

Hoppmann (1980a), S. 22.

Vgl. Hoppmann (1980a), S. 22.

Vgl. Mantzavinos (1994a), S. 19.

Kaufer (1967), S. 95.

Vgl. Herdzina (1981), S. 225.

Dieser Ansicht ist auch Kantzenbach, der dem Wettbewerb evolutorischen und ungleichgewichtigen Charakter zuschreibt und der daher nicht durch eine statische Gleichgewichtsbetrachtung erklärt werden kann. Vgl Kantzenbach (1967), S. 32. 
zumindest billigend in Kauf nehmen mussten, den Wettbewerb als einen Zustand zu interpretieren, der sich dadurch auszeichnet, dass der Wettbewerbspreis mit dem natürlichen Preis übereinstimmt. ${ }^{60}$ Auch das Wettbewerbskonzept COURNOTs, des „Schöpfers der modernen Preistheorie ${ }^{\text {‘6 }}$, welches (zumindest explizit) völlig frei von verhaltensbedingten Zusammenhängen war $^{62}$, trug wohl dazu bei, dass jener Fehlschluss in der ökonomischen Forschung immer populärer wurde, obwohl COURNOT eigentlich nur jene Situation beschreiben wolle, in der die „Wirkungen des Wettbewerbs... ihre Grenze erreicht “63 haben. ${ }^{64}$ Insofern könnte dem statischen gleichgewichtigen Endzustand, der dann als Wettbewerb etikettiert wird, immerhin wenigstens ein dynamischer Wettbewerbsprozess vorangegangen sein. ${ }^{65}$ Es scheint wohl auch einiges dafür zu sprechen, dass der Wettbewerb in der neoklassischen Theorie durchaus weiterhin als dynamischer Prozess gesehen worden ist. Immerhin hoben bedeutende Neoklassiker wie MARSHALL oder J. B. CLARK ausdrücklich auf die Bedeutung der Dynamik von Verhaltensweisen der Wettbewerber ab. ${ }^{66}$ Selbst KNIGHT - eine zentrale Gestalt bei der Erarbeitung des Modells der vollkommenen Konkurrenz - gestand rückblickend ein, dass es sich bei der Gleichsetzung des Wettbewerbs mit diesem Modell um einen terminologischen Fehlgriff handelt. ${ }^{67}$ Daraus erhellt, dass der Beurteilung der neoklassischen Theorie als vorbehaltlos "statisch“ nicht uneingeschränkt zugestimmt werden kann. An der aus wettbewerbstheoretischem Blickwinkel eher nüchtern ausfallenden Beurteilung der preistheoretischen Analysebasis der Neoklassiker hinsichtlich ihrer Sachdienlichkeit und Aussagefähigkeit vermag dies de facto allerdings wenig zu ändern, da ,ihnen [den Neoklassikern, der Verf.] allen eine adäquate theoretische Präzisierung ihrer dynamischen Vorstellung nicht gelang“. ${ }^{68}$

Vgl. Herdzina (1981), S. 225. „The natural price, or the price of free competition, ..., is the lowest which can be taken, ...the lowest which the sellers can commonly afford to take, and at the same time continue their business." Smith (1852), S. 26 Söllner (2001), S. 76.

Vgl. McNulty (1967), S. 399.

Cournot (1924), S. 78.

Vgl. Herdzina (1981), S. 225.

Diese Annahme, dass es Tendenzen gibt, welche zum Gleichgewicht hinführen (bzw. deren Richtigkeit) ist auch unbedingt notwendig, um die Gleichgewichtstheorie von dem Vorwurf freizusprechen, ein Gedankenspiel mit einem rein logischen Bezug und ohne realwirtschaftlichen Hintergrund zu sein. Vgl. dazu ausführlich Hoppmann (1980a), S. $22 \mathrm{ff}$. 
Eine dritte markante Ausprägung dieser Umgewichtungsprozesse stellt sicherlich die Einengung der Sichtweise auf rein ökonomische Aspekte des Wettbewerbs dar. ${ }^{69}$ Das Interesse der wettbewerbstheoretischen Forschung schien sich von nun an gänzlich auf die ökonomischen Wirkungen des Wettbewerbs zu reduzieren, während außerökonomische Kategorien wie bspw. der Freiheitsaspekt, welcher im Gedankengut der Klassiker noch eine zentrale Rolle einnahm, aus der Analyse verschwanden, bzw. „als vorgegeben“ zwangsverselbstverständlicht wurden. ${ }^{70}$ Zunächst ist die Konzentration auf die reine Ökonomie zwar nicht generell negativ zu beurteilen, sondern war für den Erkenntnisfortschritt sogar notwendig. ${ }^{71}$ Das Problem des Ansatzes lag vielmehr darin begründet, dass ,sich diese Selektivität des Denkens nicht auf die analytischen Aufgaben begrenzt..." ${ }^{\text {"72 }}$ hat, sondern dass man die wirtschaftspolitische Verwertung der Aussagen der reinen Ökonomie beabsichtigte. ${ }^{73}$ Rein ökonomische Sachverhalte, welche man vorher aus analytischen Gründen aus dem gesellschaftlichen Gesamtkontext herausgehoben hat, wurden gedanklich verselbstständlicht und vom gesellschaftlichen Prozess entkoppelt. ${ }^{74}$ Die breit angelegte gesellschaftspolitische und wirtschaftsphilosophische Analysebasis der Klassiker wurde damit weitgehend preisgegeben. ${ }^{75}$ Innerhalb dieses ökonomischen Aspekts war zunächst das Allokationsproblem von überragendem Interesse, die Frage nach den Bedingungen also, unter denen ein gegebener Bestand an Produktionsfaktoren in die optimale Verwendung gebracht wird bzw. bei denen sich der Marktpreis dem natürlichen Preis annähert. ${ }^{76}$ Die Frage nach den den Fortschritt fördernden Wirkungen und Marktbedingungen hingegen war zunächst von sekundärem Interesse und wurde erst zu einem späteren Zeitpunkt problematisiert. ${ }^{77}$

So bleibt zusammenfassend zu konstatieren, dass die neoklassische Preistheorie sich auf die Analyse der rein ökonomischen Wirkungen des Wettbewerbs und hier insbesondere auf das Allokationsproblem konzentrierte. Um eine Antwort auf die Frage zu finden, unter welchen Bedingungen der Wettbewerb - geleitet durch seine

69 Vgl. dazu den Gedankengang Hoppmanns, welcher hier die Idee der rein ökonomischen Analyse in den Wirtschaftswissenschaften bzw. in der Volkswirtschaftslehre erörtert. Vgl. Hoppmann (1968b), S. $70 \mathrm{f}$.

70 Vgl. Mantzavinos (1994a), S. 20.

71 Vgl. Hoppmann (1968b), S. 75.

72 Hoppmann (1968b), S. 75.

73 Vgl. Hoppmann (1968b), S. 75.

74 Vgl. Hoppmann (1968b), S. 75.

75 Vgl. Neumann (1982), S. 73.

76 Vgl. Herdzina (1981), S. 225.

77 Vgl. Herdzina (1981), S. 225. 
„unsichtbare Hand“ - einen harmonischen Ausgleich zwischen Individualnutzenmaximierung und einer maximalen gesellschaftlichen Wohlfahrt hervorzubringen vermag, wurde der Wettbewerbsprozess auf den Prozess der Marktpreisbildung reduziert. Bei der formalmathematischen Analyse der Marktpreisbildung allerdings stand nicht die Durchdringung und Veranschaulichung deren prozessualen Charakters im Vordergrund, sondern der statische Endzustand, das quantitativ messbare Marktergebnis. Den Markstein preistheoretisch fundierter Modellkonstruktion stellt dabei sicherlich das Modell der vollkommenen Konkurrenz dar. Es markiert zum einen den Höhepunkt bei den Bestrebungen nach formalmathematischer Präzision in der Wettbewerbstheorie und galt für viele Ökonomen und Politiker lange als wettbewerbspolitisches Leitbild. Gleichzeitig wurde es aber aufgrund seines stationären Charakters, seiner realitätsfernen Modellprämissen und seiner auf die Marktform des homogenen Polypols ${ }^{78}$ beschränkten wettbewerbstheoretischen Aussagekraft hinsichtlich einer unzweifelhaften Deduktion wettbewerblichen Verhaltens vielfach kritisiert. ${ }^{79}$ Deswegen versinnbildlichte das Modell der vollkommenen Konkurrenz mithin möglicherweise auch den zentralen Anknüpfungspunkt für einen wissenschaftlichen Dissens bezüglich der Adäquanz der grundsätzlichen forschungsstrategischen Ausrichtung der neoklassischen Preistheorie, welche dazu tendiert, so die Kritiker, die relevanten Sachverhalte durch die mathematische Exaktheit und die ahistorische Modellierung unangemessen zu vereinfachen. ${ }^{80}$ Im Zuge dessen bildet es den gedanklichen Referenzpunkt für zahlreiche Modifikationen der im Modell der vollkommenen Konkurrenz formulierten Bedingungen und Hypothesen, welche in der Folgezeit viele konkurrierende wettbewerbstheoretische Modelle hervorgebracht haben.

... welche allenfalls einen theoretischen Grenzfall und nur im seltensten Fall eine beobachtbare Ausprägungsform einer realen Marktform darstellt.

79 Hoppmann bspw. kritisiert den Umstand, dass jeder Anbieter im homogenen Polypol ex definitione „machtlos“ ist, weil dies impliziert, dass er unfähig ist, sich am Markt gegen Konkurrenten durchzusetzen. Ein solcher Zustand der Machtgleichheit bzw. Machtlosigkeit im Verhältnis zueinander ist ein wettbewerbloser Zustand. Hoppmann hält den sozialen Prozess des Entstehens von Machtvorsprüngen sowie deren Erosion für das konstituierende Element für Wettbewerb. Vgl. Hoppmann (1977), S. $10 \mathrm{f}$. Insofern kann das stationäre Modell der vollkommenen Konkurrenz nicht in der Lage sein, Wettbewerb zu erklären.

Vgl. dazu auch Mantzavinos (1994a), S. 20. 


\subsubsection{Wettbewerbsdeterminanten}

\subsection{Grundhypothese}

Im vorangehenden Unterabschnitt wurde der kontinuierliche Prozess der formalmathematischen Präzisierung der Wettbewerbsvorstellung in der neoklassischen Preistheorie erörtert. Dieser Prozess kulminierte mit der Ausarbeitung des Modells der vollkommenen Konkurrenz. In diesem Modell werden jene Bedingungen formuliert, unter denen ein Markt sein bestmögliches Ergebnis produziert. Es zeigt, dass dieses bestmögliche Ergebnis dann erreicht wird, wenn die Marktform des homogenen Polypols vorliegt, in der jeder der vielen Anbieter so machtlos ist, dass dem einzelnen Anbieter keine andere Möglichkeit der Marktverhaltensweise als die gewinnmaximierende Mengenanpassung an den anonym am Markt gebildeten Marktpreis übrig bleibt. Dieses Verhalten hat dann notwendigerweise bestimmte Marktergebnisse (Gleichheit von Marktpreis und Grenzkosten; Produktion zu minimalen Durchschnittskosten; optimale Faktorallokation) zur Folge. Das Modell formalisiert folglich die disziplinierende Wirkung von Wettbewerb vieler Anbieter unter Abwesenheit jeglicher Marktmacht. ${ }^{81}$ Ferner untersuchte die Neoklassik die Preisbildungsprozesse im Monopol und später auch im Falle des Vorliegens alternativer Marktformen und zeigte auf, dass das Ergebnis im Monopol wohlfahrtstheoretisch betrachtet das schlechtestmögliche ist.

Weil offensichtlich aus neoklassischer Sicht marktmorphologische Konstellationen möglicherweise die Preisbildung determinierten, war es folgerichtig, dass sich in Folge des Leitgedankens der Analyse der Preisbildungsprozesse eine dezidierte Theorie der Preisbildungsformen entwickelte. Diese versuchte nun, eine Antwort auf die Frage zu liefern, welche Verhaltensweisen aus einem Pool zuvor festgelegter "typischer Verhaltensweisen" jeweils in welchen Marktformen bzw. Marktstrukturen wahrscheinlich sind. ${ }^{82}$ Die vollzogene Zuordnung von Verhaltensweisen und Marktstrukturen waren „... dann Ausgangspunkt und Prämissen der preistheoretischen Deduktionen, deren Resultate die Herausarbeitung zahlreicher verschiedener „Formen der Preisbildung" war" ${ }^{83}$ Die Theorie der Preisbildungsformen ihrerseits griff bei ihrer Analysesystematik auf die Erkenntnisse der Marktformenlehre zurück. Im Rahmen der Marktformenlehre wiederum wurde versucht, sämtliche relevante äußere Umstände zu erfassen und zu beschreiben, welche die Verhaltensweisen der Marktteilnehmer sowie

Vgl. Knieps (2001), S. 68.

Vgl. Hoppmann (1968b), S. 74.

Hoppmann (1968b), S. 74. 
die Art und Weise der Preisbildung bestimmen ${ }^{84}$ Eine mögliche - und gleichsam die am besten ausgebaute und am weitesten verbreitete - Art der Klassifikation verschiedener Marktformen erfolgte auf der Basis der Marktmorphologie bzw. Marktstruktur. ${ }^{85}$

Hinsichtlich der Aussagekraft der Theorie der Preisbildungsformen ist zu konstatieren, dass es ihr - abgesehen vom Fall der Marktform des homogenen Polypols - nicht möglich ist, eine bestimmte, genau definierte Verhaltensweise aus dem Vorliegen einer durch bestimmte morphologische Gegebenheiten gekennzeichneten Marktform eindeutig abzuleiten. ${ }^{86}$ Die Marktform kann das Marktverhalten und mithin die Marktergebnisse allenfalls beeinflussen, jedoch nicht determinieren. ${ }^{87}$ Allerdings vermag sie, unter Zugrundelegung von „typischen Verhaltensweisen“, Hypothesen zu formulieren, welche Marktform tendenziell jeweils charakteristischerweise eher wettbewerbliche oder eher nichtwettbewerbliche Verhaltensweisen begünstigt. ${ }^{88}$ Jene Hypothesen können dann zur Grundlage wettbewerbstheoretischer Implikationen oder wohlfahrtsökonomischer Ausführungen gemacht werden. ${ }^{89}$ Derartige Hypothesen gibt es nun in vielfachen Ausprägungen, welche sich z. T. massiv widersprechen. Folglich divergieren auch die auf den jeweiligen Hypothesen fußenden wettbewerbstheoretischen Implikationen sowie die letzten Endes artikulierten wettbewerbspolitischen Empfehlungen. ${ }^{90}$ Allen Konzeptionen gemein ist jedoch die Grundhypothese, dass die Intensität des Wettbewerbs abhängt von der jeweiligen Marktform bzw. Marktstruktur $\mathbf{M S}_{\mathbf{A}}$ :

$$
\mathrm{W}=\mathrm{W}\left(\mathrm{MS}_{\mathrm{A}}\right)
$$

Der Begriff Marktstruktur wird hier (1) im Sinne des Konzeptes der Marktform verwendet und ist (2) beschränkt auf die Fragen der Marktmorphologie der Angebotsseite, da die in den diversen Konzepten formulieren Hypothesen gleichfalls auf die Angebotsseite abheben.

Vgl. Hoppmann (1968b), S. 72.

Vgl. zur Marktformenlehre allgemein sowie für Möglichkeiten der Klassifikation von Marktformen ausführlich Ott (1959).

Vgl. Herdzina (1981), S. 226.

Vgl. Hoppmann (1968b), S. 72.

Vgl. dazu die Analyseergebnisse von Ott (1959), S. 112 ff., insb. S. 116-119.

Vgl. Herdzina (1981), S. 227.

Vgl. Herdzina (1999), S. 69.
} 
Die marktmorphologische Ausrichtung der Marktformenlehre dokumentiert sich in Gestalt des sog. Marktstrukturansatzes. Dieser umfasst als Klassifizierungskriterien fur die verschiedenen Marktformen eine qualitative Dimension, den Markttyp, sowie eine quantitative Dimension, die Marktbesetzung. ${ }^{91}$

Der Markttyp wird bestimmt durch die Strukturmerkmale

(1) Vollkommenheitsgrad des Marktes. Dieser wiederum wird bestimmt durch (1a) den Grad der Markttransparenz sowie durch (1b) den Grad der Homogenität der Güter (bzw. den Grad der Produktdifferenzierung). Ein Markt gilt dann als vollkommen, wenn vollständige Markttransparenz herrscht und wenn die Güter homogen sind, d. h. keine sachlichen, räumlichen, zeitlichen oder persönlichen Unterschiede zwischen ihnen bestehen. Sind alle Bedingungen erfüllt, handelt es sich um einen vollkommenen Markt, andernfalls (also beim Vorliegen von Intransparenzen oder verschiedenartiger Güter auf dem Markt) ist der Markt mehr oder weniger unvollkommen.

(2) Offenheitsgrad des Marktes bzw. die Höhe der Marktschranken. Dieses Merkmal hebt auf die Disziplinierungswirkung potenzieller Konkurrenz im Markte ab und wird in der Ökonomik auch unter dem Label der „,contestability“ erörtert. ${ }^{92}$ Marktschranken können in Form rechtlicher Marktzugangsregelungen, wirtschaftlicher Hemmnisse oder von anderen Marktakteuren errichteter strategischer Marktschranken auftreten. Je nach dem, wie schwer oder einfach es für das einzelne Wirtschaftssubjekt ist, am Markgeschehen teilzunehmen, unterscheidet man offene bzw. mehr oder weniger geschlossene Märkte.

(3) Organisationsgrad des Marktes. Dieser wird bestimmt durch das Ausmaß, in welchem marktliche Parameter (wie bspw. Ort, Zeit, Teilnehmerkreis, Art der gehandelten Güter oder das Verfahren der Preisbildung) durch gesetzliche oder durch Konvention festgelegte Regelungen beeinflusst werden. Man kann hier zwischen mehr oder weniger stark organisierten Märkten unterscheiden.

91 Vgl. dafür und für die folgenden Erörterungen Herdzina (1999), S. 68 f. sowie Herdzina (2005), S. $152 \mathrm{ff}$.

92 Vgl. dazu grundlegend Baumol, Panzar, Willig (1982). 
Die Marktbesetzung wird bestimmt durch die Strukturmerkmale

(4) Anzahl sowie die relative Größe der Marktteilnehmer bzw. die Marktanteilsverteilung, d. h. (4a) absoluter und (4b) relativer horizontaler Grad der Anbieterkonzentration.

(5) Anzahl und Höhe der Marktanteile der mehrstufigen Unternehmen auf dem jeweiligen Markt, d. h. der vertikale Konzentrationsgrad.

(6) Anzahl und Höhe der Marktanteile der Mehrproduktunternehmen auf dem jeweiligen Markt, d. h. der diagonale bzw. konglomerate Konzentrationsgrad.

Die hier angeführten sechs Marktstrukturmerkmale entsprechen im Wesentlichen dem BaINschen Gedanken hierzu. ${ }^{93}$ Natürlich ist es durchaus denkbar, dem Katalog weitere Merkmale zur Charakterisierung von Marktstrukturen hinzuzufügen. Allerdings führen inflationär umfangreiche Listen von Strukturmerkmalen ${ }^{94}$ dazu, dass die Vergleichbarkeit von Märkten und damit nachvollziehbare, empirisch begründbare Urteile hinsichtlich des Einflusses der Marktstruktur auf das Marktverhalten nicht mehr möglich sind, da in diesem Fall „... every market has a multitude of characteristics, and every market is in some degree structurally unique."“95

\subsection{Alternative Marktstrukturhypothesen}

Mehrere der zuvor dargestellten Strukturmerkmale sind Ausgangspunkt unterschiedlicher Strukturhypothesen, welche z. T. sehr unterschiedliche Antwort auf die Frage geben, welchen Einfluss eine bestimmte Marktstruktur auf das Marktverhalten bzw. die Marktergebnisse nimmt. Die wichtigsten werden im Folgenden kurz skizziert. ${ }^{96}$

Bezüglich der Strukturmerkmale (1a), (1b) und (4a) lassen sich folgende Strukturhypothesen unterscheiden:

Bain identifiziert den Grad der Anbieterkonzentration, den Grad der Nachfragerkonzentration, den Grad der Produktdifferenzierung sowie die Marktzugangsbedingungen (,conditions of entry to the market") als "the most salient aspects or dimensions" der Marktstruktur. Bain (1968), S. 7. So bspw. zu finden bei Sosnick, der 62 Strukturmerkmale produkt-, produktions-, absatz- sowie organisationsbezogener Couleur ins Felde führt. Vgl. Sosnick (1958), Anhang IV. 
- Vollkommene-Konkurrenz-Hypothese: Diese Hypothese fußt auf der modelltheoretischen Vorstellung, dass bei vollkommener Konkurrenz, d. h. im Falle des Vorliegens eines homogenen Polypols, der Wettbewerb ein Wohlfahrtsmaximum hervorbringt. Will man die maximale Funktionsfähigkeit des Wettbewerbs und dadurch ein Maximum an Wohlstand erreichen, ergibt sich folglich zunächst die Grundüberlegung, sich zu bemühen, auf den Märkten die Marktform des homogenen Polypols zu realisieren. Allerdings sind die Modellprämissen hierzu derart streng und restriktiv formuliert, dass dies in der Realität kaum möglich ist, weshalb die vollkommene Konkurrenz realistischerweise allenfalls als wettbewerbspolitischer Idealzustand, $d$. h. als erstrebenswerte Referenzsituation, interpretiert werden kann, welcher man sich möglichst anzunähern hat. Gemäß der Vollkommene-Konkurrenz-Hypothese erscheint demnach eine Annäherung der realen marktstrukturellen Konstellation an die Modellprämissen des homogenen Polypols als das probate Mittel, den Wettbewerb maximal möglich funktionsfähig zu machen und somit maximal möglichen Wohlstand zu produzieren. Im Kern lautet die Hypothese also: die Wettbewerbsintensität steigt mit steigender Anbieterzahl auf dem Markt und mit zunehmender Marktvollkommenheit (d. h. zunehmender Güterhomogenität und Markttransparenz), wodurch sich letztlich die Qualität der Marktergebnisse verbessert.

- Second-Best-Hypothese: Die Gültigkeit der Vollkommene-KonkurrenzHypothese ist in der Folgezeit angezweifelt worden. KALDOR bspw. wies schon früh auf die Möglichkeit einer Verschlechterung der Marktergebnisse für den Fall hin, dass bei Existenz von Güterheterogenitäten auf einem Markt der Marktzutritt erleichtert wird. Durch die dann zu erwartende Erhöhung der Anbieterzahl würden Überkapazitäten produziert. ${ }^{97} \mathrm{~J}$. M. CLARK griff diesen Gedanken auf und formuliert in seinem ersten wichtigen Beitrag im Rahmen seines Workable-Competition-Konzeptes in allgemeingültigerer Form die Hypothese, dass im Falle der Existenz von Unvollkommenheitsfaktoren (im Sinne der Nichterfüllung von Modellprämissen der vollkommenen Konkurrenz) auf einem Markt ein Hinzukommen bzw. Zulassen weiterer Unvollkommenheitsfaktoren unter Umständen den Wettbewerb funktionsfähiger (,workable“) machen und damit das Marktergebnis verbessern kann. ${ }^{98}$ Ein partielles Beseitigen von Unvollkommenheiten hingegen und damit die Annäherung an die Modell- 
prämissen der vollkommenen Konkurrenz bewirkt möglicherweise genau das Gegenteil. Einzelne Unvollkommenheiten sind also in der Lage, sich gegensei-

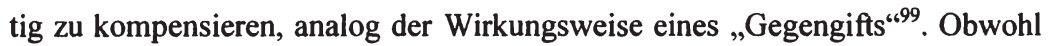
J. M. CLARK das Modell der vollkommenen Konkurrenz als wettbewerbspolitischen Idealzustand (noch) nicht in Frage stellt, bestreitet er dennoch ausdrücklich seine Realisierbarkeit ${ }^{100}$ und damit seine direkte wirtschaftspolitische Relevanz ${ }^{101}$. „Workable Competition“ indes vermag jedoch, gemessen am theoretischen Wohlfahrtsoptimum bei vollkommener Konkurrenz, allenfalls die unter den gegebenen Umständen maximal realisierbare zweitbeste (,second best") ${ }^{102}$ Lösung zu generieren. Diese zweitbeste Lösung allerdings ist immerhin „,workable“, d. h. der Wettbewerb wird auch unter Bedingungen, welche vom Vollkommenheitsideal abweichen, funktionsfähig gehalten. ${ }^{103}$

- Massenproduktionshypothese: Im Rahmen dieser Strukturhypothese wird die Auffassung vertreten, dass die Marktergebnisse sich mit sinkender Anbieterzahl auf einem Markt verbessern. Sie richtet sich damit ausdrücklich gegen das Modell der vollkommenen Konkurrenz, welches ja genau das Gegenteil postuliert. Ihr ökonomisches Fundament bezieht sie aus den Argumenten der Produktionsund Kostentheorie. Diese hebt auf Unterschiede in den Kostenstrukturen kleiner und großer Unternehmen ab, welche Großunternehmen, bedingt durch das Phänomen der Größendegression bzw. steigender Skalenerträge, effizienter arbeiten lassen als Kleinunternehmen. ${ }^{104}$ Dies bedeutet, dass weniger und größere Unternehmen den Markt effizienter versorgen können als viele kleine. Damit ist aber nicht notwendigerweise eine Erhöhung der Wettbewerbsintensität verbunden, die Hypothese hebt lediglich auf den Effizienzaspekt ab. Den Grundstein für diese sog. „Increasing-Returns-Diskussion“, die letztlich hinter dieser Hypo-

Der Begriff des "Gegengifts”, bzw. der „Gegengiftthese“ in diesem Zusammenhang wurde zuerst von Hoppmann verwendet. Vgl. Hoppmann (1966), S. 117.

Vgl. J. M. Clark (1940), S. 241.

Vgl. Mantzavinos (1994a), S. 27.

Vgl. grundsätzlich zur „Theorie des Second Best“ Lipsey, Lancaster (1956), S. 11 ff.

Vgl. Tolksdorf (1994), S. 46 f.

Beim Phänomen der Größendegression wird hier auf die Degression der langfristigen Kosten pro Produktionseinheit bei zunehmender Betriebs- oder Unternehmensgröße (im Sinne der Zunahme der Produktionskapazität) abgehoben. Das Adjektiv „langfristig“ ist dabei nicht als Ausdruck der Bezugnahme auf einen bestimmten Zeitraum oder -horizont zu verstehen, sondern gibt den konzeptionellen Hinweis auf die Tatsache, dass die Kosten unter der Bedingung der Kostenminimie- 
these steht, legte SRAFFA. ${ }^{105}$ Er thematisierte die Bedeutung zunehmender Erträge für den Wettbewerb. Er führte ferner den Einfluss von Kundenpräferenzen sowie die damit verbundenen Auswirkungen auf die Nachfragekurve des einzelnen Anbieters in das Gedankengebäude der Wettbewerbsökonomen ein. ${ }^{106}$ Darauf aufbauend identifizierte er die Monopolanalyse und deren analytischtheoretische Möglichkeiten als das eigentlich adäquate Instrument zur Erfassung des Markphänomens ${ }^{107}$ und leitete damit einen umfassenden Prozess der Modifikation des Modells der vollkommenen Konkurrenz ein ${ }^{108}$. Diese Modifikationen beanstandeten nicht mehr nur lediglich die ob seiner Realitätsferne ungenügenden Möglichkeiten zur Realisierung der Modellbedingungen, sondern wandten sich ausdrücklich gegen die Korrektheit der Annahmen und stellten die aus der Modellkonstruktion resultierenden wohlfahrtsökonomischen Schlussfolgerungen sowie insbesondere den damit einhergehenden Optimalitätsanspruch des Modells in Frage. ${ }^{109}$

- Vielfalthypothese: Der Gedanke, dass Monopolelemente für eine adäquate Erfassung des Wettbewerbsphänomens notwendigerweise in die Analyse einfließen müssen und insbesondere die Einsicht, dass reales Marktgeschehen von Produktheterogenität, d. h. von Kundenpräferenzen für einzelne Anbieter oder Produkte gekennzeichnet ist, ist in der Folgezeit von CHAMBERLIN aufgegriffen und ausgebaut worden. ${ }^{110}$ Die Vielfalthypothese besagt, dass in Anbetracht regelmäßig voneinander abweichender Geschmacksrichtungen der Nachfrager eine Vielfalt an unterschiedlichen, heterogenen Produktvarianten gewünscht wird

rung für jede vorgegebene, von einem Betrieb bzw. Unternehmen frei und ohne Friktionen wähl-

bare Produktionskapazität definiert sind. Vgl. Hofmann (1982), S. 32.

Vgl. Sraffa (1926), S. $535 \mathrm{ff}$.

Vgl. Sraffa (1926), S. 545.

Vgl. Sraffa (1926), S. 542.

Vgl. Mantzavinos (1994a), S. 21.

In diesem Sinne wird die paretianische Wohlfahrtsökonomik, welche dem Modell der vollständigen Konkurrenz zugrunde liegt, bisweilen als „Nirwana-Ansatz“ bezeichnet. Dieser Vorwurf fußt allerdings nicht primär auf der Tatsache, dass die Modellannahmen der vollständigen Konkurrenz wirklichkeitsfremd sind - eine (angemessene) Abstraktion von der Realität ist ein legitimes und notwendiges Mittel bei der Modellkonstruktion an sich. Vielmehr wird dem Modell angelastet, dass die Annahmen für die Erklärung der problematisierten Fragestellung unzweckmäßig sind, ein Erfüllen der Modellbedingungen wäre zur Lösung des Problems (Erreichung des Wohlfahrtsmaximums) möglicherweise ambivalent zu beurteilen oder gar als unerwünscht abzulehnen. Vgl. Fritsch, Wein, Ewers (1999), S. 68 f.

Vgl. Chamberlin (1933), sowie Chamberlin (1950), S. 85 ff. 
und damit ein mittlerer bzw. gesunder Grad an Produktdifferenzierung optimal ist. Daraus erhellt, dass „Monopolistic“ bzw. „Workable“ Competition nicht mehr lediglich als eine zweitbeste Lösung gelten kann, sondern wohlfahrtsökonomisch wünschenswert ist, wenn man eine realistischere Betrachtung der Strukturmerkmale vorzieht, als dies im Modell der vollkommenen Konkurrenz praktiziert wird. Dies ist wohl auch vonnöten, da ,the real world did not fulfil the assumptions of perfect competition" "11!.

- Schöpferischer-Wettbewerb-Hypothese: Im Rahmen der vier bislang vorgestellten Strukturhypothesen wurde versucht, einen Beitrag zur Beantwortung der Frage nach einer allokationsoptimalen Marktstruktur zu leisten. Diese und die folgende Hypothese hingegen beschäftigen sich mit der Frage nach der fortschrittsoptimalen Marktstruktur. Anstoß für die Beschäftigung mit den fortschrittsfördernden Marktbedingungen bildete der stationäre Charakter der Wettbewerbsanalyse, welcher aus ihrer bis dahin allzu allokationsfokussierten Ausrichtung resultierte. Es wurde die Auffassung vertreten, dass die Erforschung der wohlstandssteigernden Dynamik, welche durch unternehmerische Fortschrittsaktivitäten bewirkt wird, wichtiger ist, als lediglich die Frage nach der optimalen Allokation gegebener Produktionsfaktoren $\mathrm{zu}$ stellen. ${ }^{112}$ SCHUMPETER war der erste Ökonom, der in diesem Zusammenhang die Bedeutung der ökonomischen Figur des Unternehmers für die Entwicklungsdynamik des Wirtschaftsprozesses erkannt hat. ${ }^{113}$ Für ihn ist der endogene, evolutorische Prozess der „schöpferischen Zerstörung“ das essenzielle Faktum für den Kapitalismus. ${ }^{114}$ Dieser Prozess wird insbesondere von der unternehmerischen Initiative marktmächtiger Großunternehmen getragen und forciert, welche als hauptsächliche Träger des technischen Fortschritts durch die Einführung neuer Produkte und Produktionsprozesse, durch die Erschließung neuer Märkte und Rohstoffquellen sowie durch die Initiierung von marktstrukturverändernden Neuorganisationen „von innen heraus“ alte marktliche Strukturen unaufhörlich zerstören und gleichzeitig neue Strukturen schaffen. ${ }^{115}$ Die SchöpferischerWettbewerb-Hypothese besagt demgemäß, dass die den technischen Fortschritt

Vgl. Robinson (1933), S. 4

Vgl. Herdzina (1981), S. 232.

Vgl. Helmstädter (1990), S. 159; Mantzavinos (1994a), S. 84 f.

Vgl. Schumpeter (1975), S. 120.

Vgl. Schumpeter (1975), S. 120; Kantzenbach (1967), S. 32 ff.; Herdzina (1981), S. 233. 
und das Wachstum vorantreibende Wettbewerbsintensität mit sinkender Anbieterzahl auf dem Markt zunimmt. ${ }^{116}$ Unternehmen, welche in ihrer Existenz bedroht sind, werden zur Realisierung technischer oder organisatorischer Innovationen gezwungen und können dadurch einen Kostenvorteil gegenüber ihren Wettbewerbern herausarbeiten. Somit können sie durch Innovation die drohende Marktverdrängung abwenden und selbst in die Position des Verdrängenden kommen - ein zyklischer Prozess entsteht. ${ }^{117}$ Aufgrund des dynamischen Charakters des Ansatzes ergibt sich im Übrigen eine vergleichbare Diskrepanz zwischen Wettbewerbs- und Effizienzüberlegungen, wie sie bei der Massenproduktionshypothese zu konstatieren war, nicht. ${ }^{118}$

- Weites-Oligopol-Hypothese: Diese Strukturhypothese fußt im Wesentlichen auf den Überlegungen KANTZENBACHs, dessen Anliegen die Entwicklung der Theorie einer optimalen Wettbewerbsintensität war. Die (effektive) Wettbewerbsintensität wurde von ihm zunächst mit der „Geschwindigkeit, mit der die Vorsprunggewinne, die der technische Fortschritt den Unternehmern einbringt, von der Konkurrenz wieder weggefressen werden" gleichgesetzt. ${ }^{119}$ Diese Form der Betrachtungsweise ist Ausdruck der dynamischen Wettbewerbsgesinnung KANTZENBACHs in der Tradition SCHUMPETERs, ARNDTs und vor allem in Anlehnung an J. M. ClARK. ${ }^{120}$ KANTZENBACH interpretiert den Wettbewerb als zyklischen Prozess, der dem Wesen nach etwas Evolutorisches und Ungleichgewichtiges in sich trägt. ${ }^{121}$ Die Antwort auf die Frage nun, wie dieser Wettbe-

Es ist anzumerken, dass diese Hypothese nicht originär von Schumpeter formuliert wurde, sondern das Ergebnis der Interpretation Schumpeters Werks darstellt, welche von seiner Anhängerschaft in der Folgezeit geleistet wurde bzw. geleistet werden musste, da Schumpeter nicht genau genug klarstellte, ob er primär in der absoluten Unternehmensgröße oder im Ausmaß der Marktmachtposition des Unternehmens den entscheidenden Auslöser für Fortschrittsaktivitäten sah. Vgl. Herdzina (1990), S. 176 und S. 177 sowie Herdzina (1981), S. 233.

Vgl. Kantzenbach (1967), S. 34.

Schumpeter betrachtet die Art von Wettbewerb durch technischen Fortschritt als dem ,anderen“ Wettbewerb, welcher durch ein starres System unveränderter Bedingungen gekennzeichnet ist, als haushoch überlegen. Vgl Schumpeter (1975), S. 121. Ferner weist Schumpeter ausdrücklich auf die disziplinierende Wirkung potenzieller Konkurrenz hin. Vgl. Schumpeter (1975), S. 121.

Kantzenbach (1967), S. 38, Originalzitat von Niehans, J. (1954), Das ökonomische Problem des technischen Fortschritts, in: Schweizerische Zeitschrift für Volkswirtschaft und Statistik, Jg. 90, S. 156. Diese Definition Kantzenbachs ist Ausdruck der generellen Fortschrittsorientierung seines Ansatzes. Später verallgemeinerte er die Aussage von den fortschrittsinduzierten auf alle Arten von Vorsprungsgewinnen. Vgl. Kantzenbach (1967/68), S. 207.

$\mathrm{Vgl}$. Kantzenbach (1967), S. 14 f. und S. $32 \mathrm{ff}$.

Vgl. Kantzenbach (1967), S. 32. 
werbsprozess in optimaler Intensität abläuft, liegt nach KANTZENBACH im Zusammenspiel zwischen den beiden Komponenten der potenziellen und der effektiven Wettbewerbsintensität begründet, welche beide wiederum von denselben marktstrukturellen Faktoren abhängen. Demnach steigt die potenzielle Wettbewerbsintensität mit sinkender Anbieterzahl und steigendem Grad der Marktvollkommenheit aufgrund steigender oligopolistischer Reaktionsinterdependenz sowie steigender Unsicherheit für die Unternehmen, bis sie im homogenen Dyopol ihr Maximum erreicht hat. ${ }^{122}$ Demgegenüber stellt KANTZENBACH fest, dass mit steigender oligopolistischer Interdependenz auch die Neigung und die Möglichkeit zu wettbewerbsbeschränkenden Praktiken der Unternehmen steigen. ${ }^{123}$ Die gleichen Faktoren also, welche die potenzielle Wettbewerbsintensität erhöhen, verringern die effektive Wettbewerbsintensität - der ambivalente Charakter der oligopolistischen Interdependenz wird offenkundig. ${ }^{124}$ Daher läge die optimale Wettbewerbsintensität gemäß KANTZENBACH in einem Bereich, in dem man der maximalen potenziellen Wettbewerbsintensität schon möglichst nahe ist, die Gefahr von wettbewerbsbeschränkenden Verhaltensweisen aber noch nicht groß genug sind. ${ }^{125}$ Aus diesem Gedankengang erwächst die Weites-Oligopol-Hypothese, welche besagt, dass die optimale Wettbewerbsintensität im Bereich weiter Oligopole mit beschränkter Produkthomogenität und Markttransparenz liegt, einer mittleren Marktform also und nicht etwa in „extremen Marktformen“. ${ }^{126}$ Dabei sind die gewählten Formulierungen wie ,...im Bereich weiter Oligopole...“ oder ,... mit beschränkter Produkthomogenität..."Belege für die Tendenz, mit dem Bestreben, sich bei der Analyse der Wettbewerbsbedingungen in Richtung der tatsächlichen Bedingungen realen Wirtschaftsgeschehens zu bewegen, die anfängliche mathematische Präzision der preistheoretischen Modellannahmen aufzugeben. Dieser Präzisionsverlust liegt im Übrigen nicht nur bei der Weites-Oligopol-Hypothese vor. Vielmehr ist er bei sämtlichen hier vorgestellten Strukturhypothesen zu konstatieren, die allesamt als Antithesen zur Vollkommene-Konkurrenz-Hypothese entwickelt worden sind.

Vgl. Kantzenbach (1967), S. 87 ff.

Vgl. Kantzenbach (1967), S. 90.

Vgl. Kantzenbach (1967), S. 90 f.

Vgl. Borchert, Grossekettler (1985), S. 143.

Vgl. Kantzenbach (1967), S. 137. 
Doch nicht nur die Beziehung zwischen der absoluten Anzahl der Marktteilnehmer, dem Grad der Vollkommenheit des Marktes und der Wettbewerbsintensität bzw. dem Marktergebnis wird konträr beurteilt. Auch die übrigen Strukturmerkmale sind Gegenstand z. T. gegenläufiger Argumentationen und Hypothesen, welche hier im Einzelnen jedoch nicht dargestellt werden sollen. ${ }^{127}$

\subsubsection{Die Ansätze des Workable Competition und der Industrieökonomik}

Bisweilen werden die Forschungsrichtungen der Industrieökonomik und des Workable Competition synonym verwendet bzw. unter der dem Begriff „Harvard-Schule“ zusammengefasst. ${ }^{128}$ Dies ist allerdings aufgrund der offensichtlichen Verschiedenartigkeit der beiden Konzepte, insbesondere angesichts der unterschiedlichen Notwendigkeiten, aus denen heraus sie entstanden sind sowie angesichts der unterschiedlichen Erklärungsabsichten, welche hinter den beiden Konzepten stehen, unglücklich. ${ }^{129}$ Daher werden im Folgenden die Grundzüge beider Konzepte getrennt voneinander dargestellt, anschließend werden Unterschiede und verbindende Gemeinsamkeiten herausgearbeitet.

\subsubsection{Workable Competition}

\subsection{Die Grundlegung des Workable-Competition-Ansatzes}

Eng verbunden mit Terminus und Konzeption der Theorie des „Workable Competition" bzw. des "funktionsfähigen Wettbewerbs" sind sicherlich Name und Werk ihres Chefentwicklers und bis heute prominenten Vertreters J. M. CLARK. Er war derjenige, der diesen Begriff im Jahre 1939 anlässlich seines Vortrages vor der American Economic Association einführte und ihn mit seiner 1940 erschienenen ersten grundle-

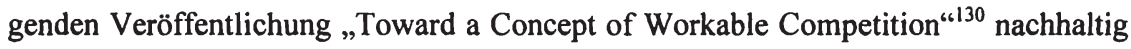
bekannt machte. ${ }^{131}$ Grundintention J. M. CLARKs war es zu diesem Zeitpunkt, die Unzulänglichkeiten der neoklassischen Preistheorie hinsichtlich ihrer Möglichkeiten, der Wettbewerbspolitik eine tragfähige und umsetzbare entscheidungstheoretische

127 Vgl. dazu im einzelnen Herdzina (1999), S. $71 \mathrm{f}$. 
Grundlage zur Realisierung eines funktionsfähigen Wettbewerbs zu liefern, zu überwinden. ${ }^{132}$ Ein funktionsfähiger Wettbewerb ist allerdings kein Idealzustand, gemessen an den für J. M. CLARK nach wie vor bindenden Optimalitätsvorstellungen des Modells der vollkommenen Konkurrenz. J. M. CLARK vertritt jedoch den Standpunkt, dass es ein Fehler sei, wie bislang über die Reduktion von Marktunvollkommenheiten zu versuchen, den Ergebnissen der vollkommenen Konkurrenz möglichst nahe zu kommen. Vielmehr besteht seine Strategie darin, den "Set" an bestehenden Unvollkommenheiten dergestalt aufeinander abzustimmen, dass sie sich gegenseitig kompensieren und den Weg zu einer tragfähigen zweitbesten Lösung im Sinne einer möglichst geringen Abweichung vom optimalen Ergebnis unter vollkommener Konkurrenz bereiten. ${ }^{133}$ J. M. CLARKs Ansatz bietet folglich, unter Berücksichtigung und bewusster Einbeziehung der nicht vermeidbaren Unvollkommenheiten und nicht änderbaren Bedingungen, die reales Wirtschaftsgeschehen nun mal zwangsläufig mit sich bringt, zumindest einen praxistauglichen Orientierungsrahmen fur die Auswahl und begriffliche Erfassung der wünschenswerten Formen des Wettbewerbs. ${ }^{134}$

Während J. M. CLARK also zunächst am Modell der vollkommenen Konkurrenz als Idealzustand festhielt und lediglich seine Realisierbarkeit in Frage stellte, sollte er seine Position später grundlegend ändern. In einer späteren Schaffensphase war seine Hauptintention die Entwicklung eines fortschrittsorientierten, dynamischen (first best) Wettbewerbskonzeptes. ${ }^{135}$ Signifikant für die angestrebte Weiterentwicklung seines Konzeptes war das Bestreben J. M. CLARKs, Elemente der dynamischen Innovationstheorie SCHUMPETERs, welche den technischen Fortschritt sowie Produkt- und Verfahrensinnovation in Beziehung zum Prozess der Wettbewerbsrivalität zum Gegenstand hatte, in sein Wettbewerbskonzept einzuarbeiten. ${ }^{136} \mathrm{Er}$ beschrieb den Wettbewerbsprozess nunmehr vor dem Hintergrund eines von der Person des Unternehmers gestalteten und getragenen Prozesses als ,.... combination of (1) initiatory actions by a business unit, and (2) a complex of responses by those with whom it deals, and by rivals“. ${ }^{137}$ Ein wesentliches Merkmal, welches die Funktionsfähigkeit dieses zyklischen Prozesses gewährleistet, ist ein ausreichender zeitlicher Abstand

\footnotetext{
132 Vgl. Tolksdorf (1994), S. 45.

133 Vgl. hierzu auch die Ausführungen zur "Second-Best-Hypothese" in Unterabschnitt 1.2.2.2.2.

134 Vgl. Clark (1940), S. 241

135

Sichtbares Zeichen für die Zäsur in Clarks Gesamtwerk ist die terminologische Nuancierung, dass er die dynamische Variante seines Wettbewerbskonzeptes nicht mehr als ,workable competition“ sondern als „effective competition“, wirksamen Wettbewerb also, bezeichnet. Vgl. Clark (1961).

137 Vgl. Schmidt (1999), S. 10.

Clark (1954), S. 326.
} 
zwischen der wettbewerblichen Vorstoßaktion und der folgenden Konkurrentenreaktion. Dieser zeitliche Abstand ist deswegen wesentlich, weil er den Unternehmen aufgrund der temporären Vorzugsstellung und dem damit verbundenen zu erwartenden Pioniergewinn für die Zeitdauer bis zur Neutralisation dieser Aktionen durch die nachfolgenden Konkurrentenreaktionen den Initialanreiz bietet, überhaupt erst wettbewerbliche Vorstoßaktionen anzustrengen. ${ }^{138}$ In J. M. CLARKs dynamisierter Variante des funktionsfähigen Wettbewerbs waren Marktunvollkommenheiten (wie bspw. mangelnde Markttransparenz, time lags in der Reaktionsgeschwindigkeit oder Produktheterogenität) demnach nicht mehr länger ein unabwendbares Übel, mit dem man sich zu arrangieren hat, sondern avancierten nun sogar zur unabdingbaren Voraussetzung für das Funktionieren des Wettbewerbsprozesses. ${ }^{139}$ Damit einher ging natürlich zwangsläufig der Bruch mit dem statischen Modell der vollkommenen Konkurrenz als wettbewerbspolitischem Leitbild. ${ }^{140}$

J. M. ClARKs Betonung der Relevanz dynamischer, fortschrittsfördernder Wirkungen des Wettbewerbs leistet folgendem Dilemma ${ }^{141}$ Vorschub, welches sich in der folgenden oder in ähnlicher Ausprägung durch die gesamte J. M. CLARK nachfolgende Workable-Competition-Literatur hindurch ziehen sollte: da der innovationsgetriebene Wettbewerbsprozess notwendigerweise mit temporären Vorzugsstellungen einzelner Unternehmen, also mit Monopolelementen, verbunden sein muss, um funktionieren zu können, kann es nicht gleichzeitig technischen Fortschritt und unbedingte wettbewerbliche Organisation von Märkten geben. ${ }^{142}$ Zwei Aspekte des Wettbewerbs - in diesem Fall: die Realisierung technischen Fortschritts und Sicherstellung unbedingter wettbewerblicher Handlungsfreiheit - sind nicht gleichzeitig erfüllbar, sind sogar miteinander unvereinbar. ${ }^{143}$ Damit ist das zentrale Problem umrissen, mit dem sich der Workable-Competition-Ansatz auseinanderzusetzen hat: Wie sind die wettbewerbspolitisch tolerierbaren, erwünschten von den nicht tolerierbaren, unerwünschten Unvollkommenheitselementen zu unterscheiden bzw. auf Basis welcher Kriterien können geeignete Konstellationen von Unvollkommenheitsfaktoren identifiziert

138

Vgl. Poeche (1970), S. 13.

Vgl. Mantzavinos (1994a), S. 27; Schmidt (1999), S. 10.

Vgl. Poeche (1970), S. 13. Clark meint hierzu: "For appraising dynamic progress "perfection" is an irrelevant criterion." Clark (1961), S. 2.

Vgl. für eine ausführliche Darstellung des sog. „Dilemma-Problems“ Herdzina (1975), S. $18 \mathrm{ff}$.

„Some departures from ,pure and perfect" competition are not only inseparable from progress, but necessary to it." Clark (1961), S. IX.

Vgl. Mantzavinos (1994a), S. 28 f. Vgl. auch die Ausführungen zur „Massenproduktionshypothese“, zur „Vielfalthypothese“, zur "Schöpferischer-Wettbewerb-Hypothese” sowie zur „WeitesOligopol-Hypothese" in Unterabschnitt 1.2.2.2.2. 
werden, welche als notwendige und/oder hinreichende Bedingung für die Funktionsfàhigkeit des Wettbewerbs betrachtet werden können. ${ }^{144}$

\subsection{Der konzeptionelle Kern des Workable-Competition-Ansatzes}

Obwohl J. M. CLARKs Konzept eine vergleichsweise klare Form aufweist, erhebt es nicht den Anspruch, den Charakter eines in sich geschlossenen Modells zu haben. Vielmehr meinte J. M. CLARK, dass sein Konzept lediglich eine Klammer darstellen sollte, innerhalb derer verschiedene Hypothesen ihren Platz finden könnten. ${ }^{145}$ Dies ist dann zwischenzeitlich auch so geschehen. Das Konzept des funktionsfähigen Wettbewerbs wurde vor allem in den USA, aber auch in Deutschland weiter intensiv beforscht, erfuhr zahlreiche Modifikationen, Umakzentuierungen und war Gegenstand umfangreicher Objektivierungsvorhaben und Systematisierungsversuche. ${ }^{146}$ Dies führte in der Folgezeit fast unweigerlich zu einer inflationär hohen Anzahl an Erscheinungsformen und konkurrierenden Definitionen für das Konzept des funktionsfähigen Wettbewerbs, was MASON diesbezüglich zu dem wenig hoffnungsfrohen Urteil veranlasst haben mag, dass "there are as many definitions of "effective“ or "workable" competition as there are effective or working economists. “147

Um zu einer Aussage zu gelangen, wie genau funktionsfähiger Wettbewerb nun auszusehen habe, gingen die Autoren in der Regel nach folgendem Schema vor: Zunächst gaben sie eine Definition ihrer jeweiligen „ganz persönlichen“ Vorstellung des Workable Competition sowie der Zielfunktionen, welche er zu erfüllen habe, ab. Danach stellten sie, auf das jeweilige Wettbewerbsverständnis abgestimmt, einen individuellen Katalog mit genau definierten kategorischen Normen auf, deren Erfüllung die Funktionsfähigkeit des Wettbewerbs garantieren würde. ${ }^{148}$ Der Grad der Erfüllung oder Nichterfüllung der Normen auf einzelnen Märkten und damit die Klassifizierung der Marktgegebenheiten und -geschehnisse in mehr oder weniger wettbewerblich sollte mithilfe entsprechender Testverfahren ermittelt werden. Dabei herrschte in der Autorenschaft prinzipiell Einvernehmen darüber, dass

Igl. Scherer, Ross (1990), S. 54; Schmidt (1999), S. 11.

Vgl. Clark (1955), S. 457.

Für einen umfassenden Überblick über die an der Diskussion beteiligten Autoren nebst den von ihnen vertretenen Positionen vgl. Poeche (1970) S. 14 ff. 
- zum Zwecke der Systematisierung der zur Identifikation sowie zur Beurteilung der Funktionsfähigkeit des Wettbewerbs definierten Normen die vertrauten Kategorien bzw. Merkmalsgruppen der Marktstruktur, des Marktverhaltens und des Marktergebnisses herangezogen werden. ${ }^{149}$ Innerhalb dieser Kategorien konnten wiederum zahlreiche Einzelmerkmale bzw. -dimensionen zum Gegenstand der Normierung im Einzelnen gemacht werden. Ferner bestand Konsens darüber, dass

- diese drei Kategorien nach Muster des sog. Marktstruktur-MarktverhaltenMarktergebnis-Paradigmas ${ }^{150}$ (im Folgenden: SVE-Paradigma) kausal miteinander verknüpft werden (bestimmte Marktstrukturen können bestimmte Marktverhaltensweisen bedingen, aus welchen wiederum bestimmte Marktergebnisse resultieren). Diese Sichtweise der Workable-Competition-Vertreter ist allerdings nicht revolutionär. Vielmehr lässt sie sich, zumindest im Grundsatz, auf die Tradition der neoklassischen Preistheorie zurückführen, welche den später im SVE-Paradigma postulierten Zusammenhang zwischen den drei Kategorien - wenngleich rudimentärer und auf einem weitaus höheren Abstraktionsniveau als im Workable Competition - schon lange vorher erfasst hat. ${ }^{151}$ Die wesentliche Neuerung des SVE-Paradigmas besteht darin, dass die Menge an Einzelmerkmalen, durch welche Struktur, Verhalten und Ergebnis eines Marktes erfasst werden sollen, exorbitant gestiegen ist. ${ }^{152}$ Insbesondere im Bereich der Marktstrukturmerkmale ist festzustellen, dass Workable Competition im Vergleich zur traditionellen Preistheorie das Marktstrukturkonzept erweitert hat, weshalb dieses nunmehr auch zahlreiche Merkmale umfasst, welche möglicherweise Wettbewerbsdeterminanten darstellen, welche aber nicht unter den eng gefassten, am Konzept der Marktform angelehnten Marktstrukturbegriff fallen. ${ }^{153}$

Weniger Einmütigkeit allerdings bestand bei der tatsächlichen Umsetzung. ${ }^{154}$ Es herrschte erhebliche Uneinigkeit darüber, „welcher Merkmalsgruppe Priorität

149 Vgl. Hoppmann (1968a), S. 38; Poeche (1970), S. 19.

Vgl. zur ausführlichen Darstellung des Marktstruktur-Marktverhalten-Marktergebnis-Paradigmas die Ausführungen im folgenden Unterabschnitt.

Vgl. hierzu die Ausführungen in Unterabschnitt 1.2.2.2.1. Vgl. ferner Hoppmann (1968a), S. 38;

Mantzavinos (1994a), S. 31.

Vgl. Herdzina (1999), S. 50. 
einzuräumen ist, in welchem Verhältnis und in welcher Rangfolge sie zueinander stehen, wie die Einzelkriterien zu bewerten sind und welche von ihnen primär oder sekundär berücksichtigt werden sollen“. ${ }^{155,}{ }^{156}$ Auf eine detaillierte Darstellung diesbezüglicher Lösungsvorschläge der einzelnen Autoren wird an dieser Stelle verzichtet, da die Zahl der Normen so groß ist und nur durch die „erfinderische Begabung" und die „Phantasie“ der Autoren begrenzt wird. ${ }^{157}$

Die zitierte Uneinigkeit bei der tatsächlichen Umsetzung des Workable-CompetitionKonzeptes ist den Schwächen seiner (preis-)theoretischen Basis zuzuschreiben. Ein Indiz hierfür mögen die verschiedenen Marktstrukturhypothesen aus Unterabschnitt 1.2.2.2.2 sein, welche das breite Spektrum an divergierenden Ansätzen zur Erfassung und Beurteilung von Zusammenhängen zwischen Marktstruktur-, Marktverhaltensund Marktergebnismerkmalen nur anzudeuten vermochten. Aber bereits die in dieser Arbeit getroffene Auswahl an Marktstrukturhypothesen vermag anschaulich zu verdeutlichen, dass es kein preistheoretisch fundiertes Wettbewerbskonzept gibt, welches Struktur, Verhalten und Ergebnis auf einem Markt exakt und eindeutig miteinander zu verknüpfen in der Lage ist. ${ }^{158}$ Dies tritt umso deutlicher zu Tage, wenn man sich angesichts des Vorhabens, reales Marktgeschehen beurteilen zu wollen, aus der sicheren Deckung, welche eine isolierte Betrachtung abstrakter Zusammenhänge ohne konkreten Realitätsbezug vermeintlich bietet, herauswagen muss und anstatt dessen die „besonderen Ergebnisse, die sich jeweils unter den eigentümlichen Bedingungen eines konkreten Marktes und einer bestimmten Industrie einstellen werden, vorauszusagen “159 beabsichtigt. Die offenkundigen Defizite der preistheoretisch fundierten Wettbewerbshypothesen fallen bei deren Anwendung auf die Komplexität realen Marktgeschehens umso mehr ins Gewicht. Diese Defizite können exemplarisch für die Marktstrukturhypothesen in den folgenden Kritikdimensionen zusammengefasst werden. ${ }^{160}$

Vgl. Poeche (1970), S. 19.

Poeche (1970), S. 19.

Vgl. zu einer Übersicht der jeweiligen diesbezüglichen Vorlieben der einzelnen Autoren sowie eine ausführliche Auflistung möglicher Einzelmerkmale innerhalb der drei Kategorien Poeche (1970), S. $17 \mathrm{ff}$.

Mantzavinos (1994a), S. 30.

Vgl. Herdzina (1981), S. 236; Hoppmann (1968a), S. 38.

Hoppmann (1977), S. 20.

Vgl. für das Folgende Herdzina (1981), S. $236 \mathrm{ff}$. 
- Widersprüchlichkeit der Wettbewerbshypothesen: Auf diesen Punkt wurde bereits mehrfach hingewiesen. Es hat sich bei der Darstellung der Strukturhypothesen bspw. gezeigt, dass in Abhängigkeit von der jeweils betrachteten Zielvorstellung unterschiedliche Marktstrukturen vorgeschlagen werden. Während bei freiheits- und verteilungsorientierten Hypothesen eher polypolistische Marktstrukturen präferiert werden, stehen bei fortschrittsorientierten Hypothesen die oligopolistischen Marktstrukturen im Vordergrund. ${ }^{161}$ Zudem werden zur Begründung einzelner Hypothesen unterschiedliche Argumentationsmuster entworfen, inwieweit und in welche Wirkungsrichtung die Zahl der Anbieter auf einem Markt die Wettbewerbsintensität beeinflusst. Augenscheinlich neigen die Ansätze dazu, plausible Zusammenhänge auf Basis einzelner struktureller Einflussfaktoren zu verabsolutieren bzw. diesen Einflussfaktoren hinsichtlich ihrer Fähigkeit, Marktverhalten zu bestimmen, ein nicht gerechtfertigtes hohes Gewicht einzuräumen. ${ }^{162}$ Die Vielzahl an sich widersprechenden Wettbewerbshypothesen kann demnach ein Indiz dafür sein, dass möglicherweise (1) verschiedene Marktstrukturen eine notwendige Voraussetzung für unterschiedliche Marktergebnisse sind und/oder (2) die Realisierung einer bestimmten Marktstruktur nicht hinreichend dafür, ein bestimmtes Marktverhalten zu initiieren. ${ }^{163}$

- Mangelnde Präzision der Wettbewerbshypothesen: Abstrahiert man von den beiden empirisch nicht nennenswert relevanten Extremkonstellationen des homogenen Polypols und des Monopols, so verbleibt die Hypothese, dass die optimale Wettbewerbsintensität beim Vorliegen eines ,gesunden Grades an Vielfalt" größerer und kleinerer Anbieter ${ }^{164}$ bzw. in "mittleren Marktformen“" zu suchen sei. Da zum einen die Grenzen dieser „mittleren Marktformen“ in den jeweiligen Konzepten sehr vage formuliert sind und da zum anderen die Bandbreite denkbarer und vorzufindender Marktverhaltensweisen in diesen „mittleren Marktformen“ von jeder Art wettbewerblichen Marktverhaltens bis hin zu Formen wettbewerbsbeschränkenden Marktverhaltens reicht, stellt sich die Frage nach dem Erklärungswert dieser Hypothese. ${ }^{165}$ Angesichts der Tatsache, dass die Charakterisierung der „mittleren Marktformen“ für die Analyse und Beurteilung realer Märkte nicht treffsicher genug ist und dass sich a-priori-Aussagen

Vgl. Herdzina (1999), S. 78.

Vgl. Hoppmann (1968a), S. 38 f.; Herdzina (1981), S. 237.

Vgl. Herdzina (1999), S. 78 f.

Vgl. Tolksdorf (1994), S. 54.

Vgl. Herdzina (1999), S. 79. 
über das Marktverhalten in „mittleren Marktformen“ offenkundig auch nicht treffen lassen, scheinen analytischer Wert und empirische Relevanz der Hypothese fragwürdig zu sein. ${ }^{166}$

- Mangelnde Operationalität der Wettbewerbshypothesen: Um den Grad der Wettbewerbsintensität auf einem Markt beurteilen zu können, muss zuvor der Wettbewerbsbereich, $d$. h. der relevante Markt, bestimmt werden. In der traditionellen preistheoretischen Analyse vollkommener Märkte stellt das kein Problem dar: Güter sind eindeutig definiert, Märkte sind exogen vorgegeben. Werden Unvollkommenheitsfaktoren in die Analyse einbezogen, wie bspw. heterogene Güter, gestaltet sich die Bestimmung des relevanten Marktes hingegen schwierig. Theoretisch kann die Marktabgrenzung zwar anhand des ökonomischen Homogenitäts- bzw. Heterogenitätsgrades der Güter vorgenommen werden, wofür auch diverse Konzeptionen ${ }^{167}$ und Maße entwickelt worden sind. ${ }^{168}$ Allerdings stellt sich die Frage, ob konkrete Werte für Marktabgrenzungsmaße (wie bspw. die Kreuzpreiselastizität der Nachfrage) empirisch überhaupt ermittelbar sind und - gesetzt den Fall, sie konnten ermittelt werden - wo der Grenzbzw. Schwellenwert liegt, bis zu bzw. ab welchem „Gleichartigkeit der Güter“ und damit die Zusammenfassung zu einem relevanten Markt zu konstatieren ist. ${ }^{169}$ Die Frage der Verortung von Marktgrenzen ist objektiv wohl nicht zu beantworten, Entscheidungen darüber müssen sich im konkreten Fall auf Werturteile der damit betrauten Fachleute bzw. -gremien stützen. ${ }^{170}$ Die Abgrenzung des relevanten Marktes ist folglich nicht die logische Voraussetzung für eine Marktanalyse, sondern ergibt sich währenddessen oder im Nachhinein. Der relevante Markt ist insofern ein normatives Konzept. ${ }^{171}$ Obwohl dieses Vorgehen willkürlich und deshalb unbefriedigend zu sein scheint, ist demgegenüber eine vorab durchgeführte, starre Marktabgrenzung aus folgenden Erwägungen heraus nicht sinnvoll: In realen Märkten ist der relevante Markt, anders als es die Wettbewerbshypothesen der traditionellen Preistheorie implizieren, kein Datum sondern eine Größe, die in Abhängigkeit der Verhaltensweisen der Marktteil-

Vgl. Herdzina (1981), S. 238. Derselben Ansicht ist auch Tolksdorf. Er meint, „dass die Wettbewerbstheorie mit der Annäherung an die Realität die Präzision ihrer Modellannahmen aufgeben musste". Tolksdorf (1994), S. 54.

$\mathrm{Vgl}$. für eine ausführliche Darstellung verschiedener Möglichkeiten zur Marktabgrenzung und deren Bewertung Bauer (1989) sowie Bauer (1995).

Vgl. Herdzina (1981), S. 239.

Vgl. Berg (1977), S. 287 f.; Herdzina (1999), S. 76.

Vgl. Herdzina (1999), S. 76. 
nehmer variabel ist. Unternehmen können durch wettbewerbliche Vorstoßaktionen (welche ja de facto Vorgänge marktstrukturverändernder Produktdifferenzierung darstellen) bzw. durch entsprechende Variation ihres Parametereinsatzes ihre Produkte dergestalt verändern, dass sie sich den Produkten anderer Anbieter annähern oder sich von ihnen entfernen. ${ }^{172}$ Märkte werden dann entweder weiter oder enger.

Aus den hier vorgestellten Kritikpunkten, welche an der mangelhaften Qualität der preistheoretisch fundierten Marktstrukturhypothesen ansetzen, erhellt, dass die Preistheorie außerstande sein dürfte, eine Referenzgröße für erwünschte Marktergebnisse in einem Untersuchungsmarkt bestimmen zu können. Ein solcher objektiver Maßstab aber wäre unabdingbar für die Beurteilung des Wettbewerbs als „workable“ oder „effective“. ${ }^{173}$

Es ist daher angesichts der vorgetragenen Beanstandungen hinsichtlich der preistheoretischen Fundierung des Workable-Competition-Ansatzes nur folgerichtig, dass es seinen Vertretern nicht gelungen ist, einen allgemein akzeptierten Katalog mit Normen aufzustellen, welche in hinreichend operationalisierbarer und justiziabler Form als Beurteilungskriterien für die Funktionsfähigkeit des Wettbewerbs herangezogen werden können. ${ }^{174}$

\subsubsection{Industrieökonomik}

\subsection{Die Grundlegung der Industrieökonomik}

Die Industrieökonomik (synonym: Industrial Organization, Industrial Organization Analysis) stellt bis heute ein nicht präzise umrissenes Teilgebiet der Volkswirtschaftslehre dar. Gemäß BÜHLER und JÄGER kann sie als „...theoriegeleitete Forschung im Bereich der Prozesse, Strukturen und Organisationen von Industrien im weitesten Sinne - den Dienstleistungssektor mit eingeschlossen..." beschrieben werden. ${ }^{175}$ SCHERER und ROSS konstatieren, dass die Industrieökonomik “... is concerned with

Vgl. Hoppmann (1974a), S. 10 f.

Vgl. Herdzina (1999), S. 77.

Vgl. Giesel (1975), S. 30.

Vgl. ausführlich Berg (1977), S. 292 ff.

Bühler, Jaeger (2002), S. 1. 
how productive activities are brought into harmony with the demand for goods and services through some organizing mechanism such as a free market, and how variations and imperfections in the organizing mechanism affect the success achieved in satisfying an economy's wants." 176 Die Industrieökonomik befasst sich demnach mit der Interaktion von Markt und Unternehmen ${ }^{177}$ und somit mit Fragestellungen bezüglich der Funktionsmechanismen von Märkten.

Die Frage nach den Funktionsmechanismen bzw. der Funktionsweise der Marktwirtschaft ist auch Gegenstand der "traditionellen“ mikroökonomischen Theorie, jedoch unterscheidet sich die Industrieökonomik in ihrer Schwerpunktsetzung von der Mikroökonomik. ${ }^{178}$ Die Industrieökonomik befasst sich in erster Linie mit marktspezifischen Partialmodellen, d.h. mit isolierten Industrien, ohne dabei die Interdependenz mit anderen Märkten zu thematisieren. ${ }^{179}$ Demgegenüber bevorzugt sowohl die allgemeine Gleichgewichtstheorie als auch die mikroökonomische Haushalts- und Unternehmenstheorie vornehmlich die simultane Betrachtung einer Vielzahl interdependenter Märkte. ${ }^{180}$ Die streng partialanalytische Vorgehensweise versetzt den Industrieökonomen in die Lage, die betreffende Industrie sehr detailliert analysieren zu können und dabei Aspekte einzubeziehen, die in der üblichen Mikroökonomik allenfalls von untergeordneter Bedeutung sind. ${ }^{181}$ Somit zeichnet sich die Industrieökonomik dadurch aus, dass $\operatorname{sie}^{182}$

- sich unmittelbar auf das reale Geschehen auf abgegrenzten Märkten konzentriert und deshalb stark anwendungsorientiert ist;

- das strategische Verhalten der Wirtschaftssubjekte berücksichtigt;

- auf marktspezifische institutionelle Gegebenheiten eingeht;

Scherer, Ross (1990), S. 1.

Vgl. Bühler, Jaeger (2002), S.I sowie Bester (2004), S. I.

Vgl. Herdzina (1981), S. 247.

Vgl. Bester (2004), S. 2.

Vgl. dazu Bühler, Jaeger (2002), S. 2.

Vgl. Bester (2004), S.2. Hier nennt er u. a. das Wettbewerbsverhalten im Oligopol, Marktzutritt und Marktaustritt sowie Forschung und Entwicklung. Auch Herdzina identifiziert die Fülle der von der Industrieökonomik untersuchten Variablen als ein wesentliches Unterscheidungsmerkmal zur Mikrotheorie. Vgl. auch Herdzina (1981), S. 247. Scherer und Ross bemerken, dass, im Vergleich zu Mikrotheoretikern, „... Industrial organization economists are more inclined towards explanations rich in quantitative and institutional detail." Scherer, Ross (1990), S. 2.

Vgl. für das folgende Bühler, Jaeger (2002), S. 2.
} 
- versucht, die Funktionsweise bzw. die Funktionsmechanismen bestimmter Märkte zu erklären und vorherzusagen;

- vor allem in der ersten Phase sehr empirisch ausgerichtet war ${ }^{183}$.

\subsection{Der konzeptionelle Kern der Industrieökonomik}

\section{Das Marktstruktur-Marktverhalten-Marktergebnis-Paradigma}

Die Anfänge der Entwicklung der industrieökonomischen Disziplin reichen bis in die frühen 1930er Jahre zurück. In dieser Zeit wurde die neue, preistheoretisch fundierte Betrachtungsweise von Vorgängen in Industrien als Resultat der Zusammenarbeit von CHAMBERLIN und MASON in Harvard begründet. ${ }^{184}$ Im Jahre 1938, also ein Jahr vor J. M. CLARK, präsentierte MASON vor der American Economic Association einen analytischen Rahmen, der als Grundmuster für die Untersuchung von Prozessen in Industrien dienen konnte: ,.... and adequate analysis of price and production policies requires consideration of (a) the influence of the organization of a firm on the character of the firm's reaction to given market situations; and (b) elements of market structure which include many more things than numbers and product differentiation." ${ }^{185}$ Das war der Zeitpunkt der Geburt des Marktstruktur-Marktverhalten-Marktergebnis-Paradigmas (im Folgenden: SVE-Paradigma). ${ }^{186}$ Später betonte MASON wiederholt ausdrücklich die Relevanz, welche dabei die Analyse der internen Organisations- und Entscheidungsstrukturen in der Unternehmung für die Güte der industrieökonomischen Analysequalität hat: „The large corporation is a complex administrative unit in which control frequently bears a very attentuated relationship to owners' interests, in which management is increasingly professionalized, in which the character of labor organization may influence price and production decisions, and in which at best a considerable area of important price decision must be routinized and delegated to subordinates. Hence management, in the determination of price and production policies, is influenced not only by market pressures but also by considerations internal

Vgl. dazu auch Kaufer (1980), S. 5; Herdzina (1981), S. 247.

Vgl. Grether (1970), S. 83; Kaufer (1980), S. 5.

Mason (1939), S. 66.

Vgl. Mantzavinos (1994b), S. 66.
} 
of the firm." 187 Die preistheoretische Basis der industrieökonomischen Analyse bedurfte folglich der Ergänzung um unternehmensinterne Variable. ${ }^{188}$

Aufgrund des im vorangehenden Unterabschnitt dargestellten Aufgabenspektrums und des daraus resultierenden Erklärungsanspruchs, den die Vertreter der Industrieökonomik daraus ableiten, erscheint der Markt im volkswirtschaftlichen Sinne bzw. die darin ablaufenden Marktprozesse das angemessene Untersuchungsobjekt zu sein. ${ }^{189}$ Anfangs war noch die einzelne Firma die relevante Untersuchungseinheit. MASON erhoffte sich davon, dass eine firmenbezogene Klassifikation von Marktstrukturen ihn hin zu einer Klassifikation von unternehmerischen Verhaltensweisen führen würde. ${ }^{190}$ Später (1947) wurde unter dem Einfluss von BAIN die MARSHALlsche Industrie als Untersuchungseinheit gewählt. ${ }^{191}$ MASON schließt sich später dieser Sichtweise an: „When the term „market“ is used, a Marshallian industry is meant; that is, a census industry appropriately adjusted for product and spatial considerations. Unless we can use the conception of the market and, with it, properly rectified industry data, the field of industrial organization is a wilderness. Triffin, with his general equilibrium of the firm, has attempted to lead us up the garden path, and if we expect to retain our virtue, we had better retreat as rapidly as possible to the shelter of the Marshallian industry". ${ }^{192}$ Die Herangehensweise, das Industriekonzept als Basis für Marktanalysen zu verwenden, war insofern also ein Ergebnis pragmatischer Erwägungen, da eine Fülle an industriebezogenem statistischem Datenmaterial in Form von qualitativ akzeptablen Zensusdaten zur Verfügung steht und folglich die Grenzen des Untersuchungsobjektes halbwegs deutlich umrissen sind. Zudem gestattet die befriedigende Datenqualität die Durchführung industrieübergreifender ökonometrischer Querschnittsanalysen.

Allerdings geht die Verwendung des Industriekonzeptes unter Umständen zulasten der Zweckmäßigkeit der Analyse, da bestehende tatsächliche Wettbewerbsbeziehungen zwischen den Marktakteuren möglicherweise nicht genau abgebildet werden können. ${ }^{193}$ Wenn man allerdings beabsichtigt und - um im MASONschen Bild zu bleiben sich dennoch in die „Wildnis“ begibt, um möglichst die gesamte Breite der relevanten

187

188

189

Mason (1959), S. 62.

Vgl. Kaufer (1980), S. 6.

So sprechen auch Scherer und Ross ausdrücklich von Marktprozessen als dem relevantem Untersuchungsgegenstand: „In the field of industrial organization, we try to ascertain how market processes direct the activities of producers in meeting consumer demands..." Scherer, Ross (1990), S. 2.

Vgl. Kaufer (1980), S. 7.

Vgl. dazu Bain (1948), S. 15 I ff.; Kaufer (1980), S. 7 f.

Mason (1959), S. 5 f. 
wettbewerblichen Verflechtungen in der Analyse zu erfassen, sieht man sich den bereits an anderer Stelle erörterten Problemen gegenüber, welche sich aus der Notwendigkeit der Abgrenzung des relevanten Marktes ergeben.

Das SVE-Paradigma sollte der positiven Analyse von Märkten dienen und konnte sich in der Folgezeit als zentrales Paradigma der Industrieökonomik etablieren. ${ }^{194} \mathrm{Die}$ Grundlage des SVE-Paradigmas ist die Hypothese einer einseitigen Kausalbeziehung zwischen Marktstruktur, Marktverhalten und Marktergebnis. Demnach bestimmt die Struktur eines Marktes das Verhalten der darin involvierten Wirtschaftssubjekte und dieses determiniert wiederum das Marktergebnis. Diese Sichtweise wird auch die „behavioristische Position“ genannt (vgl. Abbildung 1-1).

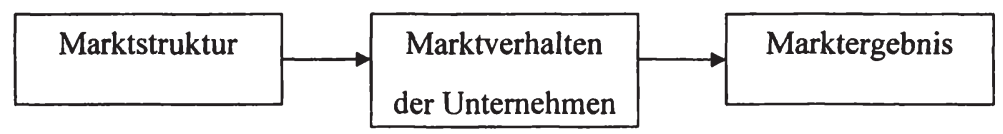

\section{Abbildung 1-1: Behavioristische Position}

Quelle: eigene Darstellung

$\mathrm{Zu}$ den exogen vorgegebenen Marktstrukturvariablen können, unter anderem, folgende Merkmalsgruppen gezählt werden ${ }^{195}$ :

- Die ökonomischen Merkmale der Produkte (Qualität, Differenzierungsgrad, Nähe zu Substituten, usw.)

- Die Produktions- und Kostenstrukturen der Unternehmen (Skalen- und Verbundvorteile, Subadditivitäten, usw.)

- Die Anzahl und die relative Größe der Nachfrager und der Anbieter sowie die Höhe der Markteintrittsbarrieren

193 Vgl. Kaufer (1980), S. 7.

194 Vgl. hierzu die Arbeiten von Mason (1949) sowie Bain (1951) und (1956). Vgl. auch Mantzavinos (1994a), S. 35. 
- Die Nachfragetrends, die saisonalen und zyklischen Schwankungen der Nachfrage sowie der Kenntnisstand der Nachfrager bezüglich des Produktes

- Die Absatzkanäle und das Vertriebssystem

Die Markstrukturvariablen bestimmen das Verhalten der Unternehmen. Die Marktverhaltensvariablen können, unter anderem, folgende Größen umfassen ${ }^{196}$ :

- Preis-, Qualitäts- und Mengensetzungsverhalten

- Investitionsverhalten

- Forschungs- und Entwicklungsanstrengungen

- Marketingverhalten

- Allianz- und Diversifizierungsstrategien sowie das Kooperationsverhalten

Die endogenen Marktverhaltensvariablen determinieren letztendlich das Marktergebnis. Hierzu können unter anderem gezählt werden ${ }^{197}$ :

- Gewinnmargen der Firmen

- Produktivität der Industrie

- Produktvarietät

- Allokative Effizienz des Marktes

- Rate des technischen Fortschritts

Im Gegensatz dazu sehen die Vertreter der „strukturalistischen Position“ (vgl. Abbildung 1-2), zu denen auch BAIN zu zählen ist, das Marktverhalten lediglich als Zwischenglied an und gehen von einer direkten Wirkungsbeziehung zwischen Vorschlag für die Einteilung in diese Merkmalsgruppen kommt von Mason. Vgl. Mason (1939), S. 69; Mason (1959), S. $65 \mathrm{f}$. 
Marktstruktur und Marktergebnis aus, weswegen die Verhaltensanalyse des Öfteren sogar übersprungen wurde. ${ }^{198}$ Diese Vorgehensweise äußerte sich in zahlreichen vorliegenden empirischen Studien, in denen die Abhängigkeit der Gewinnraten von der Anbieterkonzentration untersucht wurde. ${ }^{199}$

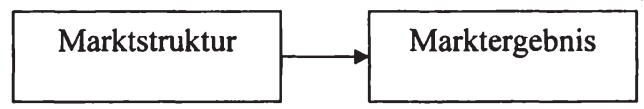

\section{Abbildung 1-2: Strukturalistische Position}

Quelle: Eigene Darstellung

Obwohl mit Hilfe des SVE-Paradigmas in der Folgezeit eine Fülle von Veröffentlichungen auf dem Gebiet der Industrieökonomik dazu beigetragen hat, bestimmte industriespezifische Problemstellungen zu identifizieren und zu klassifizieren, so war die Sichtweise der meisten Autoren bis in die 1960er Jahre hinein von gefährlicher Einseitigkeit geprägt. In diesem Zusammenhang sind zumindest zwei Kritikdimensionen zu erwähnen, eine theoretische und eine empirische. ${ }^{200}$

(1) Im Bereich der Theorie ist die Auffassung zu bemängeln, das Verhalten der Akteure sei weitgehend durch die Marktumgebung bestimmt. Die implizite Annahme, dass alle Firmen dieselbe Zielsetzung haben und sich mehr oder minder passiv an die Bedingungen ihrer industriellen Umwelt anpassen, führt zu einer groben Unterschätzung der Rolle der Verhaltensweisen. Insofern werden Veränderungen als exogen begriffen, sowohl die Verhaltensweisen als auch das Ergebnis sind durch exogene strukturelle Veränderungen determiniert. ${ }^{201}$ Ferner handelt es sich um ein eindimensionales, statisches System, das

Vgl. Bühler, Jaeger (2002), S. 6.

$\mathrm{Vgl}$. für einen umfassenden Überblick über die empirischen Studien, deren Grundbefund die positive Korrelation zwischen Konzentration und Gewinn war, Böbel (1978) und aktualisiert Böbel (1984), Teil B, insb. Kap. X. 
außer Acht lässt, dass Marktvorgänge dynamische Phänomene sind, die sich im Zeitablauf entwickeln. ${ }^{202}$

(2) Im Bereich der Empirie wurde versucht, mittels zahlreicher Branchenstudien statistisch signifikante Beziehungen zwischen Ergebnismaßen (bspw. der Gewinnrate) und Marktstrukturvariablen (bspw. dem Konzentrationsgrad) herzuleiten. Es wurden Regressionsanalysen basierend auf Querschnittsdaten ausgewählter Industrien unternommen, welche dazu dienen sollten, bestimme Thesen dahingehend zu überprüfen, ob sie auf alle Märkte übertragbar sind. ${ }^{203}$ Jedoch waren diese Analysen methodisch gesehen auf Ad-hoc-Hypothesen über den Zusammenhang von Marktstruktur und Marktergebnis angewiesen, ohne dass diese in eindeutiger Beziehung zu einem zugrunde liegenden theoretischen Modell stehen würden. Diese Hypothesen waren demnach weniger Ausdruck valider Theorie, sondern kamen vielmehr auf Basis von „Annahmen, Vermutungen und Spekulationen unterschiedlichen Plausibilitätsgrades“ zustande. ${ }^{204}$ Diese Vorgehensweise stieß folglich bald an ihre methodischen Grenzen. ${ }^{205}$ Darüber hinaus erfuhren empirisch belegte, korrelative Zusammenhänge zwischen Marktstruktur- und -ergebnisvariablen alsbald eine kausale Interpretation. ${ }^{206}$

\section{Das modifizierte Marktstruktur-Marktverhalten-Marktergebnis-Paradigma}

Aufgrund der berechtigten Kritik an den offensichtlichen Schwächen des traditionellen SVE-Ansatzes wurde dieser in der Folgezeit in mehrfacher Hinsicht modifiziert und erweitert. Dabei spielen im Wesentlichen drei Aspekte eine Rolle ${ }^{207}$ :

- Der Komplex der Markstruktur beinhaltet nunmehr spezifische unternehmensstrukturelle Faktoren wie die Kategorien der „vertical integration“ oder der „conglomerateness“. Damit einher geht die Tendenz, im Rahmen industrieökonomischer Analysen das Unternehmen, dessen interne Organisation

Vgl. Böbel (1984), S. 9; Jacquemin (1986), S. 11.

Vgl. Jacquemin (1986), S. 12 sowie Bühler, Jaeger (2002), S. 6.

Kaufer (1980), S. 10.

Vgl. Bester (2004), S. 3.

Vgl. Jacquemin (1986), S. 12.

Vgl. Scherer, Ross (1990), S. 4 ff., zusammengefasst in Herdzina (1981), S. 247 f.
} 
sowie dessen Beziehung zur Branchenstruktur expliziter und verstärkt zu berücksichtigen. ${ }^{208}$

- Es wird eine weitere Basiskategorie in Analyse miteinbezogen, die sog. „basic conditions", welche Struktur, Verhalten und Ergebnisse beeinflussen. Auf der Angebotsseite werden hier Faktoren wie die Verfügbarkeit von Rohstoffen, der Stand der Technologie, aber auch soziologische, politische und institutionelle Einflussfaktoren genannt. $\mathrm{Zu}$ den nachfrageseitig wirkenden Faktoren zählen beispielsweise die Preiselastizität der Nachfrage oder die Nachfrageentwicklung.

- Die Hypothese einer einseitigen Kausalbeziehung in der Richtung StrukturVerhalten-Ergebnis wurde durch ein „Paradigma der zirkularen Verknüpfung ${ }^{\text {¿209 }}$ ersetzt: die basic conditions und die Strukturen von Branchen und Märkten werden nicht mehr lediglich als Ursachen von Verhaltensweisen und Marktergebnissen betrachtet, sondern es werden auch Rückkopplungseffekte von Verhalten auf Struktur und basic conditions und von der Struktur auf die basic conditions berücksichtigt: „Die Marktstruktur ist selbst Resultat von Marktprozessen, und Marktprozesse vollziehen sich nicht innerhalb invarianter Strukturen. ${ }^{6210}$ HOPPMANN bemerkt richtigerweise, dass streng genommen auch die Markergebnisse ihrerseits Rückwirkungen auf Verhalten, Marktstruktur und basic conditions aufweisen müssen. ${ }^{211}$ Die Kategorien der Marktstruktur und der basic conditions werden folglich im Rahmen des modifizierten, erweiterten SVE-Paradigmas endogenisiert. Vergleiche dazu auch die Abbildung 1-3.

Vgl. dazu auch Bresnahan, Schmalensee (1987), S. 374.

Vgl. Hoppmann (1974a), S. 12.

Hoppmann (1970), S. 409.

Vgl. Hoppmann (1974a), S. 12.
} 


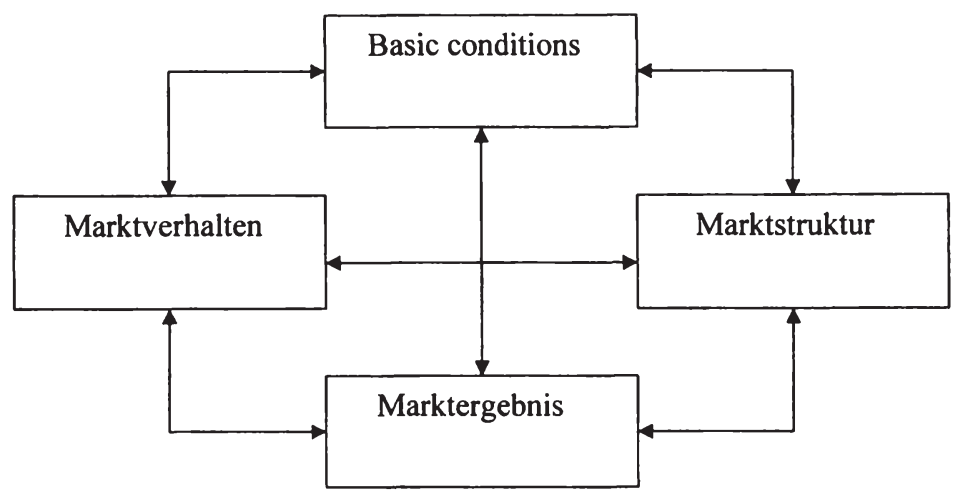

Abbildung 1-3: Paradigma der zirkularen Verknüpfung

Quelle: in Anlehnung an Hoppmann (1974a), S. 12

Mit Hilfe des modifizierten SVE-Paradigmas bietet sich dem Industrieökonomen die Möglichkeit, die im Rahmen einer positiven Branchen- bzw. Marktanalyse erschlossene Fülle an empirischen Beobachtungen und Erkenntnissen in eine erste, vorläufige Ordnung zu bringen. ${ }^{212}$ Es stellt eine Art Raster dar, damit bei der Untersuchung keine wesentlichen Fakten und Daten vergessen werden. ${ }^{213}$ In welche Kategorie ein bestimmtes Merkmal dabei sortiert wird, ist zwar oftmals diskussionswürdig ${ }^{214}$, letzten Endes aber von untergeordneter Bedeutung. Auch die unterschiedliche analytische Akzentuierung, welche die Strukturalisten bzw. die Behavioristen wählen, ist allenfalls von sekundärem Interesse. ${ }^{215}$ Unbedingt wichtig ist jedoch die Erkenntnis, dass die Kategorien im Laufe der Entwicklung eines Marktes eng miteinander verflochten sind und sich diese Verflechtungen im Zeitablauf dynamisch verändern bzw. entwickeln. ${ }^{216}$ Insofern integriert die industrieökonomische Analyse zentrale Aspekte in die Wettbewerbstheorie, welche dort bislang keine explizite Berücksichtigung fanden. Es handelt sich um (1) die Frage nach dem einzelwirtschaftlichen Wachstum der Unternehmungen und der Märkte sowie um (2) den wirtschaftlichen Strukturwandel. ${ }^{217}$ Wenngleich

Vgl. Kaufer (1980), S. 9. „The structure-conduct-performance paradigm is a very general way to organize the study of industrial organization..." Carlton, Perloff(1990), S. 3.

Vgl. Hoppmann (1983), S. 19.

Vgl. Herdzina (1981), S. 248; Kaufer (1980), S. 9.

Vgl. Kaufer (1980), S. 8.

Vgl. Kaufer (1980), S. 9.

Vgl. Herdzina (1981), S. 248. 
auch das SVE-Paradigma freilich nicht in der Lage ist, dezidiert die Entwicklungsmuster der Vorgänge innerhalb des jeweiligen untersuchten Marktes anzugeben oder gar im Einzelnen vorherzusagen, so stellt der Ansatz doch einen systematischen Untersuchungsrahmen zur Verfugung, der der Erforschung bestimmter diesbezüglicher Fragestellungen dienlich sein kann. ${ }^{218}$ So bemerken auch SCHERER und Ross einschränkend, dass, "...Even if a relatively pessimistic verdict emerges [bezüglich der Vorhersagekraft des SVE-Paradigmas, der Verf.], the paradigm is useful as a kind of „hat rack" for organizing relevant theories and facts. Those who doubt the paradigm's power should feel free to accept it in that weakened form."219

Obwohl die angesprochenen Modifikationen und Erweiterungen des SVE-Paradigmas viele Mängel an diesem Konzept zumindest entschärft haben, so verbleiben dennoch einige Beanstandungen, die immer wieder vorgetragen werden und die dem Paradigma bis heute anhaften:

- Es ist nicht abschließend geklärt, welche Merkmale letztendlich analytisch relevant sind. Diverse Autoren verwenden unterschiedliche Sets an Struktur-, Verhaltens- und Ergebniskriterien, so dass sich viele Studien hinsichtlich $\mathrm{Zu}$ sammensetzung, Rangfolge und Gewichtung der Merkmale stark voneinander unterscheiden. 220

- Der Ansatz neigt tendenziell dazu, die Nachfrageseite von Märkten bei der Analyse zu vernachlässigen. Wenngleich MASON (1939) und (1959) in seinem Katalog der Marktstrukturvariablen explizit auch die Nachfrageseite berücksichtigt hat, so bildet in der Regel die Betrachtung der Angebotsseite den Schwerpunkt der in der Folgezeit durchgeführten Analysen. ${ }^{221}$ Wenn die Industrieökonomik aber den Anspruch erhebt, Aussagen bezüglich der Funktionsmechanismen einzelner Märkte bzw. der Marktwirtschaft zu treffen, ist die angemessene Betrachtung der Nachfrageseite unabdingbar.

Im Rahmen von Marktanalysen, die auf der Basis des SVE-Paradigmas durchgeführt werden, wird natürlich auch zu Fragen des Wettbewerbs Stellung genommen. Jedoch steht bei der Industrieökonomik die positive ökonomische Analyse von Marktvorgän-

Vgl. Mantzavinos (1994a), S. 41.

Scherer, Ross (1990), S. 6.

Vgl. Kortmann (2003), S. $38 \mathrm{f}$.
} 
gen im Zentrum des Interesses, nicht aber deren Charakterisierung in wettbewerblich oder nicht, zumal in der Industrieökonomik keine normativen Aspekte bzw. Interpretationen des Wettbewerbsphänomens vorgesehen sind. ${ }^{222}$ Ähnlich resümiert auch HOPPMANN, welcher der Meinung ist, dass „die Industrial Organization Analysis zeigt, wie Industrien tatsächlich operieren und wie Marktprozesse wirklich ablaufen, sie stellt jedoch keinen normativen Standard zur Verfügung...“. ${ }^{223}$

\subsection{Wettbewerbsdeterminanten}

Die ambitionierte Zielsetzung der Industrieökonomik ist es, den Funktionsmechanismen realen Marktgeschehens mithilfe empirischer Marktanalysen auf die Spur zu kommen und dadurch auch zu neuen Erkenntnissen in der positiven Erforschung des wettbewerblichen Marktprozesses zu gelangen. Der breit angelegte, empirisch ausgerichtete Forschungsansatz der Industrieökonomik bringt es unweigerlich mit sich, dass die Liste der möglichen Wettbewerbsdeterminanten sehr umfangreich ist. ${ }^{224}$ Alle bislang betrachteten Variablen kommen in Betracht. Mutmaßliche Wettbewerbsdeterminanten sind demnach: ${ }^{225}$

- Die interne Unternehmensstruktur (US), welche sich wiederum aus Komponenten wie

$$
\begin{aligned}
& \circ \text { dem Diversifikationsgrad (d), } \\
& \circ \text { der Anzahl der Betriebe pro Unternehmen (b), } \\
& \circ \text { der Anzahl der Produktionsstufen im Unternehmen (p), } \\
& \circ \text { dem Kontrollsystem des Unternehmens (k) oder } \\
& \circ \text { der Organisationsstruktur des Unternehmens (o) }
\end{aligned}
$$

zusammensetzt.

- Die Marktstruktur $\left(\mathbf{M S}_{\mathrm{A}}\right)$, welche sich wiederum aus Komponenten wie

$$
\circ \text { der Anzahl der Unternehmen auf dem Markt }\left(z_{\mathbf{a}}\right) \text {, }
$$

Vgl. dazu Mantzavinos (1994a), S. 35 und Mantzavinos (1994b), S. 66 sowie Kaufer (1980), S. 10. 


$$
\begin{aligned}
& \circ \text { ihrer Marktanteilsverteilung }\left(\mathbf{k}_{\mathbf{x}}\right) \text { oder } \\
& \circ \text { dem Grad der Produktdifferenzierung (pd) }
\end{aligned}
$$

zusammensetzt.

- Die Produktionsfaktorenstruktur (PfS)

- Die Produktivitätsstruktur (PdS)

- Das unternehmerische Zielsystem (Z)

- Die Nachfragestruktur $\left(\mathbf{M S}_{\mathrm{N}}\right)$

- Das Eigeninteresse (E)

- Die staatliche Rahmenordnung (O)

$$
W=W\left(U S[d, b, p, k, o], M_{A}\left[z_{a}, k_{x}, p d\right], P f S, P d S, Z, M_{N}, E, O, \ldots\right)
$$

Von Interesse für die markt- bzw. wettbewerbstheoretische Analyse sind die vorgestellten Variablen nicht nur lediglich in ihrer statischen, zeitpunktbezogenen Ausprägung. Vielmehr sind auch deren absolute und relative Veränderungsraten im Zeitablauf beachtenswerte Größen, welche zur Erklärung von Markt- und Wettbewerbsprozessen beitragen können. ${ }^{226}$ Die dynamische industrieökonomische Analyse versucht dabei, die Verknüpfung der Kategorien der basic conditions, der Marktstruktur, des Marktverhaltens und der Marktergebnisse, aber auch deren Entwicklung im Zeitablauf zu erfassen. Aus dem dynamischen Charakter des industrieökonomischen Forschungsansatzes ergeben sich aber auch nachstehende Einschränkungen:

- Aus dem Umstand, dass neben Vorkopplungseffekten auch Rückkopplungseffekte, also zirkulare Verknüpfungen zwischen den einzelnen Kategorien basic conditions, Marktstruktur, Marktverhalten und Marktergebnis zugelassen werden geht hervor, dass die Industrieökonomik auf einem sehr niedrigen Abstraktionsniveau arbeitet. Daraus wiederum erhellt, dass die Liste der Wettbewerbsdeterminanten nie vollständig und abschließend formuliert werden kann.

- Ferner ergibt sich aus der Breite des industrieökonomischen Forschungsansatzes und der Fülle der möglichen Analysevariablen, dass die einzelne industrie- 
ökonomische Untersuchung sich nicht mit dem Markt- und Wettbewerbsprozess in seiner Gesamtheit beschäftigen kann. ${ }^{227}$ Stattdessen greift sie bestimmte Determinanten heraus und setzt sie in Beziehung zu ausgewählten Gesichtspunkten des Markt- bzw. Wettbewerbsprozesses. Dabei vermag sie, konkrete industriebezogene und industrieübergreifende Prozesse, also strukturellen Wandel, darzustellen und Aussagen bezüglich einzelner Determinanten qualitativ und quantitativ zu beurteilen. ${ }^{228}$ Jede einzelne Untersuchung leistet folglich einen Beitrag, das Wissen über den Markt- und Wettbewerbsprozess um weitere Mosaiksteinchen zu ergänzen, das „Bild des interdependenten Gesamtprozesses“ allerdings „wird sich dabei nie vollständig zeichnen lassen, es ist aber laufend zu ergänzen".229

\subsubsection{Gegenüberstellung und Positionierung der beiden Theorien}

Das zentrale verbindende Moment zwischen dem Workable-Competition-Ansatz und der Industrieökonomik ist das von MASON entwickelte SVE-Paradigma, welches beiden Theorien als analytischer Rahmen zugrunde liegt. Beide Theorien haben damit ihre theoretischen Wurzeln grundsätzlich in der neoklassischen Preistheorie. Beide Theorien erweiterten allerdings im Vergleich zur traditionellen Preistheorie den Katalog an betrachteten Variablen in den einzelnen Kategorien Marktstruktur, -verhalten und -ergebnis beträchtlich und weisen somit verglichen mit der traditionellen preistheoretischen Analyse einen weitaus geringeren Abstraktionsgrad auf. Allerdings sind Workable Competition und Industrieökonomik aus völlig unterschiedlichen Notwendigkeiten hervorgegangen. Sie verfolgen unterschiedliche Zielsetzungen und versuchen diese mit unterschiedlichen Methoden zu erreichen. Zwar benutzen beide dieselbe Begriffswelt, setzen diese aber auf unterschiedliche Art und Weise ein.

Workable Competition hat zum Ziel, das Modell der vollkommenen Konkurrenz als wettbewerbspolitisches Leitbild abzulösen und will an dessen Platz einen alternativen wettbewerbspolitischen Ansatz stellen. Dieser alternative Ansatz soll dem wettbewerbspolitischen Entscheidungsträger einen praxistauglichen Orientierungsrahmen an die Hand geben, welcher es gestattet, erwünschte Formen des Wettbewerbs zu identifizieren und zu realisieren sowie von den unerwünschten Formen zu unterschei-

Vgl. Herdzina (1981), S. 249.

Vgl. auch Hoppmann (1980b), S. $240 \mathrm{f}$.

Vgl. Hoppmann (1980b), S. 241.

Herdzina (1981), S. 249.
} 
den. Workable Competition ist folglich ein normativer Ansatz. Die Identifikation des Grades der Funktionsfähigkeit des Wettbewerbs erfolgt anhand von Marktstruktur-, Marktverhaltens- und Marktergebnistests, welche die tatsächliche Ausprägung von Parametern des realen Untersuchungsmarktes mit zuvor festgelegten Referenzzuständen für diese Parameter abgleichen. Aus Art und Umfang sich etwaig ergebender Abweichungen in der Parameterlandschaft des Untersuchungsmarktes von den normierten Referenzzuständen werden Rückschlüsse auf die Funktionsfähigkeit und die Intensität des Wettbewerbs im Untersuchungsmarkt gezogen.

Demgegenüber hat die Industrieökonomik zum Ziel, reale Marktvorgänge zu erklären bzw. das Wissen bezüglich der Funktionsmechanismen von Märkten zu vermehren. Dieses Ziel versucht die Industrieökonomik mithilfe empirischer industriebezogener Fallstudien zu erreichen. Innerhalb derer werden, unter Zuhilfenahme des analytischen Rahmens, den das (erweiterte) SVE-Paradigma bietet, möglichst viele statistische Daten und relevante Fakten des jeweiligen Untersuchungsmarktes systematisch gesammelt, eingeordnet und aufbereitet. Gegenstand dieser Fallstudien ist die erfahrungswissenschaftliche, positive Analyse jeweils spezifischer Fragestellungen, welche sich auf einem bestimmten Markt ergeben. Derartige Fragestellungen werden bspw. durch reale Probleme der Antitrustrechtsprechung angeregt, sie können preistheoretischer Natur sein oder die Forscher entwickeln und überprüfen eigene Hypothesen. ${ }^{230}$ Die Fragestellungen können wettbewerbsbezogener Natur sein, sie müssen es aber nicht. Ausdrücklich nicht Gegenstand industrieökonomischer Untersuchungen ist hingegen die Beurteilung der Güte des Wettbewerbs auf Basis zuvor festgelegter Normen. Wenn in Fragen des Wettbewerbs Stellung genommen wird, dann lediglich auf Basis falsifizierbarer Hypothesen, zu welchen die Ergebnisse von realen Marktanalysen Anlass geben bzw. welche sich anhand empirischer Daten ergeben haben.

Obwohl es sich, wie gezeigt, bei Workable Competition und Industrieökonomik um zwei Ansätze mit unterschiedlicher Grundgesinnung handelt, gab es zwischenzeitlich Überlegungen, die beiden miteinander zu verbinden. BAIN führt in seinem Industrieökonomik-Lehrbuch zum Verhältnis von Workable Competition und Industrieökonomik folgendes aus: „Thus we may hope to classify market structures and patterns of market conduct as "workably competitive" and "not workably competitive." ... Knowledge of what structures and patterns of conduct, or combinations thereof, are and are not workably competitive requires a knowledge of the association of structure

Vgl. Hoppmann (1968b), S. 86. 
and conduct to performance. This is one reason why the search for such an association is an important part of our study. And a thorough search, involving analysis of empirical data, is needed. There are some very simplified a priori theories concerning what may be workably and not workably competitive structure and conduct, but they are generally oversimplified, ambiguous on essential matters, and untested. Extended factual investigation is required." ${ }^{, 231} \mathrm{Er}$ stellt also klar, dass die Klassifizierung von Märkten in mehr oder weniger funktionsfähig ein Fernziel sein kann, zu dessen Erreichung die industrieökonomische Analyse jedoch - ob der einschlägig bekannten Schwächen des Workable-Competition-Ansatzes - faktisch noch einen massiven Beitrag, so bspw. zur Identifikation objektiver und justiziabler WorkabilityBeurteilungskriterien, leisten kann und muss. Von Versuchen dieser Art, die Vorstellungen des Workable Competition in die Gedankenwelt der Industrieökonomik zu integrieren, wurde allerdings bald wieder Abstand genommen. ${ }^{232}$ SCHERER und ROSS bspw. behandeln bezeichnenderweise in ihrem Industrieökonomik-Lehrbuch in aller Kürze - auf drei Seiten - Wesen und Unzulänglichkeiten (mangelnde Operationalität, mangelnde Präzision, Widersprüchlichkeit, Werturteilsbeladenheit) des WorkableCompetition-Ansatzes, unterließen es aber ausdrücklich, eine thematische Brücke zur industrieökonomischen Analyse zu schlagen. ${ }^{233}$

Insofern bleibt abschließend zu konstatieren, dass der Workable-Competition-Ansatz ob seiner theoretischen Unzulänglichkeiten in eine Sackgasse geführt hat. Seine Befürworter konnten ihr beabsichtigtes Ziel, nämlich die Entwicklung anforderungsgerechter leistungsfähiger Wettbewerbstests, nicht erreichen. ${ }^{234}$ Dies führte dazu, dass der Ansatz berechtigterweise, wie KAUFER zutreffend bemerkt, in aller Stille und ohne Trauer beerdigt wurde. ${ }^{235}$ Obwohl mit diesem Urteil dem Konzept des Workable Competition, zu dem CLARK den Anstoß gegeben hat, hinsichtlich der Frage nach seiner wettbewerbspolitischen Anwendbarkeit ein Versagen attestiert werden muss, schmälert dies den wettbewerbstheoretischen Beitrag von CLARK jedoch nicht. Sein ursprünglicher Ansatz aus dem Jahre 1940, den er später mit Ideen aus der SCHUMPETERschen Innovationstheorie und mit Gedanken der empirischen Industrieökonomik befruchtet und dynamisiert hat, kann als bedeutende Arbeit auf dem Weg zur Entwicklung einer dynamischen Wettbewerbstheorie in den folgenden Jahrzehnten gewertet

Bain (1968), S. 16.

Vgl. Mantzavinos (1994a), S. 25.

Vgl. Scherer, Ross (1990), S. 52 ff.

Vgl. Berg (1977), S. 292.

Zitiert in Mantzavinos (1994b), S. 67.
} 
werden. ${ }^{236}$ Dies ist CLARKs eigentliches Verdienst. Was den Ansatz der Industrieökonomik betrifft, so ist ihm immense Bedeutung im Bereich der empirischen Fundierung der positiven wettbewerbstheoretischen Forschung zu bescheinigen. Zusätzliche Relevanz für die Wettbewerbstheorie erlangte die Industrieökonomik sicherlich auch durch den Umstand, dass sie Anstrengungen unternahm, ihre traditionell empirische Ausrichtung um entsprechende Maßnahmen zur Theoriebasierung zu ergänzen. Diese Anstrengungen wurden sicherlich durch die bemerkenswerten methodischen Fortschritte, welche auf dem Gebiet der nicht-kooperativen Spieltheorie gemacht worden sind, entscheidend unterstützt. ${ }^{237}$ Das prinzipiell achtbare Ansinnen der Industrieökonomik, ihre empirischen Befunde auf eine theoretische Grundlage zu stellen, hat mindestens zwei erwähnenswerte Entwicklungstendenzen auf den Weg gebracht, welche (1) beachtliche Vorwärtsentwicklungen der industrieökonomischen Forschungsdisziplin in analytischer Hinsicht bewirkt und (2) eine intensive, nicht immer ertragreiche interne methodische Richtungsdebatte ausgelöst haben, welche bis heute nicht zu einem befriedigenden Ende gebracht werden konnte:

- Erstens kristallisierte sich im Rahmen des Theoriebildungsprozesses alsbald heraus, dass das statische, monokausale traditionelle SVE-Paradigma beträchtliche methodische Unzulänglichkeiten aufwies. Diese Unzulänglichkeiten des Paradigmas, welche die spieltheoretischen Modelle zutage gefördert haben, bewirkten entsprechende Reaktionen und konnten - zumindest in weiten Teilen - durch entsprechende Modifikationen hin zum modifizierten SVE-Paradigma entschärft werden.

- Zweitens läuft die moderne Industrieökonomik Gefahr, ihre empirischen Wurzeln zugunsten der formalistischen spieltheoretischen Methodik in den Hintergrund zu drängen. ${ }^{238}$ Daher liegt eine zentrale Forschungsaufgabe der modernen Industrieökonomik zukünftig darin, die beiden auseinander gedrifteten Forschungsrichtungen, die traditionelle ökonometrisch-empirische und die neuere formalistisch-spieltheoretische, wieder zueinander hinzuführen. ${ }^{239} \mathrm{Nur}$ beide zusammen können, in der richtigen Dosierung und mit angemessener Gewichtung miteinander verknüpft, das wissenschaftliche Wechselspiel von

Vgl. Hoppmann (1968b), 86; Giesel (1975), S. 29; Schmidt (1999), S. 10.

Vgl. Bühler, Jaeger (2002), S. 7.

Vgl. Bester (2004), S. 4.

Vgl. Knieps (2001), S. 45. 
theoretischer Hypothesenbildung und deren empirischer Testung für die Wettbewerbstheorie dienlich umsetzen.

\subsubsection{Die Theorie der Marktentwicklungsphasen und deren wettbewerbstheore- tische Implikationen}

\subsubsection{Die Grundlegung der Theorie der Marktentwicklungsphasen}

Bei der Darstellung der industrieökonomischen Forschungskonzeption wurde an entsprechender Stelle die intertemporale Interdependenz der Kategorien der Marktstruktur, des Marktverhaltens und der Marktergebnisse hervorgehoben. Jeder Markt durchläuft demnach im Zeitablauf Entwicklungsprozesse, welche sich in den absoluten und relativen Änderungsraten der betrachteten Variablen niederschlagen. Die Analyse von Marktprozessen hat diesem Umstand dahingehend Rechnung zu tragen, dass sie sich diese Dynamik vergegenwärtigt und zum Untersuchungsgegenstand macht. Eine besondere wettbewerbstheoretische Bedeutung inmitten der Vielzahl denkbarer marktlicher Änderungsprozesse kommt dabei der Wachstumsrate eines Marktes $\left(G_{M}\right)$ zu. Von Interesse sind sowohl die Entwicklung der Wachstumsrate eines einzelnen Marktes im Zeitablauf sowie die divergierenden Wachstumsraten verschiedener Märkte in derselben Zeitperiode, also der wirtschaftliche Strukturwandel. ${ }^{240}$ Für die Belange der Wettbewerbstheorie stellt sich nun die Frage, in welcher Art und in welchem Umfang die Entwicklung des Wachstums eines Marktes bzw. Richtung und Ausma $ß$ des Marktstrukturwandels das Marktverhalten bestimmen, ob und inwieweit sie also als Wettbewerbsdeterminante fungieren. ${ }^{241}$

Dieser Frage wird im Rahmen der Wettbewerbstheorie schon seit langem nachgegangen. Erste Ansätze zur Formulierung einer Theorie der Marktentwicklung lassen sich bereits Ende der 1920er Jahre bei YouNG finden. ${ }^{242}$ Wenig später (1937) machte ABRAMOVITZ darauf aufmerksam, dass es zweckdienlich sei, für die Untersuchung der jeweils vorherrschenden Wettbewerbsbedingungen zwischen frühen und späten Phasen der Marktentwicklung zu unterscheiden. ${ }^{243}$ Er schuf damit das Fundament für

Vgl. Herdzina (1981), S. 268.

Vgl. Herdzina (1981), S. 268 f.

Vgl. Young (1928).

Vgl. Abramovitz (1937/38), S. 312.
} 
die moderne Marktphasentheorie. Letztendlich war es im Jahr $1965 \mathrm{HEUB}^{244}$, welcher der Marktphasentheorie eine umfassende theoretische Fundierung gab.

Die Marktphasentheorie fußt auf der empirisch belegbaren Beobachtung, dass die Entwicklung der Produktion eines Gutes im Zeitablauf einem typischen Verlaufsmuster folgt. ${ }^{245}$ Dabei wird unterstellt, dass die Produktion eines Gutes zunächst progressiv und dann, nach Erreichen des Wendepunktes, nur noch degressiv zunimmt. Nach Erreichen des Maximalwertes sinkt die Produktion absolut. Es ergibt sich ein s-förmiger Kurvenverlauf des Güterproduktionsvolumens (bzw. des Marktvolumens) sowie des Umsatzes. Einzelne Entwicklungsstadien der Güterproduktion können nun zu Phasen verdichtet werden, welche zunächst noch grob (ABRAMOVITZ), später sehr detailliert (HEUB) ausgearbeitet wurden. Als Bestimmungsgründe für die s-förmigen Kurvenverläufe wiederum fungieren angebotsseitige Faktoren (wie bspw. das technologische Potenzial ( $\mathrm{T}$ ), unternehmerische Motivation, Mobilität und Verfügbarkeit geeigneter Produktionsfaktoren $\left(\mathrm{M}_{\mathrm{PF}}\right)$ ), sowie nachfrageseitige Faktoren (insbesondere die Nachfrageentwicklung $\left(\mathrm{G}_{\mathrm{N}}\right)$ ), welche durch gleichgerichtetes Zusammenwirken zunächst expansive und später kontraktive Marktentwicklungsprozesse entsprechend dem zuvor beschriebenen Marktphasenverlauf begründen. ${ }^{246}$ Diese Überlegungen jedoch implizieren die Aussicht, dass, sofern die angebotsseitigen und nachfrageseitigen Entwicklungskräfte zeitweise nicht idealtypisch in dieselbe Richtung sondern entgegengesetzt wirken, realistischerweise auch Abweichungen von den stilisierten s-förmigen Kurvenverläufen denkbar sind. Es gilt

$W=W\left(G_{M}\left[G_{N}, T, M_{P F}\right]\right)$

\subsubsection{Charakterisierung der Marktphasen nach HEUß}

HEUß unterscheidet die folgenden vier Marktphasen und ordnet jeder Phase einen korrespondierenden Unternehmertypus zu. Es sind dies ${ }^{247}$ :

- Experimentierungsphase und Pionierunternehmer,

- Expansionsphase und spontan imitierender Unternehmer, 
- Ausreifungsphase und unter Druck reagierender Unternehmer,

- Stagnations- bzw. Rückbildungsphase und immobiler Unternehmer.

Die Experimentierungsphase ist diejenige Marktphase, in welcher sowohl das Produkt als auch die Nachfrage nach diesem geschaffen werden müssen. Inventionsund Innovationsaktivitäten sowie der Prozess der Nachfragegenerierung werden hier hauptsächlich von der unternehmerischen Motivation des SCHUMPETERschen Pionierunternehmers initiiert. ${ }^{248} \mathrm{Er}$ schafft sich eine prozessuale Monopolstellung, welche er bis zu ihrer rechtlichen und/oder faktischen Absicherung offensiv auszubauen sucht. ${ }^{249}$ In der Expansionsphase begründen die spontan imitierenden Unternehmer, welche durch die realisierten Vorsprungsgewinne des Pionierunternehmers sowie durch die guten Marktchancen angelockt werden, einen intensiven dynamischen Vorstoß- und Nachfolgewettbewerb. ${ }^{250}$ Rationalisierungsbemühungen können sich in sinkenden Preisen und damit steigender Nachfrage und Marktausweitung niederschlagen. Darüber hinaus können realisierte Nachfragesteigerungen zu weiteren Kostenreduktionen infolge von Skaleneffekten und Lernprozessen führen. ${ }^{251}$ Durch das Hinzukommen neuer Anbieter verändert sich die Marktform in Richtung eines (weiten) Oligopols, welches von einer sehr intensiven Wettbewerbtätigkeit gekennzeichnet ist. ${ }^{252}$ Die Ausreifungsphase ist die Zeit, in der der Markt gesättigt ist, d. h. in der alle relevanten Nachfragepotenziale für das betreffende Produkt erschlossen sind und sich die Marktnachfrage kaum mehr ausdehnen lässt. Auch Kostensenkungen und Fortschritte im Produktionsprozess lassen sich nunmehr allenfalls noch in geringem Umfang realisieren, der ökonomische und technische Gestaltungsspielraum der Anbieter nimmt $\mathrm{ab}^{253}$ Der in dieser Marktphase dominierende Unternehmertypus ist der unter Druck reagierende Unternehmer. Er sieht sich in zunehmendem Maße mit Marktaustritten einstiger Konkurrenten konfrontiert und handelt - angesichts der Marktsituation, welche durch die Entwicklung hin zu einem ,engeren“ Markt gekennzeichnet ist - in dem Bewusstsein, dass er nun nicht initiativ, sondern reaktiv zulasten anderer Anbieter

Vgl. Heuß (1965), S. 6 ff.

Vgl. Heuß (1965), S. 26, S. 30 ff.; Schmidt, Rittaler (1987), S. 597 f.

Vgl. Schmidt, Rittaler (1987), S. 599.

Vgl. Schmidt, Rittaler (1987), S. 598; Herdzina (1981), S. 157.

Vgl. Heuß (1965), S. 42 ff.; Heuß (1968), S. 53.

Vgl. Heuß (1968), S. 53.

Vgl. Heuß (1965), S. 63 f.; Schmidt, Rittaler (1987), S. 598.
} 
konkurrieren muss. ${ }^{254}$ Dabei kann er aus den im Laufe der Zeit erworbenen Kenntnissen und Erfahrungen über den Markt und seine Konkurrenten lernen und sich diese zunutze machen. ${ }^{255}$ In der Ausreifungsphase entwickelt sich der Markt hin zur Marktform des engen Oligopols, die Reaktionsinterdependenz zwischen den Konkurrenten nimmt zu. ${ }^{256}$ In der Stagnations- bzw. Rückbildungsphase ist festzustellen, dass die Entwicklung des Marktes hinter der allgemeinen Entwicklung der Volkswirtschaft zurückbleibt. ${ }^{257}$ Der Markt erleidet einen relativen Positionsverlust und ist aufgrund der Konkurrenz durch neue Produkte ${ }^{258}$ zunächst durch Stagnation, dann durch absolute Schrumpfung (Rückbildungsphase) gekennzeichnet. ${ }^{259}$ Die dynamischen Unternehmer haben sich angesichts der mangelnden Nachfrage und der geringen realisierbaren Produktivitätsfortschritte in dieser Marktphase längst alternativen Produktionsrichtungen zugewandt. ${ }^{260}$ Übrig bleiben die immobilen Unternehmer, welche auf Marktsignale bzw. Veränderungen nicht reagieren wollen oder können. In dem Markt, welcher nun endgültig zum engen Oligopol, wenn nicht gar zum Monopol verkrustet ist, dominieren unternehmerische Verhaltensweisen, welche auf Basis eigener Erfahrungswerte über die Verhaltensweisen der verbliebenen Konkurrenten praktiziert werden - die Wettbewerbskräfte im Markt erlahmen. ${ }^{261}$

HEUB' zentrale wettbewerbstheoretische Leistung ist es, als erster die Zeitdimension in die Marktanalyse eingeführt zu haben. Er hat damit den Weg für das Bewusstsein dafür geebnet, dass jeder Markt eine individuelle Historie, eine einzigartige Vergangenheit hat, welche das Ergebnis eines Erfahrungsprozesses und Ausdruck der Lernfähigkeit der in ihm agierenden Marktakteure ist. ${ }^{262}$ Im Lichte der Marktphasentheorie betrachtet können diverse von der Preistheorie als Daten vorgegebene exogene Variable, wie bspw. die Marktform, der Offenheitsgrad des Marktes oder die Kostenstruktur, endogen erklärt werden. ${ }^{263}$ Bislang beanstandete preistheoretische Aussagen werden mit neuen Rechtfertigungsmustern versehen und werden mit einem Mal plausibel, wenn man sie einer entsprechenden Marktphase zuordnet. ${ }^{264}$ Mit Hilfe der

Vgl. Heuß (1965), S. 100.

Vgl. dazu auch Mantzavinos (1994a), S. 90.

Vgl. Heuß (1965), S. 66.

Vgl. Schmidt, Rittaler (1987), S. 598.

Vgl. Herdzina (1981), S. 157.

Vgl. Heuß (1965), S. 87 f.

Vgl. Herdzina (1981), S. 157.

Vgl. Herdzina (1981), S. 157; Schmidt, Rittaler (1987), S. 599.

Vgl. Mantzavinos (1994a), S. 90.

Vgl. Mantzavinos (1994a), S. 90.

Vgl. Herdzina (1985), S. 105. 
Marktphasenaufteilung gelingt es demnach wenigstens, den Marktprozess abschnittsweise mit dem Instrumentarium der Preis- und Markttheorie zu erfassen; es lassen sich Mustervoraussagen darüber formulieren, wann im Verlauf der Marktentwicklung tendenziell wettbewerbliches oder nicht-wettbewerbliches Marktverhalten dominiert. $^{265}$

Insofern kann der Marktphasentheorie attestieren werden, dass sie einen wesentlichen Beitrag dazu leistet, Aussagen von Preis- und Wettbewerbstheorie einander anzunähern. Sie stellt möglicherweise sogar ein Bindeglied auf dem Weg hin zu einer neuen Wettbewerbstheorie dar.

\subsubsection{Der systemtheoretische Ansatz der neuklassischen Wettbewerbstheorie}

Der Ansatz der neuklassischen Wettbewerbstheorie nimmt direkten Bezug auf die Vorstellung der Klassiker, welche den Wettbewerb als das Organisationsprinzip einer auf die Freiheit der beteiligten Handlungsträger gründenden Gesellschaftsordnung betrachteten. ${ }^{266}$ Die neuklassische Wettbewerbstheorie ist daher - wie die klassische Wettbewerbstheorie - ein Ansatz mit politökonomischer Ausrichtung, welcher den freien Wettbewerb zur wirtschaftspolitischen Norm erhoben hat. ${ }^{267}$ Sie ist in kritischer Auseinandersetzung mit den Unzulänglichkeiten der rein preistheoretisch fundierten Wettbewerbsanalyse - und hier insbesondere namentlich mit dem WorkableCompetition-Ansatz sowie dem Ansatz KANTZENBACHs - als Gegenposition entwickelt worden. ${ }^{268}$ Die Tatsache jedoch, dass der neuklassische Wettbewerbsansatz explizit als alternative Grundlage furr die Wettbewerbspolitik kreiert wurde, impliziert, dass die Theorie - wie der Workable-Competition-Ansatz - starke normative Elemente enthält, die es wiederum zum Zwecke der theoretischen Analyse des Ansatzes möglichst zu eliminieren gilt. ${ }^{269}$ Als geistigen Urheber des neuklassischen Wettbewerbsansatzes kann HOPPMANN betrachtet werden, welcher die neuklassische Position umfassend und systematisch dargestellt und kontinuierlich weiterentwickelt hat. ${ }^{270}$

Vgl. Kaufer (1980), S. 367 ff.

Vgl. Tolksdorf (1994), S. 63.

Vgl. Herdzina (1981), S. 242.

Vgl. Borchert, Grossekettler (1985), S. 146.

Vgl. Mantzavinos (1994a), S. 158.

Vgl. Herdzina (1981), S. 242.
} 


\subsubsection{Wettbewerbswirkungen und Wettbewerbsprozess}

Wie schon verschiedentlich erwähnt, sind Möglichkeiten und Qualität der wettbewerbspolitischen Gestaltung durch den Entwicklungsstand der wettbewerbstheoretischen Forschung bestimmt. Dieser wiederum ist - außer von der Qualität der Forschung und der Forscher - außerdem abhängig ,von dem, was der Erkenntnisgegenstand [in diesem Fall: Wettbewerb] überhaupt an Erkenntnis zulässt“ ${ }^{\text {. }}{ }^{271}$ Im Rahmen der neuklassischen Wettbewerbstheorie werden Märkte und Markterscheinungen als Phänomene organisierter Komplexität betrachtet, welche sich auf Basis systemtheoretischer Überlegungen erfassen lassen. ${ }^{272}$ „Organisierte“ Komplexität im Vergleich zu „unorganisierter" Komplexität bedeutet in diesem Zusammenhang, dass neben den Charakteristika der Systemelemente auch das Wesen der Verbindungen zwischen den Systemelementen bestimmend für den Charakter des Gesamtsystems ist. ${ }^{273} \mathrm{Die}$ Summe der Systemelemente sowie deren interaktives Handeln begründen jene geordnete Struktur, die kein Mensch bewusst geplant und herbeigefuhrt hat, und welche uns als Marktsystem bekannt ist. ${ }^{274}$ Vor dem Hintergrund der Wahrnehmung von Markterscheinungen als „System“ ergeben sich nun, in Reflexion der Frage, was der Erkenntnisgegenstand "Wettbewerb" an Erkenntnis denn zulasse, bestimmte methodische Konsequenzen. Zunächst muss man sich vergegenwärtigen, dass sich ein komplexes System nicht vollständig beschreiben lässt, dass also weder die Systemelemente (Unternehmungen und Individuen) noch deren wechselseitige Verbindungen vollständig beschrieben werden können. ${ }^{275}$ Will man nun von der Wettbewerbstheorie vollständige Aussagen über bestimmte Sachverhalte im Einzelnen erwarten, so müsste diese ihrerseits über vollständige Information über jedes Systemelement verfügen. Da jedoch vollständige Information über Unternehmungen und Individuen nicht verfügbar ist, kann die Wettbewerbstheorie keine vollständigen Aussagen über das Marktsystem leisten. ${ }^{276}$ Angesichts einer solchen Situation des Mangels an Wissen über relevante Fakten des Marktes und seiner Akteure übernimmt der Wettbewerb die Funktion eines Entdeckungsverfahrens im HAYEKschen Sinne, einer Suchmethode also, welche der Wissensdiffusion dient und nach und nach alle relevanten Fakten zutage fördert: „es sind jeweils die vorläufigen Ergebnisse des Marktprozesses, die den einzelnen sagen,

Schmidtchen (1978), S. 111.

Vgl. Hoppmann (1972), S. 20; Hoppmann (1980b), S. 240; Hoppmann (1981), S. 219.

Vgl. Hoppmann (1981), S. 219.

Vgl. Hoppmann (1977), S. 7.

Vgl. Schmidtchen (1978), S. 122.

Vgl. Hoppmann (1981), S. 220.
} 
wonach zu suchen es sich lohnt “. ${ }^{277}$ Das Marktsystem fungiert insofern als System zur Informationsvermittlung und zur Verwertung von Wissen, welches kein einzelner Marktteilnehmer in seiner Gesamtheit kennt. ${ }^{278}$ Daraus erhellt unmittelbar, dass die individuellen Ergebnisse des Wettbewerbsprozesses im Einzelnen nicht bekannt und nicht vorhersagbar sind, sondern dass diesbezüglich allenfalls allgemeiner gehaltene Prognosen in Form von Mustervoraussagen möglich sind. ${ }^{279}$ Infolgedessen lehnt der neuklassische Ansatz Marktergebnistests als wettbewerbspolitisches Diagnoseinstrument sowie die konkrete Definition des Wettbewerbsprozesses ab, da sowohl die Marktergebnisse als auch die Wettbewerbsprozesse, welche zu den Ergebnissen hinführen, im Einzelnen nicht bekannt sind und sein können. ${ }^{280}$ Dabei identifiziert HOPPMANN den Wettbewerbsprozess als denjenigen erwünschten Typus aus dem breiten Spektrum möglicher dynamischer ${ }^{281}$ Marktprozesse, welcher sich aus den Zielen der Wettbewerbspolitik ableiten lässt resp. sich durch sie definiert. ${ }^{282}$ HOPPMANN identifiziert zwei Zielkomplexe der Wettbewerbspolitik, welche für ihn aber gleichbedeutend mit den Wirkungen des freien Wettbewerbs sind: Wettbewerbsfreiheit und ökonomische Vorteilhaftigkeit.

Wettbewerbsfreiheit: ${ }^{283}$ Wettbewerbsrelevante Handlungs- und Entschließungsfreiheiten der Marktakteure können aus vielen Blickwinkeln betrachtet werden. Wettbewerbsfreiheit offenbart sich infolgedessen in mehreren Ausprägungen, welche sich begrifflich unterscheiden lassen. Zum einen ist die Freiheit des Wettbewerbs unter Konkurrenten zu nennen, welche sich in der Freiheit zu Initiative und Vorstoßhandlungen sowie in der Freiheit zu Imitation und Nachfolge äußert. Diese Freiheit(en) sind Voraussetzung für das Zustandekommen eines wettbewerblichen Prozesses unter den Konkurrenten und gleichermaßen Voraussetzung dafür, dass sich die Marktgegenseite der Auswahlfreiheit erfreuen kann. Ein Marktprozess ist dann wettbewerblich, wenn beide Marktseiten die dargestellten Wettbewerbsfreiheiten genießen. Dabei sind diese zunächst Voraussetzung für diesen Wettbewerbsprozess. Da sie sich jedoch wechselseitig bedingen, sind sie aber auch Konsequenz bzw. Wirkung dieses Prozesses. Wettbewerb ist demgemäß ein Marktprozess, welcher aus Freiheit erwächst und in

\footnotetext{
277 Hayek (1969), S. 253.

278 Vgl. Hayek (1952), S. $103 \mathrm{ff}$.

279 Vgl. Hoppmann (1972), S. 20 f.

280 Vgl. Herdzina (1981), S. 243.

281 Hoppmann betrachtet die Marktprozesse, also auch den Wettbewerbsprozess, als dynamische Prozesse und beruft sich dabei ausdrücklich auf J. M. Clarks (1961) Position. Vgl. dazu Hoppmann (1967), Fn. 2. 
welchem Freiheit erhalten bleibt - die Freiheit „konkretisiert“ sich gewissermaßen. Allerdings ist Freiheit in diesem Zusammenhang nicht als absolute Größe zu verstehen, sondern relativ in dem Sinne, dass die Freiheit des einen Marktakteurs durch die Freiheitsbereiche seiner Konkurrenten und der Akteure der Marktgegenseite begrenzt wird. ${ }^{284}$ Freiheitsbeschränkungen in gewissem Umfange sind also unausbleiblich. Insofern ist ein „hinreichendes Ausmaß ${ }^{\text {“285 }}$ dieser relativen Wettbewerbsfreiheit für alle Marktakteure die Voraussetzung für und zugleich Wirkung eines Wettbewerbsprozesses. Zur konkreten Beurteilung der Güte des Wettbewerbs sind daher notwendigerweise Art und Umfang noch akzeptabler Beschränkungen der Wettbewerbsfreiheit festzulegen. ${ }^{286}$

Ökonomische Vorteilhaftigkeit: Wettbewerb nötigt es den Marktteilnehmern ab, ihre Leistung zu steigern, um sich einen Vorteil gegenüber ihren Konkurrenten herauszuarbeiten. Diese Leistungssteigerung äußert sich insbesondere in Kostensenkungen, Qualitätsverbesserungen sowie technischem Fortschritt und bewirkt somit für jeden Marktteilnehmer individuelle ökonomische Vorteile, welche aus dem Wettbewerb der jeweils anderen Marktseite resultieren. Dabei ist die wechselseitige ökonomische Vorteilhaftigkeit nicht im Sinne bestimmter, festgelegter Marktergebnisse zu interpretieren, sondern sie ist Ausdruck der Tatsache, dass Wettbewerb für alle Marktteilnehmer die aufgeführten Vorteile bietet. Um diese individuellen ökonomischen Vorteile zu erreichen, ist Wettbewerbsfreiheit unabdingbar notwendig, d. h. Freiheit zu Vorstoßhandlungen, um neue Güter, neue Märkte oder neue Produktionsverfahren realisieren zu können und Freiheit zu Nachfolgehandlungen, um den ökonomischen Fortschritt zu verbreiten. Insofern sind Wettbewerbsfreiheit und ökonomische Vorteilhaftigkeit nicht als zwei voneinander isolierte Zielkomplexe zu betrachten, sondern als zwei Gesichtspunkte desselben Wettbewerbsprozesses, als „Zwei Seiten derselben Medaille“. ${ }^{287}$ Hoppmann geht somit von der "Non-Dilemma-These“ aus, welche besagt, dass man durch Realisierung und Erhaltung wettbewerblicher Freiheit in einer marktlichen Wirtschaftsordnung synchron die ökonomische Güte ihrer Ergebnisse sicherstellt. ${ }^{288}$

Vgl. für das Folgende insbesondere Hoppmann (1967); Hoppmann (1968a), S. 15 ff.

Vgl. Hoppmann (1968b), S. 90.

Hoppmann (1972), S. 16.

Vgl. Herdzina (1981), S. 244.

Hoppmann (1968a), S. 21.

Vgl. Hoppmann (1967), S. 82; Hoppmann (1968a), S. 21.
} 


\subsubsection{Wettbewerbsdeterminanten}

Wie im vorangehenden Unterabschnitt deutlich geworden sein dürfte, ist die Existenz von Wettbewerbsfreiheit (WF) aus Sicht der neuklassischen Wettbewerbstheorie die zentrale Determinante für das Zustandekommen von Wettbewerb. Die Freiheit zu wettbewerblichem Verhalten allein allerdings reicht nicht aus. Zudem müssen die Marktteilnehmer einer Marktseite eine Neigung zu wettbewerblichem Verhalten (WN) - einen sog. „spirit of competition“ ${ }^{289}$ also - verspüren, was sie dazu veranlasst, vorhandene Handlungsspielräume auch auszunutzen. Nach Auffassung der neuklassischen Wettbewerbstheorie kann allerdings davon ausgegangen werden, dass Wettbewerbsneigung grundsätzlich vorhanden ist. ${ }^{290}$ Doch selbst, wenn Wettbewerbsfreiheit und Wettbewerbsneigung beide existieren, so garantiert dies nicht unbedingt das Zustandekommen eines intensiven Wettbewerbsprozesses, wenn es an konkreten Gelegenheiten für wettbewerbliche Vorstoßaktionen mangelt. ${ }^{291}$ Doch an dieser Stelle offenbart sich der zentrale Unterschied des neuklassischen Ansatzes im Vergleich zum Workable-Competition-Ansatz. Während letzterer die Funktionsfähigkeit des Wettbewerbs mittels der Normierung des tatsächlichen Wettbewerbs anhand konkreter Struktur-, Verhaltens- oder Ergebnisnormen beurteilt, fordert der neuklassische Ansatz hingegen lediglich die Freiheit zu Wettbewerbshandlungen. Die positive Beschreibung und damit die Normierung des tatsächlichen Wettbewerbs sind aufgrund seines Charakters als ergebnisoffenem Prozess methodisch nicht möglich und derartige Versuche daher nicht zielführend. In der Argumentation nach neuklassischem Muster sind Fragen nach der Wettbewerbsintensität ohne Belang: „Entscheidend ist, ob die Wettbewerbsfreiheit wesentlich beschränkt ist, nicht dagegen, ob der Wettbewerb wesentlich ist“" 292

Um die Marktprozesse gegebenenfalls „in die gewünschten Bahnen“ lenken zu können, muss die Wirtschaftspolitik in der Lage sein, entsprechende „Spielregeln“ einzurichten. ${ }^{293}$ Obgleich die neuklassische Wettbewerbstheorie die prinzipielle Überzeugung vertritt, dass die Wettbewerbspolitik ihre politische Aufgabe, die erwünschten wettbewerblichen Marktprozesse durch wettbewerbspolitische „Spielregeln“ herbeizuführen, wahrzunehmen vermag ${ }^{294}$, muss die neuklassische Konzeption unbedingt

Vgl. Hoppmann (1968a), S. 15.

Vgl. Hoppmann (1968a), S. 12; Herdzina (1981), S. 244.

Vgl. Herdzina (1981), S. 244.

Herdzina (1981), S. 244.

Hoppmann (1968a), S. 11.

Vgl. Hoppmann (1968a), S. 12. 
operationalisiert werden, um wettbewerbspolitisch verwertbar zu sein. Insbesondere ist zum Zwecke der wettbewerbspolitischen Normierung die Determinante „Wettbewerbsfreiheit" zu konkretisieren, da im konkreten Einzelfall nicht die Frage, ob Wettbewerbsfreiheit herrscht oder nicht, Gegenstand der wettbewerbspolitischen Evaluierung ist, sondern vielmehr geklärt werden muss, wer über wie viel Wettbewerbsfreiheit verfügen darf und welches Ausmaß an Beschränkung der Wettbewerbsfreiheit noch akzeptabel ist. ${ }^{295}$ Es geht also um die optimale Mischung bzw. Kombination der einzelnen Freiheiten und um die Identifikation derjenigen Marktprozesse, welche diese optimale Mischung hervorbringen. ${ }^{296}$ Auch die These, dass Marktteilnehmer grundsätzlich dem unterstellten Verhaltensmuster des "spirit of competition“ folgen, kann nicht völlig unkritisch übernommen werden und bedarf der weiteren empirischen Untersuchung.

Angesichts dieser Überlegungen kann es wenig überraschen, dass auch eine Wettbewerbspolitik, welche auf neuklassisch-systemtheoretischer Basis betrieben wird, in letzter Konsequenz darauf angewiesen ist, möglichst viele Informationen über das reale Marktgeschehen zu sammeln. Nur das systematische Erfassen und Eruieren jener empirischer Fakten, Bedingungskonstellationen und Vorgänge, welche sich in realen Marktprozessen manifestieren, kann die Wettbewerbspolitik bei der Beurteilung der Frage unterstützen, ob Wettbewerb resp. die Freiheit zu Wettbewerb wesentlich beschränkt ist oder nicht. Im Übrigen hat die Wettbewerbspolitik keine andere Wahl, als sich an den Erkenntnissen der Markttheorie über die typischerweise zu erwartenden Marktergebnisse $\mathrm{zu}$ orientieren, wenngleich auch das diesbezüglich relevante markttheoretische Fundament oftmals auf tönernen Füßen zu stehen scheint. ${ }^{297}$

\footnotetext{
295 Vgl. Herdzina (1981), S. 246; Herdzina (1999), S. 88.

296 Vgl. Hoppmann (1968b), S. 90.

297 Vgl. Herdzina (1999), S. 88.
} 


\subsection{Ansatz zu einer systematischen Integration einzelner wettbewerbstheoreti- scher Ansätze zu einer umfassenderen Wettbewerbskonzeption}

Wie die vorstehenden Ausführungen $\mathrm{zu}$ den diversen wettbewerbstheoretischen Ansätzen, zu den im Rahmen der Preistheorie formulierten Wettbewerbshypothesen sowie zu den wettbewerbstheoretischen Implikationen der Marktstrukturphasentheorie aufgezeigt haben dürften, weist die wettbewerbstheoretische Landschaft ein überaus breites und kontrastreiches Spektrum z. T. erheblich voneinander abweichender Einzelaussagen und -hypothesen auf. Unstimmigkeiten bestehen insbesondere hinsichtlich der im Einzelnen zu erwartenden Wettbewerbswirkungen sowie hinsichtlich der zugrundezulegenden Wettbewerbsdeterminanten. Diese Unstimmigkeiten in den Einzelaussagen jedoch lassen sich möglicherweise zumindest insoweit ausräumen, dass sie den bereits zitierten Grundkonsens, welchen sämtliche vorgestellten Ansätze hinsichtlich wesentlicher Dispositionen des Wettbewerbs aufzuweisen scheinen, im Kern nicht berühren können. Der Grundkonsens wiederum ist ausbaufähig und stellt eine tragfähige Basis für die Formulierung einer umfassenderen Wettbewerbskonzeption dar. Ein entsprechender integrativ angelegter Versuch, die wettbewerbstheoretische Landschaft gewissermaßen zu „defragmentieren“ und zu einer umfassenderen Wettbewerbskonzeption zusammenzufuihren, wurde bereits von HERDZINA unternommen.' Seine Systematik und die entsprechenden Befunde, wenngleich der Aufgabenstellung entsprechend modifiziert bzw. ergänzt, bilden dennoch den grundlegenden Anknüpfungspunkt für die folgenden Erörterungen. ${ }^{2}$

\subsubsection{Wettbewerbswirkungen}

Bezüglich der Wirkungen, welche von einem als wettbewerblich charakterisierten Marktgeschehen erwartet werden, herrscht offensichtlich zumindest dahingehend Einigkeit, dass sie sich auf die zentralen gesellschaftlichen Grundwerte Freiheit, Wohlstand und Gerechtigkeit zurückführen lassen können. Dabei wird vom Wettbewerb erwartet, dass er einen positiven Beitrag zur Verwirklichung dieser drei Grund-

Vgl. Herdzina (1981), Herdzina (1985), Herdzina (1999).

Angesichts der Tatsache, dass der wettbewerbstheoretische Integrationsansatz von Herdzina im Kern bereits über 25 Jahre alt ist, mag die Entscheidung, diesen Ansatz als wettbewerbstheoretischen Bezugsrahmen für diese Arbeit zu wählen, unter Umständen mit dem kritischen Vermerk, „alten Wein in neuen Schläuchen zu präsentieren“, beschieden werden. Dem soll hier entgegengehalten werden, dass, in Ermangelung eines besseren, neuen Weines die Verwendung des alten, gereiften Weines durchaus angezeigt scheint. Aus den gleichen Beweggründen wird im Rahmen dieser Arbeit ebenfalls auf den Gebrauch von neuen Schläuchen ausdrücklich verzichtet. 
werte leistet. ${ }^{3}$ Akzeptiert man den Konsens hinsichtlich der genannten Grundwerte als formalen Ausgangspunkt, so lassen sich daraus mit den ökonomischen Wirkungen, welche auf Wohlstand und Gerechtigkeit rekurrieren sowie mit der Freiheitswirkung zwei zentrale wettbewerbliche Wirkungskomplexe entwickeln.

\subsubsection{1 Ökonomische Wirkungen des Wettbewerbs}

Verantwortlich für das allgegenwärtige Streben nach Wohlstandsmehrung ist der Umstand, dass Wohlstand nicht ubiquitär verfügbar ist. Dieser Mangel an Wohlstand findet gemäß moderner ökonomischer Terminologie sein inhaltliches Äquivalent im Phänomen der Güterknappheit. Die Forderung nach Wohlstand entspricht also der Forderung nach Knappheitsreduktion. Güterknappheit bedeutet, dass eine Lücke zwischen gewünschter und vorhandener Gütermenge existiert, welche die Wirtschaftssubjekte unter Einsatz geeigneter Mittel und Maßnahmen zu schließen suchen. ${ }^{4}$ Die Gesamtheit jener Mittel und Maßnahmen, welche geeignet sind, das Knappheitsproblem zu mindern resp. die Güterversorgung zu verbessern, können unter dem Begriff des Wirtschaftens zusammengefasst werden. Dabei lassen sich zur Knappheitsreduktion prinzipiell folgende drei Ansatzpunkte unterscheiden:

Erweiterung des Gütervolumens: ${ }^{5}$ Dieser Ansatzpunkt hebt auf die Strategie ab, das Güterangebot durch Mehrproduktion auszudehnen. Mehrproduktion ist (1) durch produktivitätssteigernden Abbau von Ineffizienzen bzw. Korrektur von Falschauslastungen der Produktionsfaktoren im Produktionsprozess innerhalb der Grenzen der Produktionsmöglichkeiten sowie (2) durch die Erweiterung der Produktionsmöglichkeiten durch Mehreinsatz der Produktionsfaktoren - also Wirtschaftswachstum realisierbar. Eine überragende Bedeutung kommt in beiden Fällen dem Prozess des technischen Fortschritts zu.

Verbesserung der Güterstruktur': Knappheit kann auch daher rühren, dass die Zusammensetzung des Güterangebotes bzw. der Einsatz der Produktionsfaktoren nicht dem geäußerten, mit Kaufkraft ausgestatteten Bedarf der Konsumenten - also der Nachfragestruktur - entspricht. Dementsprechend kann Knappheit dadurch reduziert werden, dass knappere Güter vermehrt, weniger knappe Güter in geringerem Umfang produziert werden. Die Strategie zur Knappheitsreduzierung, welche sich dahinter

\footnotetext{
Vgl. Herdzina (1999), S. 12; Herdzina (1999), S. 31.

Vgl. Herdzina (2005), S. $10 \mathrm{ff}$.

Vgl. Für das Folgende Herdzina (2005), S. $15 \mathrm{ff}$.

Vgl. für das Folgende Herdzina (2005), S. $18 \mathrm{f}$.
} 
verbirgt, ist es also, die Güterangebotsstruktur an die Nachfragestruktur und deren Änderungen anzupassen resp. die Produktionsfaktoren entsprechend der Nachfragestruktur und deren Änderungen zu (re-)alloziieren.

Verbesserung der Güterverteilung?: Ein dritter Aspekt des Knappheitsproblems ergibt sich aus der Tatsache, dass die soeben vorgeschlagene Reallokation der Produktionsfaktoren bzw. die Anpassung der Güterangebotsstruktur an die jeweilige Nachfragestruktur stets an eine gegebene Kaufkraft- bzw. Einkommensverteilung unter den Bedürfnisträgern gekoppelt ist. Bei einer starken Ungleichverteilung des Einkommens könnte dies aufgrund mangelnder Kaufkraft für zahlreiche Bedürfnisträger zu erheblichen Versorgungsmängeln führen. Entspricht die aktuelle Einkommensverteilung nicht den geltenden Gerechtigkeitsvorstellungen, so könnte dieser Unterversorgung durch eine Änderung der Güterverteilung auf Basis einer Änderung der Einkommensverteilung begegnet werden. Knappheitsreduktion würde in diesem Fall durch Umverteilung realisiert.

Durch das Ausloten der Möglichkeiten zur Knappheitsreduktion ließ sich die zunächst noch abstrakte Forderung nach Wohlstandsmehrung auf die wirtschaftspolitischen Zielsetzungen Wirtschaftswachstum, optimale Güterallokation und Verteilungsgerechtigkeit präzisieren. ${ }^{8}$ Als besonders geeignetes Instrument, die bestehenden Strategien zur Knappheitsreduktion durchzusetzen, wird aus der Reihe der denkbaren Organisations- und Koordinationsmechanismen der Wirtschaftsplanung der marktwirtschaftliche Preisbildungsmechanismus hervorgehoben. ${ }^{9}$ Dieser stellt sicher, dass

- die Wirtschaftssubjekte stets über die Knappheitsgrade und -entwicklung bei Gütern und Produktionsfaktoren informiert sind (Informationsfunktion des Preises),

- die Plankoordination zwischen den Wirtschaftssubjekten funktioniert, d. h. dass ein Ausgleich zwischen dem Güterangebot und der Güternachfrage hergestellt wird (Ausgleichs- bzw. Koordinationsfunktion des Preises),

- die Produktionsfaktoren in ihre jeweils effizienteste Verwendung gelenkt werden, um eine Höchstleistung bei der Güterproduktion entsprechend der

Vgl. für das Folgende Herdzina (2005), S. 20.

Vgl. Herdzina (1999), S. 17.

Vgl. Herdzina (1981), S. 250. 
Rangordnung der Bedürfnisse zu realisieren (Lenkungs- bzw. Allokationsfunktion des Preises).

Eine wesentliche Bedingung für den störungsfreien Ablauf von marktwirtschaftlichen Preisbildungsprozessen und damit von Knappheitsreduktion stellt die Existenz von Wettbewerb bzw. die Abwesenheit von Wettbewerbsbeschränkungen dar. Der Wettbewerb ist folglich als ein zentrales Organisationsprinzip einer marktwirtschaftlichen Ordnung $\mathrm{zu}$ betrachten ${ }^{10}$ und wird daher als fundamental wichtiges Koordinierungsinstrument und als Leistungsstimulator einer Marktwirtschaft auch im Allgemeinen akzeptiert. "Wettbewerb respektive seine Existenz stellt also in seiner Eigenschaft als notwendige Voraussetzung für das Funktionieren des Marktmechanismus sicher, dass der Preis in einer Marktwirtschaft seine ihm obliegenden Funktionen optimal erfullen kann. Wettbewerb gewährleistet somit die Funktionsfähigkeit der Selbststeuerungseigenschaften des Preissystems. ${ }^{12}$

Der Markt(prozess) als wettbewerblicher Prozess ist gekennzeichnet durch die Konkurrenz um knappe Güter und begründet starke Anreize zur Leistungssteigerung der Akteure. Diese systemimmanenten Leistungsanreize sind es, die den marktwirtschaftlichen Koordinationsmechanismus in aller Regel als vorteilig gegenüber alternativen Organisations- und Koordinationsmechanismen der Wirtschaftsplanung erscheinen lassen. ${ }^{13}$

Zuvor wurde der Wettbewerbsprozess als ein offener Prozess charakterisiert, dessen Prozessverlauf und dessen Ergebnisse bzw. Wirkungen a priori im Einzelnen nicht bekannt und vorhersagbar sind. ${ }^{14}$ Dennoch können bezüglich der Wettbewerbswirkungen ,allgemein formulierbare Erwartungen“ in Form von musterhaften Voraussagen formuliert werden. ${ }^{15}$ Diese „allgemein formulierbaren Erwartungen“ fußen auf den positiven Steuerungseigenschaften, die dem Wettbewerb innerhalb einer Marktwirtschaft zugeschrieben werden und unterstellen, dass der Wettbewerb gute ökonomische Ergebnisse produziert. Diese positiven Steuerungseigenschaften werden üblicherweise

Vgl. Kerber (2003), S. 299.

Vgl. Herdzina (1981), S. 215.

Vgl. Kerber (2003), S. 300.

Vgl. Fritsch, Wein, Ewers (1999), S. 7.

Vgl. auch Giersch (1986), S. 15.

Vgl. Herdzina (1981), S. 250 f. 
in folgenden allgemein erwarteten ökonomischen Wettbewerbswirkungen zusammengefasst: ${ }^{16}$

(1) Wettbewerb bewirkt die Anpassung der Zusammensetzung der Güterproduktion an die Änderungen der Nachfragestruktur und bringt den dafür notwendigen Reallokationsprozess der Produktionsfaktoren in Gang (Anpassungs- bzw. Allokationsfunktion des Wettbewerbs).

(2) Wettbewerb bewirkt die Vermehrung und die Verbreitung des technischen Wissens. Er sorgt dafür, dass Produktionsfaktoren in den Bereich der Forschung und Entwicklung gelenkt werden, um neue Mechanismen und Verfahren der Problemlösung zu entdecken, d. h. Produktinnovationen, Produktdiffusion und Verfahrensinnovationen in den Produktionsprozessen anzustoßen (Entdeckungs- bzw. Fortschrittsfunktion des Wettbewerbs).

(3) Wettbewerb verhindert das Entstehen funktionsloser, d. h. nicht leistungsbezogener Einkommen auf den Gütermärkten - insbesondere funktionsloser Unternehmergewinne - bzw. sorgt für einen zügigen Abbau derartiger Einkommen. Wettbewerb trägt somit zu einer akzeptablen, auf Leistungsgerechtigkeit basierenden Primärverteilung bei, welche hilfreich ist, ...,die politisch und akademisch strapazierte Leer- und Lehrformel der Gerechtigkeit inhaltlich auszufüllen und Widerspruch und Grenze offenzulegen." ${ }^{17}$ (Verteilungsfunktion des Wettbewerbs).

\subsubsection{Wirtschaftliche Freiheit und Wettbewerb}

Die Freiheit als gesellschaftlicher Grundwert ist unbestritten und in zahlreichen Verfassungen moderner Wirtschaftsgesellschaften - so auch in den Eingangsartikeln des deutschen Grundgesetzes - verankert. ${ }^{18}$ Aus den konstitutionell verbrieften Grundfreiheiten kann auch die Forderung nach wirtschaftlicher Freiheit abgeleitet werden. ${ }^{19}$ Obwohl die wirtschaftliche Freiheit als wirtschaftspolitisches Ziel einhellig anerkannt wird, führt die Tatsache, dass Freiheit sich in mehreren teils miteinander unvereinbaren Ausprägungen manifestiert, zu erheblichen Meinungsverschiedenheiten

\footnotetext{
16 Vgl. dazu Knieps (2001), S. 4 ff.; Herdzina (1981), S. 251 f.; Herdzina (1999), S. 19; Kerber (2003), S. 300; Tolksdorf (1994), S. 19 ff.

17 Recktenwald (1986), S. 249.

18 Vgl. Tolksdorf (1994), S. 18.
} 
darüber, durch welche Marktkonstellationen im Einzelnen Freiheit gekennzeichnet ist. $^{20}$

Grundsätzlich kann Freiheit aus zwei Blickrichtungen betrachtet werden. ${ }^{21}$ In negativer Auslegung ist Freiheit - in der Tradition des klassischen Liberalismus - im Sinne von Abwesenheit von Handlungszwang zu interpretieren. In positiver Auslegung stellt Freiheit die Möglichkeit zum Handeln - positive Handlungsfreiheit also - dar, welche sich im konkreten Anwendungsfall der Ökonomik in Form von Wettbewerbsfreiheit oder der Freiheit zur Auswahl zwischen verschiedenen Handlungsalternativen (Wahlfreiheit) manifestieren kann. Im Bereich der positiven Handlungsfreiheit ist es zudem möglicherweise sinnvoll, zwischen formaler und materialer Handlungsfreiheit zu unterscheiden..$^{22}$ Die formale Freiheit ist die objektive Komponente der Freiheit, die Tatsache also, dass die Wirtschaftssubjekte die gleichen gesetzlich garantierten Möglichkeiten besitzen, bestimmte Handlungen vorzunehmen. Die materiale Freiheit ist die subjektive Komponente der Freiheit, das Vermögen bzw. die Fähigkeit der Wirtschaftssubjekte also, ihre persönlichen Ziele auch aus eigener Kraft zu erreichen. Diese Unterscheidung impliziert für den Bereich der Ökonomik, dass selbst bei Vorliegen formaler ökonomischer Handlungsfreiheit (bspw. die Möglichkeit des Marktzutritts für ein Unternehmen) die materiale ökonomische Handlungsfreiheit eingeschränkt sein kann (bspw. fehlendes Kapital oder technisches Wissen, um den Marktzutritt tatsächlich durchzuführen).

Die angedeutete Vielschichtigkeit des Freiheitsbegriffs und der teilweise subjektive Charakter der Handlungsfreiheit weist auf das grundsätzliche Problem des Konzeptes hin: ${ }^{23}$ absolute Freiheit im Sinne von gleichzeitiger, totaler Freiheit für alle Subjekte ist nicht realisierbar, da die Aktionsspielräume (Freiheitsbereiche) der einzelnen Subjekte in der Regel in einem substitutiven Verhältnis zueinander stehen. Die Ausweitung des Freiheitsbereiches fur ein Subjekt hat die Einengung der Freiheitsbereiche anderer Subjekte zur Folge. Dementsprechend ist Freiheit, auch im ökonomischen Bereich, stets als eine relative Größe zu interpretieren. ${ }^{24}$ Daraus erhellt, dass nicht jede Beschränkung der ökonomischen Handlungs- bzw. Wahlmöglichkeiten eines Wirtschaftssubjektes zweckmäßigerweise als eine Freiheitsbeschränkung bezeichnet

Vgl. Herdzina (1999), S. 12.

Vgl. Herdzina (1999), S. 12.

Vgl. für das Folgende Herdzina (1999), S. 12 f.

Vgl. Tolksdorf (1994), S. $18 \mathrm{f}$.

Vgl. Herdzina (1999), S. 13.

Vgl. Hoppmann (1972), S. 16. 
werden kann, sondern nur die „unangemessenen“"25 bzw. „unbilligen“"26 Beschränkungen. Was nun im Einzelnen als „unangemessene“ Beschränkung der Handlungs- bzw. Wahlfreiheit und damit als Freiheitsbeschränkung klassifiziert werden soll und was nicht, muss in Form eines Kataloges wirtschaftlicher Spielregeln festgelegt werden.

Stellt man nun die Frage, welcher Mechanismus aus der Reihe der denkbaren Organisations- und Koordinationsmechanismen der Wirtschaftsplanung besonders geeignet ist, ein Höchstmaß an relativer Freiheit - insbesondere an materialer Handlungsfreiheit - für die Wirtschaftssubjekte zu gewährleisten, so muss abermals der marktwirtschaftliche Koordinationsmechanismus hervorgehoben werden. ${ }^{27} \mathrm{Er}$ ist gekennzeichnet durch

- dezentrale Planungskompetenz der Wirtschaftssubjekte, deren Einzelpläne auf den Märkten ausgeglichen werden sowie damit notwendigerweise einhergehend durch

- dezentrales Eigentum, d. h. Privateigentum an Produktionsfaktoren. ${ }^{28}$

Allerdings sieht sich ein realtypisches marktwirtschaftlich konzipiertes System permanent der Gefahr ausgesetzt, dass einzelne Systemelemente versuchen, ihre Planungskompetenz zulasten anderer auszudehnen und damit den Aktionsspielraum anderer Elemente einzuengen bzw. deren Freiheitsspielraum zu gefährden. Dies kann zum einen durch das Systemelement Staat geschehen, dem bekanntermaßen die Tendenz innewohnt, Planungskompetenz an sich zu ziehen. ${ }^{29}$ Derartige Versuche gehen aber auch von Marktteilnehmern aus, um ihre ökonomische Position auf Kosten anderer Marktteilnehmer (Konkurrenten oder Marktpartner der Marktgegenseite) zu verbessern. ${ }^{30}$ Sofern solche Ausdehnungen der Planungskompetenz zulasten anderer Akteure nicht mit Leistungsverbesserungen (wie das bspw. bei temporären Pioniermonopolstellungen der Fall ist) verbunden sind oder dergestalt leistungsbezogenen sind, dass sie der Marktgegenseite Vorteile bringen, sind Versuche, welche darauf abzielen abzulehnen.

Vgl. Hoppmann (1972), S. 17.

Vgl. Herdzina (1999), S. 85.

Vgl. Herdzina (1999), S. 14.

Vgl. Herdzina (2005), S. 31.

Vgl. Herdzina (1999), S. 14.

Vgl. Herdzina (1999), S. 14 f.
} 
Zwar kann - aus ähnlichen Gründen wie bei den ökonomischen Wettbewerbswirkungen - bei Vorliegen eines Systems dezentraler Planung keine Voraussage bezüglich der Ausgestaltung und des Ausmaßes an ökonomischer Handlungs- und Wahlfreiheit im konkreten Einzelfall getroffen werden. Lediglich folgende Mustervoraussage ist möglich: „Da das dezentrale, marktwirtschaftliche, wettbewerbliche Planungssystem generell größere Handlungsspielräume und Wahlmöglichkeiten aufweist als die Zentralplanwirtschaft und weil wettbewerbliches Marktverhalten zur Erhaltung dieses Systems unabdingbar ist, kann Wettbewerb insoweit als ein Instrument zur Sicherung von Freiheit angesehen werden. “31 Daraus kann gefolgert werden, dass Wettbewerb Freiheit bewirkt (Freiheitsfunktion des Wettbewerbs).

\subsubsection{Systematik der Wettbewerbswirkungen}

Die vorstehenden Ausführungen haben aus dem anfangs unterstellten Grundkonsens bezüglich der erwarteten Wettbewerbswirkungen, nämlich dass ein als wettbewerblich apostrophiertes Marktgeschehen einen Beitrag zur Realisierung von Wohlstand, Gerechtigkeit und Freiheit leisten soll, vier Wettbewerbsfunktionen entwickelt:

- Die Anpassungs- bzw. Allokationsfunktion

- Die Entdeckungs- bzw. Fortschrittsfunktion

- Die Verteilungsfunktion

- Die Freiheitsfunktion

Ähnliche Formulierungen der erwarteten Wettbewerbswirkungen finden sich in der einschlägigen Fachliteratur zuhauf. Sie unterscheiden sich im Wesentlichen in ihrem horizontalen und vertikalen Detailliertheitsgrad der formulierten Funktionen sowie in der Frage, ob die Freiheitsfunktion in den Katalog der erwarteten Wettbewerbswirkungen aufgenommen wird oder nicht. ${ }^{32}$ Die Erörterungen unter Abschnitt 1.2 haben nun aber gezeigt, dass sich hinter diesen vordergründig möglicherweise unerheblich erscheinenden Diskrepanzen erhebliche inhaltliche und methodische Divergenzen verbergen, welche wiederum auf unterschiedlichen wettbewerbstheoretischen Grundpositionen fußen.

31 Herdzina (1999), S. $15 \mathrm{f}$.

32 Vgl. Herdzina (1999), S. 31. 
Je mehr Funktionen der Gesamtkatalog umfasst (steigender horizontaler Detaillierungsgrad) bzw. je tiefer man die einzelnen Funktionen untergliedert (steigender vertikaler Detaillierungsgrad), umso optimistischer scheint man wohl dahingehend zu sein, die Wettbewerbswirkungen genau und bezogen auf den Einzelfall voraussehen zu können. Diese Sichtweise findet ihre theoretische Verwurzelung in den preistheoretisch fundierten Wettbewerbshypothesen und den aus ihnen hervorgegangenen wettbewerbstheoretischen Ansätzen, insb. dem Workable-Competition-Ansatz. Demgegenüber deutet die Wahl eines geringeren Detailliertheitsgrades - wie hier in dieser Arbeit der Fall - tendenziell auf eine etwas vorsichtigere Position hin: Zwar wird die relative ökonomische Vorteilhaftigkeit wettbewerblicher Marktprozesse gegenüber den nicht-wettbewerblichen Marktprozessen postuliert, nicht zuletzt angesichts umfangreicher empirischer Belege hierfür. Es wird aber bestritten, dass diese ökonomische Vorteilhaftigkeit genau und bezogen auf den Einzelfall spezifiziert werden kann. Diese Sichtweise findet ihre theoretische Verwurzelung in der klassischen und in der neuklassischen Wettbewerbstheorie sowie in den empirischen Marktanalysen nach industrieökonomischem Muster.

Auch die Entscheidung, welchen Stellenwert man der Freiheitsfunktion im Katalog der Wettbewerbsfunktionen einräumt, lässt sich letzen Endes auf die Haltung in der Frage sowie auf die entsprechende theoretische Position zurückführen, inwieweit man die Wirkungen des Wettbewerbs im Einzelnen voraussagen kann oder nicht. Je zuversichtlicher man diesbezüglich ist, umso eher wird man dazu tendieren, die Freiheitsfunktion komplett aus den Überlegungen auszuschließen, da - wie zuvor dargestellt - der Wettbewerb nicht in jedem Einzelfall positiv auf die Handlungs- und Wahlfreiheit aller beteiligter Wirtschaftssubjekte einwirkt. ${ }^{33}$ Ist man bezüglich der Möglichkeiten zur Vorhersage von Wettbewerbswirkungen hingegen pessimistisch und hält lediglich die Formulierung von Mustervoraussagen für realistisch, dann ist die Freiheitsfunktion ein gleichwertiger Bestandteil des Katalogs der Wettbewerbsfunktionen, möglicherweise kommt ihr sogar eine zentrale Bedeutung zu.

Dabei soll ein Wettbewerbsgeschehen dann als funktionsfähig ${ }^{34}$ bezeichnet werden, wenn es alle ihm zugedachten Funktionen befriedigend erfüllen kann. Das Konzept

33 Vgl. dazu auch Herdzina (1973), S. 279 f.

34 An dieser Stelle sei an die historische Entwicklung des Begriffs des funktionsfähigen Wettbewerbs erinnert, welche er seit seiner Einführung in die Ökonomik durch J. M. Clarks „Workable Competition“ durchlaufen hat. Das Attribut „funktionsfähig“ im Zusammenhang mit dem Wettbewerbsbegriff wurde in der Folgezeit sehr strapaziert. Es wurde und wird zum einen dafür verwendet, um ein Wettbewerbskonzept als realisierbar und praktikabel von einem unrealistischen statischen Modell abzugrenzen. Zum anderen wird das Attribut „funktionsfähig“ häufig dazu 
des funktionsfähigen Wettbewerbs in der Form, in der es hier vorgetragen und vertreten wird, soll explizit auch die Freiheitsfunktion des Wettbewerbs mit berücksichtigen.

Über die Frage, ob es möglich ist, einen Marktprozess zu formulieren, der alle Funktionen gleichzeitig erfüllt, d. h. ob und inwieweit Konflikte zwischen den unterschiedlichen Wettbewerbsfunktionen existieren, besteht in der wettbewerbspolitischen Literatur kein Konsens. ${ }^{35}$ Die Anhänger der Dilemmathese vertreten die Ansicht, dass solche Zielkonflikte existieren. So sind bspw. Marktkonstellationen denkbar, die

- für ein Höchstmaß an Anpassungsdruck und damit für optimale Faktorallokation sorgen, dadurch aber unangemessen kleine Handlungsspielräume für die Marktteilnehmer lassen $(\rightarrow$ Allokationsfunktion und Freiheitsfunktion konfligieren).

- optimale Faktorallokation zu minimalen Kosten ermöglichen, welche aber wegen zu niedriger Gewinnspielräume keinen technischen Fortschritt zulas$\operatorname{sen}(\rightarrow$ Allokationsfunktion und Fortschrittsfunktion konfligieren).

Die Gültigkeit der Dilemmathese setzt jedoch voraus, dass bestimmte wettbewerbstheoretische, zumeist preistheoretisch fundierte Basishypothesen akzeptiert werden. Zentrale Basishypothesen besagen z. B., dass aufgrund der Existenz von Größenvorteilen die erforderliche, allokationsoptimale Unternehmensgröße sehr hoch ist (vgl. auch die Massenproduktionshypothese) oder dass die Fortschrittsmöglichkeiten großer Unternehmungen um Vergleich zu kleineren grundsätzlich größer sind (vgl. auch die Schöpferischer-Wettbewerb-Hypothese).$^{36}$ Verfechter der Harmoniethese hingegen akzeptieren die Richtigkeit dieser Basishypothesen nicht vorbehaltlos und relativieren folgerichtig die aus ihnen abgeleiteten Konsequenzen. So sind sie bspw. der Ansicht, dass Größenvorteile zwar existieren, lediglich in wenigen Bereichen aber in gewichti-

verwendet, Wettbewerbskonzeptionen zu charakterisieren, welche lediglich ökonomische Wettbewerbsfunktionen beinhalten. Dahinter verbirgt sich die Ansicht, dass eine Dilemmasituation zwischen der Erreichung des Freiheitsziels und der ökonomischen Funktionen vorliegt. Es liegt dann nahe, einen Wettbewerb, welcher das Freiheitsziel erfullt, als freien Wettbewerb zu bezeichnen und einen Wettbewerb, welcher die ökonomischen Funktionen erfüllt, mit dem Attribut „funktionsfähig" zu belegen. 
gem Umfange. Zudem bezweifeln sie die These einer permanent hohen fortschrittsoptimalen Unternehmensgröße. ${ }^{37}$

Auch die Dilemmadebatte ist letzten Endes ein Abglanz der wettbewerbstheoretischen Grundsatzdebatte, ob Wettbewerbswirkungen präzise im Einzelnen oder nur als Mustervoraussage vorhergesagt werden können. Werden von den Anhängern der Dilemmathese Konfliktsituationen zwischen den Wettbewerbsfunktionen beschrieben, so geschieht dies im Wissen, dass dafür auf (meistens preistheoretisch fundierte) Basishypothesen zurückgegriffen werden muss, welche keinesfalls über alle Zweifel erhaben sind. Auf ihre Schwächen wurde an entsprechender Stelle bereits verwiesen. Sie basieren zum Großteil auf problemspezifischen, nicht verallgemeinerbaren Grundannahmen und beleuchten meist isoliert die Zusammenhänge zwischen einzelnen wenigen Variablen und nicht den Wettbewerbsprozess in seiner Gesamtheit. Sie neigen daher dazu, diese Einzelvariablen und die in der jeweiligen Hypothese postulierten Zusammenhänge $\mathrm{zu}$ verabsolutieren bzw. deren Relevanz für den Wettbewerbsprozess in seiner Gesamtheit zu überbewerten. Akzeptiert man die Korrektheit dieser preistheoretischen Basishypothesen vorbehaltlos und macht zudem die Verknüpfung mehrerer solcher Hypothesen zur methodischen Argumentationsgrundlage für die mögliche Existenz genereller Dilemmakonstellationen, so täuscht man in der wettbewerbstheoretischen Diskussion eine Sicherheit und eine Einigkeit vor, die es in dieser Form und insbesondere bei diesem Detaillierungsgrad nicht gibt. Die Anhänger der Harmoniethese hingegen setzen ihr Vertrauen auf die Leistungsfähigkeit des Wettbewerbsprozesses als ergebnisoffenem Such- und Entdeckungsverfahren, welches die unter den jeweiligen marktlichen Bedingungskonstellationen optimalen Organisationsformen, Kontrollmechanismen sowie Betriebs- und Unternehmensstrukturen aus eigener Kraft zutage fördert. Sie gehen von der generellen Vereinbarkeit der Wettbewerbsfunktionen aus, freier Wettbewerb (im Sinne des Fehlens von Freiheitsbeschränkungen) produziert in der Regel gute ökonomische Ergebnisse. Die Einschränkung ,in der Regel“ soll darauf verweisen, dass Dilemmakonstellationen im Einzelfall durchaus denkbar und im realen Marktgeschehen auch beobachtbar sind - allerdings nicht so zahlreich und in der bisweilen unterstellten Intensität. ${ }^{38}$ Dieser Sichtweise wird auch hier gefolgt.

Akzeptiert man den Katalog der Wettbewerbswirkungen und deren grundsätzlich harmonisches Zusammenspiel in der vorgestellten Form, so gilt es nun, ein Verständnis dafür zu entwickeln, wie der wettbewerbliche Prozess geartet sein muss, welcher 
geeignet ist, diese Wirkungen hervorzubringen. Die Charakterisierung dieses Wettbewerbsprozesses sowie der ihm zugrunde liegenden Verhaltensweisen sind Gegenstand des folgenden Unterabschnitts.

\subsubsection{Wettbewerbsprozess}

\subsubsection{Charakterisierung des Wettbewerbsprozesses}

Prinzipiell konnte sich innerhalb der Forschungsgemeinde die Sichtweise durchsetzen, dass der Wettbewerbsprozess in adäquater Form als erwünschter, dynamischer Marktprozess zu interpretieren ist. Dieser vermag die ökonomische Realität, d. h. die unausbleiblichen permanenten Veränderungs- bzw. Entwicklungsvorgänge marktlicher Variabler im Zeitablauf, in Richtung der bestmöglichen Realisation der erwarteten Wettbewerbswirkungen zu kanalisieren. Der Wettbewerbsprozess in seiner idealtypischen Ausgestaltung ist gekennzeichnet durch typische Abfolgen zyklischer Sequenzen, für deren Beschreibung die Autorenschaft (federführend ARNDT, SCHUMPETER, HOPPMANN und J. M. CLARK) unterschiedliche Terminologien eingefürt hat und welche demgemäß etwa mit den folgenden Formulierungen umrissen werden können:

- Der Wettbewerbsprozess dokumentiert sich als Abfolge von Vorstoßprozessen (initiatorischer, schöpferischer oder bahnbrechender Wettbewerb) und Verfolgungsprozessen (imitatorischer, nachfolgender oder nachahmender Wettbewerb). ${ }^{39}$

- Damit korrespondierend ergeben sich im Zuge unternehmerischer Vorstoßaktionen temporär Phasen der Gewinndifferenzierung, d. h. Marktkonstellationen, in denen sich einzelne Anbieter von ihren Konkurrenten absetzen und ein prozessuales (Pionier-)Monopol begründen. Diese Konstellationen werden abgelöst von Phasen der Gewinnnivellierung bzw. -eliminierung, d. h. Marktkonstellationen, in denen die Konkurrenten Verfolgungsprozesse anstrengen mit dem Ziel, den enteilten Pionier einzuholen und seine Vorsprunggewinne durch

$38 \quad \mathrm{Vgl}$.Herdzina (1999), S. 44.

39 Vgl. Herdzina (1999), S. 60; Schmidt, (1999), S. 60. 
Gewinnpartizipation zu erodieren, bis temporär wieder ein Gleichheitszustand zwischen den Marktteilnehmern hergestellt wird (prozessuales Isopol). ${ }^{40}$

Die Beschreibung des wettbewerblichen Marktprozesses in dieser allgemeinen Form als Mustervoraussage entspricht methodisch betrachtet wiederum dem Standpunkt der neuklassischen Wettbewerbstheorie, welche ja die Position vertritt, dass die Voraussage von individuellen wettbewerblichen Ergebnissen und spezifischen Ereignissen nicht möglich ist, dass Wettbewerb im Einzelnen nicht positiv $\mathrm{zu}$ definieren und $\mathrm{zu}$ normieren ist und dass die Intensität, mit welcher sich dieser Prozess im konkreten Einzelfall vollzieht, nicht bestimmbar ist. Diese allgemeine positive Prozessbeschreibung allein allerdings ist nicht ausreichend, um einen eindeutigen Erklärungszusammenhang zu den erwarteten Wettbewerbswirkungen herzustellen: ${ }^{41}$ Selbst wenn der Wettbewerbsprozess wie beschrieben in idealtypischer Form abläuft, so ist dennoch nicht gewährleistet, dass er allein auf Basis wettbewerblicher Verhaltensweisen zustande gekommen ist und nicht das Resultat wettbewerbsinkonformer Verhaltensweisen ist. Umgekehrt ist auch das Ausbleiben eines derartigen Prozesses noch kein Beweis dafür, dass das Marktgeschehen nicht von wettbewerblichen Verhaltensweisen gekennzeichnet ist. Daraus erhellt nun aber, dass nicht die nach außen sichtbare Figur des Prozessablaufes sondern nur die im Einzelnen praktizierten Verhaltensweisen der Marktteilnehmer die Grundlage für die Beschreibung eines funktionsfähigen Wettbewerbs bilden können. ${ }^{42}$ Dies gilt umso mehr als die Vorstellung von Wettbewerb als einem zyklischen Prozess von Vorstoß- und Verfolgungshandlungen mit Blick auf die ökonomischen Wettbewerbsfunktionen formuliert worden ist und nicht originär mit Blick auf den Freiheitsaspekt. ${ }^{43}$ Dabei ist - wie dargelegt - gerade die Erörterung der Frage, ob Freiheitsspielräume von Marktteilnehmern in solchen Prozessen unangemessen beschränkt sind oder nicht, ob also eine Freiheits- bzw. Wettbewerbsbeschränkung vorliegt oder nicht, entscheidend. Das gilt sowohl für den Fall möglicher (vertraglich basierter) Beschränkungen der formalen Handlungsfreiheit als auch für mögliche Beschränkungen der materialen Handlungsfreiheit mit diskriminierendem Charakter. ${ }^{44}$

\footnotetext{
Vgl. Herdzina (1981), S.253; Herdzina (1999), S. 60 f.

Vgl. Herdzina (1999), S. 61.

Vgl. Herdzina (1999), S. 61.

Vgl. Herdzina (1999), S. 62.

Vgl. Schmidt (1999), S. 30.
} 


\subsubsection{Wettbewerbliches und nichtwettbewerbliches Marktverhalten}

Um eine eindeutige Aussage über die Funktionsfähigkeit eines realen Marktprozesses treffen und wettbewerbsbeschränkende weil freiheitsbeschränkende Verhaltensweisen identifizieren zu können, müsste es möglich sein, die realen unternehmerischen Marktverhaltensweisen eindeutig als wettbewerblich und nichtwettbewerblich bzw. wettbewerbsbeschränkend zu kategorisieren. Dies ist jedoch undurchführbar. ${ }^{45}$ Eine praktikablere Herangehensweise wäre es nun, die Fülle empirisch denkbarer Marktverhaltensweisen zunächst zu Fallgruppen zu verdichten und aus diesen einen Katalog von Verhaltenstypen abzuleiten, welche dann ,mit hinlänglicher Sicherheit ${ }^{\star 46}$ den wettbewerblichen oder nichtwettbewerblichen Verhaltensweisen zugeordnet werden können. Eine entsprechende Typologie von Marktverhaltensweisen könnte möglicherweise folgendermaßen aussehen: ${ }^{47}$

(1) Kreatives Marktverhalten umfasst sämtliche Aktivitäten, die darauf abzielen, sich eine Vorsprungsposition gegenüber den Konkurrenten zu erarbeiten. Derartige Vorsprungspositionen können das Resultat realisierter Produkt- oder Verfahrensinnovationen, von Fortschritten bei Beschaffungs- und Distributionsprozessen oder im Marketingprozess sein. Damit einher geht der aktive Einsatz entsprechender Wettbewerbsparameter (bspw. Preis oder Produktqualität). Aber nicht nur die Verwirklichung technischen Fortschritts im beschriebenen Sinne, sondern auch die spontane Anpassung an Nachfragestrukturänderungen, bspw. mittels der Variation des bestehenden Produktionsprogrammes, zählt zum kreativen Marktverhalten.

(2) Adaptives Marktverhalten umschreibt die unternehmerischen Reaktionshandlungen auf das kreative Marktverhalten. Die erarbeiteten Vorsprungspositionen werden durch nachahmende Imitation oder durch eigene Innovationsaktivitäten beseitigt. Das adaptive Marktverhalten zeichnet insbesondere verantwortlich für die Diffusion von technischem Fortschritt. Die eingesetzten Wettbewerbsparameter entsprechen denen unter (1).

(3) Konsolidierendes Marktverhalten dient der Erhaltung bzw. Stabilisierung etablierter Marktpositionen. Zwar erfolgt auch hier noch aktiver Parameterein-

Vgl. Herdzina (1981), S. 255.

Herdzina (1981), S. 255.

Vgl. fur das Folgende Herdzina (1981), S. 255 ff. (insb. für die Typen (1) - (4)); Herdzina (1985),

S. 107 f.; Herdzina (1999), S. 139 ff. (für die Typen (5) - (7)). 
satz, jedoch mit Gewichtung auf Maßnahmen im Bereich des Servicewettbewerbs. Ansonsten sind Maßnahmen zur Produktdifferenzierung sowie Aktivitäten zum Aufbau von Reputation und Image wahrscheinlich.

(4) Integrierendes Marktverhalten zielt ab auf die Stärkung der eigenen Marktposition durch horizontale, vertikale und diagonale Zusammenschlüsse. Die damit einhergehende Änderung der unternehmens- und marktstrukturellen Landschaft soll möglichst überdauernd angelegt sein und dient dem Abbau von Unsicherheiten im Marktprozess. Der Zusammenschluss zwischen zwei oder mehr Unternehmen reduziert die Anzahl der rechtlich selbstständigen Wirtschaftssubjekte und verringert somit die Möglichkeit zu dezentraler marktlicher ex-post Koordinierung. ${ }^{48}$

(5) Kollektives Marktverhalten umfasst alle Aktivitäten zur ex-anteVerhaltenskoordination. Darunter fallen Verhaltensabstimmungen, welche kraft eigener Erfahrungen bezüglich der Verhaltensweisen der Konkurrenten zwar bewusst vollzogen werden, jedoch nicht explizit durch den Austausch von Informationen zwischen Marktteilnehmern abgesprochen sind (bspw. Preisführerschaft). Darunter fallen aber auch ausdrückliche Absprachen zwischen Marktteilnehmern, die dazu dienen, (a) als genehm empfundene Ausprägungen des Ablaufs des Marktprozesses, (b) den Einsatz bestimmter Wettbewerbsparameter oder (c) bestimmte Elemente der Marktergebnisse teilweise oder in Gänze im Vorhinein festzulegen. Damit werden das System marktlicher ex-postKoordination, welches nach optimalen Problemlösungen sucht, sowie die damit verbundene Unsicherheit ausgeschaltet (bspw. durch Kartelle). ${ }^{49}$ Kollektives Marktverhalten reduziert somit die Handlungsspielräume derer, die derartiges Marktverhalten praktizieren, der aktuellen und potenziellen Konkurrenten derselben Marktstufe sowie der Marktpartner der Marktgegenseite.

(6) Bindungen umfassen sämtliche Verhaltensweisen, mit denen einzelne Marktteilnehmer versuchen, Einfluss auf die Geschäftspolitik anderer Marktteilnehmer zu nehmen. In der Regel handelt es sich dabei um vertikale Bindungen zwischen Unternehmen aufeinander folgender Produktionsstufen (bspw. Preisbindungen, Ausschließlichkeitsbindungen, Kopplungsverträge). Bindungen reduzieren prinzipiell den formalen und/oder den materialen Handlungsspielraum der Gebundenen resp. die Handlungsspielräume der aktuellen und potenziellen 
Marktpartner der gebundenen Unternehmen in Bezug auf einen oder mehrere wettbewerbliche Aktionsparameter. ${ }^{50}$ Sie reduzieren ferner die Unsicherheit für die Bindenden bezüglich der Verhaltensweisen der Gebundenen und somit den Wettbewerbsdruck.

(7) Behinderungspraktiken sind darauf ausgerichtet, andere Marktteilnehmer zu schädigen bzw. schädigend auf sie zu wirken. Sie müssen von den betroffenen Marktteilnehmern unfreiwillig hingenommen werden und schränken den Handlungsspielraum anderer Marktteilnehmer in unangemessenem Ausmaß ein. Behinderungspraktiken sind zu unterscheiden von legitimen Behinderungen, welche sich aus wettbewerblichen Vorstoßhandlungen von dynamischen Unternehmern für inaktive Marktteilnehmer ergeben. ${ }^{51}$ Behinderungspraktiken dienen dem Ausbau der eigenen Marktposition und können sich gegen Marktpartner vor- oder nachgelagerter Produktionsstufen richten (Diskriminierungen, Lieferverweigerungen), aber auch gegen aktuelle und potenzielle Konkurrenten (Verdrängungs- und Marktschließungsstrategien wie bspw. Kampfpreisunterbietungen, Ansetzen eintrittsverhinderner Preise, Boykottaufrufe).

Auch dieser Entwurf einer Typologie von Marktverhaltensweisen allerdings darf nicht darüber hinwegtäuschen, dass die Zuordnung der realen unternehmerischen Marktverhaltensweisen zu einem der vorgestellten Verhaltenstypen im Einzelfall problematisch sein kann. Zudem ist die Einteilung der Verhaltenstypen in die Kategorien des wettbewerblichen und des nichtwettbewerblichen Marktverhaltens nicht unproblematisch. Wenig Diskussionsbedarf ergibt sich wohl bei der Zuordnung der beiden ersten Verhaltenstypen zum Wettbewerbsverhalten und des letzten Verhaltenstypus zum nichtwettbewerblichen Verhalten. Bei allen anderen Verhaltenstypen allerdings gelingt die Zuordnung nicht ohne Komplikationen. Konsolidierendes Marktverhalten bspw. kann tendenziell gewiss dem Wettbewerbsverhalten zugeschrieben werden, wobei allerdings nicht auszuschließen ist, dass durch Konsolidierungsmaßnahmen andere Marktteilnehmer unbillig behindert werden können. ${ }^{52}$ Die Bindungen hingegen können sicherlich angesichts ihrer freiheitsbeschränkenden Eigenschaften und insbesondere dann, wenn sie auch Behinderungen im Sinne von Typ (7) darstellen, grundsätzlich den nichtwettbewerblichen Verhaltensweisen zugerechnet werden. Dennoch lassen 
sich unter Umständen auch Formen der Bindung beschreiben, welche Ausdruck berechtigter (wettbewerbskonformer) Unternehmerinteressen sind. Dies ist möglicherweise bei einzelnen Formen von Abschlussbindungen der Fall. ${ }^{53}$ Auch das kollektive Marktverhalten ist grundsätzlich sicherlich den nichtwettbewerblichen Verhaltensweisen zuzurechnen. Allerdings sind auch hier Umstände denkbar, welche zu der Vermutung Anlass geben, dass nicht alle Ausprägungen des kollektiven Marktverhaltens wettbewerbsbeschränkend sind. Vorstellbar sind bspw. Formen des Kollektivverhaltens, welche (1) zwar die Wettbewerbsfreiheit einzelner beschränken, diese Negativwirkungen aber dadurch (über-)kompensieren, dass sie gleichzeitig auch Freiheitsspielräume für andere Marktteilnehmer erhalten bzw. ihnen neue eröffnen oder aber Formen, welche (2) die ökonomische Marktperformance unter billigender Inkaufnahme von Freiheitsbeschränkungen - und damit einer Dilemmakonstellation verbessern (bspw. durch Kartell- oder Kooperationsbildungen zum Zwecke der Rationalisierung, der Mittelstandförderung oder der Erhöhung der Markttransparenz) ${ }^{54}$ Integrierendes Marktverhalten wiederum ist unmittelbar für sich selbst genommen nicht per se wettbewerbsbeschränkend, könnte über die Reduktion der Anzahl eigenverantwortlich entscheidender Marktteilnehmer mittelbar aber die Basis für nachkommende wettbewerbsbeschränkende Handlungen werden und bildet somit zumindest den potenziellen Nährboden für nichtwettbewerbliches Verhalten. ${ }^{5 s}$ Allerdings darf nicht außer Acht gelassen werden, dass externes Unternehmenswachstum gleichsam ein adäquates und wettbewerbskonformes Instrument zur Suche und Herausbildung effizienter Unternehmensgrößen ist ${ }^{56}$ und unter Umständen auch positiv auf den Wettbewerbsprozess wirken kann (bspw. im Falle von Aufhol- oder Sanierungsfusionen) $)^{57}$.

Die Erörterungen zu den einzelnen Verhaltenstypen dürften gezeigt haben, dass lediglich die beiden ersten Typen, nämlich kreatives und adaptives Marktverhalten, vorbehaltlos der Kategorie des Wettbewerbsverhaltens zuzurechnen sind. Ist ein Marktgeschehen von diesen Verhaltensweisen gekennzeichnet, so ergibt sich infolgedessen jener als wettbewerblich apostrophierte Marktprozess, welcher die unter 1.3.1 beschriebenen Wirkungen zeitigt. Die Voraussetzungen, welche einem derart beschriebenen wettbewerblichen Marktprozess zugrunde liegen, die Determinanten

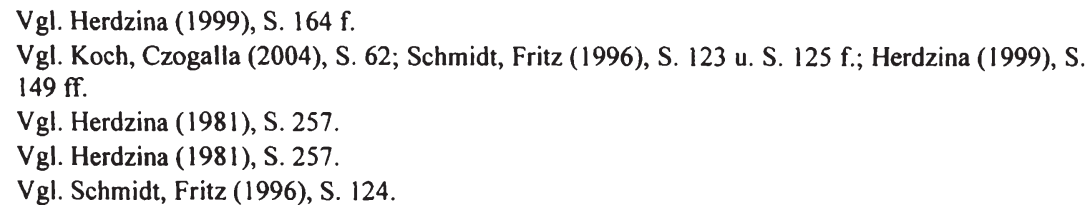


kreativen und adaptiven Marktverhaltens also, sind Gegenstand des folgenden Unterabschnitts.

\subsubsection{Wettbewerbsdeterminanten}

Die vergleichende Analyse der verschiedenen wettbewerbstheoretischen Positionen hat auch hinsichtlich der Wettbewerbsdeterminanten ein sehr unregelmäßiges Bild ergeben. Angesichts der Menge und Heterogenität der jeweils vorgeschlagenen Wettbewerbsdeterminanten scheint auch in dieser Frage prima facie keine gemeinsame Basis zu existieren. Die verschiedenen Positionen lassen sich jedoch möglicherweise einander annähern, wenn man unterstellt, dass sie Ausdruck zweier unterschiedlicher Argumentationsebenen sind, auf denen die wettbewerbstheoretischen Ansätze offenkundig zu operieren scheinen. In Anbetracht dessen vermag die Unterscheidung von

- unmittelbaren Wettbewerbsdeterminanten und ihren Komponenten sowie

- mittelbaren Wettbewerbsdeterminanten und ihren Komponenten

zur Abmilderung von Divergenzen dienlich sein und dazu beitragen, die verschiedenen Argumentationsansätze miteinander in Einklang zu bringen. ${ }^{58}$

\subsubsection{Unmittelbare Wettbewerbsdeterminanten}

Die den wettbewerblichen Marktprozess begründenden wettbewerblichen Verhaltensweisen in der Form, in der sie zuvor charakterisiert wurden, werden von den Marktteilnehmern dann praktiziert, wenn sie a) die Möglichkeit dazu haben und b) die Bereitschaft bzw. Neigung (,spirit of competition“) zu einem solchen Verhalten empfinden. ${ }^{59}$ Wettbewerbsmöglichkeit (WM) und Wettbewerbsneigung (WN) sind die unmittelbaren Wettbewerbsdeterminanten. ${ }^{60}$ Es gilt

$\mathrm{W}=\mathrm{W}(\mathrm{WM}, \mathrm{WN})$.

Vgl. Herdzina (1981), S. 258.

Vgl. Giesel (1975), S. 34 f.

60 Vgl. Herdzina (1981), S. 258; Herdzina (1985), S. 107. 
Die Möglichkeit zu Wettbewerbsverhalten haben die Marktteilnehmer dann, wenn sie a1) die Gelegenheiten zu kreativem und adaptivem Verhalten, welche der Markt ihnen bietet, auch erkennen, d. h. wenn Markttransparenz (MT) herrscht, wenn sie a2) ihre geplanten Wettbewerbshandlungen ohne unangemessene Beschränkungen in ihrer Handlungs- und Wahlfreiheit durchfüren können, d. h. wenn Wettbewerbsfreiheit (WF) herrscht, und wenn sie a3) fähig dazu sind, die geplanten Wettbewerbshandlungen durchzuführen, d. h. wenn Fähigkeit $(\mathrm{F})$ zu Wettbewerbsverhalten besteht. ${ }^{61}$ Es gilt also

$\mathrm{WM}=\mathrm{WM}(\mathrm{MT}, \mathrm{WF}, \mathrm{F})$.

Die Neigung zu Wettbewerbsverhalten wiederum wird motiviert von bl) der ihr entsprechenden, auf Eigeninteresse und Risikobereitschaft gründenden Wirtschaftsmentalität (E). Ferner ist sie abhängig vom b2) Ausmaß des Optimismus der Marktteilnehmer bezüglich der Frage, durch Wettbewerbshandlungen erfolgreich am Marktgeschehen teilnehmen und ggf. Bedrohungen erfolgreich begegnen zu können, d. h. vom Ausmaß der relativen Expansionschancen (EC), sowie b3) vom Ausmaß der Optionen für die Marktteilnehmer, sich dem wettbewerblichen Marktprozess bei Wunsch unter Umständen entziehen zu können, d. h. vom Ausmaß des Wettbewerbszwanges (WZ) ${ }^{62}$ Es gilt also

$\mathrm{WN}=\mathrm{WN}(\mathrm{E}, \mathrm{EC}, \mathrm{WZ})$

Die beiden unmittelbaren Wettbewerbsdeterminanten sowie ihre Komponenten bilden nun jene geschlossene Einheit an objektiven und (aus Sicht des einzelnen Marktteilnehmers) subjektiven Faktoren, welche direkte, notwendige Voraussetzungen für das Zustandekommen des Wettbewerbsprozesses darstellen. Es handelt sich bei den unmittelbaren Wettbewerbsdeterminanten um grundsätzliche Elemente, welche, auf vergleichsweise hohem Abstraktionsniveau formuliert, die Möglichkeiten zu wettbewerblichem Marktverhalten steuern und die Bereitschaft dazu mit positiven Anreizen versehen. Offensichtlich scheinen sich die klassische und die neuklassische Wettbewerbstheorie vornehmlich auf dieser Argumentationsebene zu bewegen. Die Klassiker

61

Vgl. Herdzina (1981), S. 259; Herdzina (1985), S. 107. 
betonen die Notwendigkeit von Markttransparenz und Wettbewerbsfreiheit für das Zustandekommen eines wettbewerblichen Marktprozesses. Ferner heben sie die Relevanz einer auf Eigeninteresse gründenden Wirtschaftsgesinnung sowie der Existenz von Wettbewerbszwang hervor. Die neuklassische Wettbewerbstheorie vertritt die Position, dass Wettbewerbsverhalten grundsätzlich durch das Bestehen von Wettbewerbsfreiheit, also eines Elementes der Möglichkeit zu Wettbewerbsverhalten, sowie durch die Existenz einer Neigung zu wettbewerblichem Verhalten determiniert wird. ${ }^{63}$ Allerdings wird letztere Determinante als gegeben angenommen. ${ }^{64}$

\subsubsection{Mittelbare Wettbewerbsdeterminanten}

Es bleibt nun zu klären, von welchen Determinanten wiederum die Wettbewerbsmöglichkeit und die Wettbewerbsneigung sowie ihre jeweiligen Komponenten abhängen, welches also die mittelbaren Wettbewerbsdeterminanten sind. Zu dieser Fragestellung wird von den preistheoretisch fundierten Ansätzen sowie von der Industrieökonomik ein umfangreiches Repertoire an Beiträgen vorgehalten. Die einschlägigen preistheoretischen Wettbewerbshypothesen beschäftigen sich (1) in allgemeiner Form mit der Verknüpfung zwischen marktstrukturellen Faktoren und der Wettbewerbsintensität oder (2) in verfeinerter Form mit dem Einfluss, den marktstrukturelle Faktoren auf einzelne Komponenten der Möglichkeit und der Neigung zu Wettbewerbsverhalten nehmen. ${ }^{65}$ Von der Industrieökonomik werden neben den marktstrukturellen zusätzlich diverse Faktoren der internen Unternehmensstruktur sowie eine Fülle weiterer Variabler in Feld geführt, welche als mutmaßliche Voraussetzungen für die unmittelbaren Wettbewerbsdeterminanten fungieren. Die wettbewerbstheoretische Aussagekraft dieser Wettbewerbshypothesen wird allerdings durch deren auffällige Divergenz hinsichtlich Wirkungsrichtung und/oder Wirkungsintensität der jeweils betrachteten marktstrukturellen, unternehmensstrukturellen oder sonstigen Variablen auf wettbewerbliche Zielgrößen relativiert. Diese Unzulänglichkeit konnte auch in empirischen Tests, wie sie zahlreich in der Industrieökonomik durchgeführt wurden, nicht in ein harmonisches, einheitliches Bild überführt werden ${ }^{66}$ Als ein Erfolg versprechender

62 Vgl. Herdzina (1981), S. 259; Herdzina (1985), S. 107.

63 Vgl. Hoppmann (1968a), S. 12 ff.

64 Vgl. Hoppmann (1968a), S. 12.

65 Vgl. Herdzina (1981), S. 259. Kantzenbach bspw. untersucht den Zusammenhang zwischen marktstrukturellen Elementen und der Möglichkeit und der Neigung zu Innovationsaktivitäten einerseits (vgl. Kantzenbach (1967), S. 42 ff.) sowie der Möglichkeit und der Neigung zu wettbewerbsbeschränkenden Verhaltensweisen andererseits (vgl. Kantzenbach (1967), S. 90 f.).

Vgl. Herdzina (1985), S. 108. 
Ansatzpunkt zur Abmilderung der Divergenzen und zur Annäherung von widersprüchlichen Aussagen wurde die Berücksichtigung der jeweiligen Marktentwicklungsphase identifiziert. Expansive resp. kontraktive Marktentwicklungsprozesse üben demnach spürbaren Einfluss auf Wettbewerbsmöglichkeit und Wettbewerbsneigung aus. ${ }^{67}$

Damit ergibt sich nun folgender Zusammenhang zwischen den unmittelbaren und den mittelbaren Wettbewerbsdeterminanten:

$$
W\left\{\begin{array}{l}
W M(M T, W F, F) \\
W N(E . E C . W Z)
\end{array}\right\}=f\left\{\begin{array}{l}
U S[d, b, p, k, o], \\
M_{A}\left[z_{a}, k_{x}, p d\right], \\
G_{M}\left[G_{N}, T, M_{P F}\right] \\
P f S, P d S, Z, M S_{N}, E \\
O, \ldots
\end{array}\right\}
$$




\subsection{Zusammenfassung}

Kapitel 1 befasste sich mit dem wirtschaftlichen Wettbewerb. Es wurde aufgezeigt, dass es sich bei Wettbewerb um ein außerordentlich vielschichtiges Phänomen handelt, das auf recht unterschiedliche Art und Weise wahrgenommen und interpretiert werden kann. Es bestehen in der wettbewerbstheoretischen Disziplin erhebliche Meinungsverschiedenheiten bezüglich der Voraussetzungen, unter denen sich Wettbewerb einstellt, bezüglich des wettbewerblichen Prozessverlaufes sowie bezüglich der Wirkungen, welche von einem als wettbewerblich etikettierten Marktgeschehen erwartet werden, was sich in z. T. stark voneinander divergierenden theoretischen Positionen niederschlägt. Folgerichtig wird auch die grundsätzliche Frage, was unter Wettbewerb zu verstehen ist - also die Frage der Wettbewerbsdefinition - in der Wettbewerbstheorie kontrovers diskutiert und konnte bislang nicht abschließend geklärt werden. Dieser unbefriedigende Umstand ist zum einen auf denselben materiellen Dissens innerhalb der Forschungsgemeinde zurückzuführen, welcher auch die divergenten theoretischen Positionen zutage gefördert hat. Zum anderen ist er aber auch das Resultat methodologischer Überlegungen. In Summe musste daher das gleichermaßen bedauerliche wie unbefriedigende Fazit gezogen werden, dass es eine allgemeingültige, positive Definition dessen, was Wettbewerb ist oder nicht ist, nicht gibt und wohl auch nicht geben kann. Die Wettbewerbstheorie ist vielmehr durch die Koexistenz unterschiedlicher, oftmals konkurrierender Definitionsansätze gekennzeichnet, welche sich dem Erkenntnisobjekt „Wettbewerb“ aus verschiedenen Blickwinkeln nähern. Die Definitionsansätze scheinen aber zumindest dahingehend miteinander vereinbar zu sein, dass sie sich in der Regel einer der drei Säulen aus der Argumentationssequenz „Determinanten - Prozess - Wirkungen“ zuordnen lassen. Dieser Umstand und die Tatsache, dass - trotz bisweilen erheblich voneinander abweichender Einzelaussagen und -hypothesen - innerhalb der Forschungsgemeinde dennoch ein theorienübergreifender Basiskonsens bezüglich einiger wesentlicher Grundeigenschaften des Wettbewerbs $\mathrm{zu}$ bestehen scheint, führten $\mathrm{zu}$ folgender Vorgehensweise bei der weiteren Auseinandersetzung mit der Wettbewerbsmaterie:

Zunächst wurden die verschiedenen wettbewerbstheoretischen Ansätze dahingehend untersucht, welchen Beitrag sie zur Erklärung des Wettbewerbs zu leisten in der Lage sind. Hierzu wurden die Aussagen der diversen wettbewerbstheoretisch verwertbaren, erfahrungswissenschaftlichen Hypothesen der einschlägigen Theorien bezüglich der jeweils vorgeschlagenen Wettbewerbsdeterminanten, bezüglich des sich vollziehenden Wettbewerbsprozesses sowie bezüglich der daraus resultierenden Wettbewerbswirkungen - möglichst entkoppelt von normativen Elementen - dargestellt. Auf dieser 
Darstellung aufbauend erfolgte anschließend die Zusammenführung der wettbewerbstheoretischen Ansätze zu einer umfassenderen Wettbewerbskonzeption, welche den Stärken der einzelnen Denkstile Rechnung trägt und welche diese aus ihrer theoretischen Isolation heraus zweckgerichtet zu einer konzeptionellen Einheit verbindet. Diese umfassendere Wettbewerbskonzeption stellt insofern ein konsensfähiges Modell zur „Defragmentierung“ der heterogenen wettbewerbstheoretischen Landschaft dar und soll der vergleichenden Analyse von Wettbewerb und Logistik in Kapitel 3 als theoretischer Bezugsrahmen dienen. 
Carsten Wander - 978-3-631-75390-3

Downloaded from PubFactory at 01/11/2019 05:34:40AM

via free access 


\section{Logistische Reorganisation}

\subsection{Methodische und theoretische Vorbemerkungen}

\subsubsection{Der industrieökonomische Ansatz als geeignete Untersuchungsmethode}

Kapitel 1 hatte zum Ziel, aus der Fülle der theoretischen Konzepte zum wirtschaftlichen Wettbewerb jene Elemente zu identifizieren, welche einen Beitrag zur Erklärung des Wettbewerbs - seiner Wirkungen, seines Prozessverlaufes und seiner Determinanten - leisten können. Auf Basis dieser Elemente wurde eine umfassendere Wettbewerbskonzeption entworfen, welche als wettbewerbstheoretischer Bezugsrahmen für diese Arbeit dient. Nunmehr gilt es, das Prozessphänomen der logistischen Reorganisation wirtschaftlicher Aktivität in ähnlicher Weise systematisch zu erfassen und einer Analyse zugänglich zu machen. Dies ist - wie bei der Wettbewerbstheorie auch - kein leichtes Unterfangen. Das junge und höchst dynamische Feld der Logistik' ist in seinen Grenzbereichen noch nicht eindeutig und abschließend konturiert und offenbart sich in mehrerlei Hinsicht als ein heterogenes Konstrukt mit hoher Eigenkomplexität ${ }^{2}$ :

- Das Vokabular, welches in der Logistikwissenschaft benutzt wird, ist uneinheitlich und gelegentlich sogar widersprüchlich. ${ }^{3}$ Die logistische Begriffswelt besteht - den Wirtschaftsräumen entsprechend, in denen die Logistik hauptsächlich Gegenstand der wissenschaftlichen Forschung ist - im Wesentlichen aus deutschen und angelsächsischen Vokabeln und entspringt damit nicht nur unterschiedlichen Sprachräumen sondern ist auch Ausdruck unterschiedlicher wissenschaftstheoretischer Denkschulen und ökonomischer Traditionen sowie jeweils unterschiedlicher logistischer Anwendungserfordernisse und Anforderungsprofile in der Wirtschaftspraxis. Dies hat zur Konsequenz, dass in der Logistikwissenschaft an sich gleichartige Fragestellungen und Sachverhalte innerhalb der logistikwissenschaftlichen Forschungsgemeinde bisweilen a) divergierende inhaltliche Interpretationen und Ausgestaltung erfahren, b) hinsichtlich der Intensität der Beforschung mit einer unterschiedlichen Gewichtung versehen werden und c) mit unterschiedlichen Begriffen belegt werden. Umgekehrt 
werden unter gemeinsam benutzten zentralen Begriffen unterschiedliche Sachverhalte subsumiert und es wird daher nicht immer zwangsläufig dasselbe darunter verstanden.

- Entsprechend weisen auch die sich hinter dem heterogenen Fachjargon verbergenden Bemühungen zur Etablierung einer konsistenten logistischen Forschungskonzeption bis dato ein wenig harmonisches Bild auf. ${ }^{4} \mathrm{Um} \mathrm{zu}$ einer einheitlicheren Forschungskonzeption zu gelangen, welche eine konsistente wissenschaftliche Plattform für die zukünftige anforderungsgerechte Analyse logistischer Fragestellungen darstellen sowie Kriterien für eine Evaluierung der Güte der Logistikforschung bereitstellen kann, sind noch immense Integrationsanstrengungen vonnöten. Integrationsbedarf besteht in der logistischen Forschungsdisziplin speziell hinsichtlich der Erzeugung eines Fits zwischen Erkenntnisobjekt, theoretischer Fundierung und eingesetzten Forschungsmethoden. ${ }^{5}$ Vergleiche dazu Abbildung 2-1:

\begin{tabular}{|c|c|c|}
\hline Erkenntnisobjekt & $\begin{array}{l}\text { Theoretische } \\
\text { Fundierung }\end{array}$ & Forschungsmethoden \\
\hline $\begin{array}{c}\text { Funktionale } \\
\text { Spezialisie- } \\
\text { rung/Transferakti- } \\
\text { vitäten }\end{array}$ & Systemtheorie & $\begin{array}{l}\text { Konzepte auf Basis } \\
\text { von Feld- und } \\
\text { Fallstudien } \\
\text { Prototypenerstel- } \\
\text { lung }\end{array}$ \\
\hline $\begin{array}{l}\text { Koordination der } \\
\text { Transferaktivitäten } \\
\text { in unternehmens- } \\
\text { weiten und - } \\
\text { übergreifenden } \\
\text { Wertschöpfungs- } \\
\text { systemen }\end{array}$ & $\begin{array}{l}\text { Organisationsfor- } \\
\text { schung }\end{array}$ & $\begin{array}{l}\text { Reine normative } \\
\text { oder deskriptive } \\
\text { Modellierung } \\
\text { Schriftliche } \\
\text { Befra- } \\
\text { gung/Interviews/Ex } \\
\text { pertenbefragungen }\end{array}$ \\
\hline
\end{tabular}

\section{Abbildung 2-1: Integrationsbedarf der Logistikforschung}

Quelle: Stölzle (2002), S. 521 
- Folgerichtig sind der verwertbare Output der Logistikforschung, d. h. die in der Logistikwissenschaft erarbeiteten theoretischen Konzepte, sowie die in der Wirtschaftspraxis angewendeten logistischen Methoden und Instrumente uneinheitlich. ${ }^{6}$ Dies liegt möglicherweise daran, dass sich angesichts der nachdrücklich geführten wissenschaftlichen Auseinandersetzung mit logistischen Problemstellungen nach dem 2. Weltkrieg und des parallel zu beobachtenden raschen Reflektierens und bereitwilligen Adaptierens logistischer Strategien und Methoden in weiten Teilen der Wirtschaftspraxis eine Atmosphäre dynamischer Vor- und Rückkopplungseffekte zwischen Theorie und Praxis ergeben hat. Derartige Effekte haben wohl zum einen die praktischen und theoretischen logistischen Konzepte wechselseitig weiterentwickelt und befruchtet und damit zu einer immens schnellen und nachhaltigen Evolution und Prominenz der Logistikdisziplin insgesamt beigetragen. Sie haben aber zum anderen auch zu einem relativ unübersichtlichen Parallelbestand an verschiedenen Logistikselbstverständnissen in der Logistikwissenschaft und damit einhergehend zu einer gleichsam unübersichtlichen Parallelanwendung logistischer Konzeptionen unterschiedlichen Entwicklungs- und Komplexitätsgrades in der Unternehmenspraxis geführt. Welche Art von Logistikkonzept in einem Unternehmen verankert wird, ist dabei neben dem konkreten logistischen Anforderungsprofil auch von der „logistischer Reife“ des jeweiligen Unternehmensmanagements abhängig $^{7}$ - der Fähigkeit des Unternehmensmanagements also, den logistischen Bedarf ihres Unternehmens zu erkennen und ihn mit dem adäquaten logistischen Konzept zu decken. Dies zeigt, dass die Frage nach dem Selbstverständnis der Logistik nicht lediglich von akademischem Interesse, sondern auch von unternehmenspraktischer Relevanz ist. ${ }^{8}$

Um nun das Feld der Logistik systematisch zu erfassen, lassen sich eine Vielzahl denkbarer Alternativen unterscheiden. Mögliche Ansatzpunkte für eine Systematisierung wären bspw.

- die Methoden und Instrumente, die in der Logistik angewendet werden,

- die Entwicklungsphasen, welche die Logistik durchlaufen hat oder

Vgl. J. Weber (1999), S. 4.

Vgl. Stabenau (2000), S. 127. 
- die Felder, in denen Logistik in der Wirtschaftstheorie und -praxis angewendet wird.

Kein Systematisierungsprinzip allerdings vermag für sich allein genommen die Komplexität und Vielfalt der Logistikmaterie in Gänze abzubilden. ${ }^{9}$

Um nun zu einer dem Anliegen der Arbeit adäquaten Form der Systematisierung der Logistik zu gelangen, d. h. die hier relevanten Aspekte der Logistik zu erfassen, ist es möglicherweise ein dienlicher Ansatzpunkt, sich zunächst einmal mit der Frage zu beschäftigen, welche Akteure bzw. welche Institutionen im Wirtschaftsprozess die Träger der Logistikprozesse sind. Diese Aufgabe der Trägerschaft von Logistikprozessen kommt dem Transfersystem bzw. dem Transfersektor zu. ${ }^{10}$ Dessen institutionelle Elemente wiederum sind die logistischen Unternehmen sowie die logistischen Fachbereiche der nicht-logistischen Industrie- und Handelsunternehmen. Für beide Akteursgruppen stellen Planung und Durchführung logistischer Aktivitäten den Hauptzweck ihrer Existenz dar - sie bieten Logistikleistungen an und fragen sie nach und begründen somit die Fortentwicklung des Prozesses der logistischen Reorganisation. Aus Sicht der Markttheorie vollzieht sich diese Gesamtheit der logistischen Aktivitäten auf dem Markt für Logistikleistungen bzw. dem Logistikmarkt. Die Aktivitäten auf einem Markt - dem Logistikmarkt - nehmen somit entscheidend Einfluss auf die Leistungserstellungsprozesse in jedem anderen Wirtschaftsbereich. Daraus erhellt, dass dem Transfer- bzw. Logistiksystem in seiner Eigenschaft als Scharnier bzw. Bindeglied innerhalb und zwischen den verschiedenen Wirtschaftsbereichen eine ausnehmend exponierte Stellung im gesamten Wirtschaftsprozess zukommt. Die Exponiertheit dieser Stellung leitet sich dabei aus der außerordentlich starken Konzentration von Möglichkeiten zur machtvollen Einflussnahme auf ökonomische Prozesse (und damit verbunden von großer Verantwortung) auf eine vergleichsweise geringe Anzahl von Wirtschaftsakteuren ab. Der Ansatz, der hier im folgenden vertreten wird, besteht nun darin, diesen Logistikmarkt zu untersuchen, um auf Basis der Analyse der institutionellen Träger des Prozesses der logistischen Reorganisation mehr Wissen über den Prozess selbst aufzubauen - über seine Deter-

Vgl. Klaus (1999), S. 16.

Vgl. Klaus, Krieger (2000), S. XIII.

Vgl. Milling, Dengel (2003), S. 135. 
minanten, über die den Prozessablauf bestimmenden unternehmerischen Verhaltensweisen und dessen Wirkungen."

Wenn es zutreffend ist, dass das Feld der Logistik unscharf konturiert ist und ein derart heterogenes Konstrukt darstellt, dann muss ähnliches auch für den Logistikmarkt zutreffend sein. Dessen äußere Konturen, dessen innere Segmentierung und dessen Charakter nämlich werden ja auch maßgeblich von den Eigenschaften des ihm zugrunde liegenden ökonomischen Gutes „Logistik“ bzw. „Logistikleistung“ determiniert. Insofern handelt sich beim Logistikmarkt um ein Gebilde, dessen Komplexität und Heterogenität ein Spiegelbild der gegenständlichen Komplexität der Logistikmaterie selbst ist. Will man den Logistikmarkt bzw. dessen Analyse für die hier angestrebte grundsätzliche Untersuchung der logistischen Reorganisation instrumentalisieren, ist es daher notwendig, diese gegenständliche Komplexität des Analysegegenstandes „Logistik“ zweckentsprechend zu kanalisieren. Für die folgende Marktanalyse hat dies konkret zweierlei zur Konsequenz:

- Erstens muss eine Vorauswahl hinsichtlich der für die Zwecke dieser Arbeit als relevant einzustufenden Aspekte des Marktgeschehens getroffen werden. Damit soll eine Verringerung der Breite des Analysegegenstandes erreicht werden. Daher liegt der Fokus bei der Marktanalyse auf der Untersuchung der institutionellen Aspekte der Logistik und deren Entwicklung.

- Zweitens muss versucht werden, ein angemessenes Abstraktionsniveau für die Marktanalyse zu finden. Ein zu hohes Maß an Abstraktion würde Informationsverlust bedeuten. Alle denkbaren Facetten, Partialfragestellungen und Verästelungen in aller Ausführlichkeit und Tiefe zu beleuchten, wäre wiederum nicht zielführend und würde zudem den Rahmen der Arbeit sprengen.

Dieses Procedere ist freilich mit nicht unerheblichen inhaltlichen Zugeständnissen verbunden, welche den Aussagewert einer Marktanalyse insbesondere dann stark einschränken würden, wenn diese eine entsprechende Zielsetzung, wie bspw. die Beurteilung der Wettbewerblichkeit des Logistikmarktes hätte. Allerdings ist hier, wie dargelegt, die Intention eine andere. Die in dieser Arbeit durchgeführte Marktanalyse

11 Auch Müller-Steinfahrt wählt die Analyse des Marktes für Logistikdienstleistungen aus der Palette denkbarer Systematisierungsalternativen und Analysemethoden, um die "Logistik in Deutschland" zu charakterisieren. Vgl. Müller-Steinfahrt (2000), S. $297 \mathrm{ff}$. 
soll ein methodisches und analytisches Vehikel darstellen, welches in erster Linie der Systematisierung relevanter Sachverhalte zum Zwecke der Aufdeckung relevanter Zusammenhänge dient. „Relevant“ bedeutet im Kontext dieser Arbeit: geeignet, einen Beitrag zur Aufdeckung von Determinanten, Prozessverlauf und Wirkungen der logistischen Reorganisation zu leisten. Allein an dieser Zielsetzung müssen sich die vorgenommenen Einschränkungen der Breite und der Tiefe des Analyseobjektes „Logistik" messen lassen.

Diese Ausführungen machen deutlich, dass der industrieökonomische Ansatz das theoretische Fundament der folgenden Marktanalyse bildet. Die Marktanalyse nach industrieökonomischem Muster wurde in Unterabschnitt 1.2.3.2 als positiver Ansatz zur Untersuchung von Marktprozessen bzw. marktlichen Funktionszusammenhängen charakterisiert. Dabei wurde auch der Umstand hervorgehoben, dass eine dem jeweiligen Analysezweck entsprechende Selektion der Analysevariablen und die damit verbundene Fokussierung auf bestimmte Zusammenhänge eines ihrer zentralen Wesensmerkmale ist. Obwohl die einzelne industrieökonomische Marktanalyse also außerstande ist, den gesamten Marktprozess auf einmal zu analysieren, so leistet sie dennoch einen Beitrag, das Wissen über den Markt- und Wettbewerbsprozess partiell zu vermehren. Dies gilt im vorliegenden Fall gleich in doppelter Hinsicht. Zum einen soll die Marktanalyse des Logistikmarktes direkt das Wissen über die Logistikmarktprozesse, d. h. über den Prozess der logistischen Reorganisation, vergrößern. Zum anderen soll die Marktanalyse des Logistikmarktes über die Integration ihrer Resultate in die wettbewerbstheoretische Konzeption indirekt das Wissen über den wettbewerblichen Marktprozess als solchen vermehren.

\subsubsection{Der Markt als Gegenstand ökonomischer Analysen}

\subsubsection{Der Begriff des Marktes}

Im Rahmen des polit-ökonomischen Ansatzes der klassischen Theorie wurde der Markt als ein komplexer Regelungs- und Steuerungsmechanismus, als gesellschaftliches Organisationsprinzip verstanden. Von zentraler Bedeutung war für die Klassiker in diesem Zusammenhang die ökonomische Strukturierungsleistung, welche von Institutionen ausgeht. ${ }^{12}$ Die institutionelle Perspektive ging jedoch in der anschließen-

12 Vgl. Schneider, Kenis (1996), S. 14 f. 
den Periode des neoklassischen Denkens weitgehend verloren. ${ }^{13}$ Nach dem Verständnis der modernen - neoklassisch geprägten - mikroökonomischen Theorie bezeichnet der Markt „als ökonomischer Ort des Tausches bzw. des Zusammentreffens von Angebot und Nachfrage“14 bzw. als ,virtueller Ort, an dem das Gesamtangebot und die Gesamtnachfrage nach einem bestimmten Gut zusammentreffen "15 denjenigen Koordinationsmechanismus, der die grundsätzlich voneinander differierenden, dezentralen Pläne der Anbieter und die Pläne der Nachfrager eines Gutes aufeinander abstimmt und zum Ausgleich bringt. Für die Analyse der marktlichen Koordinationsleistung werden in der neoklassischen, mikroökonomischen Theorie die Gesetzmäßigkeiten der Preisbildung untersucht. Dazu geht man im Rahmen der Marktgleichgewichtstheorie zunächst von konstanten Angebots- und Nachfragefunktionen während des Analysezeitraumes aus, d. h. es werden Gleichgewichtslagen untersucht, die auf den jeweiligen Märkten durch den Preisbildungsprozess zustande gekommen sind. Die Marktgleichgewichtstheorie ist also eine statische Analyse und zielt ab auf die Ausgleichsfunktion des Preises. ${ }^{16}$ Die Marktprozesstheorie indes hat die Analyse der Veränderung von Gleichgewichtslagen zum Gegenstand. Derartige Veränderungen resultieren aus der Tatsache, dass die Angebots- und Nachfragefunktionen nach einem Gut im Zeitablauf permanent Verschiebungen aufweisen und diese Verschiebungen nun explizit in die Analyse miteinbezogen werden. Wenn sich aber die Gleichgewichtslagen in Märkten ständig ändern, so müssen sich die Marktpreise ebenfalls ändern, damit sie ihre Ausgleichsfunktion weiterhin erfüllen können. Neben der Ausgleichsfunktion des Preises thematisiert die Marktprozesstheorie auch seine Informationsfunktion und die Lenkungsfunktion, d. h. die Frage, inwieweit der Preis über den jeweiligen Knappheitsgrad eines Gutes informiert und inwieweit er die Produktionsfaktoren in ihre jeweils beste Verwendung lenkt. Somit handelt die Marktprozesstheorie als dynamischer Theorieansatz von der Funktionsfähigkeit des Marktmechanismus. ${ }^{17}$ So betonen auch FRITSCH, WEIN und EWERS in ihrer Definition den prozessualen, dynamischen Charakter des Marktphänomens, indem sie einen Markt als ,sämtliche Austauschprozesse, die aus dem Zusammentreffen von Anbietern und Nachfragern (Akteuren) erwachsen", bezeichnen. ${ }^{18}$

Vgl. Schneider, Kenis (1996), S. 15.

Herdzina (2005), S. 150, im Original z. T. kursiv.

Kortmann (2002), S.351.

Vgl. Herdzina (2005), S. 149.

Vgl. Arndt (1966), S. 2 f., Herdzina (2005), S. 200.

Fritsch, Wein, Ewers (1999), S. 6, im Original z. T. kursiv. 
Obwohl die mikroökonomische Analyse die Untersuchung der marktlichen Koordinationsleistung auf die Untersuchung von Preisbildungsprozessen reduziert und dabei gleichzeitig von wesentlichen, furr real-empirische Marktanalysen relevanten Aspekten abstrahiert ${ }^{19}$, so kristallisieren sich aus obigen beispielhaft aufgeführten Definitionsansätzen dennoch die wesentlichen Bestimmungsgrößen heraus, welche auch für die empirische Untersuchung eines realen Marktgeschehens erklärungsrelevant sind. Mit KORTMANN lassen sich folgende Bestimmungsgrößen identifizieren:

- das Marktobjekt,

- die Marktrahmenbedingungen,

- das Marktangebot,

- die Marktnachfrage und

- die Marktkoordination.

Hierbei ist vor allem hervorzuheben, dass es sich bei einem Markt um ein Gebilde mit systemischem Charakter handelt, das gekennzeichnet ist durch ein Geflecht von miteinander in wechselseitiger Beziehung stehenden (System-)Komponenten. ${ }^{20}$ KORTMANN formuliert darauf aufbauend die These, dass „...ohne das Verständnis dieser fünf konstituierenden Bestandteile (...) ein Markt, welcher Art auch immer, weder vollständig noch adäquat zu beschreiben oder zu verstehen [ist]“ und dass

19 So ist bspw. die neoklassische Theorie des totalen Konkurrenzgleichgewichtes gekennzeichnet durch extrem restriktive Annahmen bezüglich des Entscheidungsverhaltens der Marktakteure (alle Haushalte sind reine Nutzenmaximierer, alle Unternehmen sind reine Gewinnmaximierer, innerhalb von Unternehmen gibt es keine divergierenden Interessen zwischen den Menschen,...). Vgl. bspw. Schumann, Meyer, Ströbele (1999), S. 3. Außerdem wird in der Preistheorie vom Problem der sachlichen und der räumlichen Marktabgrenzung abstrahiert. Vgl. dazu Kortmann (2003), S. 20. Diese Spezialisierung auf extrem hohem Abstraktionsniveau ermöglicht es zum einen verdienstvollerweise, die marktwirtschaftliche Koordination für die gesamte Volkswirtschaft zu untersuchen, setzt die neoklassische (Preis-)Theorie jedoch gleichsam dem Vorwurf aus, „dass sie zur gedanklichen Durchdringung einer Marktwirtschaft, wie sie „wirklich existiert", wenig beiträgt." Schumann, Meyer, Ströbele (1999), S. 3. Dies gilt umso mehr, als Marktprozesse adäquat nur aus konkreten Handlungsakten einzelner Individuen heraus erklärt werden können. Vgl. Fehl (1987), S. 17. Dennoch kann auch das preistheoretische Paradigma dazu dienlich sein, empirische Marktanalysen zu organisieren und Daten zu interpretieren. Vgl. dazu Carlton, Perloff (1999), S. 3. 
deshalb alle diese Bestandteile im Rahmen einer Marktanalyse thematisiert werden müssen. ${ }^{21}$

\subsubsection{Markt, Wettbewerb und Kooperation}

Im ersten Kapitel wurde die Existenz von Wettbewerb bzw. die Abwesenheit von Wettbewerbsbeschränkungen als wesentliche Voraussetzung für den störungsfreien Ablauf von Marktprozessen hervorgehoben. Als fundamentales Koordinationsinstrument stellt der Wettbewerb in einer Marktwirtschaft sicher, dass der Preis seine ihm dort übertragenen Aufgaben optimal ausfüllen kann. Wesensbestimmendes Merkmal des Marktprozesses als wettbewerblichem Prozess ist der Konkurrenzgedanke und insbesondere der damit verbundene Anreiz zur Leistungssteigerung der Akteure. Diese systemimmanenten Anreize des Wettbewerbs zur individuellen Leistungssteigerung sind der Grund dafür, dass der wettbewerbsbasierte marktwirtschaftliche Koordinationsmechanismus in der Regel den alternativen Organisations- und Koordinationsmechanismen zur Wirtschaftsplanung überlegen ist.

Unbeschadet der Tatsache, dass der Wettbewerb für das Funktionieren des Marktprozesses unabdingbar wichtig ist, so erscheint es jedoch einigermaßen problematisch, den Wettbewerbsprozess vollständig mit dem Marktprozess gleichsetzen zu wollen. Die Gleichsetzung der beiden Termini würde implizieren, „dass a priori in jedem Markt Wettbewerb herrscht, oder anders ausgedrückt, jeder Markt wettbewerblich ist. “222 Demgegenüber zeichnet sich in der Realität die Interaktion der Marktteilnehmer, d. h. die Beziehungen zwischen den Anbietern auf der einen und den Nachfragern auf der anderen Seite sowie die Beziehungen zwischen den beiden Gruppen dadurch aus, dass die Akteure zum einen miteinander konkurrieren und zum anderen kooperieren. Wettbewerb und Kooperation bilden demnach die beiden logisch trennbaren, sich ausschließenden, alternativen Arten sozialer Beziehungen, die die Marktteilnehmer eingehen können. ${ }^{23}$ Daraus erhellt aber, dass, unabhängig davon, mit welcher Gewichtung bzw. Akzentuierung Wettbewerb und Kooperation in einem Markt versehen sind, beide Phänomene in der ökonomischen Realität regelmäßig koexistieren. ${ }^{24}$ Hierbei

Kortmann (2003), S. 66.

Mantzavinos (1994a), S. 95.

Vgl. Mantzavinos (1994a), S. 95.

24 Diese Ansicht vertritt auch Kantzenbach. Obwohl er selbstverständlich den - politisch vorgegebenen - Primat des Wettbewerbs als Koordinationsinstrument in einer Marktwirtschaft anerkennt, führt er dennoch relativierend aus: „Strittig zwischen den diese [Markt] Wirtschaftordnung bejahenden politischen Kräften ist nicht der grundsätzliche Vorrang des Wettbewerbs und nicht die 
verhalten sich Wettbewerb und Kooperation substitutiv zueinander: ein Mehr an Wettbewerb bedeutet ein Weniger an Kooperation und umgekehrt. Überträgt man diese Aussage von MANTZAVINOS, welche zunächst auf abstrakte soziale Handlungsoptionen und Interaktionsprinzipien von Individuen abhebt, auf die übergeordnete Ebene der institutionellen Steuerung wirtschaftlicher Aktivität bzw. auf die Ebene des sog. „Governance-Ansatzes“, dann ist damit die Frage nach der Konfiguration der Koordinationsmechanismen aufgeworfen, welche das tatsächliche Tauschgeschehen auf realen Märkten bestimmen. ${ }^{25}$ Dabei ist der Begriff der "Kooperation“ in diesem Zusammenhang als Überbegriff mit Klammerfunktion zu verstehen, welcher stellvertretend für ein breites Spektrum verschiedener konkreter Formen von Koordinationsmechanismen steht. Als intensivste Ausprägungsform „kooperativer“ Koordination und damit als Gegenpol zur wettbewerblichen Koordination ist dabei sicherlich die Koordination durch Hierarchie - die vollständige Integration von verschiedenen Akteuren zu einem einzigen, nunmehr zentral für alle planenden Akteur also - zu sehen. Zwischen den Extrempunkten der hierarchischen Koordination und der Reinform der total dezentralen wettbewerblichen Spotmarkt-Koordination existiert ein Kontinuum an Koordinationsmechanismen, welche sowohl wettbewerbliche als auch kooperative Elemente enthalten und als sog. „diskrete Strukturalternativen ${ }^{\text {‘26 }}$, je nach Gewichtung der jeweiligen Elemente, dem einen oder dem anderen Extrempunkt näher stehen. Koordinationsmechanismen, welche aufgrund ihrer Eigenschaften zwischen den Polen Markt und Hierarchie angesiedelt sind, sind auf vielen realen Märkten zu beobachten und gewinnen dort immer mehr an Bedeutung. Sie sind als eine Reaktion auf die Komplexität der vertikalen und horizontalen Koordinationserfordernisse auf

Notwendigkeit eines Minimums zentraler Planung, sondern nur das relative Gewicht beider Steuerungsprinzipien." Kantzenbach (1967), S. 12. Zentrale Planung betrachtet er dabei als besonders wichtigen Extremfall einer Reihe anderer möglicher alternativer Koordinationsprinzipien. Angesichts der politischen Grundsatzentscheidung für den Wettbewerb als zentrales Koordinationsprinzip schreibt er der sozialökonomischen Wissenschaft lediglich als Aufgabe zu, „nur zur Herausarbeitung und Klärung der möglichen Alternativen beizutragen". Ebenda.

Die Analyse alternativer Koordinationsmechanismen vollzieht sich nicht nur auf der hier angesprochenen sektoralen bzw. industriestrukturellen Analyseebene, sondern reicht von der Ebene singulärer Organisationen über eben die sektorale bis hin zur nationalen bzw. internationalen Ebene. Vgl. Schneider, Kenis (1996), S. 16. Auf der nationalen und der internationalen Analyseebene sind die idealtypischen und realtypischen Wirtschaftssysteme sowie die Ausprägungen und die Zusammensetzung der Koordinationsmechanismen, welche sie begründen, der entsprechend kongruente Analysegegenstand. Vgl. dazu Herdzina (2005), S. 28 ff.

Vgl. zum Begriff der „Discrete Structural Alternatives“ bzw. zur "Discrete Structural Analysis“ Williamson (1991), S. $13 \mathrm{ff}$. 
den betreffenden Märkten $\mathrm{zu}$ betrachten und begründen daher notwendigerweise wettbewerbstheoretische und -politische Beachtung. ${ }^{27}$

Die Möglichkeit der Koexistenz mehrerer Koordinationsmechanismen, welche parallel in einem realen Markt wirken, wird auch von der Wettbewerbstheorie prinzipiell nicht bestritten. Naturgemäß beurteilt sie jedoch Abweichungen von der wettbewerblichen Koordination stets mit Skepsis und insbesondere dann, wenn durch sie das Postulat der Dezentralität der Wirtschaftsplanung gefährdet scheint und mit ihnen die kollektive Beseitigung von Risiken und Unsicherheiten einhergeht, in aller Regel negativ. Nichtsdestotrotz haben die Ausführungen zur Typologie der wettbewerblichen und nicht-wettbewerblichen Marktverhaltensweisen in Unterabschnitt 1.3.2.2 aber auch aufgezeigt, dass unter bestimmten Umständen kooperative Arrangements jedweder Form durchaus Ausdruck kreativer und adaptiver wettbewerblicher Marktverhaltensweisen sein können. Darüber hinaus können kooperative Verhaltensweisen, selbst wenn man geneigt ist, sie den mutmaßlich nicht-wettbewerblichen Marktverhaltensweisen zuzuordnen, dennoch per Saldo positive Wettbewerbswirkungen zeitigen, wenn man ihren offenkundig wettbewerbsbeschränkenden Wirkungen die ebenfalls existierenden wettbewerbsstimulierenden Wirkungen gegenüber stellt. Die Beurteilung kooperativer und hierarchischer Arrangements in realen Märkten aus Sicht der Wettbewerbstheorie bezüglich ihrer Wettbewerbskonformität resp. ihrer Vereinbarkeit mit wettbewerbsbasierten Marktprozessen gestaltet sich daher im Einzelfall schwierig. Die grundsätzliche Möglichkeit jedoch, derartige Arrangements mit Wettbewerb in Einklang zu bringen, ist aus Sicht der Wettbewerbstheorie gegeben.

Der Theorienkomplex der Neuen Institutionenökonomik vertritt nun die Position, dass der preisgesteuerte Tausch bzw. die Existenz funktionsfähiger Märkte kein Automatismus ist. Vielmehr bedarf es - und da geht die Neue Institutionenökonomik mit der klassischen Wettbewerbstheorie konform - bestimmter institutioneller Rahmenbedingungen, welche einen preisgesteuerten Tausch und damit das Entstehen von Märkten erst ermöglichen. ${ }^{28}$ Wirtschaftstheoretische und -politische Fragestellungen werden nicht arglos als mathematische Optimierungsprobleme behandelt, sondern als Vorgänge, deren Ablauf von den Verhaltensweisen der betroffenen Akteure bestimmt wird. ${ }^{29}$ Ein realer Markt wird folglich als komplexes Handlungssystem mit einem umfangreichen spezifischen Regelsystem begriffen. ${ }^{30}$ Angesichts des im realen

Vgl. Bickenbach, Kumkar, Soltwedel (2002), S. 217.

Vgl. Ménard, Shirley (2005), S. 1.

Vgl. Rennings (1992), S. 13.

Vgl. Jansen (2004), S. 597.
} 
Marktgeschehen empirisch zu konstatierenden Zustandes, dass die Informations- bzw. Wissenslage für den einzelnen Akteur unvollständig ist und Wissen zudem asymmetrisch auf die Akteure verteilt ist, sind Institutionen als Regelsysteme zur Koordination des Handelns in und zwischen Unternehmen auf Märkten unabdingbar. ${ }^{31}$ Institutionen strukturieren Marktprozesse, sie schaffen ein gewisses Ausmaß an Planbarkeit und reduzieren durch ein kollektives Regelwerk, welches gemeinschaftlich akzeptiert und getragen wird, die Komplexität von marktlichen und unternehmerischen Entscheidungsproblemen. ${ }^{32}$

Die Neue Institutionenökonomik beschäftigt sich eben mit diesen institutionellen Rahmenbedingungen und untersucht darauf aufbauend und unter Zugrundelegung entsprechender ökonomischer Bedingungskonstellationen, welcher Koordinationsmechanismus bzw. welches institutionelle Arrangement im Einzelfall adäquat (effizient) ist, Tauschhandlungen bzw. das Zusammentreffen von Angebot und Nachfrage im realen Marktgeschehen zu organisieren. ${ }^{33}$ Insofern bietet die Neue Institutionenökonomik also eine ergänzende und bereichernde Perspektive zur wettbewerbstheoretischen Beurteilung von zum Wettbewerb alternativen Koordinationsmechanismen an, weil sie sich darum bemüht, das Pro und Contra der Auswahl eines bestimmten Koordinationsmechanismus mit Hilfe zusätzlicher ökonomischer Argumente zu erklären, welche der Wettbewerbstheorie aufgrund ihrer zwischenzeitlich verkümmerten institutionellen Perspektive möglicherweise verschlossen bleiben würden. Die Transaktionskostentheorie als eine der tragenden Säulen der Neuen Institutionenökonomik eröffnet durch den Rückgriff auf bestimmte verhaltens- und transaktionsspezifische Annahmen bei gegebenen institutionellen Rahmenbedingungen neue ökonomische Erklärungsansätze für kooperative oder hierarchische Arrangements, welche bei einer rein wettbewerbstheoretischen Abwägung möglicherweise unbesehen als nichtwettbewerblich etikettiert worden wären.

Es wird daher ausdrücklich klargestellt, dass mit der Berücksichtigung der Transaktionskostentheorie keinesfalls der wettbewerbliche Marktprozess als der erwünschte und überlegene Marktprozess infragegestellt werden soll. Vielmehr sollte sie als zweckmäBige Ergänzung zur Wettbewerbstheorie verstanden werden. Sie gibt der Wettbewerbstheorie zusätzliche ökonomische Argumente an die Hand, damit diese ihrer Obliegenheit, kooperative und hierarchische Arrangements in realen Märkten bezüglich ihrer Wettbewerbskonformität zu beurteilen, ökonomisch begründeter nachkommen kann.

Vgl. Jansen (2004), S. $597 \mathrm{f}$.

Vgl. Jansen (2004), S. 598.

Vgl. Engerer, Voigt (2002), S. 151. 
Das entscheidende ökonomische Kriterium hierbei ist die Höhe der Transaktionskosten, welche ein bestimmtes institutionelles Arrangement produziert - bezogen sowohl auf die unmittelbar an der Transaktion beteiligten Parteien als auch auf die Gesamtheit der (mittelbar) betroffenen Marktakteure. ${ }^{34}$ Insofern erfordert die Integration des transaktionskostentheoretischen Ansatzes in die Wettbewerbstheorie keine fundamentale Neuausrichtung letzterer, sondern verschafft ihr lediglich innerhalb ihres bestehenden Gedankengebäudes neue Erklärungsoptionen durch neue Prüf- und Bewertungskriterien, welche außerhalb der Analyse von Produktions- und Kostenfunktionen angesiedelt sind. Transaktionskostentheoretische Prüf- und Bewertungskriterien basieren bspw. auf Merkmalen von Transaktionen (Komplexität, Spezifität, Unsicherheit), oder auf Verhaltenseigenschaften der Akteure.

Aufgrund der offensichtlichen Relevanz des Denkansatzes der Neuen Institutionenökonomik und hier insbesondere der Erkenntnisse der Transaktionskostentheorie für die wettbewerbstheoretischen Belange dieser Arbeit, und aufgrund der Tatsache, dass die Transaktionskostentheorie - wie noch zu zeigen sein wird - ebenfalls für die Berücksichtigung in wichtigen Teilaspekten der folgenden Analyse des Logistikmarktes qualifiziert zu sein scheint ${ }^{35}$, ist nun eine Darstellung der Transaktionskostentheorie angezeigt.

\subsubsection{Transaktionskostentheoretische Grundlagen}

\subsubsection{Koordination, Transaktionen und Transaktionskosten}

Ziel wirtschaftlichen Handelns ist es, menschliche Bedürfnisse zu befriedigen. Bedauerlicherweise übersteigen i. d. R. die menschlichen Bedürfnisse die Produktionsmöglichkeiten zur deren Befriedigung. Dieser Umstand wird in der Ökonomik als Knappheit bezeichnet. Aufgabe des Wirtschaftens ist es folglich, das Spannungsverhältnis zwischen Bedürfnissen und knappen Gütern zu überbrücken und es kann daher als „planmäßige Disposition über knappe Güter zur Befriedigung von Bedürfnissen“ definiert werden. ${ }^{36}$ Mögliche Ansatzpunkte, Knappheit zu reduzieren, stellen die Arbeitsteilung und die Spezialisierung dar. ${ }^{37}$ Arbeitsteilung bedeutet die Zerlegung eines Produktionsprozesses in Teilprozesse, wobei diese Teilprozesse sowohl

\footnotetext{
34 Vgl. Bickenbach, Kumkar, Soltwedel (2002), S. 227.

35 Vgl. dazu z. B. auch Rennings (1992), S. 13; Pfohl, Large (1992), S. 16.

36 Herdzina (2005), S. 20, im Original kursiv.

37 Vgl. Picot, Reichwald, Wigand (2003), S. 24.
} 
nebeneinander als auch nacheinander gelagert sein können. ${ }^{38}$ Die Konzentration auf Teilprozesse ermöglicht es dem einzelnen Wirtschaftssubjekt, Teilaufgaben unter Zugrundelegung seiner begrenzten zeitlichen und kognitiven Fähigkeiten selbstständig zu erledigen. Zudem können einzelne Wirtschaftssubjekte durch die Spezialisierung auf Teilaufgaben besondere Problemlösefähigkeiten und -verfahren ausbilden, die eine effizientere Bearbeitung dieser Aufgabe ermöglichen. ${ }^{39}$ Diese produktivitätssteigernde Wirkung der Arbeitsteilung und der Spezialisierung ist allerdings keine neuzeitliche Erkenntnis, sondern wurde schon 1776 von ADAM SMITH erkannt. ${ }^{40}$

Das zentrale Problem der Arbeitsteilung auf gesamtwirtschaftlicher Ebene besteht nun darin, dass der volkswirtschaftliche Produktionsprozess nicht mehr überschaubar ist: das sequenzielle und parallele Ablaufen unzähliger, voneinander wechselseitig abhängiger Produktionsteilprozesse in Millionen von Produktionsstätten erfordert daher das Vorhandensein eines Koordinationsmechanismus, der die allfälligen Austauschbeziehungen bzw. - prozesse zwischen den Wirtschaftssubjekten organisiert und somit ein planvolles Wirtschaften erst möglich macht. ${ }^{41}$

Diese Austauschprozesse können als Transaktionen interpretiert werden. ${ }^{42}$ Seinen Ursprung hat der Begriff der Transaktion bei CoMmONS. Er führt aus:“ ”.. transactions are, not the ,exchange of commodities', but the alienation and acquisition, between individuals, of the rights of property and liberty created by society, which must therefore be negotiated between the parties concerned before labor can produce, or consumers can consume, or commodities be physically exchanged." ${ }^{\$ 43}$ Auch PICOT definiert den Begriff der Transaktion unter Verwendung des Vokabulars des PropertyRights-Ansatzes als Übertragung von Verfügungsrechten, durch die ein Austauschprozess überhaupt erst angestoßen werden kann. ${ }^{44}$ Die Bedingungen, unter denen sich der Austausch bzw. die Übertragung von Verfügungsrechten vollzieht, werden im Rahmen

Vgl. Herdzina (2005), S. 26.

Vgl. Picot, Reichwald, Wigand (2003), S. 24.

Vgl. dazu das von Smith angeführte Beispiel der Stecknadelproduktion, mit dem er Wesen und Wirkungen der Arbeitsteilung darstellen wollte. Vgl. Smith (1852).

Vgl. Herdzina (2005), S. 28.

Vgl. Balling (1998), S. 58.

Commons (1931), S. 652, im Original z. T. kursiv.

Vgl. Picot (1991), S. 147. Verfügungsrechte können als ein Bündel aus Eigentumsrechten betrachtet werden, das sich aus den folgenden Einzelrechten zusammensetzt: (1) das Recht, ein Gut zu nutzen, (2) das Recht, Form und Substanz des Gutes zu verändern, (3) das Recht, sich entstehende Gewinne anzueignen und die Pflicht, resultierende Verluste zu tragen und (4) das Recht, das Gut an Dritte zu veräußern. Vgl. dazu Picot, Reichwald, Wigand (2003), S. 46 oder Rennings (1992), S. 15. 
von Verträgen rechtlich fixiert. ${ }^{45}$ Insofern kann aus transaktionskostentheoretischer Position heraus das Problem der ökonomischen Organisation auch als Vertragsproblem interpretiert werden. ${ }^{46}$ Das Schließen von Verträgen und das Durchsetzen vertraglicher Rechte und Pflichten sind diejenige gemeinsame Grundlage, auf der sämtliche institutionelle Ausgestaltungsformen ökonomischer Koordination aufbauen. ${ }^{47}$ Dabei hängt die Bindungsintensität bei institutionellen Arrangements bzw. der Autonomiegrad der Transaktionsbeteiligten von der Form der vertraglichen Ausgestaltung $a b .^{48}$

Die Übertragung von Verfügungsrechten indes ist nach der Sichtweise der Transaktionskostentheorie nicht kostenlos. Neben dem reinen Kaufpreis einer Sache fallen bei der Durchführung von Transaktionen zusätzliche Kosten an, die unausweichlich mit ihr verbunden sind. Diese zusätzlichen Kosten werden als Transaktionskosten bezeichnet. ${ }^{49}$ Transaktionskosten umfassen nach gängiger Systematisierung in der vorvertraglichen Phase die Kosten der Anbahnung und der Vereinbarung (ex-anteTransaktionskosten) und nach Abschluss des Vertrages die Kosten der Abwicklung, Kontrolle und Anpassung (ex-post-Transaktionskosten). ${ }^{50}$ ARROW spricht in diesem Zusammenhang auch von Transaktionskosten als "costs of running the economic system". ${ }^{51}$ An diese ARROWsche Definition knüpft WILLIAMSON an, der Transaktionskosten als das ökonomische Gegenstück zur Reibung in mechanischen Systemen beschreibt. ${ }^{52} \mathrm{Zu}$ beachten ist dabei, dass Transaktionskosten nicht nur bei der Durchführung von Transaktionen über den Marktmechanismus anfallen, sondern allgemein als die Kosten der Nutzung eines Koordinationsmechanismus zu interpretieren sind.

Das Erkenntnisinteresse der Transaktionskostentheorie ist es nun zum einen, Einflussgrößen für die Höhe der Transaktionskosten zu identifizieren und zum anderen, mögliche institutionelle Arrangements als Ausgestaltungsformen von Austauschprozessen hinsichtlich ihrer Transaktionskosteneffizienz zu beurteilen. ${ }^{53}$ Soziale Institutionen als in Organisationen zusammengefasste Verfügungsrechte ${ }^{54}$ spielen in diesem

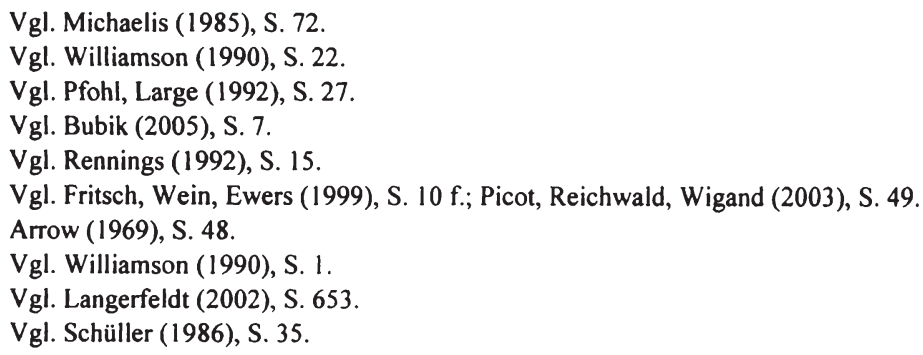


Zusammenhang die Rolle ,produktiver Kräfte“, welche in einer Marktwirtschaft die Transaktionskosten zu beherrschen helfen und mithin den Erfolg der Tauschvorgänge auf Märken wesentlich mitbestimmen. ${ }^{55}$

Transaktionskosten können somit als „Effizienzmaßstab zur Beurteilung und Auswahl unterschiedlicher institutioneller Arrangements“ interpretiert werden. ${ }^{56}$ Die Transaktionskostenanalyse stellt folglich ein Instrument dar, mit dessen Hilfe ein Beitrag zur Beantwortung der Frage geleistet werden kann, welcher Koordinationsmechanismus bestimmte Austauschprozesse am effizientesten organisiert bzw. warum aus mehreren alternativen Koordinationsformen eine bestimmte ausgewählt wurde.

In der Vorstellung der Transaktionskostentheorie bilden die Koordination über den Markt und über die Unternehmung (Hierarchie) die beiden Extrempositionen auf einem Kontinuum ökonomischer Koordinationsformen.$^{57}$ Diese Einschätzung baut auf der Feststellung von COASE auf, der bereits 1937 Märkte und Hierarchien als Alternativen zu Koordination ökonomischer Aktivitäten beschrieben hat. ${ }^{58}$ Zwischen vollständiger marktlicher und vollkommener hierarchischer Koordination existieren zahlreiche Formen der Kooperation als mögliche Alternativen bzw. Zwischenformen zur Koordination von Austauschprozessen, welche ein Mehr oder Weniger an marktlichen Elementen oder hierarchischen Strukturen aufweisen. ${ }^{59}$ Vergleiche dazu auch Abbildung 2-2. Mittels transaktionskostentheoretischer Überlegungen lässt sich die Existenz von Unternehmungen/Hierarchien bzw. von Kooperationsformen ökonomisch begründen. ${ }^{60}$ Insofern stellt die Transaktionskostentheorie einen fruchtbaren Ansatz dar, um im Rahmen einer Marktanalyse zusätzliche (ökonomisch motivierte) Erklärungsmöglichkeiten für die Existenz kooperativer und hierarchischer Arrangements bereitzustellen, welche sich als Bereicherung der Erklärungsansätze der Industrieökonomik und der Wettbewerbstheorie erweisen könnten und somit der von MANTZAVINOS geforderten getrennten Betrachtung alternativer Formen sozialer

55 Vgl. Schüller (1986), S. 34.

56 Picot, Reichwald, Wigand (2003), S. 49 f.

57 Vgl. Balling (1998), S. 57.

58 „Within a firm ... market transactions are eliminated and in place of the complicated market structure with exchange transactions is substituted the entrepreneur-co-ordinator, who directs production." Coase (1937), S. 388.

59 Vgl. Pfohl, Large (1992), S. 27.

60 Vgl. Picot (1991), S. 149 sowie Langerfeldt (2002), S. 653. Dieses Ziel verfolgte auch Coase, der versucht hat, die Existenz von Unternehmen zu erklären: "Our task is to attempt to discover why a firm emerges at all in a specialised exchange economy“. Er kam zu dem Schluss, dass "The main reason why it is profitable to establish a firm would seem to be that there is a cost of using the price mechanism." Coase (1937), S. 390. 
Interaktion mit dem gemeinsamen Ziel der Organisation von Austauschprozessen Rechnung tragen. ${ }^{61}$

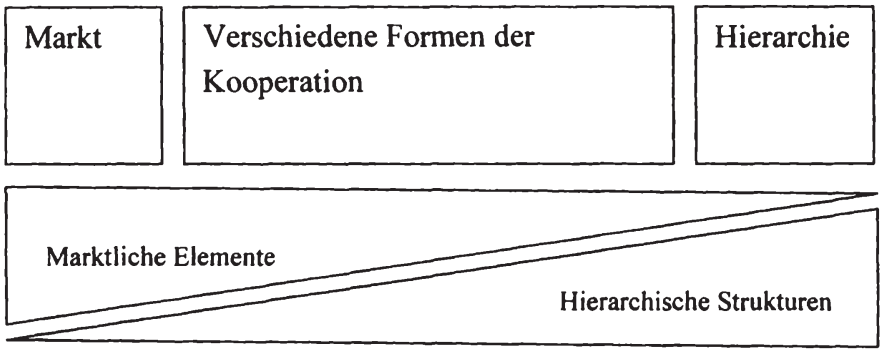

\section{Abbildung 2-2: Alternative Koordinationsmechanismen}

Quelle: Eigene Darstellung

Im Folgenden werden zunächst wesentliche Einflussgrößen auf die Höhe der Transaktionskosten dargelegt und daran anschließend die alternativen Koordinationsmechanismen (,governance structures") charakterisiert und diskutiert.

\subsubsection{Einflussgrößen auf die Transaktionskosten}

Die Höhe des Transaktionskostenniveaus und damit die relative Effizienz unterschiedlicher Koordinationsmechanismen werden von einem Bündel von Einflussgrößen bestimmt. Diese Einflussgrößen umfassen nach WILLIAMSON Annnahmen über das Verhalten der Transaktionspartner sowie Eigenschaften der Transaktion. ${ }^{62}$ Ferner führt er die Transaktionskostenatmosphäre als wesentliche Einflussgröße an. ${ }^{63}$

61 Gemäß Mantzavinos macht der Austausch den Kern des Marktes aus: „Markt ist (...) die Institutionalisierung des Austausches." Mantzavinos (1994a), S. 196. Wettbewerb, Kooperation und der Versuch der Monopolisierung stellen Handlungsalternativen der Individuen dar, Austauschprozesse durchzuführen. Somit wird deutlich, ... „dass der Wettbewerb nur eine Erscheinungsform unter anderen im Marktgeschehen darstelit.“ Mantzavinos (1994a), S. 196.

62 Vgl. Williamson (1990), S. 49.

63 Vgl. Williamson (1975), S. $37 \mathrm{ff}$. 


\subsection{Verhaltensannahmen}

In der Transaktionskostentheorie werden spezifische Annahmen bezüglich des Verhaltens der an der Transaktion beteiligten Akteure getroffen, die deutlich von der neoklassischen Theorie abweichen. In diesem Zusammenhang diskutiert WILLIAMSON insbesondere die eingeschränkte Rationalität sowie das opportunistische Verhalten der Menschen: ${ }^{64}$

- Beschränkte Rationalität bedeutet, dass ein Individuum zwar rational, in seinem Eigeninteresse nutzenmaximierend handelt. Allerdings ist ihm das aufgrund seiner begrenzten Kapazitäten zur Aufnahme, Speicherung und Verarbeitung von Informationen nicht unter Zugrundelegung aller objektiv relevanten Einflussgrößen, sondern lediglich mit der Einschränkung subjektiv begrenzter Informationen möglich. ${ }^{65}$ Insofern wird in der Transaktionskostentheorie deutlich von der neoklassischen Annahme vollständig informierter und streng rational handelnder Individuen abgewichen.

- Unter opportunistischem Verhalten wird eine verschärfte Form der neoklassischen Annahme eigennützigen Verhaltens von Individuen verstanden, welches auch die Anwendung von Hinterlist und Täuschung beinhaltet. ${ }^{66} \mathrm{Im}$ Einzelnen nennt WiLliamson Lug, Betrug sowie die unvollständige oder verzerrte Weitergabe von Informationen als Beispiele für opportunistisches Verhalten. ${ }^{67}$

\subsection{Eigenschaften von Transaktionen}

WILLIAMSON identifiziert mit der Faktorspezifität (von Investitionen), der Unsicherheit und der Häufigkeit von Transaktionen drei wesentliche transaktionskostenrelevante Eigenschaften von Transaktionen ${ }^{68}$ Hierbei ist die Faktorspezifität die deutlich gewichtigste Determinante für das Transaktionskostenniveau. ${ }^{69}$ Dabei lassen sich vier Arten von Spezifität unterscheiden:

\footnotetext{
64 Vgl. Williamson (1990), S. 49 ff.; Strohm (1988), S. 27.

65 Vgl. Williamson (1990), S. 50 f.; Schumann, Meyer, Ströbele (1999), S. 473.

66 Vgl. Schumann, Meyer, Ströbele (1999), S. 473; Stahl (1995), S. 87; Williamson (1975), S. 26.

67 Vgl. Williamson (1990), S. $54 \mathrm{ff}$.

68 Vgl. Williamson (1990), S. 59.

69 Vgl. Williamson (1988), S. 70.
} 
- Standortspezifität

- Spezifität des Sachkapitals

- Spezifität des Humankapitals

- zweckgebundene Sachwerte. ${ }^{70}$

Der Grad der Spezifität ist davon abhängig, inwieweit es möglich ist, einen Faktor einer alternativen Verwendung zuzufuhren bzw. an einen anderen Transaktionspartner zu übertragen, ohne dass dieser an Wert verliert. Je geringer dieser Wertverlust ist, umso geringer ist auch der Grad der Faktorspezifität. ${ }^{71}$ Ein hoher Spezifitätsgrad einer Leistungsbeziehung schafft demnach zwischen den Transaktionspartnern Bindungen und Abhängigkeiten, da die vorzeitige Beendigung der Transaktionsbeziehung mit einem Wertverlust verbunden ist. ${ }^{72}$ Die Transaktionspartner haben nun die Möglichkeit, diese Abhängigkeit opportunistisch zu ihrem eigenen Vorteil ausnutzen. Das Problempotenzial der Spezifität ergibt sich also aus der Annahme opportunistischen Verhaltens der Transaktionspartner. ${ }^{73}$ Folge ist ein erhöhter Bedarf an Kontroll- und Absicherungsmechanismen bei der Gestaltung des Koordinationsmechanismus.

Die Unsicherheit bei Transaktionen umfasst die Verhaltensunsicherheit und die Unsicherheit über die zukünftige Entwicklung der Umweltzustände. ${ }^{74}$ Verhaltensunsicherheit bedeutet, dass man im Vorhinein nicht weiß, ob sich ein Transaktionspartner opportunistisch oder strategisch verhalten wird. Verhaltensunsicherheit ist folglich strategischer Natur und kann auf Opportunismus zurückgeführt werden. ${ }^{75}$ Unsicherheit über die zukünftige Entwicklung der Umweltzustände wiederum resultiert aus der Verhaltensannahme beschränkter Rationalität. Den Transaktionsbeteiligten gelingt es aufgrund kognitiver Grenzen nicht, sich alle notwendigen, transaktionsrelevanten Informationen zu beschaffen. ${ }^{76}$ In enger Verbindung zur Eigenschaft der Unsicherheit steht die Eigenschaft der Komplexität von Transaktionen. Eine Transaktion kann nach PICOT und DIETL als komplex bezeichnet werden, wenn sie in einer prinzipiell

Vgl. Williamson (1990), S. 62.

Vgl. Pfohl, Large (1992), S. 22.

Vgl. Stahl (1995), S. 93.

Vgl. Picot, Reichwald, Wigand (2003), S. 51.

Vgl. Stahl (1995), S. 94.

Vgl. Williamson (1990), S. 66; Stahl (1995), S. 94.

Vgl. Picot, Reichwald, Wigand (2003), S. 52; Stahl (1995), S. 94; Williamson (1975), S. 24. 
sicheren, für die Transaktionspartner aber nicht überschaubaren Situation stattfindet. ${ }^{77}$ Unsichere oder komplexe Transaktionen sind dadurch gekennzeichnet, dass sie nicht endgültig und in all ihren Facetten darstellbar und erfassbar sind, und sie bergen folglich die Gefahr, dass Transaktionsbeteiligte diese Situation opportunistisch ausnutzen. ${ }^{78}$ Dabei sind die negativen Auswirkungen der Unsicherheit und der Komplexität auf das Transaktionskostenniveau umso gravierender, je stärker die Abhängigkeit der Transaktionspartner durch spezifische Investitionen ist. ${ }^{79}$

Die Häufigkeit ${ }^{80}$, mit der gleichartige Transaktionen getätigt werden, ist ein Kriterium dafür, inwieweit spezifische Investitionen für eine bestimmte Transaktion lohnenswert sind. PFOHL und LARGE führen aus, dass spezifische Investitionen nur bei regelmäßig wiederkehrenden, zumindest aber gelegentlichen Transaktionen zu rechtfertigen sind. ${ }^{81}$ Diese auf WILLIAMSON zurückgehende Einschätzung lässt sich damit begründen, dass die hohen Kosten, die die im Zuge spezifischer Investitionen anfallenden aufwändigen Kontroll- und Absicherungsmechanismen verursachen, bei sich wiederholenden Transaktionen leichter einzubringen sind. ${ }^{82}$ Das Häufigkeitskriterium allerdings hat bei der Auswahl des effizienten Koordinationsmechanismus keinen alleinigen entscheidungsrelevanten Einfluss, sondern hat allenfalls abschwächende oder verstärkende Wirkung. ${ }^{83}$

PICOT teilt WiLliamsons Auffassung und fügt der Auflistung der Transaktionscharakteristika als Determinanten für die Transaktionskostenhöhe die Transaktionskostenatmosphäre hinzu. ${ }^{84}$ Sie umfasst alle für die Organisation einer Leistungsbeziehung relevanten sozialen, rechtlichen und technologischen Rahmenbedingungen. Die sozialen Rahmenbedingungen spiegeln sich in den von den Transaktionspartnern akzeptierten Werthaltungen und Normen wider und sind insofern von Bedeutung, ,als vor dem Hintergrund verschiedenartiger Werthaltungen das opportunistische Verhaltenspotential grundsätzlich unterschiedlich einzuschätzen ist“ ${ }^{\text {. }}{ }^{85}$ Die rechtlichen Rahmenbedingungen schlagen sich in der konkreten Ausgestaltung der ökonomisch

$80 \quad$ Wil

80 Williamson teilt die Transaktionshäufigkeit in die Kategorien einmalig, gelegentlich und wiederkehrend ein. Vgl. Williamson (1990), S. 89.

81 Vgl. Pfohl, Large (1992), S. 23.

82 Vgl. Williamson (1990), S. 69; Picot (1991), S. 148.

83 Vgl. Stahl (1995), S. 95.

84 Vgl. Picot (1991), S. 148; Picot, Reichwald, Wigand (2003), S. 50, S. 52.

85 Picot (1991), S. 148. 
relevanten Rechtsgebiete (z. B. Arbeitsrecht, Wettbewerbsrecht) sowie in den Institutionen der Rechtsprechung und des Rechtsvollzugs nieder, die für die fraglichen Transaktionen zugrunde gelegt werden müssen. Damit stecken sie den Gestaltungsrahmen der möglichen Modalitäten für Abschluss und Durchsetzung von Verträgen $a b$ und nehmen so direkten Einfluss auf die Möglichkeit der Beherrschung und Überwachung von Transaktionen. ${ }^{86}$ Gute technologische Rahmenbedingungen letztlich können die Interaktion der Transaktionsbeteiligten erleichtern und daher transaktionskostensenkend wirken. ${ }^{87}$ So ermöglichen bspw. Fortschritte in der Informations- und Kommunikationstechnologie, dass sich der Spezifitätsgrad einer Leistungsbeziehung verändert. Zudem könnte sich dadurch der Informationsstand der Transaktionsbeteiligten verbessern, was den Grad der Unsicherheit bezüglich des Verhaltens des Partners und bezüglich des Transaktionsumfelds reduzieren würde. ${ }^{88}$

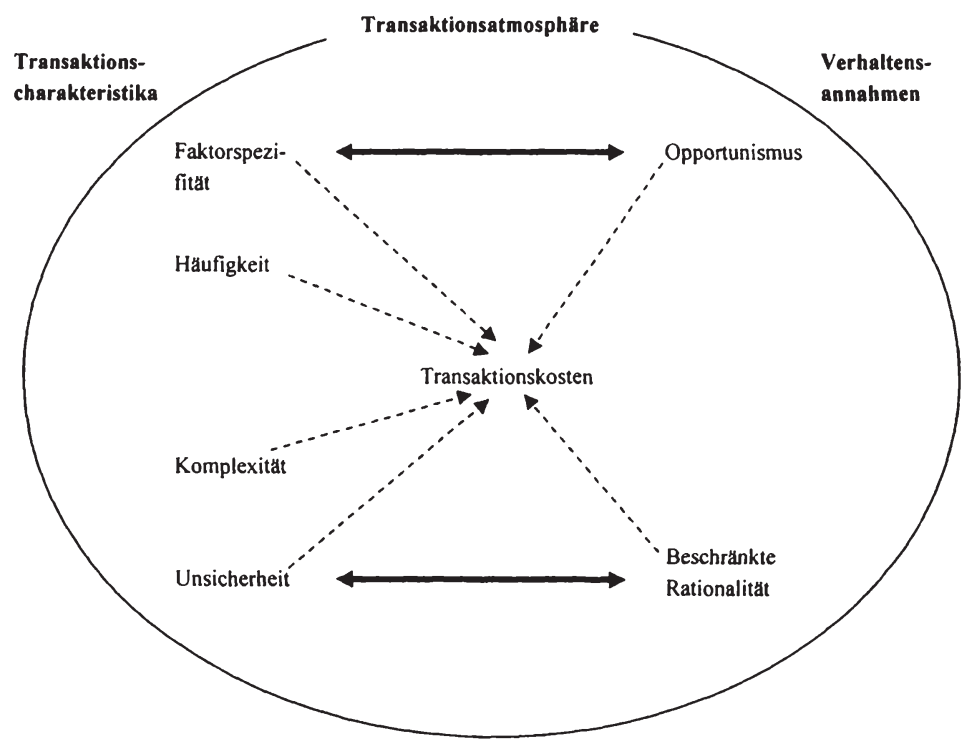

Abbildung 2-3: Einflussgrößen auf die Transaktionskosten

Quelle: Eigene Darstellung in Anlehnung an Picot, Reichwald, Wigand (2003), S. 50 
Für eine systematisierte Darstellung der Einflussgrößen auf die Transaktionskosten siehe auch Abbildung 2-3.

\subsubsection{Charakteristika alternativer Koordinationsmechanismen}

Im vorangegangenen Unterabschnitt wurden mit den Verhaltensannahmen und den Transaktionscharakteristika sowie der Transaktionskostenatmosphäre die wesentlichen Einflussfaktoren auf das Transaktionskostenniveau vorgestellt. Nun sollen die Koordinationsmechanismen (reiner) Markt, (strenge) Hierarchie und Kooperation als alternative institutionelle Ausgestaltungsformen zur Koordination von Austauschprozessen charakterisiert werden. Dabei wird sich herausstellen, dass auch die spezifischen Eigenschaften der verschiedenen Koordinationsmechanismen auf die Höhe der Transaktionskosten Einfluss nehmen. ${ }^{89}$ WILLIAMSON identifiziert vier Fragestellungen, anhand derer sich diejenigen Charakteristika von Koordinationsmechanismen herauskristallisieren, die das Transaktionskostenniveau - und damit die Effizienz des Leistungsaustauschs - in besonders hohem Maße beeinflussen: ${ }^{90}$

- Wie stark sind die Anreize für sparsamen Ressourceneinsatz?

- Wie stark sind die administrativen Kontrollmöglichkeiten zur Behebung von Transaktionsproblemen?

- Wie stark ist die autonome Anpassungsfähigkeit (d. h. die Fähigkeit einzelner Akteure, auf Störungen im Umfeld mit den richtigen Handlungen zu reagieren)?

- Wie stark ist die bilaterale Anpassungsfähigkeit (d. h. die Fähigkeit voneinander abhängiger Akteure, auf Störungen im Umfeld durch gemeinsam koordinierte Anpassung zu reagieren)?

\subsection{Koordination über den Markt}

Die Koordination von Leistungs- und Austauschprozessen über den rein marktlichen Koordinationsmechanismus anhand kurzfristiger Spotmarkt-Kontrakte bietet den teilnehmenden Wirtschaftssubjekten ein Höchstmaß an Autonomie und Flexibilität sowie starke Anreize für eine effiziente Ressourcenallokation. Dies liegt im funktionie- 
renden Preismechanismus begründet: aufgrund der Informations-, der Ausgleichs- und der Lenkungsfunktion des Preises auf dem anonymen (Spot-)Markt sehen sich die einzelnen Akteure in die Lage versetzt, Knappheiten zu erkennen, schnell auf Störungen im Umfeld zu reagieren und neue Anpassungsprozesse anzustoßen; Ressourcen werden in ihre effiziente Verwendung gelenkt. ${ }^{91}$ Marktliche Transaktionen sind somit auch durch eine hohe autonome Anpassungsfähigkeit gekennzeichnet. ${ }^{92}$ Seine effizienzfördernden Anreize kann der Markt insbesondere bei der Abwicklung von Transaktionen mit geringer Spezifität ausspielen, da diese aufgrund ihrer einfachen Vergleichbarkeit einer starken Konkurrenz und damit einem hohen Effizienzdruck unterliegen. ${ }^{93}$

Was die Möglichkeiten der Überwachung und Durchsetzung der Vertragsinhalte, auf Basis derer die Transaktionen abgewickelt werden anbetrifft, so erschöpfen sich diese in der Androhung rechtlicher Sanktionierungen oder der Verweigerung von Folgeaufträgen. Auf ein aufwändiges Kontroll- und Absicherungssystem und die daraus resultierenden administrativen Kontrollmöglichkeiten kann verzichtet werden, da die bestehenden Sanktionsmöglichkeiten bei unproblematischen Transaktionen völlig ausreichend sind. Allerdings bedeutet dies auch, dass der Marktmechanismus außerstande ist, Transaktionen, die aufgrund bestimmter Verhaltens- und Transaktionscharakteristika mit starken Transaktionsproblemen behaftet sind, kostengünstig zu beherrschen. ${ }^{94}$ Insbesondere sind unsichere und spezifische Transaktionen im Zusammenspiel mit den sich bei rein marktlicher Koordination auftuenden Spielräumen für opportunistisches Verhalten für die marktliche Koordination nicht geeignet. ${ }^{95}$ In diesen Fällen ist der Wettbewerb als Schutzmechanismus oftmals nicht wirksam oder nicht hinreichend. ${ }^{96}$

Neben den schwachen administrativen Kontrollmöglichkeiten ist der rein marktlichen Koordination weiterhin zu attestieren, dass sie den Akteuren keine Mechanismen bereitstellt, gemeinsam und koordiniert auf Störungen im Transaktionsumfeld zu reagieren. Die bilaterale Anpassungsfähigkeit ist folglich schwach ausgeprägt. ${ }^{97}$

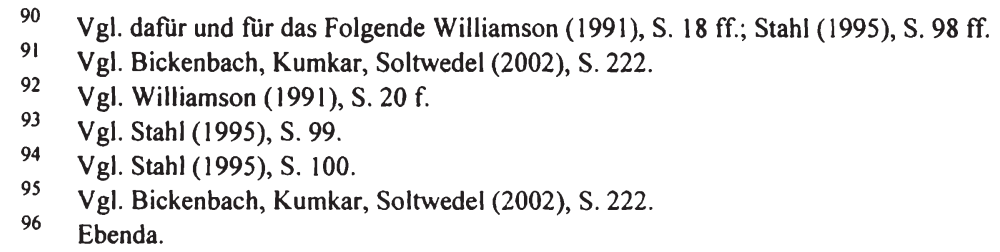




\subsection{Koordination über Hierarchie}

BICKENBACH, KUMKAR und SOLTWEDEL führen zwei wesentliche, relevante Spezifika rein hierarchischer Koordination ins Feld: ${ }^{98}$ durch die Integration von Transaktionsaktivitäten in einen hierarchischen Entscheidungskomplex mit einheitlicher Eigentümerschaft und Kontrolle wird (1) das Eigentum an physischem Kapital und der diesbezüglichen Verfügungsrechte zentralisiert und (2) die Art des Vertragsrechts, das den Transaktionen zugrunde liegt, geändert.

Die Zentralisierung von Verfügungsrechten über physisches Kapital schützt den Eigentümer zwar einerseits vor der Gefahr opportunistischer Verhaltensweisen, die praktiziert werden könnten, wenn der Produktionsprozess zwischen einer Vielzahl autonomer Eigentümer physischer Produktionsressourcen koordiniert werden müsste. ${ }^{99}$ Jedoch nehmen gleichermaßen die Anreize für eine effiziente Ressourcenverwendung $a b$, da in einer rein hierarchischen Organisation die Nichteigentümer (wie z. B. einfache Angestellte, untergeordnete Manager) allenfalls schwache Anreize haben, Investitionen in den effizienten Betrieb des Unternehmens zu leisten. Dieses Verhalten resultiert aus der begründeten Annahme der Nichteigentümer, dass die Eigentümer danach trachten, das bestehende Abhängigkeitsverhältnis ihrerseits opportunistisch für sich auszunutzen. ${ }^{100}$ Ferner ist die Koordination innerhalb einer rein hierarchischen Organisation aufgrund der verringerten Anreize und des Fehlens des Preismechanismus als dezentralem Knappheitsindikator durch eine vergleichsweise schwach ausgeprägte autonome Anpassungsfähigkeit gekennzeichnet. ${ }^{101}$

Die Änderung des relevanten Vertragsrechts umfasst die Tatsache, dass das klassische Vertragsrecht, welches vor allem bei externen Transaktionen (wie bspw. über den (Spot-)Markt) angewendet wird, für interne Transaktionen (wie bspw. in rein hierarchischen Organisationen) hingegen kaum Anwendung findet. Für interne Transaktionen gilt das Recht der ,generellen Unbeachtlichkeit“, was bedeutet, dass es im Falle einer internen Auseinandersetzung innerhalb einer rein hierarchischen Organisation (bspw. zwischen zwei Abteilungen) i. d. R. nicht möglich ist, über den normalen Rechtsweg eine gerichtliche Entscheidung durchzusetzen. ${ }^{102}$ Die rein hierarchische

\footnotetext{
97 Vgl. Williamson (1991), S. 21; Stahl (1995), S. 100.

98 Vgl. Bickenbach, Kumkar, Soltwedel (2002), S. 223.

99 Vgl. Bickenbach, Kumkar, Soltwedel (2002), S. 223.

$100 \mathrm{Vgl}$. Bickenbach, Kumkar, Soltwedel (2002), S. 224.

101 Vgl. Stahl (1995), S. 101.

102 Vgl. Williamson (1991), S. 30.
} 
Organisation ist demnach ihre „eigene oberste Berufungsinstanz ${ }^{\text {“103 }}$ was zur Folge hat, dass ihre administrativen Kontrollmöglichkeiten auf der Basis eines ausgeprägten Kontroll- und Überwachungsapparates notwendigerweise sehr stark ausgeprägt sind. ${ }^{104}$ Gleichermaßen stark ausgeprägt ist die bilaterale Anpassungsfähigkeit, da durch diesen ausgeprägten Kontroll- und Überwachungsapparat voneinander abhängige Transaktionspartner über Mechanismen und Instrumente verfügen, die sie in die Lage versetzen, gemeinsam und koordiniert auf Störungen im Transaktionsumfeld zu reagieren. ${ }^{105}$

Die Zentralisierung von Verfügungsrechten und die hohe interne Durchsetzbarkeit von Entscheidungen bewirken, dass Transaktionsprobleme und erforderliche Anpassungsreaktionen, die sich aus dem Zusammenwirken von Rationalitäts- und Opportunismusproblemen bei den Transaktionsbeteiligten bei spezifischen oder unsicheren Transaktionen ergeben, effizient und zeitnah beherrscht werden können. ${ }^{106}$

\subsection{Koordination über Kooperation}

Zwischen dem reinen Markt und der strengen Hierarchie als Extrempunkten liegt nun eine Vielzahl unterschiedlicher Formen kooperativer Arrangements zur Koordinierung ökonomischer Aktivitäten. Diese hybriden Koordinationsmechanismen sind bestrebt, die Vorteile der Koordination über Markt und Hierarchie möglichst zu realisieren und deren Nachteile weitestgehend zu vermeiden. ${ }^{107}$ Aufgrund des Zusammenwirkens marktlicher und hierarchischer Koordinationselemente bewegt sich die kooperative Zusammenarbeit stets im Spannungsfeld zwischen Autonomie und Interdependenz. ${ }^{108}$ Koordination über Kooperation reduziert im Vergleich zur rein marktlichen Koordination tendenziell den Effizienzdruck auf die Transaktionspartner, weil aufgrund der geplanten Langfristigkeit der Austauschbeziehung die zeitweilige Ineffizienz eines Transaktionspartners nicht sofort und unweigerlich zur Beendigung der Austauschbeziehung führt. Jedoch sehen sich alle Transaktionspartner permanent der Konkurrenz durch andere, potentielle oder aktuelle Partner ausgesetzt, die die betreffende Aufgabe systematisch effizienter erfüllen könnten. Der Austausch eines Partners durch einen anderen Partner innerhalb einer Kooperationsbeziehung ist also durchaus möglich.

Williamson (1991), S. 31.

Vgl. Stahl (1995), S. 101; Bickenbach, Kumkar, Soltwedel (2002), S. 223.

Vgl. Stahl (1995), S. 101.

Vgl. Picot, Reichwald, Wigand (2003), S. 54; Stahl (1995), S. 101; Williamson (1991), S. 30 ff.

Vgl. Bickenbach, Kumkar, Soltwedel (2002), S. 224.

Vgl. Arnold, EBig (2002), S. D3-21.
} 
Zwischen den Partnern besteht demnach ein höherer Effizienzdruck als innerhalb einer hierarchischen Koordination. Bezüglich der Anreizstärke für eine effiziente Ressourcenverwendung bei der Koordination über Kooperation kann folglich festgestellt werden, dass sie zwischen der Koordination über Markt und Hierarchie liegt. ${ }^{109}$

Bei der Koordination über Kooperation werden aufgrund der geplanten Längerfristigkeit der Austauschbeziehung i. d. R. Kontroll- und Absicherungssysteme vorgehalten, um opportunistisches Verhalten bei unsicheren oder spezifischen Transaktionen auch unternehmensübergreifend beherrschen und im Bedarfsfalle wirksam sanktionieren zu können. ${ }^{110}$ Demgemäß sind diese Kontroll- und Absicherungssysteme im Vergleich zur rein marktlichen Koordination stärker ausgeprägt, ohne jedoch intensitätsmäßig oder umfänglich das Niveau wie bei rein hierarchischer Koordination zu erreichen. Folglich ist der Koordination über Kooperation auch hinsichtlich der administrativen Kontrollmöglichkeiten zu attestieren, dass sie zwischen der Koordination über Markt und Hierarchie liegt. ${ }^{111}$

Das Zusammenwirken rein marktlicher und rein hierarchischer Elemente bei der Koordination über Kooperation schlägt sich auch bei der Beurteilung dieses Koordinationsmechanismus in Bezug auf den Wirkungsgrad der beiden Formen der Anpassungsfähigkeit nieder. Die durchaus vorhandenen Charakteristika marktlicher Steuerung, wie bspw. die wirksamen Anreize für eine effiziente Ressourcenverwendung, bieten den einzelnen Akteuren genügend Spielraum, angemessen auf Störungen im Transaktionsumfeld zu reagieren. Gleichermaßen versetzt der Einsatz ausgeprägter administrativer Kontroll- und Absicherungssysteme die Kooperationspartner in die Lage, gemeinsam abgestimmte Reaktionsmuster auf Störungen im Transaktionsumfeld zu entwickeln. Somit sind bei Koordination über Kooperation - wenngleich in eingeschränkter Form - beide Anpassungsfähigkeiten, sowohl die autonome als auch die bilaterale Anpassungsfähigkeit, funktionsfähig. ${ }^{112}$

Als Ergebnis kann festgehalten werden, dass

- Märkte und Hierarchien als Koordinationsmechanismen gegenläufige Eigenschaften aufweisen und sich grundlegend unterscheiden. Sie stellen „diskrete Strukturalternativen" dar. ${ }^{113}$

\footnotetext{
109 Vgl. Stahl (1995), S. 102.

110 Vgl. Picot, Reichwald, Wigand (2003), S. 54 f.; Stahl (1995), S. 102.

III Vgl. Stahl (1995), S. 102.

112 Vgl. Stahl (1995), S. 103.

113 Vgl. Williamson (1991), S. 21, S. 32.
} 
- die Kooperation als hybrider Koordinationsmechanismus sowohl hinsichtlich der Wirksamkeit der Instrumente (Anreize zur effizienten Ressourcennutzung, administrative Kontrollmöglichkeiten), als auch hinsichtlich der Anpassungsfähigkeiten zwischen dem Markt und der Hierarchie anzusiedeln ist. ${ }^{114}$ RICHARDSON führt aus, dass die Koordination über Markt oder Hierarchie in ihren Reinformen dabei lediglich einen kleinen Teil der in der Realität beobachtbaren Erscheinungsformen von Koordinationsmechanismen ausmachen. Diverse Formen der Kooperation hingegen sind allgegenwärtig: "The pure market transaction is (...) a limiting case, the ingredient of cooperation being very commonly present, (...). And just as the presence of co-operation is a matter of degree, so also is the sovereignty that any nominally independent firm is able to exercise on a de facto basis, for the substance of autonomy may often have been given up to a costumer or a licensor." 115

- die verschiedenen Koordinationsmechanismen, bedingt durch ihre spezifischen Charakteristika, unterschiedliche Möglichkeiten haben, auf problematische Verhaltensweisen der Transaktionsbeteiligten und auf problematische Transaktionscharakteristika zu reagieren und diese zu beherrschen. Folglich bilden Markt, Hierarchie und Kooperation in Abhängigkeit des betreffenden Transaktionsvorhabens effiziente, weil transaktionskostenminimale Formen der Organisation von Austauschprozessen. Dabei hängt die Vorteilhaftigkeit eines bestimmten Koordinationsmechanismus im konkreten Fall vom $\mathrm{Zu}$ sammenspiel der in Unterabschnitt 2.1.3.2 genannten Einflussgrößen auf die Transaktionskosten ab. ${ }^{116}$

Vgl. Williamson (1991), S. 32, S. 41. Einen zum Williamsonschen "Kontinuum-Konzept" alternativen Ansatz vertritt Powell, der argumentiert, dass ,although I was earlier of the view that non-market, non-hierarchical forms represented hybrid modes (...), I now find that this mixed mode or intermediate notion is not particularly helpful." Powell (1990), S. 298. Vielmehr vertritt er die Ansicht, dass "such an arrangement is neither a market transaction nor a hierarchical governance structure, but a separate, different mode of exchange, one with its own logic, a network." Powell (1990), S. 301. Eine noch extremere Position nimmt Simon ein, der den Primat des Marktes in Frage stellt und die Koordination innerhalb von Organisationen ins Zentrum seiner Betrachtungen rückt: "The economies of modern industrialized society can more appropriately be labeled organizational economies than market economies." Simon ( 1991), S.42. 
- die Transaktionskostentheorie hinsichtlich der Variation der wichtigsten Determinante für das Transaktionskostenniveau - der Faktorspezifität - c. p. folgende Gestaltungsempfehlung gibt: ${ }^{117}$

- Transaktionen mit niedrigem Spezifitätsgrad werden effizient über marktliche Transaktionen abgewickelt, weil der Markt bei derartigen Transaktionen gegenüber den anderen alternativen Organisationsformen aufgrund der absolut niedrigsten fixen Transaktionskosten (wegen fehlenden langfristigen vertraglichen Bindungen) im Vorteil ist. Für Transaktionen höherer Spezifität ist der Markt hingegen nicht geeignet, da die variablen Transaktionskosten bei marktlicher Transaktion mit zunehmender Spezifität der Leistung stark ansteigen. Dies liegt darin begründet, dass die Gefahr der opportunistischen Ausnutzung des zunehmenden Spezifitätsniveaus seitens eines Transaktionspartners durch umfassende Vorsichtsmaßnahmen in Form kostentreibender Verträge und Leistungskontrollen eingedämmt werden muss.

- Transaktionen mit hohem Spezifitätsgrad werden effizient über eine vertikale Integration (Hierarchie) abgewickelt. Die Hierarchie profitiert hier durch ihre permanent vorgehaltenen ausgeprägten Kontrollund Anreizmechanismen, welche zwar - unabhängig vom Spezifitätsgrad der Transaktion - hohe fixe Transaktionskosten bedeuten, welche aber gleichsam bewirken, dass die variablen Transaktionskosten zur Absicherung und Beherrschung der Transaktion mit zunehmender Spezifität der Leistung nur noch sehr flach ansteigen.

- Transaktionen mit mittlerem Spezifitätsgrad werden effizient über Kooperationen abgewickelt. Aufgrund der längerfristigen vertraglichen Beziehungen in Kooperationen nimmt hier das institutionalisierte Handlungspotenzial zur Sanktionierung opportunistischer Verhaltensweisen zu und es wird den opportunistischen Verhaltensweisen zumindest tendenziell durch die Interessenharmonie zwischen den Kooperationsteilnehmern entgegengewirkt. Daher ist der Anstieg der variablen Transaktionskosten in Abhängigkeit des Spezifitätsgrades, welche sich in Form kostentreibender Sanktionsmechanismen zur

117 Vgl. für das Folgende Arnold, Eßig (2002), S. D3-20 f.; Picot, Reichwald, Wiegand (2003), S. 54 f. 
Beherrschung opportunistischen Verhaltens dokumentieren, weniger steil als bei Markttransaktionen, aber steiler als bei der Hierarchie. Dafür weisen Kooperationen aber gegenüber dem Markt auch einen höheren Fixkostenblock an Transaktionskosten auf, welcher jedoch wiederum niedriger ist, als in der Hierarchie. Folglich ist die Kooperation bei mittlerer Spezifität der Transaktionen im Vorteil gegenüber dem Markt und der Hierarchie, unterliegt aber als effiziente Organisationsform im Bereich der unspezifischen Transaktionen dem Markt, im Bereich der hochspezifischen Transaktionen der Hierarchie. Diese Zusammenhänge verdeutlicht folgende Abbildung 2-4:

Transaktionskosten

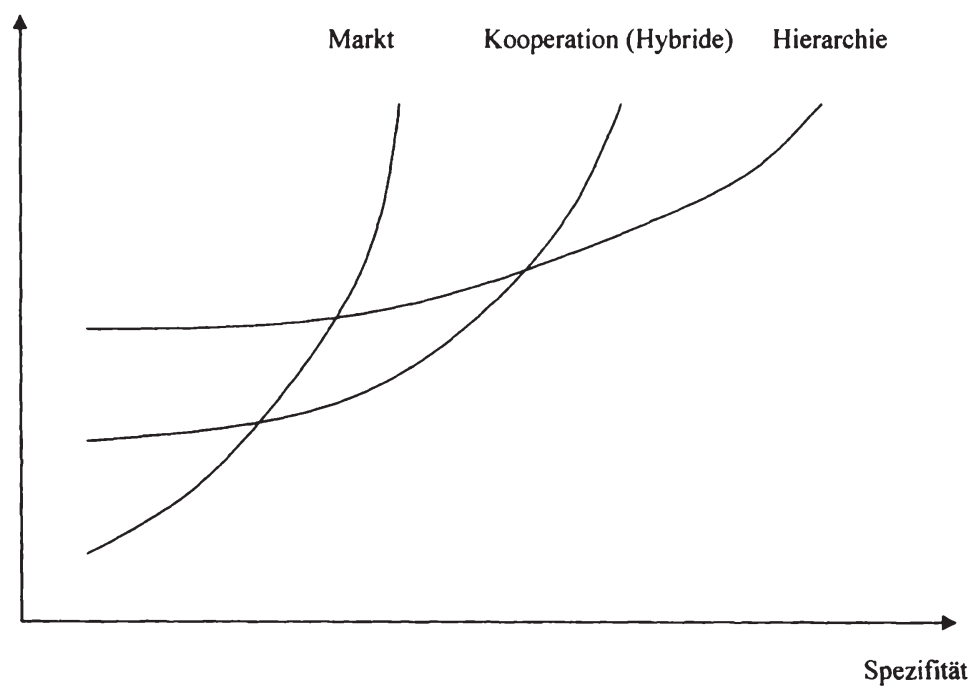

Abbildung 2-4: Auswirkung der Spezifität auf die Wahl des geeigneten Koordinationsmechanismus

Quelle: in Anlehnung an Williamson (1991), S. 24 


\subsubsection{Zusammenfassung und Schlussfolgerungen}

Im Folgenden werden wesentliche Ergebnisse der vorangegangenen Unterabschnitte zusammengefasst und darauf aufbauend Schlussfolgerungen für den weiteren Gang der Untersuchung abgeleitet.

(1) Um den Prozess der logistischen Reorganisation wirtschaftlicher Aktivität systematisch zu erfassen, wird die Marktanalyse des Logistikmarktes als geeignete Untersuchungsmethode betrachtet, da sie im Vergleich zu möglichen anderen Systematisierungsalternativen am besten dazu geeignet scheint, die hier relevanten Aspekte der komplexen und heterogenen Materie „Logistik“ umfassend und zweckgerichtet darzustellen.

(2) Die Marktanalyse soll gemäß der methodischen Grundsätze der Industrieökonomik durchgeführt werden. Dies bedeutet, dass die erkenntniswissenschaftliche, positive Analyse empirischer Fakten und tatsächlicher Zusammenhänge angestrebt wird. Diese Analyse hat zum Ziel, das Wissen bezüglich der Vorgänge auf dem Logistikmarkt, deren Determinanten sowie deren Wirkungen zu vermehren. Sie hat nicht zum Ziel, diese Vorgänge einer Beurteilung auf Basis normativ festgelegter Kriterien zu unterwerfen.

(3) Der Markt als Analysegegenstand der folgenden Untersuchung soll in Anlehnung an KORTMANN als dynamisches Gebilde mit systemischem Charakter aufgefasst werden, das aus einem Geflecht miteinander in wechselseitiger Beziehung stehender, erklärungsrelevanter Systemkomponenten besteht und als Institution dem Zwecke der Koordination bzw. der Organisation von Austauschprozessen dienen soll. Die Untersuchung gliedert sich folglich in die

- Analyse der ökonomischen Grundlagen der Logistik und der Logistikleistung, die

- Analyse der Rahmenbedingungen des Logistikmarktes, die

- Analyse des Angebotes logistischer Leistungen, die

- Analyse der Nachfrage nach logistischen Leistungen sowie die

- Analyse der Koordination von Angebot und Nachfrage nach Logistikleitungen. 
(4) Obwohl die Marktanalyse also industrieökonomischen Charakter hat, wird für deren Gliederungssystematik auf den Rahmen, den das SVE-Paradigma als zentrales Paradigma der Industrieökonomik anbietet, verzichtet. Diese Entscheidung soll dazu beitragen, die Analyse von der Vorstellung eines unidirektionalen Kausalzusammenhanges zwischen Marktstruktur, -verhalten und -ergebnis zu entkoppeln. Dessen ungeachtet bezieht die gewählte Systematik der Marktanalyse ihre inhaltliche Konkretisierung bzw. Operationalisierung natürlich im Wesentlichen aus dem der Industrieökonomik entstammenden SVE-Paradigma, zumal das SVE-Paradigma einer verunglückten Interpretation der logisch richtigen Kausalbeziehung „Determinanten - Prozess - Wirkungen“ entspringt. ${ }^{118}$ Der hinter dem SVE-Paradigma stehende eigentliche Grundgedanke ist folglich mit dem Anliegen dieser Marktanalyse, nämlich Determinanten, Prozessverlauf und Wirkungen des Prozesses der logistischen Reorganisation zu erarbeiten, kompatibel.

(5) Das Paradigma wird hier in seiner modifizierten Form als „Paradigma der zirkularen Verknüpfung“ im HOPPMANNschen Sinne zum Zwecke der positiven Marktanalyse verwendet. Hierbei finden Elemente der „basic conditions“ vor allem Eingang in die Analyse der Grundlagen der Logistik und der Logistikleistung sowie in die Analyse der Rahmenbedingungen. Struktur- und Verhaltensvariable werden hauptsächlich im Rahmen der Angebots- und der Nachfrageanalyse thematisiert. Marktergebnisvariable sind Bestandteil der Analyse der Koordination von Angebot und Nachfrage. Vergleiche für diese Zusammenhänge auch Abbildung 2-5.

(6) Obgleich für die Marktanalyse aus Gründen der Didaktik und der Handhabbarkeit eine „Grundsystematik“ vorgestellt und eingehalten werden muss, so ist es jedoch nicht von zentraler Bedeutung, welches Merkmal oder Charakteristikum in welchem Analyseschritt untersucht wird. Vielmehr ist der systemische, dynamische Charakter der Marktvorgänge hervorzuheben, der dazu führt, dass letzten Endes jeder Versuch der Zuordnung eines Merkmales zu einem bestimmten Analyseschritt willkürlich bleiben muss. Letztendlich kommt es darauf an, Zusammenhänge zwischen Variablen aufzudecken und zu erkennen, um Funktionsweise und Funktionsmechanismen des Marktes besser verstehen zu lernen. 
(7) Es wird davon ausgegangen, dass die ökonomische Realität von der Koexistenz alternativer Koordinationsmechanismen gekennzeichnet ist. Neben dem Wettbewerb spielen gleichermaßen auch kooperative Arrangements und die hierarchische Organisation als Ergebnis sozialer Interaktionen zwischen den Marktteilnehmern eine wichtige Rolle für die Erklärung realer Marktvorgänge. Unter Rückgriff auf die Argumente des transaktionskostentheoretischen Ansatzes werden die - speziell im Logistikmarkt relevanten - verschiedenen Formen kooperativer Arrangements unter den Marktteilnehmern ökonomisch bewertet.

(8) Darauf aufbauend wird der Beitrag, den die spezifische institutionelle Ausgestaltung des Logistikmarktes zu Wesen und Güte der Koordination von Angebot und Nachfrage nach Logistikleistungen leistet, erörtert. Ferner wird im Rahmen der Analyse der Koordination auf dem Logistikmarkt der Versuch unternommen zu ergründen, welches Potenzial der Logistikmarkt hinsichtlich der Beeinflussung und Gestaltung des Koordinationsprozesses von Austauschbeziehungen auf gesamtwirtschaftlicher Ebene besitzt.

(9) Abschließend sei an dieser Stelle nochmals nachdrücklich auf die hohe Relevanz von Institutionen für reales Marktgeschehen verwiesen. Ihre Gestaltungskraft und Strukturierungsleistung in ihrer Funktion als Regelsysteme wirken komplexitätsreduzierend auf marktliche und unternehmerische Entscheidungsprobleme. Die institutionelle Verankerung der Leistungskoordination im Logistikmarkt ist gerade angesichts der Beschaffenheit der Marktprozesse im Logistikmarkt, welche ja die hohe gegenständliche Komplexität der Logistikmaterie selbst widerspiegeln, von besonderer Bedeutung. Dementsprechend ist die Durchführung der gesamten Marktanalyse durch eine starke Schwerpunktsetzung auf institutionelle Aspekte des Logistikmarktes gekennzeichnet. 


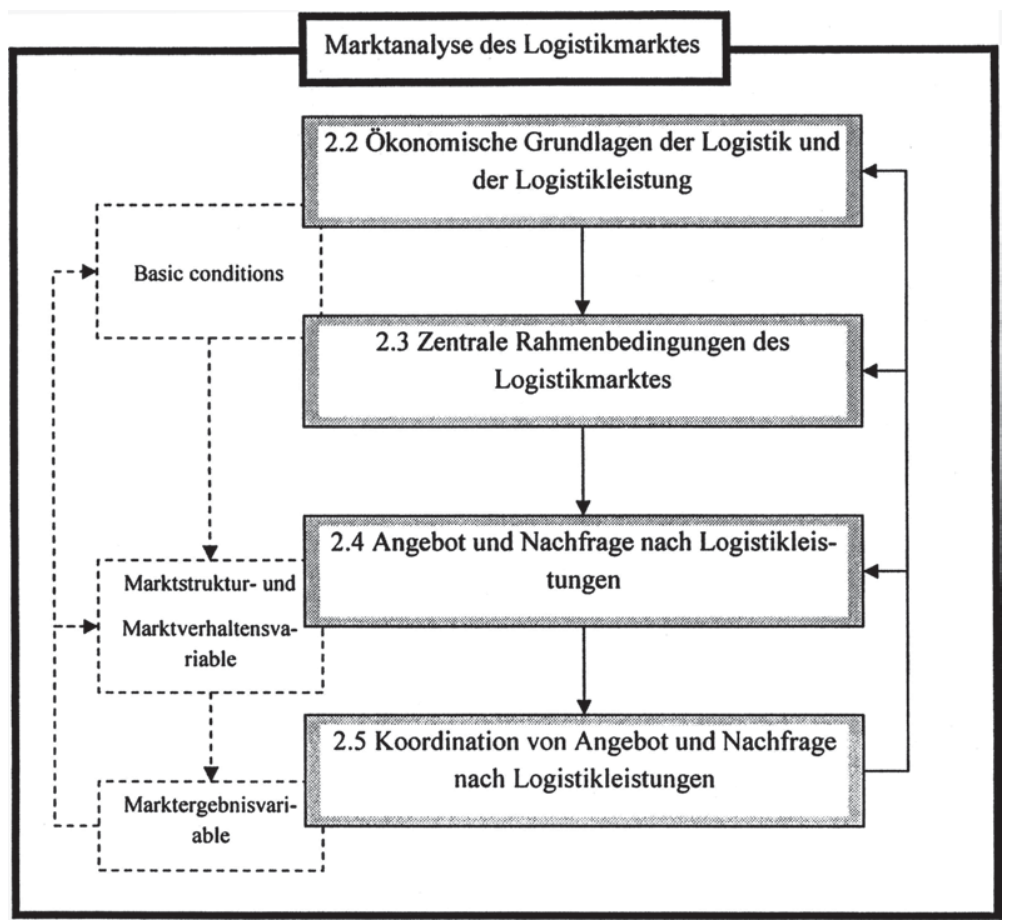

Abbildung 2-5: Weitere Vorgehensweise

Quelle: Eigene Darstellung 


\section{2 Ökonomische Grundlagen der Logistik und der Logistikleistung}

\subsubsection{Vorbemerkungen}

Die Analyse der spezifischen ökonomischen Charakteristika des zu untersuchenden Gutes ist ein wesentlicher Bestandteil einer Marktanalyse. Schon MASON betont die Relevanz der Produktcharakteristika. Er weist darauf hin, dass die Produktcharakteristika wie bspw.

- der Investitionsgut- bzw. Konsumgutcharakter des Produktes,

- die Dauerhaftigkeit des Produktes oder

- der Grad der Produktdifferenzierung bzw. der Standardisierung,

eine wichtige Bedingung für die Klassifikation von Marktstrukturen darstellen und verlangt deren Analyse.' BÜHLER und JÄGER werfen die Frage nach der Möglichkeit zur Produktsubstitution als untersuchenswertes Merkmal auf. ${ }^{2}$ Eng damit verbunden ist die von KORTMANN geforderte systematische Strukturierung des Produktes nach innen, sowie seine Abgrenzung nach außen. ${ }^{3}$ Ferner kann die Untersuchung der Verwendungsmöglichkeiten sowie der historischen und technologischen Entwicklung des Produktes im Zeitablauf wichtige Hinweise darauf geben, welche Funktion das Produkt erfüllt und welche Problemlösungsmöglichkeiten es bietet. ${ }^{4}$

Der folgende Abschnitt 2.2 soll die hier skizzierten Fragestellungen behandeln und einen Beitrag dazu leisten, ein Grundverständnis für Wesen und Spezifika der Logistik und der Logistikleistung als Basis für die weitere Marktanalyse zu entwickeln. In Unterabschnitt 2.2.2 wird die Logistikkonzeption als Ausdruck einer weiterentwickelten unternehmerischen Denkhaltung entworfen. Hierzu erfolgt zunächst die Einordnung der Logistik bzw. des Logistiksystems in den Kontext der gesamtwirtschaftlichen Gütertransformation. Anschließend werden der Begriff der Logistik sowie artverwandte Begriffe präzisiert und gegeneinander abgegrenzt. Es folgt die Systematisierung des Logistikphänomens auf der Basis institutioneller Aspekte bevor abschließend die

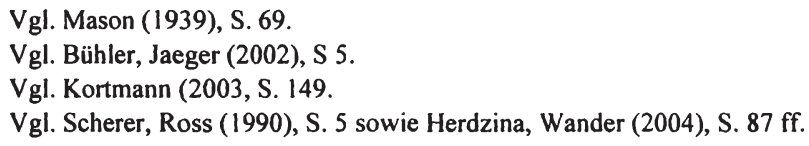


Darlegung der ökonomischen Bedeutung der Logistik erfolgt. Wie zu zeigen sein wird, kristallisieren sich aus den Ausführungen des Unterabschnitts 2.2.2 mit der Systemtheorie und der Netzwerktheorie zwei Ansätze heraus, die dazu geeignet erscheinen, das Logistikphänomen theoretisch zu fundieren. Unterabschnitt 2.2 .3 beinhaltet eine zusammenfassende Darstellung wesentlicher ökonomischer Charakteristika der Logistikleistung. Eine Zusammenfassung beschließt den Abschnitt (Unterabschnitt 2.2.4).

\subsubsection{Grundlegung der Logistikkonzeption}

\subsubsection{Logistiksysteme im Kontext der Gütertransformation}

Im vorangegangenen Unterabschnitt wurde die Arbeitsteilung als ein mögliches Instrument zur Reduzierung von Knappheit vorgestellt. Ferner wurde darauf hingewiesen, dass sich auf gesamtwirtschaftlicher Ebene in arbeitsteilig organisierten Ökonomien durch das systemimmanente hohe Komplexitätsniveau der Austauschvorgänge im volkswirtschaftlichen Produktionsprozess ein erheblicher Koordinationsbedarf ergibt. Aus arbeitsteiligem Wirtschaften, v. a. aufgrund der damit verbundenen räumlichen Trennung von Transaktionsbeteiligten, ergibt sich demnach, dass physische Gütertransfers zwischen einzelnen Wirtschaftssubjekten notwendig werden. ${ }^{5}$

Da Güterbereitstellung und Güterverwendung in der Regel zeitlich und räumlich voneinander getrennt sind, stellt sich die Frage nach einem verbindenden Element, das die durch die zeitliche und räumliche Trennung hervorgerufenen Überbrückungs- und Ausgleichsbedarfe befriedigt und damit die Systeme der Güterbereitstellung und der Güterverwendung miteinander verknüpft. Dieses verbindende Element bzw. System ist der Transfersektor (synonym: Transaktions-, Verteilungs- bzw. Zirkulationssektor). Der Transfersektor bildet in einer arbeitsteilig organisierten Volkswirtschaft dasjenige System, das die elementaren Transformationsprozesse der Güterbereitstellung (Produktion) und der Güterverwendung (Konsumtion) mittels Transferprozessen (Gütertransfers) zusammenfügt. ${ }^{6}$ Dieses Beziehungsgefüge ist in Abbildung 2-6 dargestellt.

5 6
Vgl. Ihde (2001), S. I, S. 56; Pfohl (2004a), S. 336; Köberlein (1997), S. 3.

Vgl. Ihde (2001), S. 1 f., S. 56 f. Schon Pirath erkannte die Notwendigkeit eines verbindenden Elements, welches in einer arbeitsteilig organisierten Wirtschaft die Systeme der Güterherstellung und des Güterverbrauchs koppelt: „Die Güterverteilung und der Güterumlauf sind gleichsam Hilfsmittel für die Herstellung und den Verbrauch von Gütern. Als solche sind sie um so unent- 
Dabei ist der Transfersektor zum einen als resultierender Faktor produktiver und konsumtiver Prozesse zu betrachten, da sich die Notwendigkeit der Transferleistungen direkt aus der Arbeitsteilung, der Dislozierung und den Zeitstrukturen der elementaren Transformationsprozesse ergibt. Umgekehrt hängt die Organisation der Gütertransformation wesentlich von den Voraussetzungen ab, die der Transfersektor zu schaffen in der Lage ist (bspw. Transportkosten, -zeiten). Damit stellt der Transfersektor auch einen bedingenden Faktor der volkswirtschaftlichen Gütertransformation dar. ${ }^{7}$ In diesem Zusammenhang ist in den letzten Jahren allerdings eine deutliche Bedeutungsverschiebung des Transfersektors in Richtung eines bedingenden Faktors für Organisation und Entwicklung des Gütertransformationssystems zu konstatieren. ${ }^{8}$

Vielstufige Abfolgen von Güterbereitstellungsprozessen, Transferprozessen und Güterverwendungsprozessen konstituieren Wertschöpfungsketten, die sowohl in Richtung des Ver- oder Gebrauchs laufen können, aber auch in umgekehrter Richtung als Entsorgungs- oder Recyclingkreisläufe. ${ }^{9}$ Während Güter dabei in den Systemen der Güterbereitstellung und der Güterverwendung qualitative Veränderungen erfahren, werden nach PFOHL innerhalb des Transfersektors die räumlichen und die zeitlichen Merkmale der Güter verändert. ${ }^{10}$ IHDE zählt zudem explizit die art- und mengenmäßige Umstrukturierung der Güterbestände zu den Aufgaben des Transfersektors. ${ }^{1}$

behrlicher, je intensiver die Wirtschaft und je großräumiger in ihr die Arbeitsteilung wurde." Pirath (1934), S. I f.

Vgl. Ihde (2001), S. 1. Ähnlich argumentiert auch Hesse, welcher hauptsächlich die wechselseitige Beeinflussung von Transfer (Logistik)- und Transformationssektor hinsichtlich der räumlichen Entwicklung sowie der raum-zeitlichen Konfiguration ökonomischer und gesellschaftlicher Prozesse aus der Perspektive der Raumforschung und -ordnung thematisiert. Vgl. Hesse (1998), S. 125.

Vgl. Milling, Dengel (2003), S. 134.

Vgl. Ihde (2001), S. 2.

10 Vgl. Pfohl (2004a), S. 4 f.

11 Vgl. Inde (2001), S. 56. 


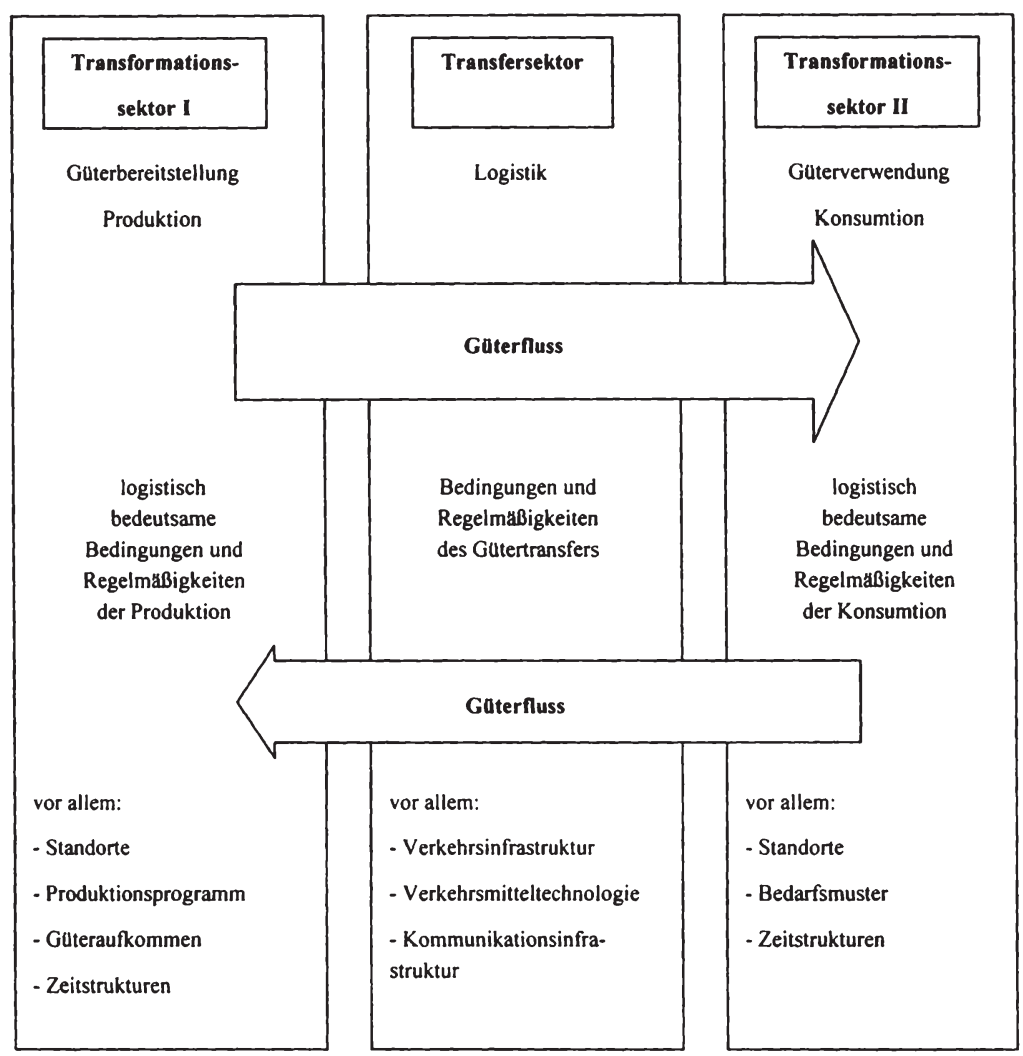

\section{Abbildung 2-6: Logistischer Systemverbund}

Quelle: Ihde (2001), S. 57

Die konkreten Anforderungen hinsichtlich des Art- und Mengenausgleichs und der Überwindung räumlicher sowie zeitlicher Zerklüftungen kennzeichnen den logistischen Bedarf eines Wirtschaftssystems. ${ }^{12}$ Zur Befriedigung dieses Bedarfes erbringt der Transfersektor Art- und Mengenausgleichsleistungen (zusammengefasst: Ordnungsleistungen) in Form von Sammel-, Sortier-, Kommissionier- und Umschlagsprozessen. Die räumliche Veränderung von Gütern wird mittels Transport- und Verkehrs- 
prozessen bewirkt, die zeitliche Veränderung von Gütern erfolgt über Lagerprozesse. ${ }^{13}$ Derartige Prozesse werden als Logistikprozesse bezeichnet. ${ }^{14}$ Logistikprozesse lösen den Güterfluss aus, welcher die Transformationssysteme der Güterbereitstellung und Güterverwendung miteinander verbindet. ${ }^{15}$ Solche Güterflusssysteme werden als Logistiksysteme bezeichnet, sie sind „funktionale Subsysteme arbeitsteilig organisierter Wirtschaftssysteme“. ${ }^{16}$ Schon EWERS weist 1973 darauf hin, dass das Güterverkehrssystem ${ }^{17}$ zwischen den Systemen der Gütererzeugung und der Güterverwendung die Funktion der "Überbrückung räumlicher und zeitlicher Friktionen zwischen Produktion und Verbrauch von Gütern" erfüllt. ${ }^{18}$ Eine ähnliche Sichtweise vertritt MÖHLMANN, der das Verkehrssystem als ökonomisches Teilsystem des Wirtschaftsund Gesellschaftssystems begreift und den Güterverkehr als integralen Bestandteil der Wirtschaft sieht: „Der Güterverkehr (...) übernimmt die Aufgabe der räumlichphysischen Güterverteilung und dient zur zeitlichen Überbrückung zwischen Produktion und Verbrauch im Rahmen des volkswirtschaftlichen Güteraustausches". ${ }^{19}$ Hierbei ist zu beachten, dass es sich bei dem Beziehungsverhältnis zwischen den Systemen der Güterbereitstellung, der Güterverwendung und des Gütertransfers keinesfalls um ein starres, unabänderbares Fixum handelt. Vielmehr ist, bedingt durch Wachstum und insbesondere Strukturveränderungen, der logistische Bedarf einer Wirtschaft permanent Veränderungen unterworfen. ${ }^{20}$

Je nach Entwicklungsstand und Ausgestaltung der Transformationssysteme kann es zu Bedeutungsverschiebungen im Spektrum der Leistungen logistischer Systeme kommen. Hierbei gilt grundsätzlich, dass im Zuge zunehmender Weiterentwicklung von Volkswirtschaften Raumüberwindungsleistungen tendenziell an Bedeutung verlieren und Zeitausgleichs- sowie Ordnungsleistungen an Bedeutung gewinnen. Gleichermaßen stellen die Leistungen logistischer Systeme wichtige Bestimmungsfaktoren für Wachstum und Strukturwandel von Volkswirtschaften dar. ${ }^{21}$

Vgl. Ihde (2001), S. I, Pfohl (2004a), S. 8 f.

Vgl. Ihde (2001), S. 1.

Vgl. Pfohl (2004a), S. 5.

Ihde (2001), S. 1. Derselben Meinung ist auch Drechsler. Vgl. Drechsler (1988), S. 20.

Die begriffliche Abgrenzung zwischen den Termini „Verkehr“ und „Logistik“ und die sich daraus ergebenden Implikationen wird im folgenden Unterabschnitt geleistet.

Ewers (1973), S. 38.

Möhlmann (1984), S. 22.

Vgl. Ihde (2001), S. 2.

Vgl. Ihde (2001), S. 3. 
Dabei spielt der Transfersektor umso mehr die Rolle eines resultierenden Faktors, als die raum-zeitliche Struktur und Organisation von Produktion und Konsumtion von natürlichen Bestimmungsgrößen determiniert wird, die außerhalb des unmittelbaren Einflussbereichs des Transfersektors liegen (bspw. Rohstoffvorkommen oder Verfügbarkeit von qualifizierten Arbeitskräften). ${ }^{22}$ In dem Ausmaß jedoch, in dem es der Transfersektor schafft, seine Leistungsfähigkeit zu steigern, also die Bedingungen für die Überwindung räumlicher Entfernungen und zeitlicher Zerklüftungen zu verbessern, dominiert der Charakter des Transfersektors als bedingender Faktor von raumzeitlicher Strukturierung und Organisation der Gütertransformation. Die verbesserten Bedingungen für den Gütertransfer verändern dann ihrerseits das Erscheinungsbild von Produktions- und Konsumtionsprozessen. ${ }^{23}$ Die Güte logistischer Systeme ist mithin eine entscheidende Determinante für Gestalt und Fortentwicklung der Transformationssysteme und zeichnet damit mitverantwortlich für den Entwicklungsstand einer Volkswirtschaft.

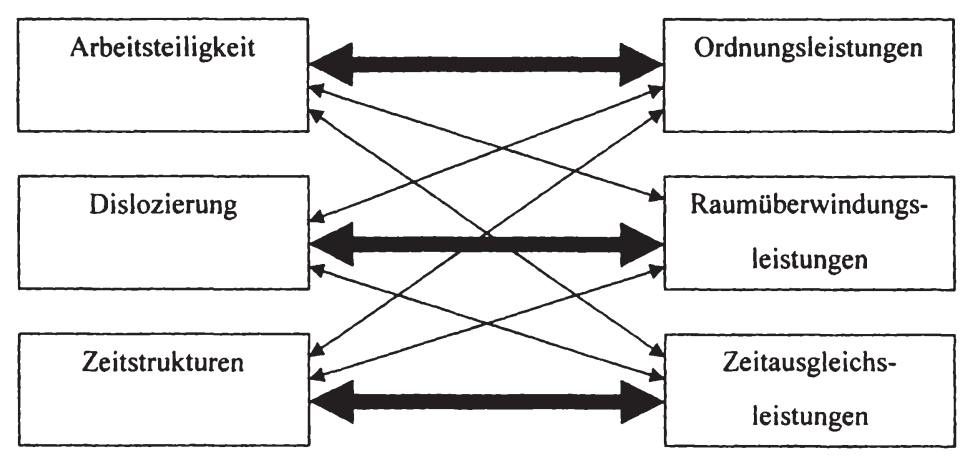

Abbildung 2-7: Bestimmungsfaktoren der Logistik

Quelle: Ihde (2001), S. 3

Damit korrespondiert auch die (überkommene, der Verf.) Versinnbildlichung des Verkehrssektors als „Diener der Wirtschaft“. Vgl. dazu auch Berkelova (1992), S. 17.

Vgl. Ihde (2001), S. 56. Auch Ewers und Möhlmann erkannten schon, dass die Güterverkehrsnachfrage nicht lediglich als abgeleitet aus den Bedürfnissen von Güterbereitstellung und Güterverwendung betrachtet werden kann, sondern dass durchaus „Rückkopplungen“ wie bspw. Anpassungsvorgänge in der Güterproduktion oder beim Güterkonsumverhalten möglich sind, die auf ökonomischen und/oder technischen Sachzwängen im Güterverkehrssystem beruhen. Vgl. Ewers (1973), S. 38 und Möhlmann (1984), S. 22. Diese Einsicht ist wegbereitend für die weiterführende Erkenntnis, dass das Güterverkehrssystem (später: das Logistiksystem) nicht nur beschränkend, sondern auch gestaltend und mithin bedingend auf Produktions- und Transformationsprozesse einwirken kann. 
Aus den bisherigen Ausführungen resultiert die schematische Darstellung wechselseitig abhängiger Determinanten für Logistiksysteme in Abbildung 2-7.

\subsubsection{Begriffsabgrenzungen: Transport, Verkehr, Logistik}

In der einschlägigen Fachliteratur werden die für diese Untersuchung konstituierenden Fachtermini „Transport“, „Verkehr" und „Logistik“ keinesfalls einheitlich verwendet. $^{24}$ Vielmehr werden diese Begriffe, die mit ihnen verbundenen Leistungsumfänge (Transport-, Verkehrs- und Logistikleistung) sowie die daraus hervorgehenden Branchen- und Marktbezeichnungen (Transport-, Verkehrs- und Logistikwirtschaft bzw. -markt) in äußerst unterschiedlichen Ausprägungen benutzt. ${ }^{25}$ Es scheint daher angezeigt, die Begriffe „Transport", „Verkehr“ und „Logistik“ zunächst gegeneinander abzugrenzen und deren Beziehung zueinander herauszuarbeiten. Auf Basis dieser Abgrenzung wird dann in den darauf folgenden Unterabschnitten versucht, ein grundsätzliches Verständnis für das Wesen und den Umfang der Logistikleistung als Grundlage für die Untersuchung des Logistikmarktes im Sinne dieser Arbeit zu entwickeln.

\subsection{Transport}

Wirtschaften dient zur Befriedigung von Bedürfnissen. Sämtliche Objekte, die in der Lage sind, Bedürfnisse zu befriedigen, werden als Güter bezeichnet. ${ }^{26}$ Alle Güter weisen spezifische sachliche, persönliche, räumliche und zeitliche Merkmale auf und

Vgl. Faller (1999), S. 80 f.

25 So analysiert Aberle bspw. unter dem Label „Transportwirtschaft“ neben dem Transport auch verkehrliche und logistische Zusammenhänge, vgl. Aberle (2003a). Pfohl benutzt den Begriff „Güterverkehrswirtschaft" zur Bezeichnung und Analyse der Institutionen, welche Logistikdienstleistungen als Primärleistungen erbringen unter dem Hinweis, dass „sich ein Begriff „Logistikwirtschaft" bisher nicht durchgesetzt hat, und man den Begriff Verkehrswirtschaft im Sinne einer Logistikwirtschaft gebraucht“. Pfohl (2004a), S. 291. Button benennt die „transport economics“ als Gegenstand seiner Analysen, wobei er feststellt, dass „transport economists are interested in the economic problems of moving goods and people..." Button (1993), S. 2. Allerdings thematisiert er dabei auch (zumindest) verkehrliche Fragestellungen wie bspw. die ökonomischen Wirkungen eines Hub-and-spoke-Netzwerkes. Vgl. Button (1993), S. 78 f. Deshalb werden im Folgenden auch Aussagen und Zusammenhänge für die Analyse von logistischen Fragestellungen berücksichtigt, die zwar von den betreffenden Autoren originär mit einer anderen Etikettierung (bspw. aus dem Themenbereich Transport oder (Güter-)Verkehr) versehen worden sind, aber letzten Endes Logistik meinen und der Analyse und dem Verständnis logistischer Fragestellungen dienlich sind bzw. auf deren Analyse übertragbar sind. 
können durch diese vollständig beschrieben werden. ${ }^{27}$ Prozesse, welche die räumlichen Merkmale eines Gutes verändern, sind Transportleistungen. ${ }^{28}$ Durch Transporte erfahren Güter eine physische Ortsveränderung, ihre Raumkoordinaten werden verändert. ${ }^{29}$ In die gleiche Richtung geht die Definition von HERCHENHEIN, die den Vorgang des Beförderns als Synonym für den Transportbegriff begreift und diesen als die Überwindung der räumlichen Distanz zwischen zwei Orten innerhalb der Transportkette betrachtet. ${ }^{30}$ Auch PREDÖHL spricht vom Transport „als Beförderung als solcher, also dem Transport im engeren Sinne" ". ${ }^{31}$ Obwohl es in der Realität nahezu ausgeschlossen ist, allein ein einzelnes Merkmal eines Gutes (hier: das räumliche Merkmal) zu verändern, ohne dabei gleichzeitig weitere Merkmale zu tangieren (bspw. die mit der Raumüberwindung unabdingbar notwendige zeitliche Manipulation des Gutes in Form eines Lagerungsprozesses oder die unabwendbare stoffliche Manipulation des Gutes in Form von Reife- oder Verderbnisprozessen während des Transportes), abstrahiert der Transportbegriff weitestgehend von stofflichen und zeitlichen Veränderungen des Gutes während des Transportvorganges. Insofern handelt es sich bei der Transportleistung lediglich um den technisch-organisatorischen Leistungsprozess der physischen Raumüberwindung von Gütern. ${ }^{32}$ Folglich stellt der Transportprozess eine anonyme, austauschbare Leistung dar.

\subsection{Verkehr}

Der Verkehrsbegriff unterscheidet sich vom Transportbegriff dadurch, dass er neben der Ortsveränderung zusätzlich zeitliche Aspekte beinhaltet. Aufgrund der Tatsache, dass die reinen Raumüberwindungsbedarfe in komplexe Strukturen von Produktion und Konsumtion eingebettet sind, sind die Transportleistungen i. d. R. von exakten Vorgaben bezüglich ihrer zeitlichen Rahmenbedingungen gekennzeichnet. Weichen Transportvorgänge von diesen zeitlichen Vorgaben ab, so reduziert sich ihr Nutzen für den Auftraggeber des Transports signifikant, weil die Güte der Durchführung von Produktions- und Konsumtionsprozessen an die räumlich und zeitlich exakt abgestimmte Zusammenführung der Einsatzfaktoren geknüpft ist. ${ }^{33}$ Der Verkehrsbegriff ist wesentlich umfangreicher als der Transportbegriff und umfasst neben der Raumüber-

\footnotetext{
Vgl. Herdzina (2005), S. 154.

Vgl. Ihde (2001), S. 3.

Vgl. Ihde (2001), S. 4 f.

Vgl. Herchenhein (2003), S. 47.

Predöhl (1964), S. 12.

Vgl. Ihde (2001). S. 5.
} 
windung auch die Einhaltung dieser zeitlichen Rahmenbedingungen. ${ }^{34}$ Insofern handelt es sich bei der Verkehrsleistung um ein im Vergleich zur Transportleistung komplexeres und individualisiertes Gut, da die zusätzlichen Leistungskomponenten stets im Kontext zu den konkreten Leistungsanforderungen der Nachfrager hinsichtlich individueller Bedarfsadäquanz der Gütertransferleistungen stehen. ${ }^{35}$ Schon PREDÖHL bezeichnet den Verkehr als „die Gesamtheit der Vorgänge, die im Bereiche der Wirtschaft der Raumüberwindung dienen. (...) Wir beschränken uns aber nicht auf den Transport als solchen, sondern rechnen zum Verkehr auch die kommerziellen Funktionen, die mit dem Transport verbunden sind (....). ${ }^{\star 36}$ ILLETSCHKO identifiziert neben der Beförderungsfunktion die Abfertigungsfunktion, die Wegsicherungsfunktion und diverse Hilfsfunktionen (wie bspw. die Lagerung und die Versicherung von Transportgütern) als Verkehrsleistungsfunktionen. ${ }^{37}$ OETTLE führt neben den bereits genannten zusätzlich die Weg-, die Fahrzeug- und die Stationsbereithaltungsfunktion an. ${ }^{38}$ Verkehrliche Zusatzfunktionen können demnach der eigentlichen Transportleistung vorgeschaltet sein, sie begleiten oder an sie anschließen.

\subsection{Logistik}

\section{Historische Entwicklung des Logistikbegriffs}

Der Begriff der Logistik lässt sich im Wesentlichen aus zwei etymologischen Richtungen herleiten: zum einen handelt es sich dabei um den griechischen Wortstamm ,lego' bzw. ,logos' (denken; Wort, Verstand, Vernunft, Rechnung) und zum anderen um den germanisch-französischen Wortstamm ,loger' bzw. ,logis' (unterbringen; Quartier, Unterkunft). ${ }^{39}$ Seinen historischen Ursprung hat die Logistik in der militärischen Begriffswelt und geht bis auf den byzantinischen Kaiser LEONTOS VI. (886 bis $911 \mathrm{n}$. Chr.) zurück. In seinem Werk „Summarische Auseinandersetzung der Kriegskunst" beschreibt er die Logistik neben der Strategie und der Taktik als dritte Kriegswissenschaft und sieht ihre Aufgabe in der umfassenden Unterstützung des

Vgl. Ihde (2001), S. 6.

Vgl. Kloster (2002), S. 36.

Vgl. Ihde (2001), S. $10 \mathrm{f}$.

Predöhl (1964), S. $11 \mathrm{f}$.

Vgl. Illetschko (1966), S. 5 ff.

Vgl. Oettle (1976), Sp. $4150 \mathrm{f}$.

Vgl. Dehler (2001), S. 9; Weber, Kummer (1998), S. 1; Ihde (2001), S. 22. 
Heeres. ${ }^{40}$ Der Begriff der militärischen Logistik wurde im 19. Jahrhundert von dem Schweizer Militärschriftsteller ANTOINE-HENRY BARON DE JOMINI dazu benutzt, um den Aufgabenbereich der von ihm geschaffenen Position eines ,maréchal de logis' (zu deutsch: eines Quartiermeisters) im Krieg zu umreißen. ${ }^{41}$ Demnach umfasst die (Militär-)Logistik alle Aufgaben, die zur Unterstützung der Streitkräfte dienen (bspw. den Transport, die Quartierung und die Versorgung der Truppen sowie den Transport, die Lagerung und die Wartung militärischer Güter). ${ }^{42}$ Nach Ende des zweiten Weltkrieges wurden zunächst in den USA die im Militärbereich gewonnenen Logistikerkenntnisse für die Lösung wirtschaftlicher Fragestellungen nutzbar gemacht und haben so Eingang in die ökonomische Fachliteratur gefunden.$^{43}$ In diesem Zusammenhang ist insbesondere MORGENSTERN zu nennen, der wohl als erster Fachvertreter den Versuch unternahm, systematisch die Ähnlichkeit zwischen "military logistics“ und „logistical problems in business" zu ergründen. ${ }^{44}$ Erst Ende der 60er bis Anfang der 70er Jahre des vergangenen Jahrhunderts wurde die Logistik auch in Deutschland zum eigenständigen Fachbereich im Theoriegebäude der Betriebswirtschaftslehre erhoben ${ }^{45}$ Seitdem hat die Logistik eine verhältnismäßig kurze, aber dafür sehr intensive Entwicklungsgeschichte durchlaufen. ${ }^{46}$ Dieser Prozess der ökonomischen Entwicklung des Logistikbegriffs und damit verbunden auch des Selbstverständnisses der Logistik wiederum wird in der einschlägigen ökonomischen Literatur üblicherweise zu einer Aufeinanderfolge einzelner Entwicklungsphasen bzw. Entwicklungsstufen verdichtet. Stellvertretend für die zahlreichen vorgetragenen Phasenschemata, welche zwar von Autor zu Autor oft unterschiedliche Systematisierungsmuster, variable zeitliche Datierungen und charakteristische Bezeichnungen pflegen, sich inhaltlich - bezogen auf die Entwicklung des organisatorischen Integrationsgrades bzw. Betrachtungsfokus ${ }^{47}$ - im Kern jedoch selten widersprechen, wird hier der Ansatz von BAUMGARTEN dargestellt. Er identifiziert folgende Entwicklungsphasen der Logistik: ${ }^{48}$

Vgl. Dehler (2001), S. 10; Mikus (2003), S. 5; Weber, Kummer (1998), S. 2.

Vgl. Mikus (2003), S. 5.

Vgl. Dehler (2001), S. 10; Pfohl (2004a), S. 11; Ihde (2001), S. 23 f.; Kirsch et al. (1973), S. 8.

Vgl. Kirsch et al. (1973), S. 8; Isermann (1994), S. 21.

Vgl. Morgenstern (1955).

Vgl. Dehler (2001), S. 10; Mikus (2003), S. 5; Klaus (1999), S. 16.

Vgl. Klaus (1999), S. 16.

Vgl. Engelsleben, Niebuer (1997), S. 9.

$\mathrm{Vgl}$. für das Folgende Baumgarten (2001), S. $9 \mathrm{ff}$. 
- Klassische Logistik (1960er - 1970er Jahre): In dieser frühen Phase war die Logistik noch zumeist dem Diktat der vorwiegend funktionalen Unternehmensorganisation unterworfen. Sie hatte zwar schon damals als eigenständiger Unternehmensbereich die Intention, mittels der Zusammenfassung von materialund warenflussbezogenen Tätigkeiten wie Transport-, Umschlag- und Lagerprozessen Spezialisierungsvorteile auszunutzen und die Verfügbarkeit von Materialien und Waren innerhalb des physischen unternehmensinternen Produktionsprozesses sicherzustellen. Die logistischen Optimierungsbemühungen blieben jedoch aufgrund der funktionalen Fokussierung der Gesamtunternehmung auf die abgegrenzten Unternehmensfunktionen beschränkt. Es handelte es sich bei dieser Form der logistischen Optimierung somit lediglich um eine beschränkt effiziente Abfolge von Teiloptimierungen und war bezogen auf die Gesamtunternehmung suboptimal.

- Logistik als Querschnittsfunktion (1980er Jahre): In dieser Phase vollzog sich ein grundlegender Wandel. Das funktionenorientierte Logistikverständnis wurde zugunsten einer prozessorientierten logistischen Betrachtungsweise zurückgedrängt. Auf Basis einer nunmehr prozessual ausgerichteten logistischen Optimierungsstrategie wurden die erkanntermaßen effektivitäts- und effizienzmindernden Schnittstellen zwischen den Unternehmensfunktionen Beschaffung, Produktion und Vertrieb auf den Prüfstand gestellt. Mittels der integrierten Betrachtung vormals voneinander unabhängig geplanter und gesteuerter Funktionen konnte die Logistik ihre logistischen Leistungen gesamthaft optimieren und vermochte dadurch, die innerhalb des funktionsübergreifenden Leistungserstellungsprozesses zwangsläufig anfallenden Schnittstellen effizienter zu überwinden.

- Logistik integriert Funktionen zu Prozessketten (1990er Jahre): Infolge ihrer immer stärkeren prozessualen Ausrichtung bekam die Logistik immer mehr den Charakter einer unternehmensweiten Koordinationsfunktion. In dieser Eigenschaft forcierte die Logistik die funktionale Integration und gliederte die Bereiche Entwicklung und Entsorgung zusätzlich zu den Hauptprozessen Beschaffung, Produktion und Distribution in den Prozess der Planung und Koordination von Material-, Güter- und nun auch in zunehmendem Maße Informationsströmen ein. Die ganzheitliche Betrachtung des unternehmensweiten Leistungserstellungsprozesses sowie der von der Logistik initiierte Abbau von Informationsdefiziten innerhalb der Prozesskette befähigt die Logistik dazu, die gesamte Prozesskette bereichsübergreifend zu optimieren. Diesem Prozessgedanken ent- 
sprechend wird das Unternehmen nicht mehr als Abfolge von Teilfunktionen begriffen, sondern als ganzheitliches System untereinander vernetzter Prozessketten.

- Logistik integriert Unternehmen zu Wertschöpfungsketten (1990er 2000er Jahre): Obwohl mit der Gesamtoptimierung unternehmensweiter Prozessketten gegenüber der Summe der funktionsbezogenen Teiloptimierungen entscheidende Fortschritte durch die Koordinationsfunktion der Logistik erzielt werden konnten, handelte es sich dabei letzten Endes jedoch wieder nur um eine „Inseloptimierung“ - wenngleich natürlich auf deutlich höherem Niveau. Die Konzentration auf die Optimierung unternehmensweiter Prozesse ist nämlich wieder suboptimal bezogen auf die gesamte Wertschöpfungskette, an welcher regelmäßig mehrere Unternehmen partnerschaftlich mitwirken. Optimiert jeder Partner lediglich seine eigenen Prozessketten, so hat dies unter Umständen zusätzliche Kosten und Leistungsverschlechterung für die gesamte Wertschöpfungskette zur Folge, weil unternehmensübergreifende kosten- und leistungsmäßige Wirkungsinterdependenzen unberücksichtigt bleiben. ${ }^{49}$ Vordringlichste Aufgabe für die Logistik war es folglich, die unternehmensübergreifende Optimierung der gesamten Wertschöpfungskette zu koordinieren. Die Beherrschung umfassender Wertschöpfungsketten bildet bis heute eine große Herausforderung für die Logistik, da sowohl Komplexität als auch geographische Ausdehnung der Wertschöpfungssysteme ständig zunehmen und es daher gilt, Suboptimalitäten in diesen Systemen mittels einer möglichst gesamthaften logistischen Koordination aufzuspüren und zu beseitigen.

Die Jahreszahlen, welche den einzelnen Entwicklungsphasen zugeordnet sind, mögen nun zu dem Schluss verleiten, dass sich die Phasen inhaltlich wie chronologisch trennscharf abgrenzen lassen, dass sie sukzessive aufeinander folgen und der Beginn einer weiterentwickelten „neuen“ Phase gleichzeitig das Ende der „,alten“ Vorgängerphase markiert. Empirisch jedoch ist vielmehr zu beobachten, dass sich die deutschen Produzenten zur selben Zeit auf höchst unterschiedlichen logistischen Entwicklungsniveaus befinden und ihr logistisches Entwicklungsziel noch lange nicht erreicht haben. Dies geht aus folgender Abbildung 2-8 hervor. Sie baut auf den vier Entwicklungsphasen von WEBER ET AL. auf ${ }^{50}$, welche aber hinsichtlich Chronologie und 
inhaltlicher Ausgestaltung weitestgehend mit den Phasen bei BAUMGARTEN vergleichbar sind. Stufe 1 entspricht dabei der niedrigsten Rangstufe logistischer Entwicklung („Klassische Logistik“), Stufe 4 der höchsten („Logistik integriert Unternehmen zu Wertschöpfungsketten").

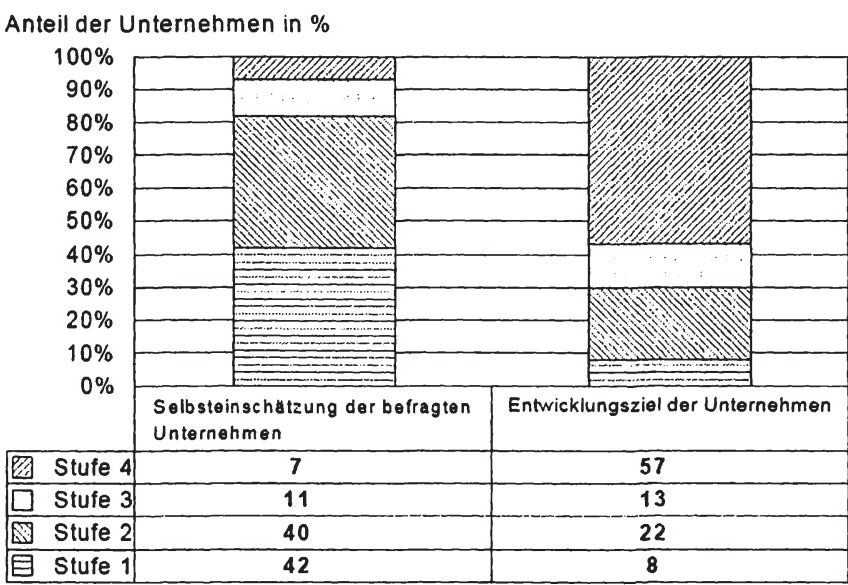

\begin{tabular}{|ll|}
\hline 0 & Stufe 4 \\
\hline$\square$ & Stufe 3 \\
\hline S & Stufe 2 \\
\hline & Stufe 1 \\
\hline
\end{tabular}

Abbildung 2-8: Tatsächlicher und gewünschter Entwicklungsstand der Logistik in deutschen Unternehmen

Quelle: in Anlehnung an Weber et al. (2002), S. 28

Vor dem Hintergrund der Evolution des Logistikbegriffs in Militär und Ökonomik sowie damit einhergehend der Entwicklung des Selbstverständnisses des Feldes der Logistik, werden nun die zentralen Wesensmerkmale des aktuellen ökonomischen Logistikbegriffs herausgearbeitet.

\section{Zum aktuellen ökonomischen Logistikbegriff}

Wenn man zunächst die Begriffe Transport und Verkehr reflektiert, und sich nochmals vergegenwärtigt, dass die Verkehrsleistung aus der Transportleistung hervorgeht und hierbei neben der Überwindung räumlicher Disparitäten zusätzlich zeitliche Disparitä- 
ten zu beherrschen hat, so gilt es nun, die Logistik bzw. die Logistikleistung begrifflich in diese Systematik einzupassen. Dabei gilt grundsätzlich, dass die Logistikleistung nicht lediglich durch einen im Vergleich zur Verkehrsleistung nochmals erweiterten Leistungsumfang beschrieben werden kann. Vielmehr ist die Logistikleistung zusätzlich durch eine veränderte Betrachtungsweise gekennzeichnet. ${ }^{51}$ Was die konkrete Definition des Logistikbegriffs anbelangt, so hat sich in der einschlägigen Fachliteratur bislang keine übereinstimmende Festlegung durchgesetzt. ${ }^{52}$ Deshalb seien an dieser Stelle stellvertretend für die zahlreichen unterschiedlichen Definitionen in Tabelle 2-1 folgende Definitionsansätze synoptisch dargestellt, welche versuchen, das weite Spektrum an Interpretationen zum Ausdruck bringen, die sich hinter dem Logistikbegriff verbergen.

\begin{tabular}{|l|l|}
\hline \multicolumn{1}{|c|}{ Autor } & \multicolumn{1}{|c|}{ Definition } \\
\hline Kirsch et al. (1973), S. 69 & $\begin{array}{l}\text { Verwendet man den Begriff Logistik zur Bezeichnung } \\
\text { realer Phänomene und nicht als Name einer entspre- } \\
\text { chenden wissenschaftlichen (Teil-)Disziplin, so } \\
\text { bezieht sich dieser Begriff auf die Gestaltung, } \\
\text { Steuerung, Regelung und Durchführung des gesamten } \\
\text { Flusses an Energie, Informationen, Personen, } \\
\text { insbesondere jedoch von Stoffen (Materie, Produkte) } \\
\text { innerhalb und zwischen Systemen. }\end{array}$ \\
\hline Stabenau (1994), S. 17 & $\begin{array}{l}\text { Logistik [ist zu verstehen als ein] zu gestaltendes } \\
\text { integriertes FlieBsystem von Waren und Materialien } \\
\text { von den Beschaffungsmärkten über die Produktions- } \\
\text { stätten bis hin zum Nutzer oder Verbraucher der } \\
\text { Fertigprodukte über den Distributionsprozess. }\end{array}$ \\
\hline Pfohl (2004a), S. 12 & $\begin{array}{l}\text { Zur Logistik gehören alle Tätigkeiten, durch die die } \\
\text { raum-zeitliche Gütertransformation und die damit } \\
\text { zusammenhängenden Transformationen hinsichtlich } \\
\text { der Gütermengen und -sorten, der Güterhandhabungs- } \\
\text { eigenschaften sowie der logistischen Determiniertheit } \\
\text { der Güter geplant, gesteuert, realisiert oder kontrolliert } \\
\text { werden. Durch das Zusammenwirken dieser Tätigkei- } \\
\text { ten soll ein Güterfluss in Gang gesetzt werden, der } \\
\text { einen Lieferpunkt mit einem Empfangspunkt mög- } \\
\text { lichst effizient verbindet. }\end{array}$ \\
\hline
\end{tabular}




\begin{tabular}{|l|l|}
\hline $\begin{array}{l}\text { CLM (Council of } \\
\text { Logistics Management) } \\
\text { (2004) }\end{array}$ & $\begin{array}{l}\text { Logistics Management is that part of Supply Chain } \\
\text { Management that plans, implements, and controls the } \\
\text { efficient, effective forward and reverse flow and } \\
\text { storage of goods, services and related information } \\
\text { between the point of origin and the point of consump- } \\
\text { tion in order to meet customers' requirements. }\end{array}$ \\
\hline Bretzke (2000), S. 314 & $\begin{array}{l}\text { Logistik kann verstanden werden als Koordination } \\
\text { sämtlicher Aktivitäten, die den Fluss von Transakti- } \\
\text { onsobjekten zwischen definierten Herkunftsorten und } \\
\text { definierten Zielorten eines Systems beeinflussen und } \\
\text { unter (teilweise konfliktären) Kosten- und Serviceas- } \\
\text { pekten auf einen bestimmten Bedarf ausrichten. }\end{array}$ \\
\hline Ihde (2001), S. 13 & $\begin{array}{l}\text { Logistische Problemlösungen sind spezifische, } \\
\text { vergängliche und virtuelle oder nachhaltige und } \\
\text { institutionalisierte Funktionsbündel. Dabei umfassen } \\
\text { diese Funktionsbündel stets physische Manipulationen } \\
\text { von Gütern, und zwar in Bezug auf deren art- und } \\
\text { mengenmäßige, räumliche und zeitliche Merkmale. }\end{array}$ \\
\hline Göpfert (2000), S. 19 & $\begin{array}{l}\text { Die Logistik ist ein spezieller Führungsansatz zur } \\
\text { Entwicklung, Gestaltung, Lenkung und Realisation } \\
\text { effektiver und effizienter Flüsse von Objekten (Güter, } \\
\text { Informationen, Gelder, Personen) in unternehmens- } \\
\text { weiten und -übergreifenden Wertschöpfungssyste- } \\
\text { men. }\end{array}$ \\
\hline
\end{tabular}

Tabelle 2-1: Logistikdefinitionen

Quelle: Eigene Darstellung

Die genannten Definitionsansätze lassen erkennen, dass zahlreiche Unterschiede, aber auch Gemeinsamkeiten hinsichtlich möglicher Interpretationen des Inhalts- und Aufgabenbereiches der Logistik existieren. Unterschiede in den Definitionen ergeben sich dabei hauptsächlich bei der Festlegung der konkreten inhaltlichen Reichweite des Objektbereiches der Logistik ${ }^{53}$ und bei der Frage, ob die Logistik im Bereich des Unternehmensführungssystems oder im Bereich des Ausführungssystems anzusiedeln

53 Vgl. hierzu auch Unterabschnitt 2.2.3.1.2, in welchem der Versuch unternommen wird, die verschiedenen denkbaren Logistikleistungen mit unterschiedlicher inhaltlicher Reichweite strukturieren. 
ist. $^{54}$ Allgemeiner Konsens scheint jedoch zumindest dahingehend $\mathrm{zu}$ bestehen, dass die Logistik in jedem Falle die Überwindung und Beherrschung von räumlichen, zeitlichen sowie von physischen Disparitäten und Friktionen zum Gegenstand hat, welche die erforderlichen Transferprozesse von Gütern innerhalb und zwischen Unternehmen systembedingt nach sich ziehen. ${ }^{55}$ Will man Logistik in dieser Form betrachten, so werden folgende Sachverhalte deutlich:

- Logistik stellt ein Phänomen dar, das aus einer gesamthaften Perspektive zu betrachten ist. Bei der Implementierung und Optimierung logistischer Strukturen steht stets das gesamte System, das flussorientierte Ineinandergreifen aller beteiligten Bereiche im Vordergrund. ${ }^{56}$ Die isolierte Gestaltung und Optimierung einzelner logistischer Teilprozesse (wie bspw. Transport-, Lager- oder Umschlagleistungen) wäre insofern suboptimal bezogen auf die gesamte Prozesskette, da dann wichtige Wirkungszusammenhänge unberücksichtigt blieben. ${ }^{57}$ Es ist deshalb unabdingbar notwendig, sich der dynamischen Wechselwirkungen zwischen dem Transfer- bzw. Logistiksystem und den vor- bzw. nachgelagerten Produktions- und Konsumtionsprozessen gewahr zu sein. Diese Wechselwirkungen implizieren nämlich, dass der Logistiksektor nicht lediglich den Restbedarf an raum-zeitlicher Überbrückung befriedigt, der von festen, unabänderlichen Produktions- und Konsumtionsprozessen ausgeht. Vielmehr ergeben sich durch die Leistungsbedingungen und die Leistungsfähigkeit des Logistiksektors auch Rückwirkungen, die den raum-zeitlichen Überbrückungsbedarf, aber auch die inhaltliche Ausgestaltung von Produktions- und Konsumptionsprozessen verändern. ${ }^{58}$

Vgl. Dehler (2001), S. 12.

Die Erweiterung der Logistikperspektive über die Unternehmensgrenzen hinaus hat auch zur Folge, dass die ausschließliche Zuordnung der Logistik zur Betriebswirtschaftlehre nicht korrekt ist. Vielmehr wird durch das Einbeziehen logistischer Sachverhalte gleichermaßen das Erkenntnisobjekt der traditionell volkswirtschaftlichen Verkehrsökonomik und der Verkehrspolitik erweitert. Vgl. dazu auch Drechsler (1988), S. 19. Aberle erkennt in der Logistik einen wesentlichen Treiber für die Veränderung des Angebotsportfolios auf den Güterverkehrsmärkten. Vgl. Aberle (2003a), S. 503.

Vgl. Heiserich (2002), S. 8; Stabenau (1994), S. 17. Auch Aberle weist auf die „ganzheitlich Betrachtungsweise aller Faktoren-, Güter- und Stoffverwertungsströme" als Charakteristikum der Logistik hin. Aberle (2003a), S. 503.

Vgl. Zöllner (1990), S. 6.

Vgl. Ihde (2001), S. 13 ff. Diesen Zusammenhang erkannte auch Predöhl, der folgendes festhält: „Der Transport schiebt sich in alle Stadien des Produktionsprozesses bis zur Bereitstellung der konsumreifen Produkte ein, (...). Dabei unterliegt die Bestimmung der Methode des Verkehrs 
- Diese angesprochenen Wechselwirkungen zwischen Gütertransfer und Gütertransformation, die Tatsache also, dass Transfer- und Transformationsprozesse fließend ineinander übergehen können, macht es erforderlich, die Perspektive der logistischen Analyse über bloße Transport-, Umschlag- und Lagerprozesse hinaus auf Güterflusssysteme auszuweiten. ${ }^{59}$ Güterflusssysteme sind aus logistischem Blickwinkel betrachtete unternehmensübergreifende Wertschöpfungssysteme. Sie sind durch ineinander greifende sequenziell und/oder parallel ablaufende Transformations- und Transferprozesse gekennzeichnet, welche „Güterströme art- und mengenmäßig, räumlich und zeitlich verändern, genauer: zielgerichtet entwickeln. ${ }^{\text {(660 }}$

Auch DelFmanN gelangt zu dieser Ansicht und betrachtet die Logistik konzeptionell als einen spezifisch systemischen Ansatz. ${ }^{61}$ Er identifiziert im Rahmen seines Ansatzes mit dem Netzwerkmodell und der Flussperspektive zwei theoretische Anknüpfungspunkte zu Analyse und Design logistischer Systeme. DELFMANN zur Folge ist das wesentliche Charakteristikum der systemischen Logistikkonzeption, „die Prozessabläufe in arbeitsteiligen Wirtschaftssystemen als Flüsse von Objekten in Netzwerken zu interpretieren."62

Zusammenfassend betrachtet haben sich aus der Analyse des Logistikbegriffes drei wesentliche Prinzipien bzw. Konzeptmerkmale herausgebildet, die für die Charakterisierung der Logistik bedeutsam sind und die im Folgenden noch eine Rolle spielen werden:

- Die gesamthafte, systemische Perspektive logistischer Betrachtung,

- das Denken in Netzen sowie

den gleichen Prinzipien wie die Wahl der Produktionsmethode überhaupt, ja auch die Frage, in welchem Umfang Transport für Produktion im engeren Sinne oder Produktion im engeren Sinne für Transport substituiert wird. Ob, in welchem Umfange und in welcher Art Verkehrsakte innerhalb des Produktionsprozesses stattfinden, ist eine Frage der ökonomischen Kalkulation bei gegebenen technischen Koeffizienten von Verkehr und Produktion, also nichts anderes als die Wahl der ökonomisch besten Produktionsmethode im weitesten Sinne unter verschiedenen technischen Möglichkeiten.“. Predöhl (1964), S. 12.

Vgl. Ihde (2001), S. 15.

Ihde (2001), S. 15.

Vgl. Delfmann (2000a), S. 322.

Delfmann (2000a), S. 323. 
- die (Güter-)Flussorientierung ${ }^{63}$.

\subsection{Verknüpfung von Transport, Verkehr und Logistik}

Aus dem bislang in Unterabschnitt 2.2.2.2 Gesagten erhellt, dass Transportvorgänge als eine Untermenge von Verkehrsvorgängen betrachtet werden können und Verkehr als eine echte Untermenge von Logistikprozessen (vgl. Abbildung 2-9).

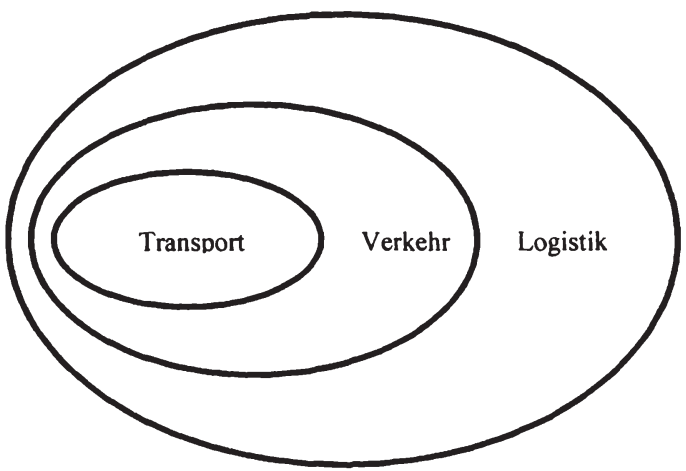

\section{Abbildung 2-9: Logische Verknüpfung der Problembereiche Trans- port/Verkehr/Logistik}

Quelle: Ihde (2001), S. XV

Zur (Güter-)Flussorientierung siehe auch ausführlich das Werk von Klaus, der die Logistik als Wissenschaft vom „Flow Management" kennzeichnet und ihr in diesem Zusammenhang die Aufgabe überträgt, die Wertschöpfung mittels der Optimierung der Güterflüsse zu maximieren. Für Rümenapp stellt die „flussorientierte Netzwerkperspektive“ eine Art gemeinsames Ergebnis der Kritik der unterschiedlichen Interpretationen der Logistikkonzeption dar. Vgl. Rümenapp (2002), S. 12. Die Durchsetzung der Flussorientierung in einem ökonomischen Umfeld, das Unternehmen und die Wirtschaft in ihrer Gesamtheit als „vielschichtiges Netzwerk von Flüssen“ interpretiert, bildet den Schlüssel zum Unternehmenserfolg. Vgl. Klaus (1999), S. 28 ff.; Klaus (2000a), S. 336. Auch nach Weber und Kummer ist es das primäre Ziel der Logistik, ,das Unternehmen als Ganzes flussorientiert auszugestalten". Weber, Kummer (1998), S. 22; Weber, J. (1999), S. 12. Die Fliesssystemorientierung wird in diesem Zusammenhang als dritte und - vorerst - letzte Entwicklungsphase der Logistik betrachtet. Vgl. Weber, J. (1999), S. 11 ff. Sogar von einer neuen „Weltsicht" ist die Rede, wonach die Fliesssystemorientierung der Logistik einen Paradigmenwechsel in der Betriebswirtschaftslehre begründet. Vgl. Klaus (1999), S. 16. Dem muss stark relativierend entgegengehalten werden, dass die Fliesssystemperspektive schon von Beginn an ein wesentliches Merkmal der Logistik gewesen ist. Vgl. dazu bspw. Kirsch et al. (1973), S. 282 ff.; Ihde (1972). 
Gegenstand von Transportvorgängen ist die physische Raumüberwindung von Gütern mit dem Ziel, die räumlichen Merkmale der Transportgüter zu verändern. Der Verkehrsvorgang dient ebenfalls der physischen Raumüberwindung von Gütern, fügt diese Raumüberwindungsleistung jedoch in die kundenindividuellen Bedürfnisstrukturen bezüglich ihrer zeitlichen Einbettung in die komplexen Leistungserstellungsstrukturen der Verkehrsleistungsnachfrager ein. Neben räumlichen Merkmalen werden also zusätzlich zeitliche Merkmale verändert. Aus der Verkehrsleistung geht die Logistikleistung zunächst durch einen nochmals erweiterten Leistungsumfang hervor. Das konstituierende Merkmal jedoch, welches die Logistikleistung über die Verkehrsleistung erhebt, ist die der Logistik eigene, modifizierte Betrachtungsweise: Logistik zeichnet sich durch eine gesamthafte, systemische, netzwerkorientierte, flussorientierte Sicht auf Güterströme aus.

\subsubsection{Systeme der Logistik}

\subsection{Systemtheoretische Grundlagen der Logistik}

Im vorangegangenen Unterabschnitt wurde die systemische Perspektive respektive die Notwendigkeit einer gesamthaften Betrachtung der Wirkungszusammenhänge innerhalb von Güterflusssystemen als wesentliches Konzeptmerkmal logistischer Überlegungen hervorgehoben. Insofern stellt die Systemtheorie einen zweckdienlichen theoretischen Denkrahmen für die Logistik dar. ${ }^{64}$ BOWERSOX und CLOSS führen diesbezüglich aus, dass „four factors are common to all logistical reengineering initiatives. First, the objective is to increase integration of some or all aspects of the activities under review. The analytical foundations for integration draw on principles of systems analysis..." ${ }^{65}$ Sie führen weiterhin aus, dass „when evaluated from a systems viewpoint, integrated logistics identifies a need for compromise between and among functional areas..."66 und thematisieren damit auch die zentrale Funktion der Logistik, (logistische ) Schnittstellenprobleme an einzelnen (logistischen) Systemgrenzen im Sinne einer Optimierung des gesamten Güterflusssystems auf der Grundlage

Vgl. Stabenau (2000), S. 130; Milling, Dengel (2003), S. 134; Aberle (2003a), S. 505. Dies gilt umso mehr, als der Ausdruck Logistik nicht selten für die Erklärung und Darstellung von Logistiksystemen benutzt wird. Vgl. Mikus (2003), S. 24. Auch für Freichel stellen die Systemtheorie bzw. das Systemdenken und das damit einhergehende Netzwerkdenken den Ausgangspunkt der Logistikkonzeption dar. Vgl. Freichel (1992), S. 8 und S. 8, Fn. 6.

65 Bowersox, Closs (1996), S. $458 \mathrm{f}$.

66 Bowersox, Closs (1996), S. 459.
} 
des Systemdenkens zu überwinden. ${ }^{67}$ Schnittstellen können dabei grundsätzlich als Systemgrenzen interpretiert werden. ${ }^{68}$

Allgemein kann aus systemtheoretischer Sicht ein System als „eine Menge irgendwelcher Elemente (Teile, Komponenten), zwischen denen Beziehungen bestehen “ betrachtet werden. ${ }^{69,}{ }^{70}$ Als Elemente logistischer Systeme können sämtliche Institutionen, Personen und sonstige Einrichtungen bezeichnet werden, welche als Ausgangsoder Endpunkt an Transferprozessen beteiligt sind. ${ }^{71}$ Besagte Beziehungen werden durch eben diese Transferprozesse dargestellt, durch Prozesse also, welche räumliche, zeitliche und physische Disparitäten und Friktionen zwischen den Elementen überwinden und beherrschen sollen. ${ }^{72}$

Im Rahmen systemtheoretischer Überlegungen und Analysen können Logistiksysteme je nach Umfang des Bezugssystems in eine hierarchische Struktur gebracht werden. ${ }^{73}$ Hierbei sind Systeme höherer Ordnung (Supersysteme) und Systeme niedererer Ordnung (Subsysteme) zu unterscheiden, wobei Elemente eines Supersystems über die hierarchische Verknüpfung wiederum als eigenständige (Sub-)Systeme auf einer niedereren Hierarchiestufe angesehen werden können. Wenn man das Wirtschafts- und Gesellschaftssystem als Supersystem begreift, dann kann das Logistiksystem bzw. Transfersystem im Systemverbund der Gütertransformation neben den elementaren Transformationssystemen der Güterbereitstellung und der Güterverwendung als Subsystem dieses Supersystems verstanden werden. ${ }^{74}$ Das Logistiksystem lässt sich nun anhand diverser Kriterien weiter in Subsysteme aufgliedern. ${ }^{75}$ Dies ist auch notwendig, da sich das als gesamtwirtschaftliches Transfersystem gekennzeichnete Logistiksystem als Ganzes aufgrund seiner mangelnden Transparenz und seiner

67

68

69

70

Vgl. Pfohl (2004a), S. 308.

Vgl. Pfohl (2004a), S. 308.

Vgl. Kirsch et al. (1973), S. 41.

Der systemorientierte Ansatz ist dabei zwischen dem individualistischen Ansatz und dem holistischen Ansatz positioniert. Ersterer richtet den Fokus auf das Individuum und auf dessen losgelöste Einzelentscheidungen unter weitgehendem Verzicht auf die Einbindung des Individuums in einen größeren Gesamtzusammenhang. Letzterer postuliert, dass „das Verständnis des Ganzen nur durch eine Betrachtung der Gesamtheit der Elemente möglich ist und eine Zergliederung in Einzelkomponenten das Verständnis nicht fördert". Rümenapp (2002), S. 14. Im Falle der Logistik erweist sich das Denken in Systemelementen und das Erkennen von deren Beziehungen untereinander als sowohl der isolierten Betrachtung einzelner Elemente als auch der Betrachtung eines unzergliederten Ganzen als überlegen. Vgl. Pfohl (2004a), S. 25 ff.

Vgl. Delfmann (2000a), S. 323; Mikus (2003), S. 24 f.

Vgl. Delfmann (2000a), S. 323.

Vgl. Drechsler (1988), S. 21.

Vgl. Ihde (2001), S. 1. 
Systemkomplexität jeder wissenschaftlichen Analyse und Bewertung entzieht. Das für die Analyse jeweils adäquate Auflösungsniveau der Systemhierarchien und das zu benutzende Unterteilungskriterium sind dabei von der zu untersuchenden Problemstellung abhängig. ${ }^{76} \mathrm{Im}$ Folgenden wird mit dem institutionellen Aspekt ein wesentliches und für diese Untersuchung problemadäquates Gliederungskriterium diskutiert, mit Hilfe dessen das Logistiksystem weiter in Logistiksubsysteme unterteilt, $d$. h. horizontal und vertikal aufgelöst werden kann. Denn insbesondere die Prinzipien einer adäquaten institutionellen Verankerung der Erstellung logistischer Leistungen und damit die Grundsätze deren Koordination sind ausdrücklich Bestandteil der Logistikkonzeption. $^{77}$

\subsection{Institutionelle Gliederung von Logistiksystemen}

Legt man einer Unterteilung von Logistiksystemen institutionelle Gesichtspunkte, d. h. Art und Anzahl der jeweils in das System eingebundenen Institutionen zugrunde, dann kann zwischen makrologistischen, metalogistischen und mikrologistischen Systemen unterschieden werden. ${ }^{78}$

\section{Makrologistische Systeme}

Das systembedingt hohe Komplexitätsniveau der Transferbeziehungen zwischen den einzelnen Wirtschaftssubjekten aufgrund der arbeitsteiligen Organisation des Gesamtwirtschaftssystems wurde schon mehrfach angesprochen. Prinzipiell ist jedes Wirtschaftssubjekt in seiner Eigenschaft als Element des Gesamtwirtschaftssystems regelmäßig als Quelle (Anfangspunkt) oder Senke (Endpunkt) von Transferprozessen

Vgl. Milling, Dengel (2003), S. 134; Ihde (1999), S. 116. Generell ist dabei nach der Maßgabe zu verfahren, einen möglichst hohen Vernetzungsgrad innerhalb des Systems bei gleichzeitig minimaler Vernetzung nach außerhalb zu erreichen. Vgl. Ihde (2001), S. 40. Dabei ist die Systemgrenze des zu untersuchenden Systems jeweils so zu ziehen, dass alle Elemente in die Untersuchung einbezogen werden, von denen ein fühlbarer und spezifischer Einfluss auf das Funktionieren des Systems ausgeht. Zu berücksichtigen ist dabei allerdings auch, dass mit jeder Erweiterung des Systems um zusätzliche Elemente sein Komplexitätsgrad wieder zunimmt und mithin dessen Analyse erschwert wird. Vgl. dazu Seidenfus (1973), S. 20.

Vgl. Pfohl (2004a), S. 14 ff. Für eine ausgiebige und kritische Diskussion dieser Systematik und für einen alternativen Gliederungsvorschlag in Makro-, Mikro-, Meta- (im Sinne der Vereinigung mehrerer Mikrologistiken entlang eines logistischen Kanals in vertikaler Richtung) und Mesologistik (im Sinne der Vereinigung mehrerer Metalogistiken in horizontaler Richtung) siehe Drechsler (1988), S. $21 \mathrm{ff}$. 
in makrologistische Güterflussnetzwerke involviert. ${ }^{79}$ Bedingt durch ihre inhärente Komplexität müssen diese makrologistischen Güterflussnetzwerke operationalisiert werden, um einer wissenschaftlichen Analyse zugänglich zu sein. IHDE schlägt in diesem Zusammenhang eine Operationalisierung mittels der Zusammenfassung einzelner, gleichartiger Quellen und Senken hinsichtlich leistungs- und kostenmäßiger Interdependenzen vor, die sich aufgrund der gemeinsamen, rivalisierenden Nutzung von Verkehrswegen und Verkehrstechnologien ergeben. ${ }^{80}$ In diesem Sinne können die Komponenten der materiellen Verkehrsinfrastruktur - die Verkehrsträger - aufgrund ihrer Eigenschaft als umfassende und nachhaltige Determinanten logistischer Prozesse als Abgrenzungskriterium gewählt werden. Makrologistische Systeme können folglich in Seeschifffahrt, Binnenschifffahrt, Eisenbahnverkehr, Straßenverkehr, Luftverkehr und Rohrleitungsverkehr unterschieden werden. ${ }^{81}$ Makrologistische Systeme sind also gesamtwirtschaftlicher Natur. ${ }^{82}$

\section{Mikrologistische Systeme}

Mikrologistische Systeme sind einzelwirtschaftliche Systeme, sie stellen die institutionellen Elemente der makrologistischen Systeme dar. Zur Abgrenzung von mikrologistischen Systemen aus der makrologistischen Umwelt benutzt IHDE das Kriterium der „logistischen Kontrollspanne“. Demzufolge werden einem mikrologistischen System alle diejenigen Güterbewegungen zugeordnet, auf die die jeweilige Institution (Einzelwirtschaft) Einfluss zu nehmen in der Lage ist. ${ }^{83}$ PFOHL hingegen sieht die rechtlichen Grenzen einer Organisation (Unternehmung) als die maximale Außengrenze mikrologistischer Systeme und fasst diese somit enger. ${ }^{84}$ Im Rahmen dieser Arbeit sollen mikrologistische Systeme gemäß der PfoHLschen Systematik als rein intraorga-

Vgl. Ihde (2001), S. 134.

Vgl. Ihde (2001), S. 134; Pfohl (2004a), S. 335. Weitere Möglichkeiten der Operationalisierung wäre die Zusammenfassung gleichartiger Elemente hinsichtlich räumlicher Nähe (bspw. in Form regionaler Verflechtungsmatrizen) oder bestimmter Güterarten (bspw. alle nationalen Transporte von Eisenerz). Vgl. Ihde (2001), S. 134.

Vgl. Ihde (1999), S. 116; Ihde (2001), S. 135; Milling, Dengel (2003), S. 135. Kirsch et al. nehmen im Gegensatz dazu eine alternative terminologische Einordnung vor, indem sie das gesamte Verkehrssystem einer Volkswirtschaft als "das" makrologistische System bezeichnen und die Verkehrsträger als funktionale Subsysteme des gesellschaftlichen Verkehrssystems begreifen. Vgl. Kirsch et al. (1973), S. 89 f.

Vgl. Pfohl (2004a), S. 15.

Vgl. Ihde (2001), S. $40 \mathrm{f}$.

Vgl. Pfohl (2004a), S. 15 f. 
nisatorische Logistiksysteme bzw. Beziehungsgefüge aufgefasst werden. Diese können - und hier herrscht wiederum Konsens mit IHDE - danach unterschieden werden, ob

- der primäre Geschäftszweck der betreffenden Unternehmung die Produktion von Logistikleistungen für Dritte ist, oder ob

- die Wahrnehmung logistischer Aufgaben lediglich in Verbindung mit der Erfullung des originären Geschäftszweckes vollzogen wird.

Während letztere als mikrologistische Subsysteme bzw. als funktionale Subsysteme der Organisationen, deren logistische Aufgaben sie wahrnehmen, bezeichnet werden können, handelt es sich bei ersteren um Logistikunternehmen (synonym: Logistikdienstleistungsunternehmen, Logistikdienstleister) ${ }^{85}$ Der Organisationsbegriff wird hier im Sinne des Unternehmensbegriffes verwendet, unter intraorganisatorischen Beziehungsgefügen werden demnach auch die Aspekte der innerbetrieblichen und der zwischenbetrieblichen Logistik von Industrie-, Handels-, Logistik- und Dienstleistungsunternehmen erfasst. ${ }^{86}$

\section{Metalogistische Systeme}

Stellen mikrologistische Systeme definitionsgemäß intraorganisatorische Logistiksysteme dar, so handelt es sich bei metalogistischen Systemen um interorganisatorische Logistiksysteme bzw. Beziehungsgefüge. Darunter sind solche Systeme zu verstehen, welche verschiedene Mikrologistiken zur Erfüllung einer bestimmten logistischen

85 Pfohl unterteilt Mikrologistiken geordnet nach Aufgabenart in Krankenhaus-, Militär-, Unternehmenslogistik sowie die Logistik sonstiger Organisationen. Die Unternehmenslogistik wiederum gliedert er in Industrie-, Handels- und Dienstleistungslogistik. Innerhalb der Dienstleistungslogistik kommt der zu der hier angesprochenen Unterteilung. Vgl. Pfohl (2004a), S. 16. Ihde leitet diese Unterteilung direkt aus der Gegenüberstellung von arbeitsteilig wahrgenommenen Logistikaufgaben im Rahmen der Unternehmenslogistik (bspw. als Beschaffungs-, Produktions-, Distributions- und Entsorgungslogistik) und Unternehmen, deren primärer Organisationszweck die Produktion logistischer (Dienst-)Leistungen ist, ab. Vgl Ihde (2001), S. 41. Auch Kirsch et al. kommen zu der Unterscheidung zwischen mikrologistischen Systemen als funktionalen Subsystemen von Betriebswirtschaften einerseits und logistischen Betrieben andererseits, jedoch ohne dabei die "logistischen Betriebe“ explizit als mikrologistische Systeme zu bezeichnen. Vgl. Kirsch et al. (1973), S. 83 ff. Faller verwendet hinsichtlich der mikrologistischen Systeme dieselbe Gliederungssystematik und bezeichnet dabei die logistischen Betriebe als „Teilmenge der Mikrologistischen Systeme“. Faller (1999), S. 79. 
Aufgabe kooperativ miteinander verknüpfen. ${ }^{87}$ Hierbei können metalogistische Systeme danach unterschieden werden, welche Unternehmen bei der logistischen Aufgabenerfüllung miteinander kooperieren. ${ }^{88}$ Eine mögliche Systematisierung der Ausgestaltungsformen metalogistischer Systeme kann in Abhängigkeit der Richtung vorgenommen werden, in welcher die Kooperation stattfindet. Es existieren drei Hauptformen:

- horizontal strukturierte metalogistische Systeme,

- vertikal strukturierte metalogistische Systeme und

- diagonal strukturierte metalogistische Systeme. ${ }^{89}$

Unter horizontal strukturierten metalogistischen Systemen werden solche Systeme verstanden, in welchen Unternehmen kooperieren, die auf derselben Wertschöpfungsstufe tätig sind bzw. die Leistungen auf derselben Stufe des Logistikkanals erbringen. Beispiele hierfür wären Speditionskooperationen oder Frachtführerkooperationen. Vertikal strukturierte metalogistische Systeme bezeichnen Systeme, in denen am Güterfluss beteiligte Unternehmen vor- bzw. nachgelagerter Wertschöpfungsstufen miteinander kooperieren, von Unternehmen also, welche Leistungen auf verschiedenen Stufen des Logistikkanals erbringen. Dies trifft auf Kooperationen zwischen Speditionen und Frachtführern oder zwischen Verladern ${ }^{90}$ und Speditionen zu. Diagonal strukturierte metalogistische Systeme schließlich umfassen die Zusammenarbeit verschiedener Verkehrstechniken bzw. Verkehrsträger (bspw. Transportketten des kombinierten Verkehrs) bzw. von Institutionen verschiedener Branchen oder Verkehrsgebiete.

87 Vgl. Pfohl (2004a), S. 15 f. Auch Ihde stellt fest, dass die Bildung „funktionaler Zwischensysteme" notwendig ist, allerdings ohne diese explizit als metalogistische Systeme zu bezeichnen. Sie sind besonders bedeutsam für Organisation und Optimierung unternehmensübergreifender Güterflussnetzwerke und basieren als kooperative Logistiksysteme auf den güterwirtschaftlichen Beziehungen zwischen den Unternehmen. Vgl. Ihde (2001), S. 53

88 Vgl. Freichel (1992), S. 9.

89 Vgl. dafür und für das Folgende Freichel (1992), S. 61 f.; Ihde (2001), S. 53 f.; Pfohl (2004a), S. 316 ff.; Kleeberg (2000), S. 21 f.

90 Der Begriff des Verladers bezeichnet die Nachfrager nach logistischen Dienstleistungen, die Kunden von Logistikdienstleistungsunternehmen also. Velader können sowohl als Lieferant bzw. Versender als auch als Kunde bzw. Empfänger eines Gutes fungieren. Vgl. Rümenapp (2002), S. 103. 
Zusammenfassend kann festgestellt werden, dass metalogistische Systeme logistische Verflechtungen mit unternehmens- und wirtschaftsbereichsübergreifendem Charakter thematisieren ${ }^{91}$ und insofern als „Zwischensysteme“ zwischen den makrologistischen und den mikrologistischen Systemen anzusiedeln sind..$^{92}$ Metalogistiken sind wahrscheinlich diejenigen logistischen Systeme, welche Nutzen und Intention der systemtheoretisch orientierten Betrachtung logistischer Vorgänge am besten ausdrücken. Der Vorteil des systemischen Logistikdenkens besteht ja gerade darin, eine auf die einzelne Institution bezogene Perspektive durch eine integrierte Perspektive auf alle am logistischen Prozess beteiligen Elemente zu ersetzen. ${ }^{93}$ Neben den mikrologistischen Systemen bilden die metalogistischen Systeme die konstituierenden Elemente der makrologistischen Systeme. ${ }^{94}$ Diese Beziehungen sind in Abbildung 2-10 dargestellt.

Da dieser Teil der Arbeit die Vorgänge auf dem Markt für Logistikleistungen zum Gegenstand hat, beschäftigen wir uns im Folgenden in erster Linie mit denjenigen mikrologistischen Systemen, deren primärer Geschäftszweck die Produktion von Logistikleistungen für Dritte ist sowie mit metalogistischen Systemen in Gestalt sämtlicher Formen von Logistikkooperationen, an denen Logistikdienstleister beteiligt sind. Auch die logistischen Fachbereiche der nicht-logistischen Unternehmen werden, sofern erforderlich, in die Analyse mit einbezogen.

Vgl. Aberle (2003a), S. 504.

Vgl. Grüner (1997), S. 65.

93 Vgl. zum Nutzen der systemtheoretischen Betrachtung von Verkehrs- und Logistikproblemen bspw. Kirsch et al. (1973), S. 66 ff.; Kloster (2002), S. 35 f. 


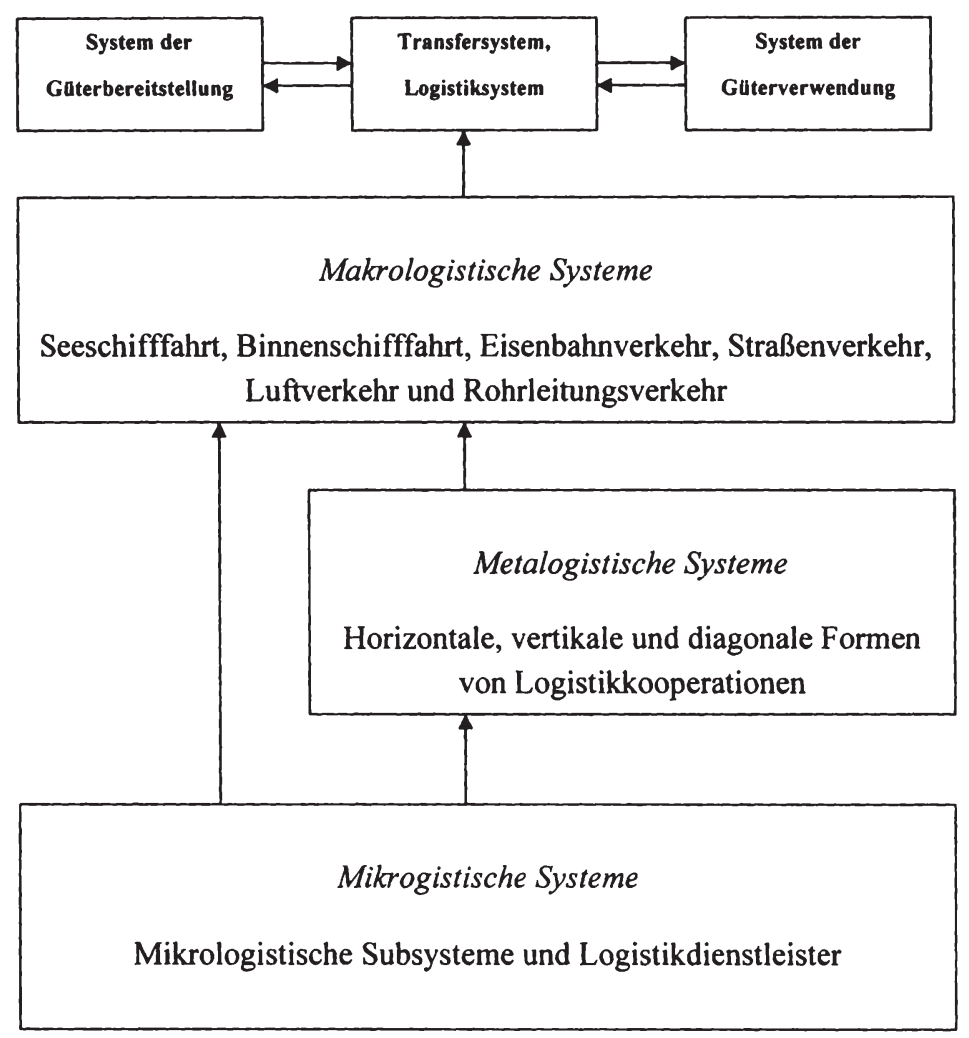

Abbildung 2-10: Logistiksysteme

Quelle: Eigene Darstellung

\subsubsection{4 Ökonomische Bedeutung der Logistik}

\subsection{Gesamtwirtschaftliche Bedeutung der Logistik}

Der Ansatz zur Erklärung der gesamtwirtschaftlichen Bedeutung der Logistik fußt im Wesentlichen auf den Ausführungen, die unter Unterabschnitt 2.2.2.1 vorgetragen wurden. Dort wurde das Logistiksystem als Bindeglied der elementaren Transformationsprozesse der Güterbereitstellung und der Güterverwendung charakterisiert, dem im gesamtwirtschaftlichen Zusammenhang eine systembindende und systemkoppelnde Aufgabe zuteil wird. Insofern muss eine Abschätzung der gesamtwirtschaftlichen 
Bedeutung der Logistik, die lediglich auf der Basis ihres monetären Anteils an einer gesamtwirtschaftlichen Kennziffer, bspw. am Sozialprodukt, beruht, unvollkommen bleiben. Die Relevanz der Logistik würde deutlich unterbewertet. ${ }^{95}$ Vielmehr nimmt die Logistik als „enabling technology“ entscheidend gestalterischen Einfluss auf gesamtwirtschaftliche Größen wie bspw. die Arbeitsteilung, die internationale Vernetzung oder die Wettbewerbsintensität. ${ }^{96}$ Bisweilen wird der Logistik resp. den Logistikunternehmen sogar überschwänglich attestiert, dass sie über ihren Beitrag zur ökonomischen Vernetzung, welchen sie im Zuge der Produktion logistischer Leistungen leisten, „die volkswirtschaftliche Arbeitsteilung schlechthin“ realisieren. ${ }^{97}$ ABERLE indes sieht sogar die Gefahr, dass Ineffizienzen im gesamtwirtschaftlichen Logistiksystem wettbewerbserschwerend bis existenzbedrohend auf diejenigen Wirtschaftszweige wirken können, welche in besonderem Maße von der effizienten Ausgestaltung ihrer Logistiksysteme abhängig sind. ${ }^{98}$ Er fordert daher, dass die Optimierung sämtlicher Rahmenbedingungen zum Zwecke der Optimierung des gesamtwirtschaftlichen Logistiksystems Gegenstand ordnungspolitischer, verkehrspolitischer und telekommunikationspolitischer Überlegungen und Maßnahmen sein sollten. ${ }^{99}$ GÖPFERT wirft zudem die Frage auf, inwieweit Logistik auf das allgemeine unternehmerische Innovationsverhalten bzw. die Innovationslandschaft Einfluss zu nehmen vermag. ${ }^{100}$ Sie schreibt der Logistik bzw. der Logistikleistung aufgrund ihrer Funktion als wesentlicher Wettbewerbsfaktor eine wichtige Rolle in der bislang maßgeblich von Sachgüterinnovationen dominierten Innovationsdiskussion zu. Sie fordert daher eine verstärkte Beschäftigung mit Fragen des Innovationsmanagements in der Logistik zumal durchaus und realistischerweise die Möglichkeit bestünde, dass im Zuge der wachsenden Bedeutung der Logistik Logistikinnovationen Produktinnovationen anstoßen können. Ähnlich argumentiert KLAUS, welcher der modernen Logistik die Rolle als „Impulsgeber" und „Enabler" für Innovationsaktivitäten in vielen Bereichen der Wirtschaft zuschreibt. ${ }^{101}$ BAUM schreibt dem Verkehr bzw. der Verkehrsleistung und damit einem zentralen Teilbereich der Logistik - positive gesamtwirtschaftliche Effekte $\mathrm{zu}$, da er produktivitäts- und daraus resultierend wachstumssteigernde

Vgl. Bretzke (1999), S. 220; Bretzke (2000), S. 316.

Vgl. Bretzke (1999), S. 220.

Eckstein (1985), S. 3 f.

Vgl. Aberle (2003b), S. 278.

Vgl. Aberle (2003b), S. 278.

Vgl. dafür und für das Folgende Göpfert (2000), S. 276 ff.

Vgl. Klaus (2003), S. 27.
} 
Wirkungen entfaltet. ${ }^{102}$ Diese Produktivitäts- und Wachstumseffekte resultieren unter anderem aus der Tatsache, dass Verkehr neue, vertiefte Formen industrieller Arbeitsteilung und entsprechende Reorganisationsgewinne begünstigt, dass er der Realisierung von Innovationen und der Generierung von technischem Wissen zuträglich ist, oder dass er den sektoralen Strukturwandel beschleunigt und damit dazu beiträgt, Produktionsfaktoren in produktivere Verwendungen zu lenken. ${ }^{103}$ Bei einem Teil dieser positiven Effekte handelt es sich zudem um technologische positive externe Effekte, welche also nicht über das Markt- und Preissystem abgegolten werden. ${ }^{104}$

\subsection{Einzelwirtschaftliche Bedeutung der Logistik}

Aus einzelwirtschaftlicher Sicht sind mit dem logistischen Rationalisierungspotenzial sowie mit dem logistischen Wettbewerbspotenzial zwei Bestimmungsfaktoren zu unterscheiden, mit Hilfe derer sich die zunehmende ökonomische Relevanz der Logistik aufzeigen und begründen lässt.

\section{Das logistische Rationalisierungspotenzial}

Seit jeher stand der Produktionsbereich aufgrund der Fülle der dort vorhandenen technischen und organisatorischen Verbesserungsmöglichkeiten sowie aufgrund der immensen Kostenhöhe im Zentrum der unternehmerischen Rationalisierungsbemühungen. Mittels zahlreicher Prozessinnovationen technischer und organisatorischer Art konnten hier permanent Rationalisierungsreserven erschlossen werden, was die kontinuierliche Verbesserung der Produktivität der Produktionsprozesse zur Folge hatte. Wesentliche Meilensteine produktivitätssteigernder Maßnahmen waren bspw. die Mechanisierung und Automatisierung der Fertigung, die Normierung von Teilen sowie die Typisierung von Produkten. ${ }^{105}$ Demgegenüber blieb das logistische Rationalisierungspotenzial lange Zeit unbeachtet und war nicht Gegenstand der ökonomischen Diskussion. Erst nachdem im Produktionsbereich Rationalisierungsgrenzen spürbar wurden und die Relevanz von Logistikkosten im Leistungserstellungsprozess voll umfänglich erkannt worden ist, begann man, sich intensiv mit den Möglichkeiten auseinanderzusetzen, welche die Logistik zur Kostensenkung bereitstellt. ${ }^{106}$

Vgl. Baum (1997), S. 27.

103 Vgl. Baum, Esser, Höhnscheid (1998), S. 108; Baum (1997), S. 27 f. 
Das Erkennen logistischer Kostensenkungspotenziale ist eng verbunden mit der systemischen, güterflussbezogenen Perspektive der Logistik hinsichtlich der Betrachtungsweise des Leistungserstellungsprozesses. ${ }^{107}$ So sieht ABERLE in der systematischen Überprüfung aller inner- und zwischenbetrieblichen Güterbewegungen und Stoffströme zum Zwecke der Identifizierung von Rationalisierungspotenzialen zur Kostensenkung eines der zentralen Ziele der Logistik. ${ }^{108}$ Kostenverursachende Schnittstellenprobleme ergeben sich nämlich regelmäßig an und zwischen den Systemgrenzen (Schnittstellen) der einzelnen einzelwirtschaftlichen Subsysteme. Die Logistik hat in diesem Zusammenhang die Aufgabe, Schnittstellenprobleme zu erkennen und zu überwinden. Damit soll eine Verbesserung der Koppelung der Aktivitäten entlang der unternehmensinternen und insbesondere auch der unternehmensübergreifenden logistischen Prozessketten zu Kostensenkungen führen. ${ }^{109}$

\section{Das logistische Wettbewerbspotenzial}

Neben den positiven Effekten auf die Kostenhöhe zeitigt die Logistik gleichermaßen auch Marktwirkungen, indem sie die Markt- bzw. Wettbewerbsposition eines Unternehmens positiv beeinflussen kann. ${ }^{110}$ Würde man sich bei der Analyse der Logistik lediglich auf deren kostenseitiges Wirkungspotenzial beschränken, dann bliebe die Tatsache unberücksichtigt, dass, wie oben beschrieben, das Logistiksystem (Transfersystem) über seine passive, kostensenkende Funktion hinaus als bedingender Faktor auch eine aktive, gestalterische Funktion hinsichtlich des Aufbaus und der Entwicklung von Transformationsprozessen innehat. Übertragen auf die einzelwirtschaftliche Analyse bedeutet dies, dass im unternehmerischen Produktionsprozess die Logistikqualität neben der eigentlichen Produktqualität (im Sinne der Gebrauchsfähigkeit und des Erlebniswertes der Güter) einen nicht minder marktwirksamen Wettbewerbsfaktor darstellt. ${ }^{\text {II }}$ Ihr Wettbewerbspotenzial bezieht die Logistik dabei aus Veränderungsvorgängen auf den Produktmärkten, welche es den Anbietern erlauben, mittels der Steigerung der logistischen Effizienz ein Mehr an marktwirksamem Kundennutzen zu generieren. ${ }^{112}$ IHDE identifiziert folgende Marktentwicklungen als Faktoren, welche positiv auf die Relevanz der Logistikqualität einwirken:

\footnotetext{
107

108 Vl. Pfohl (1974), S. 579.

Vgl. Aberle (2003a), S. 506.

109 Vgl. Heiserich (2002), S. 18 f.

110 Vgl. Ihde (2001), S. 34 f.

111 Vgl. Aberle (2003b), S. 276.

112 Vgl. Inde (2001), S. 35.
} 
- Angebotsüberhänge auf relevanten Produktmärkten,

- zunehmende Produktdifferenzierung, Variantenvielfalt,

- hohe Markttransparenz,

- beschleunigte Diffusion und Imitation,

- räumliche und zeitliche Flüchtigkeit der Nachfrage. ${ }^{113}$

Das Vorliegen von Angebotsüberhängen auf relevanten Produktmärkten versetzt die Nachfrager, bei gleichzeitiger Existenz mehrerer Anbieter auf den betreffenden Märken, in die Lage, ihre Bedarfe problemlos aus alternativen und substitutiven Bezugsquellen zu befriedigen. Damit sich jedoch aus dieser Situation das den Wettbewerbsprozess auslösende Wechselspiel von Vorstoß und Verfolgung auf Seiten der Anbieter und von Bezugsquellenänderungsprozessen auf Seiten der Nachfrager einstellt, ist ein Mindestmaß an Marktunvollkommenheiten erforderlich. Denn nur, wenn der Markt bis zu einem gewissen Grad intransparent ist und die Güter ungleich sind, bestehen für die Anbieter Anreize, innovierende Vorstoßaktionen durchzuführen und für die Nachfrager, den Anbieter zu wechseln. ${ }^{114}$ Hätte nämlich der Markt ausgeprägte Vollkommenheitsmerkmale, dann wären sowohl unternehmerische Vorstoßaktionen als auch Wechselprozesse der Nachfrager bedingt durch schnelle im Extremfall unendlich schnelle - Reaktions- und Anpassungsprozesse der Verfolger zwecklos bzw. unnötig. ${ }^{115}$

Demgegenüber ist auf vielen Produktmärkten zu beobachten, dass die Markttransparenz permanent verbessert worden ist und sich die Produkte folglich schneller und nachdrücklicher aneinander annähern, Diffusion und Imitation der Produkte als Ausdruck unternehmerischer Anpassungsprozesse beschleunigt werden. ${ }^{116}$ Diese Entwicklung ist wohl vor allem auf die Fortschritte auf dem Gebiet der modernen

Vgl. dafür und für das Folgende Ihde (2001), S. 35 ff. Ähnliche Faktoren der Marktentwicklung identifiziert auch Haubold. Sie wertet diese Faktoren als Bestimmungsgründe für den Übergang von der traditionellen Massenproduktion hin in Richtung der Restrukturierung intra- und interorganisatorischer Arbeitsteilung gemäß des Konzeptes der „Lean Production“. Damit einher ging die Verbindung der Vorteile der Standardisierung (nach dem Muster der Massenproduktion) mit der Notwendigkeit, die industriellen Produktionsabläufe zu flexibilisieren und sie unternehmensübergreifend zu rationalisieren. Vgl. Haubold (1994), S. 65 ff. Die Bedeutung dieser Entwicklung für die Logistik wird damit offensichtlich.

Vgl. Ihde (2001), S. 35.

Vgl. Herdzina (2005), S. 213 f.

Vgl. Ihde (2001), S. 35. 
Informations- und Kommunikationstechnologie (IKT) und den damit verbundenen vereinfachten und günstigeren Möglichkeiten für Konsumenten und Produzenten, sich marktrelevante Informationen zu beschaffen, zurückzuführen.

Die soeben beschriebenen Entwicklungen führen nun dazu, dass die Nachfrage auf den betreffenden Märkten räumlich und zeitlich flüchtig wird. D. h. die sofortige, unverzügliche räumliche und die zeitliche Verfügbarkeit der Güter genau dort und genau dann, wo und wann der potenzielle Nachfrager seine Konsumabsicht äußert, wird zu einem entscheidenden Kriterium, ob der Konsum stattfindet oder nicht. Der Grad der Güterverfügbarkeit, bzw. der Grad der logistischen Effizienz, wirkt folglich, bei ansonsten weitgehend ähnlichen Gütern hinsichtlich ihres Preises und ihrer technischen Produktqualität, entscheidend auf die Konsumentscheidung der Nachfrager ein. ${ }^{117}$

Auch auf der Beschaffungsseite ist das Wettbewerbspotenzial der Logistik offensichtlich. Die Etablierung effizienter Logistiksysteme erweist sich auch hier als geeignetes Instrument zu nachhaltiger, marktwirksamer Produktdifferenzierung. ${ }^{18}$ Dies gilt umso mehr, als bei zahlreichen Produkten die steigende Variantenvielfalt dazu fuhrt, dass im Produktionsprozess eine immer größer werdende Zahl an einzelnen Zulieferteilen unter Zugrundelegung immer restriktiverer zeitlicher Vorgaben koordiniert werden muss. ${ }^{119}$

Aus dem Gesagten kann zusammenfassend geschlossen werden, dass die Logistik ihr Wettbewerbspotenzial im Wesentlichen aus der Tatsache bezieht, dass sie aufgrund ihrer Eigenkomplexität und Unanschaulichkeit für den außenstehenden, unternehmensexternen Betrachter ein vergleichsweise schwer erkennbares und vergleichbares Leistungssystem ist. Ein überlegenes Logistiksystem kann daher von Konkurrenten nur schwer imitiert werden und bietet den Unternehmen bei ansonsten substituierbaren Produkten die Möglichkeit, ihr Produktangebot zu heterogenisieren, bzw. nachhaltige, wettbewerbswirksame Differenzierungs- oder im Extremfall sogar Alleinstellungsmerkmale zu entwickeln. ${ }^{120}$ Logistik wirkt folglich aufgrund ihrer Tendenz, die Markttransparenz zu reduzieren, prinzipiell stimulierend auf den Wettbewerbsprozess. $^{121}$

117 Vgl. Baumgarten (2001), S. 31 f.; Ihde (2001), S. 36; Aberle (2003b), S. 276 f.; Pfohl (1997), S. 272; Pfohl (2004a), S. 58.

118 Vgl. Baumgarten (2001), S. 24, 3 If.

119 Vgl. Ihde (2001), S. 36.

120 Vgl. Bretzke (2000), S. 317; Pfohl (2004a), S. 58; Ihde (1999), S. 117 f.

121 Vgl. Ihde (2001), S. 37. 


\subsection{3 Ökonomische Charakteristika der Logistikleistung}

\subsubsection{Wesen und Umfang der Logistikleistung}

\subsection{Der Dienstleistungscharakter der Logistikleistung}

Das Leistungsprogramm von Logistikdienstleistern besteht aus Logistikleistungen, welche unmittelbar und mittelbar die Realisierung der Güterverteilung betreffen. Arteigen weisen Logistikleistungen eine Reihe von allgemein dienstleistungstypischen Charakteristika auf, weswegen sie sich von Sachleistungen eines Industriebetriebes erheblich unterscheiden. ${ }^{122}$ Einige wesentliche Dienstleistungscharakteristika der Logistikleistung werden im Folgenden kurz dargestellt.

\section{Dominanz immaterieller Produktionsfaktoren}

Ein wesentlicher Unterschied bei der Produktion von Dienstleistungen im Vergleich zur Produktion von Sachgütern besteht darin, dass der Einsatz von Rohstoffen entfällt. ${ }^{123}$ So sind auch Logistikleistungen prinzipiell durch Immaterialität (bzw. durch immaterielle Produktionsfaktoren) gekennzeichnet, sie stellen nicht gegenständliche, nicht greifbare Leistungsversprechen ohne eigene raum-zeitliche Existenz dar. ${ }^{124} \mathrm{Die}$ Immaterialität der Dienstleistung kommt dabei vor allem in der Angebotsphase und in der Wirkungsphase zum Tragen. ${ }^{125}$ Dies soll folgendes Beispiel verdeutlichen: Während ein Logistikprozess bzw. dessen Ergebnis materiell bzw. greifbar sein kann (ein fahrender LKW mit einem Transportgut, ein vollzogener Transport von Ort A nach Ort B), so sind die angebotenen Potenziale bzw. Leistungsfähigkeiten (die Fähigkeit, ein Gut von Ort A nach Ort B zu transportieren) grundsätzlich immateriell. Ebenfalls sind die durch die Erbringung der Logistikleistung beabsichtigten Wirkungen (das Gut an Ort B ökonomisch verfügbar zu machen) immateriell.

Aus der Immaterialität der Logistikleistung ergibt sich ein für alle Dienstleistungen geltendes Spezifikum, nämlich dass der Produktions- und der Konsumakt zeitlich zusammenfallen, Logistikleistungen also nicht auf Vorrat produzierbar sind. ${ }^{126}$ Daraus

Vgl. Rösler (2003), S. 58; Kloster (2002), S. 39 ff.

Vgl. Maleri (1991), S. 102.

Vgl. Rösler (2003), S. 58 f.; Sibbel, Hartmann (2005), S. 78.

Vgl. Meyer, Blümelhuber (1994), S. 8.

Vgl. Stabenau (1994), S. 51.
} 
folgt, dass der Kunde der Logistikleistung die Qualität der Leistung vor dem Konsumakt nicht beurteilen kann. Logistikleistungen weisen dementsprechend den Charakter eines Vertrauensgutes auf. ${ }^{127}$

\section{Integration externer Produktionsfaktoren}

Dienstleistungen werden an Menschen oder Objekten vollzogen. Das bedeutet, dass für die Realisierung der Dienstleistung neben internen Produktionsfaktoren ${ }^{128}$ auch die Mitwirkung bzw. die Integration eines externen Produktionsfaktors in der Gestalt eines Kunden oder eines Kundenobjektes in den Dienstleistungsprozess zwingend erforderlich ist. ${ }^{129}$ So wird auch die Produktion von Logistikleistungen maßgeblich durch externe Produktionsfaktoren bedingt, diejenigen Objekte also, welche stets im Eigentum des Dienstleistungsempfängers bleiben und an denen logistische Manipulationen zeitlicher, räumlicher oder physischer Eigenschaften vorgenommen werden. ${ }^{130}$ Auch DIEDERICH thematisiert den Dienstleistungscharakter logistischer Teilleistungen. Er führt aus, dass die Verkehrsbetriebe aufgrund der erforderlichen Integration externer Produktionsfaktoren nicht in der Lage sind, ihre Dienstleistungen auf Vorrat zu produzieren, sondern immer nur nach konkret erfolgter Leistungsanforderung durch den Nachfrager. ${ }^{131}$ Ferner gibt DIEDERICH zu bedenken, dass dieser Umstand für die Verkehrsbetriebe gravierende Kapazitätsplanungs- und Auslastungsprobleme nach sich zieht, da die Nachfrage nach Verkehrsleistungen im Zeitablauf stark schwanke. ${ }^{132}$

Vgl. Pfohl (2004a), S. 25; vgl. ähnlich auch Grüner (1997), S. 12.

Interne Produktionsfaktoren sind solche Produktionsfaktoren, welche ein Dienstleistungsunternehmen vom Beschaffungsmarkt beziehen kann, oder für welche er ein Nutzungsrecht hat. Vgl. Pfohl (2004a), S. 281.

Vgl. Meyer, Blümelhuber (1994), S. 9; Sibbel, Hartmann (2005), S. 78; Grüner (1997), S. 12.

Vgl. Isermann (1994), S. 22; Pfohl (2004a), S. 281; Rösler (2003), S. 59. Schon Brauer bemerkt zur Thematik Immaterialitä/Integration externer Produktionsfaktoren: „Diese immateriellen Leistungen bestehen beim Verkehrsbetrieb typischerweise aus vollzogenen Veränderungen der ökonomisch wesentlichen Eigenschaften materieller Objekte, an bestimmten Orten und/oder zu bestimmten Zeiten verfügbar zu sein. Grundlegende Voraussetzung für die Erstellung derartiger Leistungen ist, dass Personen sich selbst oder ihre Güter als Verkehrsobjekte leistungsbereiten Verkehrsbetrieben zur Verfuggung stellen." Brauer (1979), S. 13.

Vgl. Diederich (1977), S. 46. Auch Grüner sieht in der Notwendigkeit, einen externen Faktor in den Produktionsprozess integrieren zu müssen, den Grund für die Unmöglichkeit der Vorratsproduktion von Dienstleistungen. Vgl Grüner (1997), S. 15.

Vgl. Diederich (1977), S. 46. Auch Seidenfus weist auf die durch Nachfrageschwankungen bedingte „außerordentlich mangelhafte Anpassungsfähigkeit“ der Verkehrsbetriebe im Hinblick auf Kapazitätsfragen hin. Seidenfus (1995), S. 99. 
In der vorliegenden Arbeit wird der Begriff der Logistikleistung lediglich für diejenigen Leistungen benutzt, welche Logistikdienstleistungsunternehmen für andere erbringen. ${ }^{133}$ Dabei darf nicht vergessen werden, dass natürlich auch diejenigen Leistungen, welche eine Logistikabteilung eines Handels- oder Industrieunternehmens selbst erbringt, prinzipiell die Dienstleistungskriterien erfüllen. ${ }^{134}$

\subsection{Strukturierung von Logistikleistungen}

Um einen Eindruck zu vermitteln, welch breites Spektrum unterschiedlicher Logistikleistungen denkbar ist, soll im Folgenden ein systematischer Überblick über mögliche unterschiedliche Logistikleistungen gegeben werden. Hierzu wird auf einen auf STABENAU zurückgehenden und später von PFOHL aufgegriffenen Vorschlag für eine mögliche Strukturierung von Logistikleistungen zurückgegriffen. Demnach können die von Logistikunternehmen übernommenen Dienstleistungsfunktionen untergliedert werden in Hauptfunktionen, Ergänzungsfunktionen bzw. Komplementärfunktionen sowie Sonderfunktionen. ${ }^{135}$

- Den Kern der Hauptfunktionen bildet die Beförderungsfunktion, d. h. die Erbringung von Transportleistungen im engeren Sinne, welche primär die räumlichen Merkmale der Güter verändern. Darüber hinaus ist den Hauptfunktionen die Dispositionsfunktion zuzurechnen, welche die eng mit der Transportleistung verbundenen Verkehrsleistungen zum Gegenstand hat.

- Die Ergänzungsfunktionen bestehen im Wesentlichen aus Verkehrsleistungen im weiteren Sinne (Umschlags- und Lagerleistungen sowie die damit verbundenen Tätigkeiten), welche an einem festen Standort erbracht werden und welche primär die zeitlichen Merkmale der Güter verändern.

- Unter den Sonderfunktionen sollen diejenigen logistischen, z. T. aber auch nicht-logistischen Leistungen verstanden werden, welche von den Logistikdienstleistern zusätzlich zu den Haupt- und Ergänzungsfunktionen erbracht

Drechsler vertritt dieselbe Sichtweise. Vgl. Drechsler (1988), S. 25. Rümenapp hingegen lehnt den Begriff „Logistikdienstleistung“ bzw. „Logistikdienstleister" zugunsten der Begriffe „Logistikleistung“" bzw. „Logistikunternehmen“ ab. Er verweist -richtigerweise- darauf, dass zahlreiche Leistungen von Logistikunternehmen, insbesondere im Bereich der nichtlogistischen Zusatzleistungen, nicht die typischen Dienstleistungscharakteristika aufweisen, also keine echten Dienstleistungen sind. Vgl. Rümenapp (2002), S. 19.

Vgl. dazu Isermann (1994), S. 22. 
werden und im weitesten Sinne im Zusammenhang mit der Güterverteilung stehen.

Eine zusammenfassende Darstellung über die Arten von Dienstleistungen, die von Logistikunternehmen erbracht werden, vermittelt die folgende Abbildung 2-11.

\begin{tabular}{|c|c|}
\hline Funktionen & Funktionsträger \\
\hline Hauptfunktionen & \\
\hline $\begin{array}{l}\text { Dispositionsfunktion } \\
\text { - Beratung, Analyse, Planung, Organisation } \\
\text { - Wahl der Transportmittel, der Wege, des Tarifs } \\
\text { - Abschluss von Frachtverträgen } \\
\text { - Ausstellung der Transportdokumente } \\
\text { - Frachtenkontrolle } \\
\text { Beförderungsfunktion } \\
\text { - Nahverkehr: Sammel- und Verteilverkehr, Vortransport } \\
\quad \text { zum Hauptlauf mit anderen Verkehrsträgern } \\
\text { - Fernverkehr: national und international }\end{array}$ & $\begin{array}{l}\text { Spediteure, Frachtfuhrer, } \\
\text { Makler, Agenten }\end{array}$ \\
\hline Ergänzungs- bzw. Komplementärfunktionen & \\
\hline $\begin{array}{l}\text { Umschlagsfunktion } \\
\text { - Organisation und Durchführung des Umschlags } \\
\text { - Bewirtschaftung von Stationen/Terminals } \\
\text { Lagerfunktion } \\
\text { - Einlagern, Auslagern, Lagerung, Kommissionierung } \\
\text { - Wahrnehmung der Manipulationsfunktion im Zusammenhang } \\
\text { mit der Lagerung } \\
\text { - Bewirtschaftung von Lagern (z. B. Bestandsführung) }\end{array}$ & $\begin{array}{l}\text { Frachtführer } \\
\text { Umschlagsgesellschaften }\end{array}$ \\
\hline
\end{tabular}




\begin{tabular}{|c|c|}
\hline Sammelverkehrsfunktion (bei Kleingut) & \\
\hline - Sammeln und Verteilen von Stückgut & Spediteure \\
\hline - Zusammenstellung von Ladungseinheiten & Frachtführer \\
\hline Verpackungsfunktion & \\
\hline - Beratung und Auswahl der Transportverpackung & Frachtbetriebe \\
\hline - Transporthilfsmittel & Spediteure \\
\hline - Einpacken, Auspacken & Verpackungsbetriebe \\
\hline Manipulationsfunktion & \\
\hline - sendungsbezogene Manipulation (z. B. Stauung, Markierung) & Frachtführer \\
\hline $\begin{array}{l}\text { - warenbezogene Manipulation (z. B. spezielle Sicherheits- } \\
\text { maßnahmen) }\end{array}$ & $\begin{array}{l}\text { Verpackungsbetriebe } \\
\text { Umschlagsbetriebe } \\
\text { Stauereien }\end{array}$ \\
\hline Informationsfunktion & \\
\hline - Aufbau von Informationsketten zur Planung, Koordinierung, & Spediteure \\
\hline $\begin{array}{l}\text { Steuerung und Kontrolle des Transportablautes, der Lagerung } \\
\text { und der Statusverfolgung }\end{array}$ & Frachtführer \\
\hline & Datenbanken \\
\hline Sonderfunktionen & \\
\hline Verkaufsförderungsfunktion (merchandising) & \\
\hline - Übernahme von Verkaufsförderungsmaßnahmen im Auftrag & Spediteure \\
\hline des Versenders zugunsten des Emptängers (z. B. Regalservice) & Frachtführer \\
\hline Kundendienstfunktionen & \\
\hline $\begin{array}{l}\text { - Übernahme von Kundendienstfunktionen im Auftrag des } \\
\text { Versenders zugunsten des Empfängers (z. B. Ersatzteilvorhal- }\end{array}$ & Spediteure \\
\hline tung, Wartung) & Frachtführer \\
\hline & Lagerhalter \\
\hline Transportversicherungsfunktion & \\
\hline - risk-management im Transportversicherungsbereich & Spediteure \\
\hline - Abschluss von Versicherungsverträgen & Agenten \\
\hline - Abwicklung von Schadensfällen & Makler \\
\hline Zollbehandlungsfunktion & \\
\hline - Zolldeklarierung und -anmeldung & Spediteure \\
\hline - Zollabfertigung & Zollagenten \\
\hline
\end{tabular}




\begin{tabular}{|l|l|}
\hline Kreditfunktion & \\
- Fracht- und Zollvorlagen & Spediteure \\
\hline
\end{tabular}

\section{Abbildung 2-11: Funktionen von Logistikunternehmen}

Quelle: Stabenau (1994), S. 15 f.

Eine eindeutige Zuordnung einzelner, konkreter Logistikleistungen zu bestimmten Bereichen ist jedoch schwierig, da Logistikleistungen einer immensen marktgetriebenen Dynamik unterliegen und sich folglich permanent Veränderungen in der entsprechenden Zuordnung ergeben können. ${ }^{136}$ Ferner lässt diese Einteilung vermuten, dass die realen Ausprägungsformen von Logistikleistungen kaum eindeutig und überschneidungsfrei in das bereits vorgestellte Raster Transportleistung - Verkehrsleistung - Logistikleistung eingepasst werden können. Insbesondere die Frage, ob eine in Diskussion stehende Dienstleistung nun eine Verkehrsleistung darstellt oder ob sie die Kriterien für eine Logistikleistung i. e. S. erfüllt, ist schwer und allenfalls im konkreten Einzelfall abschließend zu beurteilen. So handelt es sich bei einer Lagerdienstleistung bspw. um eine Verkehrsdienstleistung, wenn sie dazu dient, als Hilfsdienstleistung einen Transport in eine vom Verlader geforderte zeitliche Vorgabe zu planen. Wird die Lagerdienstleistung vom Logistikdienstleister allerdings im Rahmen eines mehrere Dienstleistungen umfassenden Gesamtkonzeptes für den Verlader erbracht, das die gesamten Güterbewegungen des Verladers gesamthaft optimieren soll, so stellt die Lagerdienstleistung eine Logistikleistung i. e. S. dar. ${ }^{137}$

Es scheint also so zu sein, dass die einzelnen Logistikteildienstleistungen in Abhängigkeit des konkreten Kundenauftrages unterschiedliche Wertigkeit besitzen können. Bei Logistikleistungen handelt es sich demnach um höchst differenzierte, kundenindividuelle, wandelbare Leistungsbündel. Die Logistikteildienstleistungen wirken fallspezifisch komplementär (bspw. die Lagerdienstleistung und die Umschlagsdienstleistung als Hilfsfunktionen für die Transportdienstleistung) und teilweise substitutiv (bspw. ersetzen im Rahmen eines auf bedarfsadäquate Anlieferung abzielenden Justlogistischer Teilleistungen als ein Problem, „dessen Lösung zwangsläufig nicht frei von Willkür sein kann“. Drechsler (1988), S. 25 f. 
in-Time-Konzeptes eine Vielzahl von Transporten die Lagerhaltung) zueinander. ${ }^{138}$ Diese Erkenntnis hat nicht unerhebliche Implikationen für die (sachliche) Marktabgrenzung, was an entsprechender Stelle noch zu erörtern sein wird. ${ }^{139}$

\subsubsection{Der abgeleitete Charakter der Nachfrage nach LogistikJeistungen}

Prinzipiell gilt, dass die Nachfrage nach bestimmten Gütern erfolgt, um mit ihnen bestimmte Bedürfnisse zu befriedigen. Die Nachfrage nach Logistikleistungen dient folglich der Befriedigung von logistischen Bedürfnissen $d$. $h$. von Bedürfnissen hinsichtlich der Manipulation räumlicher, zeitlicher und bestimmter sachlicher Merkmale von Logistikobjekten. Bereits SAX konstatiert in diesem Zusammenhang jedoch (allerdings bezogen auf die Verkehrsleistung), dass es ein originäres Bedürfnis nach räumlicher und zeitlicher Veränderung von Gütermerkmalen nicht gibt, Verkehr kein Selbstzweck, sondern nur Mittel zum Zweck ist. ${ }^{140}$ Er folgert daraus, dass es sich bei Verkehrsbedürfnissen nicht um originäre sondern um abgeleitete Bedürfnisse handelt und mithin, dass es sich bei der Verkehrsnachfrage in der Regel nicht um eine originäre sondern um eine abgeleitete Nachfrage handelt. ${ }^{141}$ Diese Erkenntnis, dass die Verkehrsnachfrage nicht um ihrer selbst Willen erfolgt, sondern lediglich im Zuge und verbunden mit nicht-verkehrlicher Geschäftstätigkeit bzw. nicht-verkehrlichen Produktionsprozessen, wurde auch in der Folgezeit immer wieder vorgetragen und bestätigt. ${ }^{142}$ Aus der Charakterisierung der Verkehrsnachfrage als abgeleitete Nachfra-

Vgl. Oettle (1976), Sp. 4153 ff. Bemerkenswert ist hier vor allem, dass Oettle schon damals die,substitutiven Beziehungen [von Verkehrsleistungen] zu bestimmten nicht-verkehrlichen betriebswirtschaftlichen Mitteln, so zur Standort-, Wohnsitz- und Arbeitsplatzwahl, zu materialgewichtsparenden Produktionsverfahren und (mit der Zuverlässigkeit) zur Lagerhaltung“ erkannt hat. Oettle (1976), Sp. 4154.

139 Auch Drechsler thematisiert die Marktabgrenzung des Gesamtmarktes logistischer Leistungen und macht dabei Überlegungen zu den Komplementär- und Substitutionsbeziehungen einzelner logistischer Teilleistungen zum Ausgangspunkt seine Analyse. Er teilt den Gesamtmarkt in drei Teilmärkte: einen LSS-Markt (Logistic System Supplier), auf dem die Anbieter logistischer Systeme agieren, einen LCC-Markt (Logistic Component Company) für Anbieter von Verkehrsleistungen und sonstigen Logistikleistungen, welche noch nicht in ein Logistiksystem eingebunden sind, welche aber eigens zur Integration in Logistiksysteme erbracht werden und schließlich einen NSO-Markt (Non System Oriented), auf dem Leistungen angeboten werden, die nicht Bestandteil einer logistischen Systemdienstleistung werden sollen. Vgl. Drechsler (1988), S. 29 ff. Vgl. Sax (1918).

Vgl. Sax (1918).

Vgl. dazu bspw. Oettle (1976), Sp. 4155; Stabenau (1994), S. 56; Köberlein (1997), S. 50 ff.; Monopolkommission (2007), Tz. 69. 
ge ergeben sich einige gewichtige Implikationen für die Anbieter von Güterverkehrsleistungen:

- Das Gesamtvolumen der zu verladenden Gütermengen kann grundsätzlich von der Verkehrswirtschaft nicht durch eigenes Angebotsverhalten beeinflusst werden. Lediglich die Verteilung dieses exogen vorgegebenen Gesamtvolumens auf die einzelnen Verkehrsträger (der sog. modal split) sowie die Verteilung zwischen den einzelnen Marktteilnehmern kann aktiv beeinflusst werden. $^{143}$

- Die direkte Preiselastizität der Gesamtnachfrage nach Verkehrsleistungen ist relativ gering, die Nachfrage reagiert relativ unelastisch auf Preisänderungen. ${ }^{144}$

- Die Nachfrage nach Verkehrsleistungen ist starken Schwankungen unterworfen, welche sowohl saisonal als auch konjunkturell bedingt sein können. ${ }^{145}$ Diese Nachfrageschwankungen stellen die Verkehrsbetriebe vor Probleme bei der Planung ihrer Produktionskapazitäten und bergen die Gefahr einer Unterauslastung der Kapazitäten bei Nachfragebaisse. ${ }^{146}$

Die bislang in diesem Unterabschnitt vorgetragenen Überlegungen gelten für die Nachfrage nach Verkehrsleistungen. Nun ist zu überlegen, inwieweit diese Überlegungen auch auf die Nachfrage nach Logistikleistungen übertragbar sind.

Das wesentliche Spezifikum, welches die Logistikleistung über die Verkehrsleistung erhebt, ist neben der Ausdehnung des Leistungsumfanges vor allem die systemische, flussbezogene Betrachtung von Gütertransfer- und Gütertransformationsprozessen. In dem Umfange, in dem realisierte Leistungssteigerungen im Gütertransfersystem bzw. Logistiksystem dazu fuhren, dass Logistikleistungen dabei die Position eines bedingenden Faktors von raum-zeitlicher Strukturierung und Organisation der Gütertrans-

Vgl. Stabenau (1994), S. 56 f;; Oettle (1976), Sp. 4155.

Vgl. Köberlein (1997), S. 50 f.; Oettle (1976), Sp. 4155 ; Hamm (1989), S. 78.

„This tendency for peaks and troughs in the demand for transport is a reflection of fluctuations in the demand for the final products made accessible by transport services. (...) Longer-term fluctuations in the demand for shipping services reflect the state of business cycles in the trading nations - at the nadir of such cycles demand slumps, at the zenith it is extremely buoyant." Button (1993), S. 39 ; vgl. dazu auch Pirath (1934), S. 4; Köberlein (1997), S. 51.

Vgl. Brauer (1980), S. 81 f. 
formation einnehmen, verliert die Nachfrage nach Logistikleistungen ihren abgeleiteten Charakter. In letzter Konsequenz kann Logistik das Erscheinungsbild von produktiven und konsumtiven Prozessen sogar determinieren. ${ }^{147}$ Dies gilt umso mehr, als die Logistikqualität in den Transformationssektoren zunehmend einen wichtigen Wettbewerbsfaktor darstellt ${ }^{148}$ und dadurch $\mathrm{zu}$ einem aktiven Gestaltungsinstrument unternehmenspolitischer Überlegungen avanciert ist. Diese These wird gestützt durch die GöPFERTsche Einschätzung, dass die Bedeutung der Logistik als Auslöser für Produktinnovationen und generell für Innovationen anwachsen wird $^{149}$ und damit die Logistikinnovation (zumindest) gleichrangig mit der Produktinnovation als wettbewerbswirksames Instrument erkannt wird.

Die Nachfrage nach Logistikleistungen weist somit neben den unbestreitbar vorhandenen Tendenzen $\mathrm{zu}$ einer abgeleiteten Nachfrage ${ }^{150}$ - vor allem im Bereich der Nachfrage nach Verkehrsleistungen - ebenfalls Elemente einer originären Nachfrage auf. Diese Elemente gewinnen in dem Ausmaß an Bedeutung, als ein optimierter Güterfluss und damit die Nachfrage nach Logistikleistungen als Beitrag zu einer nachhaltigen Steigerung des Kundennutzens erkannt wird und nicht mehr lediglich als notwendiger Lückenschluss zwischen ansonsten isoliert optimierten Komponenten der Gütertransformation betrachtet wird. In diesem Falle ist auch eine aktive Einflussnahme auf das Volumen der Gesamtnachfrage nach Logistikleistungen seitens der Logistikwirtschaft möglich, welche dann in zunehmendem Maße auch entkoppelt von saisonalen oder konjunkturellen Ausschlägen des Produktionsvolumens von den Logistiknachfragern geäußert wird.

So weist Stabenau darauf hin, dass die durch die Nutzung neuer oder veränderter Transporttechnologien bewirkte Steigerung der Leistungsfähigkeit einzelner Transportsysteme bzw. Senkungen der Produktionskosten langfristig zu einer Steigerung der Transportnachfrage führt. Vgl dazu Stabenau (1994), S. 56. Will man dieses Argumentationsmuster „modern“ interpretieren, so kann damit nur die durch logistische Reorganisation bewirkte Leistungssteigerung und Dominanz logistischer Prozesse gemeint sein. Pfohl weist in diesem Zusammenhang darauf hin, dass die Nachfrage nach den Dienstleistungen von Logistikunternehmen zwar prinzipiell eine abgeleitete Nachfrage ist, jedoch dadurch nicht ausgeschlossen ist, „dass erst durch die Erbringung einer spezifischen logistischen Dienstleistung die Nachfrage nach einem Produkt „produziert" werden kann." Er führt als Beispiel dafür das Angebot von Blumen und Früchten aus Afrika oder dem Nahen Osten an. Pfohl (2004a), S. 280. 


\subsubsection{Besonderheiten bei der Produktion ausgewählter Logistikleistungen}

Unter den logistischen Dienstleistungen weist insbesondere die Transportleistung weitere untersuchungsrelevante Eigenheiten auf. ${ }^{151}$ Dies rührt daher, dass die Transportleistung im Gegensatz zu allen anderen Logistikleistungen nicht ortsfest produziert wird. Während Umschlag, Verpackung oder Lagerung nämlich dienstleistungstypisch durch zeitlich und örtlich zusammenfallende Produktions- und Konsumakte gekennzeichnet sind und somit in der Regel keine Besonderheiten gegenüber anderer Dienstleistungen aufweisen, ist das bei der Transportleistung nicht der Fall. ${ }^{152}$ Ziel des Transportvorganges ist die Raumüberbrückung, Transportleistungen haben somit keinen festen Standort der Produktion. ${ }^{153}$ Die damit verbundenen Besonderheiten werden im Folgenden erläutert.

\subsection{Transportleistung als organisatorisches Kuppelprodukt}

Wird ein Transport von B nach $\mathrm{C}$ nachgefragt, dann steht das für die Durchführung des Transportes vorgesehene Fahrzeug am Punkt B in der Regel nicht zur Verfügung. Es muss daher in einem Bereitstellungsverkehr von seinem Standort A an den Ort B herangeführt werden. Nach erfolgtem Transport an den Ort $C$ muss das Fahrzeug dann in aller Regel aus organisatorischen Gründen in einem Rücklaufverkehr an seinen Standort A zurückgeführt werden. Neben der eigentlich nachgefragten Transportdienstleistung $(B-C)$ entstehen also mit dem Bereitstellungs- $(A-B)$ und dem Rücklaufverkehr (C - A) zwei zusätzliche, nicht nachgefragte Verkehre (nicht Transporte!) als Kuppelprodukte. ${ }^{154}$ Diese Kuppelprodukte stellen keine durch eine unabdingbare, technische Verbundenheit mit dem Ausgangsprodukt anfallenden Kuppelprodukte im klassischen Sinne dar, sondern entstehen allein aus organisatorischer Notwendigkeit aufgrund der arteigenen Spezifika bei der Produktion der Transportleistung. Sie sind daher als organisatorische Kuppelprodukte zu bezeichnen. ${ }^{155}$ Vergleiche dazu die folgende Abbildung 2-12.

\footnotetext{
151 Vgl. Pfohl (2004a), S. $288 \mathrm{ff}$.

152 Vgl. Stabenau (1994), S. 51.

153 Ebenda.

154 Vgl. Rösler (2003), S. 59.

$155 \mathrm{Vgl}$. Stabenau (1994), S. 52.
} 


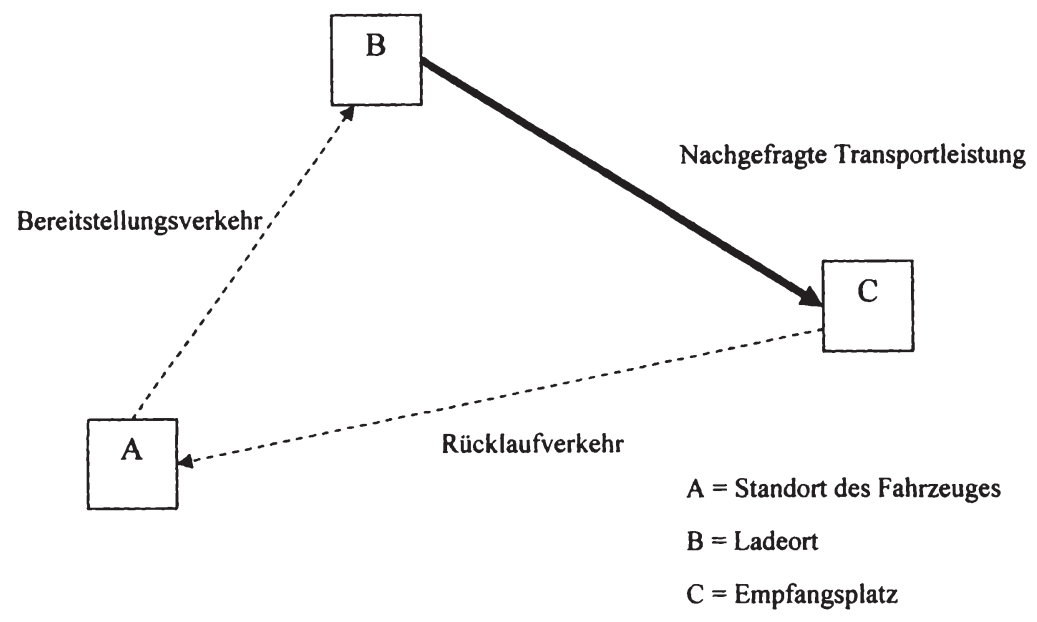

\section{Abbildung 2-12: Organisatorisches Kuppelprodukt bei der Produktion von Transportleistungen}

Quelle: Stabenau (1994), S. 53

Natürlich kann versucht werden, die mit leerem Fahrzeug gefahrenen Bereitstellungsund Rücklaufverkehre als zusätzliche Transporte zu vermarkten. Dies ist grundsätzlich möglich und wird auch in gewissem Umfang praktiziert. Allerdings sind dieser Zusatzvermarktung der Kuppelprodukte Grenzen gesetzt, welche vor allem in der Unpaarigkeit der Verkehrsströme bedingt ist. ${ }^{156}$ Unpaarige Verkehrsströme sind das Resultat der Tatsache, dass ein Fahrzeug, welches einen Transport von A nach B durchgeführt hat, nicht zwangsläufig eine adäquate Rückladung von $\mathrm{B}$ nach $\mathrm{A}$ finden kann. Die Ursachen dafür, dass die Nachfragen nach Transportleistungen an Ort A und an Ort B einander nicht entsprechen, sind nach PFOHL in den unterschiedlichen Wirtschaftsstrukturen der beiden Orte sowie in der administrativen Einflussnahme auf die Marktgeschehnisse auf den nationalen und internationalen Verkehrs- und Logistikmärkten zu suchen. ${ }^{157}$ 


\subsection{Differenzierte Produktionsverfahren}

Ein weiteres Spezifikum der Produktion der Transportleistung stellt das breite Spektrum verschiedener technologischer Verfahren dar, mit der Logistikdienstleister diese Dienstleistung produzieren. So erfolgt die Leistungserstellung bei den Verkehrsträgern Straßengüterverkehr, Eisenbahn, Schifffahrt, Luftverkehr oder Leitungsverkehr mit völlig unterschiedlichen Produktionsverfahren, die sich aus der Nutzung der unterschiedlichen Verkehrswege ergeben. ${ }^{158}$ Dies schlägt sich zwangsläufig in sehr unterschiedlichen Kostenstrukturen bei den Logistikunternehmen nieder. ${ }^{159}$ Diese unterschiedlichen Kostenstrukturen führen zu differenziertem Angebots- und Kalkulationsverhalten der Logistikunternehmen in Abhängigkeit von den jeweiligen betrieblichen Produktionsbedingungen und -prozessen. Dabei stehen die alternativen Produktionstechnologien grundsätzlich in Wettbewerb zueinander (sog. intermodaler Wettbewerb). ${ }^{160}$ Art, Intensität und Grenzen dieser verkehrsträgerübergreifenden Wettbewerbsbeziehungen werden dadurch bestimmt, inwieweit technologische Restriktionen bei den benutzten Verkehrswegen und -mitteln die bedarfsadäquate Bedienung des Marktes gewährleisten. Entscheidend sind hierbei die spezifischen Anforderungen, welche die jeweiligen Transportgüter (d. h. die externen Produktionsfaktoren) an die Transporttechnologie zur Erfüllung der Transportfunktion haben. ${ }^{161}$ Sie bestimmen somit maßgeblich den Grad der Substituierbarkeit alternativer Transportproduktionstechnologien und damit den Grad der Wettbewerbsbeziehung.

Dieses spezifische Anforderungsprofil der Transport-, und Verkehrsgüter, an die Qualität der Verkehrsleistung skizziert VoIGT mit dem Begriff der Verkehrsaffinität. ${ }^{162}$ Die Verkehrsaffinität drückt also ein aus den spezifischen Merkmalen und Eigenschaften des Transportgutes hervorgehendes und auf Nachfragerbeurteilungen basierendes Maß aus, ob und wenn ja, in welchem Umfang einer oder mehrere Verkehrsträger in der Lage sind, den Transportauftrag effizient abzuwickeln.

Vgl. Zöllner (1990), S. 57.

Vgl. Köberlein (1997), S. 76 ff.; Pfohl (2004a), S. 290; Stabenau (1994), S. 54 f. So ist bspw. der Anteil fixer Kostenbestandteile bei der Eisenbahn wesentlich höher als bei Straßengüterverkehr, der Personalkostenanteil bei der Binnenschifffahrt wesentlich geringer als bei Straßengüterverkehr und Eisenbahn.

Vgl. Isermann (2002), S. D2-7; Zöllner (1990), S. 57; Köberlein (1997), S. 106.

Vgl. Köberlein (1997), S. 106; Zöllner (1990), S. 59. Ein ähnliches Argumentationsmuster kann auf weitere von Logistikunternehmen erbrachte Leistungen angewendet werden. So determinieren die Anforderungen der logistischen Güter bspw. an die Lagerfunktion gleichermaßen die technologischen Ausstattungsanforderungen hinsichtlich der Lagergestaltung. Vgl. Zöllner (1990), S. 59.

Vgl. Voigt (1973), S. 108. 
Dazu werden den Verkehrsaffinitäten der Transportgüter die die verkehrsträgerspezifischen Leistungsfähigkeiten ausdrückenden Qualitätsmaßstäbe in Form von Verkehrswertigkeiten gegenübergestellt. ${ }^{163}$ VOIGT unterscheidet dabei folgende Teilaffinitäten bzw. Teilwertigkeiten: ${ }^{164}$

- Massenleistungsfähigkeit,

- Schnelligkeit, Transportdauer, Transportgeschwindigkeit,

- Netzbildungsfähigkeit,

- Berechenbarkeit,

- Zeitliche Flexibilität, Häufigkeit der Verkehrsbedienung,

- Räumliche Flexibilität,

- Sicherheit.

Der Abgleich der Struktur der Verkehrsaffinitäten des Verkehrsgutes mit den Verkehrswertigkeiten der zur Verfügung stehenden Verkehrsträger erlaubt es, jedem Transportauftrag ein dafür optimales Transportmittel bzw. einen optimalen Verkehrsträger zuzuordnen. ${ }^{165}$ Zudem erlaubt die Bezugnahme auf Verkehrsaffinitäten bzw. Verkehrswertigkeiten, Aussagen hinsichtlich der Entwicklung der Verkehrsteilung, d. h. der Aufteilung der gesamtwirtschaftlichen Verkehrsleistung auf die einzelnen Verkehrsträger, zu treffen. ${ }^{166}$

KÖBERLEIN macht in diesem Zusammenhang zwei wichtige Anmerkungen. Zum einen weist er darauf hin, dass die Verkehrsaffinitäten das Ergebnis von Nachfragerbeurteilungen darstellen und somit die Verkehrsaffinität ein und desselben Gutes im Zeitablauf Veränderungen unterworfen sein kann. ${ }^{167}$ Zum anderen deutet er an, dass eine auf logistischer Reorganisation basierende Veränderung der Produktionsabläufe (bspw. Just-in-Time-Produktion) gleichsam Konsequenzen für die Anforderungen an die Transportabläufe haben kann: die Just-in-Time-Produktion, die weitgehend auf Lagerhaltung verzichtet und höchsten Wert auf eine termingerechte, bedarfsgenaue

\footnotetext{
$163 \mathrm{Vgl}$. Pfohl (2004a), S. 338.

164 Vgl. Voigt (1973), S. $71 \mathrm{ff}$

165 Vgl. Ihde (2001), S. 198.

Vgl. Ihde (2001), S. 197.

Vgl. Köberlein (1997), S. 70.
} 
Anlieferung der für die Produktion benötigten Inputfaktoren legt, stellt besonders hohe Anforderungen an die Pünktlichkeit und Flexibilität der Transportprozesse. ${ }^{168}$ Logistische Reorganisation der Gütertransformation kann folglich Einfluss auf das Affinitätsprofil einzelner Güter nehmen.

\subsubsection{Zusammenfassung}

Die Analyse der ökonomischen Grundlagen der Logistik im Abschnitt 2.2 hat deutlich gemacht, dass es sich bei der Logistik bzw. der Logistikleistung um ein ausgesprochen komplexes Phänomen handelt. Diese Komplexität schlägt sich zuerst in teils miteinander harmonierenden, teils miteinander konkurrierenden theoretischen Interpretationen des Logistikbegriffes sowie artverwandter Begriffe nieder. Obwohl dem Abschnitt ein Vorschlag fur eine der Problemstellung angemessene theoretische Systematisierung und Strukturierung der Begrifflichkeiten Transport(leistung), Verkehr(leistung), Logistik(leistung) entspringt, muss dennoch einschränkend hinzugefügt werden, dass reale Ausprägungsformen von Logistik(leistungen) nur schwer und allenfalls fallweise in eine konsistente Systematisierung einzupassen sind. Den folgenden Ausführungen eine als allgemeinverbindlich apostrophierte Systematisierung logistischer Leistungen voranzustellen würde bedeuten, einen Konsens innerhalb der Forschungsgemeinde vorzutäuschen, den es so nicht gibt. Erschwerend kommt in diesem Zusammenhang hinzu, dass die einzelnen konkreten Logistikteilleistungen in Abhängigkeit des jeweiligen Kundenauftrages unterschiedliche Wertigkeit besitzen können und diese damit höchst differenzierte, auf die jeweiligen Kundenwünsche abgestimmte Leistungskomponenten bzw. -systeme darstellen. Daraus erhellt, dass die gesamte Vielfalt des Feldes der Logistik kaum vollständig zu erfassen ist. ${ }^{169}$ Ferner lässt sich daraus die Schlussfolgerung ableiten, dass das Selbstverständnis des Logistikfeldes wohl noch nicht gefestigt ist. Das wiederum stört den inneren Frieden sowie die innere Homogenität der Disziplin und ist dadurch bedingt letzten Endes auch der Außenwirkung und der Kontinuität des Wissen- bzw. Methodentransfers in die Wirtschaftspraxis abträglich. ${ }^{170}$

Diese eher formale Komplexität der Logistik(leistung) fußt auf einer starken materiellen Komplexität. So liegen die Definitions- und Abgrenzungsprobleme beim Logistik-

Vgl. Köberlein (1997), S. 70.

...und man somit vielleicht zusammen mit Klaus und Krieger resignierend feststellen muss, dass die Herausforderung, Logistik systematisieren zu wollen, gleichbedeutend ist mit der Frage „Wie den Pudding an die Wand nageln?" Klaus, Krieger (2000), S. XIII. 
begriff sicherlich zu einem Großteil darin begründet, dass sich die Logistik mit einer vergleichsweise unübersichtlichen Materie, nämlich der der umfassenden Optimierung leistungssystemübergreifender Güterflüsse und -netze, beschäftigt. Aber eben genau diese gesamthaft systemorientierte, güterflussorientierte, netzwerkorientierte Herangehensweise der logistischen Analyse wird in den allermeisten Definitionsvorschlägen explizit oder implizit als konstituierendes Konzeptmerkmal für den Logistikbegriff benannt und stellt somit eine Art ausbaufähigen Grundkonsens dar.

Das daraus resultierende Denken in hierarchisch strukturierten Logistiksystemen wiederum gibt in zweierlei Hinsicht entscheidende Anstöße für den Fortgang dieser Marktanalyse. Das Systemdenken bewirkt zum einen, dass die konzeptionelle Lücke zwischen dem abstrakten Verständnis der Logistik als Transfersystem auf der gesamtwirtschaftlichen Betrachtungsebene und der für die Marktanalyse notwendigen Betrachtungsebene der institutionellen Trägerschaft dieses Transfersystems und damit der institutionellen Verankerung der logistischen Leistungserstellung analytisch stringent geschlossen werden kann. Zum anderen ist das Systemdenken hilfreich, die Resultate der Marktanalyse in einem gesamtwirtschaftlichen Zusammenhang $\mathrm{zu}$ interpretieren und damit für eine vergleichende Analyse mit dem wirtschaftlichen Wettbewerb zugänglich zu machen.

Darüber hinaus bietet das logistische Fluss- und Systemdenken einen geeigneten Anknüpfungspunkt für die Untersuchung der ökonomischen Bedeutung der Logistik. Diese wurde im vorangehenden Unterabschnitt aus einzel- und aus gesamtwirtschaftlicher Betrachtungsperspektive durchgeführt. Auf einzelwirtschaftlicher Ebene wurden dabei mit dem logistischen Rationalisierungspotenzial und dem logistischen Wettbewerbspotenzial zwei Wirkungskomplexe unterschieden. Die Entdeckung des Rationalisierungspotenzials steht in enger Verbindung zur flussorientierten Betrachtung von Leistungserstellungsprozessen in den Industrie- und Handelsunternehmen. Die logistische Reorganisation der Leistungserstellungsprozesse von Industrie- und Handelsunternehmen legt kostentreibende Schnittstellenprobleme an den institutionellen und funktionalen Übergängen zwischen einzelwirtschaftlichen Subsystemen offen und hilft sie zu überwinden. Logistische Reorganisation fördert folglich durch die Offenlegung von neuartigen Kostensenkungspotenzialen bislang im Verborgenen gebliebene Rationalisierungsreserven zutage. Darüber hinaus führen diverse Veränderungen auf den Produktmärkten dazu, dass die Logistikqualität in Gegenüberstellung zur Produktqualität einen deutlichen Bedeutungszugewinn im Rahmen der Leistungserstellung erfährt. Aus dieser Tatsache bezieht die logistische Reorganisation ihr 
Wettbewerbspotenzial, indem sie unmittelbar auf die Markt- und Wettbewerbsposition des Verladerunternehmens einwirkt.

Die Erörterungen zu den beiden einzelwirtschaftlichen Wirkungskomplexen hinsichtlich der ökonomischen Relevanz der Logistik konkretisieren und veranschaulichen die systembindende und die systemkoppelnde Funktion, welche der Logistik in abstrakter Formulierung auf der gesamtwirtschaftlichen Betrachtungsebene beigemessen wird. Das Logistiksystem koppelt und verbindet die Systeme der Güterbereitstellung und der Güterverwendung und wirkt damit als Regulativ für die Koordination von gesamtwirtschaftlichen Produktions- und Konsumprozessen. Dabei gilt: In dem Umfang, in dem sich die Leistungsfähigkeit des Logistiksystems erhöht und Akzeptanz sowie Realisierung logistischer Reorganisationsvorhaben sich in Güterbereitstellungs- und Güterverwendungssystem ausweiten, bestimmt das Logistiksystem die Organisation der Gütertransformation. Das Logistiksystem stellt dann einen bedingenden Faktor der volkswirtschaftlichen Gütertransformation dar. Insbesondere nimmt es Einfluss auf gesamtwirtschaftliche Produktivität und Wachstum, indem sie neue Formen horizontaler und vertikaler Arbeitsteilung und ökonomischer Vernetzung vorantreibt und positiv auf die Realisierung von Innovationen und die Vermehrung von technischem Wissen auch außerhalb des Logistiksystems - einwirkt.

Die Frage nach der Bedeutsamkeit der beiden Themenkomplexe der Vernetzung und der Arbeitsteilung für die Logistik - und hier insbesondere deren institutionelle Ausgestaltungsformen - wird im Folgenden aufgegriffen und aus der Perspektive der Netzwerkökonomik und des gesamtwirtschaftlichen Strukturwandels vertiefend erörtert. 


\subsection{Zentrale Rahmenbedingungen des Logistikmarktes}

\subsubsection{Vorbemerkungen}

Die Analyse der Marktrahmenbedingungen, d. h. aller Bestimmungsfaktoren und Einflussgrößen, welche von außerhalb auf Angebot, Nachfrage und Koordinationsprozesse auf dem Untersuchungsmarkt einwirken, bildet den zweiten Baustein der Marktanalyse. Wie schon bei der Vorstellung des modifizierten SVE-Paradigmas angesprochen, existiert eine Vielzahl marktexterner Faktoren, welche unmittelbar (bspw. in Form eines direkten staatlichen Markteingriffes) und mittelbar (bspw. in Form durch sich ändernde ökonomische Rahmenbedingungen) Einfluss auf das Marktgeschehen zu nehmen vermögen. Diese Faktoren werden dabei unter den „basic conditions" subsumiert.'

So ist auch das Umfeld des Logistikmarktes gekennzeichnet durch eine Vielzahl denkbarer Bestimmungsfaktoren von denen - wie zu zeigen sein wird - einige bereits einer langen Tradition folgend Einfluss auf die Geschehnisse auf dem Logistikmarkt nehmen, andere wiederum erst vergleichsweise kürzlich an Bedeutung gewonnen haben. Diese Bestimmungsfaktoren werden in Abschnitt 2.3 Zweckmäßigkeitsüberlegungen folgend in

- verkehrspolitische Rahmenbedingungen (Unterabschnitt 2.3.2) sowie in

- ökonomische Rahmenbedingungen (Unterabschnitt 2.3.3)

aufgeteilt. Eine Zusammenfassung beschließt den Abschnitt (Unterabschnitt 2.3.4).

\subsubsection{Verkehrspolitik}

\subsubsection{Begründungen für verkehrspolitischen Handlungsbedarf}

Obwohl die marktliche und wettbewerbliche Selbststeuerung als fundamentale Grundlage einer an der Marktwirtschaft ausgerichteten Wirtschaftsordnung, wie sie in Deutschland in der Ausprägung einer Sozialen Marktwirtschaft vorliegt, eingestuft

Vgl. dazu Unterabschnitt 1.2.3.2.2. 
werden $\mathrm{kann}^{2}$, so ist die staatliche, regulierende Einflussnahme auf das Marktgeschehen trotzdem auf vielen Märkten zu beobachten und nimmt mitunter erhebliche Ausmaße an.

Wohl kaum ein anderer Wirtschaftssektor war und ist in einem vergleichbaren Umfange Gegenstand staatlicher Interventionsmaßnahmen wie der Verkehrssektor. In Anbetracht der im vorangegangenen Abschnitt 2.2 bereits ausgeführten ökonomischen Relevanz des Transfersystems - wovon der Verkehrssektor einen zentralen Bestandteil darstellt - verzichtet kein Staat mit einer arbeits- oder kapitalintensiven Wirtschaft auf eine aktive Verkehrspolitik. ${ }^{3}$ Um das verkehrspolitische Eingriffshandeln systematisch zu beschreiben und zu erklären, stehen mit dem normativ-theoretischen Ansatz und dem positiv theoretischen Ansatz zwei alternative regulierungstheoretische Erklärungsmuster zur Verfügung.

\subsection{Normativ- theoretischer Ansatz}

Im Rahmen des normativ- theoretischen Ansatzes wird der Frage nach der ökonomischen Sinnhaftigkeit von staatlichen Eingriffen in Marktprozesse - in diesem Falle der Sinnhaftigkeit der Verkehrsmarktregulierung - nachgegangen. ${ }^{4}$ Dabei wird geprüft, ob die vorgetragenen Gründe für staatliche Regulierung des Wettbewerbs auf den Verkehrsmärkten ökonomisch haltbar sind, d. h. staatliche Verkehrsmarktintervention gerechtfertigt ist. ${ }^{5}$ Staatliche Marktintervention kann dann als gerechtfertigt angesehen werden, wenn die individuellen marktlichen Transaktionen zwischen frei agierenden Wirtschaftssubjekten systematisch und dauerhaft ineffizient sind, d. h. wenn marktliche Funktionsmängel bestehen. ${ }^{6}$ Das Bestehen marktlicher Funktionsmängel wird häufig als Marktversagen bezeichnet. ${ }^{7}$ Im Verkehrssektor wurde lange Zeit die These vom Marktversagen postuliert und der Versuch unternommen, diese aus im Wesentlichen vier klassischen Argumenten theoretisch herzuleiten und zu untermauern: ${ }^{8}$

Vgl. Langfeldt (1986), S. 207.

Vgl. Köberlein (1997), S. 18.

Vgl. Aberle (2003a), S. 99.

Vgl. Laaser (1991), S. 51.

Vgl. Kruse, Berger (1996), S. 27 f.

Vgl. Kruse, Berger (1996), S. 28.

Vgl. Ihde (2001), S. 103 f.; Aberle (2003a), S. 99. Zu den vier Marktversagenstatbeständen vgl. grundsätzlich Krakowski (1988), S. 25 ff.; Fritsch, Wein, Ewers (1999). 
- Die Existenz natürlicher Monopole in der Verkehrswirtschaft,

- die den Verkehrsmärkten innewohnende Tendenz zu ruinöser Konkurrenz,

- die Bedeutung externer Effekte in der Verkehrswirtschaft sowie

- der Charakter bestimmter Verkehrsträger bzw. -leistungen als öffentliche Güter.

Aus dem normativ-theoretischen Ansatz bzw. aus den Marktversagensargumenten lassen sich staatliche Markteingriffe im Verkehrsbereich grundsätzlich und einzelfallbezogen ableiten. So kann das Wegstreckennetz der Eisenbahnen oder die Infrastruktur eines Flughafens als ein nicht angreifbares, natürliches Monopol betrachtet werden, welches Regulierungsaktivitäten begründen kann. ${ }^{9}$ Zudem ist der Verkehrssektor durch die Existenz von externen Kosten in Form von Umweltkosten, Stauungskosten oder Unfallkosten gekennzeichnet, was ebenfalls Regulierungseingriffe rechtfertigt. ${ }^{10}$ Für Teilbereiche der Verkehrsinfrastrukturnutzung gilt, dass sie bei der Preisbildung den Gesetzmäßigkeiten öffentlicher Güter folgt und somit regulierungsbedürftig ist. "

Daraus erhellt, dass der normativ-theoretische Ansatz zwar in der Lage ist, im Einzelfall und für einzelne Teilbereiche des Verkehrssektors einen partiellen Regulierungsbedarf herzuleiten. Jedoch vermag der normativ-theoretische Ansatz nicht die Jahrzehnte lang andauernde generelle und umfassende staatliche Regulierung der Verkehrswirtschaft (die sog. „Verkehrsmarktordnung") in dem Ausmaß, in dem sie stattgefunden hat, $\mathrm{zu}$ rechtfertigen. ${ }^{12}$ In den meisten in Rede stehenden Fällen verkehrswirtschaftlicher Regulierungsaktivität konnte und kann ein Marktversagen nicht nachgewiesen werden, bzw. sind staatliche oder private, den Wettbewerb beschränkende, Eingriffe in die Marktprozesse nicht das adäquate Mittel, um existierende Fehlentwicklungen zu korrigieren. ${ }^{13}$ Überlegungen, welche eine Fehlsteuerung des unregulierten Marktmechanismus im Verkehrswesen postulieren, liefern allenfalls wenig stichhaltige Argumente; zahlreiche so genannte Besonderheiten des Verkehrs,

\footnotetext{
Vgl. Berkelova (1992), S.163; Ihde (2001), S. 104 f.

Vgl. Köberlein (1997), S. 130.

Vgl. Ihde (2001), S. $107 \mathrm{f}$.

Diese Ansicht vertritt auch Ihde (2001), S. 109.

Vgl. Berkelova (1992), S. 165.
} 
welche vordergründig Regulierungsaktivitäten erforderlich mach(t)en, sind bei näherer Betrachtung eher Folge denn Ursache der Regulierung. ${ }^{14}$

\subsection{Positiv-theoretischer Ansatz}

Der positiv-theoretische Ansatz fragt nicht nach der Rechtfertigung, sondern nach der Erklärung der staatlichen Marktintervention. ${ }^{15}$ Er sucht Antworten auf die Frage nach Entstehung, Anwendung, Ablauf, Angebot und Nachfrage nach Regulierungstätigkeit und versucht zu erklären, warum ökonomisch nicht nachzuvollziehende und unter Umständen sogar gesamtwirtschaftlich schädliche Marktinterventionen trotzdem fortbestehen. ${ }^{16}$ Ausgangspunkt der Überlegungen ist dabei, dass Nachfrage nach Regulierung deshalb entsteht, weil die mit der Regulierung einhergehenden Wettbewerbsbeschränkungen einzelnen Beteiligten oder Beteiligtengruppen zugute kommen (Theorie des Rentseeking). ${ }^{17}$ Dies kann sogar dazu führen, dass sich Interessenharmonien zwischen den Regulierungsbehörden und den Adressaten der Regulierung einstellen (Capture Theory), da auch die Regulierungsbehörden von der Regulierung profitieren. ${ }^{18}$

Im Verkehrssektor finden sich zahlreiche Beispiele, welche Relevanz und Erklärungspotenzial des positiv-theoretischen Ansatzes eindrucksvoll belegen. ${ }^{19}$ Die eigens zum Schutze der Bahn initiierte Regulierung im Bereich des Straßengüterfernverkehrs (mittels Preisregulierung, Kontingentierung, Konzessionierung) zum Beispiel bewirkte ein Erlahmen des Wettbewerbs innerhalb des Verkehrsgewerbes, diente aber keinesfalls dem Schutz der Bahn. Daraus erhellt fast folgerichtig, dass der regulierte Straßengüterfernverkehr gute Gründe hatte, den Fortbestand der Regulierung zu befürworten. ${ }^{20}$ Zudem wurde die zuständige staatliche Überwachungsbehörde, die Bundesanstalt für den Güterfernverkehr (BAG), durch Umlagen des Straßengüterver-

\footnotetext{
14 Vgl. Laaser (1986), S. 330.

15 Vgl. Krakowski (1988), S. 95; Ihde (2001), S. 109.

16 Vgl. Köberlein (1997), S. 132. Der positiv-theoretische Ansatz zerfällt dabei in mehrere Teilgebiete, von einem einheitlichen, in sich geschlossenen Theoriegebäude kann nicht ausgegangen werden. Wesentliche Teilgebiete sind die Capture Theory, die Theorie des Rentseeking sowie der Bürokratietheoretische Erklärungsansatz. Vgl dazu Köberlein (1997), S. $132 \mathrm{ff}$.

18 Vgl. Aberle (2003a), S. 106; Ihde (2001), S. 109.

19 Auch Ihde konstatiert in diesem Zusammenhang, dass „dort, wo an Regulierung festgehalten wird, eine Gewichtsverschiebung der Argumente von der normativen zur positiven Theorie" $z u$ beobachten ist. Ihde (2001), S. 111. 
kehrsgewerbes sowie des Werkverkehrs finanziell getragen. ${ }^{21}$ Dieser Umstand dürfte auch seitens der BAG einem regen Interesse an einem möglichst langen Fortbestand der Regulierungsaktivitäten Vorschub geleistet haben.

\subsubsection{Erscheinungsformen, Verlauf und Wirkungen verkehrspolitischer Marktintervention auf den deutschen Verkehrsmärkten}

\subsection{Deutsche Verkehrspolitik bis zum Zweiten Weltkrieg}

Staatliche Einflussnahme auf die Geschehnisse im Verkehrssektor folgt in Deutschland einer langen Tradition, welche schon vor einem halben Jahrtausend von den Landesfürsten im Rahmen ihrer territorialen Weisungsbefugnis begründet und in der Folgezeit mit großem Eifer gepflegt worden ist. ${ }^{22}$ Das Recht für Dritte, Verkehrsleistungen jeglicher Art erbringen zu dürfen, war erlaubnispflichtig und an Abgabenzahlungen oder an das Gewähren sonstiger Vergünstigungen geknüpft. ${ }^{23}$

Mit Aufkommen der Eisenbahntechnik im 19ten Jahrhundert bekam die verkehrspolitische Einflussnahme eine neue Dimension. Die Eisenbahn als flächendeckendes, zuverlässiges, effizientes und mengen-leistungsfähiges Verkehrsmittel ermöglichte und beschleunigte die produktivitätssteigernde Arbeitsteilung in der industriellen Produktion und begründete damit Wohlstand und Massenmobilität von Gütern und Menschen. ${ }^{24}$ Die Anfänge der Entwicklung der Eisenbahn sind weitestgehend auf der Basis privatwirtschaftlicher Initiativen vollzogen worden, es bildeten sich im Binnenverkehr zahlreiche, gewinnträchtig arbeitende Gebietsmonopole heraus. ${ }^{25}$ Jedoch wurde im Wissen um die entwicklungs- und strukturpolitische Bedeutung der Eisenbahn die Forderung nach staatlichem Engagement in Form einer einheitlichen, deutschlandweiten (Eisenbahn-)Verkehrspolitik mit zunehmendem Nachdruck vorgetragen. ${ }^{26}$ Diese Forderung wurde dann schließlich, auch begünstigt durch die vollzogene territoriale Vereinheitlichung Deutschlands im Zuge der Gründung des Deutschen Reiches und dem Übergang in die Weimarer Republik, mit der Gründung der Deutschen Reichsbahn im Jahre 1920 voll umfänglich erfüllt. Zuträglich war

\footnotetext{
Vgl. Aberle (2003a), S. $106 \mathrm{f}$.

Vgl. Köberlein (1997), S. 136.

Vgl. Köberlein (1997), S. 136.

Vgl. Frahm, Klaus (2000), S. 513.

Vgl. Berkelova (1992), S. 47.

Vgl. Frahm, Klaus (2000), S. 513.
} 
dieser Entwicklung wohl auch der Umstand, dass die Eisenbahn neben ihrer bereits angesprochenen Relevanz für die Entwicklungs- und Strukturpolitik zudem fiskalpolitisch nutzbringend instrumentalisiert werden konnte. So wurde die Deutsche Reichsbahn dank ihrer gewaltigen Monopolgewinne für die teilweise Finanzierung der Staatshaushalte und für die Ableistung der Reparationszahlungen nach dem Ersten Weltkrieg (rd. 4,2 Mrd. Reichsmark) herangezogen. ${ }^{27}$ Zudem wurde die Reichsbahn aufgrund ihrer Stellung als Monopolist sog. „Gemeinwirtschaftlichen Verpflichtungen" unterworfen. Diese Verpflichtungen bestanden vorrangig aus der Betriebspflicht, der Tarifpflicht sowie der Beförderungspflicht. ${ }^{28}$

Das starke Aufkommen des motorisierten Straßenverkehrs, und hier insbesondere des Lastkraftwagens, als alternatives Transportmittel in den 1920er Jahren bewirkte die sukzessive Erodierung von traditionellen Monopolstellungen der Reichsbahn in den Bereichen des Gütertransports, in denen sie nicht schon vorher in Konkurrenz zur Binnenschifffahrt stand. ${ }^{29}$ Um die Reichsbahn, deren politische und ökonomische Bedeutung schon damals unbestritten war, vor dem Wettbewerb mit der Straße zu schützen, wurde der gewerbliche Straßengüterverkehr ab Beginn der 1930er Jahre einem engmaschigen und überdauernden Regulierungsregime unterworfen. ${ }^{30}$ Die wesentlichen Kernelemente dieses Regulierungsregimes waren die folgenden:

- Im Rahmen der „Überlandverkehrsverordnung“ von 1931 wurden für den Straßengüterfernverkehr (Transportradius von $>50 \mathrm{~km}$ Luftlinie um den Fahrzeugstandort) in Form einer Konzessionierung Marktzugangsbeschränkungen eingeführt, welche sich zunächst noch an subjektiven, qualitativen Kriterien (bspw. persönliche Zuverlässigkeit, fachliche Eignung) orientierten."

- Ferner wurde in dieser Verordnung der sog. Reichskraftwagentarif (RKT) erlassen. Der RKT war ein verbindlicher Tarif, der als Mindesttarif an den

Vgl. Aberle (2003a), S. 118.

Vgl. van Suntum (1993), S. 4; Eickhof, Berkelova (1990), S. 594; Aberle (2003a), S. 117 f. sowie ausführlich Laaser (1991), S. $104 \mathrm{ff}$.

Vgl. Laaser (1991), S. 136; Aberle (2003a), S. 118.

Vgl. Willeke (1995), S. 168; Eickhof, Berkelova (1990), S. 594. Im Rahmen der die Regulierung des Straßengüterverkehrs betreffenden sog. „Überlandverkehrsverordnung“ von 1931 wurde der Schutz des Verkehrsträgers Eisenbahn vor der Konkurrenz des Straßengüterverkehrs zum ersten Mal explizit und offiziell als Ziel der deutschen Verkehrspolitik genannt. Vgl. Berkelova (1992), S. 50.

Vgl. Laaser (1986), S. 329. 
Deutschen Eisenbahngütertarif (DEGT) gekoppelt war und diesen nicht unterscheiten durfte. ${ }^{32}$ Der intramodale individuelle Preiswettbewerb im StraBengüterfernverkehr sowie der intermodale individuelle Preiswettbewerb zwischen Schiene und Straße waren damit faktisch außer Kraft gesetzt.

- Im „Gesetz über den Güterfernverkehr mit Kraftfahrzeugen“ von 1935 kamen objektive, quantitative Marktzugangsbeschränkungen hinzu. Die Erteilung einer Fernverkehrskonzession wurde an die (für die Verkehrsunternehmen unbeeinflussbare) Größe des sog. „volkswirtschaftlichen Verkehrsbedürfnis“ gekoppelt. Diese Maßnahme war wegbereitend für die spätere Kontingentierung, d. h. der staatlichen Festlegung von Höchstzahlen für die Anzahl der Konzessionen. ${ }^{33}$

- Alle zugelassenen Fernverkehrsunternehmen mussten sich im sog Reichskraftwagen-Betriebsverband (RKB), einem öffentlich-rechtlichen Zwangskartell, zusammenschließen. Der RKB hatte in erster Linie die Funktion, die Festlegung und Einhaltung des RKT u. a. im Einvernehmen mit der Deutschen Reichsbahn zu initiieren, zu überwachen und durchzusetzen. ${ }^{34}$

- Der Straßengüternahverkehr (Transportradius $\leq 50 \mathrm{~km}$ Luftlinie um den Fahrzeugstandort) sowie der Werkverkehr (Beförderung von Gütern für eigene Zwecke) blieben zunächst - aufgrund der Existenz allenfalls schwacher Konkurrenzbeziehungen zur Reichsbahn - von der Regulierung unberührt. ${ }^{35}$

Wie der gewerbliche Straßengüterverkehr sah sich auch der Binnenschifffahrtsverkehr massiver Marktinterventionen gegenüber. Ziel dieser Interventionen war zum einen ebenfalls der Schutz der Eisenbahn. ${ }^{36}$ Zum anderen spielten mittelstandspolitische Überlegungen eine Rolle: da der Nachfrageeinbruch in Folge der Weltwirtschaftskrise 1929 zu immensen Überkapazitäten bei den kleinen Binnenschiffern (Partikulieren) führte, sollte die daraus erwachsende Gefahr ruinöser Preisunterbietungen ordnungspolitisch abgewehrt werden. ${ }^{37}$ Hierzu wurden die Partikuliere in den Jahren 1931 und 1932 mittels zweier Rechtsverordnungen in Zwangskartellen, den sog. Schifferbe-

\footnotetext{
Vgl. Aberle (2003a), S. 118.

Vgl. Eickhof, Berkelova (1990), S. 594.

Vgl. Wacker-Theodorakopoulos (1988), S. 298; Köberlein (1997), S. 140.

Vgl. Wacker-Theodorakopoulos (1988), S. 298.

Vgl. Eickhof (1993), S. 453; Aberle (2003a), S. 119.

$\mathrm{Vgl}$. dafür und für den folgenden Abschnitt Berkelova (1992), S. 52; Aberle (2003a), S. 119. 
triebsverbänden („stromgebietsmäßig geordnete Zwangsstrukturkrisenkartelle“38) organisiert. Ferner wurden sog. Frachtenausschüsse etabliert. Die Schifferbetriebsverbände hatten die Funktion, die Frachtaufträge, welche von den Reedereien erteilt wurden, nach festen Schlüsseln gleichmäßig auf den vorhandenen Laderaum aufzuteilen. Die Frachtenausschüsse legten zum Schutz der Partikuliere vor den Großreedereien und der Reichsbahn verbindlich „kostendeckende“ Beförderungsentgelte für nationale Binnenschifffahrtsleistungen fest und setzten - wie im gewerblichen Straßengüterverkehr - den intra- und den intermodalen Preiswettbewerb außer Kraft. ${ }^{39}$

\subsection{Deutsche Verkehrspolitik in der Zeit nach dem Zweiten Weltkrieg bis in die 1960er Jahre}

Nach Ende des Zweiten Weltkrieges wurde die prinzipielle verkehrspolitische Gesinnungshaltung, Prozesse auf den Verkehrsmärkten unter strenger staatlicher Kontrolle und losgelöst von Marktmechanismen zu belassen, zunächst voll umfänglich übernommen. ${ }^{40}$ Zentrales Anliegen war nach wie vor der Schutz der Eisenbahn vor zu starker Konkurrenz unter Berufung auf die Funktion der Eisenbahn als Instrument zur Durchsetzung einer Vielzahl politischer Zielsetzungen. ${ }^{4 l}$ Eine dringend erforderliche grundlegende Neugestaltung der rechtlichen und organisatorischen Strukturen der Eisenbahn, um den Verkehrsträger an die veränderten marktlichen und wettbewerblichen Anforderungen anzupassen, unterblieb jedoch. Ersatzweise wurden die konkurrierenden Verkehrsträger, und hier insbesondere der Straßengüterfernverkehr, umfassenden Regulierungsmaßnahmen unterzogen. ${ }^{42}$ Die wesentlichen Kernelemente des Regulierungsregimes der Nachkriegszeit im Straßengüterverkehr waren die folgenden:

Vgl. Laaser (1991), S. 140; Willeke (1995), S. 168.

Vgl. Köberlein (1997), S. 139 f.; Laaser (1991), S. 140.

Willeke bemerkt dazu kritisch:,Was zu Beginn ausdrücklich als Provisorium und Übergangshilfe gedacht war, wurde nicht nur volkswirtschaftliche Dauerlast, sondern Norm. In Deutschland war eine Denkschule entstanden, die für den Verkehr ordnungsrelevante Besonderheiten technischer, ökonomischer und politischer Natur behauptete, welche ein zielgemäßes Funktionieren des ,freien Wettbewerbs" nach den normalen Regeln der Marktwirtschaft ausschließen würden. (...) Das Regulierungswerk und die scheinwissenschaftliche Apologie der Besonderheitenlehre zeigten sich jedenfalls für den Verkehr der Bundesrepublik etabliert und resistent." Willeke (1995), S. $168 \mathrm{f}$.

Vgl. Eickhof (1993), S. 454; Aberle (2003a), S. 120.

Vgl. Aberle (2003a), S. 120. 
- Im Güterkraftverkehrsgesetz (GüKG) von 1952 wurde neben den subjektiven Marktzugangsbeschränkungen die Kontingentierung, d. h. die staatlich festgelegte Beschränkung der Konzessionen im Fernverkehr als objektive Marktzugangsbeschränkung gesetzlich festgeschrieben. ${ }^{43}$ Zudem wurden die Eingriffe in die Preisbildung im Fernverkehr bestätigt: der RKT blieb als Festtarif, gekoppelt an den DEGT, bestehen. ${ }^{44}$

- Zur Überwachung und Durchsetzung der Einhaltung des Tarifzwanges sowie der sonstigen wettbewerbsbeschränkenden Parameter der Verkehrsmarktordnung wurde für den aufgelösten RKB die Bundesanstalt für den Güterfernverkehr (BAG) geschaffen. ${ }^{45}$

- Für den Straßengüternahverkehr und den Werkverkehr wurden weitaus weniger restriktive Regelungen getroffen. Der Straßengüternahverkehr wurde mit einer an subjektive Kriterien angelehnten Konzessionspflicht belegt, es galt seit 1959 ein zum RKT abweichender, flexiblerer Güternahverkehrstarif (GNT) als Margentarif (Höchst-Mindest-Preis). ${ }^{46,47}$

- Für den Werkverkehr bestanden keine nennenswerten Marktzugangsbeschränkungen ${ }^{48}$, jedoch wurde der Werkverkehr durch das sog. „Drittladeverbot", d. h. das Verbot, Transporte für Dritte durchführen zu dürfen ${ }^{49}$, massiv beschränkt und von den Märkten für gewerbliche Straßengüterverkehrsleistungen hermetisch abgeschottet.

Vgl Köberlein (1997), S. 145; Soltwedel et al. (1987), S. 81 f.

Vgl. Soltwedel et al. (1987), S. 83.

Vgl. Berkelova (1992), S. 57. Zu Modalitäten des Preisbildungsverfahrens sowie zu Rolle und Befugnissen der BAG hinsichtlich der Überwachung und Durchsetzung des Tarifzwanges vgl. ausführlicher Lammich (1994), S. 20. Vgl. Berkelova (1992), S. 57 f.

Im Jahr 1992 wurde die Nahzone, und damit auch die vergleichsweise moderate Regulierung, auf $75 \mathrm{~km}$ ausgedehnt, vgl. Aberle (2003a), S. 124.

Es bestand einzig eine spezielle Meldepflicht für den Werk(fern)verkehr, durch welche alternative Wettbewerbsangebote der gewerblichen Anbieter angeregt werden sollten. Die spezielle Meldepflicht wurde dann 1986 abgeschafft. Vgl. Aberle (2003a), S. 124. Vgl. zum Werk(fern)verkehr ausführlicher Hamm (1994), S. 177 ff.

Vgl. Soltwedel et al. (1987), S. 84. 
Im Rahmen des Binnenschiffahrtsverkehrsgesetzes (BSchVG) von 1953 wurden die vor dem Krieg geltenden Funktionen und Aufgaben der Schifferbetriebsverbände sowie der Frachtenausschüsse weitestgehend übernommen. ${ }^{50}$

Die wettbewerbspolitische Sonderstellung der Verkehrswirtschaft wurde im Gesetz gegen Wettbewerbsbeschränkungen (GWB) von 1957 nachdrücklich unterstrichen. Der Verkehrssektor wurde zu einem wettbewerbspolitischen Ausnahmebereich erklärt (§99 GWB a. F.), auf den die allgemeinen Vorschriften des GWB gar nicht (Abs. 1) oder nur partiell (Abs. 2) anzuwenden waren. ${ }^{51}$ Damit wurden im Verkehrssektor neben den in den einschlägigen Verkehrsgesetzen kodifizierten staatlichen Wettbewerbsbeschränkungen zusätzlich auch private Wettbewerbsbeschränkungen nach Maßgabe des GWB legalisiert. ${ }^{52}$

\subsection{Wirkungen der Verkehrsmarktregulierung}

Von einer derart strengen Marktregulierung, wie sie im deutschen Verkehrssektor praktiziert worden ist, müssen auf Dauer ökonomische Fehlentwicklungen erwartet werden. ${ }^{53}$ Tatsächlich führten die Verfechter einer Liberalisierung der Verkehrsmärkte eine Reihe negativer Wirkungen der deutschen Verkehrspolitik ins Felde, welche im Folgenden dargestellt werden sollen. ${ }^{54}$

- Die Regulierung verursachte immense direkte Regulierungskosten in Form von Kosten für die Überwachung und Durchsetzung des Regulierungsregimes. ABERLE beziffert diese Kosten mit einer Höhe von jährlich ca. 100 Mio. $€^{55}$

- Die Transportpreise für Binnenverkehrsdienstleistungen waren regulierungsbedingt, verglichen mit einer Situation freier Marktpreisbildung, bei allen Binnenverkehrsträgern - insbesondere im Straßengüterfernverkehr - über-

Vgl. Eickhof, Berkelova (1990), S. 595; Eickhof (1993), S. 454.

Vgl. Berkelova (1992), S. 58 f.

52 Vgl. Eickhof, Berkelova (1990), S. 595. Der $\S 99$ enthielt für einen festgelegten Adressatenkreis bspw. Ausnahmen vom Kartellverbot oder den Bestimmungen über Preis- und Ausschließlichkeitsbindungen, vgl. dazu ausführlich Berkelova (1992), S. 59 ff.

Vgl. Laaser (1991), S. 21.

54 Vgl. dafür und für das Folgende Berkelova (1992), S. 100 ff.; Wacker-Theodorakopoulos (1988), S. 315 ff.; Aberle (2003a), S. 109 ff.; Laaser (1991), S. 21 ff.; Monopolkommission (1990), Tz. $764 \mathrm{ff}$.

55 Vgl. Aberle (2003a), S. 109.
} 
höht. ${ }^{56}$ Diese Hypothese wird durch folgende Indizien gestützt: a) es existierten starke Preisdisparitäten zwischen den (stark regulierten) nationalen Verkehren und den (vergleichsweise schwächer regulierten) grenzüberschreitenden Verkehren ${ }^{57}$, b) die überwiegende Mehrzahl der in Deutschland nach Tarif vereinbarten Transportentgelte lag an der unteren Margengrenze $\left.{ }^{58}, c\right)$ das Niveau der mit größeren Preismargen ausgestatteten Transportentgelte im Straßengüternahverkehr lag weit unterhalb des Preisniveaus im Güterfernver$k^{2} r^{59}$ und letztlich d) beim Verkauf von Unternehmen bzw. von Unternehmensteilen haben sich für den Eigenwert einer Konzessionen (und damit für den Marktzugang) nach Schätzung der Monopolkommission Knappheitspreise von bis zu 300.000 DM herausgebildet. ${ }^{60}$

- Ferner entstanden Kosten durch die künstliche Ausweitung des Werkverkehrs mit der Zielsetzung, die restriktiven Vorschriften des gewerblichen (vor allem Straßen-)Güterverkehrs zu umgehen. Angesichts der leistungsfeindlichen künstlichen Angebotsverknappung und der Zwangstarifierung im gewerblichen Güterverkehr, welcher sich die Verlader gegenüber sahen, benutzen diese die Möglichkeit, Werkverkehre zu betreiben, als willkommenes Regulativ. ${ }^{61}$

- Das erklärte verkehrspolitische Ziel, die Eisenbahn vor intermodaler Konkurrenz zu schützen, wurde nicht erreicht. ${ }^{62}$

Vgl. Berkelova (1992), S. 100.

Vgl. Monopolkommission (1990), Tz. 773; So lag bis Ende 1993 das Entgelt für eine Schiffsbeförderung von Mannheim nach Rotterdam unterhalb der Frachtkosten für eine Beförderung von Duisburg nach Mannheim. Der GFT überstieg vergleichbare Preise im Ausland um bis zu $40 \%$. Vgl. dazu Aberle (2003a), S. 110.

Die Margentarife wirkten also de facto wie Festtarife. Vgl. Berkelova (1992), S. 102 sowie Hamm (1989), S. 17.

Vgl. Monopolkommission (1990), Tz. 773.

Vgl. Monopolkommission (1990), Tz. 773. Und dies, obwohl der Handel mit Konzessionen eigentlich verboten war.

Vgl. Aberle (2003a), S. 110 f.; Monopolkommission (1990), Tz. 775 f. Diese Entwicklung war volkswirtschaftlich insbesondere deswegen negativ zu bewerten, weil der Werkverkehr im Vergleich zum gewerblichen Güterverkehr deutlich schlechtere Auslastungswerte aufweist und somit Ressourcen verschwendet werden. Als Grund hierfür ist das Drittladeverbot, dem der Werkverkehr unterlag, anzusehen. Vgl. Laaser (1991), S. $41 \mathrm{f}$.

Während seit den 1960er Jahren die Defizite der Deutschen Bundesbahn ständig anwuchsen (Jahresfehlbetrag 1960: 477 Mio. DM, 1989: ca. 4 Mrd. DM), war ein gleichzeitiger kontinuierlicher Rückgang des Marktanteils bei der Gesamtleistung am Güterverkehr zu verzeichnen (Marktanteil 1960: 38,2\%, 1989: 21,6\%). Vgl. Berkelova (1992), S. 100. Vgl. auch Laaser (1991), S. 21 ff. 
- Zudem wurde durch die Regulierung der Verkehrsmärkte jegliche Form von Wettbewerbsdynamik paralysiert: Angesichts der Tarifierung der Güterverkehrsleistungen unterließen es die Anbieter, innovatorische Aktivitäten oder Maßnahmen zur Verbesserung ihrer Produktivität zu unternehmen. Solche effizienzbedingten Wettbewerbsvorteile hätten am Markt aufgrund des eingeengten preispolitischen Spielraumes nicht umgesetzt werden können. ${ }^{63}$ Zudem sendeten die administrierten Transportpreise falsche Produktions- und Investitionssignale. Sie mindern das Investitionsrisiko der Anbieter und führten somit leicht zu Überkapazitäten. ${ }^{64}$

- Auch die quantitativen Marktzugangsbeschränkungen bewirkten ein Erlahmen wettbewerblicher Aktivitäten. Einerseits wurden die etablierten Unternehmen vor potentieller Konkurrenz geschützt, was der Bereitschaft zu Innovation und Angebotsverbesserung abträglich war. ${ }^{65}$ Ferner ermöglichte ein solches System, dass auch diejenigen Unternehmen im Markt verbleiben konnten, welche bei freiem Wettbewerb nicht mehr marktfähig gewesen wären (sog. submarginale Anbieter) ${ }^{66}$ Der regulierungsbedingte Verbleib submarginaler Anbieterschaft und der somit versagende wettbewerbliche Selektionsmechanismus in den Verkehrsmärkten führte zum Entstehen nicht marktfähiger Betriebsgrößen. ${ }^{67}$ Dies galt insbesondere für den Straßengüterverkehr.

- Die Marktregulierung im Verkehr löste erhebliche Allokationsverzerrungen aus und bewirkte eine suboptimale Arbeitsteilung. Dies wird wohl am Deutlichsten, wenn man sich die Entwicklung des Werk(fern)verkehrs im Vergleich zum gewerblichen Straßengüterverkehr vergegenwärtigt. Der Werk(fern)verkehr wurde von vielen Verladern bevorzugt praktiziert, obwohl

63 Dazu hätten die Anbieter aus dem Zwangskartell ausscheren müssen. Dazu hätten sie weder die Möglichkeit noch den Anreiz gehabt. Vgl. Laaser (1991), S. 41. Vgl. auch Hamm (1989), S. 23 f.; Berkelova (1992), S. 103.

Vgl. Hamm (1989), S. 26 f.; Eickhof, Berkelova (1990), S. 596.

Vgl. Berkelova (1992), S. 103; Monopolkommission (1990), Tz. 678. Von Verladerseite wurde oft beklagt, dass die von den gewerblichen Anbietern angebotenen Verkehrs- und Transportleistungen $\mathrm{zu}$ unflexibel seien und dass $\mathrm{zu}$ wenig auf Kundenwünsche eingegangen würde. $\mathrm{Vgl}$. Laaser (1991), S. 41. Auch Aberle weist auf die regulierungsbedingt niedrigen Angebotsqualitäten hin, welche das Ausbleiben von leistungsförderndem und sanktionierendem Wettbewerb begünstigt hat. Vgl. Aberle (2003a), S. 114.

Vgl. Aberle (2003a), S. 113; Hamm (1989), S. 24.

Vgl. Aberle (2003a), S. 113. 
er systemimmanent bedingt mindereffizient ist. ${ }^{68}$ Zudem bewirkte die künstliche Marktsegmentierung in Straßengüternah-, -bezirks- und -fernverkehr eine Verzerrung der relativen Transportkosten „bei gleichen Entfernungen zwischen dem Verkehr innerhalb von Ballungsräumen und demjenigen innerhalb peripherer Regionen“. ${ }^{69}$

- Letztlich wäre zu erwähnen, dass die Marktregulierung tendenziell mittelstandsfeindliche Züge aufwies. Während nämlich größere Logistikunternehmen die Möglichkeit hatten, dem Verlader logistische Komplettpakete anzubieten, welche zum Teil aus preisgebundenen Teilleistungen (bspw. Transportleistungen) und zum Teil aus preisungebundenen Teilleistungen (bspw. Komplementär- und Sonderleistungen ${ }^{70}$ ) bestanden, war dies den meisten kleinen, regional aktiven Verkehrsunternehmen nicht möglich. Mittels der Kombination von preisgebundenen und -ungebundenen Teilleistungen war die Möglichkeit zur Mischkalkulation und damit zum Unterlaufen der Preistarife mittels verdeckter Preisnachlässe gegeben, welche vor allem von international agierenden Logistikunternehmen rege ausgenutzt wurde. ${ }^{11}$

\subsubsection{Reform- und Deregulierungsprozesse in der deutschen Verkehrspolitik}

Seit Beginn der 1960er Jahre wurden nach und nach behutsame Liberalisierungsschritte in der deutschen Verkehrspolitik durchgeführt. Die „Kleine Verkehrsreform“ von 1961 brachte dabei die ersten Schritte zur Flexibilisierung der Verkehrsmarktordnung: ${ }^{72}$ Die Tarifparität ${ }^{73}$ zwischen den drei Binnenverkehrsträgern (Schiene, Straße,

Dies ist ein Indiz für mangelnde Angebotsqualität und/oder Preisflexibilität der gewerblichen Anbieter und bezeugt somit das Leistungsdefizit des Regulierungsregimes. Vgl. Berkelova (1992), S. $105 \mathrm{f}$.

Laaser (1991), S. 43. Unternehmen nämlich, die ihren Standort innerhalb der 50-km-Zone um Ballungsräume herum haben, kamen regelmäßig in den Genuss der günstigeren Nahverkehrstari$\mathrm{fe}$, während die Transporte zu den in peripheren Regionen gelegenen Unternehmen ( $>$ als $50 \mathrm{~km}$ von Ballungsräumen entfernt) meist zu den teureren Fernverkehrskonditionen abgewickelt werden mussten. $\mathrm{Vgl}$ ebenda. Die künstliche Marktsegmentierung bewirkte demnach de facto eine Schlechterstellung peripherer Regionen.

Vgl. Unterabschnitt 2.2.3.1.2.

71 Vgl. Berkelova (1992), S. 107. Internationale Marktakteure konnten zusätzlich die innerdeutschen (=tarifgebundenen) und die grenzüberschreitenden (= nicht-tarifgebundenen) Transporte gemischt kalkulieren.

Vgl. dafür und für das Folgende Wacker-Theodorakopoulos (1988), S. 301 ff.; Aberle (2003a), S.

121 f.; Eckey, Stock (2000), S. 321 f. 
Binnenschifffahrt) wurde gelockert und der Modus der Tarifbildung in Richtung einer „begrenzten Tarifautonomie ${ }^{\text {c67 }}$ modifiziert.

- Im gewerblichen Straßengüterfernverkehr wurden sog. Tarifkommissionen, bestehend aus Vertretern der Fernverkehrsunternehmer bzw. deren Verbände, sowie in beratender Funktion Verladerausschüsse, bestehend aus Vertretern der Verladerschaft, gegründet. Die Tarifkommission beschloss und beantragte Tarifänderungen (losgelöst vom DEGT) welche von den Verladerausschüssen mit einer ablehnenden bzw. befürwortenden Stellungnahme versehen an das Bundesverkehrsministerium weitergeleitet wurden. Das Bundesverkehrsministerium hatte die Tarifveränderungen in Einvernehmen mit dem Bundeswirtschaftsministerium als RKT festzusetzen und zu veröffentlichen. Mit dem Konstrukt der Tarifkommission wurde die bis dahin de jure geltende Befugnis und Verpflichtung des Bundesverkehrsministers, die Verkehrstarife zu koordinieren, aufgehoben und die Beteiligung der Marktakteure an der Preisbildung gestärkt. ${ }^{75}$ Zunächst war der $\mathrm{RKT}^{76}$ noch ein Festtarif, wurde dann später in einen Margentarif umgewidmet.

- Im gewerblichen Straßengüternahverkehr etablierten sich Margentarife mit sehr weiten Margen (40\%) und der Möglichkeit zu diversen Sondervereinbahrungen. Die Tarifkommissionen waren paritätisch mit Gewerbe- und Verladervertretern besetzt. Dem Bundesverkehrsminister blieb vor der Genehmigung der Preisänderungsempfehlungen ein Prüfungsrecht vorbehalten.

- Im innerdeutschen Binnenschifffahrtsverkehr erfolgte die Tarifbildung nach einem dem Straßengüternahverkehr ähnlichen System.

Nach einem zeitweiligen Rückschritt im verkehrspolitischen Liberalisierungsprozess Ende der 1960er bis Anfang der 1970er Jahre ${ }^{77}$ war die deutsche Verkehrsmarktord-

Tarifparität meint die Ausschaltung jeglichen Preiswettbewerbs zwischen den einzelnen Verkehrsträgern mittels aneinander gekoppelter Festtarife. Vgl. Eickhof, Berkelova (1990), S. 595.

Köberlein (1997), S. 150.

Vgl. Köberlein (1997), S. 149; Eickhof, Berkelova (1990), S. 595.

Welcher im Übrigen erst 1990 in Deutscher Güterfernverkehrstarif (GFT) umbenannt worden ist! In dieser Zeit griff der 1967 vorgelegte sog. „Leber-Plan“, welcher, wiederum zum Schutz der Bahn, umfassende dirigistische Maßnahmen gegen die konkurrierenden Verkehrsträger, insbesondere gegen die Straße, vorsah. Ziel war die Verlagerung von Transporten von der Straße auf 
nung seit Begin der 1980er Jahre durch durchgreifende Deregulierungsprozesse gekennzeichnet, deren wesentliche Stationen wie folgt skizziert werden können:

- Im Bereich der Marktzugangsregulierung im Straßengüterverkehr erfolgten 1991 erste Liberalisierungsansätze. Die bis dahin gültige Unterscheidung der Genehmigungen in Straßengüterfernverkehrs-, Bezirksgüterfernverkehrs-, internationale Fernverkehrskonzessionen usw. wurde abgeschafft und es wurden nur noch allgemeine Fernverkehrsgenehmigungen ausgegeben. Damit wurde zum einen bewirkt, dass die künstliche Marktsegmentierung in die o. g. voneinander abgeschotteten Teilmärkte abgeschwächt wurde. Zum anderen wurde im Rahmen dieser sog. „Farbenbereinigung،"78 die Zahl der allgemein gültigen Fernverkehrsgenehmigungen angehoben ${ }^{79}$. In den Folgejahren wurde die Anzahl der allgemeinen Straßengüterfernverkehrskonzessionen sukzessive erhöht, bis das Kontingentierungssystem zum 1. Juli 1998 dann endgültig abgeschafft worden ist. ${ }^{80}$

- Die Preisregulierung wurde durch das Inkraftreten des „Tarifaufhebungsgesetzes“ mit Wirkung zum 1. Januar 1994 für alle Binnenverkehrsträger aufgehoben. Seither können die Preise für Transport- bzw. Verkehrsdienstleistungen am Markt frei verhandelt werden, die Anbieter solcher Leistungen können Preise selbst kalkulieren und müssen sich nicht mehr an ein vorgegebenes Tarifwerk halten. ${ }^{81}$

- Ferner wurde zum 1. Januar 1994 die Bundesanstalt für den Güterfernverkehr (BAG) in das Bundesamt für Güterverkehr (BAG) umgewandelt. Das Aufgabengebiet des Bundesamtes umfasst vor allem die Marktbeobachtung des Verkehrsmarktes sowie die Kontrolle der Einhaltung von Vorschriften (Lenkund Ruhezeiten, technischer Zustand der Fahrzeuge).

- Mit der Zielsetzung, den Verkehrsträger Schiene wettbewerbs- und leistungsfähiger zu machen, trat ebenfalls zum 1. Januar 1994 die Bahnstrukturreform

die Schiene. Aufgrund des immensen politischen Widerstandes wurde dieser Plan nur in Teilen und kurzzeitig umgesetzt. Vgl. Aberle (2003a), S. 122. Vgl. auch Eckey, Stock (2000), S. 322 f. Die einzelnen Konzessionsarten wurden anhand der Farbe der Urkunde unterschieden, auf der sie ausgestellt waren: rote Fernverkehrskonzessionen, blaue Bezirksgüterfernverkehrskonzessionen, gelbe Möbelfernverkehrskonzessionen usw.

Vgl. Boss et al. (1996), S. 91.

Vgl. Aberle (2003a), S. 124.

Vgl. Boss et al. (1996), S. 91. 
in Kraft. In mehreren aufeinander folgenden Schritten wurde beginnend $a b$ diesem Datum die Bahn sukzessive privatisiert, zuerst in eigenständige Geschäftsbereiche unter dem Dach einer Holding (der Deutsche Bahn AG - Holding) und später in eigenverantwortliche, selbstständige Aktiengesellschaften aufgegliedert. Ein Kernstück dieser Reform war das Vorhaben, die Schienenwege der Deutsche Bahn AG für Dritte Anbieter zu öffnen. ${ }^{82}$

\subsubsection{Grundzüge der europäischen Verkehrspolitik}

\subsection{Verkehrspolitische Regelungen im EWG-Vertrag}

Schon der 1958 in Kraft getretene Vertrag zur Gründung der Europäischen Wirtschaftsgemeinschaft (EWG-Vertrag) sah eine gemeinsame europäische Verkehrspolitik (Art. 3e EWG-Vertrag) mit einer grundsätzlich marktwirtschaftlichen Ausrichtung vor. ${ }^{83}$ Der Vertrag enthielt keine expliziten Vorgaben über die konkrete Ausgestaltung der gemeinsamen europäischen Verkehrspolitik, übertrug dem Verkehrsministerrat jedoch die Aufgabe,

- gemeinsame Regeln für den grenzüberschreitenden Verkehr, bzw. den Transitverkehr zwischen den einzelnen Mitgliedstaaten zu schaffen sowie

- Bedingungen für die Zulassung von Unternehmen zum Verkehr innerhalb eines Mitgliedstaates, in dem sie nicht ansässig sind (sog. Kabotage), festzulegen (Art. 75 EWG-Vertrag). ${ }^{84}$

Diesen Obliegenheiten ist der Verkehrsministerrat jedoch bis Mitte der 1980er Jahre nicht nachgekommen. ${ }^{85}$ Der zentrale Grund dafür war, dass die Ansichten der Mitgliedstaaten hinsichtlich der Grundausrichtung der gemeinsamen Verkehrspolitik weit auseinanderklafften. Während die kleineren Länder wie die Benelux-Staaten bspw. die schnelle Errichtung eines freien europäischen Verkehrsmarktes befürworteten (Vorrang des Liberalisierungsgedankens), verlangten die großen Flächenländer wie

\footnotetext{
82 Vgl. ausführlich zu Verlauf sowie Wirkungen der Bahnstrukturreform Aberle (2003a), S. $141 \mathrm{ff}$.

83 Vgl. Eickhof (1993), S. 456.

84 Vgl. Köberlein (1997), S. 287.

85 Vgl. Eickhof, Berkelova (1990), S. 596.
} 
Frankreich, Italien und - allen voran - Deutschland, dass der Liberalisierung der nationalen Märkte eine weitgehende Angleichung der wettbewerbswirksamen Rahmenbedingungen voranzugehen habe (Vorrang des Harmonisierungsgedankens). ${ }^{86}$ Bedingt durch den grundsätzlichen materiellen Dissens hinsichtlich des Umfanges und der zeitlichen Priorität von Liberalisierungs- und Harmonisierungsmaßnahmen zur Angleichung der Wettbewerbsbedingungen war der Entwicklungsprozess hin zu einer gemeinsamen europäische Verkehrspolitik jahrzehntelang nahezu vollständig erlahmt. So wurden in der Zeit von 1958 bis Mitte der 1980er Jahre zahlreiche Vorschläge der europäischen Kommission, welche die Liberalisierung der europäischen Verkehrsmärkte bezweckten, vom Verkehrsministerrat verspätet oder nur teilweise umgesetzt, oder überhaupt nicht beschieden. ${ }^{87}$

Die gültigen Regelungen für den binneneuropäischen Verkehr sahen eine quantitative Beschränkung des Marktzuganges zum grenzüberschreitenden Verkehr mittels einer Kontingentierung vor. Ferner galt ein duales Tarifsystem für die Beförderungsentgelte. ${ }^{88}$ Kabotageverkehre waren weitestgehend verboten. ${ }^{89}$ Diese Regelungen machen deutlich, dass die Liberalisierungsgegner ihre Vorstellungen bezüglich der Ausgestaltung der gemeinsamen Verkehrspolitik weitestgehend durchsetzen konnten.

\subsection{Das Untätigkeitsurteil von 1985}

Die entscheidende Wende erfuhr die europäische Verkehrspolitik erst im Jahre 1985 in Form eines wegbereitenden Urteilsspruches des EuGH vom 22. Mai 1985, welcher den Liberalisierungsprozess der europäischen Verkehrsmärkte maßgeblich mit angestoßen hat. ${ }^{90}$ Das europäische Parlament hat den Verkehrsministerrat „wegen langjähriger Untätigkeit und Nichtbeachtung der in den Art. 71 und 75 [EWG-Vertrag, der Verf.] festgelegten zeitlichen Fristen" verklagt. ${ }^{91}$ Der EuGH stellte in seinem Urteil die Untätigkeit des Ministerrates auf dem Gebiet der gemeinsamen Verkehrspo-

Vgl. Eickhof, Berkelova (1990), S. 596. Köberlein stellt dazu fest: „Im Interesse eines rechtzeitigen Inkraftretens des EWG-Vertrages musste eine Einigung über die gemeinsame Verkehrspolitik vertagt werden, so dass der Vertragstext einen Kompromiss mit verschiedenen Auslegungsmöglichkeiten darstellt." Köberlein (1997), S. 288.

87 Vgl. Köberlein (1997), S. 291.

88 Zwischen den sechs EWG-Gründerstaaten (Deutschland, Italien, Frankreich, Belgien, Niederlande, Luxemburg) galten jeweils bilateral ausgehandelte obligatorische Margentarife, im Verkehr mit und zwischen den später beigetretenen Mitgliedstaaten wurden lediglich Referenztarife (= unverbindliche Preisempfehlungen) festgelegt. Vgl. Köberlein (1997), S. 293.

Vgl. Eickhof (1993), S. 456.

Aberle (2003a), S. 173. 
litik fest. Der Verkehrsministerrat habe unter Verletzung des EWG-Vertrages versäumt, auf dem Gebiet des Verkehrs die Dienstleistungsfreiheit im Sinne des EWGVertrages herzustellen. ${ }^{92}$ Folgerichtig verlangte der EuGH die Umsetzung der in Art. 75 EWG-Vertrag festgelegten Dienstleistungsfreiheit in einem angemessenen Zeitraum, vor allem mittels

- der Etablierung eines diskriminierungsfreien Marktzuganges der Verkehrsunternehmen aller Mitgliedstaaten zum grenzüberschreitenden Verkehr und

- der Schaffung von Regelungen zur freien Kabotage. ${ }^{93}$

Obwohl das Urteil keine konkreten ordnungspolitischen Vorgaben für die künftige Ausgestaltung der gemeinsamen Verkehrspolitik enthielt ${ }^{94}$, so stellte der EuGH doch ein für allemal klar, dass die Liberalisierung der europäischen Verkehrsmärkte unabhängig von der Frage nach der Harmonisierung der Rahmenbedingungen vorangetrieben werden muss. ${ }^{95}$ Der EuGH löste die Liberalisierungs-HarmonisierungsDebatte zugunsten der Liberalisierung auf und befand damit, dass es kein Junktim zwischen der Beseitigung von den Wettbewerb beeinträchtigenden Regelungen und der Harmonisierung von Wettbewerbsbedingungen gibt. Das Urteil hatte weit reichende Konsequenzen und bewirkte die Beschleunigung des Liberalisierungsprozesses.

\subsection{Liberalisierungsprozesse in der europäischen Verkehrspolitik}

Einige wesentliche Stationen dieses Prozesses sind im Folgenden skizzenhaft dargestellt: ${ }^{96}$

Vgl. Berkelova (1992), S. 199.

Vgl. Berkelova (1992), S. 200.

Vgl. Köberlein (1997), S. 291.

Vgl. Berkelova (1992), S. 200.

Das EuGH-Urteil schloß zwar grundsätzlich aller Verkehrsträger mit ein, jedoch betraf der angestoßene Liberalisierungsprozess vornehmlich den Straßengüterfernverkehr, weil die anderen Verkehrsträger zu diesem Zeitpunkt bereits weitestgehend dereguliert waren (wie bspw. die Binnenschifffahrt), ihr Leistungsangebot de facto auf das jeweilige Staatsgebiet beschränkt war (wie bspw. der Straßengüternahverkehr oder die Eisenbahnen) oder weil die Verkehrsträger noch vom EuGH ausgeklammert worden sind (wie bspw. die Luftfahrt oder die Seeschifffahrt). Vgl. Eickhof (1993), S. 456. Deswegen beschränken wir uns im Folgenden darauf, die den Straßengüterfernverkehr betreffenden Regelungen bzw. deren Änderungen vorzustellen. 
- Der diskriminierungsfreie Marktzugang zum grenzüberschreitenden StraBengüterverkehr wurde durch die jährliche Aufstockung des EGGemeinschaftskontingents bis zur endgültigen Aufhebung sämtlicher Obergrenzen für die Kontingente zum 1. Januar 1993 voll umfänglich gewährt. ${ }^{97}$

- Hinsichtlich einer durchgreifenden Kabotageregelung kam es mit Wirkung zum 1. Juli $1990 \mathrm{zu}$ ersten wirksamen Beschlüssen. Es wurden zunächst 15.000 Zwei-Monats-Genehmigungen an die EG-Mitgliedstaaten ausgegeben, welche dann sukzessive aufgestockt wurden, bis zur Einführung der quantitativ unbeschränkten Regelkabotage (die auch für den Werkfernverkehr galt) zum 1. Juli 1998. ${ }^{98}$

- Mit Wirkung zum 1. Januar 1989 wurden sämtliche gültige obligatorische Tarife in Referenztarife umgewidmet. Zum 1. Januar 1990 wurde dann schließlich die freie Preisbildung für sämtliche innereuropäische grenzüberschreitende Transportdienstleistungen durchgesetzt. ${ }^{99}$

\title{
2.3.2.4.4 Auswirkungen der europäischen Verkehrspolitik auf die deutsche Verkehrspolitik
}

Zwar ergaben sich aus den Entwicklungen in der europäischen Verkehrspolitik keine unmittelbaren rechtlichen Konsequenzen oder Verpflichtungen für die deutsche Verkehrsmarktordnung. ${ }^{100}$ Dennoch bewirkte die Deregulierungsinitiative der Europäischen Gemeinschaft, und insbesondere das Untätigkeitsurteil von 1985, eine grundlegende Umorientierung der Entscheidungsträger der nationalen Verkehrspolitiken hin zu Liberalisierung und Deregulierung. ${ }^{101}$ Dieser Entwicklung konnte sich auch

\author{
Vgl. Boss et al. (1996), S. 94. \\ Vgl. Aberle (2003a), S. 174. \\ Vgl. Eickhof (1993), S. 457; Eickhof, Berkelova (1990), S. 597 f. \\ Vgl. Eickhof, Berkelova (1990), S. 598.
}

Vgl. Aberle (2003a), S. 188. Natürlich darf nicht verkannt werden, dass auch gewichtige ökonomische Gründe massiv für eine die Effizienz steigernde Modifikation des ordnungspolitischen Rahmens des Verkehrssektors sprachen. Willeke ist sogar der Ansicht, dass die Deregulierung allein „der Wucht des Strukturwandels selbst" - also der ökonomischen Notwendigkeit zuzuschreiben ist und das Untätigkeitsurteil folglich eher „Anlass und nicht Ursache der einsetzenden Deregulierung" war. Willeke (1995), S. 183 f. Aberle ist hingegen sehr pessimistisch, was die ökonomische Ratio der Verkehrspolitiker anbelangt: „Zu glauben, dass... [die Liberalisierungstendenzen in der deutschen Verkehrspolitik, der Verf.]... in Deutschland überwiegend auf bessere Einsicht zurückzuführen sei[en], muss als Illusion charakterisiert werden." Aberle (2003a), S. 188. Ferner glaubt er, und da herrscht Konsens mit Willeke, dass die deutschen Verkehrspolitiker überaus resistent gegenüber der Politikberatung seitens der Verkehrswissenschaft waren wobei er insbesondere ,auffallende Interessenharmonien zwischen der verkehrspolitischen 
Deutschland nicht entziehen. Angesichts der von der europäischen Verkehrspolitik für den europäischen Binnenverkehr durchgesetzten Erleichterungen war die strenge deutsche Verkehrsmarktordnung mit einem obligatorischen Tarifsystem und einer quantitativen Marktzugangsbeschränkung für Inländer nicht mehr haltbar, die nationale Deregulierung nur noch eine Frage der Zeit. ${ }^{102}$

Mit der völligen Deregulierung des grenzüberschreitenden Straßengüterverkehrs und der gleichzeitigen Zulassung von ausländischen Anbietern in nationalen Binnenverkehren bis hin zur unbeschränkten Regelkabotage 1998 waren das deutsche obligatorische Tarifsystem und die deutsche Kontingentregelung nicht mehr durchsetzbar. Ein Festhalten an den Tarifen und der Kontingentierung wäre gleichbedeutend mit einer massiven Inländerdiskriminierung gewesen. Die in der Gestaltung ihrer Preis- und Mengenpolitik stark eingeschränkten deutschen Anbieter wären im Falle des Beibehaltens der nationalen Verkehrsmarktordnung der Konkurrenz ausländischer Anbieter ausgesetzt gewesen, die ungehindert und frei in der Gestaltung des Einsatzes der Wettbewerbsparameter in gewinnbringende deutsche Binnenmärkte hätten eindringen können. ${ }^{103}$

Parallel dazu sah sich die deutsche Verkehrspolitik und das deutsche Verkehrsgewerbe immer stärkerer Kritik aus den Reihen der verladenden Wirtschaft ausgesetzt, welche das regulierungsbedingt hohe Transportpreisniveau und die mangelnde, nicht den Bedürfnissen der Verladerschaft entsprechende Dienstleistungsqualität als Ursachen für ihre mangelnde internationale Wettbewerbsfähigkeit reklamierten. ${ }^{104}$ Zudem wurden von vielen Vertretern aus der verkehrswissenschaftlichen Forschungsgemeinde die allokativen und distributiven Fehlentwicklungen, die die deutsche Verkehrsmarktordnung produzierte, theoretisch immer besser aufgearbeitet und deren negative Konsequenzen zunehmend glaubhaft vorgetragen. ${ }^{105}$

Insofern war die Deregulierung des deutschen Verkehrssektors als eine ökonomische und politische Notwendigkeit zu betrachten, welche aber erst durch den mit der

Administration und den regulierten Bereichen der Verkehrswirtschaft (... $)^{\text {“ }}$ für die Abblockung von stufenweisen Deregulierungsschritten verantwortlich macht. Aberle (2003a), S. 188.

Vgl. Boss et al. (1996), S. $94 \mathrm{f}$.

Vgl. Aberle (2003a), S. 188 f. Diese sog. „Umkehrdiskriminierung“ trug maßgeblich dazu bei, dass sogar das deutsche Straßengüterverkehrsgewerbe selbst, das bis dahin vehement die Beibehaltung der Marktregulierung einforderte, für Deregulierungsmaßnahmen auf der nationalen Ebene plädierte. Vgl. van Suntum (1993), S. 4.

Vgl. Lammich (1994), S. 20 f.

Vgl. Willeke (1995), S. 183. 
europäischen Deregulierungsoffensive erzwungenen Anpassungsdruck ausgelöst worden ist.

\subsubsection{Wirkungen der Deregulierung}

Im Anschluss werden anhand ausgewählter Parameter und Indikatoren die Veränderungen dargestellt, welche sich nach der Deregulierung auf den deutschen Verkehrsmärkten ergeben haben. Dies geschieht exemplarisch am Beispiel des Straßengüterverkehrs, da der Verkehrsträger Straße aufgrund seines Leistungsvermögens und profils der schärfste Konkurrent der Eisenbahn ist und folgerichtig der umfassendsten Regulierung unterzogen war. Auswirkungen der Deregulierung im Sinne der Beseitigung von Fehlentwicklungen durch die Regulierung wurden daher insbesondere im gewerblichen Straßengüterverkehr erwartungsgemäß schnell augenfällig. Was die Entwicklung der Transportpreise betrifft, so sanken die Frachtsätze im inländischen Straßengüterfernverkehr im Zeitraum zwischen der zweiten Jahreshälfte 1993 und dem ersten Quartal 1994 um durchschnittlich 24\% gegenüber der bis dahin gültigen Margenuntergrenze des GFT. ${ }^{106}$ Ferner waren im gleichen Zeitraum bereits starke regionale sowie güterbezogene Preisdifferenzierungen $\mathrm{zu}$ beobachten. ${ }^{107}$ Beide Entwicklungen sind wohl hauptsächlich auf die Abschaffung der Tarifpflicht und den daraus resultierenden Preiswettbewerb zurückzuführen, da sie sich zwar synchron zu einer konjunkturellen Schwächeperiode vollzogen haben, sich aber dennoch abgekoppelt haben zum im selben Zeitraum konstant gebliebenen Preisniveau der (bereits liberalisierten) Transportpreise im grenzüberschreitenden Güterverkehr zu Partnerländern mit ähnlichem Konjunkturverlauf. ${ }^{108}$ Seither verharren die Frachtsätze, abgesehen von wettbewerbsüblichen Schwankungen, auf konstant niedrigem Niveau ${ }^{109}$ und liegen zwischen 25 und 40\% unterhalb der unteren Margengrenze des GFT. ${ }^{110}$ Die Anlehnung der Marktpreise an den GFT oder an individuelle „Haustarife“, welche wiederum auf dem GFT basieren, war - vor allem in der Anfangszeit nach der Preisfreigabe - für Transportunternehmer, aber auch für viele Verlader ein probates Instrument zu Preiskalkulation und -findung, da dadurch die Vergleichbarkeit zu frühren Preisvereinbarungen gewährleistet sowie die Sicherheit bei der Preisfindung für beide Parteien

Vgl. Wein (2004), S. 138; Boss et al. (1996), S. 96.

Vgl. Boss et al. (1996), S. 97.

Vgl. Boss et al. (1996), S. 98; Wein (2004), S. 138.

Vgl. dafür die Resultate der Marktbeobachtung des Bundesamtes für Güterverkehr: BAG (1999a), S. 14; BAG (2000), S. 15; BAG (2001), S. 8; BAG (2002), S. 10; BAG (2003), S. 11; BAG (2004), S. 14; BAG (2005a), S. 11.
} 
erhöht werden konnte. ${ }^{111}$ Korrekte individuelle Preiskalkulation allein auf Basis von Kosten- und Nachfrageaspekten war und ist insbesondere für kleinere Anbieter aufgrund des Fehlens eines aussagefähigen internen Rechnungswesens und mangelnder Routine bzw. Erfahrung mit marktlichen Preisfindungsprozessen schwer zu bewerkstelligen und muss daher bis heute mit Kalkulationshilfen und (kartellrechtlich erlaubten) unverbindlichen Preisempfehlungen seitens der verkehrswirtschaftlichen Fachverbände unterstützt werden. ${ }^{12}$ Seit dem Jahr 2005 ist ein leichter Anstieg der Transportentgelte - insbesondere im Spotmarkt-Geschäft - zu verzeichnen, welcher aufgrund der Weitergabe von eigenen Kostensteigerungen (Kraftstoffkosten, Kosten durch die Einführung der streckenbezogenen Maut) an die Auftraggeber durchgesetzt werden konnte. ${ }^{113} \mathrm{Da}$ im Stammkundengeschäft in der Regel längerfristige Verträge geschlossen werden, konnten diese Erhöhungen dort jedoch nicht in ähnlichem Umfang realisiert werden. ${ }^{114}$ Die Laderaumkapazitäten haben sich nach der Aufhebung der Kontingentierung im Straßengüterfernverkehr mit Wirkung Juli 1998 bis zum Jahr 1999 erhöht. Dies liegt vornehmlich daran, dass nun diejenigen Transportunternehmen, welche ihre Kapazitäten in Ermangelung einer Konzession bislang nur im Nahverkehr anbieten durften nun auch im Regional- und Fernverkehr als Anbieter auftreten und somit die Wettbewerbsintensität in diesem Marktsegment verstärken. ${ }^{115}$ Angesichts der Angebotsausweitung auf dem Güterfernverkehrsmarkt aufgrund der gestiegenen Laderaumkapazitäten durch Marktzutritte ausländischer und inländischer Transportunternehmer sowie angesichts der damit verbunden sinkenden Transportpreise gerieten eine Vielzahl kleiner und mittlerer Anbieter in existenzielle Nöte, da ihnen die Möglichkeiten fehlen, ihr traditionelles Leistungsportfolio ad hoc um logistische Leistungen zu erweitern und damit marktwirksam zu individualisieren. ${ }^{116}$ Größere Unternehmen mit internationalen Markterfahrungen aus bereits deregulierten ausländischen Märkten sowie spezialisierte Nischenanbieter konnten durch derartige Strategien positive Entwicklungen verzeichnen und von der Deregulierung profitieren. Diese differenzierte Entwicklung innerhalb der Anbieterschaft kann als Anstoß des marktlichen Ausleseprozesses von (sub-)marginalen Anbietern gewertet werden, welcher zu Regulierungszeiten weitgehend ausblieb und welcher

\footnotetext{
110 Vgl. Aberle (2003a), S. 373.

III Vgl. Aberle (2003a), S. 373.

112 Vgl. Aberle (2003a), S. 373 f.

113 Vgl. BAG (2006), S. 13; BAG (2007), S. 16.

114 Vgl. BAG (2007), S. 16.

115 Vgl. Cardeneo (2002), S. C3-4; BAG (1999b).

116 Vgl. BAG (2000), S. 21.
} 
sich nunmehr zwar mit zeitlicher Verzögerung, dafür aber umso heftiger vollziehen sollte. Diejenigen Anbieter - und das waren vornehmlich die kleinen und die mittleren Transportanbieter ohne fundiertes Wissen über Logistikleistungen und ohne Erfahrung mit wettbewerblichen Marktprozessen in bereits deregulierten internationalen Verkehrsmärkten -, welche es in der Sicherheit der regulierungsbedingt dauerhaft hohen Transportpreise schuldhaft unterlassen haben, Rationalisierungsmaßnahmen in ausreichendem Umfang einzuleiten und sich angemessen auf die sich absehbar ändernden Rahmenbedingungen vorzubereiten, mussten erkennen, dass diese Sicherheit trügerisch war und dass sie unter einem wettbewerblichen Regime in wirtschaftliche Bedrängnis geraten sollten. ${ }^{117}$ Der zunehmende Wettbewerbsdruck begründete Anreize für die Anbieter, vorhandene kostensenkende Rationalisierungspotentiale zu ergründen und $\mathrm{zu}$ erschließen sowie leistungssteigernde Anpassungsstrategien umzusetzen. ${ }^{118}$ Dies wiederum hatte zur Folge, dass der Leerfahrtenanteil aufgrund der deregulierungsbedingt gewonnenen Planungskompetenzen und abgeforderten Dispositionsleistungen für die Güterverkehrsunternehmen kontinuierlich sank. ${ }^{119}$

Insgesamt kann also konstatiert werden, dass die lethargische Bequemlichkeit, welche eine Vielzahl der Anbieter im Straßengüterverkehr zu Regulierungszeiten pflegte, deregulierungsbedingt einem intensiv geführten Wettbewerb gewichen ist, welcher die Transportpreise nachhaltig gesenkt, auf Zahl und Größe der Anbieter eingewirkt und die Anbieter zu ökonomischer Beweglichkeit veranlasst hat.

\subsection{3 Ökonomische Rahmenbedingungen}

\subsubsection{Netzwerkökonomik}

\subsection{Zu Begriff und Charakteristika der Netzwerkökonomik}

Die zunehmende ökonomische Relevanz digitaler Netzwerke sowie die wachsende Bedeutung von Informations- und Netzwerkgütern verlangen von allen Wirtschaftssubjekten entsprechende Maßnahmen, ihre Strategien an die veränderten Rahmenbe-

\footnotetext{
117 Vgl. Cardeneo (2002), S. C3-3 f.; Boss et al. (1996), S. 107.

118 Vgl. BAG (2000), S. 22.

119 Vgl. Cardeneo (2002), S. C3-4. Im Zeitraum von 1995 bis 2003 stieg der Anteil der Lastkilometer deutscher Lastkraftfahrzeuge kontinuierlich von $71,4 \%$ auf $78,1 \%$.Vgl. BAG (2004), S. 11.
} 
dingungen anzupassen. ${ }^{120}$ Insbesondere durch die Möglichkeiten, die uns die Netzwerktechnologien des Internet hinsichtlich der Verbreitung von Informationen und Informationsprodukten erschlossen haben, wurden in praktisch allen Wirtschaftsbereichen fundamentale Suchprozesse in Gang gesetzt, wie die neuen Produkt- und Leistungskomponenten effizient zu bündeln, die neuen Technologien zu alloziieren und bestehende Organisationsstrukturen entsprechend anzupassen sind. ${ }^{121}$ Ihren sichtbaren Niederschlag finden diese Effizienzsuchprozesse bspw. in neuen Formen der Spezialisierung durch Arbeitsteilung, der Erschließung von Kostensenkungspotentialen, der Realisierung von Größen- und Bündelungsvorteilen auf der Angebotsseite, der wachsenden Bedeutung von Netzwerkexternalitäten auf der Nachfrageseite sowie in neuartigen Formen der Kooperation und vernetzten Zusammenarbeit zwischen Produzenten, zwischen Konsumenten sowie auch zwischen Produzenten und Konsumenten. $^{122}$

Diese von SCHECHLER als „„̈konomisch-technologischer Strukturbruch“'123 bezeichnete Konstellation, mit welcher sich die Ökonomien gegenwärtig konfrontiert sehen, erfährt in Wissenschaftstheorie und in der ökonomischen Praxis gleichermaßen höchst unterschiedliche Etikettierungen. ${ }^{124}$ Insbesondere der häufig benutzte Begriff der „New Economy" erscheint jedoch in diesem Zusammenhang wenig geeignet, diese „neue“ Konstellation begrifflich zu umreißen. Der Neuigkeitsgrad eines ökonomischen Entwicklungsstadiums ist nämlich immer bezogen auf den Vergleich eines vergangenen mit einem gegenwärtigen Zustand und folglich relativ zu bewerten. So begründete das Auftreten von Basisinnovationen in der Vergangenheit schon mehrfach den Beginn einer ,relativen Neuen Ökonomie“. ${ }^{125}$ Deshalb ist es, SCHECHLERs Einschätzung folgend, zum Zwecke der Bemessung eines ökonomischen Entwicklungsstadi-

120

Vgl. Schechler (2002), S. 169.

Vgl. Hofmann (2001), Vorwort; Schechler (2002), S. 169. Auch Laaser und Soltwedel sind der Ansicht, dass der ökonomische und gesellschaftliche Wandel hin zu einer informations- und wissensbasierten Ökonomie vor allem durch die Ausstrahlung und Adaptionsprozesse der Netzwerktechnologien in die Wertschöpfungsprozesse möglichst vieler Branchen vorangetrieben wird. Vgl. Laaser, Soltwedel (2001), S. 173. Insbesondere den Zusammenhang zwischen Organisationsstruktur und technologischer Veränderung thematisiert Weber, S.-M. (1999), S. 7.

Vgl. Picot, Neuburger (2000), S. 591.

Schechler (2002), S. 12.

Die „Internet-Ökonomie“, die „schwerelose Ökonomie“, die „Informationsökonomie“ sowie allen voran - die „New Economy“ sind nur einige der gebräuchlichen Bezeichnungen. Vgl. Klodt (2001), S. 78.

Vgl. dazu insbesondere die Theorie der langen Wellen von Kondratieff (1926); vgl. auch Scherrer (1996). 
ums sinnvoll, dessen konstituierende Prinzipien und Charakteristika zu benennen. ${ }^{126}$ Bezogen auf die „gegenwärtige New Economy“ können die folgenden konstituierenden Prinzipien identifiziert werden:

- Bedingt durch den technischen Fortschritt im Bereich der Informations- und Kommunikationstechnologien (IuK-Technologien) wird der Aufbau digitaler Netzwerke ermöglicht und forciert. Auf diesen digitalen Netzwerken basierend stehen die Technologien als Querschnittstechnologien in nahezu allen Bereichen der Wirtschaft zur Verfügung und fungieren dabei als Träger der Informations- und Technologiediffusion. ${ }^{127}$ Folgerichtig nehmen die digitalen Netzwerke sektorenübergreifend Einfluss sowohl auf das Produktivitätsniveau als auch die Produktivitätsstruktur wobei diejenigen Wirtschaftssektoren profitieren, die sich die neuen Technologien besonders intensiv zunutze machen können. ${ }^{28}$

- Neben den Informationstechnologien als Medium zum Bewegen von Informationen nehmen auch Informationsgüter selbst eine zentrale Position ein. Netzwerkbasierte IuK-Technologien erhöhen die Diffusionsgeschwindigkeit von Informationen und erleichtern den Zugang zu ihnen. ${ }^{129}$ In diesem $\mathrm{Zu}$ sammenhang wird immer wieder die positive Eigenschaft der Informationsgüter hervorgehoben, die Transaktionskosten zu senken, da sie Kostensenkungspotenziale bergen, welche Markttransparenz zu erhöhen und Unsicherheit zu reduzieren in der Lage sind. ${ }^{130}$

- Informationen sind zu einem preiswerten, reichlich verfügbaren Wirtschaftsgut geworden ${ }^{131}$, welches konsequenterweise vermehrt nachgefragt wird. Als wesentlich knapperer Komplementärinputfaktor dazu könnte sich das $\mathrm{Hu}$ mankapital erweisen, d.h. „die nicht vermehrbare Fähigkeit, Information in Wissen umzuwandeln“. ${ }^{132}$ Informationen müssen für die Transformation in Wissen entsprechend verarbeitet werden; neben technologischen Netzwerken sind die veränderten Anforderungen an die Wirtschaftsakteure hinsichtlich ih-

Vgl. Schechler (2002), S. 169 f.

Vgl. Sachverständigenrat (2000), S. 127, 182; Klodt (2001), S. 78; Schechler (2002), S. 170.

Vgl. Freytag (2000), S. 305; Klodt (2001), S. 78.

Vgl. Freytag (2000), S. 305.

Vgl. Siebert (2000), S. 9.

Vgl. Weber, S.-M. (1999), S. 7.

Klodt (2001), S. 79; vgl. auch Laaser, Soltwedel (2001), S. 174. 
rer fachlichen Qualifikation sowie ihrer sozio-kommunikativen Fähigkeiten also gleichermaßen zu bedenken. ${ }^{133}$

Das zentrale Charakteristikum der hier beschriebenen "neuen“ ökonomischen Konstellation liegt also in der fortschreitenden qualitativen und quantitativen Vernetzung von Wirtschaftsakteuren, Abläufen, Informationen und Technologien wobei die modernen IuK-Technologien als „enabling technology“134 die treibende Kraft darstellen. Netzwerke avancieren zum zentralen Strukturprinzip ${ }^{135}$, werden zu einer überragend wichtigen Institution zur Koordination von Wirtschaftsaktivitäten. Es zeigt sich dabei, dass sich die Netzwerkökonomik in „wissenschaftlicher Reichweite “136 zur Transaktionskostentheorie befindet, welche ja den Versuch unternimmt, Funktionsweise und Leistungsfähigkeit alternativer institutioneller Arrangements zum Zwecke der Koordination ökonomischer Aktivitäten zu erklären. ${ }^{137}$ Und gerade die Organisation der institutionellen Bedingungen, welche die Transaktionskosten ökonomischer Austauschprozesse determinieren, gewinnt in der Netzwerkökonomik an Bedeutung: Dem prinzipiell transaktionskostensenkenden Potenzial (v. a. der Such- und Informationskosten) der modernen IuK-Technologien stehen auch transaktionskostenerhöhende Momente gegenüber: Der technische Fortschritt im Bereich der IuK-Technologien führt nämlich dazu, dass sich die Anzahl potenzieller Transaktionspartner aufgrund steigender Marktgröße erhöht, Marktprozesse beschleunigt werden, Markteintrittsbarrieren sinken und folglich der Wettbewerbsdruck insgesamt erhöht wird. ${ }^{138}$ Die Unternehmen in der Netzwerkökonomie sind demnach einer hohen Dynamik ausgesetzt. ${ }^{139} \mathrm{Um}$ unter solchen Bedingungen wettbewerbsfähig $\mathrm{zu}$ bleiben, müssen Unternehmen neue Formen der Arbeitsteilung realisieren; sie müssen jegliche sich bietende Spezialisierungsvorteile ausnutzen und sind zunehmend gezwungen, sich auf ihre Kernkompetenzen zu konzentrieren. ${ }^{140}$ Zunehmende Spezialisierung und Arbeits-

Vgl. Tapscott (1996), S. 24; Schechler (2002), S. 171.

Vgl. Wirtz (2001), S. 22.

Vgl. Schechler (2002), S. 171.

Schechler (2002), S. 171.

Vgl. dazu Unterabschnitt 2.1.3. Netzwerke lassen sich folglich transaktionskostentheoretisch orientiert interpretieren.

Vgl. Durth (2000), S. 639; Picot, Neuburger (2000), S. 593.

Vgl. Heger (2003), S. 10.

Auch Klodt betont die Auswirkungen der Netzwerkökonomik auf die Organisationsstrukturen von Unternehmen. Er stellt fest, dass viele etablierte Unternehmen die IuK-Technologien dazu benutzen, ihre Hierarchieebenen effizienter zu vernetzen und mittels Outsourcing und Lean- 
teilung wirkt nun aber tendenziell transaktionskostenerhöhend, die IuK-Technologien nehmen folglich auch mittelbar Einfluss auf die Höhe der Transaktionskosten ökonomischer Austauschprozesse. ${ }^{141}$ Zunehmende Arbeitsteilung zwischen spezialisierten Unternehmen kann nur bedingt über idealtypische (Spot)Markttransaktionen abgewickelt werden und erfordert daher eine Intensivierung der Zusammenarbeit mit Dritten, mit Partnern. ${ }^{142}$ Gleichermaßen ziehen Spezialisierung und Arbeitsteilung zwangsläufig das Auflösen vertikal integrierter Organisationsstrukturen nach sich; horizontale Strukturen ersetzen vertikale Strukturen, die Relevanz interorganisatorischer Koordinationsprozesse nimmt zu. ${ }^{143}$

Die Nutzung digitaler Netzwerke erleichtert derartige Formen der Zusammenarbeit, Ressourcen können partnerschaftlich genutzt werden. ${ }^{144}$ Kooperation als Interaktionsmuster bzw. Netzwerke als Institutionen erscheinen bedingt durch die typischen Transaktionsmerkmale (überdauernde, spezifische Investitionen bei gleichzeitig langfristigen Geschäftsbeziehungen und Verhaltensunsicherheit) in der Netzwerkökonomik aus der Transaktionskostenperspektive geboten und werden infolgedessen $\mathrm{zu}$ bedeutenden Mechanismen wirtschaftlicher Koordination. ${ }^{145}$

Folglich wird eine Ökonomie, in der diese Charakteristika an Relevanz gewinnen, im Folgenden als Netzwerkökonomie bezeichnet. Die ökonomische Lehre, welche sich mit der Analyse dieser Faktoren beschäftigt, wird als Netzwerkökonomik bezeichnet. Für den Begriff des (ökonomischen) Netzwerkes soll im Folgenden UMBHAUERs Definition zugrunde gelegt werden: „Für Ökonomen verweist das Konzept eines Netzwerkes sowohl auf die Struktur der Interaktionen der Akteure bzw. Agenten hin als auch auf die Eigenschaft von positiven Netzwerkexternalitäten. So können Netzwerke sowohl als eine Menge von Verbindungen (engl. Links), die die Interaktion zwischen Agenten ermöglichen, und als eine Menge von Agenten, die ein ähnliches Verhalten für verschiedene ökonomische Aufgaben zeigen, angesehen werden. “146 An dieser Stelle wird nochmals betont, dass

production-Konzepte eine Fokussierung auf ihre Kernkompetenzen zu erreichen. $\mathrm{Vgl}$. Klodt (2001), S. $90 \mathrm{f}$.

Vgl. Durth (2000), S. 639.

Vgl. Picot, Neuburger (2000), S. 593.

Vgl. Alt, Schmid (2000), S. 76.

Vgl. Weber et al. (2002), S. 53.

Zu diesem Ergebnis kommt auch Weber, S.-M. (1999), S. 7.

Umbhauer (1998), S. I. 
- in Unternehmen natürlich schon seit Langem elektronische Medien genutzt werden (z. B. EDI). Der zentrale Unterschied der einstigen zu der nun beschriebenen Situation ist, dass die IuK-Technologien in der Netzwerkökonomik eine systembildende Funktion innehaben, während sie vormals in der Regel lediglich den Charakter einer Unterstützungsfunktion für die Prozesse und Prozessketten hatten, ${ }^{147}$

- es sich bei den charakteristischen Veränderungsprozessen in der Netzwerkökonomik um Vorgänge handelt, die, wenngleich auch in unterschiedlich starkem Ausmaß, aber prinzipiell doch alle Wirtschaftszweige zumindest mehr oder weniger tangieren und daher nicht auf bestimmte einzelne Branchen beschränkt werden können und

- der netzwerkökonomische Entwicklungs- und Orientierungsprozess hier folgerichtig als für sämtliche Wirtschaftsbereiche mehr oder minder relevantes und als überdauerndes Phänomen begriffen werden soll, das unbeschadet des ökonomischen Misserfolges zahlreicher Dotcom-Unternehmungen der sog. „New Economy“ nach wie vor allgegenwärtig ist und jegliche ökonomische Interaktion beeinflusst und auch in Zukunft beeinflussen wird.

Entscheidend für die ökonomische Sinnhaftigkeit von Netzwerkverbindungen ist, dass die Etablierung und die Unterhaltung von Netzwerken kostenseitige und nutzenseitige Wirkungen zeitigen und dabei die Nutzen aus dem jeweiligen Netzwerkarrangement dessen Kosten übersteigen müssen ${ }^{148}$ Solche unter Effizienzgesichtspunkten getroffenen Entscheidungen hinsichtlich

- Form und Intensität der Vernetzung von Akteuren und Abläufen,

- der Bündelung von Produkt- und Leistungskomponenten in sämtlichen Feldern der Wertschöpfungskette oder

- der Allokation neuer Technologien

basieren dabei nicht auf für die Netzwerkökonomie neu geschaffenen Regeln, sondern folgen prinzipiell den altbekannten ökonomischen Gesetzmäßigkeiten: „Technology 
changes. Economic laws do not. “149 Allerdings können die veränderten Rahmenbedingungen dazu führen, dass bei der Anwendung dieser Gesetzmäßigkeiten in der Netzwerkökonomik der analytische Denkrahmen der traditionellen Ökonomik um zusätzliche Aspekte erweitert werden muss. ${ }^{150}$ SHAPIRO und VARIAN heben bspw. die immense Bedeutung von Netzwerkeffekten in der "neuen Informationsökonomie“ hervor, während die „alte industrielle Ökonomie“ maßgeblich durch Skalenerträge angetrieben wurde. ${ }^{151}$ SCHECHLER stellt ebenfalls auf die steigende Bedeutung von Netzwerkeffekten und deren Auswirkungen auf Marktvorgänge für die Netzwerkökonomik ab. Ferner führt er die Relevanz von Technologie- und Kommunikationsstandards ins Feld: „Das Argument der Standardsteuerung komplettiert die These, Netzwerke als Strukturmerkmal eines neuen wirtschaftstheoretischen Paradigmas anzuerkennen: Digitale und soziale Netzwerke erfordern Standards in technokommunikativer aber auch in sozio-kommunikativer Hinsicht. Gleichzeitig nehmen komplementäre Beziehungen zwischen Gütern und Anwendungskompetenzen zu. Damit spielen aus ökonomischer Sicht die Netzwerkeffekte, insbesondere die Netzwerkexternalitäten und deren marktprozessuale Folgewirkungen, eine immer größere Rolle in den volkswirtschaftlichen Untersuchungen. “152 Bislang weniger wichtige Gesichtspunkte gewinnen demnach an Bedeutung während vormals wichtigere Aspekte an Relevanz abnehmen, ohne jedoch völlig bedeutungslos zu werden. Was sich also in einem Veränderungsprozess begriffen sieht, sind demzufolge nicht die „Economic laws“ selbst, sondern die Akzentuierung einzelner Aspekte dieser Gesetzmäßigkeiten.

\section{Positive Rückkopplung, Netzeffekte}

Grundsätzlich beschreibt das Konzept der Rückkopplung den Einfluss, welchen die zunehmende Verbreitung eines Gutes auf dessen Wert für das einzelne Wirtschaftssubjekt hat. Eine positive Rückkopplung liegt demgemäß dann vor, wenn sich der Wert eines Gutes bedingt durch eine zunehmende Verbreitung erhöht. ${ }^{153}$ Diese Wertsteigerung wiederum veranlasst weitere Nutzer dazu, dem Netzwerk beizutreten um somit seinen Wert abermals zu steigern. Dies impliziert, dass Netzwerke über selbstverstär-

Vgl. Blankart, Knieps (1992), S. 73.

Shapiro, Varian (1999), S. 1 f.

Vgl. Erber, Hagemann (2002), S. 283.

Vgl. Shapiro, Varian (1999), S. 173.

Schechler (2002), S. 172.

Vgl. Hess (2000), S. 96.
} 
kende Kreisläufe positiver Rückkopplung verfügen. ${ }^{154}$ Auslösendes Moment für diese Kreisläufe in der Netzwerkökonomik ist die Existenz von Netzeffekten. ${ }^{155}$ Netzeffekte stellen jene Form positiver externer Effekte dar, welche entstehen, wenn durch die Vernetzung der Nutzer eines Produktes für den einzelnen ein nicht über den Marktmechanismus abgegoltener Zusatznutzen entsteht. Dabei kann sich die Beteiligung neuer Teilnehmer an einem Netzwerk sowohl direkt als auch indirekt auf die etablierten Netzwerkteilnehmer auswirken, was zu der Unterscheidung zwischen direkten und indirekten Netzeffekten führt. ${ }^{156}$ Bei direkten Netzeffekten steigt der Wert eines Netzproduktes mit der Anzahl seiner Nutzer. Beispiel hierfür sind Kommunikationsleistungen wie Telefon, Telefax usw.: Je mehr Teilnehmer das jeweilige Netzwerk hat, desto mehr potentielle Kommunikationspartner stehen dem einzelnen Teilnehmer zur Verfügung und umso größer ist der Wert des Netzwerkes. ${ }^{157}$ Indirekte Netzeffekte hingegen liegen vor, wenn sich der Zusatznutzen für den einzelnen Teilnehmer ohne direkte Interaktion mit anderen Teilnehmern ergibt. ${ }^{158}$ Beispiele für indirekte Netzeffekte sind komplementäre Systemprodukte in der Informationstechnologie: ${ }^{159}$ aufbauend auf einer zuvor implementierten Basissystemarchitektur (Betriebssystem) ist die Entscheidungsfreiheit hinsichtlich nachträglich zuzukaufender Systemkomponenten (Anwendungssoftware) deutlich eingeschränkt, da die Systemkomponenten mit dem Basissystem kompatibel sein müssen. Folglich hängt bei indirekten Netzeffekten der Wert eines Gutes (Betriebssystem) von der Verfügbarkeit kompatibler Komplementärgüter (Anwendungssoftware) ab, ein Betriebssystem ohne ein ausreichendes Bündel an kompatibler Anwendungssoftware wäre nutzlos. Je größer wiederum das Netzwerk des Betriebssystems ist, desto mehr Anstrengungen werden die Produzenten von Komplementärprodukten unternehmen, kompatible Produkte auf den Markt zu bringen. Die Verknüpfung zwischen Netzwerkgröße und Wert des Netzwerkes für den einzelnen besteht folglich nur indirekt. ${ }^{160}$

Vgl. Laupper (2005), S. 95.

Vgl. Zerdick et al. (1999), S. 157.

Vgl. Zerdick et al. (1999), S. 155.

Vgl. Katz, Shapiro (1985), S. 424.

Vgl. Kloster (2002), S. 26 f.

Vgl. Katz, Shapiro (1986), S. 822 f.

Vgl. Zerdick et al. (1999), S. 156.
} 


\section{Die kritische Masse}

Da die Kreisläufe positiver Rückkopplung in der Regel nicht selbstständig in Gang kommen, müssen die Anbieter von Netzwerkgütern bestrebt sein, diejenige Netzwerkteilnehmerzahl zu erreichen, ab derer die positiven Netzeffekte wirksam werden - die sog. ,kritische Masse“ ${ }^{\text {“61 }}$ Dazu stehen den Anbietern folgende vier Anknüpfungspunkte zur Verfügung:

- In der Startphase sollte sich der Preis des Netzwerkgutes vorrangig an der Zahlungsbereitschaft der relevanten Klientel orientieren und nur nachrangig an den Kosten der Leistungserstellung. U. U. ist es in dieser Marktphase sogar sinnvoll, einen negativen Deckungsbeitrag hinzunehmen. ${ }^{162}$

- Sofern sich in einer frühen Marktphase noch kein technologischer Standard durchgesetzt hat, sind Kaufsituationen für den Nachfrager von immenser Unsicherheit ${ }^{163}$ gekennzeichnet: er muss fürchten, sich für eine der konkurrierenden Technologien zu entscheiden, welche sich später am Markt nicht durchsetzt, und dabei alle Chancen auf die Realisierung von Netzeffekten zu verlieren. ${ }^{164}$ Diese Unsicherheit kann zu einer Kaufzurückhaltung der Nachfrager führen, welche dafür verantwortlich zeichnet, dass der Zyklus positiver Rückkopplung für keine der konkurrierenden Technologien anspringt. Daher ist es sinnvoll, dass sich die Konkurrenten in einer frühen Marktphase auf eine Standardisierung einigen. ${ }^{165}$

- Anbieter von Basissystemen sollten bestrebt sein, möglichst frühzeitig die technischen Spezifikationen ihrer Schnittstellen zu den Anwendungskomponenten offen zu legen. Damit wird den Anbietern dieser Anwendungskomponenten ermöglicht, schnell kompatible Komplementärgüter bereitzustellen. Dadurch wird die Realisierung indirekter Netzeffekte ermöglicht. ${ }^{166}$

\footnotetext{
161 Vgl. Hess (2000), S. 97; Ernst, Walpuski (1997), S. 269.

Vgl. Hess (2000), S. 97.

Vgl. Heger (2003), S. 10.

Vgl. Zerdick et al. (1999), S. 159.

Vgl. Hess (2000), S. 97; Ernst, Walpuski (1997), S. 273 f. Auch Heger betont die Bedeutung von Standards für eine flexible Zusammenarbeit in Netzwerken. Standards tragen wesentlich dazu bei, die Potenziale der modernen luK-Technologien zu nutzen, Teilsysteme miteinander kompatibel zu machen und somit fragmentierte Wertschöpfungsketten erfolgreich zu vernetzen. $\mathrm{Vgl}$. Heger (2003), S. 11.

Vgl. Hess (2000), S. 97.
} 
- Der Wert eines Netzwerkproduktes hängt nicht allein von der Entwicklung der tatsächlichen Netzwerkteilnehmerzahl ab, sondern gleichermaßen von den Erwartungen hinsichtlich ihrer zukünftigen Entwicklung. Deswegen ist das „Management von Erwartungen“ i. S. einer aktiven Vorankündigungspolitik notwendig, um die rasche Durchsetzung eines Netzwerkproduktes am Markt zu beschleunigen und ggf. erst zu ermöglichen. ${ }^{167}$

Die Tendenz zur Vernetzung und die damit verbundenen Modifikationen der institutionellen Strukturen zur Koordination wirtschaftlicher Aktivitäten bleiben nicht ohne Folgen für die Beziehungen zwischen Akteuren sowohl derselben Marktseite als auch der Marktgegenseite. Im Folgenden werden mit den business-to-business-Netzwerken und den business-to-consumer-Netzwerken die für diese Untersuchung relevanten Netzwerkkategorien der Netzwerkökonomik untersucht. ${ }^{168}$ Beide Bereiche vermögen, Einfluss auf logistische Prozesse zu nehmen. ${ }^{169}$

\subsection{Business-to-business-Netzwerke}

Unter business-to-business-Netzwerken (B2B-Netzwerken) sollen im Folgenden Netzwerke zwischen Unternehmen, also kooperative Verbindungen zwischen Akteuren der Marktangebotsseite, verstanden werden. B2B-Interaktionen dienen vornehmlich der Effizienzsteigerung mittels transaktionskostensenkenden Optimierungsstrategien im Leistungserstellungsprozess. ${ }^{170}$ Leistungsfähige digitale Netzwerke in der Netzwerkökonomie ermöglichen den Unternehmen eine effiziente interne und bilaterale Kommunikation, was sich auch positiv auf deren Möglichkeit und Fähigkeit zur Kooperation auswirkt. ${ }^{171}$ Um sich dieses kooperationsfördernde Potenzial der Netzwerkökonomik nutzbar machen zu können, müssen die Unternehmen ihre Informationsbeschaffungs- und Informationsverarbeitungsprozesse anpassen und optimieren.

167

Vgl. Laupper (2005), S. 100; Zerdick et al. (1999), S. 159.

Diese Einteilung der Netzwerkkategorien orientiert sich begrifflich an der Interaktionsmustermatrix des Electronic Business von Wirtz. Wirtz versteht unter Electronic Business „die Anbahnung sowie die teilweise respektive vollständige Unterstützung, Abwicklung und Aufrechterhaltung von Leistungsaustauschprozessen mittels elektronischer Netze..." Wirtz (2001), S. 34. Auch aus Sicht von Weber et al. (2002) ist die Art der Transaktionspartner ein entscheidendes Kriterium für die Unterscheidung verschiedener Ausprägungen der Netzwerkökonomik. Vgl. Weber et al. (2002), S. $44 \mathrm{f}$.

Vgl. Weber et al. (2002), S. 45.

Vgl. Wirtz, Kleineicken (2000), S. 628 f.

Vgl. Schechler (2002), S. 173. 
Während vor dem Vordringen der digitalen Netzwerktechnologien das Hauptaugenmerk der Unternehmen noch darauf lag, betriebsinterne Abläufe mittels datenbankenbasierter Datenintegration zu reorganisieren, konnten sie die Leitidee der Datenintegration später, als die Netzwerktechnologien zur Verfügung standen, auf betriebs- und unternehmensübergreifende Abläufe ausweiten. Die Netzwerktechnologien der Netzwerkökonomik sind insofern als Komplement zur Datenbanktechnologie zu begreifen, welcher die Vorteile der Datenintegration von betriebsinternen auf betriebsund unternehmensübergreifende Leistungserstellungsprozesse übertragen könnte. ${ }^{172}$ Die Nutzen der Datenintegration liegen nach HOFMANN insbesondere in

- der Beschleunigung und Verbesserung des Informationsflusses und der Informationsversorgung,

- der Verbesserung der Datenqualität sowie

- dem Potenzial zur Funktionsintegration, das sich den Unternehmen dadurch bietet. $^{173}$

Diese Vorteile der Datenintegration in Verbindung mit der verbesserten Leistungsfähigkeit der digitalen Netzwerktechnologien der Netzwerkökonomik können von B2BNetzwerken genutzt werden, indem sie im Verbund über standardisierte unternehmensübergreifende Schnittstellen eine netzwerkweite Daten-, Informations- und darauf aufbauend eine netzwerkweite Funktions- und Leistungsintegration vornehmen. Die Netzwerkökonomik verschafft den Unternehmensnetzwerken folglich strategische Wettbewerbsvorteile. ${ }^{174}$ B2B-Netzwerke stellen eine Ausprägungsform der „wirtschaftlichen Koordination über Kooperation" i. S. der Transaktionskostentheorie dar. Sie verbinden die Vorteile marktlicher Koordination (effiziente Ressourcenverwendung, starke autonome Anpassungsfähigkeit) mit den Vorteilen der Koordination über Hierarchie (effektive Kontroll- und Sanktionsmechanismen, stark ausgeprägte bilaterale Anpassungsfähigkeit): ${ }^{175}$ Informationen können gemeinsam genutzt, Teilleistungen zu marktfähigen Endprodukten zusammengeführt werden. Dies geschieht

\footnotetext{
172 Vgl. Hofmann (2001), S. 134, 135.

$\mathrm{Vgl}$. Hofmann (2001), S. $134 \mathrm{f}$.

Vgl. Schechler (2002), S. 173.

Vgl. Unterabschnitt 2.1.3.3.
} 
- auf der Basis datenbasierter Integration, die prinzipiell reversibel ist,

- notwendigerweise in einer Atmosphäre transaktionskostensenkenden, gegenseitigen Vertrauens ${ }^{176}$ und

- ohne rechtlich bindende vertikale Integration.

Bei den B2B-Netzwerken kann zwischen vertikalen und horizontalen Netzwerken unterschieden werden. Vertikale Netzwerke verknüpfen Unternehmen unterschiedlicher Produktionsstufen, horizontale Netzwerke verbinden Unternehmen, die auf derselben Produktionsstufe tätig sind.

\section{Vertikale B2B-Netzwerke}

Zwischen den entlang der Wertschöpfungskette am Leistungserstellungsprozess beteiligten Unternehmen existieren zahlreiche Interdependenzen, sowohl was den Informationsfluss als auch was den physischen Leistungserstellungsprozess betrifft. Mittels des Einsatzes moderner IuK-Technologien der Netzwerkökonomik kann in vertikalen B2B-Netzwerken ein Höchstmaß an datenmäßiger und informatorischer Integration erreicht werden. Dies ist die Voraussetzung dafür, die am Netzwerk beteiligten Unternehmen auch produktionstechnologisch zu integrieren, und zwar dergestalt, dass auf der Basis eines netzwerkweit optimierten Informationsflusses auch der physische Fluss der Inputfaktoren und Teilleistungen über die gesamte Wertschöpfungskette hinweg effizient und ohne Reibungsverluste an den interorganisatorischen Schnittstellen bis hin zum marktfähigen Endprodukt abläuft.

\section{Horizontale B2B-Netzwerke}

Horizontale B2B-Netzwerke betreffen die Verknüpfung von Unternehmen, die auf derselben Wertschöpfungsstufe der Angebotsseite eines Marktes tätig sind, also prinzipiell in einer Konkurrenzsituation zueinander stehen. In diesem Fall werden die jeweiligen Outputs der am Netzwerk beteiligten Unternehmen, welche in einem zueinander komplementären Verhältnis stehen müssen, zu einer aus Kundensicht präferenzadäquaten Systemleistung zusammengefasst. Diese Systemleistung genießt in der Regel einen Wettbewerbsvorteil gegenüber isoliert erbrachten Leistungskomponenten, da sie sowohl leistungsmäßig (bspw. durch eine höhere Anzahl an räumlichen 
Orten, an denen die Systemleistung verfügbar ist) als auch kostenmäßig (bspw. durch die Einsparung von Transaktionskosten oder die gemeinschaftliche Nutzung von Ressourcen aller Netzwerkpartner) für den Nachfrager attraktiver ist.

\subsection{Business-to-consumer-Netzwerke}

Business-to-consumer-Netzwerke (B2C-Netzwerke) thematisieren die Verknüpfung von Akteuren der Marktangebots- und der Marktnachfrageseite. Aus der Perspektive der Nachfrager bewirkt die Netzwerkökonomik eine Erhöhung der Markttransparenz, erleichtert den Vergleich der angebotenen Güter sowie deren Preise und stärkt ferner die Kommunikation mit anderen Nachfragern. Intermediäre auf Zwischenhandelsstufen können dabei der Gefahr, im Wertschöpfungsprozess obsolet zu werden, nur dadurch entgehen, dass sie ihre Existenz mit Mehrwertleistungen rechtfertigen. ${ }^{177}$ Aus Anbietersicht eröffnet die Netzwerkökonomik die Möglichkeit Produkte und (Massen)Märkte zu individualisieren. Einerseits werden die Nachfrager von diesen Individualisierungstendenzen profitieren können, da sie dadurch mit präferenzadäquateren Produkten bedient werden (Produktdifferenzierung). Andererseits zeitigt die informatorische Vernetzung der Nachfrager mit den Anbietern gleichermaßen auch Nachteile für erstere: da relevante Informationen über Nachfrageverhalten und Kaufgewohnheiten einfach und kostengünstig beschafft, technisch verarbeitet und ökonomisch nutzbar gemacht werden können, laufen die Nachfrager Gefahr, ihre wahre Zahlungsbereitschaft zu offenbaren. Anbieter können dann mittels Preisdifferenzierungsmaßnahmen versuchen, Konsumentenrenten abzuschöpfen. ${ }^{178}$

Die Etablierung eines stabilen B2C-Netzwerkes macht die Integration von Nachfrageund Produktionsprozessdaten erforderlich. Informationen bezüglich des Nachfragerverhaltens gehen dabei in Planung und Organisation des Leistungserstellungsprozesses ein und bedingen ihn im Idealfall maßgeblich. In der Regel hat ein stabiles B2CNetzwerk eine Besserstellung beider Marktpartner zum Resultat; der Anbieter erringt einen Wettbewerbsvorteil, da er auf Nachfragerwünsche schnell und individuell reagieren kann, der Nachfrager wird im Gegenzug mit präferenzadäquaten Gütern versorgt. ${ }^{179}$

\footnotetext{
$176 \mathrm{Vgl}$. Schechler (2002), S. 175.

$177 \mathrm{Vgl}$. Hofmann (2001), S. 8.

178 Vgl. Schechler (2002), S. $188 \mathrm{f}$.

179 Vgl. Schechler (2002), S. 189.
} 


\subsection{Netzwerkökonomik und Logistik bzw. Logistikleistung}

Wenn man sich die Netzwerkökonomik wie hier dargestellt als eine Konstellation vergegenwärtigt, deren wesentliches Charakteristikum in der von IuK-Technologien getriebenen Vernetzung ökonomischer Akteure und Prozesse besteht, so erscheint deren Relevanz für die Logistik bzw. für die Logistikleistung klar ersichtlich. Für die nachhaltige Etablierung zahlreicher zeitgemäßer Logistikleistungsprodukte ist die Anwendung moderner IuK-Technologien unabdingbar notwendig. Die logistische Prozesssteuerung von physischen Güterströmen zur raum-zeitlichen Transformation erfordert in aller Regel die Erhebung, Verarbeitung, Speicherung sowie die Weitergabe von güterbezogenen Daten. ${ }^{180}$ Für die systemweite, interorganisatorische Optimierung von Logistikprozessen bedeutet dies, dass die Beteiligten parallel zu der Verknüpfung der Güterströme auch die Integration der Datenflüsse mittels geeigneter IuKTechnologien anstreben müssen. ${ }^{181}$ Die Technologien der Netzwerkökonomik, welche jenes zu leisten in der Lage sind, sind mithin wesentliche Treiber für die erfolgreiche Umsetzung logistischer Konzeptionen. Die Realisierung eines systemübergreifenden effizienten Informationsaustausches sowie die Implementierung und Beherrschung der dazu notwendigen Infrastrukturen gelten als „kritische Erfolgsfaktoren“. ${ }^{182}$ Dabei wirkt sich das Potenzial der Netzwerktechnologien als „enabling technologies" sowohl auf der Ebene der Prozessoptimierung von Logistikprozessen selbst, als auch auf der Ebene der institutionellen Ausgestaltung und Veränderung der diesen Prozessen zugrunde liegenden Netzwerke und Netzwerkbeziehungen aus. ${ }^{183}$ Zwar benutzten die Logistikunternehmen schon in jener Zeit, bevor die Netzwerkökonomik an Relevanz gewann, IuK-Technologien. Jedoch hatten sie lediglich eine Unterstützungsfunktion bei der Abwicklung physischer logistischer Aktivitäten inne. ${ }^{184}$ Im Unterschied dazu hat der Einsatz von IuK-Technologien zur Prozesssteuerung im netzwerkökonomischen Kontext zudem eine systembildende und systemkoppelnde Funktion. ${ }^{185}$

Umgekehrt gilt aber auch, dass die im Rahmen der Netzwerkökonomik vorangetriebenen neuen Formen der Arbeitsteilung sowie der Kooperation innerhalb und zwischen den Gruppen der Produzenten und der Konsumenten nur dann realisierbar sind, wenn die ursprünglich auf Basis von Optimierungsüberlegungen zu digitalen Netzwerken und (immateriellen) Informationsgütern getroffenen institutionellen Arrangements auf

\footnotetext{
180 Vgl. Baumgarten (2001), S. 22.

181 Vgl. Straube, Butz (2005), S. 670.

$182 \mathrm{Vgl}$. Voß, Domschke (1999), S. 329.

183 Vgl. Straube (2001), S. 182.

184 Vgl. Koldau (2002), S. 453; Kummer, Fuster (1999), S. 382.
} 
einem entsprechenden physischen „Fulfillment“ gründen, welches in Sachen Dynamik und Stabilität mit den digitalen Netzwerken Schritt halten kann. ${ }^{186}$ Die als wesentliche Konzeptmerkmale der Logistik herausgearbeiteten Charakteristika a) gesamthafte, systemische Perspektive logistischer Betrachtung, b) das Denken in Netzen und c) die (Güter-)Flussorientierung erweisen sich dabei als Leitprinzipien, welche mit den Anforderungen der Netzwerkökonomik an die Gestaltung eines solchen physischen Fulfillments zusammenpassen. ${ }^{187}$ Die Logistik hat dementsprechend eine zu den auf der virtuellen Ebene angelegten Strategien der Netzwerkökonomik kompatible Intention bezogen auf die Ebene des physischen Güterflusses und komplettiert sie. Die Logistik wird daher auch bisweilen als „kritischer Erfolgsfaktor“ insbesondere für diejenigen Unternehmen interpretiert, welche sich eines Geschäftsmodells bedienen, das vornehmlich auf die Nutzung von Netzwerktechnologien der Netzwerkökonomik ausgerichtet ist. ${ }^{188}$ Ein Zurückbleiben der Qualität der physischen Logistikprozesse hinter der Güte der digitalen Vernetzung würde dazu führen, dass die hohe Erwartungshaltung der Kunden, nämlich dass nun „business at internet speed“ abläuft, durch physische Leistungsmängel enttäuscht würde. ${ }^{189}$

Somit kann die Beziehung der Logistik zur Netzwerkökonomik in zweifacher Hinsicht interpretiert werden:

- Einerseits kann die Logistik in erheblichem Umfang an den Potenzialen der IuK-Technologien der Netzwerkökonomik partizipieren, um leistungsfähige Logistiksysteme zu etablieren. Insbesondere werden die transaktionskostensenkenden Wirkungen des technischen Fortschritts, welcher im Bereich der IuKTechnologien der Netzwerkökonomik realisiert wurde, von der Logistik für die Zwecke der Optimierung der unternehmensübergreifenden Prozesskoordination instrumentalisiert. Ferner nutzt die Logistik die positiven Impulse für die Wissensdiffusion, welche von den neuen IuK-Technologien ausgehen, um Informationsasymmetrien und Informationsdefizite innerhalb und entlang der logisti- 
schen Prozesskette abzubauen. ${ }^{190}$ Logistik ist somit ein Anwendungsbereich der Netzwerkökonomik. ${ }^{191}$

- Andererseits muss die Netzwerkökonomik die angestrebte umfangreiche qualitative und quantitative ökonomische Vernetzung von Akteuren, Prozessen und Informationen stets auf Basis funktionsfähiger unternehmensübergreifender physischer Leistungserstellungsprozesse gestalten. Und hier ist es wiederum die Logistik, welcher die Aufgabe zufällt, die unternehmensübergreifende Optimierung unternehmensübergreifender Wertschöpfungssysteme zu koordinieren und diese physisch zu beherrschen. Insbesondere wird die zunehmende Komplexität der real-marktlichen Koordination, welche aus den transaktionskostenerhöhenden Wirkungen der Netzwerkökonomik resultiert, durch die Etablierung zweckentsprechender Logistiksysteme kontrollier- und beherrschbarer gemacht. Logistik ist somit ein Bestandteil der Netzwerkökonomik. ${ }^{192}$

Die erfolgreiche Umsetzung von aus der Netzwerkökonomik entstammenden neuen Geschäftsmodellen - insbesondere außerhalb des engen Bereichs der Produktion immaterieller Güter - ist somit abhängig von einer funktionierenden Integration von „neuen“ digitalen Informations- und Kommunikationsprozessen und „alten“ physischen Prozessabläufen unter dem gemeinsamen Dach anforderungsgerecht konzipierter Logistiksysteme. ${ }^{193}$ Bei der Logistik und der Netzwerkökonomik handelt es sich folglich um zwei Konzeptionen, welche zueinander komplementär sind, sich wechselseitig bedingen und sich in ihrer Weiterentwicklung gegenseitig voranbringen. ${ }^{194} \mathrm{Sie}$ sind Ausdruck sich positiv verstärkender, kongruenter Denk- und Gestaltungsansätze zur Beherrschung komplexer vertikaler und horizontaler real-marktlicher Koordinationserfordernisse.

Um nun die Wechselwirkungen der Netzwerkökonomik mit dem Logistiksystem differenzierter aufzeigen zu können, wird auf die unter 2.3.3.1.2 und 2.3.3.1.3

190 Vgl. Straube, Butz (2005), S. 670.

191 Vgl. ähnlich Alt, Schmid (2000), S. 81, welche ihre Ausführungen auf die Beziehung von Logistik zu einzelnen Phasen eines mit luK-Technologien unterstützten Transaktionssystems beziehen.

Vgl. ähnlich Alt, Schmid (2000), S. 81, welche ihre Ausführungen allerdings auf die Beziehung von Logistik zu einer konkreten, mit luK-Technologien unterstützten Transaktion beziehen.

Vgl. Femerling (2003), S. 206; Schmitt (2003), S. 177. 
vorgestellten Netzwerkkategorien der Netzwerkökonomik zurückgegriffen. Diese werden dahingehend modifiziert und erweitert, dass

- innerhalb des Unternehmenspols („,business") die Gruppe der Verlader als die Nachfrager logistischer Dienstleistungen und die Gruppe der Logistikdienstleistungsunternehmen getrennt voneinander betrachtet werden sollen und dass

- ein zusätzlicher Pol „Administration“, welcher die Gruppe der Träger öffentlicher Gewalt umfassen soll, in das Analyseraster mit auigenommen wird. ${ }^{195}$

Damit ergibt sich das in der folgenden Abbildung 2-13 dargestellte System möglicher Netzwerkbeziehungen. Die Pfeile symbolisieren alle sinnvoll möglichen Dimensionen netzwerkökonomischer Beziehungsmuster, die dicken Pfeile symbolisieren die hier betrachteten Interaktionsrichtungen:

Business (B)

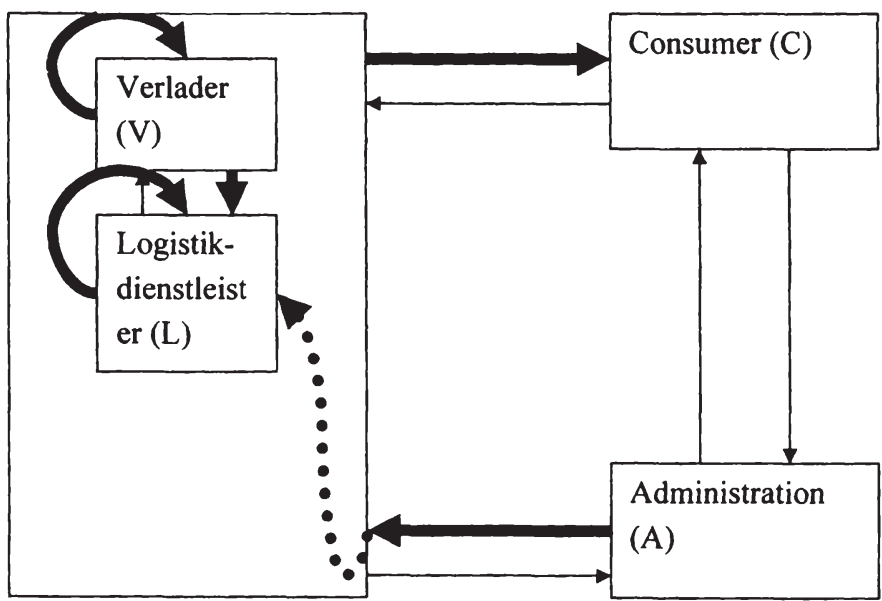

\section{Abbildung 2-13: Mögliche Netzwerkbeziehungen zwischen Stakeholdern im Logistikmarkt}

Quelle: Eigene Darstellung in Anlehnung an Nemoto, Visser, Yoshimoto (2001), S. 3 
Die Differenzierung zwischen Verladern und Logistikdienstleistungsunternehmen erscheint deshalb als sinnvoll, da der Begriff B2B in der Regel lediglich auf die Transaktionen zwischen Verladern abhebt (V2V). Die Transaktionen im Logistikmarkt umfassen jedoch gleichermaßen die von IuK-Technologien gestützten Netzwerkbeziehungen zwischen Verladern und Logistikdienstleistungsunternehmen (V2L) sowie zwischen Logistikdienstleistungsunternehmen (L2L). ${ }^{196}$ V2L-Netzwerke stellen dabei stets eine Ausprägung vertikaler B2B-Netzwerke dar, L2L-Netzwerke können sowohl in Form vertikaler als auch horizontaler B2B-Netzwerke vorkommen. Die Einfuhrung der Administration erscheint deshalb als sinnvoll, da sie unter Berücksichtigung und mit Rückgriff auf die vorhandenen Netzwerktechnologien der Netzwerkökonomik Verkehrs- und Logistikpolitik betreibt und somit ebenso Einfluss auf den Logistikmarkt nimmt (A2L). ${ }^{197}$

Im Folgenden sollen die bis hierhin eingeführten Netzwerkkategorien B2B (resp. V2V), B2C, V2L, L2L und A2L, welche die für unsere Zwecke wesentlichen Dimensionen netzwerkökonomischer Beziehungsmuster darstellen, nacheinander auf ihren Einfluss auf die Gestaltung logistischer Systeme untersucht werden.

\section{(a) Einfluss der Netzwerkökonomik auf das Logistiksystem aus Perspektive der Verlader: B2B- und B2C-Netzwerke}

Die wachsende Relevanz der digitalen Netzwerke und IuK-Technologien der Netzwerkökonomik für die Transaktionen zwischen Unternehmen sowie zwischen Unternehmen und Endkunden wird terminologisch eng mit dem Begriff des Electronic Commerce (E-Commerce) verknüpft. ${ }^{198}$ So bezeichnet E-Commerce i. w. S. die elektronische Unterstützung sämtlicher ökonomischer Wertschöpfungsaktivitäten, ECommerce i. e. S. lediglich die elektronische Unterstutzung von Informations-, Vereinbarungs- und Abwicklungsaktivitäten. ${ }^{199}$ Auf welche ökonomischen Aktivitäten konkret man den Begriff des E-Commerce nun im Einzelfall ausdehnen oder be-

Vgl. Nemoto, Visser, Yoshimoto (2001), S. 2 f.

Vgl. Nemoto, Visser, Yoshimoto (2001), S. 2.

Vgl. dazu bspw. Weber et al. (2002).

Vgl. Alt (2000), S. 112. Dabei ist der Begriff des E-Commerce nicht trennscharf vom Begriff des E-Business abzugrenzen. Letzterer beinhaltet in einer im Vergleich zum Begriff des E-Commerce umfassenderen Definition „die elektronische Unterstützung von Geschäftsprozessen zwischen Unternehmen, öffentlichen Einrichtungen und/oder Privatpersonen durch öffentliche, teilöffentliche und/oder private Netzwerke", wird aber teilweise auch synonym verwandt, vgl. Krieger (2000), S. 100. 
schränken möchte, ist hier jedoch nicht von zentraler Bedeutung. Wichtig ist jedoch die Erkenntnis, dass

- zwischen den Begriffen des E-Commerce und der Netzwerkökonomik sowohl eine terminologische als auch eine inhaltliche Sinnverwandtschaft besteht ${ }^{200}$ und dass

- das Vordringen des E-Commerce erhebliche Veränderungen im Aufbau von Supply Chains nach sich zieht. ${ }^{201}$

Sämtliche Beteiligte werden versuchen, an den Effizienz- und Rationalisierungspotenzialen $^{202}$ innerhalb der Supply Chain, welche durch die Netzwerkökonomik eröffnet werden, möglichst umfänglich zu partizipieren. Dies verlangt den Unternehmen zum einen die Begrenzung ihrer Geschäftstätigkeit auf wertschöpfende Aktivitäten, d. h. auf ihre Kernkompetenzen ab. Daraus resultiert die Reduktion der Produktionstiefe; nicht wertschöpfende Teilfunktionen - wie bspw. die Logistik - werden tendenziell an Spezialisten fremdvergeben (,outgesourct"). ${ }^{203}$ Zum anderen werden unter den gegebenen Umständen zur Transaktionskostenminimierung geeignete kooperative Arrangements zur Koordination der ökonomischen Aktivitäten vorangetrieben, der Aufbau von B2B- und B2C-Netzwerken wird begünstigt. ${ }^{204}$ Dabei wirkt der Einsatz von IuK-Technologien der Netzwerkökonomik transaktionskostensenkend. ${ }^{205} \mathrm{E}$ Commerce verschiebt also organisatorische Grenzlinien und verändert grundlegend die Methodik der Transaktionen zwischen Verladern untereinander sowie zwischen

Vgl. Laaser und Soltwedel, welche den E-Commerce als diejenige wichtige Ausprägung der New Economy (wobei der Begriff der New Economy im Sinne der Netzwerkökonomik benutzt wird) hervorheben, welche unter Einsatz moderner luK-Technologien die Anbahnung, den Abschluss und die Erfüllung wirtschaftlicher Transaktionen zwischen räumlich getrennten Vertragspartnern koordiniert. Vgl. Laaser, Soltwedel (2001), S. 174 f. Vgl. auch Schmitt, dessen fünf phänomenologische Prinzipien des E-Commerce (Digitalisierung, Vernetzung, Interaktivität, Unmittelbarkeit, Standardisierung) ebenfalls einen deutlichen Bezug zur Netzwerkökonomik aufweisen. Vgl. Schmitt (2003), S. 170.

Vgl. Nemoto, Visser, Yoshimoto (2001), S. 4.

Vgl. Schmitt (2003), S. 185; Ernst, Walpuski (1993), S. 110.

$\mathrm{Vgl}$. Weber et al. (2002), S. 45, 51. Dabei fungieren die modernen IuK-Technologien einerseits als „Enabler" für eine Reorganisation betrieblicher und überbetrieblicher Wertschöpfungssysteme und sind andererseits deren Voraussetzung. Vgl. Weber, S.-M. (1999), S. 7. 
Verladern und Endkunden. ${ }^{206}$ Die daraus erwachsenden Anforderungen an schnittstellen- und medienübergreifende Informations- sowie an physische Funktionsintegration verändern den logistischen Bedarf der verladenden Unternehmen. ${ }^{207}$

Die Netzwerkökonomik beeinflusst die Vorgänge auf dem Logistikmarkt folglich indirekt, indem sie

- den Umfang an mengen- und wertmäßigen Akquisitionsmöglichkeiten für Logistikdienstleister erhöht, welche auf der zunehmenden Neigung der Verladerschaft zum Outsourcing fußen und

- die Anforderungen an die Leistungserstellungsprozesse der Logistikdienstleister durch die zunehmende Relevanz von Netzwerktechnologien und Netzwerkarrangements modifiziert. So betonen auch WEBER ET AL. das indirekte Wirkungspotenzial auf die Logistik und etikettieren den E-Commerce - hier sinngleich verwendet in der Bedeutung der Netzwerkökonomik - in diesem Zusammenhang als ,strategischen Katalysator" für Veränderungen im Umfeld des Logistikmarktes. ${ }^{208}$ Ferner wird dem E-Commerce - wieder sinngleich verwendet in der Bedeutung der Netzwerkökonomik - aufgrund seiner Affinität zur Nutzung offener, standardisierter Netzwerke attestiert, dass er

- eine wesentliche Voraussetzung für die Evolution der Logistik in Richtung eines Ansatzes mit unternehmensübergreifender Flussorientierung ist. ${ }^{209}$

(b) Einfluss der Netzwerkökonomik auf das Logistiksystem aus Perspektive der Logistikdienstleister:V2L- und L2L-Netzwerke

Dem veränderten logistischen Bedarf der verladenden Unternehmen haben die Anbieter logistischer Dienstleistungen Rechnung zu tragen. Sie initieren die von der Netzwerkökonomik postulierte Vernetzung von Wirtschaftsakteuren, Abläufen, Informationen und Technologien aktiv und bringen sich unter Einsatz von IuKTechnologien zunehmend intensiver in die Versorgungsketten der Verlader ein. Dies führt zur Entwicklung entsprechender Logistiksysteme und -prozesse, welche dazu geeignet sind, die Geschäftsprozesse der verladenden Unternehmen auf der Ebene der

Vgl. Schmitt (2003), S. 174.

Vgl. Nemoto, Visser, Yoshimoto (2001), S. 4.

Vgl. Weber et al. (2002), S. 57.

Vgl. Schmitt (2003), S. 177 f.
} 
physischen Abwicklung sowohl in administrativer als auch in operativer Hinsicht abzubilden. Auf der institutionellen Ebene der Koordination schlägt sich dies im Aufbau von V2L-Netzwerken und L2L-Netzwerken nieder. Die auf die Umsetzung der Optimierungsstrategien und Erfüllung der Effizienzerfordernisse der netzwerkökonomischen Geschäftsmodelle ausgerichtete Entwicklung und Abstimmung logistischer Prozess- und netzwerkartiger Koordinationsstrukturen wird bisweilen auch unter dem Begriff der Electronic Logistics (E-Logistics) subsumiert. ${ }^{210}$ E-Logistics trägt insbesondere dazu bei, die transaktionskostenerhöhenden Momente der Netzwerkökonomik $^{211}$ in B2B- und B2C-Netzwerken abzuschwächen oder anders ausgedrückt, die wachsende Koordinationskomplexität in der Supply Chain zu reduzieren. V2L- und L2L-Netzwerke stellen dabei die transaktionskostenminimierende Ausgestaltungsformen der Koordination dar und gewährleisten die unternehmensübergreifende effiziente Daten- und Funktionsintegration entlang der gesamten Supply Chain. In diesen Netzwerken kann dann auf IuK-basierte, weltweit anerkannte faktische Standards wie bspw. EDIFACT ${ }^{212}$ oder den EAN-Barcode zurückgegriffen werden, was ebenfalls deutlich transaktionskostensenkend wirkt. Neben den bis hier angeführten Aspekten, welche hauptsächlich auf die zwischen- und überbetriebliche Anwendungsgebiete der Netzwerkökonomik abheben, ist ferner die innerbetriebliche Anwendung netzwerkökonomischer Technologien zu nennen. Auch auf der innerbetrieblichen Ebene bieten die IuK-Technologien nützliche Anwendungen für die Logistikdienstleister, die ihre Leistungsprozesse um informationslogistische Komponenten erweitern und in den einzelnen Phasen der physischen Leistungserstellung optimieren. ${ }^{213}$

Insgesamt kann festgehalten werden, dass die Funktionsfähigkeit der unternehmensweiten und -übergreifenden, auf der Anwendung von IuK-Technologien fußenden Informationslogistik unabdingbar wichtig für die Umsetzung der physischen Logistikanforderungen von Produktion und Handel ist. ${ }^{214}$ Die Technologien der Netzwerkökonomik eröffnen den Logistikdienstleistern zahlreiche neue Möglichkeiten, ihre Informationslogistik funktionsfähig zu gestalten. Allerdings darf bei der Diskussion um Positionierung und Wert der Netzwerkökonomik im Prozess der Informationsorientierung der Logistik nicht außer Acht gelassen werden, dass die Relevanz der IuKUnterstützung physischer Logistikprozesse schon seit Langem erkannt ist und daher auch vor der Verfügbarkeit der netzwerkökonomischen Technologien entsprechend

\footnotetext{
210 Vgl. Straube (2001), S. 182, S. 187.

211 Vgl. Unterabschnitt 2.3.3.1.1.

212 Vgl. Klaus (2003), S. 20.

213 Vgl. Daduna (2003), S. 753 f.; Ernst, Walpuski (1993), S. 108.
} 
nachdrücklich vorangetrieben worden ist. Insofern stellt die Netzwerkökonomik keinesfalls grundsätzlich „Neuland“ hinsichtlich der Gestaltung von Logistikprozessen dar. Vielmehr bietet sie ein bislang fehlendes technologisches und organisatorisches Rüstzeug, um Logistikoperationen mit einer den Verladeranforderungen entsprechenden Autorität in Fragen des Systemgrenzen überschreitenden, entscheidungsorientierten Informationsmanagements zu gestalten. ${ }^{215}$

Die Netzwerkökonomik beeinflusst die Vorgänge auf dem Logistikmarkt folglich auch direkt, indem sie

- den Logistikdienstleistern informations- und kommunikationstechnologische Optionen an die Hand gibt, die dazu geeignet sind, dem geänderten logistischen Bedarf der Verlader reaktiv Rechnung zu tragen und gleichsam ihr Leistungsportfolio aktiv zu erweitern und

- den Logistikdienstleistern zudem eine institutionelle Perspektive gibt, wie sie die Organisation der Leistungskoordination innerhalb des Logistiksektors sowie zwischen den Logistikdienstleistungsunternehmen und den verladenden Unternehmen vornehmen können und

- den Logistikdienstleistern damit Möglichkeiten zu adaptivem und kreativem Marktverhalten eröffnet, um ihre Leistungsqualität zu verbessern.

Aus dem Zusammenwirken der indirekten und direkten Beeinflussung des Logistikmarktes durch die Netzwerkökonomik ergibt sich folgende bemerkenswerte Konsequenz: Die Netzwerkökonomik verlangt den Anbietern logistischer Leistungen auf der einen Seite fundamentale Modifikationen in ihren Leistungserstellungsprozessen und die Anpassung ihrer Leistungserstellungsstrukturen ab, stellt ihnen aber gleichzeitig die hierzu erforderlichen Technologien und institutionellen Lösungsstrategien zur Verfügung. Sie schafft Koordinationskomplexität und bietet gleichzeitig Lösungsansätze zu deren Reduktion. Offensichtlich bieten die Potenziale der Netzwerkökonomik also eine gemeinsame Plattform zur ökonomischen Evolution für nahezu alle Wirtschaftsakteure, die im Logistiksystem oder im Transformationssystem agieren. Der entscheidende Engpassfaktor für die Realisierung der in Aussicht gestellten ökonomischen Evolution ist die fachliche und die sozio-kommunikative Fähigkeit und Neigung 
der Wirtschaftsakteure, den in der Netzwerkökonomik reichlich vorhandenen Bestand an Informationen - konkret bezogen auf ihren Wirtschaftssektor - in echtes Wissen zu überführen und damit erst ökonomisch verwertbar zu machen. ${ }^{216}$ Auf die Akteure des Logistikmarktes übertragen bedeutet dies, dass ihr Markterfolg davon abhängt, (1) inwieweit sie fähig sind, Know-how im Bereich der verfügbaren IuK-Technologien sowie im Bereich der logistischen Prozessgestaltung aufzubauen und zum anderen (2) inwieweit sie über die entsprechenden finanziellen und personellen Entwicklungskräfte verfügen, dieses Know-how in konkrete kundenbezogene Anwendungen und organisatorische Lösungen - kurz: in marktfähige Produkte - umzusetzen. ${ }^{217}$

\section{(c) Einfluss der Netzwerkökonomik auf das Logistiksystem aus Perspektive der Verkehrswissenschaft und -politik: Telematik und A2L-Netzwerke}

Aus dem Blickwinkel der Verkehrwissenschaft und der Verkehrspolitik sind zunächst vor allem die Wirkungen der Netzwerkökonomik auf das Logistiksystem von Interesse, welche Einfluss auf Ausgestaltung und Systematik der physischen Güterverkehrsströme nehmen. In der Verkehrswissenschaft werden Fragestellungen rund um diese Thematik unter dem Schlagwort „Telematik“ diskutiert. Telematik ist ein Kunstwort aus den beiden Begriffen Telekommunikation und Informatik und soll die Verschmelzung von digitalen Informationsübertragungssystemen und Informationsverarbeitungstechnologien versinnbildlichen. ${ }^{218}$ Obwohl sich der Begriff der Telematik und der sich dahinter verbergende Denkansatz damit inhaltlich nahtlos in das Argumentationsgebäude der Netzwerkökonomik einpassen ließe, so ist er doch weder im netzwerkökonomischen Kontext noch in der praktischen und der wissenschaftlichen Logistik sehr gebräuchlich, sondern hat hauptsächlich Eingang in die verkehrswissenschaftliche und -politische Diskussion gefunden.

Die Verkehrswissenschaft verwendet ihn insbesondere, um damit diejenigen Wirkungskonsequenzen $\mathrm{zu}$ analysieren, welche sich aus der Anwendung von IuKTechnologien und digitalen Netzwerken im Logistiksektor hinsichtlich der einzelwirtschaftlichen und gesamtwirtschaftlichen Effizienz von physischen Güterverkehrsleistungen zur Raumüberwindung ergeben. Gegenstand der verkehrswissenschaftlich orientierten Analyse sind in diesem Zusammenhang die Effizienzauswirkungen der Telematik auf administrative sowie operative Transport- und Verkehrsprozesse, 
welche bspw. die Transportmittelwahl, die Transportmittelauslastung, die Transportmittelüberwachung bzw. -ortung, die Transportmittelzielführung bzw. -information oder aber die Verkehrsinfrastrukturbenutzung (Verkehrsvermeidung, Verkehrssteuerung, Verkehrsmanagementsysteme, Verkehrsinformationssysteme) organisieren. ${ }^{219}$ Telematikanwendungen zielen folglich hauptsächlich auf die Ebene des Verkehrssystems ab, also auf einen Teilbereich des Logistiksystems. Im Zentrum des Interesses steht dabei das Straßenverkehrssystem. ${ }^{220}$ Aus verkehrspolitischer Sicht wiederum stellt die Telematik ein mögliches Instrument zur Verfolgung und Durchsetzung verkehrspolitischer Strategien dar. ${ }^{221}$ Entsprechende verkehrliche Problemkomplexe, welche typischerweise Auslöser solcher verkehrspolitischen Strategien sind, sind die

- verursachergerechte Abgeltung von Verkehrswegekosten (bspw. durch telematikgestütztes „Road Pricing“ im Bereich der Straßenverkehrsinfrastruktur) und die

- Internalisierung externer Kosten des Verkehrs: Der Verkehrssektor - und hier insbesondere der Straßenverkehr - gilt als typischer Bereich, an welchem die Existenz externer Effekte demonstriert werden kann. ${ }^{222} \mathrm{Zu}$ den Erscheinungsformen der externen Kosten im Verkehrssektor, genauer des Verkehrsmittelbetriebes $^{223}$, zählen insbesondere

- die Umweltkosten (Emission von Schadstoffen wie bspw. $\mathrm{CO}, \mathrm{CO}_{2}$, $\mathrm{NO}_{\mathrm{x}}$, usw. sowie Kosten von Lärmemissionen),

- die Verkehrsunfall- und -unfallfolgekosten (sofern diese nicht schon über Versicherungsleistungen internalisiert sind) sowie

○ Staukosten. ${ }^{224}$

219

220

221

222

Vgl. Ihde (2001), S. 196 f.; ähnlich auch Heng (2004), S. 374; Aberle (2003a), S. 569.

Vgl. Aberle (2003a), S. 570.

Vgl. Ernst (2000), S. 42.

Vgl. Berkelova (1992), S. 151.

Von den externen Kosten des Verkehrsmittelbetriebes zu unterscheiden wären die externen Kosten der Verkehrsinfrastruktur. Letztere bestehen aus Bodenversiegelungseffekten (Auswirkungen von Infrastrukturmaßnahmen auf Grundwasser, Flora und Fauna), Trenneffekten (Zerschneidungen von Kulturflächen und Siedlungen durch Verkehrsinfrastrukturen) sowie Landverbrauchseffekten. Die externen Kosten der Verkehrsinfrastruktur spielen im Vergleich zu den externen Kosten des Verkehrsmittelbetriebes aber eine untergeordnete Rolle. Vgl. Aberle (2003a), S. 582.

Vgl. dazu bspw. Köberlein (1997), S. 201 ff;; Aberle (2003a), S. 582; Laaser (1991), S. 96 ff. 
Das Anforderungsprofil, welches die Verkehrspolitik an die Telematik stellt, ist dementsprechend komplex, die Erwartungen sind vielfältig und hoch. ${ }^{225}$

Hinsichtlich der verkehrsbezogenen Wirkungskonsequenzen der Telematik lassen sich nun aus verkehrswissenschaftlicher Sicht prinzipiell folgende wesentliche Haupttypen unterscheiden: $:^{226}$

- Komplementarität: Hier wird auf die Anwendung von Telematiksystemen innerhalb des Logistiksektors im inner- und zwischenbetrieblichen Bereich abgehoben. Telematiksysteme dienen - wie oben bereits ausgeführt - der Optimierung physischer Verkehrs- und (mittelbar) Logistikprozesse und weisen somit eine komplementäre Beziehung zum physischen Verkehr auf, da dieser seine Aufgaben ohne Verknüpfung mit Telematiksystemen - wenn überhaupt - allenfalls weniger effizient erfüllen könnte. ${ }^{227}$

- Substitution: Die Übertragung von Informationen kann physischen Verkehr auch ersetzen. Dies ist überall dort denkbar wo der physische Verkehr nur ein bislang unerlässliches „Nebenprodukt“ beim Transport von Informationsgütern darstellt, welcher aufgrund mangelnder luK-Technologien nicht von der physischen Ortsveränderung des Informationsträgers abgekoppelt werden konnte.

- Induktion: Telematiksysteme können auch zusätzlichen physischen Verkehr schaffen. Dies ist dann denkbar, wenn die Möglichkeiten, welche durch neue IuK-Technologien eröffnet werden, zusätzliche neue Raumüberwindungsbedürfnisse begründen (direkte Induktion) oder wenn die Lösung von bestimmten Raumüberwindungsproblemen mit Hilfe von Telematiksystemen realisiert werden konnte und die nun freien Kapazitäten für zusätzliche physische Verkehre genutzt werden (indirekte Induktion).

Sind Logistikunternehmen die institutionellen Träger und Initiatoren von Telematiksystemen, dann sind die verkehrsbezogenen Effizienzwirkungen der Telematik im

Vgl. Denkhaus (1995), S. 50.

Vgl. für das Folgende Ernst, Walpuski (1997), S. 62 f.

Vgl. Daduna (2003), S. 755. 
Kontext der unter (b) benannten direkten Wirkungen der Netzwerkökonomik auf das Logistiksystem zu bewerten. Art, Umfang, Intensität und Grenzlinien der Anwendung von Telematik sind dann als das Resultat des individuellen ökonomischen Optimierungskalküls von logistischen Einzelwirtschaften zu betrachten. Diese intendieren, mit Hilfe der Telematik Produktivitätssteigerungen im Transport und/oder Rationalisierung in den transportbezogenen administrativen Prozessen zu realisieren um damit Logistikprozesse möglichst effizient abzuwickeln. ${ }^{228}$ Die Telematikanwendungen weisen dann in aller Regel Komplementarität zu physischen Verkehrsleistungen auf. ${ }^{229}$ Sie wirken - analog der unter (a) und (b) benannten Wirkungen der Netzwerkökonomik - unmittelbar direkt auf mikro- und metalogistische Systeme und haben folglich einzelwirtschaftlichen Charakter.

Sind hingegen öffentlich-rechtliche Institutionen (wie bspw. Verkehrsüberwachungsbehörden) die Träger und Initiatoren von Telematiksystemen, so folgen die Grundsätze der Telematikanwendung regelmäßig verkehrspolitischen Zielsetzungen, welche sich aus einem kollektiven Optimierungskalkül ableiten lassen. Hierbei geht es dann nicht mehr darum, mit Hilfe von Telematik physische Verkehrströme aus einer der individuellen Effizienzlogik folgenden ökonomischen Prozessperspektive mikro- und metalogistischer Systeme zu optimieren, sondern aus einer übergeordneten Steuerungs- und Regelungsperspektive auf die Gesamtheit der Verkehrsströme optimierend einzuwirken. Geeigneter Anknüpfungspunkt für die Durchsetzung der möglichen verkehrsbezogenen Effizienzwirkungen der Telematik sind dann konsequenterweise die makrologistischen Systeme, welche an anderer Stelle als die Komponenten der materiellen Verkehrsinfrastruktur, d. h. die Verkehrsträger, identifiziert worden sind. Insofern weisen Telematikanwendungen dann gesamtwirtschaftlichen Charakter auf und folgen dementsprechend einer gesamtwirtschaftlichen Effizienzlogik. ${ }^{230}$

Telematik als verkehrspolitisches Instrument bewegt sich im Spannungsfeld zwischen vielen, zum Teil widersprüchlich angelegten verkehrspolitischen Strategien. Entspre-

Vgl. Daduna (2003), S. 755.

Allerdings sind auch Verkehrsinduzierung und Verkehrssubstitution denkbar. Zumindest was die vollständige Verkehrssubstitution durch Telematik jedoch anbetriff - das Zustellen digitaler, immaterieller Güter an den Kunden direkt über Kommunikationsnetzwerke ohne die Einschaltung physischer Verkehrsmittel und -infrastrukturen also -, existieren in der ökonomischen Realität enge Grenzen. Vgl. Heng (2004), S. 376. Die Substitution physischer Logistikleistungen durch nichtphysische informationstechnische Leistungen wird in der einschlägigen Literatur bisweilen auch als ,Substitutionseffekt" bezeichnet. Vgl. bspw. Frahm, Klaus (2000), S. 512.

Vgl. Denkhaus (1995), S. 51. 
chende strategische Ansatzpunkte der Verkehrspolitik mit der Telematik als Bestandteil der Problemlösungsstrategie lassen sich wie folgt beschreiben: ${ }^{231}$

- Kapazitätsauslastung der Verkehrsinfrastruktur,

- Verkehrssteuerung,

- Verkehrssicherheit,

- Verkehrsverlagerung,

- Verkehrsverminderung und

- Verkehrsvermeidung.

Im Rahmen der ersten drei strategischen Ansatzpunkte Kapazitätsauslastung, Verkehrssteuerung und Verkehrssicherheit können die (insbesondere infrastrukturgestützten) Verkehrstelematiksysteme dazu benutzt werden, physische Verkehrsströme zu beeinflussen und damit zu einer optimalen Ausnutzung bestehender Verkehrsinfrastrukturkapazitäten beitragen. ${ }^{232}$ Die Beziehung zwischen Telematik und physischem Verkehr sind in diesem Zusammenhang hauptsächlich komplementärer und z. T. auch induzierender Natur, da hier die Effizienz bei der Nutzung der makrologistischen Systeme verbessert wird. Im Rahmen der letzten drei strategischen Ansatzpunkte Verkehrsverlagerung, Verkehrsverminderung und Verkehrsvermeidung soll die Telematikanwendung grundsätzlich der Reduktion des physischen Verkehrs dienen: Dort wo Verkehr nicht komplett vermieden werden kann, soll der notwendigerweise anfallende Verkehr auf bestimmten Relationen zumindest vermindert werden, was fallweise über eine partielle Verlagerung von Verkehrsströmen auf (verkehrspolitisch mehr erwünschte) alternative Verkehrsträger - also über eine Veränderung des Modal Split - erreicht werden kann. ${ }^{233}$ Letztere drei Strategien nutzen demzufolge das Substitutionspotenzial der Telematik und begründen somit deren ambivalenten Charakter als verkehrspolitisches Instrument. ${ }^{234}$

Obwohl die verkehrspolitisch intendierten Telematikwirkungen zunächst auf die Optimierung der makrologistischen Systeme abzielen, so wirken sie dennoch indirekt 
auch auf die mikro- und metalogistischen Systeme ein, da ihre gesamtwirtschaftlichen Effekte in Gestalt kollektiver Verkehrsbeeinflussung als feststehende Planungsrestriktionen in die Planungsüberlegungen der Mikro- und Metalogistiken zur Gestaltung ihrer jeweiligen Leistungserstellungsprozesse einzubringen sind.

\subsubsection{Gesamtwirtschaftlicher Strukturwandel}

\subsubsection{1 $\mathrm{Zu}$ den Begriffen der Struktur und des Strukturwandels}

In der Terminologie der ökonomischen Theorie wird der Begriff der „Struktur“ weder einheitlich definiert noch einheitlich verwendet. ${ }^{235}$ In Anbetracht der außerordentlichen Heterogenität des Erscheinungsbildes von Strukturphänomenen und -begriffen muss dieser Zustand als überaus unbefriedigend empfunden werden. ${ }^{236}$ HERDZINA identifiziert in diesem Zusammenhang zumindest drei Problemkomplexe, welche dem Anliegen einer einheitlichen Verwendung des Strukturkonzeptes in der Ökonomik abträglich sind: $:^{237}$

(1) Bei zahlreichen Strukturdefinitionen tritt die wesentliche Basisaussage, nämlich dass es bei Strukturphänomenen immer um die Beantwortung der Frage geht, wie sich Teile eines Untersuchungsobjektes untereinander und zur Gesamtheit verhalten, in den Hintergrund. Dient der Strukturbegriff lediglich der Erörterung diverser Rahmenbedingungen des Untersuchungsobjektes oder der Aufzählung besonders prägnanter Charakteristika ${ }^{238}$, so wird er dermaßen unscharf und beliebig, ,dass man jeden beliebigen ökonomischen Tatbestand darunter subsumieren kann ${ }^{6239} \cdot{ }^{240}$ Daher empfiehlt es sich, bei der Verwendung

Vgl. Meißner, Fassing (1989), S. 11; Bombach (1964), S. 10. Akerman bspw. unterscheidet in der Debatte zur Strukturterminologie verschiedene Strukturkonzepte: das historische, das rein ökonomische, das statistische, das ökonometrische (,macro-dynamic“) sowie das kausalanalytische Strukturkonzept. Vgl. Akerman (1960), S. $183 \mathrm{ff}$. Eine weitere detaillierte und gleichermaßen verwirrende Einteilung findet sich bei Machlup. Vgl. Machlup (1958), S. $280 \mathrm{ff}$. Vgl. Herdzina (1981), S. 118.

$\mathrm{Vgl}$. dafür und für das Folgende Herdzina (1981), S. $119 \mathrm{ff}$.

Machlup führt hierzu die Marktstrukturanalyse an, welche bisweilen ähnlich einer "collection of facts" anmutet. Machlup (1958), S. 291.

Herdzina (1981), S. 119.

„Structure, I am afraid, is often a weaselword used to avoid commitment to a definite and clear thought". Machlup (1958), S. 281. 
des Strukturbegriffes stets, den inneren Aufbau einer Größe zu thematisieren und nicht auf die Größe an sich bzw. deren Merkmale abzuheben.

(2) Bisweilen wird in der Strukturdebatte die Position vertreten, der Strukturbegriff impliziere eine gewisse Invarianz ökonomischer Größen sowie deren Verhältnis zueinander. ${ }^{241}$ Eine derartige Sichtweise ist jedoch aus zumindest einem Grund unzweckmäßig: die Haltbarkeit der Aussage einer prinzipiellen Invarianz von Strukturen hängt nämlich von dem für die entsprechende Analyse zugrunde gelegten Zeithorizont $a b$ und kann daher nicht absolut richtig oder falsch sein.

(3) Ferner wird in der Strukturdebatte die Position vertreten, bei Strukturen bzw. deren Veränderungen handele es sich um irreversible Vorgänge. ${ }^{242}$ Auch diese Sichtweise ist problematisch und letzten Endes nicht haltbar. Es empfiehlt sich daher, bei der Betrachtung von Struktur- und Strukturwandelphänomenen zu berücksichtigen, dass diese auch prinzipiell durch kurz- und mittelfristige, endogen reversible Veränderungen gekennzeichnet sein können.

Im Folgenden soll der Begriff der ökonomischen Struktur im Sinne des inneren Aufbaues ökonomischer Größen verwendet werden. Dieser innere Aufbau äußert sich in spezifischen Relationen zwischen den einzelnen Teilgrößen untereinander sowie zwischen den Teilgrößen und der Gesamtgröße. ${ }^{243}$ Zentrale Strukturmerkmale sind hierbei die Anzahl der Teilgrößen, ihre qualitative Beschaffenheit sowie ihre relative Häufigkeit. ${ }^{244}$ Unter Strukturwandel ist die Veränderung dieser Relationen zu

Machlup bspw. führt dazu aus: "This set of given conditions, $i$ fit is assumed to be invariant for a variety of problems, may be regarded as the economic „structure“...” Machlup (1958), S. 284, im Original z. T. kursiv.

242 Diese Position fußt auf der grundsätzlich sinnvollen Trennung zwischen der Niveau- und Strukturbetrachtung und der daraus abgeleiteten Unterscheidung zwischen Strukturänderungen und Konjunkturschwankungen. Zum einen wird diese Unterscheidung zur Abgrenzung zwischen der Analyse von Veränderungen des absoluten Wertes eines ökonomischen Ganzen (Niveau) und der Analyse der Veränderung seiner Zusammensetzung (Struktur) herangezogen. Neben dieser sinnstiftenden Interpretation existiert jedoch auch noch jene Interpretation, welche in Konjunkturschwankungen zyklische Veränderungen sieht und Strukturänderungen bzw. -schwankungen als irreversible, grundsätzlich aperiodische und azyklische Veränderungen betrachtet. Vgl. dazu Herdzina (1981), S. 121. riffes lehnt am statistischen Strukturbegriff an, welcher sich in der Ökonomie großer Beliebtheit erfreut und häufig angewendet wird. Vgl. Klatt (1975), S. 12 f. 
verstehen. ${ }^{245}$ Struktur- bzw. Strukturwandelphänomene sind als im Zeitablauf veränderbare Phänomene zu betrachten und können prinzipiell reversiblen Charakter haben.

Aus den bisherigen Ausführungen erhellt, dass aufgrund der offenkundigen Vielzahl ökonomischer Größen und der vielfältigen Möglichkeiten, diese miteinander zu verknüpfen, immens viele Strukturphänomene resultieren und folglich ebenso viele Arten von Strukturwandel existieren. Deshalb müssen im Folgenden notwendige Einschränkungen gemacht werden. Die nachfolgenden Ausführungen beschränken sich daher auf diejenigen Arten des Strukturwandels, welche für die Logistik(dienstleistung) bedeutsam sind. Hierbei erscheint insbesondere die Güterangebotsstruktur der Transformationssektoren relevant.

\subsection{Logistikrelevante Arten des Strukturwandels}

\section{Güterangebotsseitige Komponenten logistikrelevanter Strukturen und Arten logistikrelevanten Strukturwandels}

Im Folgenden werden mit den Konzepten der Güterstruktur, der Unternehmensstruktur sowie der Produktionsstruktur drei Komponenten der Güterangebotsstruktur unterschieden, welche erwiesenermaßen eine charakteristische Bedeutsamkeit fur die Logistik bzw. die Logistikleistung aufweisen und somit auch Einfluss auf die Geschehnisse auf dem Markt für Logistikleistungen ausüben.

Die Kernfrage beim Konzept der Güterstruktur lautet, wie hoch die prozentualen Anteile der einzelnen Güter bzw. Gütergruppen am Gesamtgüterangebot sind und wie sich diese Anteile verändern. ${ }^{246}$ Dabei hängt die relative Häufigkeit der Gütergruppen wesentlich davon ab, wie viele Gütergruppen zuvor gebildet worden sind. Die Anzahl verschiedener Gütergruppen fußt wiederum auf deren innerer Segmentierung resp. auf deren Abgrenzung zueinander und beruht folglich auf den ihnen zugeschriebenen Qualitätsmerkmalen. Als wesentliches Erfolgskriterium für die Güte der Darstellung der Güterstruktur und der Messung des Güterstrukturwandels erweist sich also das Vorhandensein bzw. die Auswahl eines geeigneten Einteilungskriteriums für die Gütergruppen. Die Wettbewerbstheorie, die sich ja eingehend mit der Frage nach der Abgrenzung des relevanten Marktes befasst, schlägt in diesem Zusammenhang als 
Einteilungskriterium den Heterogenitätsgrad der Güter bzw. den Grad der Produktdifferenzierung vor. ${ }^{247}$ Daher konstatiert HERDZINA zusammenfassend, dass ein Wandel der Güterstruktur in dreierlei Hinsicht ausgelöst werden kann, und zwar

- in Form der Veränderung der Anzahl der Gütergruppen, was wiederum eine Veränderung der relativen Güterhäufigkeiten zur Folge hat,

- in Form einer Veränderung des Heterogenitätsgrades der Güter, was auch Veränderungen bezüglich der Gruppenzugehörigkeit sowie bezüglich der Anzahl der Gütergruppen zur Folge hat und somit auch Anteilsverschiebungen bewirkt,

- in Form von Veränderungen der relativen Häufigkeit der Gütergruppen, ohne dass dabei Anzahl oder Heterogenitätsgrad der Güter direkt betroffen sind. ${ }^{248}$

Das Konzept der Unternehmensstruktur rückt die Unternehmen als diejenigen Institutionen, welche Güter anbieten, ins Zentrum der Strukturanalyse. Dabei sind insbesondere die folgenden Fragestellungen von Interesse:

- Wie verändert sich die Anzahl der Unternehmen bezogen auf ein übergeordnetes Aggregat (die Volkswirtschaft, einen Markt usw.)? Thematisiert wird hier das Ausmaß der absoluten Unternehmenskonzentration.

- Wie verändern sich die Anteile der Unternehmen bzw. Unternehmensgruppen an einem übergeordneten ökonomischen Ganzen (dem Bruttosozialprodukt, dem Umsatz einer Branche usw.)? Thematisiert wird hier das Ausmaß der relativen Unternehmenskonzentration.

Mehr noch als bei der Güterstruktur bietet das Konzept der Unternehmensstruktur jedoch neben diesen quantitativen Aspekten auch Raum für qualitative Überlegungen. Unternehmensgruppen können nämlich neben den zuvor beschriebenen Größenmerkmalen auch nach verschiedenen Gesichtspunkten ihrer internen Organisation des 
Leistungserstellungsprozesses voneinander abgegrenzt werden. ${ }^{249}$ WAGNER geht sogar so weit, den Begriff der Unternehmensstruktur mit dem der Organisationsstruktur im Sinne der unternehmensinternen Aufbau- und Ablauforganisation gleichzusetzen. ${ }^{250}$ Die sich daraus ergebende dritte Fragestellung, welche insbesondere mit Blick auf die Logistik von erheblicher Relevanz ist, wäre demnach:

- Wie verändern sich die internen Unternehmensstrukturen?

Das Konzept der Produktionsstruktur erfährt unterschiedliche Interpretationen. HELMSTÄDTER bspw. benutzt den Begriff im Sinne des zeitlichen Aufbaus der Produktion. ${ }^{251}$ Die anfänglich vorherrschende Vorstellung, die Produktionsprozesse würden - in Anlehnung an die unabwendbare Linearität des Ablaufes der Zeit ebenfalls linear vom Zeitpunkt der ersten Produktion bis zum Zeitpunkt des letzten Konsums verlaufen, wich später dann der Vorstellung der Zirkularität des arbeitsteiligen volkswirtschaftlichen Produktionsprozesses. ${ }^{252}$ Eine mögliche Form der Darstellung der zirkular verflochtenen Produktionsprozesse sind Input-Output-Tabellen, welche die Lieferströme zwischen den beteiligten Wirtschaftssubjekten visualisieren. CLASEN hingegen sieht in der Produktionsstruktur eine Wertestruktur, welche sich zu einem bestimmten Zeitpunkt durch die jeweils bestehenden quantitativen Verhältnisse zwischen der Produktion der Wirtschaftszweige einerseits und der Gesamtproduktion der Volkswirtschaft andererseits ausdrückt. ${ }^{253}$ Beide zuvor genannte Interpretationsvarianten beziehen sich auf die Outputseite des Produktionsprozesses und bergen die Gefahr, dabei den Produktionsaspekt zu wenig zu beleuchten, das Konzept der Produktionsstruktur degeneriert zu einem Konzept der Produktstruktur. Um dem eigentlichen Produktionsaspekt wieder mehr Beachtung zu schenken, bietet es sich an, sich vornehmlich auf die Inputseite des Produktionsprozesses zu konzentrieren, also die Produktion selbst. Die Produktionsstruktur soll daher im Sinne einer Produktions-

Vgl. Herdzina (1981), S. 127.

Vgl. Wagner (2001), S. 43.

Vgl. Helmstädter (1958), S. $175 \mathrm{ff}$.

Vgl. Helmstädter (1958), S. 175 f.

Vgl. Clasen (1966), S. 10.
} 
faktorenstruktur begriffen werden und zwar dergestalt, dass dabei die Relation der einzelnen Produktionsfaktoren zueinander thematisiert wird. ${ }^{254}$

\subsection{Ausprägung und Entwicklung logistikrelevanter Strukturen}

\section{Gesamtwirtschafiliche Güter- und Produktionsstruktur}

Gegenstand logistischer Prozeduren im Transfersystem sind die Veränderung räumlicher und zeitlicher Merkmale von Gütern sowie die art- und mengenmäßige Umstrukturierung der Güterbestände. Niveau und Zusammensetzung der Güterproduktion in den Transformationssystemen sowie deren Entwicklung im Zeitablauf induzieren Änderungen beim Nachfrageverhalten nach logistischen Leistungen und wirken somit entscheidend auf das logistische Anforderungsprofil ein, welchem das Transfersystem Rechnung zu tragen hat.

Die Entwicklung der gesamtwirtschaftlichen Güterproduktion ist gekennzeichnet von einem Anstieg des Anteils hochwertiger Konsum- und Investitionsgüter bei gleichzeitig stagnierender bzw. absolut zurückgehender Produktion in der Grundstoffindustrie. ${ }^{255}$ Diese Entwicklung ist in der Hauptsache auf Bedarfssättigungstendenzen und Spezialisierungstendenzen in der Güterproduktion zurückzuführen und ist folglich das Resultat nachfrage- und angebotsseitiger Einflussfaktoren. ${ }^{256}$ Detaillierten Aufschluss gibt Tabelle 2-2. Sie zeigt, dass im produzierenden Gewerbe auf intersektoraler Ebene Anteilsverschiebungen stattgefunden haben: Der Sektor des verarbeitenden Gewerbes konnte bezogen auf die Gesamt-Bruttowertschöpfung im produzierenden Gewerbe Anteilsgewinne verzeichnen, welche zulasten der Anteile der Sektoren des Baugewerbes sowie des Bergbaues und Gewinnung von Steinen und Erden gingen. Auf intrasektoraler Ebene im verarbeitenden Gewerbe sind ebenfalls deutliche Umschichtungen zu beobachten. Hier konnten insbesondere der Fahrzeugbau, der Bereich der Herstellung von Büromaschinen, DV-Geräten und Elektrotechnik sowie der Maschinenbau Anteilsgewinne realisieren während vor allem die Bereiche Glasgewerbe, Herstellung von Keramik, Verarbeitung von Steinen und Erden sowie Papier-, Verlags- und Druckgewerbe Anteilseinbußen hinnehmen mussten.

So auch Herdzina (1981), S. 130. Wird das Konzept der Produktionsstruktur in dieser Art und Weise interpretiert, dann ähnelt es dem der Unternehmensstruktur, sofern der Analyse der Unternehmensstruktur Inputgrößen zugrunde gelegt werden.

Vgl. Ihde (2001), S. 63. 


\begin{tabular}{|c|c|c|c|c|c|}
\hline Wirtschaftszweig & 1999 & & 2004 & & $\begin{array}{l}\text { Anteils- } \\
\text { verănde- } \\
\text { rung in } \\
\text { Prozent- } \\
\text { punkten }\end{array}$ \\
\hline & abs. in Mrd. $\mathcal{E}$ & $\%$ & abs. in Mrd. $€$ & $\%$ & \\
\hline Produzierendes Gewerbe & 547,86 & 100,00 & 575,90 & 100,00 & \\
\hline $\begin{array}{l}\text { Produzierendes } \\
\text { Gewerbe ohne Bauge- } \\
\text { werbe }\end{array}$ & 448,63 & 81,89 & 493,15 & 85,63 & 3,74 \\
\hline $\begin{array}{l}\text { Bergbau und Gewinnung } \\
\text { v. Steinen und Erden }\end{array}$ & 4,99 & 0,91 & 4,04 & 0,70 & $-0,21$ \\
\hline Verarbeitendes Gewerbe & 404,74 & 73,88 & 449,73 & 78,09 & 4,22 \\
\hline Fahrzeugbau & 58,99 & 10,77 & 73,12 & 12,70 & 1,93 \\
\hline $\begin{array}{l}\text { Herstellung v. Büromaschinen, } \\
\text { DV-Gerăten; Elektrotechnik }\end{array}$ & 57,84 & 10,56 & 67,65 & 11,75 & 1,19 \\
\hline Maschinenbau & 58,35 & 10,65 & 67,18 & 11,67 & 1.01 \\
\hline $\begin{array}{l}\text { Herstellung v. chemischen } \\
\text { Erzeugnissen }\end{array}$ & 38,69 & 7,06 & 45,55 & 7,91 & 0,85 \\
\hline $\begin{array}{l}\text { Kokerei, Mineralolverarbeitung, } \\
\text { Herstellung v. Brutstoffen }\end{array}$ & 2,08 & 0,38 & 4,76 & 0,83 & 0,45 \\
\hline $\begin{array}{l}\text { Metallerzeugung und - } \\
\text { bearbeitung, Herstellung v. } \\
\text { Metallerzeugnissen }\end{array}$ & 53,04 & 9,68 & 58,16 & 10,10 & 0,42 \\
\hline $\begin{array}{l}\text { Ernahrungsgewerbe und } \\
\text { Tabakverarbeitung }\end{array}$ & 36,02 & 6,57 & 39,05 & 6,78 & 0,21 \\
\hline $\begin{array}{l}\text { Herstellung v. Gummi- und } \\
\text { Kunststoffwaren }\end{array}$ & 20,00 & 3,65 & 21,79 & 3,78 & 0,13 \\
\hline Ledergewerbe & 1,09 & 0,20 & 1,03 & 0,18 & $-0,02$ \\
\hline Holzgewerbe & 8,00 & 1,46 & 7,33 & 1,27 & $-0,19$ \\
\hline Textil- und Bekleidungsgewerbe & 8,76 & 1,60 & 7,63 & 1,32 & $-0,27$ \\
\hline $\begin{array}{l}\text { Herstellung v. Mobeln, Schmuck, } \\
\text { Musikinstrumenten usw.; } \\
\text { Recycling }\end{array}$ & 12,53 & 2,29 & 11,35 & 1,97 & $-0,32$ \\
\hline $\begin{array}{l}\text { Papier-, Verlags- und } \\
\text { Druckgewerbe }\end{array}$ & 32,73 & 5,97 & 31,21 & 5,42 & $-0,55$ \\
\hline $\begin{array}{l}\text { Glasgewerbe, Herstellung v. } \\
\text { Keramik, Verarbeitung v. Steinen } \\
\text { und Erden }\end{array}$ & 16,62 & 3,03 & 13,92 & 2,42 & $-0,62$ \\
\hline $\begin{array}{l}\text { Energie- und Wasserver- } \\
\text { sorgung }\end{array}$ & 38,90 & 7,10 & 39,38 & 6,84 & $-0,26$ \\
\hline Baugewerbe & 99,23 & 18,11 & 82,75 & 14,37 & $-3,74$ \\
\hline
\end{tabular}

Tabelle 2-2: Vergleich der nationalen Bruttowertschöpfung in jeweiligen Preisen nach Wirtschaftszweigen in den Jahren 1999 - 2004

Quelle: Eigene Berechnungen auf Basis von SBA (2007a), S. 640 f. 
Entsprechende inter- und intrasektorale Umschichtungsprozesse konnte PUF bereits für die 1960er und 1970er Jahre ${ }^{257}$, DRECHSLER für die 1980er Jahre nachweisen ${ }^{258}$. Die Auswirkungen dieser Veränderungsprozesse in der gesamtwirtschaftlichen Güterproduktion - welche sich in ähnlicher Form prinzipiell für alle hoch entwickelten Volkswirtschaften nachweisen lassen ${ }^{259}$ - auf die Nachfrage nach logistischen Leistungen werden im Allgemeinen mit dem Güterstruktureffekt beschrieben.

Der Güterstruktureffekt kennzeichnet jene Entwicklung, dass - den Umschichtungsprozessen in der gesamtwirtschaftlichen Güterproduktion entsprechend - der Anteil relativ homogener Massengüter der Grundstoffindustrie am gesamten Güterverkehrsaufkommen abnimmt, während der Anteil von vergleichsweise heterogenen Stückgütern der hochwertigen Konsum- und Investitionsgüterindustrien hingegen zunimmt. ${ }^{260}$

Aus Tabelle 2-3 ist ersichtlich, dass Eisenbahn und Binnenschifffahrt im Jahr 2006 ihre höchsten Leistungsanteile in den stagnierenden bzw. rückläufigen Güterabteilungen aufwiesen. Beide Verkehrsträger wickeln jeweils überdurchschnittliche $55 \%$ des Verkehrsaufkommens, das sie insgesamt haben, in diesen Grundstoffindustrien ab. Beim Straßengüterverkehr sind es hingegen lediglich unterdurchschnittliche $14 \%$. Über alle Binnenverkehrsträger gerechnet haben die Grundstoffindustrien durchschnittlich einen Anteil von $21 \%$ am Gesamtgüterverkehrsaufkommen. Demgegenüber verzeichnet der Straßengüterverkehr im Bereich jener Güterabteilungen, welchen die hochwertigen Konsum- und Investitionsgüter zuzuordnen sind, bezogen auf das insgesamt durch ihn abgewickelte Verkehrsaufkommen überdurchschnittlich hohe Leistungsanteile (39\%), während die beiden anderen Binnenverkehrsträger Eisenbahn (32\%) und Binnenschifffahrt (21\%) unterdurchschnittlich mit Transporten aus diesen Güterabteilungen betraut sind (Durchschnitt über alle Binnenverkehrsträger: 37\%).

Bei dieser Betrachtung fällt insbesondere der Umstand ins Gewicht, dass der Straßengüterverkehr in den Wachstumsbereichen - den hochwertigen Konsum- und Investitionsgütern -, bezogen auf das Gesamtverkehrsaufkommen in diesen Güterabteilungen einen Marktanteil von $88 \%$ hat, während Eisenbahn (8\%) und Binnenschifffahrt (4\%) hier zusammen nur einen Marktanteil von $12 \%$ aufweisen. Die starke Dominanz des Straßengüterverkehrs im Wachstumsbereich der hochwertigen Konsum- und Investitionsgüter in Verbindung mit der beträchtlichen Abhängigkeit der Eisenbahn und der 
Binnenschifffahrt vom Stagnations- bzw. Rückbildungsbereich der Grundstoffindustrien impliziert nun, dass der Straßengüterverkehr tendenziell von den Umschichtungsprozessen in der gesamtwirtschaftlichen Güterproduktion profitiert, während die Eisenbahn und die Binnenschifffahrt negativ von den Auswirkungen diesen Entwicklungen betroffen sind.

\begin{tabular}{|c|c|c|c|c|c|c|c|c|}
\hline Guterabtellung & 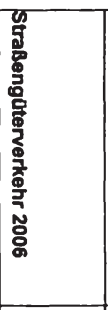 & & 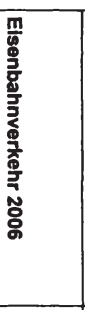 & & 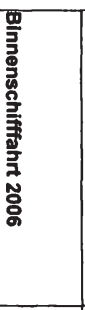 & & 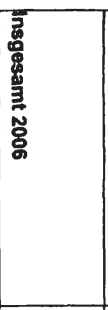 & \\
\hline & in $1.000 t$ & $\%$ & $\begin{array}{l}\text { in } \\
1.000 t\end{array}$ & $\%$ & $\begin{array}{l}\text { in } \\
1.000 t\end{array}$ & $\%$ & in 1000 t & $\%$ \\
\hline $\begin{array}{l}\text { Land-, forstwirtschaft- } \\
\text { liche und verwandte } \\
\text { Erzeugnisse }\end{array}$ & 161.537 & 5,53 & 10.694 & 3,09 & 10.791 & 4,43 & 183.031 & 5,22 \\
\hline $\begin{array}{l}\text { Andere Nahrungs- und } \\
\text { Futtermittel }\end{array}$ & 329.041 & 11,27 & 2.979 & 0,86 & 14.641 & 6,01 & 346.673 & 9,88 \\
\hline $\begin{array}{l}\text { Feste mineralische } \\
\text { Brennstoffe }\end{array}$ & 13.237 & 0,45 & 51.312 & 14,83 & 36.009 & 14,79 & 100.573 & 2,87 \\
\hline $\begin{array}{l}\text { Erdol, Mineraloler- } \\
\text { zeugnisse, Gase }\end{array}$ & 112.779 & 3,86 & 36.832 & 10,64 & 39.138 & 16,07 & 188.764 & 5,38 \\
\hline Erze und Metallabfälle & 38.388 & 1,31 & 31.463 & 9,09 & 35.964 & 14,77 & 105.825 & 3,02 \\
\hline $\begin{array}{l}\text { Eisen, Stahl und NE- } \\
\text { Metalle }\end{array}$ & 86.141 & 2,95 & 59.388 & 17,16 & 13.829 & 5,68 & 159.378 & 4,54 \\
\hline Steine und Erden & 1.349 .344 & 46,22 & 39.584 & 11,44 & 49.750 & 20,43 & 1.438 .736 & 41,00 \\
\hline Dungemittel & 23.156 & 0,79 & 7.725 & 2,23 & 5.771 & 2,37 & 36.655 & 1,04 \\
\hline $\begin{array}{l}\text { Chemische } \\
\text { Erzeugnisse }\end{array}$ & 226.239 & 7,75 & 24.929 & 7,20 & 20.085 & 8,25 & 271.268 & 7,73 \\
\hline $\begin{array}{l}\text { Andere Halb- und } \\
\text { Fertlgwaren }\end{array}$ & 579.465 & 19,85 & 81.212 & 23,46 & 17.518 & 7,19 & 678.238 & 19,33 \\
\hline Insgesamt & 2.919 .327 & 100,00 & 346.118 & 100,00 & 243.496 & 100,00 & 3.509 .241 & 100,00 \\
\hline
\end{tabular}

\begin{tabular}{|l|l|l|l|l|l|l|l|l|}
\hline $\begin{array}{l}\text { Grundstoffindustrien: } \\
\text { Land-, forstwirtschaftli- } \\
\text { che und verwandte } \\
\text { Erzeugnisse; Feste } \\
\text { mineralische } \\
\text { Brennstoffe; Erdol, } \\
\text { Mineralolerzeugnisse, } \\
\text { Gase; Erze und } \\
\begin{array}{l}\text { Metallabfalle; Eisen, } \\
\text { Stahl und NE-Metalle }\end{array}\end{array}$ & 412.082 & 14,12 & 189.689 & 54,80 & 135.731 & 55,74 & 737.571 & 21,02 \\
\hline
\end{tabular}




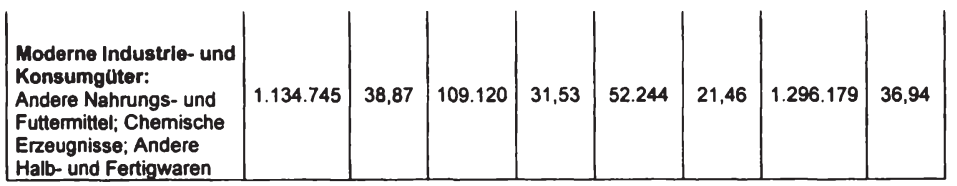

Tabelle 2-3: Güterverkehrsaufkommen der Binnenverkehrsträger in 1000t nach Güterabteilungen im Jahr 2006

Quelle: SBA (2007b)

Die Ursache dafür, dass die Binnenverkehrsträger unterschiedlich auf den Strukturwandel in der gesamtwirtschaftlichen Güter- bzw. Produktionsstruktur reagieren, ist zum einen in den spezifischen Leistungsanforderungen der Transportgüter an die Transporttechnologie und zum anderen in den Systemeigenschaften der Verkehrsträger zu suchen. Dieser Kompatibilitätsabgleich von Leistungsanforderungen an die Transportabwicklung und verkehrsträgerspezifischer Leistungsfähigkeit bzw. systembedingtem Leistungspotenzial zum Zwecke der möglichst effizienten Abwicklung von Transport- und Verkehrsaufgaben wurde weiter oben unter Zuhilfenahme der Begriffe „Verkehrsaffinität“ und „Verkehrswertigkeit“ diskutiert. ${ }^{261}$ Mit VOIGT wurden folgende Teilaffinitäten bzw. Teilwertigkeiten unterschieden: ${ }^{262}$

- Massenleistungsfähigkeit

- Schnelligkeit, Transportdauer, Transportgeschwindigkeit

- Netzbildungsfähigkeit

- Berechenbarkeit

- Zeitliche Flexibilität, Häufigkeit der Verkehrsbedienung

- Räumliche Flexibilität

- Sicherheit. 
Bei diesem Kompatibilitätsabgleich, welcher die ökonomische Fundierung der Verkehrsmittelwahlentscheidung der Verkehrsnachfrager darstellt, ${ }^{263}$ zeigt sich nun, dass der Straßengüterverkehr aufgrund seiner Systemeigenschaften (entspricht Verkehrsteilwertigkeiten)

- Flexibilität, d. h. der Fähigkeit, sich in erforderlichem Umfang an Zeit- und Raumvorgaben, Taktung und Rhythmen der Produktions- und Handelsprozesse anzupassen,

- Variabilität, d. h. insbesondere, unterschiedliche Transportgefäße und Transportaufbauten vorhalten zu können (bspw. für temperaturgeführte Transporte) und

- Netzbildungsfähigkeit, d. h. insbesondere, infrastrukturbedingte Vorteile bei der Haus-zu-Haus- bzw. Band-zu-Band-Erreichbarkeit ausnutzen zu können $^{264}$

die komplexen Leistungsanforderungen, welche die Güter der gesamtwirtschaftlichen Wachstumsbereiche an die Qualität der Transport- bzw. Verkehrsleistung haben, am besten erfüllen und daher seine Position gegenüber den anderen Verkehrsträgern stärken kann. ${ }^{265}$ Dieser Entwicklung wird auch dadurch Vorschub geleistet, dass mit den Umschichtungen in der gesamtwirtschaftlichen Produktions- und Güterstruktur hin zu hochwertigen Investitions- und Konsumgütern eine deutliche Dislozierung der Sendungsstruktur sowie eine spürbare Steigerung des Wertes je transportierter Gewichts- oder Volumeneinheit (Güterwerteffekt) ${ }^{266}$ einhergehen.

D. h. die Güter weisen aufgrund ihrer Leistungsanforderungen eine deutliche Affinität zum Straßengüterverkehr auf, während die Massengüter der stagnierenden bzw. sich zurückbildenden Bereiche hingegen eine deutliche Affinität zum Schienen- und Binnenschifffahrtsverkehr haben. ${ }^{267}$

Vgl. Monopolkommission (2007), Tz. 70.

Diese Netzbildungsfähigkeit, welche den Straßengüterverkehr aufgrund dessen Systemeigenschaften gegenüber den übrigen Verkehrsträgern begünstigt, wird bisweilen auch als „Schnittstelleneffekt" bezeichnet. Vgl. Pfohl (2004a), S. 339.

Vgl. Stahl (1995), S.18 f.; Aberle (2003a), S. 94; Frahm, Klaus (2000), S. 512.

Vgl. Stahl (1995), S. 19.

Vgl. Pfohl (2004a), S. 338. 
Einen Transfer des primär transport- und verkehrsbezogenen Wirkungspotenzials des Güterstruktureffektes auf das umfassendere Feld der Logistik stellt KLAUS her. Er diskutiert die Umwandlung großer, mit großzügigen und daher relativ unkritischen Vorgaben hinsichtlich der raum-zeitlichen Taktung erteilter Transportaufträge bzw. abrufe in „kontinuierliche, kleine, präzise terminierte Flüsse „feinkörniger" Lieferungen" und damit einhergehend die Bedeutungsverschiebung von Massen- und Ladungstransportsystemen hin zu reaktionsschnellen, auf präzise raum-zeitliche Eintaktung ausgerichtete logistische Systeme. ${ }^{268}$ Diesen Effekt, welcher aus den neuen Anforderungen an die Unternehmen entlang der Wertschöpfungsketten in punkto Produktentwicklungs-, Auftragsentwicklungs- und Reaktionsschnelligkeit abgeleitet werden kann, belegt KLAUS mit dem Begriff Logistik-Güterstruktureffekt. ${ }^{269}$ Der LogistikGüterstruktureffekt hebt also auf Aspekte innerhalb der Leistungserstellungsprozesse einzelner Unternehmen ab und leitet damit von der gesamtwirtschaftlichen Güter- und Produktionsstruktur zur Unternehmens- und einzelwirtschaftlichen Produktionsstruktur als logistikrelevante Ausprägungen von ökonomischen Strukturen über.

\section{Unternehmensstruktur und einzelwirtschafiliche Produktionsstruktur}

Aus der Fülle denkbarer unternehmensbezogener Strukturvariablen sind insbesondere die Elemente des unternehmerischen Organisationssystems mit raum-zeitlichem Strukturierungs- und Gestaltungspotenzial von Bedeutung für die Logistik, d. h. Elemente, welche die räumlichen und zeitlichen Gütermerkmale in den Güterbereitstellungs- und Güterverwendungsprozessen in den Transformationssektoren berühren. Hierbei erweist sich vor allem die Ausgestaltung der überbetrieblichen Arbeitsteilung als relevantes Faktum, welches die Anforderungen an das makrologistische System der Güterverteilung beeinflusst. ${ }^{270}$ Von herausragendem Interesse für die Logistik sind diejenigen Ausgestaltungsformen der Arbeitsteilung, welche mit einer räumlichen Trennung der einzelnen Leistungserstellungsprozesse und - damit verbunden - der ökonomischen Institutionen einhergehen. ${ }^{271}$ Es lassen sich hierbei mit der Art- und der Mengenteilung zwei Formen der Arbeitsteilung unterscheiden, welche in unterschiedlicher Art und Weise auf das Logistiksystem einwirken. ${ }^{272}$

\footnotetext{
268 Vgl. Klaus (2003), S. 23.

269 Vgl. Klaus (2003), S. 23.

270 Vgl. Pfohl (2004a), S. 336.

271 Vgl. Inde (2001), S. 66.

272 Vgl. Ihde (2001), S. 66 ff.; Pfohl (2004a), S. 336 f.
} 
Die Artteilung bewirkt durch die Zusammenführung artgleicher Aufgaben zunächst eine Reduktion der Aufgabenkomplexität und damit eine Spezialisierung der einzelnen Aufgabenträger, Betriebe oder Unternehmen. Diese Spezialisierung schafft Rationalisierungspotenziale in den Leistungserstellungsprozessen des Güterbereitstellungssystems, bspw. durch Auflagendegressions- oder Lerneffekte. Die Realisierung spezialisierungsbedingter Produktionskostenvorteile allerdings ist zwangsläufig verbunden mit einer Vervielfachung von Güteraustauschbeziehungen im Gesamtwirtschaftssystem, welche aufgrund der gestiegenen Überbrückungs-, Ausgleichs- und Ordnungsanforderungen zunehmend komplexen Charakter aufweisen und daher kostenintensiv sind. Rationalisierungseffekte durch Komplexitätsreduktion im Gütertransformationssystem werden also mit höheren Logistikkosten und Komplexitätsanstieg im System der Güterverteilung erkauft. ${ }^{273}$ Artteilige Produktion (Standortteilung) als Strategie zur Standortstrukturgestaltung führt folglich zu einer Verlagerung von Systemkomplexität vom Transformations- hin zum Transfersystem. Die Mengenteilung hingegen lässt keine spezialisierungsbedingten Produktionskostensenkungen im Transformationssystem erwarten. Im Rahmen der Mengenteilung wird vielmehr versucht, Produktionsvorteile aus der Optimierung der Betriebsgröße zu realisieren. Die entsprechende Fragestellung lautet demnach, ob es sinnvoll ist, einen Markt zentral von einem oder dezentral von mehreren Produktionsstandorten aus mit den erforderlichen Gütermengen zu versorgen. Auch in Fragen der Mengenteilung üben die Logistikkosten entscheidenden Einfluss auf die unternehmerische Entscheidungsfindung aus. Denn selbst wenn aus produktionskostentheoretischen Erwägungen noch zentrale Marktversorgung geboten sein sollte, könnte die Berücksichtigung der Logistikkosten die dezentrale Versorgungsalternative favorisieren: ${ }^{.74}$ Die Logistikmehrkosten, welche sich bei zentraler Produktion aus den zunehmenden durchschnittlichen Bezugs- und Versandweiten sowie aus der zunehmenden Verweildauer der Güter im Transfersystem ergeben, können die Produktionsminderkosten überwiegen und die mengenteilige Produktion (Standortspaltung) als Strategie zur Standortstrukturgestaltung bedingen.

Aus den Erörterungen zu Artteilung und Mengenteilung ergibt sich nun die Konsequenz, dass die Umsetzung der Vorteile, welche sich aus der räumlichen (Re-) Strukturierung der Arbeitsteilung ergeben, stets mit der Inkaufnahme von zusätzlichen Logistikkosten verbunden und folglich an die Leistungsfähigkeit des Logistiksystems gekoppelt ist. Grundsätzlich gilt, dass in Volkswirtschaften mit einer leistungsfähigen makrologistischen Infrastruktur die zentralisierte Leistungserstellung sowie arbeits- 
und standortteilige Produktionsstrukturen tendenziell begünstigt werden. ${ }^{275} \mathrm{Die}$ Vorteile zentralisierter und spezialisierter Produktion überkompensieren den mit ihr verbundenen zusätzlichen Aufwand im Logistiksystem. Dabei treten mit zunehmender Variantenvielfalt und Beschleunigung der Produktzyklen in den Leistungserstellungsprozessen die ursprünglich dominierenden Größeneffekte in den Hintergrund und die Realisierung von Verbundeffekten - insbesondere von räumlichen Verbundeffekten wie urbanization economies und localization economies - greift Platz. ${ }^{276}$ Wird zudem in Rechnung gestellt, dass aufgrund des Vordringens der Netzwerkökonomik die Möglichkeiten für die (transaktionskosten-)effiziente Beherrschung komplexer Beschaffungs- und Absatztransaktionen stark verbessert wurden, kann somit die empirisch feststellbare Tendenz zur abnehmenden Fertigungstiefe in Unternehmen (zunehmende vertikale Arbeitsteilung) einerseits sowie zur raumdifferenzierenden Auflösung von Wertschöfpungsketten zum Zwecke der Ausnutzung standortbezogener Vorteile von Produktionsfaktoren andererseits erklärt werden. ${ }^{277}$ Der Trend zur abnehmenden Fertigungstiefe und die damit verbundene Reduktion verladerseitig anfallender Koordinationskomplexität werden bisweilen auch als Produktionsstruktureffekt bezeichnet. ${ }^{278}$

Derartige Reorganisationsprozesse in den Unternehmens- und Produktionsstrukturen sind wegbereitend für den Logistikeffekt und verstärken diesen. ${ }^{279}$ Der Logistikeffekt resultiert aus der zunehmenden Verbreitung des logistischen Denkansatzes in den Industrie- und Handelsunternehmen, welcher ja die unternehmensübergreifende, flussorientierte Betrachtung des Leistungserstellungsprozesses impliziert. ${ }^{280}$ Dabei begründet die unternehmensübergreifende Flussorientierung notwendigerweise die Anpassung von Leistungserstellungsprozessen. Diese Anpassungsprozesse dokumentieren sich in der Auflösung und Trennung bisher vertikal integrierter Fertigungsketten und gehen oftmals mit der Reduzierung der Fertigungstiefe oder anders ausgedrückt: der Fokussierung auf Kernkompetenzen im Leistungserstellungsprozess einher. ${ }^{281}$ Nicht als Kernkompetenzen erkannte, bislang jedoch eigenerstellte Leistungsprozesse,

Vgl. Ihde (2001), S. 68.

Vgl. Lieb, Lange (2003), S. 447; Ihde (2001), S. 68, S. 71.

Vgl. Stahl (1995), S. 20. Die möglichen gestalterischen Einflüsse, welche von den Netzwerktechnologien der Netzwerkökonomik auf die Differenzierung der ökonomischen Raum- und Standortstruktur der Güterproduktion ausgehen, werden auch von Dohse et al. (2005), S. 3 ff. ausführlich diskutiert.

Vgl. Wendlandt, Böttiger (2007), S. 2.

Vgl. Ihde (2001), S. 69.

Vgl. Stahl (1995), S. 19.

Vgl. Aberle (2005), S. 4. 
werden von den Verladerunternehmen aus Industrie und Handel in aller Regel an spezialisierte Dienstleister fremdvergeben, $d$. h. outgesourct, um damit die Systemkomplexität und deren Kosten innerhalb der eigenen Unternehmensgrenzen zu reduzieren und gleichzeitig das Know-how der Dienstleister zur Effizienzsteigerung in die eigenen Geschäftsprozesse zu integrieren. ${ }^{282}$ Diese neuen, arbeits- und standortteilig organisierten Gestaltungsformen industrieller Fertigung oder des Handeltreibens bedingen jedoch, bezogen auf den gesamten unternehmensübergreifenden Leistungserstellungsprozess, ein erhöhtes Aufkommen koordinierungsintensiver Schnittstellen ${ }^{283}$ und damit einhergehend komplexe zwischenbetriebliche Güterverkehre - das Gut wird auf verschiedenen Stufen seiner Wertschöpfung und in der Regel mehrfach transportiert. ${ }^{284}$ Derartige Güterverkehre führen zu veränderten Anforderungen an die Logistikleistungserbringung hinsichtlich der produktionssynchronen Steuerung der Güterströme und hierbei insbesondere hinsichtlich der Exaktheit bei der räumlichen und zeitlichen Zusammenführung der Güter. ${ }^{285}$ Hierbei erweist sich die Integration der Güter-, Material- und Informationsflüsse (Prozessebene) sowie der beteiligten Unternehmen (institutionelle Ebene), die Verknüpfung von Subsystemen zu einem Gesamtsystem also, als Kernaufgabe für die Logistik. ${ }^{286}$

Im Übrigen zeigt sich auch beim Logistikeffekt, dass es seine Systemeigenschaften sind, welche dem Straßengüterverkehr bei logistikrelevanten Gütern einen Vorteil gegenüber den übrigen Verkehrsträgern einbringen. Insofern verstärkt der Logistikeffekt die Wirkungen des Güterstruktureffektes bezüglich Richtung und Intensität der disproportionalen Entwicklung der Verkehrsträger. ${ }^{287}$

\subsubsection{Zusammenfassung}

Der Verkehrsbereich, ein wesentlicher Bestandteil des Logistiksystems, war in Deutschland über viele Jahrzehnte Gegenstand eines umfassenden und überdauernden Regulierungsregimes, dessen letzte wesentlichen Fundamentalvorschriften erst in den 90er Jahren des vorigen Jahrhunderts außer Kraft gesetzt wurden. Maßgeblichen Anteil an Initiative zur und Umsetzung der Deregulierung in Deutschland hatten die

Vgl. Klaus (2003), S. 27; OECD (2002), S. 15.

Vgl. Klaus (2003), S. 28.

Vgl. Ihde (2001), S. 59 f.; OECD (2002), S. 12.

Vgl. Ihde (2001), S. 60.

Vgl. Pfohl (2004b), S. 22.

Vgl. Aberle (2003a), S. 95.
} 
intensiven Deregulierungsanstrengungen, welche auf der Ebene der europäischen Verkehrspolitik (spätestens) seit den 1980er Jahren betrieben worden sind.

Das Regulierungsregime hat im Verkehrsbereich zu gravierenden ökonomischen Fehlentwicklungen geführt, welche aufgrund der langen Regulierungsdauer intensiv ausgeprägt und gefestigt waren und deren Spuren auch im heutigen Logistikmarkt zum Teil noch deutlich sichtbar sind. In der Hauptsache waren es der fehlende inter- und intramodale Preiswettbewerb sowie die objektiven Marktzugangsbeschränkungen, welche die Wettbewerbskräfte im Verkehrsbereich zum Erlahmen brachten. Wesentliche sichtbare Ausprägungsformen des weitestgehend wettbewerbslosen Zustandes waren der Mangel an Innovations- und Rationalisierungsbemühungen der Verkehrsunternehmen, das Ausbleiben eines angemessenen wettbewerblichen Ausleseprozesses, Allokationsverzerrungen sowie eine durch die künstliche Marktsegmentierung hervorgerufene suboptimale Ausgestaltung der Arbeitsteilung. Suboptimal war die Arbeitsteilung in zweifacher Hinsicht. Zum einen war die Aufteilung der verkehrlichen Aufgaben zwischen den Verkehrsträgern, der sog. modal split, nicht aufgabenadäquat. Zum anderen war die Aufteilung der verkehrlichen Aufgaben auf die beiden grundsätzlichen Alternativen (1) Eigenproduktion von Verkehrsleistungen durch produzierende oder Handel treibende Verlader (Werkverkehr) und (2) Einsatz gewerblicher Logistikunternehmen (insb. Speditionen und Straßengüterverkehrsunternehmen) unsachgemäß. Verlader wählten zu Regulierungszeiten häufig die - systembedingt ökonomisch grundsätzlich mindereffiziente - Alternative der Eigenproduktion von Verkehrsleistungen in Form des Werksverkehrs mit der Intention, dem regulierungsbedingt nicht marktgerechten Preis- und verladeranforderungsgerechten Leistungsniveau der gewerblichen Anbieter von Verkehrsleistungen auszuweichen. ${ }^{288}$

Nach weitgehend vollzogener Deregulierung der deutschen Verkehrsmärkte konnten insbesondere hinsichtlich der Senkung der Transportpreise im ökonomisch höchst relevanten Straßengüterfernverkehr kurzfristig augenfällige Erfolge erzielt werden. Ebenfalls geben die zu beobachtenden Entwicklungen auf den Verkehrsmärkten zu der Vermutung Anlass, dass die Rücküberantwortung der Verkehrsprozesse an die wettbewerbsbasierte Marktkoordination - in aller Regel auf positive Art und Weise auf Zahl und Größe der Anbieter eingewirkt und die Anbieter dazu veranlasst hat, die für ihr unternehmerisches Fortbestehen notwendigen ökonomischen Planungsgrundsätze und -methoden zu erlernen und sich anzueignen. Dadurch erwarben die Unter- 
nehmen die notwendigen Fähigkeiten dazu, wettbewerbliche Verhaltensweisen zu praktizieren.

Vor dem Hintergrund der unternehmensübergreifenden, güterflussorientierten Perspektive der Logistikkonzeption stellen in dieser Beziehung insbesondere die sich deregulierungsbedingt neu eröffneten Möglichkeiten für die Akteure der Angebotsund der Nachfrageseite im Logistikmarkt

- zur unbeschränkten logistischen Vernetzung i. S. der Verknüpfung von bzw. der Abstimmung zwischen mikrologistischen Systemen, ${ }^{289}$

- zur freien Wahl dafür geeigneter institutioneller Arrangements ${ }^{290}$ sowie damit verbunden

- zur Bestimmung von zweckentsprechenden Ausgestaltungsformen arbeitsteiliger Wahrnehmung von Logistikaufgaben, ${ }^{291}$

welche das Ergebnis ökonomischer Überlegungen und nicht regulierungsbedingter Notwendigkeiten sind, wichtige Stellgrößen für die Akteure im Logistikmarkt dar.

Eben diese Aspekte wurden anschließend zunächst aus der Perspektive der Netzwerkökonomik beleuchtet. Dabei zeigte sich, dass es sich bei der Logistik und der Netzwerkökonomik um zwei komplementäre, sich bedingende und sich positiv verstärkende Denk- und Gestaltungsansätze zur Beherrschung vertikaler und horizontaler realmarktlicher Koordinationserfordernisse mit hohem Komplexitätsniveau handelt: Auf der einen Seite ist die Logistik einer der Nutznießerbereiche der netzwerkökonomischen Netzwerktechnologien und Vernetzungspotenziale, da sie diese für die Zwecke der physischen und informationstechnischen Optimierung der unternehmensübergreifenden Prozesskoordination zu instrumentalisieren in der Lage ist. Auf der anderen Seite kann die Netzwerkökonomik ihre großen Potenziale für eine möglichst umfängliche qualitative und quantitative ökonomische Vernetzung von Akteuren, Prozessen und Informationen nur auf Basis funktionsfähiger unternehmensübergreifender physischer Leistungserstellungsprozesse erschließen, deren Gestaltung und Beherrschung wiederum die Kernaufgabe der Logistik ist. Logistik ist folglich gleichzeitig zentraler Anwendungsbereich und zentraler erfolgstreibender Bestandteil der Netz-

Vgl. Hoffmann, Stölzle (2005), S. 2.

Vgl. Hoffmann, Stölzle (2005), S. 2. 
werkökonomik. Wird der weiteren Analyse diese Basishypothese zugrunde gelegt, so kann das Wirkungspotenzial, welches von der Netzwerkökonomik auf die Vorgänge auf dem Logistikmarkt ausgeht, im konkreten Fall in eine indirekte und eine direkte Beeinflussungsebene unterschieden werden.

Indirekten Einfluss auf die Vorgänge auf dem Logistikmarkt nimmt die Netzwerkökonomik vor allem dadurch, dass sie bei den produzierenden und handeltreibenden Verladern Veränderungen in den Leistungserstellungsprozessen bewirkt und sie tendenziell zur Reduzierung ihrer (auch) logistischen Leistungstiefe (Outsourcing) veranlasst. Dadurch verändert die Netzwerkökonomik das Anforderungsprofil der Verladerunternehmen an das Logistiksystem (d. h. ihren logistischen Bedarf) sowie in Konsequenz den Vernetzungsgrad und die Arbeitsteilung in und zwischen den mikrologistischen Systemen. Direkter Einfluss auf die Vorgänge auf dem Logistikmarkt geht von der Netzwerkökonomik dadurch aus, dass sie den Anbietern und Nachfragern nach Logistikleistungen informations- und kommunikationstechnische sowie institutionelle Gestaltungsoptionen zur Verfügung stellt, welche dazu geeignet sind, (1) die zitierten Veränderungen des logistischen Bedarfes der Verlader leistungsmäßig abzubilden und (2) die institutionelle Organisation der Leistungskoordination im Logistiksystem an diesen veränderten logistischen Bedarf anzupassen.

Bei der Netzwerkökonomik und der Logistik scheint es sich folglich - in zweckentsprechender Koppelung - um zwei konzeptionelle Gestaltungsansätze zu handeln, welche dazu geeignet sind, einen ökonomischen Evolutionsprozess in Gang zu setzen und voranzutreiben, welcher

- institutionelle Arrangements zur Leistungskoordination neu konfiguriert (Evolution auf der institutionellen Ebene),

- die Integration neuer Technologien in traditionelle Leistungserstellungsprozesse vorantreibt und die Leistungserstellungsprozesse dadurch verbessert (Evolution auf der Prozessebene) und welcher dabei

- sowohl auf die Transformationssysteme als auch auf das Transfersystem ausstrahlt. 
An die Erörterung der netzwerkökonomischen Aspekte anschließend wurden mit (1) der gesamtwirtschaftlichen Güter- und Produktionsstruktur sowie mit (2) der Unternehmens- und einzelwirtschaftlichen Produktionsstruktur zwei logistikrelevante Themenblöcke von Strukturwandelphänomenen herausgearbeitet. Die Analyse der gesamtwirtschaftlichen Güter- und Produktionsstruktur hat zutage gefördert, dass deren Wandel über den Güterstruktureffekt zunächst insbesondere Auswirkungen auf den logistischen Leistungsteilbereich der Verkehrsleistung produziert. Der Güterstruktureffekt impliziert, dass die veränderten Anforderungen hinsichtlich Flexibilität, Variabilität und Netzbildungsfähigkeit, welche sich aus der Veränderung der gesamtwirtschaftlichen Güter- und Produktionsstruktur an die Verkehrsleistungen ergeben, aufgrund seiner Systemeigenschaften am besten vom Verkehrsträger Straße erfüllt werden können. Dies wiederum impliziert eine Verschiebung des modal split in Richtung Straßengüterverkehr zulasten der auf homogene Massengüterverkehre ausgelegten Verkehrsträger Schiene und Binnenschifffahrt und bewirkt somit eine Veränderung der Arbeitsteilung zwischen den Verkehrsträgern. Eine Ausweitung des primär transport- und verkehrsbezogenen Wirkungspotenzials des Güterstruktureffektes auf das umfassendere Feld der Logistik wird mit dem Begriff des LogistikGüterstruktureffektes beschrieben. Der Logistik-Güterstruktureffekt thematisiert die gestiegenen Anforderungen, welche sich für die Unternehmen entlang von Wertschöpfungsketten - unter Berücksichtigung des gesamtwirtschaftlichen Güter- und Produktionsstrukturwandels - hinsichtlich Kontinuität, Präzision und Flexibilität bei der raumzeitlichen Eintaktung und Zusammenführung von Güter-, Material- und Informationsströmen ergeben. Der Logistik-Güterstruktureffekt drückt folglich die Konvergenz gesamtwirtschaftlicher und einzelwirtschaftlicher, unternehmensbezogener Aspekte des Produktionsstrukturwandels aus und leitet somit auf den zweiten Themenblock logistikrelevanter Strukturen, nämlich den der Unternehmensstruktur und der einzelwirtschaftlichen Produktionsstruktur über. Aus der Vielzahl unternehmensbezogener Strukturvariablen erweisen sich insbesondere diejenigen Elemente des unternehmerischen Organisationssystems als logistikrelevant, welche für die Gestaltung der raum-zeitlichen Komponenten der Leistungserstellungsprozesse verantwortlich zeichnen und damit den Übergang zum Transfersystem markieren. Ein wesentliches Element stellt in dieser Beziehung die Ausgestaltung der zwischen- und überbetrieblichen Arbeitsteilung in den Transformationssystemen dar und hier wiederum insbesondere jene Formen, welche einen Raumbezug aufweisen, d. h. welche einzelne Leistungserstellungsprozesse und die beteiligten ökonomischen Institutionen räumlich voneinander trennen. Es lassen sich hierbei mit der Art- und der Mengenteilung zwei Formen der Arbeitsteilung unterscheiden, welche in unterschiedlicher Art und Weise 
auf das Logistiksystem einwirken. Artteilige Produktion (Standortteilung) als Strategie zur Standortstrukturgestaltung bewirkt zunächst eine Reduktion der Aufgabenkomplexität im Gütertransformationssystem und soll dort Rationalisierungseffekte durch Spezialisierungsvorteile freisetzen. Diese Rationalisierung jedoch wird erkauft mit einem Kosten- und Komplexitätsanstieg im Transfersystem und bewirkt folglich keine Reduktion der Gesamtsystemkomplexität, sondern eine Verlagerung von Systemkomplexität vom Transformations- in das Transfersystem. Mengenteilige Produktion (Standortspaltung) als Strategie zur Standortstrukturgestaltung hingegen hat die Optimierung der Betriebsgrößen und damit des Grades an Zentralität oder Dezentralität der Marktversorgung zum Gegenstand. Die Güte des Logistiksystems ist zu deren Bestimmung ein wichtiger Parameter.

Daraus erhellt, dass die tatsächliche Realisierung der erzielbaren produktions- und raumbezogenen Größen- und Verbundeffekte in den Transformationssystemen eng an die Leistungsfähigkeit des makrologistischen Systems und dessen institutioneller Elemente - und hier speziell an seine Eignung, die dem Logistiksystem neu überantwortete Koordinationskomplexität zu beherrschen - gekoppelt ist. Wesentliche positive Impulse auf die Leistungsfähigkeit des Logistiksystems und insbesondere auf dessen Befähigung, die hohe Systemkomplexität von Logistikprozessen zu verringern und $\mathrm{zu}$ beherrschen sowie die aufkommenden Unsicherheiten durch die neuen outsourcingbedingten Ausgestaltungsformen von Leistungsbeziehungsstrukturen zwischen den Unternehmen in der Logistikkette abzubauen, gehen von der Integration der netzwerkökonomischen Technologien in die Logistik aus. ${ }^{292}$ Je leistungsfähiger das Logistiksystem also ist, umso eher sehen sich Industrie- und Handelsunternehmen dazu in der Lage,

- Systeme zentralisierter Leistungserstellung sowie arbeits- und standortteiliger Produktionsstrukturen zu etablieren,

- das Potenzial der standortbezogenen Vorteile von Produktionsfaktoren zu erschließen, welches sich aus der raumdifferenzierenden Auflösung bzw. Trennung bisher vertikal integrierter Wertschöpfungsketten ergibt,

- ihre Fertigungstiefe zu reduzieren und Logistikaufgaben auf Dienstleistungsunternehmen zu übertragen (zunehmende vertikale Arbeitsteilung durch Outsourcing der nicht zu den Kernkompetenzen zählenden Aktivitäten) mit dem Ziel, 
Systemkomplexität und deren Kosten innerhalb der eigenen Unternehmensgrenzen zu verringern.

Die Möglichkeit und Neigung zu den hier erörterten Reorganisationsprozessen in den Unternehmens- und Produktionsstrukturen auf Unternehmensebene wiederum sind die Basis dafür, dass sich solche Reorganisationsprozesse ausgeweitet auf die unternehmensübergreifende Ebene entwickeln können. Derartige, den gesamten unternehmensübergreifenden Leistungserstellungsprozess umfassende sowie arbeits- und standortteilig organisierte Gestaltungsformen industrieller Fertigung oder des Handeltreibens führen allerdings dazu, dass sich die Anzahl koordinierungsintensiver Schnittstellen und damit einhergehend die Anzahl komplexer zwischenbetrieblicher Güterverkehre entlang der Wertschöpfungskette potenziert. Dies macht deutlich, dass es bei der Durchsetzung des logistischen Denkansatzes in den Wertschöpfungsketten der Industrie- und Handelsunternehmen umso mehr noch darauf ankommt, dass das Logistiksystem Lösungen findet, die ihm neu auferlegte Koordinationskomplexität der logistischen Transaktionen effizient zu beherrschen. 


\subsection{Angebot und Nachfrage nach Logistikleistungen}

\subsubsection{Vorbemerkungen}

Den nächsten Baustein der Marktanalyse bilden die Untersuchung der Marktangebotsund der Marktnachfrageseite. Gegenstand werden hierbei Gegebenheiten, Determinanten und Prozesse sein, welche direkt die Bereitstellung und die Nachfrage von Logistikleistungen betreffen. Hierzu kann auf die dafür geeigneten Anknüpfungspunkte zurückgegriffen werden, welche im Rahmen des modifizierten SVE-Paradigmas in den Kategorien der Marktstruktur, des Marktverhaltens sowie zum Teil auch in den basic conditions erarbeitet worden sind.

Dementsprechend gliedert sich der folgende Abschnitt 2.4 in Anlehnung an die Nomenklatur der SVE-Analyse folgendermaßen: Nach der allfälligen Abgrenzung des relevanten Marktes (Unterabschnitt 2.4.2) folgt die Ermittlung des LogistikMarktvolumens (Unterabschnitt 2.4.3). Anschließend werden mit der horizontalen, der vertikalen und der diagonalen Anbieterkonzentration die wesentlichen Komponenten der Angebotsstruktur thematisiert (Unterabschnitt 2.4.4). Die Darstellung verschiedener Typen von Marktakteuren sowie deren Marktstrategien ist Gegenstand des Unterabschnittes 2.4.5. Eine Zusammenfassung beschließt den Abschnitt (Unterabschnitt 2.4.6).

\subsubsection{Der relevante Markt für Logistikleistungen}

Für die Analyse eines Marktes ist es unabdingbar notwendig, ihn eindeutig gegenüber anderen Märkten abzugrenzen.' Insbesondere dann, wenn eine wettbewerbspolitische Beurteilung des Marktgeschehens beabsichtigt ist, ist eine angemessene Marktabgrenzung von zentraler Bedeutung, weil „mit ihr die Ausprägungen verschiedener Marktstrukturkriterien beeinflusst werden können“. ${ }^{2}$ Dessen ungeachtet haftet jeglicher Form der Marktabgrenzung jedoch immer der leichte Makel willkürlicher Beliebigkeit an, da das Marktsystem als Ganzes an sich einheitlich und nicht zerlegbar ist. ${ }^{3}$ Eine Marktabgrenzung sowie eine daraus abgeleitete Interpretation bzw. Beurteilung der Güte des Marktgeschehens unterliegt daher immer einem dem jeweiligen

Vgl. Herdzina, Wander (2004), S. 96.

Fritz (2000), S. 167. Vgl. dazu auch Herdzina (1999), S. 73 f.

Vgl. Hoppmann (1977), S. 9. 
Analysezweck anpassbaren Werturteil. ${ }^{4}$ WOLL bestreitet sogar die bloße Existenz objektiver Maßstäbe zur Bestimmung des relevanten Marktes. ${ }^{5}$ BAUER versteht den Vorgang der Marktabgrenzung als ,um eine Grenzziehung erweiterte Marktstrukturierung" und begreift das Abgrenzen folglich als denjenigen Prozess, der dazu dient, „bestimmte Konturen [von Teilmengen, der Verf.] hervorzuheben und (...) Grenzen zwischen Teilmengen zu betrachten ". ${ }^{6}$ Dabei sollte die Marktabgrenzung immer adäquat zum angedachten Analysezweck erfolgen. ${ }^{7}$ Wird nun im Folgenden eine Marktabgrenzung vorgenommen, so geschieht dies zum einen im Bewusstsein, dass damit ein normatives Konzept verwendet wird und zum anderen mit dem wiederholten ausdrücklichen Verweis, dass die Marktanalyse keine wettbewerbspolitische Beurteilung des Marktgeschehens zum Gegenstand hat.

Üblicherweise wird der relevante Markt in sachlicher, räumlicher, zeitlicher und personeller Hinsicht abgegrenzt. ${ }^{8}$ Für den Logistikmarkt erscheinen dabei insbesondere die sachliche und die räumliche Dimension relevant. Die theoretische Analysebasis bildet dabei das Substitutionskonzept sowie das Produktionsflexibilitätskonzept. ${ }^{9}$

\subsubsection{Abgrenzung des sachlich relevanten Marktes}

Ziel der sachlichen Marktabgrenzung ist es, aus dem volkswirtschaftlichen Gesamtmarktgeschehen denjenigen Teilbereich herauszufiltern, der die Anbieter und Nachfrager einer für den jeweiligen Analysezweck als relevant bestimmten Ware oder Dienstleistung erfasst. ${ }^{10}$ Andere nicht zu dieser Gruppe gehörende Wirtschaftssubjekte sollen keinen oder allenfalls vernachlässigbaren Einfluss auf diesen Teilbereich ausüben.

„Es ist nicht so, dass der Richter zuerst den relevanten Markt abgrenzt, um anschließend zu fragen, was innerhalb dieses zuvor abgegrenzten Marktes geschieht. Vielmehr entsteht die Abgrenzung eines relevanten Marktes als Ergebnis der richterlichen Entscheidung, d. h. die Abgrenzung ist nicht logische Voraussetzung der Marktanalyse, sondern sie ist deren Ergebnis. Der relevante Markt ist insofern ein normatives Konzept und seine Abgrenzung ein methodisches Verfahren, das auf wechselnde Sachverhalte und Wertungen angewendet werden kann." Hoppmann (1974a), S. 10 f. Vgl. auch Hoppmann (1972), S.56 f., Bauer (1995), Sp. 1709. Vgl. Woll (2005), S. 1275.

Bauer (1995), Sp. 1709 f., im Original z. T. kursiv.

„Die jeweiligen, allgemeinen oder auch ganz speziellen Zwecke präjudizieren sowohl die an die Marktabgrenzung zu stellenden Anforderungen als auch diese selbst.“ Bauer (1989), S. 23.

Vgl. Herdzina, Wander (2004), S. 96.

9 Für eine Übersicht über die gängigen Marktabgrenzungskonzepte sowie eine detaillierte Beschreibung der hier verwendeten Konzepte siehe Herdzina (1999), S. 73 ff. 
Wie in Abschnitt 2.2 dargelegt, bildet der Transfersektor in einer arbeitsteilig organisierten Volkswirtschaft dasjenige System, das die elementaren Transformationsprozesse der Güterbereitstellung (Produktion) und der Güterverwendung (Konsumtion) mittels Transferprozessen (Gütertransfers) zusammenfügt. Die konkreten Anforderungen an den Transfersektor hinsichtlich des güterbezogenen Art- und Mengenausgleichs sowie hinsichtlich der Überwindung räumlicher und zeitlicher Zerklüftungen kennzeichnen den logistischen Bedarf eines Wirtschaftssystems und konstituieren Güterflusssysteme bzw. Logistiksysteme. In sachlicher Hinsicht hat der Logistikmarkt die Funktion, den mit Kaufkraft ausgestatteten und geäußerten logistischen Bedarf des Wirtschaftssystems - die Nachfrage nach logistischen Leistungen also - und das Angebot logistischer Leistungen durch die mikrologistischen Systeme zum Ausgleich zu bringen. Der Logistikmarkt kann folglich als eine denkbare Form der Operationalisierung derjenigen Prozesse aufgefasst werden, welche innerhalb des gesamtwirtschaftlichen Transfersektors ablaufen. Er umfasst demzufolge

- den Logistikdienstleistungsmarkt, d. h. die prinzipielle Grundkonstellation, dass Logistikdienstleistungsunternehmen Logistikleistungen anbieten und Industrieund Handelsunternehmen der Transformationssektoren die Logistikleistungen nachfragen, aber auch

- die Eigenproduktion logistischer Leistungen von den Verladerunternehmen aus Industrie und Handel zum Eigenbedarf.

Diese beiden grundsätzlichen Komponenten des Logistikmarktes symbolisieren den grundsätzlichen institutionell-organisatorischen Handlungsrahmen zwischen Fremdbezug logistischer Leistungen und deren Eigenproduktion, mit welchem sich die Logistikmarktkoordination in seinen verschiedensten Ausgestaltungsformen auseinanderzusetzen hat. $"$

Aus Nachfragersicht stellt sich die Logistikleistung als äußerst komplexe, teils standardisierte, teils individualisierte Dienstleistung dar. ${ }^{12}$ Es stehen den Anbietern

11 Vgl. Unterabschnitt 2.5.2.

12 Während bestimmte logistische Teilleistungen (bspw. Stückgutverkehre) das sichtbare Ergebnis erfolgreicher Standardisierungsbemühungen in den 80er Jahren sind, gibt es heute aufgrund anhaltender Outsourcingprozesse innerhalb der Verladerschaft auch eine deutlich erkennbare Tendenz zur Individualisierung des Leistungsangebotes hin zu kunden- und branchenspezifischen Distributions- und Kontraktlogistik-Dienstleistungspaketen („Mass-Customization“). Vgl. Mül- 
dabei unterschiedlichste, prinzipiell substituierbare Produktionsverfahren und strategien zur Verfügung, die verschiedenartigen logistischen Problemstellungen der Nachfrager zu lösen:

- So können räumliche Zerklüftungen bspw. mit Transport- bzw. Verkehrsleistungen unterschiedlicher Verkehrsträger geschlossen werden, sofern die Systemeigenschaften der verschiedenen Verkehrsträger gleichermaßen dazu geeignet sind, die Anforderungen des Verladers an den Transport zu erfüllen. ${ }^{13}$

- Ein nachfragerseitiges Logistikproblem, welches die Veränderung räumlicher und zeitlicher Merkmale von Gütern zum Gegenstand hat, kann zum Teil substitutiv, zum Teil komplementär mittels unterschiedlicher sequentiell oder parallel ineinander greifenden Transport- und Lagerleistungen gelöst werden. ${ }^{14}$

- Sachliche Gütermerkmale können mittels Kommissionier- und sonstigen Logistikleistungen verändert werden, womit das Transfer- bzw. Logistiksystem den originären Aufgabenbereich der Transformationssektoren tangiert und somit die Grenzziehung zwischen den einzelnen Sektoren erschwert wird.

Einstmals war der Logistikmarkt aufgrund bestehender administrativer Einflussnahme (Regulierung des Marktes mittels Kontingentierung und Tarifierung) in strikt voneinander abgeschottete Teilmärkte aufgeteilt, so dass es eine Vielzahl unterschiedlicher und voneinander unhabhängiger sachlich relevanter Märkte gab. Paradebeispiel hierfür war etwa die Trennung zwischen Straßengüternahverkehrsmarkt und Straßengüterfernverkehrsmarkt. Erst nach vollzogener Deregulierung verschwand diese maßgeblich politisch motivierte, künstliche Marktspaltung, welche im Grunde jeglicher Sachlogik entbehrte.

ler-Steinfahrt (2000), S. 304. Die allfälligen Strategieentscheidungen der Logistikdienstleister sowie der Verlader pro oder contra Standardisierung bzw. Individualisierung fördern dabei nicht selten Trade-Off-Beziehungen zwischen Logistikkosten auf der einen und Lieferservice bzw. Flexibilität auf der anderen Seite zutage: Während Standardisierung tendenziell die Logistikkosten senkt, nehmen Flexibilität und Lieferservice gleichermaßen ab und vice versa. Diese TradeOffs verdeutlichen die immense Bedeutung von logistiksystemweiten, interorganisatorischen Abstimmungs- und Integrationsprozessen. Vgl. Delfmann (2000b), S. 213. Zugleich sind diese Trade-Offs wiederum Ausdruck des dualen Charakters der logistischen Effizienz zwischen dem Streben nach Logistikkostenreduktion und Steigerung der Marktqualität desjenigen Produktes, welches der logistischen Manipulation unterliegt. Vgl. Aberle (2003b), S. 277.

Vgl. Delfmann (2000b), S. 213. 
Heute ist der Logistikmarkt ein vergleichsweise uneinheitlicher und heterogener Markt ${ }^{15}$, in dem einzelne Segmente der angebotenen Leistungen fallweise miteinander konkurrieren, sich aber auch zu Leistungsbündeln ergänzen können. Die einzelnen Segmente logistischer Leistungen sind dabei teils durch funktionelle Äquivalenz (Austauschbarkeit vom Standpunkt des spezifischen Verwendungszwecks) und reaktive Äquivalenz (Austauschbarkeit aus Sicht der Konsumenten der Dienstleistung) gekennzeichnet, ohne dabei zwangsläufig physikalisch-technisch äquivalent sein zu müssen. ${ }^{16} \mathrm{Da}$ also alle logistischen Teilleistungen zumindest prinzipiell und fallweise austauschbar sind, sind sie demselben sachlich relevanten Markt zuzuordnen. Der sachlich relevante Logistikmarkt umfasst somit alle Leistungen, welche von Logistikdienstleistungsunternehmen für Dritte bzw. welche von logistischen Fachabteilungen von verladenden Unternehmen selbst erbracht werden und die dazu geeignet sind, räumliche, zeitliche und sachliche Merkmale von Gütern zu verändern um damit den logistischen Bedarf der Nachfrager zu decken. Nichtsdestotrotz steht jedoch auch außer Frage, dass, bezogen auf im Einzelfall geäußerte konkrete logistische Bedarfe von Unternehmen, nicht alle Logistikleistungen mühelos austauschbar sind und es daher sinnvoll scheint, innerhalb des Gesamt-Logistikmarktes einzelne Teilsegmente differenziert voneinander zu betrachten.

Die Segmentierung des Gesamt-Logistikmarktes wiederum ist grundsätzlich nach vielen verschiedenen Aspekten möglich, wie bspw. nach (1) Transportobjekten (Lebensmitteltransporte, Elektronikartikeltransporte), (2) Auftraggeberbranchen oder Kundentypen (Reifenlogistik, Metalllogistik), (3) Auftrags- und Abwicklungstypen (Expressgüter), (4) Transportmittel (Silotransporte), (5) Verkehrsträgern (Straßengüterverkehr, Schienengüterverkehr, Binnenschifffahrt) oder (6) Funktionszusammenhängen (Beschaffungslogistik, Distributionslogistik). ${ }^{17}$ Teils sind diese Teilsegmente regulierungsbedingt historisch gewachsen und gestalten die Marktgeschehnisse noch immer nachhaltig mit wie dies bspw. bei den diversen Frachtführermärkten sowie bei den Speditionsmärkten der Fall ist. Teils existieren Sondermärkte für bestimmte logistische Problemstellungen, welche angesichts ihres besonderen Anforderungsprofils an Know-how und Ausrüstung der Logistikdienstleister getrennt von anderen Teilmärkten betrachtet werden müssen. Ferner sind grenzüberschreitende Logistikleistungen gesondert von denjenigen Leistungen, welche lediglich den nationalen

Vgl. Freichel (1992), S. 23.

Vgl. für die verschiedenen Formen der Äquivalenz und der Substituierbarkeit/Austauschbarkeit als Abgrenzungskriterium für den sachlich relevanten Markt Hoppmann (1974a), S. 34 ff.

17 Vgl. Müller-Steinfahrt (2000), S. 299.
} 
deutschen Markt betreffen, zu betrachten. Klaus bzw. KlauS und MülleRSTEINFAHRT haben dazu folgende Systematik einer Segmentierung des Logistikmarktes erarbeitet, welche zugleich wesentliche Grundlage der vorliegenden Abhandlung darstellen soll. ${ }^{18}$ Diese Systematik stellt eine in der Praxis weithin gebräuchliche Form der Marktsegmentierung dar, welche einige der zuvor genannten Segmentierungsgesichtspunkte miteinander vermengt und daher fallweise inhaltliche Überschneidungen aufweist. ${ }^{19}$ Die Teilmärkte sind hinsichtlich des Komplexitätsgrades der erbrachten Logistikleistungen Ausdruck einer groben Ordnung von wenig differenzierten, einfachen, vornehmlich national erbrachten Transportleistungen zu höher differenzierten logistischen Spezialleistungen mit zunehmend internationalem Charakter. ${ }^{20}$

\section{Ladungstransporte und „Bulk“-Logistikmärkte}

- Teilmarkt 1: Nationale Massengutlogistik

- Teilmarkt 2: Nationaler allgemeiner Ladungsverkehr

- Teilmarkt 3: Schwertransporte und Krandienste

- Teilmarkt 4: Nationale Tank- und Silotransporte

- Teilmarkt 5: Nationaler sonstiger Ladungsverkehr mit speziellem Equipment

\section{Märkte für Stückgut und sonstige handlingsbedürftige Güter}

- Teilmarkt 6: Nationaler allgemeiner Stückgutverkehr

- Teilmarkt 7: Konsumgüterdistribution, Konsumgüterkontraktlogistik

- Teilmarkt 8: Industrielle Kontraktlogistik, insbesondere industrielle Produktionsversorgung, Ersatzteildistribution und sonstige business-to-business Kontraktlogistik

- Teilmarkt 9: Hängende Kleider-Logistik

- Teilmarkt 10: High-Tech-Güter, Messelogistik, Neumöbel- und Umzugstransporte

- Teilmarkt 11: KEP- Paket-, echte Kurier- und spezialisierte Expressdienste

18 Vgl. Klaus, Müller-Steinfahrt (2000), S. $102 \mathrm{ff}$.

19 Vgl. Müller-Steinfahrt (2000), S. 299.

20 Vgl. Klaus (2003), S. 79 ff.; basierend auf: Klaus, Müller-Steinfahrt (2000), S. 30. 
- Teilmarkt 12: Terminaldienste, nicht integrierte Lagerei-, Umschlags- und sonstige logistische Zusatzleistungen

\section{Märkte für grenzüberschreitende Transporte}

- Teilmarkt 13: Grenzüberschreitende Transport- und Speditionsleistungen, Schwerpunkt Straße und Schiene

- Teilmarkt 14: Grenzüberschreitende Transport- und Speditionsleistungen, Schwerpunkte Seeschifffahrt/ Seehafenspedition

- Teilmarkt 15: Grenzüberschreitende Aircargo-Carrier und Leistungen der Luftfrachtspedition

Prinzipiell treten in jedem der 15 Teilmärkte sowohl Logistikdienstleistungsunternehmen als auch Verladerunternehmen aus Industrie und Handel als Anbieter der entsprechenden Logistikleistungen auf. Das Anteilsverhältnis zwischen auf Logistikdienstleister übertragenen Logistikleistungen einerseits und von Verladern eigenproduzierten Logistikleistungen andererseits hingegen variiert zwischen den einzelnen Teilmärkten erheblich. ${ }^{21}$

\subsubsection{Abgrenzung des räumlich relevanten Marktes}

Prinzipiell gilt, dass die räumliche Grenze des Marktes dort gezogen wird, wo es für Nachfrager eines Gutes oder einer Leistung unmöglich oder zumindest „nur unter Inkaufnahme erheblicher Unbequemlichkeit oder unzumutbarer Fracht- und Wegekosten möglich wäre", das besagte Gut oder die besagte Leistung von außerhalb des zuvor als relevanten Markt benannten Gebietes zu beziehen. ${ }^{22}$ Aus Anbietersicht wäre die Grenze dort zu ziehen, wo eine Belieferung der Nachfrager von außerhalb des zuvor als relevanten Markt benannten Gebietes nicht oder nur sehr schwer möglich ist. ${ }^{23}$ Das Konzept des räumlich relevanten Marktes stellt demnach auf die ökonomische Entfernung zwischen den Standorten verschiedener Anbieter und die daraus resultierenden Wettbewerbsbeziehungen $a b .{ }^{24}$

\footnotetext{
$21 \quad$ Vgl. Unterabschnitt 2.4.3.2.

22 Hoppmann (1974a), S. 32.

23 Vgl. Hoppmann (1974a), S. 32.

24 Vgl. Schmidt (1998), S. 23.
} 
Mögliche Abgrenzungskriterien wurden von KOTTMANN auf Grundlage der Rechtsprechung in der Praxis der europäischen Zusammenschlusskontrolle formuliert. Sie unterscheidet hinsichtlich der räumlichen Marktabgrenzung zwischen mehreren Determinantengruppen und unterstellt dabei, dass in unvollkommenen Märkten der räumlichen Ausweitung von Angebot und Nachfrage Barrieren entgegenstehen können. Sie systematisiert diese Barrieren in enger terminologischer Anlehnung an die BAINsche ${ }^{25}$ Begriffswelt in

- politisch-administrative Barrieren (bspw. handelspolitische Instrumente zur Importbeschränkung, sonstige administrative Importbarrieren),

- strukturelle Barrieren (bspw. Transportkosten, Kommunikationskosten, branchenspezifische Produktionsbedingungen, regional differenzierte Präferenzen und ihre Ursachen),

- durch Anbieterverhalten errichtete Barrieren.

Ferner führt sie ergänzend dazu Eigenschaften der Nachfrager (bspw. Größenvorteile, Wettbewerbsdruck und Kostensituation auf der Nachfragerseite) als Determinanten der räumlichen Marktgröße an. ${ }^{26}$

Für den Logistikmarkt lassen sich sowohl Faktoren, welche für eine weite räumliche Marktabgrenzung sprechen, als auch Faktoren, welche eine enge Abgrenzung begünstigen, identifizieren. Während die fortschreitende europäische Integration und damit verbunden der vollzogene Liberalisierungsprozess auf den nationalen Verkehrsmärkten der Mitgliedsstaaten den Aufbau eines einheitlichen europäischen Marktes für Verkehrs- und Logistikleistungen vorantreibt, sind es vor allem die logistikbranchenspezifischen Produktionsbedingungen, welche (noch) für eine engere Grenzziehung für den räumlich relevanten Markt sprechen. Sie sorgen nämlich dafür, dass Leistungen, die grenzüberschreitenden (wie bspw. grenzüberschreitende Transporte) oder internationalen (wie bspw. Logistikleistungen eines ausländischen Anbieters im Inland) Charakter haben, spezifischen Anforderungen an den Leistungserstellungsprozess genügen müssen, welche sich signifikant von den Anforderungen

25

Vgl. Kottmann (2000), S. $101 \mathrm{ff}$. Sie weist ferner darauf hin, dass die aus der Theorie abzuleitenden Kriterien zur räumlichen Marktabgrenzung nur schwer auf die Frage der praktischen Abgren- 
an den Leistungserstellungsprozess nationaler Logistikleistungen unterscheiden. Solche Spezifika sind bspw.:

- Die Pflicht, bei grenzüberschreitenden Transporten besondere Transportdokumente mitführen zu müssen

- Die unterschiedlichen Bestimmungen bezüglich Lenk- und Ruhezeiten, europaweit unterschiedliche Benutzungsbestimmungen für die unterschiedlichen Verkehrsinfrastrukturen

- Die europaweit unterschiedlichen gültigen zulässigen Gesamtgewichte und Maße für die Transportmittel

- Der Umstand, dass (sofern ein Logistikdienstleister kein eigenes Tochterunternehmen im Ausland unterhält) bei grenzüberschreitenden und internationalen Logistikprodukten mit ausländischen Partnerunternehmen zusammengearbeitet werden muss, bspw. als Empfangsspediteur, Frachtführer oder Vermittler

Diese Besonderheiten bergen allesamt transaktionskostenerhöhende Momente. Daher werden solche Logistikprodukte in den Logistikunternehmen in der Regel organisatorisch ausgegliedert und - in Abhängigkeit von der internationalisierungsstrategischen Ausrichtung des Unternehmens - in internationalen Abteilungen, in einem Tochterunternehmen im Inland mit internationaler Ausrichtung oder in einem Partner- bzw. Tochterunternehmen im jeweiligen Ausland abgewickelt, um dadurch Spezialisierungsvorteile und Transaktionskostenersparnisse bei der Leistungserstellung $\mathrm{zu}$ realisieren. Diese organisatorische Sonderstellung international ausgerichteter Leistungen, welche sich auch in eigenen sachlichen Teilmärkten dokumentiert (Teilmärkte 13 - 15), spricht auch für das parallele Vorliegen von Märkten mit unterschiedlicher räumlicher Ausdehnung - engere nationale und weitere internationale.

Ein weiteres Faktum, welches im nationalen Bereich eine engere räumliche Marktabgrenzung begünstigt, basiert abermals auf einem logistikbranchenspezifischen Charakteristikum der Leistungserstellung. Angesprochen sind hier insbesondere diejenigen 
Teilmärkte, welche die Überwindung räumlicher Distanzen zum Gegenstand haben (insb. Teilmärkte 1-5, 6, 10,11). Um nämlich solche transport- bzw. verkehrsbasierte Logistikleistungen erbringen zu können, muss der Logistikdienstleister zunächst in den Besitz des dafür unabdingbar notwendigen externen Produktionsfaktors, also des logistischen $\mathrm{Objekts}^{27}$, gelangen. Dies geschieht entweder durch Verbringen des logistischen Objektes in eine Betriebsstätte des Logistikdienstleisters ${ }^{28}$ oder durch Bearbeitung des logistischen Objektes in der Betriebsstätte des Verladers mit Hilfe von Verlade- bzw. Transportmitteln des Logistikdienstleisters ${ }^{29}$. In beiden Fällen hat der Logistikdienstleister zunächst die Strecke zwischen eigener Betriebsstätte und der Betriebsstätte des Verladers zurückzulegen. Die Länge dieser Strecke wiederum beeinflusst das ökonomische Kalkül bei der Leistungserstellung in zweierlei Hinsicht: zum einen verursacht sie Kosten, was die Preisangebote mit zunehmender räumlicher Entfernung vom Verlader immer weniger konkurrenzfähig erscheinen lässt. Zum anderen können bei weiten Abholentfernungen die engen Vorgaben und Erfordernisse moderner, zeitkritischer Verkehrs- und Logistiksysteme hinsichtlich eines (möglichst späten) Abholzeitpunktes beim Verlader nicht mehr eingehalten, bestimmte Logistikprodukte folglich nicht mehr kundenanforderungsgerecht angeboten werden. ${ }^{30,31}$ Insofern erscheint es für bestimmte Logistikleistungen aus Logistikdienstleistersicht sinnvoll, Kunden zu akquirieren, die möglichst nahe um den eigenen Standort liegen. Für die Kunden wiederum erscheint es sinnvoll, mit Logistikunternehmen zusammenzuarbeiten, welche in akzeptabler Nähe zum eigenen Standort liegen. Für derartige transport- und verkehrsbasierte Logistikteilmärkte ergibt sich ein Kontinuum von sich

Bei einem logistischen Objekt handelt es sich um das sich im Eigentum und (zunächst) Besitz des Verladers befindliche Gut, an welchem die logistische Manipulation vorgenommen werden soll. So bspw. bei Sammel- bzw. Stückgutverkehren und zum Teil bei Teilladungsverkehren.

So bspw. bei Komplettladungsverkehren und unter Umständen auch bei Teilladungsverkehren.

Der Verlader versucht in der Regel, einen möglichst späten Abholzeitpunkt für seine Guter mit dem Logistikdienstleister zu vereinbaren, da er möglichst auch die spät eingehenden Kundenaufträge noch am selben Tag versenden möchte. Der Logistikdienstleister wiederum möchte einen möglichst frühen Abholzeitpunkt beim Verlader realisieren, um maximal viel Zeit für die Durchführung der entsprechenden Logistikleistung zu haben, da die Qualität dieser Logistikleistung wiederum von der Einhaltung einer Reihe nacheinander liegender Zeitfenster bei der Leistungserstellung abhängt. Diese gegensätzliche Interessenlage fällt mit zunehmender Entfernung zwischen den Betriebsstätten von Verlader und Logistikdienstleister immer mehr ins Gewicht.

Vgl. auch Kallfaß (1997), S. 113, der die „Kosten der Bewältigung der Entfernung“, deren Höhe auch von den Anforderungen der Kunden an Termintreue und Zuverlässigkeit der Leistungserbringung determiniert werden, als Hindernis für raumüberwindende, marktvergrößernde Arbitragegeschäfte betrachtet. 
teilweise überlappenden räumlichen Teilmärkten, welches sich unter Rückgriff auf ökonomische Standorttheorien wie folgt herleiten lässt: ${ }^{32}$

Unterstellt man zunächst vereinfachend, dass ähnliche Abstände zwischen den Betriebsstätten der Logistikunternehmen vorliegen, so hat jeder Betrieb einen engen Bereich, in dem er die Logistikleistung bezogen auf die Vorholkosten (d. h. Verbringung der logistischen Objekte vom Verlader zur Betriebsstätte des Logistikdienstleisters) kostengünstiger und qualitativ besser erbringen kann als die Konkurrenz. Es bilden sich in der Folge Strukturen der funktionalen räumlichen Gliederung heraus, welche in Analogie zu den sog. „LAUNHARDTschen (Preis-)Trichtern“ auf den betriebsstättenbezogenen Herstellkosten sowie auf den entfernungsabhängigen Transportstückkosten (hier interpretiert als Vorholkosten und Opportunitätskosten in Form von Qualitätsverlust durch lange Vorholzeiten) aufbauen (vgl. Abbildung 2-14). Damit entstehen, in Abhängigkeit vom Abstand zwischen den einzelnen Betriebsstätten, mehr oder minder große „monopolistische“ Preissetzungsspielräume für die Logistikunternehmen. Jenseits dieser Spielräume ist einerseits Eindringungspotential in Nachbargebiete gegeben (Akquisition von Kunden aus Nachbargebieten) ${ }^{33}$, jedoch besteht andererseits auch Gefährdungspotential durch Nachbarbetriebsstätten von Konkurrenten (Akquisition von Kunden aus dem ,eigenen“ Gebiet durch Konkurrenten): zwischen den Nachbarbetriebsstätten liegt eine Wettbewerbssituation vor. haben, kostengünstig vorgeholt werden können, weil Sendungsempfänger einer Auslieferungstour im eigenen Gebiet in der Nähe dieses Kunden liegen. Vorholungs- und Auslieferungsleistung werden dann in Verbundproduktion erstellt. 


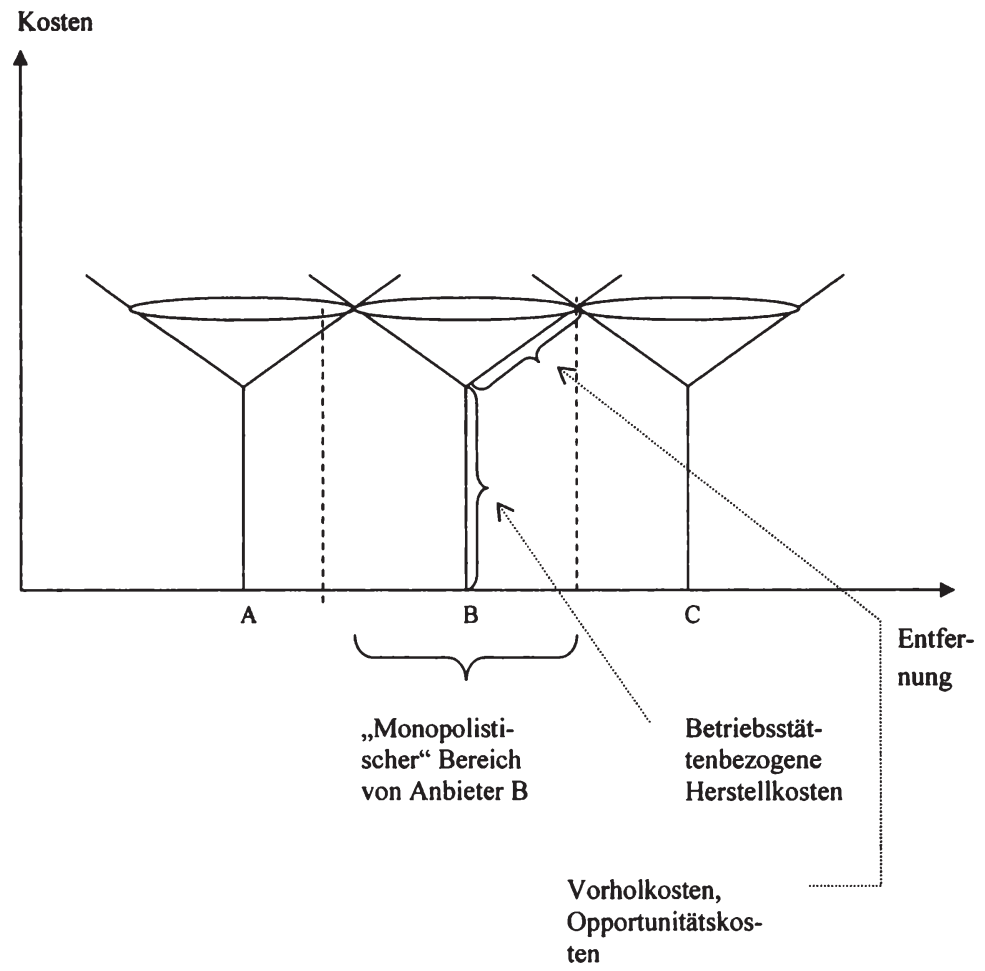

Abbildung 2-14: Stilisierte Darstellung von Launhardtschen Trichtern Quelle: Eigene Darstellung, basierend auf Herdzina, Wander (2004), S. 98

Zur Verdeutlichung hierzu lassen sich als geometrisches Schema zunächst gleichgroße, sich tangierende Kreise gedanklich herleiten, welche Märkte ohne Überlappung, also mit unversorgten Gebieten, darstellen (vgl. Abbildung 2-15). 


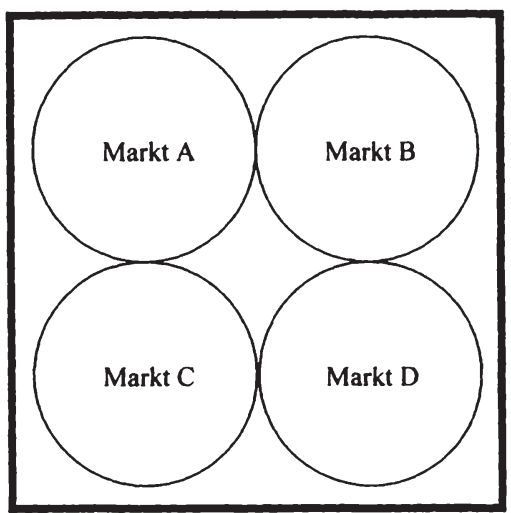

\section{Abbildung 2-15: Märkte ohne Überlappung mit unversorgten Gebieten}

Quelle: Eigene Darstellung, basierend auf Herdzina, Wander (2004), S. 99

Diese Märkte schrumpfen bei größerer räumlicher Nähe zu einem Netz aus Sechsecken zusammen. Nun überlappen sich die Märkte teilweise und weisen dann keine ineffizienten Leerräume mehr auf und gewährleisten eine vollständige, ökonomisch effiziente Flächendeckung (vgl. Abbildung 2-16). Die Entstehung solcher Märkte beschreibt CHRISTALLER im Rahmen seiner Theorie der zentralen Orte explizit. Die sich überlappenden Märkte ohne unversorgte Gebiete entsprechen CHRISTALLERs Gedanken des sog. „,Markt- oder Versorgungsprinzips“. Diesem Prinzip entsprechend soll die Marktlandschaft aus einem Netz (1) mit einer minimalen Anzahl zentraler Angebotsorte und (2) ohne unversorgte Gebiete bestehen. ${ }^{34}$ Übertragen auf die hier in Rede stehenden Logistikteilmärkte kann dieser Gedanke des „Versorgungsprinzips“, bezogen auf die Vorholung der Sendungen, auch als „Entsorgungsprinzip“ interpretiert werden: es wird sichergestellt, dass die Sendungen eines jeden Verladers/Versenders vorgeholt werden. 


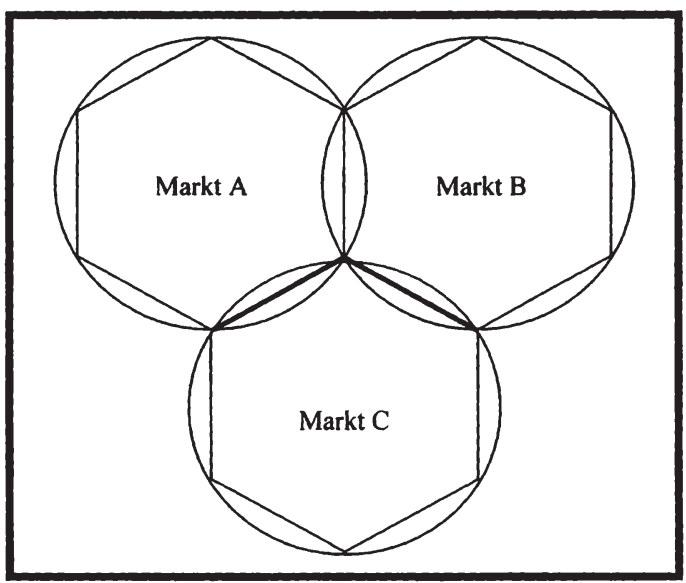

\section{Abbildung 2-16: Märkte mit Überlappung ohne unversorgte Gebiete}

Quelle: Eigene Darstellung, basierend auf Herdzina, Wander (2004), S. 100

Dieses Kontinuum von sich überlappenden Märkten ergibt letzten Endes ein Bienenwabenschema flächendeckender Sechsecke (vgl. Abbildung 2-17). ${ }^{35,36}$ In diesem Schema hat jeder einzelne Anbieter (bspw. Anbieter A) einen eigenen „monopolistischen" Bereich, ein Feld von unmittelbaren Konkurrenten (B, C, D, E, F, G) und darüber hinaus durchaus noch weitere Konkurrenten ( $\mathrm{H}, \mathrm{I}, \mathrm{K}, \mathrm{L}, \mathrm{M}$, usw.) der „Zweiten Reihe“ und noch weiter (N, O, P, usw.) einer „dritten Reihe“, usw. Dabei werden die Konkurrenzbeziehungen mit zunehmendem Abstand schwächer, bis sie sich nach Überschreiten des maximal möglichen Transportweges gänzlich verlieren. Dieses Schema gilt für jeden Anbieter, so z. B. auch für den Anbieter C. Seine unmittelbaren Konkurrenten sind A, B, H, I, K und D, die nächsten N, O, L, M, E, usw. 


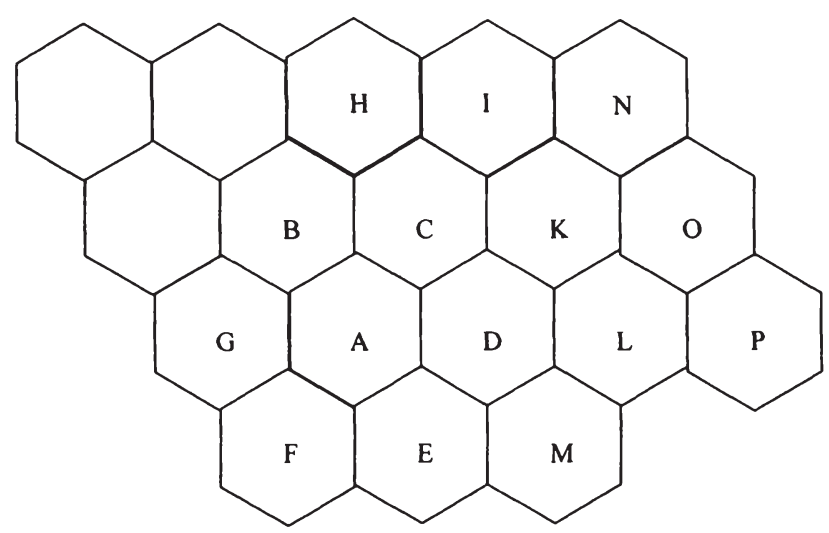

\section{Abbildung 2-17: Schematische Darstellung der einzelnen Logistik(teil)märkte}

Quelle: Eigene Darstellung, basierend auf Herdzina, Wander (2004), S. 100

Man kann dieses Schema als „unternehmungsbezogenes Marktschema“ (firm-centered industry nach PAPANDREOU) bezeichnen. ${ }^{37}$ Dieses zeichnet sich dadurch aus, dass jedes einzelne Unternehmen einen kleinen monopolistischen Bereich besitzt, eine oligopolistische Beziehung zu seinen unmittelbaren Nachbarkonkurrenten und polypolistische Beziehungen zu den entfernter liegenden Konkurrenten. Es entsteht ein Kettensystem von Überlappungseffekten, die mit zunehmender Entfernung schwächer werden. D. h. die Substitutionsmöglichkeit und die Produktionsflexibilität nehmen mit steigender Entfernung ab. Zöge man nun die jeweilige räumliche Marktgrenze dort, wo sich die Substitutionsbeziehungen vollends verflüchtigen, so gelänge man in letzter Konsequenz für jede einzelne Unternehmung zu einem unternehmensbezogenen Markt, welcher einer jeweils gesonderten Partialbetrachtung unterzogen werden könnte. $^{38}$

Dieses vereinfachte Schema hexagonaler Marktstrukturen gilt zunächst bei gleichmäBig verteilter Nachfrage sowie bei gleichen Kostenstrukturen und Produktionsbedingungen. ${ }^{39}$ Divergieren die Nachfragedichten, so entstehen unterschiedlich dichte

Vgl. Papandreou (1949), S. 887. Im Konzept der firm-centered industry wird die Sichtweise vertreten, dass ein Markt "from the point of view of firm $i$ may be defined to include all firms which compete in selling with firm i." Papandreou (1949), S. 887.

Vgl. Ihde (2001), S. 77. 
Wabennetze. Bei höherer Nachfragedichte (Großstadtbereiche) befinden sich mehr Produktionsstätten auf engem Raum; die monopolistischen Bereiche schrumpfen (möglicherweise auf Null), die polypolistischen Beziehungen nehmen zu.

Gleiches gilt für die Kostensituation. Produktionsstätten mit niedrigeren produktionsstättenbezogenen Herstellkosten können niedrigere Preise berechnen - die LAUNHARDTschen Trichter haben einen kürzeren Trichterstiel, bei niedrigeren Vorholkosten fallen die Kosten pro Entfernung weniger stark ins Gewicht - die LAUNHARDTschen Trichter werden flacher. Die eigenen monopolistischen Bereiche vergrößern sich in beiden Fällen, die polypolistischen Beziehungen gehen zurück. Haben umgekehrt die nahe gelegenen Konkurrenten niedrigere Kosten, dann verkleinert sich der eigene monopolistische Bereich und die polypolistischen Beziehungen nehmen zu.

In ländlichen Gebieten mit geringerer Nachfragedichte sind die Überlappungseffekte von vornherein schwächer. Damit werden die monopolistischen Bereiche tendenziell größer, ebenso die oligopolistischen Beziehungen, während die polypolistischen Beziehungen schwächer werden.

Aufgrund wechselnder geografischer Gegebenheiten in Deutschland (Wechsel von Verdichtungsräumen, Randzonen um die Verdichtungsräume und ländlichen Räumen; Sperren durch Gebirge und Flüsse; divergierende Qualität der Verkehrsinfrastrukturen) entsteht ein kompliziertes Geflecht von Lokal- und Regionalmärkten. Das zuvor erwähnte Kontinuum von sich überlappenden räumlichen Märkten wird dadurch immer wieder unterbrochen.

Vor dem Hintergrund der vorstehenden Ausführungen wird in der vorliegenden Arbeit folgendes Vorgehen gewählt: Analog der Organisationsstruktur in den Logistikunternehmen wird zunächst der nationale deutsche Markt als räumlich relevant angesehen. Dienstleistungsprodukte mit explizit internationalem oder grenzüberschreitendem Charakter werden in isolierten sachlich relevanten Teilmärkten betrachtet. ${ }^{40}$ Dies stellt insofern einen Kompromiss dar, als sich viele Marktteilnehmer, insbesondere die kleinen und mittelständischen Unternehmen, allenfalls auf ausgewählten Lokal- und Regionalmärkten betätigen. Die größeren Mittelständler und die z. T. vertikal sachlichen Marktabgrenzung verquickt. Für die wechselseitige Beziehung zwischen räumlicher und sachlicher Marktabgrenzung vgl. ausführlich Kottmann (2000), S. 14 f. Die teilweise Verquickung sachlicher und räumlicher Aspekte bei der Marktabgrenzung resultiert im hier behandelten Logistikmarkt wohl hauptsächlich aus der Tatsache, dass die Transportleistung als wesentlicher (sachlicher) Teilbereich der Logistik die Überwindung räumlicher Entfernungen zum Gegenstand hat und somit die räumliche Komponente der relevanten Marktdimension in den transport- und verkehrsorientierten Logistikteilmärkten von der sachlichen Komponente nicht zu trennen ist. 
integrierten Konzernunternehmen hingegen haben mehrere Betriebsstätten, sind Mitglieder in Kooperationsnetzwerken bzw. unterhalten eigene Filialnetzwerke und agieren deutschlandweit, u. U. sogar europa- und weltweit. Somit sind die zuvor dargestellten Regionalmarktgrenzen für die größeren Mittelständler und die Konzernunternehmen nur teilweise und sehr bedingt bzw. gar nicht relevant. Ferner spricht für den deutschen Markt als relevanten Markt der Umstand, dass auch die kleinen und mittelständischen Unternehmen mit lediglich einer Betriebsstätte fallweise mit Unternehmen konkurrieren, welche weit außerhalb ihrer Lokal- und Regionalmärkte beheimatet sind. Aufgrund des Kuppelproduktcharakters der Transportleistung nämlich akquirieren Logistikunternehmen, welche Transportleistungen erbringen (und hier hauptsächlich im Bereich der Teil- und Komplettladungsverkehre des Straßengütertransportes, Teilmarkt 2), Ladungen im Bereich des Standortes des Sendungsempfängers, um auf der Rückfahrt zum eigenen Standort Leerfahrten zu vermeiden. ${ }^{41}$ Insofern sind Konkurrenzbeziehungen zwischen kleinen und mittelständischen Unternehmen aus unterschiedlichen Lokal- oder Regionalmärkten denkbar. Diese fallen jedoch vergleichsweise schwach aus und beziehen sich in der Regel nicht auf den gesamten Lokal- oder Regionalmarkt, sondern allenfalls auf einzelne Versender entlang bestimmter Transportrouten innerhalb der Märkte.

Im Übrigen gilt natürlich, dass Unternehmen, welche mehrere unterschiedliche Logistikleistungen produzieren (sog. „Mehrproduktunternehmen“) den für sie sachlich und räumlich relevanten Markt für jede einzelne Logistikleistung bestimmen müssen. Es ist demzufolge gang und gäbe, dass Mehrprodukt-Logistikunternehmen auf mehreren sachlichen Logistikteilmärkten agieren, sich daher u. U. zeitgleich mit unterschiedlichen räumlichen Marktgrenzen befassen und sich dementsprechend parallel mit unterschiedlichen Konkurrentengruppen auseinandersetzen müssen.

\subsubsection{Das Logistik-Marktvolumen}

\subsubsection{Operationalisierung des Logistikbegriffes zur Bestimmung des Marktvo- lumens}

Der ökonomische Logistikbegriff wurde bereits in Unterabschnitt 2.2.2.2.3 theoretisch entwickelt, erörtert und abgegrenzt. Um das Marktvolumen des deutschen Logistikmarktes bestimmen zu können, muss dieser ökonomische Logistikbegriff greifbar, $d$. 
h. mengen- und wertmäßig erfassbar gemacht werden. Der Verwirklichung dieses Vorhabens allerdings steht ein eklatanter Mangel an systematischem Datenmaterial und Informationen über die Logistikwirtschaft entgegen, welchen KLAUS folgendermaßen erklärt: ${ }^{42}$

- Aufgrund der Tatsache, dass die einschlägigen amtlichen Statistiken auf regionaler, nationaler und supranationaler Ebene zu Zeiten entworfen worden sind, in denen es die Logistik in ihrer heutigen Form als Berufsbild und Wissenschaftsdisziplin noch nicht gab, ist logistikrelevantes Datenmaterial in unterschiedlichen Abteilungen der Statistik (u. a. in der Transport-, Verkehrs-, Industrie- und Handelsrubrik) verstreut und in aufeinander nicht abgestimmter Form vorzufinden.

- Der Logistikmarkt umfasst eine erhebliche Anzahl kleiner und kleinster Marktakteure. Deren Umsätze werden aufgrund fehlender Publizitätspflicht und aufgrund der Tatsache, dass sie ihre Leistungen in der Regel als Subunternehmer oder als Sub-Subunternehmer für andere Logistikdienstleister erbringen und entsprechend auch an diese abrechnen, bisweilen gar nicht, nur teilweise oder doppelt erfasst.

- Ferner wird ein wesentlicher Teil an Logistikleistungen als produktionsstätteninterne Werkslogistik kosten- und leistungsmäßig dem Produktions- und dem Vertriebsbereich von Industrie- und Handelsunternehmen zugeschlagen. Über diesen Teil der Logistikleistungen gibt es kein gesondertes Berichtswesen.

- Sind nun Daten vorhanden, werden diese vor dem Hintergrund des noch nicht abschließend gefestigten Logistikselbstverständnisses auf der Basis unterschiedlicher Interpretationen des Logistikphänomens ebenso unterschiedlich verarbeitet. Auch dies führt zu einem erheblich heterogenen Daten- und Informationsbestand zur Logistikwirtschaft.

Mit Bedacht auf diese Schwierigkeiten sollen zum Zwecke der Operationalisierung des Logistikbegriffs zunächst zwei Begriffe eingeführt werden, nämlich der der TULLogistik sowie der der Koordinationslogistik. Auf diese Logistikbegriffe wird auch im Rahmen der anschließenden Konzentrationsanalyse zurückgegriffen. Der Begriff der 
TUL-Logistik gibt eine praxisübliche und weit verbreitete Auffassung der Logistik wieder und bezeichnet die elementaren physischen Aktivitäten in der Logistik. Diese Aktivitäten umfassen Transportleistungen (Veränderung räumlicher Merkmale von Gütern), Umschlagsleistungen (Veränderung von sachlichen Gütermerkmalen, welche den Art- und Mengenausgleich betreffen, wie bspw. Kommissionier- und Verpackungsleistungen) sowie Lagerleistungen (Veränderung zeitlicher Gütermerkmale) ${ }^{43}$ Dieser Logistikbegriff stellt insofern eine enge, eingeschränkte Fassung dar, als er lediglich die produktionsstättenexternen Logistikaktivitäten berücksichtigt, diejenigen Aktivitäten also, welche zwischen den Produktions- und Verkaufsstätten von Industrie und Handel erfolgen. ${ }^{44}$ Dabei beinhaltet der TUL-Logistik-Begriff sowohl Leistungen, welche mit verladereigenen Mitteln (Werkverkehr; Läger, die von Verladern in Eigenregie unterhalten werden) erbracht werden, als auch die an Logistikdienstleister outgesourcten Leistungen. ${ }^{45}$ Die rein innerbetrieblichen Logistikaktivitäten in Produktions- und Handelsunternehmen hingegen werden ausgeblendet. Obwohl der TUL-Logistik-Begriff auf vergleichsweise gutem und eindeutigem Datenmaterial fußt ${ }^{46}$, ist er nicht frei von Ungenauigkeiten. Gewisse Unschärfen ergeben sich bspw. dadurch, dass die Trennung zwischen produktionsstättenexternen und -internen Aktivitäten nicht immer eindeutig vollzogen werden kann oder dass bestimmte betriebs- und produktionsstätteninterne Logistikleistungen, welche nicht unter den TUL-Logistik-Begriff fallen, an Dienstleister outgesourct und damit zu echten externen Logistikleistungen werden. ${ }^{47}$

Ein weiter gefasster Logistikbegriff, hier Koordinationslogistik genannt, umfasst neben den produktionsexternen Aktivitäten der TUL-Logistik auch alle betriebs- und produktionsinternen Logistikleistungen. Dazu zählen neben den produktionsstätteninternen TUL-Aktivitäten ebenfalls die produktionsstätteninternen administrativen Logistikleistungen wie bspw. Dispositions- und Auftragsabwicklungsaktivitäten, Kundendienstleistungen sowie Dispositions- und Kapitalkosten für das Beständemanagement. ${ }^{48}$ Ungenauigkeiten bei der zahlen- bzw. wertmäßigen Abschätzung der

43 Vgl. Klaus, Müller-Steinfahrt (1997), S. $11 \mathrm{f}$.

44 Vgl. Müller-Steinfahrt (2000), S. 298.

45 Vgl. Klaus, Müller-Steinfahrt (1997), S. 11. Die Anteile der Aktivitäten im Logistikmarkt, welche von den Verladern selbst als Werkverkehr durchgeführt werden, sind in dieser Darstellung als zusätzliches „potentielles Marktvolumen“ aus Sicht der Logistikdienstleister zu betrachten. Die Berücksichtigung dieses Anteils in der Analyse ist daher zweckmäßig.

Das gilt insbesondere für die Transportleistungen, für welche in der amtlichen Statistik umfängliches Datenmaterial vorliegt. 
Koordinationslogistik können sich aus der Tatsache ergeben, dass die Trennung zwischen Verwaltungstätigkeiten, die der Produktionslogistik zuzuordnen sind und allgemeinen Verwaltungstätigkeiten nicht immer unstrittig ist. ${ }^{49}$

\subsubsection{Ermittlung und Aufteilung des Logistik-Marktvolumens nach KLAUS und MÜLLER-STEINFAHRT}

KLAUS und MÜLLER-STEINFAHRT verwenden drei voneinander unabhängige Methoden, um zu einer robusten Abschätzung des Gesamt-Marktvolumens für den deutschen Logistikmarkt zu gelangen: eine Schätzung durch Analogieschluss, eine nachfrageseitige Schätzung sowie eine angebotsseitige Schätzung. ${ }^{50}$ Basis für das GesamtMarktvolumen sind die fakturierten Umsätze der land- und binnengewässerorientierten Logistikdienstleistungsunternehmen, welche innerdeutsche und grenzüberschreitende Logistikleistungen betreffen. Nicht berlicksichtigt werden Umsätze von Logistikleistungen, welche im Ausland von Auslandsniederlassungen und -Gesellschaften deutscher Logistikdienstleister für ausländische Verlader erbracht wurden. ${ }^{51}$ Die Anwendung aller drei Schätzmethoden förderte in den Untersuchungsjahren 1996, 1998, 2002 und 2004 vergleichbare Zahlen für das Logistik-Marktvolumen zutage und indiziert damit die „Robustheit“ der von KLAUS und MÜLLER-STEINFAHRT bzw. von KLAUS vorgenommenen Schätzungen. Für die vier Untersuchungsjahre ergeben sich nach der Zusammenfügung der drei unabhängigen Schätzmethoden folgende Zahlenwerte:

49 Vgl. Klaus, Müller-Steinfahrt (2000), S. 26.

so Vgl. dafür und für das Folgende Klaus, Müller-Steinfahrt (1997), S. 19 ff.; Klaus, MüllerSteinfahrt (2000), S. 88 ff.; Müller-Steinfahrt (2000), S. 300 ff. Der Methode „Schätzung durch Analogieschluss" liegt die Basishypothese zugrunde, dass sich der Anteil der TUL-Logistikkosten an Umsätzen der Unternehmen betrachteter Branchen in den Industrieländern Nordamerikas und Europas in ähnlichen Dimensionen bewegt. So schätzt das amerikanische Marktforschungsinstitut HERBERT W. DAVIS AND COMPANY in Deutschland den durchschnittlichen Anteil der TULLogistikkosten an den Unternehmensumsätzen bezogen auf das Untersuchungsjahr 1996 auf 6,4\%, den Anteil der Koordinationslogistikkosten auf 9,7\%. Verkettet man die DAVISProzentzahlen mit den kumulierten Umsätzen der deutschen Industrie- und Handelunternehmen, so ergibt sich eine erste Gesamtschätzung des Logistik-Marktvolumens. Bei der nachfrageseitigen Schätzung werden die Kostenanteile für TUL-Leistungen mittels branchentypischer TULLogistikkostenprozentsätze aus den finanzamtlich dokumentierten Branchenumsätzen der Wirtschaftsbereiche in Deutschland hochgerechnet und somit das Gesamtnachfragevolumen nach TUL-Logistikleistungen ermittelt. Die angebotsseitige Schätzung ergibt sich aus der Addition der Umsätze der Logistikdienstleister zuzüglich der Kostenwerte derjenigen TUL-Logistikleistungen, welche verladerseitig im Rahmen von Werkverkehren und sonstigen Werksleistungen erbracht werden.

Vgl. Muller-Steinfahrt (2000), S. 300. 


\begin{tabular}{|l|l|l|l|l|}
\hline Logistik-Marktvolumen fur Deutschland in Mrd. $€$ & 1996 & 1998 & 2002 & 2004 \\
\hline TUL-Logistik gesamt & 92,1 & 87,0 & 101,1 & 118,1 \\
\hline davon gewerbliche TUL-Logistik & 44,9 & 40,5 & - & 69,3 \\
\hline davon werksseitige TUL-Logistik & 47,2 & 46,5 & - & 48,8 \\
\hline Koordinationslogistik gesamt & 131,5 & 124,4 & $150,0^{52}$ & 170,0 \\
\hline davon gewerbliche Koordinationslogistik & - & 47,4 & 67,5 & 79,0 \\
\hline davon werksseitige Koordinationslogistik & - & 77,0 & 82,5 & 91,0 \\
\hline $\begin{array}{l}\text { Anteil der von gewerblichen Logistikdienstleistern } \\
\text { erbrachten Dienstleistungen an TUL-Logistik gesamt in \% }\end{array}$ & 49 & 55 & $60^{53}$ & 59 \\
\hline $\begin{array}{l}\text { Anteil der von gewerblichen Logistikdienstleistern } \\
\text { erbrachten Dienstleistungen an Koordinationslogistik } \\
\text { gesamt in \% }\end{array}$ & - & 38 & 45 & 46 \\
\hline
\end{tabular}

Tabelle 2-4: Das deutsche Logistik-Marktvolumen in den Jahren 1996 - 2002

Quelle: Eigene Berechnungen auf Basis der Daten von Klaus, Müller-Steinfahrt (1997); Klaus, Müller-Steinfahrt (2000); Klaus (2003) und Klaus, Kille (2006)

Aus Tabelle 2-4 kann entnommen werden, dass das deutsche Logistik-Marktvolumen, sowohl in der Definition der TUL-Logistik als auch in der Definition der Koordinationslogistik, im Zeitraum von 1996 bis 2004 deutlich zugenommen hat. Der Anteil der an Logistikdienstleister outgesourcten Logistikleistungen ist im gleichen Zeitraum ebenfalls kontinuierlich angestiegen und belief sich im Jahr 2004 auf 59\% bezogen auf Leistungen im Rahmen der engeren TUL-Logistik-Definition und $46 \%$ bezogen auf Leistungen im Rahmen der Koordinationslogistik. Die Diskrepanz dieser beiden Prozentwerte impliziert, dass der Prozess des Outsourcings in denjenigen Leistungsbereichen, welche über die TUL-Logistikleistungen hinausgehen und welche in der Definition der Koordinationslogistik mit erfasst werden, also betriebs- und produktionsinterne Logistikleistungen wie

Die Erhöhung des Jahreswertes von 2002 im Vergleich zu 1998 ist nicht allein auf eine Steigerung des absoluten Marktvolumens zurückzuführen, sondern ist das Ergebnis einer Verbesserung der Erhebungsmethodik der Studie. Vgl. Klaus (2003), S. 41. Der Ergebniswert für die Koordinationslogistik von $€ 150,0$ Mrd. wurde angesichts einer verbesserten Datengrundlage rückwirkend auf ca. $€ 160,0$ Mrd. angepasst. Vgl. Klaus, Kille (2006), S. VII. 
- produktionsstätteninterne TUL-Aktivitäten,

- produktionsstätteninterne administrative Logistikleistungen wie bspw. Dispositions- und Auftragsabwicklungsaktivitäten, Kundendienstleistungen sowie

- Dispositions- und Kapitalkosten für das Beständemanagement

noch nicht so weit fortgeschritten ist. Die Verladerunternehmen aus Industrie und Handel sehen sich bei derartigen Logistikleistungen offensichtlich noch stark zur Eigenproduktion veranlasst. Eine differenzierte Betrachtung der Logistikteilmärkte und des jeweiligen Anteils der an Logistikdienstleister outgesourcten Logistikleistungen ergibt, bezogen auf die Koordinationslogistik, für die Jahre 2002 und 2004 folgendes Bild:

\begin{tabular}{|c|c|c|c|c|c|c|c|c|}
\hline \multirow{3}{*}{ Teilmärkte 1 -15 } & \multicolumn{4}{|c|}{2002} & \multicolumn{4}{|c|}{2004} \\
\hline & \multicolumn{2}{|c|}{ 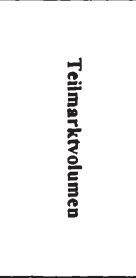 } & \multicolumn{2}{|c|}{ 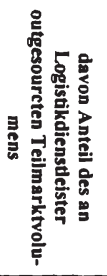 } & \multicolumn{2}{|c|}{ 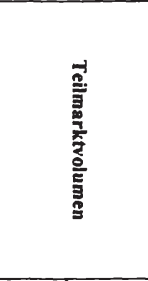 } & \multicolumn{2}{|c|}{ 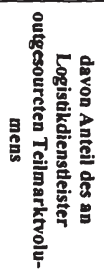 } \\
\hline & $\begin{array}{l}\overline{3} \\
\text { za } \\
\text { a }\end{array}$ & 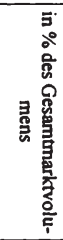 & $\begin{array}{l}5 \\
3 \\
3 \\
0 \\
0\end{array}$ & $\stackrel{5}{\circ}$ & $\begin{array}{l}5 \\
3 \\
3 \\
0 \\
0\end{array}$ & 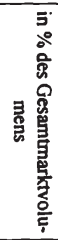 & 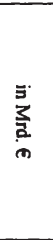 & $\stackrel{5}{\circ}$ \\
\hline Nationale Massengutlogistik & 10,0 & 6,7 & 5,0 & 50 & 10,0 & 5,9 & 5,5 & 55 \\
\hline $\begin{array}{l}\text { Nationaler allgemeiner } \\
\text { Ladungsverkehr }\end{array}$ & 12,6 & 8,4 & 6,0 & 48 & 14,0 & 8,2 & 7,7 & 55 \\
\hline Schwertransporte und Krandienste & 0,9 & 0,6 & 0,8 & 89 & 0,8 & 0,5 & 0,7 & 90 \\
\hline Nationale Tank- und Silotransporte & 5,0 & 3,3 & 3,2 & 64 & 5,5 & 3,2 & 3,3 & 60 \\
\hline $\begin{array}{l}\text { Nationaler sonstiger Ladungsverkehr mit } \\
\text { speziellem Equipment }\end{array}$ & 8,0 & 5,3 & 3,0 & 38 & 8,5 & 5,0 & 2,6 & 30 \\
\hline Nationaler allgemeiner Stuckgutverkehr & 5,0 & 3,3 & 4,0 & 80 & 5,5 & 3,2 & 5,0 & 90 \\
\hline $\begin{array}{l}\text { Konsumguterdistribution und - } \\
\text { kontraktlogistik }\end{array}$ & 19,3 & 12,9 & 5,0 & 26 & 21,5 & 12,7 & 6,5 & 30 \\
\hline
\end{tabular}

53 Der Wert von $60 \%$ für gewerblich erbrachte TUL-Logistikleistungen bezieht sich hier ausdrücklich nur auf die Transportleistungen, nicht aber auf Umschlags- und Lagerleistungen. Vgl. Klaus (2003), S. 71. 


\begin{tabular}{|l|c|c|c|c|c|c|c|c|}
\hline $\begin{array}{l}\text { Industrielle Kontraktlogistik, insbesondere } \\
\text { Produktionsversorgung, Ersatzteildistribution } \\
\text { und sonstige business-to-business- } \\
\text { Kontraktlogistik }\end{array}$ & 39,3 & 26,2 & 6,0 & 15 & 45,5 & 26,8 & 9,1 & 20 \\
\hline Hangende Kleider-Logistik & 0,7 & 0,5 & 0,5 & 71 & 0,6 & 0,4 & 0,4 & 70 \\
\hline $\begin{array}{l}\text { High-Tech-Goter, Messelogistik, Neumobel- } \\
\text { und Umzugstransporte }\end{array}$ & 4,0 & 2,7 & 2,5 & 63 & 4,5 & 2,6 & 2,7 & 60 \\
\hline $\begin{array}{l}\text { KEP- Pakte-, echte Kurier- und spezialisierte } \\
\text { Expressdienste }\end{array}$ & 8,0 & 5,3 & 7,5 & 94 & 9,0 & 5,3 & 8,6 & 95 \\
\hline $\begin{array}{l}\text { Terminaldienste, nicht integrierte Lagerei-, } \\
\text { Umschlags- und sonstige logistische } \\
\text { Zusatzleistungen }\end{array}$ & 16,4 & 10,9 & 5,0 & 30 & 19,0 & 11,2 & 4,8 & 25 \\
\hline $\begin{array}{l}\text { Grenzoberschreitende Transport- und } \\
\text { Speditionsleistungen, Schwerpunkt } \\
\text { Strabe/Schiene }\end{array}$ & 7,5 & 5,0 & 6,0 & 80 & 9,0 & 5,3 & 8,1 & 90 \\
\hline $\begin{array}{l}\text { Grenzuberschreitende Transport- und } \\
\text { Speditionsleistungen, Schwerpunkt } \\
\text { SeeschifffahrtSeehafenspedition }\end{array}$ & 7,9 & 5,3 & 7,5 & 95 & 10,1 & 5,9 & 9,1 & 90 \\
\hline $\begin{array}{l}\text { Grenzuberschreitende Aircargo-Carrier und } \\
\text { Leistungen der Luftfrachtspedition }\end{array}$ & 5,4 & 3,6 & 5,0 & 93 & 6,5 & 3,8 & 6,2 & 95 \\
\hline Summe & 150,0 & 100,0 & 67,0 & & 170,0 & 100,0 & 80,3 & \\
\hline
\end{tabular}

Tabelle 2-5: Das deutsche Logistik-Marktvolumen nach Marktsegmenten in den Jahren 2002 und 2004

Quelle: Eigene Darstellung auf Basis der Berechnungen von Klaus (2003) und Klaus, Kille (2006)

Aus Tabelle 2-5 geht hervor, dass der Outsourcinganteil im Jahr 2004 in folgenden Marktsegmenten mit einem Wert von $\geq 80 \%$ sehr hoch ist:

1. KEP - Paket-, echte Kurier- und spezialisierte Expressdienste (95\%),

2. Grenzüberschreitende Aircargo-Carrier und Leistungen der Luffrachtspedition (95\%),

3. Nationaler allgemeiner Stückgutverkehr (90\%),

4. Schwertransporte und Krandienste (90\%),

5. Grenzüberschreitende Transport- und Speditionsleistungen, Schwerpunkt Seeschifffahrt/Seehafenspedition $(90 \%)$ und

6. Grenzüberschreitende Transport- und Speditionsleistungen, Schwerpunkt StraBe/Schiene (90\%). 
Bei diesen Teilmärkten handelt es sich ausnahmslos um netzgebundene Logistikmarktsegmente mit der Schwerpunktsetzung auf TUL-Logistikaktivitäten. Sie zeichnen sich dadurch aus, dass komplexe Verkehrssysteme vorgehalten werden müssen, um eine verladeranforderungsgerechte Raum-Zeit-Überbrückungsleistung zu ermöglichen. Auf institutioneller Ebene müssen derartige netzgebundene Logistikleistungen im Rahmen großer mikrologistischer Systeme (große, integrierte KonzernLogistikdienstleister, Großspeditionen) oder im Rahmen horizontaler metalogistischer Systeme (System-Kooperationsverbünde mittelständischer Logistikdienstleister) erbracht werden, damit Größen-, Dichte- und Verbundvorteile in den Verkehrsnetzen zum Tragen kommen können und damit Verkehrsnetze mit erforderlicher Reichweite und in erforderlicher Leistungsqualität entstehen können. Zudem handelt es sich bei den Teilmärkten ausnahmslos um Logistikmarktsegmente, in welchen die Logistikdienstleister marktwirksame Spezialisierungsvorteile erringen können, weil sie eine aus Verladersicht hochkomplexe, manchmal sogar einzigartige Logistikleistung häufig und furr viele Verlader gleichzeitig erbringen und dadurch eine kostensenkende Abwicklungsroutine erreichen, welche einem einzelnen Verladerunternehmen bei Eigenproduktion der jeweiligen Logistikleistung nicht möglich wäre. Diese Faktoren sprechen für den beobachteten hohen Outsourcinganteil. Tabelle 2-5 belegt dementsprechend, dass in den Marktsegmenten mit hohem Outsourcinganteil die Anteilswerte im Zeitraum zwischen 2002 und 2004 ein stabil hohes Niveau und - mit Ausnahme des Marktsegments „Grenzüberschreitende Transport- und Speditionsleistungen, Schwerpunkt Seeschifffahrt/Seehafenspedition“ - steigende Tendenz ausweisen.

Ferner weist Tabelle 2-5 für folgende Marktsegmente mit einem Wert von $\leq 30 \%$ einen sehr geringen Outsourcinganteil aus:

1. Industrielle Kontraktlogistik, insbesondere Produktionsversorgung, Ersatzteildistribution und sonstige business-to-business-Kontraktlogistik (20\%),

2. Terminaldienste, nicht integrierte Lagerei-, Umschlags- und sonstige logistische Zusatzleistungen (25\%),

3. Konsumgüterdistribution und-kontraktlogistik (30\%) und

4. Nationaler sonstiger Ladungsverkehr mit speziellem Equipment (30\%). 
Diese Teilmärkte sind dadurch gekennzeichnet, dass hier in der Regel verladerindividuelle Logistikleistungen abgefordert werden, deren Schwerpunktsetzung auf Leistungsaspekten liegt, welche inhaltlich über die TUL-Logistikaktivitäten hinausgehen und in weiten Teilen im Bereich der betriebs- und produktionsinternen Logistikleistungen zu verorten sind (insb. bei 1. und 3.) bzw. bei denen branchen- und verladerspezifisches Equipment erforderlich ist, um die Logistikleistung durchführen zu können (bei 4.) bzw. bei welchen ortsfeste Logistikleistungen branchen- oder verladerspezifisch und entkoppelt von Transport- und Distributionssystemen erbracht werden (bei 2.). Aufgrund der hohen Spezifität der Logistikleistungen hinsichtlich des erforderlichen Equipments sowie hinsichtlich der hohen Know-how-Anforderungen an den Leistungserbringer in diesen Marktsegmenten haben sich viele Verlader bislang nicht für Outsourcing entscheiden können.

In den letztgenannten Marktsegmenten mit geringem Outsourcinganteil verbleibt folglich noch viel Akquisitionspotenzial für die Logistikdienstleister. ${ }^{54}$ Diese Konstellation ist für die weitere Dynamik der Gesamt-Logistikmarktentwicklung insbesondere aus zwei Gründen von großer Bedeutung, nämlich:

- weil die von Logistikdienstleistern noch am wenigsten erschlossenen Teilmärkte im Jahr 2004 mit ca. $€ 94,5$ Mrd. in Summe einen Anteil am GesamtMarktvolumen von rd. $56 \%$ ausmachen, während die Teilmärkte mit hohem Outsourcinganteil mit lediglich $€ 40,9$ Mrd. in Summe einen Anteil am GesamtMarktvolumen von rd. $24 \%$ auf sich vereinigen. Das wertmäßige Outsourcingpotenzial ist demnach enorm;

- weil es sich insbesondere beim umsatzmäßig mit Abstand größten Teilmarkt für industrielle Kontraktlogistik um ein ungebrochen umsatzwachstumsstarkes Segment innerhalb des Gesamt-Logistikmarktes handelt ${ }^{55}$ während sich der bereits fast vollständig in Dienstleisterhand befindliche nationale Stückgutmarkt und auch der KEP-Markt in der Reife- bzw. Stagnationsphase befinden. Logistikdienstleister müssen folglich versuchen, in den Wachstumsteilmärkten Fuß zu fassen, um deren enorme wertmäßige Potenziale zu erschließen. 
In den Marktsegmenten mit geringem Outsourcinganteil ist zu beobachten, dass dieser Anteil in den beiden Kontraktlogistikteilmärkten zwischen 2002 und 2004 anstieg, während er in den anderen beiden Teilmärkten abfiel. Auch diese Entwicklung belegt, dass die Kontraktlogistik von den Logistikdienstleistern als wichtiges Aktionsfeld erkannt worden ist und entsprechend bearbeitet wird.

\subsubsection{Angebotsstruktur}

In diesem Unterabschnitt werden Merkmale untersucht, mit Hilfe derer sich die Angebotsstruktur des deutschen Logistikmarktes beschreiben lässt. Der Begriff der Angebotsstruktur soll hier eng im Sinne des inneren Aufbaues des Logistikleistungsangebotes verstanden werden. ${ }^{56}$ Als zentrale Strukturmerkmale werden hierbei

- die Anzahl der Anbieter (absolute horizontale Anbieterkonzentration) sowie die Verteilung der Marktanteile auf die Anbieter auf dem Markt (relative horizontale Anbieterkonzentration),

- die Anzahl und die Marktanteile der mehrstufigen Unternehmen auf dem Markt (vertikaler Konzentrationsgrad),

- die Anzahl und die Marktanteile der Mehrproduktunternehmen auf dem Markt (diagonaler, konglomerater Konzentrationsgrad) sowie

- der Grad der Offenheit des Marktes

untersucht. ${ }^{57}$ Der Untersuchung der Anbieterkonzentration kommt insbesondere im Rahmen von Marktanalysen, welche die Beurteilung des Grades der Wettbewerblichkeit des Untersuchungsmarktes zum Gegenstand haben, große Bedeutung zu, da die Anbieterkonzentration als entscheidende Determinante für Entstehung und Gradmesser für Verfestigung wettbewerbsgefährdender Marktstrukturen gilt. Obwohl die vorliegende Marktanalyse eine andere Grundintention hat, ist die Konzentrationsanalyse dennoch ein aufschlussreicher Bestandteil, da die Anzahl der aktiven und

56

57

Vgl. zum ökonomischen Strukturbegriff die Ausführungen in Unterabschnitt 2.3.3.2.1.

Vgl. Herdzina (1999), S. 68 f. Als weiteres Strukturmerkmal gilt der Grad der Produktdifferenzierung, also die Anzahl und die relative Häufigkeit einzelner Güter, Gütergruppen bzw. Güterqualitäten auf dem Markt. Die Frage nach dem Grad der Produktdifferenzierung, gleichbedeutend mit der Frage nach dem Homogenitäts- bzw. Heterogenitätsgrad des ökonomischen Gutes „Logistikleistung" wurde bereits ausführlich in Abschnitt 2.2 erörtert. 
potenziellen Konkurrenten, der mehrstufigen Unternehmen und der Mehrproduktunternehmen im Markt sowie die Marktanteilsverteilung auf die Anbieter koordinationsrelevante Fakten darstellen, deren Bedeutsamkeit nicht allein auf den Wettbewerblichkeitsgesichtspunkt reduziert werden sollte. ${ }^{58}$ Vielmehr sind Kenntnisse zu Ausgestaltung und Umfang der Logistikmarkt-Konzentration sowie das Verständnis der entsprechenden Motive der Unternehmen für die Bildung konzentrativer Arrangements dienliche Anknüpfungspunkte dazu, die vertiefenden Überlegungen zu den institutionellen Gesichtspunkten der Marktkoordination zu komplettieren. Dies geschieht in Abschnitt 2.5.

Anschließend wird zunächst die ökonomische Konzentration im Lichte ihrer wettbewerbsgefährdenden Potenziale begrifflich erörtert - die Praktizierung wettbewerbsbeschränkender Verhaltensweisen wird dabei als eines der denkbaren Konzentrationsmotive betrachtet. Anschließend wird die Anbieterkonzentration im GesamtLogistikmarkt sowie in den logistischen Teilmärkten dargestellt. Im Rahmen des Unterabschnitts 2.5.3.4 erfolgen dann Erläuterungen zu den verschiedenen Ausprägungsformen unternehmerischer Konzentrationsstrategien, zu deren Beziehungsrichtungen sowie zu den restlichen, überwiegend ökonomisch begründeten Motiven für das Eingehen konzentrativer Arrangements.

Als Konzentrationsmaß kommen im Rahmen dieser Arbeit Konzentrationsraten zur Anwendung. Die Konzentrationsrate $\mathrm{CR}_{\mathrm{k}}$ weist den zusammengefassten Anteil der $\mathrm{k}$ größten Unternehmen an einer Maßgröße (in der Regel am Umsatz $u$ ) des gesamten Marktes aus. ${ }^{59}$

Bei n Unternehmen im gesamten Markt gilt für die k größten Unternehmen daher definitionsgemäß Folgendes für die Konzentrationsrate $\mathrm{CR}_{\mathrm{k}}$ :

$$
\mathrm{CR}_{\mathrm{k}}=\sum_{\mathrm{i}=1}^{\mathrm{k}} \mathrm{a}_{\mathrm{i}}
$$

Dies gilt umso mehr, wenn man sich nochmals in Erinnerung ruft, dass der konkrete zu erwartende Beitrag von Marktstrukturanalysen zur Beurteilung der Wettbewerbsintensität aufgrund theoretischer Unzulänglichkeiten allenfalls spekulativen Charakters ist und möglicherweise ebenso viele Fragen aufwirft wie sie beantwortet. Vgl. für die Mängel marktstrukturbasierter Wettbewerbshypothesen Unterabschnitte 1.2.2.2.2 und 1.2.3.1.2.

$\mathrm{Zu}$ den Problemen, die mit der Verwendung lediglich eines Konzentrationsmerkmales (bspw. des Umsatzes) als Indikator für Konzentrationsgrade oder-prozesse verbunden sind vgl. ausführlich Haubrock (1994), S. 50. 
wobei $a_{i}$ den jeweiligen Marktanteil des einzelnen Unternehmens darstellt und es gilt $a_{i}=u_{i} / u$ mit

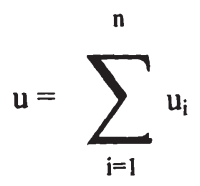

Konzentrationsraten werden aufgrund ihrer einfachen Berechnungsmethode und ihrer Anschaulichkeit, insbesondere vor dem Hintergrund oftmals schlechter Verfugbarkeit der notwendigen Daten, häufig verwendet. ${ }^{60}$ Jedoch weist das Konzept auch Schwächen auf, wodurch ihre Aussagekraft einschränkt wird. Zentraler Kritikpunkt in diesem Zusammenhang ist der Umstand, dass sämtliche Informationen, die möglicherweise über diejenigen kleinen Unternehmen vorliegen, welche nicht zur Kerngruppe der $\mathbf{k}$ größten Unternehmen zählen, nicht genutzt werden. ${ }^{61}$ Weder der absolute Wert der Marktanteile der „Kleinen“, noch deren Veränderung im Zeitablauf werden thematisiert. Ferner wird kritisiert, dass die Wahl des Parameters k die Höhe der Konzentration maßgeblich mitbeeinflusst. So kann bspw. bei dem Vergleich zweier Märkte eine entsprechende Wahl von $\mathrm{k}$ unterschiedliche Ergebnisse hinsichtlich ihrer Konzentration zutage fördern. ${ }^{62}$ Obwohl die Schwächen dieses Konzept offensichtlich sind, hat es Eingang in das deutsche, das europäische und in das US-amerikanische Wettbewerbsrecht gefunden.

Die Verwendung von Konzentrationsraten in dieser Arbeit ist das Resultat der problematischen Datenlage für die Logistikwirtschaft, welche bereits in Unterabschnitt 2.4.3.1 erläutert wurde. Sie erfolgt aber in Kenntnis um deren Schwächen. Daher werden die „kleinen“ Marktakteure, deren Einfluss von den Konzentrationsraten nicht erfasst wird, welche aber im Logistikmarkt nichtsdestotrotz eine gewichtige Rolle spielen, gesondert betrachtet.

\subsubsection{Begriff und Wettbewerbswirkungen der ökonomischen Konzentration}

Generell kann unter Konzentration im ökonomischen Kontext diejenige Konstellation verstanden werden, in der eine Ballung von Verfügungsmacht bei einem oder wenigen

\footnotetext{
60 Vgl. Greer (1984), S. 99 f.; Schulze (2003), S. 98.

61 Vgl. Schulze, (2003), S. 98; Vorgrimler (2003), S. 76; Greer (1984), S. 100 f.; Kaufer (1980), S. 32.

62 Vgl. Vorgrimler (2003), S. 76.
} 
Wirtschaftssubjekten oder die Existenz erheblicher Größenunterschiede zwischen den Wirtschaftssubjekten vorliegt. ${ }^{63}$ Hierbei wird der Begriff der Konzentration in zwei unterschiedlichen möglichen Erscheinungsformen verwendet:

- Von Konzentration i. S. eines Konzentrationsprozesses spricht man, wenn im Zeitablauf die Zahl der selbstständigen Unternehmen in ihrer Funktion als Entscheidungsträger am Markt zurückgeht (absolute Konzentration) oder wenn die Marktanteile der größten Unternehmen am Markt ansteigen (relative Konzentration, Zunahme der Disparität). ${ }^{64}$

- Ökonomische Konzentration i. S. eines (markt-)strukturellen Zustandes, eines Konzentrationsgrades am Ende eines Konzentrationsprozesses, liegt hingegen vor, wenn eine geringe Zahl von selbstständigen Unternehmen am Markt verblieben ist (absolute Konzentration) oder wenn die Marktanteile ungleich auf die Unternehmen verteilt sind (relative Konzentration, Disparität). ${ }^{65}$

Im Rahmen dieser Arbeit wird schwerpunktmäßig auf den Konzentrationsbegriff im zweiten Sinne als Konzentrationsgrad abgestellt (Unterabschnitt 2.4.4.2). Jedoch können mittels einer komparativ-statischen Analyse der Konzentrationsgrade verschiedener Perioden auch Aussagen bezüglich der Verlaufsform des Konzentrationsprozesses angedeutet werden.

In Abhängigkeit des jeweils betrachteten ökonomischen Zusammenhanges können mit der Produktionshöhe, der Produktionstiefe sowie der Breite des Produktionsprogrammes drei mögliche Bezugspunkte gewählt werden, was die differenzierte Betrachtung der Dimensionen der

- horizontalen Konzentration (Produktionshöhe), der

- vertikalen Konzentration (Produktionstiefe) sowie der

- konglomeraten Konzentration (Produktionsprogramm)

63 Vgl. Eckey, Kosfeld, Dreger (2000), S. 87; Haubrock (1994), S. 43 f.

64 Vgl. Herdzina (1999), S. 182; Schmidt (1999), S. 134; Fritz (2000), S. 210.

65 Vgl. Schmidt (1999), S. 134; Herdzina (1999), S. 182. 
sinnvoll erscheinen lässt. ${ }^{66}$ Wettbewerbspolitisch relevant ist die ökonomische Konzentration insbesondere deshalb, weil beständig hohe Konzentrationsgrade nach herrschendem, wettbewerbstheoretischem Verständnis wettbewerbsgefährdende Marktstrukturen begründen können. ${ }^{67}$ Allerdings ist es der wissenschaftlichen Wettbewerbspolitik angesichts einer unsicheren wettbewerbstheoretischen Basis bislang nicht gelungen, konkrete Angaben darüber zu machen, bei welchen Konzentrationsgraden die wettbewerbsgefährdende Marktstruktur beginnt. ${ }^{68}$

Die Wettbewerbsgefährdung, welche von hohen horizontalen, vertikalen oder diagonalen Konzentrationsgraden ausgeht, umfasst zwei Dimensionen:

- Einerseits wird durch hohe Konzentrationsgrade das Praktizieren von wettbewerbsbeschränkenden Marktverhaltensweisen begünstigt.

- Zum anderen würden eigentlich als unbedenklich einzustufende Marktverhaltensweisen in einem entsprechend hochkonzentrierten Markt eventuell einen zusätzlichen, wettbewerbsbeschränkenden Effekt bekommen.

Dabei kann das wettbewerbsgefährdende Potenzial hoher Konzentration im Einzelnen folgendermaßen umrissen werden: ${ }^{69}$

Bei hohen absoluten horizontalen Konzentrationsgraden sind die Möglichkeit und die Neigung, kollektives Marktverhalten zu praktizieren, hoch. ${ }^{70}$ Insbesondere werden die Entstehung der für die kollektive Marktkontrolle ausschlaggebenden Interessensymmetrie zwischen den Beteiligten sowie das kollektive Gruppenbewusstsein gefördert. Dadurch können sich überragende Marktstellungen oder Musterformen unternehmerischer Verhaltenskoordinierung in oligopolistischen Marktangebotsstrukturen herausbilden, wodurch der Preiswettbewerb zum Zwecke einer gemeinsamen Gewinnmaximierung rechtlich (bspw. in Form von Absprachen) oder faktisch (bspw. durch Gruppendisziplin oder Preisführerschaft) beschränkt oder ganz ausgeblendet werden kann. ${ }^{7}$ Derartige Verhaltensweisen ziehen wiederum gesamtwirtschaftlich ineffiziente Fehlallokationen nach sich, bspw. durch überhöhte Preise und Kosten oder

Vgl. Herdzina (1999), S. 182.

Vgl. Herdzina (1999), S. 182.

Vgl. Herdzina (1999, S. 183.

Vgl. dazu und für das Folgende Herdzina (1999), S. 183; Schmidt (1999), S. 138 ff.

Vgl. Herdzina (1999), S. 183.

Vgl. Schmidt (1999), S. 138; Schmidt, Röhrich (1992), S. 182. 
aber durch ein Ausweichen auf bestimmte Formen des Nicht-Preiswettbewerbs (bspw. extreme Produktdifferenzierung), die die (Konsumenten-)Wohlfahrt nicht zu erhöhen vermögen. ${ }^{72}$ Ferner können Bindungs- und Behinderungspraktiken gegenüber anderen Marktakteuren, insbesondere gegenüber kleineren Marktteilnehmern, leichter durchgesetzt werden. ${ }^{73}$ Bei hohen relativen horizontalen Konzentrationsgraden wird ebenfalls dem kollektiven Marktverhalten - innerhalb der Gruppe der großen Marktteilnehmer - Vorschub geleistet; gleiches gilt für Behinderungspraktiken gegenüber kleineren Konkurrenten. ${ }^{74}$ Das wettbewerbsgefährdende Potenzial hoher vertikaler Konzentration liegt darin begründet, dass nicht vertikal integrierte Unternehmen (Einstufenunternehmen) von vertikal integrierten Unternehmen (Mehrstufenunternehmen) behindert werden könnten. Insbesondere können Verdrängungs- und Marktschließungsstrategien (bspw. durch geschlossene Vertriebssysteme) potentielle Konkurrenten in ihrer Marktzutrittsfreiheit beschränken. ${ }^{75}$ Marktzutrittsschranken ergeben sich für potentielle Newcomer hierbei insbesondere aus der abschreckenden Wirkung des hohen Kapitalbedarfes bei Markteintritt und aus Wissensdefiziten hinsichtlich der Koordination der erforderlichen Produktionstechnologien. ${ }^{76}$ Hohe diagonale Konzentration ermöglicht es den großen diversifizierten Unternehmen, untereinander kollektives Marktverhalten zu praktizieren. ${ }^{77}$ Dies ist insbesondere dann eine sinnvolle Strategie für die Konglomerate, wenn sie sich auf verschiedenen Märkten mit unterschiedlichen Geschäftsbereichen konkurrenzieren. Andernfalls würde nämlich jede wettbewerbliche Vorstoßaktion eines Unternehmens auf einem Markt mit einer Vergeltungsmaßnahme des Konkurrenzkonglomerates auf einem Markt, auf dem das agierende Unternehmen schwächer positioniert ist, beantwortet werden. In diesem Falle ist die Kooperation zwecks gemeinschaftlicher Marktkontrolle offenkundig sinnvoll. ${ }^{78}$ Ferner steigen durch diagonale Konzentration die Möglichkeiten für diversifizierte Mehrproduktunternehmen, andere Marktteilnehmer, insbesondere kleinere, nicht diversifizierte Unternehmen, durch Behinderungs-

Vgl. Bubik (2005), S. 10 f.

Vgl. Herdzina (1999), S. 183.

Vgl. Herdzina (1999), S. 183.

Vgl. dazu auch Kaufer (1980), S. 32; ebenso Herdzina (1999), S. 183. Auch die Monopolkommission identifiziert die Verdrängung von Konkurrenten, die Erhöhung von Marktzutrittsschranken sowie die verbesserte Möglichkeit zur Preisdifferenzierung als wesentliche negative marktstrategische Implikationen der vertikalen Integration. Vgl. Monopolkommission (1984), Tz. 725 ff.

Vgl. Schmidt (1999), S. 140.

Vgl. Herdzina (1999), S. 183.

Vgl. Bubik (2005), S. 13. 
praktiken in ihrer Wettbewerbsfreiheit zu beschränken. ${ }^{79}$ Hier ist insbesondere die potenzielle Benachteiligung kleinerer Mitwettbewerber durch Kopplungsgeschäfte, reziproke Transaktionen, durch die Möglichkeit der Konglomerate zur Mischkalkulation sowie zur Überwälzung von Marktrisiken zu nennen. ${ }^{80}$

\subsubsection{Das Ausmaß der Anbieterkonzentration im Gesamt-Logistikmarkt und in den Logistikteilmärkten}

\subsection{Horizontale Konzentration}

Bezogen auf den Gesamt-Logistikmarkt ergeben sich für die absolute horizontale Marktkonzentration in den Berichtsjahren stabile, wenig veränderliche, mäßige Werte.

\begin{tabular}{|c|c|c|c|c|c|c|}
\hline & & & & & & \\
\hline & 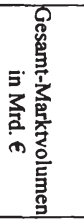 & 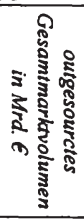 & 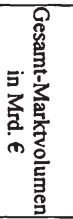 & 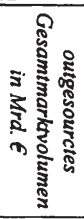 & 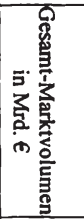 & 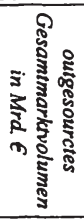 \\
\hline & 124,4 & 47.4 & 150 & 67.5 & 170 & 79 \\
\hline Umsatz des Marktfuhrers in Mrd. $€$ & 3,6 & 3,6 & 4,4 & 4,4 & 5,6 & 5,6 \\
\hline $\mathbf{C R}_{1}$-Wert in \% & 3 & 8 & 3 & 7 & 3 & 7 \\
\hline Umsatz der TOP 3 in Mrd. $€$ & 7 & 7 & 9,8 & 9,8 & 12,1 & $12, I$ \\
\hline $\mathbf{C R}_{3}$-Wert in \% & 6 & 15 & 7 & 15 & 7 & 15 \\
\hline Umsatz der TOP 5 in Mrd. $\epsilon$ & 9,8 & 9,8 & 12,8 & 12,8 & 14,8 & 14,8 \\
\hline $\mathbf{C R}_{5}$-Wert in \% & 8 & 21 & 9 & 19 & 9 & 19 \\
\hline Umsatz der TOP 10 in Mrd. $\epsilon$ & 14,1 & 14,1 & 18,2 & 18,2 & 19,7 & 19,7 \\
\hline $\mathbf{C R}_{10}$-Wert in \% & 11 & 30 & 12 & 27 & 12 & 25 \\
\hline
\end{tabular}

Tabelle 2-6: Horizontale Anbieterkonzentration im Gesamt-Logistikmarkt in den Jahren 1998, 2002 und 2004

Quelle: Eigene Berechnungen auf Basis der Daten von Klaus, Müller-Steinfahrt (2000), Klaus (2003) und Klaus, Kille (2006)

\footnotetext{
79 Vgl. Herdzina (1999), S. 183; Schmidt, Röhrich (1992), S. 183.

80 Vgl. Schmidt (1999), S. 141; Schmidt, Röhrich (1992), S. 183.
} 
Dies gilt sowohl dann, wenn man als umsatzmäßige Bezugsgröße für die Berechnung der $\mathrm{CR}_{\mathrm{k}}$-Werte das Gesamt-Marktvolumen heranzieht, als auch für den Fall, dass - in engerer Auslegung - lediglich der an Logistikdienstleister outgesourcte Anteil des Gesamt-Marktvolumens zugrunde gelegt wird (vgl. Tabelle 2-6).

Eine differenzierte Betrachtung der horizontalen Marktkonzentration getrennt nach Marktsegmenten ergibt für die $\mathrm{CR}_{10}$-Werte folgendes Bild (vgl. Tabelle 2-7):

Es zeigt sich, dass die $\mathrm{CR}_{10}$-Werte zwischen einzelnen Marktsegmenten stark variieren. Besonders hervorzuheben sind zunächst die außerordentlich hohen Werte in den Marktsegmenten „KEP - Paket-, echte Kurier- und spezialisierte Expressdienste“ und „Nationaler allgemeiner Stückgutverkehr“. Beide Teilmärkte gehören zu denjenigen netzwerkbasierten Logistikteilmärkten, welche ja angesichts ihrer spezifischen Produktionsbedingungen durch einen sehr hohen Outsourcinganteil gekennzeichnet sind. ${ }^{81}$ Tabelle 2-7 belegt nun, dass mit eben diesen Produktionsbedingungen einhergehend gleichsam hohe $\mathrm{CR}_{\mathrm{k}}$-Werte zu konstatieren sind, welche die beiden in Rede stehenden Teilmärkte möglicherweise bereits an die kritische Schwelle zu einer wettbewerbsgefährdenden Konzentration befördern: im KEP-Markt ergeben sich bezogen auf das deutsche Gesamt-Teilmarktvolumen (auf das outgesourcte Teilmarktvolumen) für das Jahr $2004 \mathrm{CR}_{1}=31 \%(33 \%), \mathrm{CR}_{3}=51 \%(54 \%)$ und $\mathrm{CR}_{5}=65 \%$ $(68 \%)^{82}$, im Stückgutmarkt sind $\mathrm{CR}_{1}=11 \%(12 \%), \mathrm{CR}_{3}=27 \%(29 \%)$ und $\mathrm{CR}_{5}=40 \%$ $(44 \%)^{83}$ zu beobachten.

Relativ niedrige $\mathrm{CR}_{10}$-Werte ergeben sich hauptsächlich in den beiden Kontraktlogistikmarktsegmenten, dem Teilmarkt „Terminaldienste, nicht integrierte Lagerei-, Umschlags- und sonstige logistische Zusatzleistungen“ sowie im Teilmarkt „Nationaler allgemeiner Ladungsverkehr". Die ersten drei Marktsegmente weisen allerdings mit Blick auf den geringen Outsourcinganteil eine starke Diskrepanz zwischen der Konzentration bezogen auf das Gesamt-Teilmarktvolumen (niedrige $\mathrm{CR}_{10}$-Werte) und bezogen auf das outgesourcte Teilmarktvolumen (höhere $\mathrm{CR}_{10}$-Werte) auf. Daraus erhellt, dass ein großer Anteil des Umsatzvolumens, welcher in diesen Teilmärkten bereits an Logistikdienstleister outgesourct wurde, sich auf relativ wenige Anbieter konzentriert. 


\begin{tabular}{|c|c|c|c|c|}
\hline \multirow[b]{3}{*}{ Teilmärkte $1-15$} & \multicolumn{2}{|c|}{2002} & \multicolumn{2}{|c|}{2004} \\
\hline & \multicolumn{2}{|c|}{ 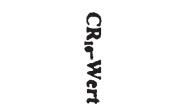 } & \multicolumn{2}{|c|}{$\frac{9}{9}$} \\
\hline & 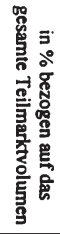 & 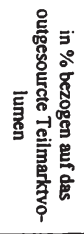 & 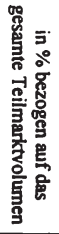 & 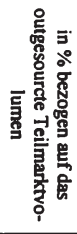 \\
\hline Nationale Massengutlogistik & 24 & 48 & 26 & 47 \\
\hline $\begin{array}{l}\text { Nationaler allgemeiner } \\
\text { Ladungsverkehr }\end{array}$ & 16 & 33 & 12 & 22 \\
\hline Schwertransporte und Krandienste & 44 & 50 & 38 & 42 \\
\hline Nationale Tank- und Silotransporte & 28 & 43 & 21 & 35 \\
\hline $\begin{array}{l}\text { Nationaler sonstiger Ladungsverkehr mit } \\
\text { speziellem Equipment }\end{array}$ & 17 & 45 & 16 & 53 \\
\hline Nationaler allgemeiner Stuckgutverkehr & 64 & 80 & 64 & 71 \\
\hline $\begin{array}{l}\text { Konsumguterdistribution und - } \\
\text { kontraktlogistik }\end{array}$ & 14 & 55 & 14 & 48 \\
\hline $\begin{array}{l}\text { Industrielle Kontraktlogistik, insbesondere } \\
\text { Produktionsversorgung, Ersatzteildistribution } \\
\text { und sonstige business-to-business- } \\
\text { Kontraktlogistik }\end{array}$ & 7 & 44 & 6 & 30 \\
\hline Hangende Kleider-Logistik & 43 & 60 & 50 & 71 \\
\hline $\begin{array}{l}\text { High-Tech-Guter, Messelogistik, Neumobel- } \\
\text { und Umzugstransporte }\end{array}$ & 26 & 41 & 26 & 44 \\
\hline $\begin{array}{l}\text { KEP - Pakte-, echte Kurier- und spezialisierte } \\
\text { Expressdienste }\end{array}$ & 69 & 73 & 78 & 82 \\
\hline $\begin{array}{l}\text { Terminaldienste, nicht integrierte Lagerei-, } \\
\text { Umschlags- und sonstige logistische } \\
\text { Zusatzleistungen }\end{array}$ & 12 & 39 & 11 & 44 \\
\hline $\begin{array}{l}\text { Grenzuberschreitende Transport- und } \\
\text { Speditionsleistungen, Schwerpunkt } \\
\text { StraBe/Schiene }\end{array}$ & 34 & 43 & 32 & 35 \\
\hline $\begin{array}{l}\text { Grenzuberschreitende Transport- und } \\
\text { Speditionsleistungen, Schwerpunkt } \\
\text { Seeschifffahrt/Seehafenspedition }\end{array}$ & 36 & 38 & 38 & 43 \\
\hline $\begin{array}{l}\text { Grenzuberschreitende Aircargo-Carrier und } \\
\text { Leistungen der Luftfrachtspedition }\end{array}$ & 53 & 57 & 36 & 38 \\
\hline
\end{tabular}

\section{Tabelle 2-7: Horizontale Anbieterkonzentration $\left(\mathrm{CR}_{10}\right.$-Wert) getrennt nach Marktsegmenten in den Jahren 2002 und 2004}

Quelle: Eigene Berechnungen auf Basis der Daten von Klaus (2003) und Klaus, Kille (2006) 
Insbesondere die vergleichsweise niedrige Teilmarktkonzentration, sowohl bezogen auf das Gesamt-Teilmarktvolumen als auch bezogen auf das outgesourcte Teilmarktvolumen im Teilmarkt „Nationaler allgemeiner Ladungsverkehr" hingegen veranschaulicht eine andere wichtige angebotsstrukturelle Komponente des Logistikmarktes, welche allein durch die Analyse von Konzentrationsraten nicht adäquat zu erfassen ist. ${ }^{84}$ Am Beispiel des Ladungsverkehrsmarktes wird nämlich deutlich, dass es sich beim deutschen Logistikmarkt um einen Markt handelt, welcher in weiten Teilen originär kleinbetrieblich und mittelständisch strukturiert ist. ${ }^{85}$ Diese kleinbetrieblich und mittelständisch geprägte Marktstruktur ist, wie auch die Ausführungen des Unterabschnitts 2.3.2 gezeigt haben dürften, nicht zuletzt ein Überbleibsel aus einer langen verkehrspolitisch-regulierungsökonomischen Historie, in welcher die Herausbildung jener Marktstruktur in der heute zu konstatierenden Ausprägung sicherlich als eine der gravierenden negativen Regulierungswirkungen bezeichnet werden kann. Die Beseitigung dieser negativen Regulierungswirkung nach vollzogener Marktderegulierung ist bis heute noch nicht vollständig abgeschlossen. Die amtliche Unternehmensstatistik des BAG bspw. wies für das Jahr 2002 insgesamt rund 57.000 Unternehmen auf, welche gewerblichen Güterkraftverkehr betreiben. ${ }^{86}$ Allein ca. $57 \%$ dieser 57.000 Unternehmen gehören zur Gruppe der kleinen und selbstfahrenden Transportunternehmer und haben nicht mehr als drei LKWs im Einsatz. Ca. 29\% dieser 57.000 Unternehmen betreiben zwischen 4 und 10 LKWs. Das BAG geht davon aus, dass ca. $75-80 \%$ dieser Gruppe von Unternehmen bis zu 10 Fahrzeugen - also ca. 36.600 39.000 Unternehmen - in erster Linie als Subunternehmer agieren und in dieser Funktion Frachtführeraufgaben für größere Transportunternehmen, Speditionen und KEP-Dienstleister wahrnehmen. ${ }^{87}$ KLAUS und KILLE beziffern die Unternehmensanzahl im Jahr 2006 mit ca. 45.000 genehmigungspflichtigen Straßengüterverkehrsunternehmen, von denen allein über 10.000 im nationalen Ladungsverkehrsmarkt aktiv sein dürften. ${ }^{88}$

Eine ähnliche Konstellation zeigt sich im Teilmarkt 1 „Nationale Massengutlogistik“, in welchem - in Abgrenzung zu den übrigen Ladungsverkehrsmärkten (Teilmärkte 25) - durchschnittliche Auftragsmengen und Transportlose abgewickelt werden, welche

Vgl. dazu die Ausführungen in diesem Unterabschnitt hinsichtlich der Wahl von Konzentrationsraten als Konzentrationsmaß.

85 Vgl. BAG (2005b), S. 3.

86 Vgl. BAG (2005b), S. 3

87 Vgl. BAG (2005b), S. 5 .

88 Vgl. Klaus, Kille (2006), S. 100.
} 
größer sind als die Kapazität einer LKW- oder Bahnwaggon-Ladung. ${ }^{89}$ Die entsprechenden Produktionsressourcen sind demnach je nach Charakter des zu befördernden Massengutes Binnenschiffe, Pipelines, Teil- und Ganzzugverkehre in Eisenbahnen und - in der nahverkehrlichen Beförderung - LKW-Flotten. ${ }^{90}$ Auch in diesem relativ hoch konzentrierten Teilmarkt greifen die marktführenden Akteure für die physische Abwicklung der reinen Transportleistungskomponenten oftmals auf den Einsatz von Subunternehmern zurück, welche wiederum so kleinbetrieblich strukturiert sind, dass deren Existenz und Leistungsbeitrag bei einer Konzentrationsanalyse mit Hilfe von Konzentrationsraten nicht berücksichtigt werden. Zu nennen sind hier bspw. die ca. 1.000 Partikuliere (selbstständige Betreiber von Binnenschiffen) oder die gewerblichen Betreiber von LKW-Kipperfahrzeugen für Massenguttransporte im Subsegment Bau, Steine und Erden, welche ca. 60.000 Fahrzeuge vorhalten. ${ }^{91}$

Offensichtlich befinden sich also weite Teile der Laderaumkapazitäten, welche für das Erbringen von physischen Transportleistungen unabdingbar notwendig sind, in der Hand kleiner und mittelständischer Transportunternehmen. Diese Laderaumkapazitäten werden von den jeweils marktführenden Unternehmen über UnternehmerSubunternehmerbeziehungen als Inputkomponenten in ihre eigenen netzwerkbasierten Logistikleistungen integriert. Dabei ist gegenwärtig eine Entwicklung zu vermerken, wonach auch größere Transportunternehmen von großen nationalen und international agierenden Logistikunternehmen (in der Regel Speditionen) aus gewachsenen Direktbeziehungen zu Verladern verdrängt und in die Subunternehmerrolle gezwungen werden. Diese wachsende Einflussnahme großer Unternehmen auf die Marktbeziehungen kleinerer Transportunternehmen zu den Verladern ist im Wesentlichen auf zwei Ursachen zurückzuführen. ${ }^{92}$ Zum einen wünschen Verlader (1) zunehmend, ihr gesamtes Auftragsvolumen über einen einzigen Dienstleister abzuwickeln, weswegen kleinere Unternehmen, die aufgrund fehlender Größe und/oder Leistungsfähigkeit nicht in der Verfassung sind, als Alleindienstleister zu fungieren, bei der Auftragsvergabe häufig nicht mehr berücksichtigt werden. Zum anderen müssen die großen Logistikunternehmen (2) ihre Transport- und Systemverkehrsnetzwerke möglichst hoch auslasten, um effizient produzieren zu können. Daher sind sie fortwährend um eine Steigerung ihres Marktanteiles bemüht. Da sich die netzwerkbasierten, primär auf verkehrliche Logistikleistungen ausgerichteten Logistikteilmärkte durch allenfalls

Vgl. Klaus, Kille (2006), S. 92.

Vgl. Klaus, Kille (2006), S. 93.

Vgl. Klaus, Kille (2006), S. 94 ff.

$\mathrm{Vgl}$. für das Folgende BAG (2005b), S. 7 f.
} 
mäßige Marktwachstumsraten auszeichnen, müssen die großen Logistikunternehmen dazu auch auf die Sendungsaufkommen der traditionell von kleineren Transportunternehmen bedienten Direktkunden zurückgreifen. Dieses Sendungsaufkommen war wegen der relativ geringen Einzelvolumina in der Vergangenheit eher von untergeordnetem Interesse für die großen Logistikunternehmen: der Aufwand, welcher für die Integration vieler kleiner Sendungsvolumina in ihre Transportnetzwerke vonnöten war, überstieg den damit verbundenen Umsatznutzen regelmäßig. Daher liegt der eigentliche Fokus der großen Logistikunternehmen bei der Akquisition dieser Sendungsaufkommen auch weniger auf der reinen Transportabwicklung. Vielmehr soll die Abwicklung der Transportleistungen als Plattform für die Übernahme weiterer Elemente der logistischen Gesamtabwicklung der Auftraggeber dienen. Was die reine Transportleistung hingegen betriff, übernimmt das große Logistikunternehmen in der Regel lediglich die Koordination der raum-zeitlichen Eintaktung der Transporte in die eigenen Transport- oder Systemverkehrsnetzwerke. Die physische Abwicklung der Transportleistung wird an Subunternehmer vergeben - nicht selten genau and diejenigen Unternehmen, welche dieselben Transportleistungen vorher in einer direkten Dienstleister-Verlader-Beziehung erbracht haben.

Doch der Logistikmarkt ist jedoch nicht nur im Bereich der frachtführenden Transportunternehmen kleinbetrieblich und mittelständisch geprägt, sondern auch im Bereich der organisierenden und koordinierenden Speditionsunternehmen. Eine Studie des Bundesverbandes Spedition und Logistik e.V. (BSL), basierend auf einer Umfrage in 3.000 Betrieben der Mitgliedsunternehmen des Verbandes, kam hinsichtlich der Betriebsgrößenstruktur und der Anzahl der unterhaltenen Niederlassungen im Jahr $2000 \mathrm{zu}$ folgendem Ergebnis:

\begin{tabular}{|c|c|c|c|}
\hline $\begin{array}{c}\text { Beschäftigte } \\
\text { pro Betrieb }\end{array}$ & $\begin{array}{c}\text { Betriebe } \\
\text { insgesamt } \\
\text { in \% }\end{array}$ & $\begin{array}{c}\text { Betriebe ohne } \\
\text { Niederlassungen } \\
\text { in \% }\end{array}$ & $\begin{array}{c}\text { Betriebe mit } \\
\text { Niederlassungen } \\
\text { in \% }\end{array}$ \\
\hline bis 10 & 22 & 30 & 14 \\
\hline $11-50$ & 46 & 51 & 40 \\
\hline $51-100$ & 16 & 11 & 21 \\
\hline $101-200$ & 9 & 6 & 13 \\
\hline über 200 & 7 & 2 & 12 \\
\hline Gesamt & $\mathbf{1 0 0}$ & $\mathbf{1 0 0}$ & $\mathbf{1 0 0}$ \\
\hline
\end{tabular}

Tabelle 2-8: Betriebsgrößen nach Zahl der Beschäftigten im Jahr 2000

Quelle: BSL (2000), S. 25 
In Tabelle 2-8 zeigt sich der mittelständische Charakter des Speditions- und Logistikgewerbes insbesondere im großen Anteil der kleinen und mittleren Unternehmen ohne Niederlassungen..$^{93} 81 \%$ der Einbetriebsunternehmen haben 50 und weniger Mitarbeiter, $30 \%$ der Einbetriebsunternehmen gar 10 und weniger Mitarbeiter.

Zusammenfassend kann also festgehalten werden, dass die absolute horizontale Konzentration im deutschen Gesamt-Logistikmarkt seit 1998 stabil auf einem mäßig hohen Niveau verharrt. Eine Betrachtung getrennt nach Teilmärkten allerdings ergibt eine starke Ungleichverteilung der Konzentrationswerte zwischen den einzelnen Teilmärkten. Die $\mathrm{CR}_{\mathbf{k}}$-Werte in den besonders hoch konzentrierten Teilmärkten (KEPMarkt, nationaler Stückgutmarkt) weisen zudem noch steigende Tendenz auf und implizieren die Gefahr wettbewerbsgefährdender Marktstrukturen in den betreffenden Teilmärkten. Andere Teilmärkte wiederum sind allenfalls mäßig bis schwach konzentriert.

Was die relative horizontale Konzentration - die Frage nach dem Grad der Marktanteilsdisparität zwischen den Marktteilnehmern also - betrift, so kann davon ausgegangen werden, dass auch diese in bestimmten Teilmärkten spürbar hoch ist. Vor allem in den netzwerkbasierten, primär auf Transport- und Verkehrsaufgaben ausgerichteten, in der Regel auch hoch absolut konzentrierten Teilmärkten (insbesondere Teilmärkte 1, $2,5,6,11)$ sind eine Vielzahl kleiner und mittlerer Unternehmen aktiv, welche als Frachtfuhrer, oftmals in der Funktion untergeordneter Subunternehmer innerhalb der Transport- und Verkehrssysteme der größeren, marktführenden Unternehmen, physische Transportleistungen erbringen. Derartige Unternehmer-Subunternehmerbeziehungen scheinen zunehmend Direktkundenbeziehungen von kleinen und mittelständischen Transportunternehmen zu ersetzen, sodass eine zunehmende Verschiebung verladerkundenbezogener Außenumsätze von kleineren zu größeren Marktteilnehmern ein wahrscheinliches Marktszenario darstellt. Die kleinen und mittelständischen Unternehmen weisen also in der Regel geringe Marktanteile auf, während an der Spitze dieser Teilmärkte eine mehr oder minder große Oligopolgruppe signifikant hohe Marktanteilswerte auf sich vereinigt. Daher können die hier beschriebenen Teilmärkte wohl am besten als enge bis weite Teiloligopole charakterisiert werden. Entsprechendes lässt sich, allerdings in abgeschwächter Form, auch auf die übrigen Logistikteilmärkte übertragen. In jedem Teilmarkt agieren neben den jeweiligen großen, marktführenden Unternehmen auch kleinere Unternehmen mit geringen

Vgl. BSL (2000), S. 25. 
Marktanteilen, sodass prinzipiell überall eine wahrnehmbare Ungleichverteilung der Marktanteile und damit relative horizontale Konzentration zu verzeichnen ist.

\subsection{Vertikale und diagonale Konzentration}

Nachdem die Analyse der horizontalen Konzentration auf die Produktionshöhe der einzelnen Unternehmen ausgerichtet war, steht nun bei der Analyse der vertikalen und bei der diagonalen Konzentration die Frage nach der Produktionstiefe bzw. nach dem Produktionsprogramm der Unternehmen im Mittelpunkt. Der vertikale bzw. diagonale Konzentrationsgrad wird bestimmt durch Anzahl und Marktanteile von mehrstufigen bzw. Mehrproduktunternehmen. Im Falle des Logistikmarktes ist es allerdings kaum möglich, vertikale und diagonale Marktkonzentration getrennt voneinander zu untersuchen, weil der ökonomische Leistungszusammenhang, welcher ja die Form der Konzentration determiniert, bei einer angebotsmäßigen Zusammenführung einzelner, verschiedenen Teilmärkten zuzuordnender Leistungskomponenten durch ein Logistikunternehmen $\mathrm{zu}$ kundenbezogenen Leistungsbündeln im konkreten Einzelfall unterschiedlich beurteilt werden kann. Würde man bspw. die Zusammenführung transportlogistischer Leistungskomponenten (etwa aus dem Teilmarkt 6 „Nationaler allgemeiner Stückgutverkehr") und kontraktlogistischer Leistungskomponenten (etwa aus dem Teilmarkt 8 „Industrielle Kontraktlogistik, insbesondere industrielle Produktversorgung, Einzelteildistribution und sonstige business-to-business-Kontraktlogistik“) durch ein Logistikunternehmen zu einem kundenbezogenen Komplettleistungspaket als vertikale Integration von Logistikleistungen aufeinander folgender Markt- bzw. Produktionsstufen interpretieren, welche in einer Vorleistungs-Leistungsbeziehung miteinander stehen, so wären derartige Konstellationen Ausdruck vertikaler Konzentration, das bündelnde Logistikunternehmen wäre als vertikal integriertes, mehrstufiges Unternehmen zu bezeichnen. Würde man hingegen eine solche Zusammenführung von Leistungskomponenten als Integration von Logistikleistungen nicht aufeinander folgender Markt- bzw. Produktionsstufen interpretieren, so wären derartige Konstellationen Ausdruck diagonaler Konzentration, das bündelnde Logistikunternehmen wäre demnach als diversifiziertes Mehrproduktunternehmen zu klassifizieren.

Eine derartige Beurteilung des ökonomischen Leistungszusammenhanges verschiedener Logistikleistungskomponenten in einem Leistungspaket und damit verbunden eine Beurteilung der sich dahinter verbergenden Konzentrationsform lässt im Einzelfall Interpretationsspielräume offen, sodass eine gemeinsame Untersuchung der beiden Konzentrationsformen im Logistikmarkt angezeigt scheint, um diese Beurteilungsproblematik zu umgehen. 
Als Ausgangspunkt für die Analyse der vertikalen und diagonalen Marktkonzentration wurden in Tabelle 2-9 die 20 marktführenden Logistikunternehmen des GesamtLogistikmarktes im Jahr 2004 erfasst und es wurde untersucht, in welchen Teilmärkten die „TOP 20“ auch zu den „Teilmarkt TOP 20“ zählen, welchen Rangplatz sie in den jeweiligen Teilmärkten einnehmen und welchen Umsatzanteil sie dort erwirtschaften.

Tabelle 2-9 zeigt nun, dass - mit Ausnahme von 5 Unternehmen - alle marktführenden Logistikunternehmen in mehreren Teilmärkten aktiv sind. Jedes der „TOP 3“ Unternehmen des Gesamt-Logistikmarktes bedient über die Hälfte der Logistikteilmärkte, der Marktführer Deutsche Bahn sogar über zwei Drittel. In allen Teilmärkten belegen sie vordere Rangplätze und decken mit ihrem Leistungsprogramm das gesamte mögliche Spektrum an netzwerkbasierten nationalen und internationalen Transportund Verkehrsleistungen sowie an kunden- und branchenbezogenen Kontraktlogistikleistungen ab. Auch die meisten nachfolgenden Unternehmen, welche die Rangplätze 4 bis 20 im Gesamt-Logistikmarkt belegen, weisen ein breit gefächertes Leistungsprogramm auf. Die Teilmarkt-Rangplätze geben dabei Aufschluss über die relative Spezialisierung der Unternehmen. So dominiert die Deutsche Bahn offenkundig die Ladungstransporte und die „Bulk“-Logistikmärkte, während die Deutsche Post im KEP-Markt und bei den landgestützten grenzüberschreitenden Transport- und Speditionsleistungen eine führende Marktstellung einnimmt. ${ }^{94}$ Kühne \& Nagel führt die Märkte für luft- und seegestützte grenzüberschreitende Transport- und Speditionsleistungen an.

Insgesamt kann für die Gruppe der großen, marktführenden Logistikunternehmen festgehalten werden, dass die Ausgestaltung ihres Leistungsportfolios auf eine spürbar hohe vertikale und diagonale Marktkonzentration hindeutet. ${ }^{95} \mathrm{Ihr}$ Leistungsprogramm umfasst verschiedenartige Logistikleistungskomponenten, welche fallweise $\mathrm{zu}$ unterschiedlichen Leistungspaketen verbunden werden können. Insofern ist ein Übergewicht vertikal integrierter Mehrstufen- bzw. diversifizierter Mehrproduktunternehmen gegenüber Einstufen- bzw. Einproduktunternehmen zu konstatieren.

Die Akquisition des britischen Logistikunternehmens Exel durch die Deutsche Post im Jahr 2005, welche in dieser Tabelle, die ja auf Daten des Jahres 2004 basiert, noch nicht berücksichtigt werden konnte, bringt die Deutsche Post auch im Markt für industrielle Kontraktlogistik (Teilmarkt 8) in eine marktführende Position Vgl. auch Unterabschnitt 2.5.3.4.3. Exel nimmt im deutschen Logistik-Gesamtmarkt den Rangplatz 31 ein, im Teilmarkt für industrielle Kontraktlogistik den Rangplatz 10 mit einem Umsatz von 112 Mrd. €. Vgl. Klaus, Kille (2006), S. 129. Logistiksparten auch nichtlogistische Leistungssparten betreiben. 


\begin{tabular}{|c|c|c|c|c|c|c|}
\hline Rangplatz & Unternehmen & $\begin{array}{l}\text { Umsatz } \\
2004 \text { in } \\
\text { Mio. } €\end{array}$ & $\begin{array}{l}\text { Mitarbeiter } \\
\text { in } \\
\text { Deutschland }\end{array}$ & $\begin{array}{c}\text { aktiv in den } \\
\text { Teilm }\end{array}$ & Teilmarktrangplatz & $\begin{array}{c}\text { Teilmarktumsatz } \\
2004 \text { in Mio. } €\end{array}$ \\
\hline \multirow[t]{12}{*}{1} & Deutsche Bahn & 5.567 & 55.000 & & & \\
\hline & & & & 1 & 1 & 1.251 \\
\hline & & & & 2 & 1 & 955 \\
\hline & & & & 3 & 1 & 95 \\
\hline & & & & 4 & 1 & 500 \\
\hline & & & & 5 & 1 & 500 \\
\hline & & & & 6 & 3 & 425 \\
\hline & & & & 8 & 3 & 385 \\
\hline & & & & 10 & 5 & 85 \\
\hline & & & & 13 & 2 & 450 \\
\hline & & & & 14 & 4 & 350 \\
\hline & & & & 15 & 2 & 511 \\
\hline \multirow[t]{9}{*}{2} & Deutsche Post & 4.600 & 34.486 & & & \\
\hline & & & & 6 & 5 & 350 \\
\hline & & & & 7 & 10 & 150 \\
\hline & & & & 8 & 6 & 200 \\
\hline & & & & 10 & 11 & 25 \\
\hline & & & & 12 & 1 & 2.800 \\
\hline & & & & 13 & 1 & 700 \\
\hline & & & & 14 & 8 & 150 \\
\hline & & & & 15 & 5 & 200 \\
\hline \multirow[t]{9}{*}{3} & Kahne \& Nagel & 1.977 & 4.900 & & & \\
\hline & & & & 2 & 3 & 101 \\
\hline & & & & 3 & 3 & 44 \\
\hline & & & & 7 & 13 & 136 \\
\hline & & & & 10 & 12 & 24 \\
\hline & & & & 11 & 9 & 96 \\
\hline & & & & 13 & 12 & 112 \\
\hline & & & & 14 & 1 & 885 \\
\hline & & & & 15 & 1 & 530 \\
\hline \multirow[t]{6}{*}{4} & Dachser & 1.538 & 7.550 & & & \\
\hline & & & & 2 & 5 & 74 \\
\hline & & & & 6 & 1 & 594 \\
\hline & & & & 7 & 6 & 300 \\
\hline & & & & 13 & 3 & 350 \\
\hline & & & & 15 & 6 & 160 \\
\hline \multirow[t]{4}{*}{5} & \begin{tabular}{|l|} 
Volkswagen \\
Transport
\end{tabular} & 1.100 & 1.519 & & & \\
\hline & & & & 5 & 2 & 350 \\
\hline & & & & 8 & 1 & 590 \\
\hline & & & & 13 & 14 & 100 \\
\hline \multirow[t]{2}{*}{6} & DPD & 1.066 & 12.500 & & & \\
\hline & & & & 12 & 2 & 1.066 \\
\hline \multirow[t]{3}{*}{7} & UPS & 1.000 & 1.500 & & & \\
\hline & & & & 10 & 1 & 250 \\
\hline & & & & 12 & 3 & 750 \\
\hline \multirow[t]{6}{*}{8} & Rhenus & 982 & 5.800 & & & \\
\hline & & & & 1 & 3 & 230 \\
\hline & & & & 2 & 14 & 40 \\
\hline & & & & 7 & 11 & 147 \\
\hline & & & & 8 & 13 & 100 \\
\hline & & & & 11 & 2 & 410 \\
\hline 9 & Panalpina & 970 & 1.454 & & & \\
\hline
\end{tabular}




\begin{tabular}{|c|c|c|c|c|c|c|}
\hline & & & & 10 & 14 & 20 \\
\hline & & & & 13 & 5 & 240 \\
\hline & & & & 14 & 5 & 340 \\
\hline & & & & 15 & 4 & 290 \\
\hline \multirow[t]{5}{*}{10} & Fiege & 900 & 11.100 & & & \\
\hline & & & & 6 & 14 & 55 \\
\hline & & & & 7 & 5 & 340 \\
\hline & & & & 8 & 2 & 400 \\
\hline & $\begin{array}{l}\text { Zwischensumme } \\
\text { der TOP } 10 \text { * }\end{array}$ & 19.700 & 149.309 & & & \\
\hline \multirow[t]{7}{*}{11} & Thiel & 837 & 5.000 & & & \\
\hline & & & & 7 & 14 & 132 \\
\hline & & & & 8 & 5 & 299 \\
\hline & & & & 10 & 6 & 67 \\
\hline & & & & 14 & 13 & 95 \\
\hline & & & & 15 & 11 & 42 \\
\hline & & & & 9 & 3 & 69 \\
\hline \multirow[t]{2}{*}{12} & Hapag Lloyd & 800 & 3.607 & & & \\
\hline & & & & 14 & 2 & 800 \\
\hline \multirow[t]{5}{*}{13} & Hellmann & 723 & 6.011 & & & \\
\hline & & & & 2 & 7 & 58 \\
\hline & & & & 13 & 13 & 110 \\
\hline & & & & 14 & 11 & 110 \\
\hline & & & & 15 & 9 & 85 \\
\hline \multirow[t]{2}{*}{14} & Hermes & 710 & 1.300 & & & \\
\hline & & & & 12 & 4 & 710 \\
\hline \multirow[t]{2}{*}{15} & Senator Lines & 670 & 481 & & & \\
\hline & & & & 14 & 3 & 670 \\
\hline \multirow[t]{6}{*}{16} & $\begin{array}{l}\text { Wincanton } \\
\text { Trans European }\end{array}$ & 660 & 3.610 & & & \\
\hline & & & & 10 & 8 & 50 \\
\hline & & & & 1 & 8 & 86 \\
\hline & & & & 2 & 10 & 50 \\
\hline & & & & 6 & 15 & 55 \\
\hline & & & & 8 & 4 & 300 \\
\hline \multirow[t]{3}{*}{17} & MGL & 630 & n.a. & & & \\
\hline & & & & 7 & 1 & 520 \\
\hline & & & & 9 & 2 & 70 \\
\hline \multirow[t]{5}{*}{18} & $\begin{array}{l}\text { Imperial } \\
\text { Logistics } \\
\end{array}$ & 616 & 3.386 & & & \\
\hline & & & & 1 & 4 & 188 \\
\hline & & & & 8 & 17 & 87 \\
\hline & & & & 11 & 6 & 105 \\
\hline & & & & 14 & 7 & 180 \\
\hline \multirow[t]{3}{*}{19} & arvato logistics & 590 & 6.200 & & & \\
\hline & & & & 8 & 15 & 90 \\
\hline & & & & 7 & 2 & 500 \\
\hline \multirow[t]{2}{*}{20} & HHLA & 589 & 3.334 & & & \\
\hline & & & & 11 & 1 & 589 \\
\hline
\end{tabular}

Tabelle 2-9: Die „TOP 20“ des Gesamt-Logistikmarktes und deren Teilmarktaktivitäten im Jahr 2004

Quelle: Eigene Darstellung auf Basis der Daten von Klaus, Kille (2006) 
Für die Gruppe der kleineren, den „TOP 20" nachgeordneten Logistikunternehmen dürfen - wenngleich nicht im gleichen Umfang wie bei den „TOP 20“ - entsprechende, mehrere Teilmärkte umfassende Leistungsportfolios unterstellt werden. $\mathrm{Zu}$ dieser Vermutung gibt wiederum eine Studie des BSL Anlass. Sie kommt zu dem Ergebnis, dass das Leistungsspektrum von Speditions- und Logistikbetrieben mit zunehmender Betriebsgröße deutlich zunimmt. In Betrieben mit bis zu 10 Beschäftigten ist jeder dritte Betrieb nur in bis zu drei verschiedenen Leistungsbereichen aktiv, in Betrieben mit über 100 Beschäftigten werden in der Hälfte aller Betriebe mindestens neun Leistungsbereiche, häufig auch mehr angeboten. ${ }^{96}$

Lediglich die Gruppe der kleinsten Logistikunternehmen, welche vorwiegend in Subunternehmerfunktion physische Transportleistungen für die größeren Logistikunternehmen erbringt, weist typischerweise einstufige Einprodukt-Leistungsstrukturen auf.

\subsubsection{Typen von Marktakteuren und deren Marktstrategien}

Die Marktakteure auf dem Logistikmarkt sind die Anbieter von und die Nachfrager nach logistischen Leistungen. Wie bei der sachlichen Marktabgrenzung bereits ausgefüht, sind dies die mikrologistischen Systeme: auf dem Logistikdienstleistungsmarkt als Teilbereich des Gesamt-Logistikmarktes ist die Konstellation gegeben, dass Logistikdienstleistungsunternehmen (mikrologistische Systeme in Gestalt logistischer Betriebe) Logistikleistungen anbieten und Industrie- und Handelsunternehmen der Transformationssektoren die Logistikleistungen nachfragen. Als zweiter Teilbereich des Gesamt-Logistikmarktes ist die Eigenproduktion logistischer Leistungen innerhalb der beiden Transformationssektoren der Güterbereitstellung und der Güterverwendung zum Eigenbedarf zu betrachten. Hier treten die Industrie- und Handelsunternehmen, resp. ihre Logistikabteilungen (mikrologistische Systeme in Gestalt mikrologistischer Subsysteme des Unternehmens), selbst als Anbieter logistischer Leistungen auf, mit der Absicht, logistische Aufgabenstellungen in Abstimmung auf die bestmögliche Erfüllung des originären Geschäftszweckes der Unternehmung wahrzunehmen.

Wie allerdings in der vorangehenden Konzentrationsanalyse bereits angedeutet wurde, bilden die Marktakteure auf dem Logistikmarkt, und hier vor allem die Logistikdienstleistungsunternehmen, keinesfalls keine homogene Masse. Vielmehr stellt die

BSL (2000), S. 11. 
Gesamtheit der Marktakteure ein in Summe uneinheitliches Gebilde dar, welches durch ein Nebeneinander

- von großen, mehrbetrieblich aufgestellten Konzern- oder konzernähnlichen Unternehmen und einbetrieblich strukturierten kleinen und mittelständischen Unternehmen sowie

- von mehrstufigen bzw. diversifizierten Mehrproduktunternehmen und einstufigen Einproduktunternehmen

gekennzeichnet ist. Zudem bestehen offensichtlich mehr oder minder überdauernde, institutionalisierte Leistungsverflechtungen zwischen verschiednen Marktakteursgruppen, welche möglicherweise eine - bisweilen auch hierarchisch strukturierte Systematik der Aufgabenverteilung zwischen einzelnen Marktakteuren begründen. Daher scheint es angezeigt, sich mit den Typen von Marktakteuren im Logistikmarkt sowie mit deren Marktstrategien näher zu beschäftigen. Aus Zweckmäßigkeitsüberlegungen soll sich die folgende Analyse auf die Typologisierung und Systematisierung von Logistikdienstleistungsunternehmen beschränken, diejenigen mikrologistischen Systeme also, deren primärer Geschäftszweck die Produktion von Logistikleistungen für Dritte ist. Die mikrologistischen Subsysteme der Industrie- und Handelsunternehmen werden nicht gesondert betrachtet.

Um Logistikdienstleistungsunternehmen voneinander $\mathrm{zu}$ unterscheiden, kann als Differenzierungskriterium auf die von den Unternehmen übernommenen Dienstleistungsfunktionen abgestellt werden. Diese Dienstleistungsfunktionen wurden in Unterabschnitt 2.2.3.1.2 in Hauptfunktionen, Ergänzungsfunktionen bzw. Komplementärfunktionen sowie Sonderfunktionen systematisiert. Zwar ermöglicht eine Unterscheidung der Logistikdienstleistungsunternehmen, welche sich am Prinzip der institutionellen Trägerschaft von einzelnen Logistikleistungsfunktionen orientiert, eine erste mögliche Systematisierung, welche oftmals auch in Form von Legaldefinitionen in die einschlägigen Gesetzestexte Eingang gefunden hat. Jedoch ist eine klare, trennscharfe Abgrenzung der Unternehmen nach entsprechenden Funktionsbereichen nicht möglich. ${ }^{97}$ Vielmehr zeigt sich in der ökonomischen Realität, dass auf dem Logistikmarkt viele Unternehmen tätig sind, welche überaus unterschiedliche Funktionen, die in Art und Umfang höchst differenziert sind, wahrnehmen. Diese 
Marktakteure passen die „Funktionenbündel“ permanent an sich ändernde Kundenanforderungen an und entwickeln sie in Art und Umfang weiter. ${ }^{98}$ Dementsprechend ist die anschließende Typologisierung von Logistikdienstleistungsunternehmen als Darstellung von idealtypischen Erscheinungsformen in der Gestalt von Basistypen aufgebaut, auf deren Grundlage sich, je nach Gewicht der verschiedenen logistischen Leistungskomponenten, weitere in der Wirtschaftspraxis agierende realtypische Erscheinungsformen als Mischformen herausbilden. Während dabei die Basistypen noch sichtbares Zeichen der vormals politisch-regulierungstheoretisch tradierten Arbeitsteilung in der Logistikwirtschaft sind, sind die Mischformen das Resultat der unternehmerischen Bemühungen, ihr Angebot nachfrageadäquat umzugestalten bzw weiterzuentwickeln. Nichtsdestotrotz existieren in der Wirtschaftspraxis aber auch Logistikunternehmen, welche sich aus freiem ökonomischem Willen im Wesentlichen auf das basistypische Leistungsportfolio eines Frachtführers oder etwa einer Spedition beschränken. Infolgedessen ist die für lange Zeit de jure geltende, traditionelle Arbeitsteilung nicht per se als marktinkonform einzustufen.

\subsubsection{Basisformen von Marktakteuren}

\subsection{Frachtführer}

Frachtfuihrer (engl.: „Carrier") sind diejenigen Institutionen, welche Transportmittel (Seeschiff, Binnenschiff, Eisenbahn, Lastkraftwagen, Flugzeug) betreiben ${ }^{99}$ und den eigentlichen Transportvorgang abwickeln. ${ }^{100}$ Sie werden daher von IHDE auch als prototypische Verkehrsbetriebe bezeichnet. ${ }^{101}$ Der Aufgabenbereich des Frachtführers schlägt sich auch in der Legaldefinition des HGB nieder. In $\S 407$ (I) HGB wird als Frachtführer derjenige bezeichnet, der durch einen Frachtvertrag dazu verpflichtet wird, das Gut zum Bestimmungsort zu befördern und dort an den Empfänger abzuliefern. Frachtführer verändern also stets die räumlichen Merkmale der logistischen Güter und nehmen dabei die Hauptfunktion der Beförderung sowie die dafür unmittelbar notwendigen Ergänzungsfunktionen (z.B. Umschlagen, Bildung von Sammelverkehren, usw.) wahr. ${ }^{102}$ Der Schwerpunkt ihrer Aufgaben besteht im Kapazitäts- und

99 gl. Pfohl (2004a), S. 291; Stabenau (1994), S. 14

Vgl. Pfohl (2004a), S. 292. Für eine Übersicht und eine detaillierte Beschreibung der einzelnen Transportmittel vgl. Pfohl (2004a), S. $167 \mathrm{ff}$.

Vgl. Ihde (2001), S. 43.

Vgl. Abbildung 2-11.
} 
Auslastungsmanagement der Transportmittel. ${ }^{103}$ Ferner bedingt der anhaltende Trend zur Standardisierung der Transportbehälter und -abläufe sowie der damit verbundenen Informationsaustauschprozesse einen immensen technischen Wandel im Bereich der Produktion von Transport- und Umschlagsleistungen. Dies erfordert die ständige Bereitschaft und Möglichkeit seitens der Frachtführer, in leistungsfähige, möglichst flächendeckende Transportsysteme $\mathrm{zu}$ investieren um eine durchgängige ggf. multimodale Transportleistung in angemessener Leistungsqualität anbieten zu können. ${ }^{104}$

\subsection{Lager-, Umschlags- und Verpackungsunternehmen}

Das gewerbsmäßige Lagergeschäft wird in den $\S \S 467$ ff. HGB geregelt. In $\S 467$ (I) HGB wird der Lagerhalter durch den Lagervertrag verpflichtet, „, das Gut zu lagern und aufzubewahren“.

JAEGER und LAUDEL unterscheiden folgende Lagerungsgründe: ${ }^{105}$ Die

- beschaffungsbedingte Lagerung (dient dazu, eine störungsfreie Produktion zu gewährleisten), die

- produktionsbedingte Lagerung (wird ggf. dann erforderlich, wenn der Produktionsprozess die Verbesserung der Qualität mittels Reifungsprozessen vorsieht, bspw. bei der Produktion von Wein oder Käse), die

- absatzbedingte Lagerung (dient dazu, eine stetige Produktion zu ermöglichen, ohne sich dabei an den Schwankungen des Absatzmarktes orientieren zu müssen) und die

- transportbedingte Lagerung (bspw. zum Zwecke von Umschlagsprozessen im Rahmen von Sammelladungsverkehren).

$\mathrm{Zu}$ beachten ist, dass ein gewerbsmäßiges Lagergeschäft nur dann vorliegt, wenn es sich bei der Lagerung um die Hauptpflicht des Unternehmens handelt und nicht die Nebenpflicht eines anderen Gewerbes darstellt (wie bspw. die transportbedingte

Vgl. Weber et al. (2002), S. 29.

Vgl. Stabenau (1999), S. 92.

Vgl. dazu Jaeger, Laudel (2000), S. 326. 
Zwischenlagerung im Rahmen von Umschlagsprozessen). ${ }^{106}$ Neben den selbstständigen Lagerunternehmen treten häufig auch Speditionen als Lageristen auf.

Umschlags- und Verpackungsunternehmen stellen die störungsfreie Kopplung von Güterverteilprozessen sicher und gewährleisten die reibungslose Abwicklung von sequenziell ablaufenden Transport-, Umschlags- und Lagerprozessen. ${ }^{107} \mathrm{Zu}$ den Umschlagsunternehmen zählen vor allem von Bahn und Hafenbehörden betriebene Container-Terminals, Luftfrachtterminals von Flug- oder Flughafengesellschaften, Sammelgutumschlagsstellen von Sammelgutspeditionen sowie Paketumschlagstellen von Post oder Paketdiensten. ${ }^{108}$ Spezialisierte Verpackungsunternehmen werden vornehmlich dann eingesetzt, wenn der Verpackungsbedarf des betreffenden Gutes stark schwankt und spezielle Fachkenntnisse erforderlich sind (wie bspw. im Sondermaschinen- und Anlagenbau). ${ }^{109}$

\subsection{Speditionen und Vermittler}

Originäres, traditionelles Aufgabengebiet der Spedition ist die Organisation der Güterversendung. Nach $\S 407$ HGB a. F. war Spediteur, „wer es gewerbsmäßig übernimmt, Güterversendungen durch Frachtführer oder durch Verfrachter von Seeschiffen für Rechnung eines anderen in eigenem Namen zu besorgen". Nach der Transportrechtsreform von 1998 findet sich die entsprechende Regelung im § 453 (I) HGB mit folgendem Wortlaut: "Durch den Speditionsvertrag wird der Spediteur verpflichtet, die Versendung des Gutes zu besorgen.“ $§ 454$ (I), (II) HGB konkretisiert die Verpflichtung des Spediteurs zur Besorgung von Sendungen. Hier wird ausgeführt, dass zu den Aufgaben des Spediteurs

- die Organisation der Beförderung, insbesondere

○ die Bestimmung des Beförderungsmittels und des Beförderungsweges,

o die Auswahl ausfuhrender Unternehmer,

○ der Abschluss der für die Versendung erforderlichen Fracht-, Lager- und Speditionsverträge,

Vgl. Pfohl (2004a), S. 297.

Vgl. Ihde (2001), S. 45.

Vgl. Brauer (1979), S. 91.

Vgl. Ihde (2001), S. 45.
} 
○ die Erteilung von Informationen und Weisungen an die ausführenden Unternehmer sowie

○ die Sicherung von Schadensersatzansprüchen des Versenders

gehören. Ferner zählen die Ausführung sonstiger vereinbarter auf die Beförderung bezogener Leistungen wie die Versicherung und Verpackung des Gutes, seine Kennzeichnung und die Zollbehandlung zu den Pflichten des Spediteurs. Zudem kann der Spediteur die Güterbeförderung im sog. Selbsteintritt selbst durchführen und damit als Frachtfuhrer auftreten ( $\$ 458 \mathrm{HGB}$ ).

Der Gesetzgeber schreibt der Spedition offensichtlich eine immense Bandbreite an Aufgaben zu, welche primär dispositiven Charakter haben und an der Organisation von Transporten anknüpfen. Die idealtypische Sichtweise der Spedition als „Vermittler im Spannungsfeld zwischen Verladerschaft und Verkehrswirtschaft ${ }^{\text {" }}{ }^{110}$ ist jedoch nicht mehr zeitgemäß. "' Die „klassischen“ Speditionsfunktionen, welche auch aus der ausführlichen Legaldefinition des HGB abgeleitet werden können, vermögen das speditionelle Aufgabenspektrum von heute nur unzureichend zu erfassen. ${ }^{112}$ Das Betätigungsfeld der Spedition umfasst gegenwärtig neben der traditionellen Verkehrsvermittlung vielmehr sämtliche Dienstleistungen von der Transportdurchführung im Selbsteintritt bis hin zur Planung, Realisierung und Steuerung verladerindividueller Systemdienstleistungen. ${ }^{113}$ Hierbei fungiert der Spediteur als Unternehmen, das Logistikleistungen und nicht-logistische Leistungen einkauft, diese - sofern erforderlich - um selbst erstellte Leistungen ergänzt und dann die Leistungen einzeln oder als spezifische Leistungsbündel an den Auftraggeber verkauft. ${ }^{114}$ Das Aufgabenspektrum der Spedition umreißt IHDE folgendermaßen: ${ }^{115}$

110 Vogel (1979), S. 287.

III Vgl. Zänker (1997), S. 970 f.

$112 \mathrm{Vgl}$. Freichel (1992), S. 23; Ihde (2001), S. 229.

113 Vgl. Aberle (2003a), S. 270 ff.; Ihde (2001), S. 229. Dieses Aufgabenspektrum schlägt sich auch in den Allgemeinen Deutschen Spediteurbedingungen (ADSp) nieder. Bei den ADSp handelt es sich nach ständiger höchstrichterlicher Rechtsprechung um eine fertig bereitliegende Rechts- und Haftungsordnung für speditionelle Dienstleistungen. Ziffer 2.1 der ADSp benennt neben den Verkehrsverträgen, ,welche üblicherweise zum Speditionsgewerbe gehörende Geschäfte betreffen“ ausdrücklich auch „speditionsübliche logistische Leistungen, wenn diese mit der Beförderung oder Lagerung von Gütern in Zusammenhang stehen“ als Gegenstand der ADSp. Vgl. Griesshaber (2000), S. 345.

Vgl. Pfohl (2004a), S. 299; Ihde (2001), S. 229. 
- Speditionelle Kernleistungen (Planung und Steuerung der Transportkette, Auswahl der Verkehrsträger und -mittel, Abschluss der Frachtverträge, Erstellen der Transportdokumente)

- Logistische Kernleistungen (Transport-, Umschlags-, Lagerleistungen)

- Logistische Zusatzleistungen (bspw. Kommissionierungs-, Verpackungs-, Markierungsleistungen)

- Logistische Informationsleistungen (bspw. Sendungsverfolgung, Materialdisposition, Lagerverwaltung, Auftragsabwicklung)

- Nicht-logistische Zusatzleistungen (bspw. Verzollung, Versicherung, Logistikberatung)

Das Leistungsportfolio der Spedition ist somit erheblich breiter geworden, umfasst den An- und Verkauf sämtlicher logistischer und nicht-logistischer Leistungskomponenten und ist nicht mehr primär auf die Organisation der Beförderungsleistung fokussiert, wie es die Legaldefinition im HGB noch impliziert. ${ }^{116}$ Deshalb kann die Spedition auch als „Keimzelle für Logistikunternehmen“ bezeichnet werden, ..."die komplette logistische Dienstleistungen anzubieten in der Lage sind..."."17 Die Spedition trägt damit maßgeblich zum Aufbau metalogistischer Systeme bei. ${ }^{118}$ Auch nach ABERLE sind Speditionen von allen Verkehrsbetrieben am besten geeignet, „den Schritt zum Logistikpartner der verladenden Wirtschaft erfolgreich zu vollziehen“. ${ }^{119}$ Treibende Kräfte für die Veränderungsprozesse in der Spedition hinsichtlich Umfang und Preisentwicklung des Leistungsangebotes, Entwicklung des Wettbewerbs sowie organisatorisch-technischer Rationalisierungsmaßnahmen sind vor allem die Verkehrsmarktderegulierung sowie die Anpassungsprozesse an die geänderten Verladeranforderungen. ${ }^{120}$

Jedoch sind die Anstrengungen der Spedition, ihr Leistungsportfolio immer weiter auszudehnen und anzupassen keinesfalls ein neues Phänomen. Vielmehr gab es bereits in den 1970er Jahren Bemühungen, neue Märkte zu erschließen. In dem Maße nämlich, in dem sich die Verkehrsströme verdichteten und die Verkehrsabwicklung

Vgl. Ihde (2001), S. 229 f., in Anlehnung an Isermann (1998), S. $35 \mathrm{ff}$.

Vgl. Kremer (2000), S. 11 f.; Haubold (1994), S. 103; Aberle (2003a), S. 24.

Pfohl (2004a), S. 299.

Vgl. Ihde (2001), S. 47.

Aberle (2003a), S. 530; ähnlich auch Aberle (2003b), S. 280.
} 
aufgrund technisch-organisatorischer Verfahrensfortschritte auch ohne die Einschaltung eines Speditionsunternehmens rationell durchführbar wurde, drohten Speditionsdienstleistungen obsolet zu werden. Die Spedition musste folglich den drohenden Verlust traditioneller Märkte mit der Erschließung neuer Märkte kompensieren. ${ }^{121}$ Schon damals konnte der Spediteur analog zu seiner heutigen Stellung als Organisator und Architekt logistischer Systeme betrachtet werden. Er fungierte damals - in einer Zeit also, welche regulierungsbedingt durch stark eingeschränkte unternehmerische Entscheidungsfreiheit gekennzeichnet war - wie heute als Institution, welche Effizienzsuchprozesse hinsichtlich der Bündelung und Neukombination des verfügbaren logistischen Know-hows anstößt und bis zur Marktreife vorantreibt. So formulierte VOGEL im Jahre 1979 dazu: „Das Tätigkeitsfeld des Speditionsgewerbes setzt sich aus einer Reihe funktional unterschiedlicher Leistungsbereiche zusammen, die zumeist miteinander kombiniert und als Leistungsbündel dem Verlader angeboten werden und in ihrer Gesamtheit heute praktisch alle mit der Beförderung von Gütern zusammenhängenden Funktionen abdecken." 122 Auch FIEGE beschreibt die Spedition als diejenige Institution, welche als erste und federführend auf die Entwicklungen in der Logistik von Industrie- und Handelsunternehmen reagiert und ihr Dienstleistungsangebot in Richtung komplexerer Dienstleistungspakete entwickelt hat. ${ }^{123}$

Die Existenz von Speditionen als Absatzmittler logistischer Leistungen kann mit Hilfe der Transaktionskostentheorie erklärt werden. Danach ist der Einsatz eines Speditionsunternehmens dann sinnvoll, wenn die dadurch zusätzlich entstehenden Transaktionsund Produktionskosten der Spedition durch Kostenreduktion beim Verlader und bei den Logistikkomponentenanbietern mindestens aufgewogen werden. ${ }^{124}$ Dies ist in der Regel der Fall, da der Verlader bei Zwischenschaltung eines Spediteurs lediglich mit diesem einen Geschäftsbesorgungsvertrag abschließen muss und sich die aufgrund fehlender Marktübersicht bei den Logistikkomponentenanbietern anfallenden Abschluss-, Such- und Kontrollkosten spart. ${ }^{125}$ Die Transaktionskostenersparnisse werden dann umso höher sein, wenn der Spediteur im Sinne einer Sortimentsbildung verschiedene - aus seiner Sicht - standardisierte Leistungskomponenten zu einem -

\footnotetext{
120 Vgl. Ihde (2001), S. 231 f.

121 Vgl. Vogel (1979), S. 288.

122 Vogel (1979), S. 289.

$123 \mathrm{Vgl}$. Fiege (1998), S. 77. Er datiert dort die zeitlichen Ursprünge einer aktiven Auseinandersetzung der Verkehrswirtschaft mit der Thematik „Logistik“ auf Mitte der 80er Jahre.

125 Die Zwischenschaltung eines Spediteurs ist insbesondere deshalb sinnvoll, da die Frachtführerseite ihrerseits stark fragmentiert ist. Vgl. Weber et al. (2002), S. 29.
} 
aus Verladersicht - hochkomplexen Leistungsbündel zusammenfügt und der Verlader selbst nur über beschränkte Markttransparenz verfügt. ${ }^{126}$ Diese die Markttransparenz erhöhende Funktion der Spedition und die damit einhergehenden Beratungsleistungen bei kundenspezifischen logistischen Problemstellungen zeitigen zudem positive Wirkungen auf die einzel- und auf die gesamtwirtschaftliche Ressourcenallokation. ${ }^{127}$

Neben den Speditionen existieren weitere Institutionen, die als Vermittler auf dem Logistikmarkt tätig werden. Hier kann zwischen Maklern und Agenten unterschieden werden. Aufgabe der Makler ist die gewerbsmäßige, unabhängige und neutrale Vermittlung von Verträgen, ohne dass sie die Möglichkeit zur Eigenproduktion logistischer Leistungen haben. ${ }^{128}$ Aufgrund der dazu erforderlichen Marktkenntnis tragen Makler, ähnlich wie die Spediteure, wesentlich zur Verbesserung der Markttransparenz und zur Reduktion der Transaktionskosten bei. Anders als die Makler sind die Agenten, die formaljuristisch den Bestimmungen über die Handelsvertreter unterliegen ( $\S 84 \mathrm{ff}$. HGB), mindestens für ein Logistikunternehmen auf Dauer tätig und vertreten dementsprechend dessen Interessen. Hauptaufgabengebiete für Agenten sind die Ladungsakquisition für Reedereien oder Luftverkehrsgesellschaften. ${ }^{129}$ Aufgrund der spezifischen Interessenlage der Agenten tragen diese weitaus weniger zur Schaffung von höherer Markttransparenz bei.

\subsubsection{Mischformen von Marktakteuren}

Wie bereits erwähnt stellen realtypische Erscheinungsformen von Logistikunternehmen in aller Regel Mischformen aus den Idealtypen dar. Dennoch sind im Leistungsportfolio der Logistikunternehmen für gewöhnlich Schwerpunkte erkennbar, welche die verhältnismäßige Nähe zu einzelnen Basistypen dokumentieren und welche oftmals auch auf die "gewerblichen Wurzeln“ des Unternehmens hindeuten. Die Frachtführer, Lager-, Umschlags- und Verpackungsunternehmen, Spediteure und Vermittler stellen dabei einen Baukasten mit idealtypischen, logistischen Leistungskomponenten zur Verfügung, derer sich die Logistikunternehmen bedienen, um daraus je nach dem Anforderungsprofil der jeweiligen logistischen Aufgabenstellung eine Lösung zu erarbeiten. Dabei haben sich die Speditionen aufgrund ihres traditionellen Leistungsportfolios und aufgrund ihrer Stellung als Intermediär als prädestiniert dazu

\footnotetext{
126 Vgl. Pfohl, Large (1992), S. 39.

$127 \mathrm{Vgl}$. Ihde (2001), S. 47.

128

Vgl. Ihde (2001), S. 46.

Vgl. Brauer (1979), S. 95 f.
} 
erwiesen, logistische Funktionen zu integrieren und die logistische Grundidee einer gesamthaften, systemischen, unternehmensübergreifenden, netzwerkbezogenen Optimierung von Güterflusssystemen am Markt aktiv durchzusetzen.

In aller Regel führen die Logistikunternehmen, ihrer jeweiligen Spezialisierung entsprechend, die traditionellen, „klassischen“ Gewerbebezeichnungen (Spedition, Internationale Spedition, Transportunternehmen usw.) im Firmennamen. ${ }^{130}$ Unbeschadet dessen haben sich in der Wirtschaftspraxis und in der wirtschaftswissenschaftlichen Literatur einige, nicht selten dem angelsächsischen Sprachraum entstammende Bezeichnungen für verschiedene Mischformen von Logistikunternehmen durchgesetzt. Diese Bezeichnungen sind Ausdruck bestimmter schwerpunktmäßiger Kombinationen logistischer Teilleistungen im Leistungsportfolio der Unternehmen und spiegeln somit die strategische Marktpositionierung der Unternehmen wider. ZENTES und MORSCHETT bezeichnen diese Entwicklung auch als (logistik-)"intrasektorales Outsourcing":131 Innerhalb des Logistikmarktes ergibt sich dadurch eine stark differenzierte Anbieterlandschaft. Einige Anbieter führen nach wie vor primär operative Aufgaben aus (Frachtführeraufgaben), während andere Anbieter primär Systemintegration betreiben, ohne dabei notwendigerweise selbst und voll umfänglich operativ tätig werden zu müssen.

Einige wichtige Bezeichnungen sollen im Folgenden erläutert und unter Bezugnahme auf die Basistypen klassifiziert werden.

\subsection{Kurier-, Express- und Paketdienstleister}

Kurier-, Express- und Paketdienstleister (KEP-Dienstleister) sind Speditionen, welche sich auf die Organisation von Transporten gewichts- oder volumenmäßig eingegrenzter Gütersendungen spezialisiert haben. Diese Transporte führen sie dann entweder im Selbsteintritt oder mittels eingesetzter Frachtführer durch. Durch die Einschränkung bezüglich der Maße und/oder der Volumina der im Transportsystem zugelassenen Güter wird ein hohes Maß an Standardisierung bzw. Uniformierung der Produktionsabläufe erreicht, so dass der Güterumschlag leicht automatisiert werden kann. ${ }^{132}$ Standardisierung und Automatisierung der Produktionsprozesse wiederum ermöglichen ein Höchstma $ß$ an Qualität und bedingen kosteneffiziente Dienstleistungsproduktion und gleichzeitig kurze Transportzeiten, welche in der Regel auch zuverlässig

Vgl. Freichel (1992), S. 10.

Vgl. Zentes, Morschett (2003), S. 428.

Vgl. Ihde (2001), S. 237.
} 
eingehalten werden können. ${ }^{133}$ Ein wesentlicher Treiber für die Leistungsfähigkeit der KEP-Dienstleister war und ist der Umstand, dass sie schon frühzeitig die Bedeutung von IuK-Technologien für die Verbesserung ihrer Leistungserstellungsprozesse erkannt haben und diese Technologien intensiv nutzen. ${ }^{134}$ Dieses Leistungsbild prädestiniert den KEP-Dienstleister dazu, die Endkundendistribution zu besorgen. ${ }^{135}$

Da der KEP-Markt seiner Sättigungsphase immer näher kommt bzw. als ausgereift gelten kann ${ }^{136}$, sind die KEP-Dienstleister darum bemüht, Innovationsprozesse anzustoßen und ihr traditionelles Leistungsportfolio um Mehrwertdienstleistungen zu erweitern. ${ }^{137}$ GATZKE spricht in diesem Zusammenhang von einem zukünftigen KEAV-Markt (Kurier, Express und Added Value) ${ }^{138} \mathrm{Er}$ identifiziert bzw. prognostiziert fünf Entwicklungsfaktoren, welche das derzeitige und das künftige Bild der KEP-Dienstleister prägen: ${ }^{139}$

- Anhaltende Konsolidierungsprozesse (Fusionen, Übernahmen und Allianzen führen zu zunehmender Marktkonzentration),

- steigende Qualitätsanforderungen (Durch die fortgeschrittene Marktreife des KEP-Marktes sowie die hohe Wettbewerbsintensität avanciert die Leistungsqualität von einer „bloßen“ Kundenanforderung zu einer Markteintrittsbarriere),

- Veränderung der Sendungsstruktur (Die durchschnittliche Sendungsgröße wird aufgrund des zunehmend dezentralisierten und aufgesplitterten Warenbestellverhaltens der Endverbraucher im Zuge der Möglichkeiten, die sich aus dem elektronischen B2C-Handel ergeben, sinken), ${ }^{140}$

- Nachfrage nach Added-Value-Leistungen (KEP-Dienstleister bedienen die Nachfrage nach Zusatzdienstleistungen, mit Hilfe derer die Kunden ihre eigene Logistikkette optimieren können, wie bspw. administrative Leistungen, Lagerhaltung, Inkassoleistungen) sowie

- Nachfrage nach E-Commerce-affinen Produkten und Dienstleistungen.

Vgl. Ihde (2001), S. 237.

Vgl. Manner-Romberg (2001).

Vgl. Weber et al. (2002), S. 31.

Vgl. Klaus (2003), S. 131.

Vgl. Schneider, Siebel (2002), S. 60.

Vgl. Gatzke (2001), S. 236.

Vgl. Gatzke (2001), S. $236 \mathrm{ff}$.

Vgl. dazu auch Schneider, Siebel (2002), S. 61. 
Auch KRUSE betont, dass neben dem sicheren und pünktlichen Transport eines Paketes vor allem die der Distribution vorgeschalteten Mehrwertdienstleistungen, insbesondere im Bereich des klassischen Versandhandels und des E-Commerce, unabdingbar wichtige Angebotsfelder für KEP-Dienstleister sind. ${ }^{141}$ WEBER ET AL. schreiben ihnen zudem den „Aufbau und die Steuerung hoch komplexer, teilweise globaler Distributionsnetzwerke" als ihre Kernkompetenz zu. ${ }^{142}$

\subsection{Integrators}

Bei den Integrators handelt es sich um Speditionen oder KEP-Dienstleister, welche sich auf „weltweite, schnelle und zeitdefinierte Transportleistungen“ spezialisiert haben. ${ }^{143}$ Sie verfolgen dabei die Strategie der totalen Funktionsintegration: sie bieten Haus-zu-Haus-Transporte auf der Basis von physisch und informationstechnisch integrierten Land- und Luftverkehrsnetzen in komplett eigener Regie an, sind hinsichtlich Organisation und Produktion des gesamten logistischen Prozesses der einzige involvierte Partner. ${ }^{144}$ Dabei produzieren sie die Dienstleistung ausschließlich mit unternehmenseigenen Transportmitteln (insb. Flugzeuge, LKWs), Transportgeräten und Infrastrukturen (insb. Flughäfen, Terminals, Depots). ${ }^{145}$ Diese Form der Leistungserstellung bedeutet den Wegfall sämtlicher interorganisatorischer Schnittstellen und aller damit verbundener Probleme. Integrators haben permanenten physischen, steuernden und informationstechnischen (via Sendungsverfolgungssysteme) Zugriff auf die Gütersendungen, da diese sich stets im unternehmerischen Verfügungsbereich befinden. ${ }^{146}$ Bedingt durch die mit der Vorhaltung zahlreicher Infrastrukturkomponenten und physischer Transportmittel sowie -geräte verbundenen Fixkostenintensität der Leistungserstellung haben die Integrators notwendigerweise in erheblichem Umfang Effizienzsuch- und Innovationsprozesse mit dem Ziel einer permanent hohen und gleichmäßigen Auslastung ihrer Transportsysteme sowie ihrer Umschlagseinrichtungen in Gang gesetzt. ${ }^{147}$ Aufgrund ihrer hohen Autorität in zahlreichen logistischen Teilbereichen erscheinen Integrators dazu geeignet, zusätzliche Mehrwertdienstleistungen zur eigentlichen Güterbeförderung anzubieten.

141

142

143

144

145

146

147

Vgl. Kruse (2003), S. 440 f.

Vgl. Weber et al. (2002), S. 31.

Ihde (2001), S. 238.

Vgl. Freichel (1992), S. 30.

Vgl. Aberle (2003a), S. 555 f.; Jaeger, Laudel (2000), S. 298.

Vgl. Aberle (2003a), S. 556; Ihde (2001), S. 238.

Vgl. Ihde (2001), S. $238 \mathrm{f}$. 


\subsection{Kontraktlogistikdienstleister}

Bei Kontraktlogistikdienstleistern handelt es sich um Speditionen, die über ihre traditionelle Vermittlerrolle hinausgehend Logistikdienstleitungen fur ihre Kunden erbringen. In der Regel werden dabei mehrere Basisdienstleistungen wie Transport, Umschlag, Lagerhaltung kundenindividuell miteinander kombiniert und auf der Basis einer längerfristigen Vertragsvereinbarung abgewickelt. ${ }^{148}$ Der Kontraktlogistikdienstleister hat dabei ausdrücklich einen Auftrag zur Planung und Steuerung der vom ihm kundenbezogen individualisierten Leistungskomponenten. ${ }^{149}$ Durch den langfristigen Charakter der Vertragsbeziehung sowie durch das gegenseitige Abhängigkeitsverhältnis aufgrund der beiderseitig in die Partnerschaft eingebrachten (gegebenenfalls irreversiblen) Investitionen erhöht sich die Stabilität der Verlader-DienstleisterBeziehung, zumal sich mit zunehmender Dauer der Beziehung Transaktionskostenersparnisse einstellen können. ${ }^{150}$ Zudem bietet die Übernahme von verladerspezifischen Kontraktlogistikleistungen und die damit notwendigerweise verbundene Integration in die Leistungserstellungsprozesse des Verladers dem Logistikdienstleister die Möglichkeit, aus dem Mehr an geschaffenem Kundennutzen eine Alleinstellungsposition zu generieren, welche ihm eine stabilere Wettbewerbsposition und damit auch vergleichsweise hohe Renditen beschert. ${ }^{\mid 51}$

\subsection{Third-Party-Logistics-Provider und Fourth-Party-Logistics-Provider}

Unter einem Third-Party-Logistics-Provider (3 PL) wird gemeinhin ein Spediteur verstanden, welcher zusätzlich zu seinem ,klassischen“ speditionellen Aufgabenspektrum und entsprechenden Transportleistungen auch Kontraktlogistikleistungen (Lagerund Umschlagsleistungen) anbietet. ${ }^{152}$ Insbesondere bei der Planung und der Steuerung der Supply Chain haben sie sich Kompetenzen angeeignet. ${ }^{153}$ Der 3 PL ist somit in der Lage, dem Verlader als „Logistiksystemanbieter“ ein weitgehend komplettes Logistiksystem anzubieten. ${ }^{154} \mathrm{Er}$ fungiert als Systemintegrator und gestaltet im Range eines Logistikpartners eigenverantwortlich weite Teile der Wertschöpfungskette des

Vgl. Stein (2000), S. 243; Weber et al. (2001), S. $58 \mathrm{f}$.

Vgl. Weber et al. (2002); S. 30.

Vgl. Stein (2000), S. 244.

Vgl. Stein (2000), S. 244.

Vgl. Straube (2001), S. 194 f.; Aberle (2003a), S. 536. Bisweilen wird der Begriff des 3 PL sogar synonym für Speditionen benutzt, allerdings erfolgt die Begriffsverwendung nicht einheitlich. Vgl. Weber et al. (2001), S. 59.

Vgl. Weber et al. (2001), S. 59.

Vgl. Weber et al. (2002), S. 31; Zentes, Morschett (2003), S. 428. 
Kunden. ${ }^{155}$ Entscheidend für die Einordnung als $3 \mathrm{PL}$ ist dabei, dass der betreffende Dienstleister neben Know-how auch spezifische Wirtschafts- und Vermögensgüter (,assets“) wie Transportmittel, Lager- und Umschlagseinrichtungen u. ä. vorhält. ${ }^{156}$

Im Gegensatz dazu gilt der Fourth-Party-Logistics-Provider (4 PL) als... "Integrator, der die Ressourcen, Kapazitäten und Technologien seiner eigenen Organisation mit denen anderer Dienstleiter zusammenführt und managt, um für den Kunden eine vollständige Supply-Chain-Lösung zu entwerfen, zu entwickeln und zu betreiben. “157 Der 4 PL erbringt dabei lediglich Konzeptionierungs- und Koordinationsleistungen, kauft Logistikleistungen ein und fügt diese zu einer Gesamtleistung zusammen, ohne dabei selbst über eigene assets zu verfügen. ${ }^{158} \mathrm{Er}$ führt folglich ein Bündel an komplexen Dienstleistungen anderer Produzenten in für die Kunden individueller Komposition zusammen ${ }^{159}$ und fungiert insofern als „Generalunternehmer" für Logistikleistungen. Er schaltet sich dabei selbst in Planung, Konzeption, Steuerung und Kontrolle der Supply Chain des Kunden ein. ${ }^{160}$

$\mathrm{Zu}$ den Vorteilen des 4-PL-Konzeptes zählen sicherlich die Neutralität des 4 PL bei der Auswahl der eingesetzten Ausführungsunternehmen, seine Prozess- und ITKompetenz sowie seine Kooperationsfähigkeit. ${ }^{161}$ Ferner kann der Einsatz eines 4 PL für den Logistikkunden transaktions- und produktionskostensenkend wirken. ${ }^{162}$ Kritisch angemerkt werden muss jedoch, dass es fraglich ist, ob ein $4 \mathrm{PL}$ ohne speditionelles Hintergrundwissen, ohne die Möglichkeit, bei Bedarf auf eigenes physisches Equipment zurückgreifen zu können und insbesondere ohne den dauerhaften Zugang zu Transportnetzwerken den erforderlichen Qualitätsstandards zu genügen vermag. ${ }^{163}$ Auch die drohende Abhängigkeit von einem einzelnen Dienstleister, der ja im Rahmen seiner Aufgabe ,zusätzliche intime Kenntnisse aller Güter- und Zahlungsströme erhält", wird bisweilen als kritisch angesehen. ${ }^{164}$

Vgl. Baumgarten (2001), S. 19.

Vgl. Aberle (2003a), S. 272.

Weber et al. (2002), S. 93.

Vgl. Aberle (2003a), S. 536.

Vgl. Stabenau (2003), S. 392.

Vgl. Weber et al. (2002), S. 93; Aberle (2003b), S. 284 f.

Vgl. Straube (2001), S. 194.

Dadurch, dass 4 PL mit einer großen Anzahl an Industrie- und Handelsunternehmen zusammenarbeiten, können die Kosten für die Implementierung eines innovativen Logistiksystems über Lernkurveneffekte erheblich gesenkt werden. Vgl. Baumgarten (2001), 21.

Vgl. Zinn (2002), S. 36; Aberle (2003a), S. 536; Aberle (2003b), S. 284.

Aberle (2003b), S. 284. 
Um dem Umstand Rechnung zu tragen, dass der unverzügliche Zugriff auf physische Netzwerke und die entsprechenden assets gleichermaßen wichtig für die Leistungsqualität der Logistikunternehmen ist, wie es die rein koordinativen Leistungen sind, wurde der sog. 3,5 PL als „logistikaktiver Spediteur mit eigenen Assets, der als ausgegliedertes Unternehmen zusätzlich als 4 PL auftritt" ins begriffliche Leben gerufen. ${ }^{165}$ Ein weiteres Konzept aus der Reihe derer, welche als Antwort der asset-basierten 3 PL auf das 4-PL-Konzept zu verstehen sind, ist das des Lead Logistics Providers (LLP). Dieser fungiert als zentraler („Lead“-)Ansprechpartner für den Verlader und bietet zusätzlich zu seinem physischen Netzwerk Steuerungsleistungen an. ${ }^{166}$ Der LLP ist somit als Hybrid von 3 PL und 4 PL zu begreifen, dessen Nimbus der Neutralität bei der Leistungsvergabe (wie ihn der 4 PL inne hat) zwar durch das Einbringen eigener Assets in Frage gestellt werden kann, der aber vielleicht gerade durch die eigene physische logistische Infrastruktur eine höhere Glaubwürdigkeit hinsichtlich seiner Fähigkeit zur Umsetzung konkreter Logistikprojekte ausstrahlt. ${ }^{167}$

Abschließend sei allerdings bemerkt, dass es sich beim 4 PL (noch) um ein hypothetisches Geschäftsmodell handelt; derzeit existiert noch kein Anbieter auf dem deutschen oder dem europäischen Markt, der der Gesamtheit der theoretischen Anforderungen des 4 PL genügen würde. ${ }^{168}$ Dennoch bemerkenswert ist das Konzept des 4 PL jedoch vor allem deshalb, weil es Ausdruck eines Sinneswandels in der Logistikbranche ist: Während in der Vergangenheit die Logistikdienstleister eher passiv, abwartend und auf Verladerwünsche reagierend handelten ${ }^{169}$, treten immer mehr Logistikdienstleister aktiv mit innovativen, wissenschaftsgetriebenen Logistikkonzepten und Geschäftsmodellen am Markt auf - mit Konzepten, die in Richtung der 4 PL, der 3,5 PL oder der LLP gehen. ${ }^{170}$ Insofern ist KLAUS zuzustimmen, welcher die so skizzierten „befreiten und neuen Vertreter der Logistik-Dienstleistungswirtschaft" als gestaltende Elemente bzw. als „Impulsgeber und Enabler für Innovationen“ in vielen Bereichen außerhalb logistischer Systeme apostrophiert. ${ }^{171}$

Vgl. Aberle (2003a), S. 536.

Vgl. Baumgarten, Zadek, Kieffer (2003), S. 28. Vgl. zum Konzept des LLP auch Klaus, Kille (2006), S. 117.

Vgl. Hauptmann (2007), S. 21.

Vgl. Weber et al. (2002), S. 93.

So sind bspw. die Aktivitäten der Spedition in den 80er Jahren und zu Beginn der 90er Jahre des letzten Jahrhunderts zu bewerten.

Vgl. Baumgarten, Zadek, Kieffer (2003), S. 28; Segerer, Benz (2002), S. 24.

Klaus (2003), S. 27. 
Der Vollständigkeit halber sei erwähnt, dass der „,klassische“ Spediteur der vorgestellten Nomenklatur entsprechend bisweilen als 2 PL, der Frachtführer als 1 PL bezeichnet wird. ${ }^{172}$

\subsubsection{Systematisierung von Logistikdienstleistungsunternehmen}

Nachdem eine Systematisierung der Logistikdienstleistungsunternehmen nach einzelnen abgedeckten Funktionsbereichen bereits als nicht durchführbar festgestellt worden ist, soll an dieser Stelle eine alternative Systematisierungsmöglichkeit vorgeschlagen werden.

DRECHSLER unterscheidet mit den Logistiksystemanbietern („Logistics Systems Suppliers"), den Logistikkomponentenanbietern („Logistics Component Companies“) und den nicht-systemgebundenen Anbietern („Non System Oriented Suppliers“) drei Kategorien, in welche die zuvor dargestellten Anbietertypen eingegliedert werden können. ${ }^{173}$ Logistiksystemanbieter sind in der Lage, ein logistisches Gesamtleistungssystem zu erbringen, wobei sie die einzelnen Systemkomponenten selbst erstellen oder von Subunternehmern erstellen lassen. Logistikkomponentenanbieter sind Unternehmen, die lediglich einzelne Komponenten als Bestandteile eines logistischen Gesamtleistungssystems erstellen. Nicht-systemgebundene Anbieter sind Unternehmen, welche lediglich einzelne Logistikkomponenten produzieren, ohne dabei vor dem Hintergrund der Systemintegration operative oder strategische Überlegungen hinsichtlich der Integration der Dienstleistungen in ein logistisches Gesamtleistungssystem anzustellen. Zwischen den drei Anbieterkategorien bestehen intensive wechselseitige Abhängigkeiten:

- Zum einen müssen die Logistiksystemanbieter ggf. auf die Leistungen der Logistikkomponentenanbieter zurückgreifen, wenn sie nicht alle Leistungskomponenten eines Logistiksystems selbst produzieren können oder wollen. ${ }^{174}$

- Logistikkomponentenanbieter wiederum, welche - vor dem Vordringen der systemischen, gesamthaften Logistikkonzeptionen - autonom handelnde Anbieter im Verkehrsmarkt waren, müssen sich nunmehr oftmals mit der Rolle des Subunternehmers begnügen, wenn sie an den Marktpotenzialen der Logistiksys- 
temleistungen partizipieren wollen; einstmals bestehende direkte Geschäftsverbindungen zu Verladern werden durch Verbindungen zu den Logistiksystemanbietern ersetzt. ${ }^{175}$

- Für die nicht-systemgebundenen Anbieter letztlich sind die Marktpotenziale der Logistiksystemleistungen nicht erschließbar, wenn sie keine Netzwerkbzw. Kooperationskompetenz aufbauen und sich zu Logistikkomponentenanbietern weiterentwickeln. Aufgrund der Tatsache, dass mit logistischen Systemen neue, verbesserte Lösungsansätze für die Problemstellungen der Verlader angeboten werden, sind deutliche Nachfragesubstitutionseffekte von den nichtsystemgebundenen Logistikleistungen zu den Systemleistungen wahrscheinlich. Logistiksystemanbieter sowie Logistikkomponentenanbieter als deren Kooperationspartner bzw. Subunternehmer profitieren im Gegensatz zu den nichtsystemgebundenen Anbietern von dieser Entwicklung. Für die nichtsystemgebundenen Anbieter, welche sich nicht weiterentwickeln können oder wollen, verbleibt lediglich die Befriedigung desjenigen Teilbereichs der Nachfrage nach Logistikteilleistungen, welcher losgelöst von einem umfassenden Logistiksystem anfällt - desjenigen Leistungsumfanges also, welcher vor Etablierung moderner Logistikkonzeptionen noch nahezu das gesamte Marktpotenzial des Gesamt-Verkehrsmarktes ausgemacht hat.

Die DRECHSLERsche Systematik lässt, wie in Abbildung 2-18 dargestellt, folgende Einordnung der Basis- und der Mischformen von Logistikunternehmen zu. Die Pfeile sollen denkbare Evolutionspfade einzelner Unternehmenstypen vom nichtsystemorientierten Anbieter bzw. Logistikkomponentenanbieter in Richtung eines Logistiksystemanbieters andeuten: 

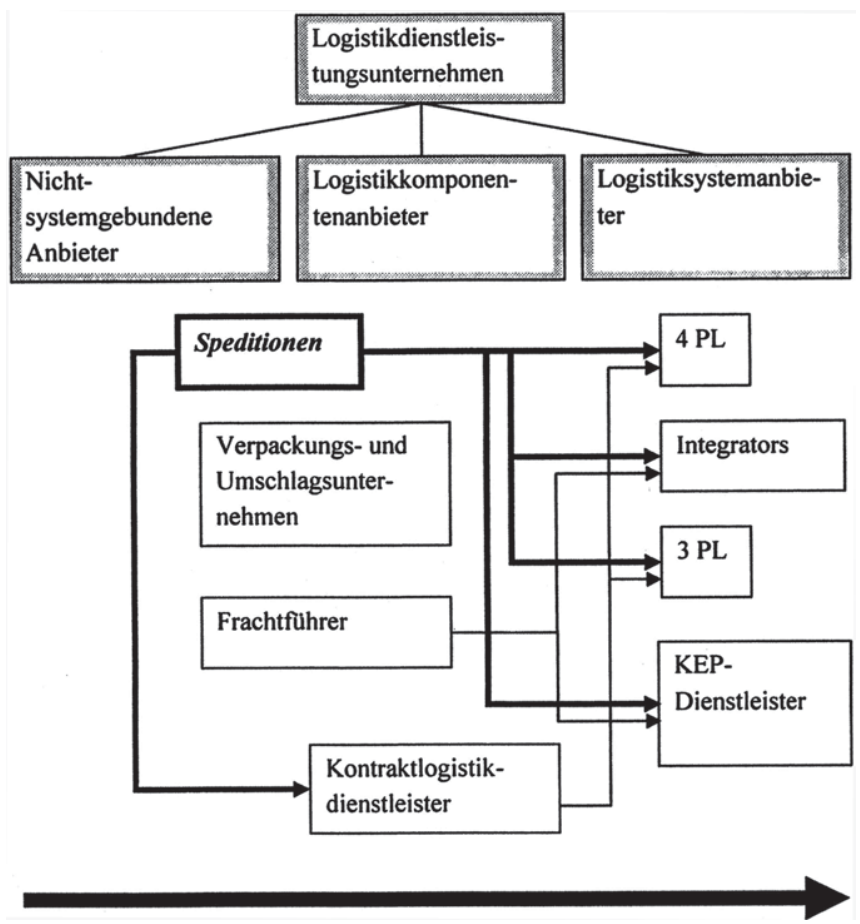

zunehmender Systemcharakter der Logistikleistung

\section{Abbildung 2-18: Systematisierung von Logistikunternehmen}

Quelle: Eigene Darstellung

\subsubsection{Strategische Stoßrichtungen und Trends}

\subsection{Prinzipielle Überlegungen}

Die Erörterungen zu Typologisierung und Systematisierung der Logistikdienstleistungsunternehmen lassen nachstehende Folgerungen bezüglich strategischer Stoßrichtungen der Marktakteure zu: 
- Zum einen ist bei den Anbietern ein Trend auf der produktionsprozessbezogenen Ebene in Richtung der Standardisierung und Automatisierung von bestimmten, dafür geeigneten netzwerkbasierten Logistikleistungskomponenten absehbar. Beispiele für diesen Trend lassen sich bei Speditionen, KEPDienstleistern und bei den Integrators finden, welche in ihren Transportnetzwerken ggf. Art und Abmessungen der Transportgüter, benutzte Transportmittel, physische Prozessabläufe und den Austausch transportrelevanter Informationen standardisieren und insbesondere die im Zuge des Transportes anfallenden Umschlagsprozesse mittels aufwendiger Sortieranlagen sowie mittels informations- und kommunikationstechnischer Infrastruktur (bspw. Barcodescannung) automatisieren. Dies führt zu höherer Prozesssicherheit, verbunden mit der Reduzierung der Fehleranfälligkeit und Verbesserung der Leistungsfähigkeit (bspw. durch Laufzeitverkürzung).

- Gleichzeitig ist ein Trend auf der kundenbezogenen Ebene hin zur Individualisierung des Leistungsangebotes entsprechend der Wünsche der Verladerschaft zu konstatieren. Hier sind es vor allem Speditionen, Kontraktdienstleister, 3 PL und $4 \mathrm{PL}$, welche sich um den Aufbau von charakteristischem, branchen- und kundenbezogenem Fach-Know-how bemühen, um dadurch kundenspezifischen Anforderungen besser zu genügen. In diesem Zusammenhang bemühen sich diese Anbieter auch um die Erweiterung von methodischer Kompetenz im Bereich des Prozess- und Kooperationsmanagements. ${ }^{176}$

Logistische Leistungserstellung vollzieht sich dann mit einem Maximum an Transaktions- und Produktionskosteneffizienz, wenn sich der Logistikdienstleister für sein Angebot aus einem Baukasten möglichst standardisierter Leistungskomponenten bedienen kann, um daraus modular eine komplexe und aus Kundensicht einzigartige Systemleistung zu erstellen. ${ }^{177}$ Dieses Ziel der standardbasierten, kundenbezogenen Individualisierung kann entweder realisiert werden

Der Aufbau von Methoden- und Projektmanagementkompetenz, sowohl was das eingesetzte Humankapital als auch was die eingesetzten Analyse- und Kalkulationstools anbetriff, ist vornehmlich in mittelständischen Speditionen/Logistikunternehmen vonnöten, wenn sie erfolgreich zum Kontraktlogistiker avancieren wollen. Vgl. Tripp (2004), S. 55. Vgl. dazu auch Segerer, Benz (2002), S. 24. 
- über die Strategie der Verwirklichung eines kundenunabhängigen funktionalen Spezialisierungsprozesses, wobei in der Regel die reine Raumüberwindungsfunktion (Transport- und Verkehrsleistungen) im Zentrum der Geschäftsaktivităten steht $(\rightarrow$ transportorientierte sog. „Netzdienstleister“, bspw. ein Frachtfürer, welcher zum KEP-Dienstleister oder gar zum Integrator avanciert),

- oder aber uber die Strategie der Verwirklichung eines an Mehrwertdienstleistungen ausgerichteten, kundenorientierten Differenzierungsprozesses des Dienstleistungsspektrums, wobei die organisierenden, die Logistikkette steuernden Funktionen vorherrschen $(\rightarrow$ speditionsorientierte sog. „SCMLogistikdienstleister", bspw. eine Spedition, die zum Kontraktlogistikdienstleister, zum 3 PL oder gar zum 4 PL avanciert). ${ }^{178}$

Standardbasierte, kundenbezogene Individualisierung kann folglich aus zwei Richtungen kommend erreicht werden: (1) Verfolgt ein Anbieter die Strategie einer funktionalen Spezialisierung, so ist er bestrebt, durch Standardisierung und Automatisierung ein stabiles, engmaschiges und kundenunabhängiges $\mathrm{Ba}$ sis-Verkehrsnetzwerk bereitzustellen, welches ohne konkreten Kundenbezug

Vgl. zur Einteilung von Logistikunternehmen in "transportorientiert" einerseits und „speditionsorientiert" andererseits auch BAG (2005b), S. 3 f. Zur Einteilung der Logistikdienstleister in „Netzdienstleister“, „SCM-Logistikdienstleister" und deren Kombination, die sog. „Vollsortimenter" vgl. Lieb, Lange (2003), S. 451 ff. Auch Boecker betrachtet das Geschäftsmodell des „funktionalen Spezialisten“ (bspw. den reinen Carrier, Terminalbetreiber) und des „Full-ServiceProviders“ (Systemanbieter) neben dem „Branchenspezialisten“ als die im Logistikdienstleistungsmarkt führenden Geschäftsmodelle. Vgl. Boecker (2002), S. 29. Dabei beruft er sich auf eine von der Personal- und Unternehmensberatung Wagener \& Herbst Management Consultants $\mathrm{GmbH}$ in Zusammenarbeit mit Prof. Dr. Rainer Lasch, Lehrstuhl fur Logistik an der TU Dresden durchgeführte Delphi-Studie.

Rümenapp, welcher Musterformen möglicher strategischer Konfigurationen von Logistikunternehmen untersucht hat, identifiziert in diesem Zusammenhang fünf Konfigurationen: der „Standard-Komponentenbetreiber" wickelt ständig wiederkehrende Routineaufgaben ab, produziert standardisierte logistische Einzelleistungen mit dem Fokus auf deren möglichst effiziente Abwicklung. Der „Versorgungskettenarchitekt“ hingegen tritt als Innovator auf und entwickelt mit dem Fokus auf Innovation neue Lösungsoptionen für logistische Problemstellungen. Der „Komplexitätsreduzierer" integriert logistische Einzelleistungen zu kundenindividuellen Leistungsbündeln, der „Funktionsspezialist“ befasst sich mit Sondersituationen eines Versorgungskettenabschnitts, die er mit routinisierten, standardisierten Problemlösungsverfahren und -mechanismen berechenbarer macht. Der „Systemanbieter“ letztlich stellt eine Hybridform zwischen dem „Versorgungskettenarchitekt" und dem „Komplexitätsreduzierer" dar, die den mitunter konfligierenden Anforderungen beider Konfigurationen Rechnung tragen muss. Der „Systemanbieter“ kann als Institution charakterisiert werden, welche Innovationsaufgaben und komplexe Routineaufgaben miteinander verbinden muss. Vgl. dazu Rümenapp (2002). 
möglichst viele Quellen und Senken von Gütertransporten ohne bzw. allenfalls mit einem Minimum an Abweichungen von Standardprozessen abbilden kann. Eine aus Verladersicht komplexe Anforderung (bspw. mehrteilige, multimodale Transporte mit atypischen Laufzeitanforderungen in unkonventionelle Destinationen) kann dann in den Leistungsstandard eines Logistikunternehmens integriert und dementsprechend effizient abgewickelt werden. Individualisierung über Standardisierung funktioniert folglich bei Logistikleistungskomponenten, deren effiziente Produktion sich auf das Vorhandensein eines möglichst stabilen, engmaschigen und umfassenden physischen und informationstechnischen Netzwerkes stützen. Dies betrifft folglich Logistikleistungskomponenten, welche die physische Raumüberwindung zum Gegenstand haben. (2) Verfolgt ein Anbieter eine Differenzierungsstrategie, so setzt er sich aktiv mit den Bedürfnissen des einzelnen Logistikkunden auseinander und richtet seine Leistungen individuell auf diesen aus. Dieses Know-how ist vornehmlich dispositiver Natur und befasst sich mit Spezifika bei der Steuerung der unternehmensübergreifenden Logistikkette des Kunden. Der Logistikdienstleister erwirbt in diesem $\mathrm{Zu}$ sammenhang Wissen über Eckpunkte und Rahmendaten des Material- und/oder Güterflusses beim Kunden. Seine Aufgabe umfasst das Eruieren und Ergreifen passender Maßnahmen zur optimalen Gestaltung dieses Material- und/oder Güterflusses. Teil dieser Aufgabe ist in der Regel auch, eine raum-zeitliche Transformation der logistischen Güter des Kunden vorzunehmen, d. h. sie unter Einhaltung zeitlicher Restriktionen zu transportieren. Um diese physische Raumüberwindung effizient abzuwickeln, braucht der Logistikdienstleister wiederum ein physisches und informationstechnisches Transportnetzwerk. Hält er kein eigenes Netzwerk vor, so benötigt er zwingend den Zugang zu einem externen physischen Netzwerk. Individualisierung über Differenzierung funktioniert folglich über den Erwerb kundenspezifischen Wissens zum Zwecke der Übernahme komplexer logistischer Leistungsbündel. Beinhaltet dieses Leistungsbündel jedoch Elemente der raum-zeitlichen Gütertransformation, dann sind Existenz und Zugriffsmöglichkeit auf ein den Anforderungen entsprechendes physisches Basis-Transportnetzwerk sowie das Vorhandensein von entsprechender Netzwerkkompetenz wiederum - ähnlich wie bei (1) - entscheidende Determinanten der Leistungsfähigkeit der logistischen Gesamtleistung.

Es zeigt sich, dass gleichzeitig sowohl Standardisierungs-/Automatisierungsaspekte als auch Individualisierungsaspekte in die beiden Strategien des funktionalen Spezialisie- 
rungsprozesses und des Differenzierungsprozesses einfließen und dadurch einen Beitrag zum Ziel der standardbasierten, kundenbezogenen Individualisierung leisten. Im Falle der Strategie des funktionalen Spezialisierungsprozesses erfolgt die Annäherung an die standardbasierte, kundenbezogene Individualisierung kundenunabhängig aus Richtung der produktionsprozessbezogenen Ebene, im Falle der Strategie des Differenzierungsprozesses erfolgt die Annäherung aus Richtung der kundenbezogen Ebene. Bei beiden Strategien allerdings ergänzen sich Standardisierungs- und Individualisierungsaspekte wechselseitig und verbessern die Qualität der Logistikleistung. Standardisierung und Individualisierung sind folglich sich positiv verstärkende Trends im Logistikmarkt. In jedem Fall führt die standardbasierte, kundenbezogene Individualisierung der Logistikleistung aufgrund der zahlreichen Kombinationsmöglichkeiten verschiedener Logistikleistungskomponenten zu einem hohen Grad an Produktdifferenzierung innerhalb von Logistiksystemen. ${ }^{179}$

In diesem Zusammenhang erlangt das Thema Outsourcing - die Überlegung also, ob Logistikleistungen selbst erstellt oder fremdvergeben werden - auch innerhalb des Logistikdienstleistungsmarktes eine immer größere Relevanz. Während die Outsourcing- bzw. Make-or-Buy-Debatte in der Vergangenheit nämlich in erster Linie auf die Frage fokussiert war, ob Industrie- und Handelsunternehmen ihre Logistikbedarfe durch Eigenproduktion decken, oder Logistikleistungen von Logistikdienstleistern beziehen ${ }^{180}$, so greifen in der modernen Logistik derartige Make-or-BuyFragestellungen vermehrt auch in den Reihen der Logistikdienstleistungsunternehmen selbst Platz. Ihre Vorläufer hatten solche Fragestellungen bereits zu Regulierungszeiten, als Verladerunternehmen, welche Transportleistungen fremdbezogen haben, einen Spediteur zwischenschalteten, um Transaktionskosten zu reduzieren. ${ }^{181}$ Der Spediteur wiederum traf die Entscheidung, welche Leistungskomponenten er selbst produziert und welche er einkauft. Er betrieb somit schon damals eine Form von Outsourcing. ${ }^{182}$ Als Folge und verfeinerte Weiterentwicklung derartiger „klassischer" SpediteurModelle sind heutzutage mehrstufige, hierarchische Strukturen der Zusammenarbeit innerhalb der Systeme der Logistikdienstleister zur Erfüllung von Logistikaufgaben bei Verladern gängige Praxis. ${ }^{183}$ An der Spitze solcher Strukturen stehen in aller Regel Logistiksystemanbieter mit planender, koordinierender und integrierender Funktion, aber ohne bzw. mit geringem Einsatz an eigenen assets (bspw. ein 4 PL oder

Vgl. Drechsler (1988), S. 225.

Vgl. Rennings (1992), S. 13.

Vgl. ausführlich Unterabschnitt 2.4.5.1.3.

Vgl. Pfohl, Large (1992), S. 33. 
ein Lead Logistics Provider). Dieser Führungsdienstleister fungiert als zentraler Ansprechpartner für den Verlader und reduziert damit dessen Transaktionsaufwendungen für Auswahl, Steuerung und Überwachung der externen Logistikdienstleister. ${ }^{184}$ Unter diesem Führungsdienstleister befindet sich nachfolgend ein „kaskadenartiger“ Unterbau an ausführenden Logistikdienstleistern, welche als Subunternehmen (Logistikkomponentenanbieter wie bspw. eine Spedition, ein Kontraktdienstleister, ein KEP-Dienstleister) bzw. als Sub-Subunternehmen (bspw. ein Frachtführer, ein Lagerhalter) in zunehmendem $\mathrm{Maße}$ asset-basierte (Teil-)Leistungen erbringen. ${ }^{185}$ Dabei ist es wichtig, dass die Subunternehmer kooperations- bzw. netzwerkfähig sind, um den Erfolg des Gesamtlogistiksystems zu gewährleisten. ${ }^{186}$ Damit wird auch deutlich, dass auf dem Logistikdienstleistungsmarkt neben den verladenden Unternehmen aus Industrie und Handel, welche immer die Endnachfrager von Logistikleistungen sind, auch die Logistikdienstleister selbst in die Rolle der Nachfrager nach Logistikleistungen wechseln und somit im konkreten Fall Anbieter und/oder Nachfrager logistischer Leistungskomponenten sein können.

Damit wird die Spedition nochmals als diejenige zentrale Institution im Logistikmarkt hervorgehoben, welche aufgrund ihres ursprünglichen, logistikkomponentenorientierten Leistungsportfolios und aufgrund der im Laufe ihrer langen Historie erworbenen Kompetenz als integrativ wirkender Intermediär das Entwicklungspotenzial dazu besitzt, zum Kontraktlogistikdienstleister, zum 3 PL, zum KEP-Dienstleister, zum Integrator oder gar zum 4 PL zu avancieren. Sie versetzt sich damit in die Lage, den logistischen Kerngedanken einer gesamthaften, systemischen, unternehmensübergreifenden, netzwerkbezogenen Optimierung von Güterflusssystemen marktfähig anzubieten.

Die hier vorgestellten strategischen Handlungsalternativen zeigen sich prinzipiell in allen Teilmärkten des Gesamt-Logistikmarktes. Besonders evident sind sie allerdings in den Teilmärkten 6 „Nationaler allgemeiner Stückgutverkehr“ und 11 „KEP - Paket-, echte Kurier- und spezialisierte Expressdienste“ $(\rightarrow$ Standardisierung und Automatisierung von netzwerkbasierten Logistikleistungskomponenten), sowie in den Teil-

183

184

Vgl. Klaus (2003), S. 29.

Vgl. Eisenkopf et al. (2002), S. 44. Die dahinter stehende Taktik der Verlader, die Anzahl der direkt mit ihnen in Verbindung tretenden Logistikdienstleister möglichst zu reduzieren, soll dazu beitragen, die Transaktions- und Produktionskostenvorteile durch die Komplexitätsreduktion im eigenen Leistungserstellungsprozess, welche das Outsourcing von Leistungen an Logistikdienstleister bewirkt hat, nicht mit transaktionskostenbegründenden Schnittstellen zu zahlreichen Outsourcingpartnern wieder aufzuzehren.

Vgl. Klaus (2003), S. $28 \mathrm{f}$. 
märkten 7 „Konsumgüterdistribution und Konsumgüterkontraktlogistik“ und 8 „Industrielle Kontraktlogistik, insbesondere industrielle Produktionsversorgung, Ersatzteildistribution und sonstige business-to-business Kontraktlogistik" ( $\rightarrow$ kundenbezogene Individualisierung des Leistungsangebotes). Im Folgenden werden die beiden grundsätzlichen Strategieoptionen der Marktakteure exemplarisch unter Bezugnahme auf diese „prototypischen“" Teilmärkte veranschaulicht.

\subsection{Standardisierung und Automatisierung von netzwerkbasierten Logistik- leistungskomponenten}

\section{Nationaler allgemeiner Stückgutmarkt}

In diesem Teilmarkt werden Stückguttransporte abgewickelt. Als Stückgüter gelten im Allgemeinen kleingewichtige Sendungen individuell etikettierter, zusammenladefähiger Trocken- und Stapelgüter mit einem Sendungsgewicht von 0 bis $2.500 \mathrm{~kg}$. Derartige Sendungen sind angesichts komplexer arbeits- und standortteilig organisierter Gestaltungsformen industrieller Fertigung und angesichts der damit einhergehenden komplexen zwischenbetrieblichen Güterverkehre mit überwiegend geringer Losgröße von großer ökonomischer Relevanz. Der Stückgutmarkt ist in seiner Eigenschaft als Kernbereich der Logistikleistung daher folgerichtig als unentbehrliche Infrastruktur eines modernen Industrielandes zu bezeichnen. ${ }^{187}$

Der allgemeine Stückgutbereich wickelt in der Regel Sendungen ab einem Gewicht von ca. $30 \mathrm{~kg}$ ab, Sendungen mit kleinerem Gewicht fallen in den KEP-Markt. Stückgutverkehrssysteme sind sog. "offene“ Logistikleistungssysteme, welche zu jedem Zeitpunkt die notwendige physische, administrative und informationstechnische Infrastruktur vorhalten müssen, welche die Logistikunternehmen dazu befähigt, eine im Vorhinein schwer planbare Menge - von Transportaufträgen für ein Vielzahl heterogener Verlader zeitgleich abzuwickeln. ${ }^{188}$ Derartige Stückgutverkehrssysteme werden auf institutioneller Ebene entweder im Rahmen großer mikrologistischer Systeme (große, integrierte Konzern-Logistikdienstleister, Großspeditionen) oder aber im Rahmen horizontaler metalogistischer Systeme (System-Kooperationsverbünde

\footnotetext{
186 Vgl. Eisenkopf et al. (2002), S. 44.

187 Vgl. Klaus (2003), S. 102.

188 Vgl. Tripp (2003), S. 5.
} 
mittelständischer Speditionen) besorgt. Der Stückgut-Leistungserstellungsprozess kann idealtypisch in die folgenden Abwicklungsphasen aufgeteilt werden: ${ }^{189}$

- Regionale Abholung beim Versender („Pick-Up“),

- relationsorientierte Sortierung in einem Ausgangsdepot,

- ein- oder zweistufiger (über ein „Hub“, „Zwischenumschlag“) gebündelter Fernverkehrstransportvorgang,

- touren- oder empfängerorientierte weitere Sortierung im Empfangsdepot sowie

- gebündelte regionale Endauslieferung mit Verteilerfahrzeugen beim Empfänger („Delivery“).

Als kritische Erfolgsfaktoren im Stückgutmarkt können die lückenlose Flächendeckung des Netzwerks sowie die Produktion und Überwachung durchgängig hoher Servicequalität genannt werden. ${ }^{190}$ Servicequalität im Stückgutmarkt wird in Form zuverlässiger Laufzeiten - marktüblich ist ein Werktag von Abholung bis Zustellung gemessen, zur Überwachung der Laufzeit sowie des Sendungsstatus wird in zunehmendem Maße auf barcode-gestützte elektronische Sendungsverfolgungssysteme („Tracking und Tracing“) zurückgegriffen. ${ }^{191}$ Die Betreiber der Stückgutverkehrssysteme stehen, angesichts der Fixkostenintensität des Netzwerkes und der daraus resultierenden Auslastungssensitivität der Unternehmensgewinne, in intensivem Preisund Mengenwettbewerb um Marktanteile, welcher sich bereits in einer hohen Teilmarktkonzentration niederschlägt. ${ }^{192}$ Dieser Wettbewerb zwingt die Anbieter, permanent neue Möglichkeiten zur Produktivitätsverbesserung und zur Kostenreduktion im Leistungserstellungsprozess zu sondieren. Diesbezüglich Erfolg versprechende Ansatzpunkte sind

\footnotetext{
189 Vgl. Klaus (2003), S. 102.

190 Vgl. Klaus (2003), S. 103.

191 Vgl. Tripp (2003), S. 14.

192 Vgl. Tripp (2003), S. 14.
} 
- die weitere Standardisierung der Abläufe,

- die Optimierung administrativer Abwicklungsprozesse sowie

- die Realisierung möglicher Größeneffekte. ${ }^{193}$

Unternehmerische Bemühungen zur Standardisierung umfassen grundsätzlich alle Formen der Vereinheitlichung von Objekten. ${ }^{194}$ Im Stückgutmarkt konzentrieren sich solche Bemühungen in erster Linie auf Maßnahmen zur Vereinheitlichung der im System transportierten logistischen Objekte mittels der Eliminierung von im System nicht effizient handelbarer Güter (Langgut, nicht stapelbare oder palettisierbare Güter). ${ }^{195}$ Ziel der Stückgutverkehrssystemanbieter ist es, ihre Leistungserstellungssysteme über diese Standardisierungsstrategie an den durchschnittlichen Anforderungen und Erwartungen einer möglichst großen Anzahl von Nachfragern mit möglichst homogenen Produktpräferenzen auszurichten. ${ }^{196}$ Dabei schafft die relative Homogenität der gehandelten Güter auch Spielräume für einen höheren logistischen Automatisierungsgrad (bspw. im Bereich der notwendigen Güterumschlagsprozesse durch die Verwendung gleichartiger Verladehilfsmittel) und dadurch wiederum Möglichkeiten für die Realisierung von Skaleneffekten bei Wachstum der abgewickelten Menge im System. ${ }^{197}$ Auch im Bereich der administrativen Abwicklungsprozesse eröffnet die Durchsetzung von systemweiten - vor allem informationstechnischen - Standards Optimierungspotenzial. Derartige Standards zur Datengenerierung und zum systemweiten Datenaustausch leisten insbesondere einen Beitrag zur Steigerung der Qualität bzw. zur Reduzierung des Aufwandes für (1) systemweite Bearbeitung und Abwicklung der transportbegleitenden Dokumente und Informationen (Tendenz zur sog. „papierlosen Spedition“) sowie für (2) die Fakturierungsprozesse innerhalb der Kooperationsverbünde (sog. „Clearingsysteme“). ${ }^{198}$ Standardisierung operativer und administrativer Abläufe in Stückgutverkehrssystemen erlaubt die effiziente Abwicklung großer Transportvolumina und leistet somit der Durchsetzung von unternehmerischen Mengenstrategien Vorschub, mit denen möglichst umfangreiche Größeneffekte im System erzielt werden sollen. Größeneffekte werden in der ökonomischen Theorie folgendermaßen umrissen:

Vgl. Klaus (2003), S. 104.

Vgl. Delfmann (2000c), S. 431.

Vgl. Klaus (2003), S. 104.

Vgl. Delfmann (2000c), S. 432.

Vgl. Delfmann (2000c), S. 432.

Vgl. Tripp (2003), S. 15.
} 


\section{Exkurs: Größeneffekte}

Die Diskussion um Größeneffekte in der ökonomischen Literatur ist durch uneinheitliche Begriffsverwendung und mangelnde inhaltliche Abgrenzung einzelner Größeneffekte zueinander gekennzeichnet, was wohl auf die beträchtlichen Überschneidungen zwischen Einzeleffekten zurückzuführen ist. ${ }^{199}$ Eine zweckmäßige Systematik zeigt möglicherweise die folgende Abbildung 2-19.

Generell sind Economies of Scale (potenzielle) Stückkostenvorteile, die große Produktionseinheiten gegenüber kleineren haben. ${ }^{200}$ Ein bewährtes produktions- und kostentheoretisch fundiertes Konstrukt zu Darstellung und Analyse von statischen Economies of Scale ist die langfristige Durchschnittskostenkurve (LDK-Kurve). Der Begriff der "langfristigen Durchschnittskostenkurve" ist in diesem Zusammenhang jedoch explizit nicht Ausdruck eines bestimmten Zeitbezuges. Lediglich die Berücksichtigung der Tatsache, dass diejenigen Technologien, welche die langfristigen Durchschnittskosten realisieren, von Irreversibilitäten gekennzeichnet sein können und damit die LDK-Kurve in Abhängigkeit zu einer Anlagen-Mindestnutzungsdauer gebracht werden kann, bewirkt einen allenfalls mittelbaren Zeitbezug des LDKKonzeptes. ${ }^{201}$ Definitionsgemäß handelt es sich bei der LDK-Kurve um eine hypothetische Plankostenkurve. Diese zeigt für alternative Produktionskapazitäten die minimalen Durchschnitts- bzw. Stückkosten auf, welche unter der Bedingung optimaler Kapazitätsauslastung bei gleichzeitigem Einsatz der für die jeweilige Produktionskapazität effektivsten Produktionstechnologie realisiert werden können. ${ }^{202}$ Da sich das technische Wissen im Zeitablauf jedoch ändert, kann eine LDK-Kurve immer nur für einen bestimmten, eng abgegrenzten Zeitraum definiert werden. Da die LDK-Kurve technischen Fortschritt ausschließt, handelt es sich beim LDK-Konzept um ein statisches Konzept, bei den aus diesem Konzept abgeleiteten Economies of Scale folglich um statische Economies of Scale. ${ }^{203}$

Vgl. Henning et al. (2003), S. 400.

Vgl. Kruse, Berger (1996), S. 215.

Vgl. Kruse (1985), S. 24.

Vgl. Kaufer (1980), S. 59 f.; Monopolkommission (1986), Tz. 592.

Vgl. Kaufer (1980), S. 60.
} 


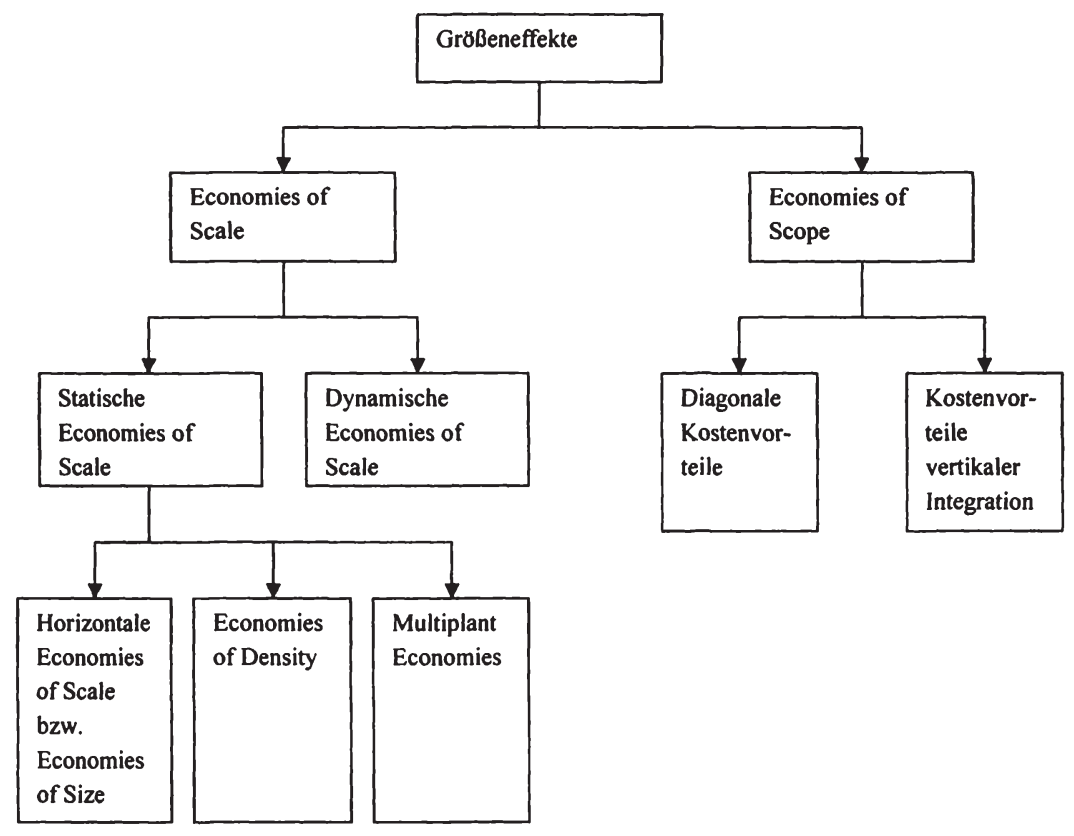

Abbildung 2-19: Größeneffekte

Quelle: Eigene Darstellung

Horizontale Economies of Scale bzw. Economies of Size in Reinform liegen dann vor, wenn im relevanten Output-Bereich die LDK-Kurve einen fallenden Verlauf aufweist, d. h. wenn die LDK bei zunehmender Produktionsmenge respektive zunehmender Betriebsgröße abnehmen. ${ }^{204}$ Im Ein-Güter-Fall gilt dann:

LDK $(\mathrm{P})>\operatorname{LDK}(\mathrm{P}+1)$ mit $\mathrm{P}=$ Produktionsmenge bzw. Produktionskapazität.

Abzugrenzen sind horizontale Economies of Scale von der Kostensubadditivität. Subadditivität in der Kostenfunktion liegt dann vor, wenn die Produktion einer gegebenen Produktionsmenge $\mathrm{Y}$ durch ein Unternehmen zu geringeren Kosten

Vgl. Henning et al. (2003), S. 401; Kruse (1985), S. 24. 
möglich ist, als wenn $\mathrm{Y}$ durch zwei oder mehr Unternehmen produziert würde. ${ }^{205}$ Folglich gilt für die Beziehung zwischen Economies of Scale und Subadditivität: Economies of Scale implizieren immer Subadditivität, der Umkehrschluss allerdings ist nicht zulässig.

Economies of Density (Dichtevorteile) stellen einen Spezialfall der Economies of Scale dar und bezeichnen diejenigen Stückkostenvorteile, die mit steigender Produktions- oder Liefermenge in ein bestimmtes Gebiet oder aber mit zunehmender Nachfragemenge auf einer bestimmten Relation realisiert werden können. ${ }^{206}$ Unter Muliplant Economies können diejenigen Kostenvorteile verstanden werden, die sich daraus ergeben, dass ein Unternehmen die gesamte Produktionsmenge nicht in einem, sondern in mehreren Betrieben produziert. ${ }^{207}$

Dynamische Economies of Scale sind Ausdruck des Umstandes, dass im Zeitablauf - selbst bei ansonsten vorgegebenen Produktionstechnologien - bspw. durch Lernen oder durch zunehmende Erfahrung bei bzw. in der Durchführung einzelner Tätigkeiten die Arbeitsproduktivität ansteigt. ${ }^{208}$ Diese dynamischen Lern- und/oder Erfahrungskurveneffekte manifestieren sich als eine Art „ungebundener technischer Fortschritt ${ }^{\text {‘209 }}$ in sinkenden Durchschnitts- bzw. Stückkosten bei Zunahme der historischen kumulierten Gesamtausbringungsmenge. ${ }^{210}$ Dynamische Economies of Scale verschieben - im Gegensatz zu den statischen Economies of Scale - die zugehörige Durchschnitts- bzw. Stückkostenkurve. ${ }^{211}$ Sie sind unabhängig von der Betriebsgröße.

Bei Economies of Scope handelt es sich um Verbundvorteile, die aus Kostenkomplementaritäten bei der Mehrproduktproduktion unterschiedlicher Produkte in demselben Betrieb bzw. Unternehmen auftreten können. ${ }^{212}$ Die Kosten für zwei Produkte X und Y sind bei der Produktion durch ein diversifiziertes Unternehmen geringer als bei der Produktion in zwei Einproduktunternehmen. ${ }^{213}$ Die Bedingung für das Vorliegen von Economies of Scope in der allgemeinen Form von diagonalen Kostenvorteilen kann im Zwei-Güter-Fall wie folgt formuliert werden:

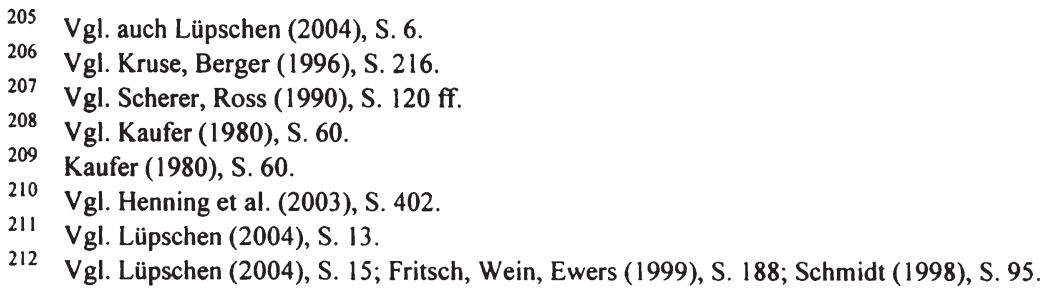


TK $(X+Y)<T K(X, 0)+T K(0, Y)$ mit TK = Totalkosten und $X, Y=$ unterschiedliche Produkte

Kostenvorteile der vertikalen Integration können dann auftreten, wenn es sich bei den beiden betrachteten Produkten X und Y um Produkte handelt, welche in einem Input-Output-Verhältnis zueinander stehen, es sich also um vor- bzw. nachgelagerte Produktionsstufen handelt. Kostenvorteile der vertikalen Integration stellen folglich einen Sonderfall der Economies of Scope dar. ${ }^{214}$ Im Grundsatz handelt es sich bei der Fragestellung nach dem Vorliegen derartiger Kostenvorteile um das originär institutionenökonomische Kalkül, ob die Gesamtkosten bei Bereitstellung des Gutes/der Leistung über den Markt und damit bei dezentraler marktlicher Koordination oder aber bei integrierter Produktion der Güter/Leistungen innerhalb eines Unternehmens und damit bei hierarchischer Koordination geringer sind. Eine zentrale Entscheidungsgröße im Rahmen dieser Debatte stellen die Transaktionskosten dar. ${ }^{215}$

\section{Exkurs Ende}

Die geplante Realisierung von Größeneffekten, bzw. umfassender - unter Einbeziehung nutzenbasierter Wirkungskomponenten - formuliert: Netzeffekten, stellt folglich den zentralen Treiber von Vernetzungsaktivitäten dar. ${ }^{216}$ KLOSTER hat sich intensiv mit Netzeffekten i. S. v. kosten- und nutzenbasierten Größen- und Dichteeffekten in netzbasierten Logistiksystemen auseinandergesetzt. Er identifiziert die

- kostenbasierten Betriebsgrößennetzeffekte (Supply Side Network Economies of Size) und die Betriebsdichtenetzeffekte (Supply Side Network Economies of Density), welche zu einem subadditiven Kostenanstieg im integrierten System führen sowie

- die nutzenbasierten Netzgrößennetzeffekte (Demand Side Network Economies of Size) und die Netzdichtenetzeffekte (Demand Side Network Economies of lungen zur Konzentration vgl. auch Schmidt, Röhrich (1992), S. 180.

216 Vgl. Hoffmann, Stölzle (2005), S. 2. 
Density), welche zu einem superadditiven Nutzenanstieg im integrierten System führen

als mögliche relevante Basiseffekte. ${ }^{217}$ Betriebsgrößennetzeffekte im Stückgutmarkt ergeben sich bspw. durch Stückkostendegression aufgrund der Investition in eine verbesserte Produktionstechnologie (größere Verkehrsmittel oder Automatisierung des Güterumschlages). ${ }^{218}$ Betriebsdichtenetzeffekte hingegen resultieren aus der besseren Auslastung des bestehenden Netzwerkes, bspw. durch die bessere Auslastung der bestehenden Verkehrsmittel oder der bestehenden Umschlagskapazitäten. ${ }^{219}$ NetzgröBennetzeffekte beruhen auf der höheren Attraktivität, welche ein Netzwerk für die Nachfrager durch die Zusammenarbeit/den Zusammenschluss mehrerer Netzwerke hat, bspw. durch die Möglichkeit der Einschleusung von Gütern aus einem Stückgutnetzwerk in ein anderes (mehrseitige Beschickung der Stückgutnetzwerke). ${ }^{220}$ Netzdichtenetzeffekte letztlich ergeben sich, wenn Verkehrsverbindungen zwischen Knotenpunkten innerhalb eines bestehenden Netzwerks durch effizientere Organisation der Produktion verbessert werden können, bspw. durch höhere Verkehrsfrequenzen, höhere Zuverlässigkeit der Leistungserbringung, kürzere Umschlagsdauer oder spätere Abholzeiten beim Verlader. ${ }^{221}$

Es zeigt sich, dass Standardisierungs- und Automatisierungsmaßnahmen im operativen und im administrativen Leistungserstellungsprozess die Basis für alle vier hier dargestellten Netzeffekte sein können. Ebenso zeigt sich aber auch, dass die kostenund nutzenbasierten Effekte, welche sich in den Stückgutnetzen ergeben, nicht immer zwangsläufig in dieselbe Richtung wirken müssen, sondern sehr wohl auch konfligieren können. ${ }^{222}$ Kostenbezogene, auslastungsoptimierende Stückgutverkehrsorganisation durch die zeitliche Bündelung von Transporten bspw. kann unter Umständen negative Auswirkungen auf die Transportfrequenzen und Abholzeiten bei bestimmten

Vgl. Kloster (2002), S. $92 \mathrm{ff}$.

218 Vgl. Kloster (2002), S. 96. Vgl. zum Vorliegen von Economies of Size im Transport- und Umschlagsbereich auch Henning et al. (2003), S. $406 \mathrm{f}$. Vgl. zum Vorliegen von Economies of Size im Transportbereich auch Lüpschen (2004), S. 40 f.

Vgl. Kloster (2002), S. 96. Vgl. zum Vorliegen von Economies of Density im Transport- und Umschlagsbereich auch Henning et al. (2003), S. 404 ff. Vgl. zum Vorliegen kostenbasierter Economies of Density im Transportbereich auch Lüpschen (2004), S. 41 ff.

Vgl. Tripp (2003), S. 14

Vgl. Kloster (2002), S. 96.

Vgl. Kloster (2002), S. 97. 
Verladern haben, so dass für diese der Nutzwert des Netzwerkes sinkt. ${ }^{223}$ Umgekehrt führt verladernutzenbezogene Abholzeitenoptimierung unter Umständen zu einer kostentreibenden Verlangsamung bzw. Störung der Produktionsabläufe. Eine mögliche Lösungsstrategie besteht in der räumlichen Bündelung von Transporten (Betriebsdichtenetzeffekt) durch Ladungs- und/oder Empfängerakquisition, um Transportströme zu konsolidieren. ${ }^{224}$ So kann unter Umständen der Widerspruch zwischen der Realisierung von kosten- und nutzenbasierten Netzeffekten abgeschwächt werden. Daher gilt es bei der Organisation von Stückgutverkehrssystemen auf der Basis von Netzeffekten im konkreten Einzelfall, Wirkungsintensität, Wirkungsrichtung und unternehmerische bewertete Relevanz der verschiedenen Basiseffekte gegeneinander abzuwägen und das System unter Berücksichtigung der dargestellten Wechselwirkungen zwischen den Effekten zu optimieren. ${ }^{225}$

\section{KEP - Paket-, echte Kurier- und spezialisierte Expressdienste}

Kernleistungsbereich des KEP-Marktes ist die Durchführung von Paketfrachtleistungen durch nationale und internationale Paketdienstleister. ${ }^{226}$ In diesem wichtigsten Teilmarktsegment des KEP-Marktes werden Pakete oberhalb des durch das Postmonopol für Briefe geschützten Gewichtsbereichs bis zu einer Gewichtsobergrenze von ca. $31 \mathrm{~kg}$ transportiert. Das Prozessmuster der Leistungserstellung entspricht im Wesentlichen dem der Stückgut-Leistungserstellung. Die Paketfrachtleistungen allerdings werden in höchst standardisierten, vertikal integrierten Paketfrachtsystemen erbracht und zeichnen sich insbesondere durch sehr präzise Begrenzungen der Maße und Gewichte der im System zugelassenen Packstücke sowie durch hoch standardisierte und hoch automatisierte Leistungserstellungsprozesse aus. ${ }^{227}$ Für die Etablierung und die Entwicklung des deutschen Marktes für Paketfrachtleistungen war das Leistungsangebot der großen, international operierenden Integrators richtungweisend. ${ }^{228}$

Wichtige kritische Erfolgsfaktoren im KEP-Teilsegment der netzbasierten Paketfrachtleistungen sind (1) die Bedienungsdichte, d. h. das Sendungsaufkommen pro Versen-

224 Vgl. Henning et al. (2003), S. 407. Vgl. zum Verhältnis von Economies of Scope zu kostenbasierten Economies of Density Lüpschen (2004), S. $45 \mathrm{f}$.

225

Vgl. ähnlich Henning et al. (2003). S. 407.

Vgl. Klaus, Müller-Steinfahrt (2000), S. 132.

Vgl. Klaus (2003), S. 127.

Vgl. Freichel (1992), S. 30. 
der und insbesondere pro Empfänger (sog. „Stoppfaktor"), (2) die durchgängige Leistungsqualität, d. h. die Einhaltung von Auslieferzeiten (marktüblich ist die Zustellung am Vormittag des der Abholung folgenden Werktags) und die Transparenz der Leistungssysteme für die Kunden („Tracking und Tracing“) sowie (3) die Personalkosten, welche trotz des hohen Automatisierungsgrades in den Bereichen Sortierung/Güterumschlag und Pick-Up/Delivery sehr hoch sind. ${ }^{229}$ Um den Personalkostenblock zu reduzieren, vergeben viele Betreiber der Paketfrachtsysteme - wie die der Stückgutverkehrssysteme auch - die Pick-Up- und Delivery-Transporte an Subunternehmer, diese wiederum teilweise an Sub-Subunternehmer. Es bilden sich Ausprägungsformen der weiter oben zitierten mehrstufigen, hierarchischen Strukturen der Zusammenarbeit innerhalb der Systeme der Logistikdienstleister heraus - vertikale metalogistische Systeme. Ansonsten gilt, dass auch im KEP-Markt vor allem die standard- und automatisierungsbasierte Optimierung der Leistungserstellungsprozesse zur Realisierung möglicher Größen- und Netzeffekte die zentrale strategische Option ist. ${ }^{230}$ Die extrem homogenen Güterstrukturen, die automatisierten Förder-, Sortierund Umschlagsanlagen sowie die umfassende Informations- und Kommunikationsinfrastruktur ermöglichen den massenhaften Durchfluss gleichartiger, berechenbarer Güterströme durch die standardisierten Beförderungssysteme. Die Leistungserstellungssysteme der Paketdienstleister können daher auf hohe Aufkommensmengen ausgerichtet werden und trotzdem eine gleich bleibend hohe Leistungsqualität erzeugen. ${ }^{231}$ Es zeigt sich, dass auch im Bereich der Paketfrachtleistungen die kostenbasierten Betriebsgrößennetzeffekte (Einsatz größerer Verkehrsmittel sowie Automatisierung von Sortier- und Umschlagsprozessen) und die Betriebsdichtenetzeffekte (Erhöhung des Auslastungsgrades der Verkehrsmittel, Erhöhung der Bedienungsdichte) sowie die nutzenbasierten Netzdichtenetzeffekte (höhere Zuverlässigkeit der Leistungserbringung, höhere Verkehrsfrequenz) wirksam werden.

\subsection{Individualisierung des Leistungsangebotes}

In den beiden Teilmärkten „Konsumgüterdistribution und Konsumgüterkontraktlogistik“ sowie „Industrielle Kontraktlogistik, insbesondere industrielle Produktionsversorgung, Ersatzteildistribution und sonstige business-to-business Kontraktlogistik“ werden Kontraktlogistikgeschäfte abgewickelt. In der Definition von KLAUS fallen unter den Kontraktlogistikbegriff sämtliche Aktivitäten, welche auf einer engen, 
individuell zwischen Logistikdienstleister und Verlader gestalteten Beziehung gründen, in welcher die Integration mehrerer logistischer Funktionen Gegenstand eines längerfristig angelegten vertraglichen Arrangements ist und deren Geschäftsvolumen einen Mindestumsatz von ca. 0,5 - 1 Mio. $€$ p. a. übersteigt. ${ }^{232}$ Der Kontraktlogistikbegriff umfasst somit definitionsgemäß nicht die standardisierten Leistungen des Stückgutmarktes oder des KEP-Marktes und grenzt ihn von diesen ab. Gleichermaßen macht die Definition das immense Wachstumspotenzial der Kontraktlogistikmärkte deutlich, da die größeren Industrie- und Handelsunternehmen Outsourcing-Projekte in aller Regel in Form bilateral individualisierter, längerfristig vertraglich abgesicherter Leistungspaketkomplexe mit entsprechend großen Umsatzvolumina verwirklichen. ${ }^{233}$

Kritische Erfolgsfaktoren im Konsumgüterbereich sind (1) eine möglichst nationale Flächendeckung des Lager-, Umschlags- und LKW-Warenverteilsystems, (2) eine hohe Kompetenz auf den Gebieten der Informationstechnologie sowie der ITImplementierung, insbesondere für das Betreiben von Warehouse-Management- und integrierten Auftragsabwicklungssystemen, (3) die Fähigkeit seitens der Logistikunternehmen zur informationstechnischen Integration der Logistik in die ERP- und SCM-Systeme der Auftraggeber und (4) eine hohe Qualität von Personal und Equipment. ${ }^{234}$ Als kritische Erfolgsfaktoren im Industriebereich kommen prinzipiell die gleichen Komponenten in Betracht, wobei hier der Aspekt der nationalen Flächendeckung in der Distribution naturgemäß eine nachrangige Rolle spielt, da industrielle Kontraktlogistikprojekte in der Regel gebietsweise oder bezogen auf die nähere Umgebung um den Standort des Aufraggebers vergeben werden. ${ }^{235}$ Was jedoch ITKompetenz und Fähigkeit zur IT-Integration anbelangt, so gilt das zum Konsumgüterbereich Ausgefuhrte uneingeschränkt. Zudem wird von den Logistikunternehmen in zunehmendem Maße die Übernahme von originär nicht-logistischen Leistungen (bspw. Behälter-Management, Montagearbeiten, Kundendienstfunktionen) verlangt. ${ }^{236}$

Mittlerweile hat sich die „durchschnittliche kontraktlogistische Qualifikation“ der Logistikdienstleistungsbranche offensichtlich soweit gesteigert, dass der Wettbewerb um ausgeschriebene Kontraktlogistikprojekte zunehmend intensiver geführt wird. Ein weiterer zentraler Erfolgsfaktor für Akquisition und Durchführung von Kontraktlogis-

Vgl. Helmke (2006), S. 48.

Vgl. Klaus (2007), S. 94; Klaus (2003), S. 107.

Vgl. Klaus (2003), S. 107.

Vgl. Tripp (2004), S. 17 f. Vgl ähnlich auch Aberle (2003b), S. 281 f.

Vgl. Klaus (2003), S. 118.

Vgl. Tripp (2004), S. 24.
} 
tikprojekten, welcher in Zukunft daher wohl noch mehr an Bedeutung gewinnen dürfte, ist die Fähigkeit und die Bereitschaft des Kontraktlogistikers, eigeninitiativ konstruktive Beiträge zur Optimierung von Aufbau- und Prozessorganisation des Auftraggebers und zur Erschließung von Synergiepotenzialen in die Partnerschaft einzubringen. ${ }^{237}$ Dazu ist ein tiefes Eindringen der Logistikunternehmen in die spezifischen materiellen, informations- und kommunikationstechnischen und organisatorischen Problemstellungen sowie in die logistischen und nicht-logistischen Leistungserstellungsbedingungen der Auftraggeber vonnöten. ${ }^{238}$ Insofern geht die Tendenz auf den Kontraktlogistikmärkten in zunehmendem Maße in Richtung Individualisierung. Kontraktlogistikleistungen sind dementsprechend gleichbedeutend mit (einzel-) auftragsbezogenen, individualisierten Systemleistungen, welche sich aus einer Vielzahl unterschiedlicher logistischer und nicht-logistischer Leistungskomponenten zusammensetzen. ${ }^{239}$ Auf institutioneller Ebene werden sie innerhalb längerfristig angelegter vertikaler metalogistischer Systeme erbracht.

\subsubsection{Zusammenfassung}

Am Anfang der Analyse von Angebot und Nachfrage nach Logistikleistungen stand die Abgrenzung des relevanten Marktes. Zur methodischen Verankerung der sachlichen Marktabgrenzung wurde auf die systemtheoretisch fundierte Grundsystematik der gesamtwirtschaftlichen Sektorenstruktur zurückgegriffen, welche in Abschnitt 2.2 erarbeitet wurde. Gemäß dieser Grundsystematik kann der Logistikmarkt als mögliche Form der Operationalisierung derjenigen Prozesse aufgefasst werden, welche innerhalb des gesamtwirtschaftlichen Transfersektors ablaufen. Dabei präsentierte sich der Logistikmarkt als komplexes, heterogenes Gebilde mit einer Vielzahl von unterscheidbaren Marktsegmenten und erwies sich damit folgerichtig als Spiegelbild der bereits im Abschnitt 2.2 erörterten materiellen und formal-begrifflichen Komplexität der Logistikleistung. Als grundlegend wichtiger, sowohl für den GesamtLogistikmarkt als auch für die einzelnen Teilmarktsegmente relevanter Gesichtspunkt wurde im Zuge der Marktabgrenzung die Entscheidungsfrage nach Eigenerstellung oder Fremdbezug von Logistikleistungen aufgeworfen. Angesichts seiner Bedeutsamkeit wurde dieser institutionelle Aspekt zu einem späteren Zeitpunkt im Rahmen der Darstellung des Marktvolumens, bei der daran anschließenden Konzentrationsanalyse

Vgl. Klaus (2003), S. 118.

Vgl. Tripp (2004), S. 25.

Vgl. Delfmann (2000c), S. 432 f.
} 
sowie bei der Analyse der Marktakteure und Marktstrategien aufgegriffen. Hierbei wurde insbesondere der Frage nach dem Anteilsverhältnis zwischen auf Logistikdienstleister übertragenen Logistikleistungen einerseits und von Verladern eigenproduzierten Logistikleistungen andererseits weiter nachgegangen. Die hohe Eigenkomplexität der Logistikmaterie und die daraus resultierende Komplexität des Logistikmarktgebildes in sachlicher Hinsicht hat auch spürbare Auswirkungen für das Procedere der räumlichen Abgrenzung des Logistikmarktes. Wenn hier im Ergebnis der deutsche Markt als relevanter Marktbereich festgestellt wird, so geschieht dies im Wissen, dass es sich dabei um einen Kompromiss handelt und dass diese Marktgrenze im Falle einer separaten Einzelbetrachtung bestimmter Teilmärkte und Akteursgruppen $u$. U. deutlich nach innen, in Richtung eines Regional- oder gar Lokalmarktes, oder aber nach außen, in Richtung eines europäischen oder gar Weltmarktes verschoben werden müsste. Für die Zwecke dieser Arbeit ist das Ergebnis der räumlichen Marktabgrenzung insofern aufschlussreich, als es die Vielgestaltigkeit und Komplexität der Zusammenhänge in und zwischen den sachlichen Teilmärkten mit deren räumlichen Implikationen verknüpft und in Beziehung zu den verschiedenen Marktakteursgruppen setzt.

An die Marktabgrenzung anschließend erfolgte zunächst eine Operationalisierung des Logistikbegriffs mit dem Ziel, ihn einer Messung zugänglich zu machen und damit das Logistikmarktvolumen zu quantifizieren. In diesem Kontext musste zunächst eine äußerst inkonsistente und problematische Datenlage konstatiert werden, welche jegliche Form von Messvorhaben im Bereich der Logistikmarktgrößen zu einem schwierigen Unterfangen macht. Mit Augenmerk auf die Datenproblematik wurden für die Zwecke dieser Arbeit mit den Begriffen der TUL-Logistik und der Koordinationslogistik nach KLAUS und MÜLLER-STEINFAHRT eine enger und eine weiter gefasste messbare Interpretation eingeführt. Diese beiden Begriffe resp. die sich dahinter verbergenden Marktdatenerhebungen und Marktdatenschätzungen bildeten dann die Grundlage für die Bestimmung des Gesamtmarktvolumens und der Teilmarktvolumina sowie für die anschließende Konzentrationsanalyse.

Was das Gesamt-Logistikmarktvolumen betrifft, so ergab sich aus der Analyse der Daten von KLAUS und MÜLLER-STEINFAHRT ein seit 1998 andauerndes Marktwachstum. Ferner konnte ein steigender Outsourcinganteil konstatiert werden, wobei das Outsourcing, den Gesamtmarkt betrachtet, bei den über die Definition der TULLogistikleistungen hinausgehenden betriebs- und produktionsinternen Logistikleistungen generell weniger ausgeprägt zu sein scheint als im Bereich der TUL-Leistungen. Getrennt nach Marktsegmenten betrachtet weisen die netzgebundenen Teilmärkte mit 
Fokus auf TUL-Leistungen die höchsten Outsourcinganteile auf. Die niedrigsten Outsourcinganteile sind entsprechend bei den Teilmärkten mit verladerindividuellem Anforderungsprofil hinsichtlich des einzubringenden Know-hows und des notwendigen Equipments zu beobachten. Der Fokus liegt hier auf Leistungskomponenten, welche inhaltlich über die TUL-Leistungen hinausgehen. Das in diesen zuletzt genannten Teilmärkten noch $\mathrm{zu}$ erschließende Outsourcingpotenzial ist für die Dynamik der Logistikmarktentwicklung deshalb von besonderer Wichtigkeit, weil es (1) wertmäßig außerordentlich hoch ist und sich (2) auf Wachstumsmärkten auftut, während die sich fast vollständig in Dienstleisterhand befindlichen Teilmärkte schon in einer Phase der Marktreife bzw. -stagnation operieren.

Die anschließende Konzentrationsanalyse wies für den deutschen GesamtLogistikmarkt insgesamt zunächst eine stabile, mäßig hohe absolute horizontale Konzentration aus, welche allerdings zwischen den einzelnen Teilmärkten stark variiert. Einige Teilmärkte sind sehr hoch konzentriert und bewegen sich an der Schwelle zu wettbewerbsgefährdenden Marktstrukturen, andere Teilmärkte wiederum sind nur mäßig bis schwach konzentriert. Auch die relative horizontale Konzentration scheint in einzelnen Teilmärkten ein spürbar hohes Niveau zu erreichen, während sie in anderen Teilmärkten geringer ausfällt. Ähnliche Resultate ergaben sich bei der Analyse der vertikalen/diagonalen Konzentration. Als das wesentliche Ergebnis der Konzentrationsanalyse kann festgehalten werden, dass die Anbieterlandschaft im Logistikmarkt kein homogenes, sondern ein sehr uneinheitliches Gebilde darstellt, welches sich durch die parallele Existenz

- von großen, mehrbetrieblich aufgestellten Konzern- oder konzernähnlichen Unternehmen und einbetrieblich strukturierten, kleinen und mittelständischen Unternehmen sowie

- von mehrstufigen bzw. diversifizierten Mehrproduktunternehmen und einstufigen Einproduktunternehmen

auszeichnet, wobei die einzelnen Marktakteursgruppen bei der Leistungserstellung offensichtlich über mehr oder minder überdauernde, institutionalisierte Leistungsbeziehungen - oftmals in der Form von Unternehmer-Subunternehmer-Beziehungen miteinander verflochten sind. Die Ergebnisse der Konzentrationsanalyse implizieren die Notwendigkeit, die verschiedenen Marktakteursgruppen und deren marktstrategische Ausrichtungen zu untersuchen. 
Der anschließende Teil des Abschnitts befasste sich dann folgerichtig mit diesem Themenkomplex. Ausgangspunkt war zunächst die Erörterung von Möglichkeiten zu Typologisierung und Systematisierung von Logistikunternehmen. Ausgehend von der These, dass die im Einzelnen von ihnen erbrachten logistischen Dienstleistungsfunktionen für sich allein genommen nicht als Merkmale ausreichen, um Logistikdienstleister adäquat voneinander abzugrenzen, wurde für die Typologisierung von Logistikunternehmen folgende Konstruktion gewählt: Zunächst wurden idealtypische Erscheinungsformen in der Gestalt von Basistypen aufgezeigt, bei welchen in der Regel eine bestimmte Dienstleistungsfunktion dominiert. Diese Basistypen beziehen ihre institutionelle Verankerung aus der vormals politisch-regulierungstheoretisch tradierten Vorstellung von Arbeitsteilung innerhalb der Logistikwirtschaft. Die Basistypen sind jedoch nicht lediglich ein theoretisches Gedankenspiel, sondern sie sind auch heute noch Bestandteil der ökonomischen Realität und insbesondere deshalb von wirtschaftspraktischer Relevanz, weil sie in den einschlägigen Gesetzestexten verankert sind. Entsprechend müssen auch die den Basistypen zuzuordnenden vertraglichen Basisarrangements (Frachtverträge, Lagerverträge, Speditionsverträge) als wichtige formal-juristische Grundbedingungen für die institutionelle Koordination im Logistikmarkt Beachtung finden. Auf Basis der Idealtypen wurden realtypische Erscheinungsformen als Mischformen entwickelt. Diese Mischformen zeichnen sich vor allem dadurch aus, dass sie logistische Dienstleistungsfunktionen zu flexiblen und wandelbaren Funktionenbündeln kombinieren, welche nachfrageadäquat weiterentwickelt und in Logistiksystemen zusammengefügt werden. Eben diese Befähigung der Logistikunternehmen, einzelne Leistungsfunktionen zu Systemleistungen zusammenzufügen bzw. als Leistungskomponenten in Systemleistungen einzuspeisen, wurde als Kriterium zur Systematisierung der Logistikunternehmen herangezogen. Mit Logistiksystemanbietern, Logistikkomponentenanbietern und nicht-systemgebundenen Anbietern wurden drei Kategorien benannt, welche sich hinsichtlich des Systemcharakters ihrer erbrachten Leistungen signifikant unterscheiden. Die zuvor diskutierten Basistypen und Mischformen wurden den drei Kategorien zugeordnet, wodurch der Bogen zwischen Typologisierung und Systematisierung der Logistikunternehmen geschlossen wurde.

Die Erörterungen zu Typologisierung und Systematisierung lassen nachstehende Ableitungen hinsichtlich der Marktstrategien zu. Zunächst wurden zwei grundsätzliche strategische Trends identifiziert: Zum einen vollzieht sich ein Entwicklungstrend auf der produktionsprozessbezogenen Ebene in Richtung der Standardisierung und Automatisierung von netzwerkbasierten Leistungskomponenten. Zum anderen ist ein Entwicklungsprozess auf der kundenbezogenen Ebene in Richtung der Individualisie- 
rung des Dienstleistungsangebotes zu konstatieren. Die Leistungsproduktion ist für die Logistikunternehmen dann mit maximaler Effizienz realisierbar, wenn sie auf möglichst standardisierte Leistungskomponenten zurückgreifen können, um aus diesen modular eine komplexe und aus Kundenperspektive einzigartige Systemleistung zu erstellen. Dieses Ansinnen wurde als standardbasierte, kundenbezogene Individualisierung bezeichnet.

Standardbasierte, kundenbezogene Individualisierung wiederum kann über die beiden Strategien eines funktionalen Spezialisierungsprozesses oder eines Differenzierungsprozesses verwirklicht werden, wobei sich erstere kundenunabhängig aus Richtung der produktionsprozessbezogenen Ebene, letztere aus Richtung der kundenbezogen Ebene an das Thema der standardbasierten, kundenbezogenen Individualisierung annähert. In beide Strategien fließen gleichzeitig sowohl Standardisierungs- bzw. Automatisierungsaspekte als auch Individualisierungsaspekte ein, welche sich wechselseitig ergänzen und daher als sich positiv verstärkende Trends im Logistikmarkt bezeichnet werden können. Durch das Zusammenspiel standardisierender/automatisierender und individualisierender/differenzierender Momente und angesichts der sich dadurch ergebenden Möglichkeiten, Leistungskomponenten zu kombinieren, führt die standardbasierte, kundenbezogene Individualisierung zu einem hohen Produktdifferenzierungsgrad innerhalb von Logistiksystemen.

Auch im Kontext der Analyse der Marktstrategien erweist sich die Fragestellung nach der institutionellen Ausgestaltung des arbeitsteiligen Zusammenwirkens zwischen den Akteuren auf dem Logistikmarkt als relevanter Aspekt. Dies betrifft sowohl die Arbeitsteilung zwischen Logistikunternehmen und verladenden Unternehmen aus Industrie und Handel als auch die Arbeitsteilung innerhalb der Gruppe der Logistikunternehmen. Was die institutionelle Verankerung der leistungsmäßigen Beziehungsverflechtungen zwischen Logistikunternehmen zur Erfüllung von Logistikaufgaben für Velader betrifft, so haben sich in Verfeinerung und Weiterentwicklung klassischer Spediteurs-Modelle mehrstufige, hierarchische Strukturen der Zusammenarbeit innerhalb der Systeme der Logistikunternehmen herausgebildet. Derartige institutionelle Formationen sind in aller Regel durch ein kooperatives Zusammenwirken innerhalb von Logistikunternehmenskaskaden gekennzeichnet, an deren Spitze Logistiksystemanbieter steuernde Führungsfunktionen ohne oder mit geringem Einsatz eigener assets wahrnehmen und weitere Logistikunternehmen in nachgeordneter Subunternehmer- oder Sub-Subunternehmerposition zunehmend asset-basierte Ausführungsfunktionen übernehmen. Integrationsfähigkeit sowie Kooperations- bzw. Netzwerkfähigkeit sind dementsprechend für den Erfolg des Gesamtlogistiksystems 
unabdingbar wichtige Komponenten des Kompetenzprofils der am Logistiksystem beteiligten Logistikunternehmen. 


\subsection{Koordination von Angebot und Nachfrage nach Logistikleistungen}

\subsubsection{Vorbemerkungen}

In diesem letzten Teil der Marktanalyse werden zentrale Aspekte der Leistungskoordination auf dem Logistikmarkt zusammenfassend dargestellt. Die tatsächliche Ausgestaltung der Leistungskoordination ist dabei Ausdruck des Zusammen- und Wechselwirkens von Angebot und Nachfrage nach Logistikleistungen unter Zugrundelegung der geltenden Rahmenbedingungen; sie ist das Resultat der Art und Weise, wie die Transaktionsbeziehungen zwischen den Anbietern und Nachfragern organisiert sind.' Angesichts des unternehmensübergreifenden, systembindenden und -koppelnden Charakters der Logistikkonzeption scheint für die Frage nach der Organisation der Transaktionsbeziehungen im Logistikmarkt und damit nach der Leistungskoordination insbesondere die entsprechende institutionelle Verankerung der Leistungserstellung von zentraler Relevanz. ${ }^{2}$ Diese Einsicht führt wieder zurück zur Notwendigkeit, die Frage nach den Prinzipien und den Bestimmungsgründen für Existenz, Auswahl und Umgestaltung bestimmter institutioneller Arrangements zwischen den Anbietern und Nachfragern nach Logistikleistungen innerhalb von Logistiksystemen zu stellen und zu beantworten. Dazu werden im folgenden Abschnitt 2.5 die bislang in der Marktanalyse erarbeiteten koordinationsrelevanten Fakten zu einer Gesamtschau zusammengeführt. Damit verbunden erfolgt eine Abschätzung der Vorteilhaftigkeit einzelner institutioneller Abwicklungsalternativen zur Koordination in Logistiksystemen unter den jeweils geltenden Bedingungen (Unterabschnitte 2.5.2 und 2.5.3). Eine Zusammenfassung beschließt den Abschnitt (Unterabschnitt 2.5.4).

\subsubsection{Eigenerstellung oder Fremdbezug von Logistikleistungen als Grundfrage- stellung}

Grundlegend für die institutionelle Organisation von Logistiksystemen bzw. für die Leistungskoordination im Logistikmarkt ist zunächst die Frage nach Gestaltung und Optimierung der individuellen logistischen Leistungstiefe, also dem Grad der Einbindung von Logistikprozessen in den Organisationsrahmen des eigenen Unternehmens. ${ }^{3}$ Hierzu sieht sich jedes Unternehmen vor die beiden grundsätzlichen

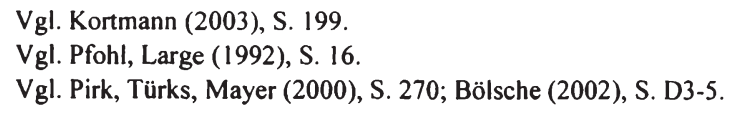

Vgl. Kortmann (2003), S. 199.

Vgl. Pfohl, Large (1992), S. 16.

Vgl. Pirk, Türks, Mayer (2000), S. 270; Bölsche (2002), S. D3-5. 
Alternativen gestellt, Logistikleistungen selbst $\mathrm{zu}$ produzieren oder sie einzukaufen (sog. Make-or-Buy-Entscheidung). Diese Fragestellung des „Make or Buy“ ist im Logistikmarkt gleich in zweifacher Hinsicht relevant. Zum einen stellt sie sich den Industrie- und Handelsunternehmen, die zu entscheiden haben, ob und in welchem Ausmaß Logistikleistungskomponenten innerhalb der Unternehmensgrenzen durch eigene mikrologistische (Sub-)Systeme (bspw. Logistikabteilungen) produziert oder am Markt von Logistikunternehmen eingekauft werden. Zum anderen haben auch die Logistikunternehmen ihrerseits zu entscheiden, welche Logistikleistungskomponenten sie selbst erstellen und welche sie von anderen Logistikunternehmen beziehen. Daraus erhellt, dass prinzipiell jeder Akteur auf dem Logistikmarkt fallweise als Anbieter oder Nachfrager von Logistikleistungen auftreten kann.

Die organisatorische Optimierung der logistischen Leistungstiefe soll einen langfristigen Beitrag zum Unternehmenserfolg leisten. Wird im Rahmen eines Make-or-BuyEntscheidungsprozesses die Veränderung der logistischen Leistungstiefe erwogen, $d$. h. wird möglicherweise Outsourcing (Verringerung der logistischen Leistungstiefe durch Fremdvergabe von Logistikleistungen an Dienstleister) oder Insourcing (Erhöhung der logistischen Leistungstiefe durch Eingliederung von Logistikleistungen) betrieben, so sollte damit im Ergebnis eine strategische Nutzensteigerung im Logistiksystem der Wertschöpfungskette des/der Entscheider/s und damit eine nachhaltige Steigerung des Unternehmenserfolges verbunden sein. ${ }^{4}$ Dabei können strategische Nutzensteigerungen auch als Ausdruck realisierter Synergiepotenziale interpretiert werden, welche sich auf Basis diverser Bündelungseffekte ergeben. Beim Outsourcing begründet die Bündelung von gleichartigen logistischen (Teil-)Leistungen für mehrere Leistungsnehmer externe Synergien aus Sicht des Outsourcenden, beim Insourcing fuhrt die Bündelung verschiedenartiger logistischer und nichtlogistischer (Teil-)Leistungen auf einen Leistungsnehmer zur Ausnutzung von internen Synergien aus Sicht des Insourcenden. ${ }^{5}$ Potenziale zu möglichen Nutzensteigerungen/Synergien können aus unterschiedlichen Perspektiven hergeleitet werden:

- Sie ergeben sich bspw. aus der vergleichenden Gegenüberstellung von Produktionskosten bei Eigenerstellung und Beschaffungskosten bei Fremdbezug. ${ }^{6}$ Externe Synergien ergeben sich bei einer kostenorientierten Gestaltung der lo-

Vgl. Pirk, Türks, Mayer (2000), S. 270 f.

Vgl. Pirk, Türks, Mayer (2000), S. 271.

Vgl. Rennings (1992), S. 28. 
gistischen Leistungstiefe bspw. aufgrund branchenbezogener Arbitragevorteile (Lohnkostenunterschiede zwischen verschiednen Branchen), durch eine Verlagerung des Auslastungsrisikos auf einen anderen Wertschöpfungspartner oder durch eine Partizipation am Rationalisierungspotenzial des Wertschöpfungspartners (Volumen-, Lern- oder Spezialisierungseffekte). ${ }^{?}$

- Eine weitere wesentliche Perspektive, welcher in der Vergangenheit sowohl in der ökonomischen Literatur als auch in den unternehmerischen Entscheidungsfindungsprozessen vergleichsweise wenig Beachtung geschenkt worden ist, ist die Transaktionskostenperspektive. ${ }^{8}$ Doch gerade aus dem Vergleich der anfallenden Transaktionskosten bei Eigenerstellung und bei Fremdbezug können zusätzliche wichtige nutzenrelevante Anhaltspunkte für Make-or-BuyEntscheidungen gewonnen werden. ${ }^{9}$ Zwar ist eine genaue Trennung zwischen Produktions- bzw. Beschaffungskosten auf der einen und Transaktionskosten auf der anderen Seite oftmals nicht möglich, jedoch zählt für die Entscheidung pro oder contra Eigenerstellung bzw. Fremdbezug ohnedies nur der Gesamtkostenvergleich, d. h. die Summe der Produktions- und Transaktionskosten bei Eigenerstellung auf der einen gegenüber der Summe der Beschaffungs- und der Transaktionskosten bei Fremdbezug auf der anderen Seite. ${ }^{10}$ Welche Kostenkomponenten dabei im Einzelnen nun den Produktions-/Beschaffungskosten und welche den Transaktionskosten zugerechnet werden, ist nur von sekundärer Bedeutung. Viel wichtiger ist der absolute Erkenntniszugewinn, den die Transaktionskostenperspektive für Make-or-Buy-Entscheidungsprozesse bietet, indem sie mit den spezifischen Eigenschaften der in Rede stehenden Transaktionen, den Verhaltenscharakteristika der Transaktionspartner sowie den Rahmenbedingungen, unter denen sich das Transaktionsvorhaben abspielt gänzlich neue Argumente in den Entscheidungsfindungsprozess einbringt und dadurch die Güte der Entscheidung potenziell verbessert. Relativierend muss allerdings hinzugefügt werden, dass Transaktionskosten schwer beschreib- und quantifizierbar sind und daher tendenziell eher in Form einer qualitativen UrsacheWirkungs-Analyse einen Beitrag zu den Effizienzüberlegungen im Rahmen von Make-Or-Buy-Entscheidungsprozessen leisten. ${ }^{\prime \prime}$

Vgl. Bölsche (2002), S. D3-2.

Vgl. Fonger (1992), S. 69.

Vgl. Rennings (1992), S. 28.

Vgl. Rennings (1992), S. 29.

Vgl. Freichel (1992), S. 52. 
- Ferner kann die Frage nach der Nutzensteigerung von Veränderungen der Logistikleistungstiefe aus der Qualitäts- (Nutzensteigerung durch Erhöhung der Leistungsqualität im Logistiksystem) oder der Umsatzperspektive (Nutzensteigerung durch Umsatzsteigerung) betrachtet werden. ${ }^{12}$ Was die Qualitätsperspektive betrifft, so ist die Bewertung alternativer logistischer Leistungstiefen vor dem Hintergrund der Frage vorzunehmen, welche Alternative dem primären Sachziel der logistischen Leistungserstellung, nämlich der Sicherung der logistischen Qualitätsanforderung, am Besten entspricht. ${ }^{13}$ Vorgenommen werden kann eine solche Bewertung bspw. anhand eines Qualitätskostenvergleiches. Im Rahmen strategischer Make-or-Buy-Entscheidungen sind dabei insbesondere die (den einzelnen Alternativen direkt zuordenbare) antizipierbaren strategischen Fehlerfolgekosten relevant, welche als Kosten einer im Sinne der logistischen Qualitätsanforderung mangelhaften Leistungserstellung interpretiert werden können. ${ }^{14}$ Strategische Fehlerfolgekosten wiederum dokumentieren sich bspw. als Opportunitätskosten in Form entgangener Umsätze aufgrund von Kundenabwanderung infolge einer unerfüllten logistischen Qualitätsanforderung. ${ }^{15}$

Obwohl die bisherigen Ausführungen möglicherweise anderes vermuten lassen, so darf die Make-or-Buy-Entscheidung dennoch nicht als ein dichotomisches EntwederOder, also eine vermeintlich einfache Wahlentscheidung zwischen unternehmensinterner und unternehmensexterner Leistungserstellung, missverstanden werden. Vielmehr ist, wie in Unterabschnitt 2.1.3 dargelegt, im Lichte der Transaktionskostentheorie ein Kontinuum verschiedener institutioneller Arrangements zur Leistungskoordination denkbar, welche mittels vertraglicher Vereinbarungen unterschiedlichen Charakters fixiert werden, wobei sich die Vertragsformen insbesondere hinsichtlich des Autonomie- bzw. Bindungsgrades der Aufgabenträger unterscheiden. ${ }^{16}$ Dabei sind sowohl das idealtypische „Make“ (bspw. auf Basis von Arbeitsverträgen, Gesellschaftsvertrag) als auch das idealtypische „Buy“ (bspw. auf Basis von Werkverträgen, kurzfristigen Kaufverträgen) lediglich als die Extrempunkte des Kontinuums zu verstehen. Die optimale Gestaltung der individuellen logistischen Leistungstiefe präsentiert sich

Vgl. Pirk, Türks, Mayer (2000), S. 271.

Vgl. Bölsche (2002), S. D3-3.

Vgl. Bölsche (2002), S. D3-4.

Vgl. Bölsche (2002), S. D3-4.

Vgl. Pfohl, Large (1992), S. 29 f. 
folglich als komplexe Optimierungsaufgabe innerhalb eines breiten Spektrums von Möglichkeiten. ${ }^{17}$ Vor diesem Hintergrund wäre die hier in Rede stehende Grundfragestellung entsprechend zu erweitern in „Make or Buy or Cooperate“. ${ }^{18}$

Die Effizienzsuchprozesse in Bezug auf Gestaltung und Veränderung der logistischen Leistungstiefe sowie damit verbunden die institutionelle Verankerung der logistischen Leistungskoordination haben im Logistikmarkt in den letzten knapp zwei Jahrzehnten außerordentlich dynamische Züge und auch zunehmend strategischen Charakter ${ }^{19}$ angenommen. Bestimmungsgründe, welche dieser Entwicklung Vorschub leisten, haben sich im Laufe dieser Marktanalyse insbesondere aus folgenden Überlegungen ergeben:

- Nach vollzogener Deregulierung des Verkehrsbereiches, welcher einen logistischen Kernbereich darstellt, konnten regulierungsbedingte Fehlentwicklungen und Suboptimalitäten bei der Arbeitsteilung zwischen den Verkehrsträgern sowie zwischen Industrie- und Handelsunternehmen und gewerblichen Logistikunternehmen berichtigt werden. Die Rücküberantwortung der Verkehrsprozesse an die wettbewerbsbasierte Marktkoordination (hier insbesondere der freie Preiswettbewerb, die Abschaffung der objektiven Marktzutrittsschranken und die Abschaffung des Drittladeverbotes für den Werkverkehr) hat dazu geführt, dass Entscheidungen über die eigene logistische Leistungstiefe, über deren Veränderung sowie über die zugehörige institutionelle Ausgestaltung auf Basis eines unbeschränkten ökonomischen Kalküls getroffen werden konnten und nicht mehr länger an regulierungsbedingte Begrenzungen gebunden waren. Insofern hat die Deregulierung des Verkehrsbereiches entscheidend dazu beigetragen, dass sich das Angebot von Logistikleistungen - und hier auch insbesondere hinsichtlich neuer Möglichkeiten zur logistischen Prozessvernetzung sowie deren institutioneller Vernetzung - auf ein dem logistischen Bedarf entsprechendes Niveau weiterentwickeln konnte.

- Auch aus netzwerkökonomischer Perspektive sind Suchprozesse für neue institutionelle Gestaltungsformen zur Organisation logistischer Systeme geboten, um die von der Netzwerkökonomik bewirkten Veränderungen in den Leistungserstellungsprozessen der beteiligten Unternehmen institutionell adäquat 
abzubilden. Hierbei ist zunächst insbesondere der Umstand von Bedeutung, dass die netzwerkökonomischen Potenziale die Industrie- und Handelsunternehmen, aber auch die Logistikunternehmen dazu animieren, Make-or-BuyEntscheidungsfindungsprozesse anzustoßen, um auszuloten, ob durch eine Veränderung der logistischen Leistungstiefe möglicherweise besser an diesen Potenzialen partizipiert werden kann. Die Netzwerkökonomik sieht als entsprechende Lösungsansätze für diese Entscheidungsfindungsprozesse alternative institutionelle Arrangements zur kooperativen Leistungskoordination vor und bewirkt damit in Summe eine Erhöhung des Vernetzungsgrades zwischen den Akteuren im Logistikmarkt.

- Bei der Analyse des Wandels logistikrelevanter Strukturen war festzustellen, dass die Veränderungen in der gesamtwirtschaftlichen Güter- und Produktionsstruktur über den Güterstruktureffekt zunächst primär das Verkehrssystem beeinflussen. Bezieht man die Veränderungen auf Unternehmensebene hinsichtlich bestimmter Aspekte der Unternehmensstruktur sowie der einzelwirtschaftlichen Produktionsstruktur in die Analyse mit ein, dann greift das Wirkungspotenzial des Strukturwandels über die Veränderung des unternehmerischen logistischen Bedarfsprofiles (Logistik-Güterstruktureffekt, Logistikeffekt), welche er unweigerlich bedingt, auf das gesamte Logistiksystem durch. Auch in diesem Kontext erweist sich eine adäquate Ausgestaltung der institutionellen Leistungskoordination logistischer Aktivitäten als wichtiger Gestaltungsparameter, um mögliche strukturwandelbedingte produktions- und raumbezogene Größenund Verbundeffekte in den Transformationssystemen tatsächlich realisieren zu können. In welchem Umfang derartige Effekte realisiert werden können, hängt entscheidend von der Qualität des Logistiksystems und hier insbesondere von seiner Fähigkeit ab, die dem Logistiksystem im Rahmen der Strukturwandelprozesse neu überantwortete Koordinationskomplexität zu beherrschen.

Diese Überlegungen machen deutlich, dass sich die Industrie- und Handelsunternehmen sowie die Logistikunternehmen vor dem Hintergrund der Veränderungen der rechtlichen, ökonomischen und technologischen Rahmenbedingungen des Logistikmarktes zunehmend veranlasst sehen, die gegenwärtige Ausgestaltung der Arbeitsteilung in und zwischen mikrologistischen Systemen sowie in horizontalen und vertikalen metalogistischen Systemen zu überprüfen und zu hinterfragen. ${ }^{20}$ Die anstehenden 
Make-or-Buy-or-Cooperate-Entscheidungsprozesse im Logistikmarkt werden dabei in zunehmendem Maße von strategischen Kosten- und Qualitätsüberlegungen geleitet; die rein operativen, auf kurzfristige Kostenwirkungen des Outsourcings ausgerichteten Überlegungen, welche früher (insbesondere vor den 1990er Jahren) dominiert haben, verlieren an Gewicht. ${ }^{21}$ Die Resultate dieser Make-or-Buy-or-Cooperate-Entscheidungsprozesse dokumentieren sich im Logistikmarkt in Gestalt unterschiedlichster Ausprägungen der institutionellen Leistungskoordination, welche von kurzfristig angelegten Spotmarkt-Kontrakten über verschiedene Formen der Kooperation bis hin zu völliger vertikaler Integration innerhalb der Grenzen eines Unternehmens reichen.

\subsubsection{Ausprägungsformen institutioneller Koordination im Logistikmarkt}

Im Folgenden wird, aufbauend auf die bis hierhin vorgetragenen Überlegungen zu Gestaltung der logistischen Leistungstiefe und zu deren Veränderung im Rahmen von Make-or-Buy-or-Cooperate-Entscheidungsprozessen, die institutionelle Ausgestaltung der Leistungskoordination im Logistikmarkt systematisiert dargestellt und ökonomisch beurteilt. Dies geschieht mittels der Verknüpfung von modellhafter Erörterung anhand abstrakter Musterformen institutioneller Koordination und exemplarischer Erörterung anhand konkreter Ausprägungsformen institutioneller Koordination.

\subsubsection{Zur Systematisierung der Darstellung}

Um zu einer Systematisierung für die folgende Darstellung zu gelangen, wird in Anlehnung an die Transaktionskostentheorie in einem ersten Schritt zunächst auf die grundsätzlich denkbaren Alternativen zurückgegriffen, welche aus dem Spannungsfeld zwischen der Koordination über den reinen Markt, der Koordination über Kooperation sowie der Koordination über die reine Hierarchie abstrakt für die logistikmarktliche Betrachtungsebene resultieren. In diesem Zusammenhang wird allerdings nochmals ausdrücklich auf die These RICHARDSONs hingewiesen, wonach hybride, kooperative Formen der Koordination ökonomischer Aktivitäten, welche sich durch eine Kombination marktlicher (preis- bzw. tauschbasierter) und hierarchischer (anweisungsbasierter) Prinzipien auszeichnen, im real-marktlichen Wirtschaftsgeschehen regelmäßig dominieren, wohingegen marktliche und hierarchische Koordination in ihren Reinformen lediglich einen kleinen Teil der in der Wirtschaftspraxis beobachtbaren Erscheinungs- 
formen von Koordinationsmechanismen ausmachen. ${ }^{22}$ Diese These findet sich im Logistikmarkt in besonderem Ausmaß bestätigt. Deshalb wird angesichts der besonderen Bedeutung von Kooperationen in der Logistik ${ }^{23}$, welche im Laufe der Untersuchung schon mehrfach hervorgehoben wurde, der Koordination über Kooperation im Folgenden besondere Aufmerksamkeit geschenkt. Dessen ungeachtet lässt sich im Logistikmarkt selbstverständlich ebenso die Existenz institutioneller Arrangements aufzeigen, bei denen rein-marktliche bzw. streng hierarchische Elemente der Koordination dominieren und welche sich daher in der Nähe der beiden Endpunkte des Kontinuums denkbarer Koordinationsmechanismen befinden. Zur beurteilenden und begründenden Auseinandersetzung mit den verschiedenen Formen der Leistungskoordination werden die entsprechenden Argumente, welche sich aus der Kostenperspektive (Transaktionskostentheorie sowie Produktions- bzw. Beschaffungskostentheorie) und der Leistungsperspektive ergeben, herangezogen.

Die transaktionskostentheoretisch hergeleiteten institutionellen Arrangements zur Leistungskoordination im Logistikmarkt in ihren alternativen Ausgestaltungsformen können in einem zweiten Schritt auf die Betrachtungsebene der Organisation (Unternehmung) konkretisiert als organisatorisch-institutionelle Koordinationsmuster auf der Grundlage interorganisatorischer Beziehungsgefüge aufgefasst werden. ${ }^{24}$

Dergestalt interpretiert lässt sich das Beziehungsgefüge aus der Sicht eines Unternehmens wie folgt darstellen: ${ }^{25}$

Vgl. Unterabschnitt 2.1.3.3.3.

Vgl. Pfohl, Large (1992), S. 36.

Vgl. Freichel (1992), S. 50.

Vgl. in Anlehnung an Pfohl (2004a) S. 311; zurückgehend auf Freichel (1992), S. 54; Abels (1980), S.83. 


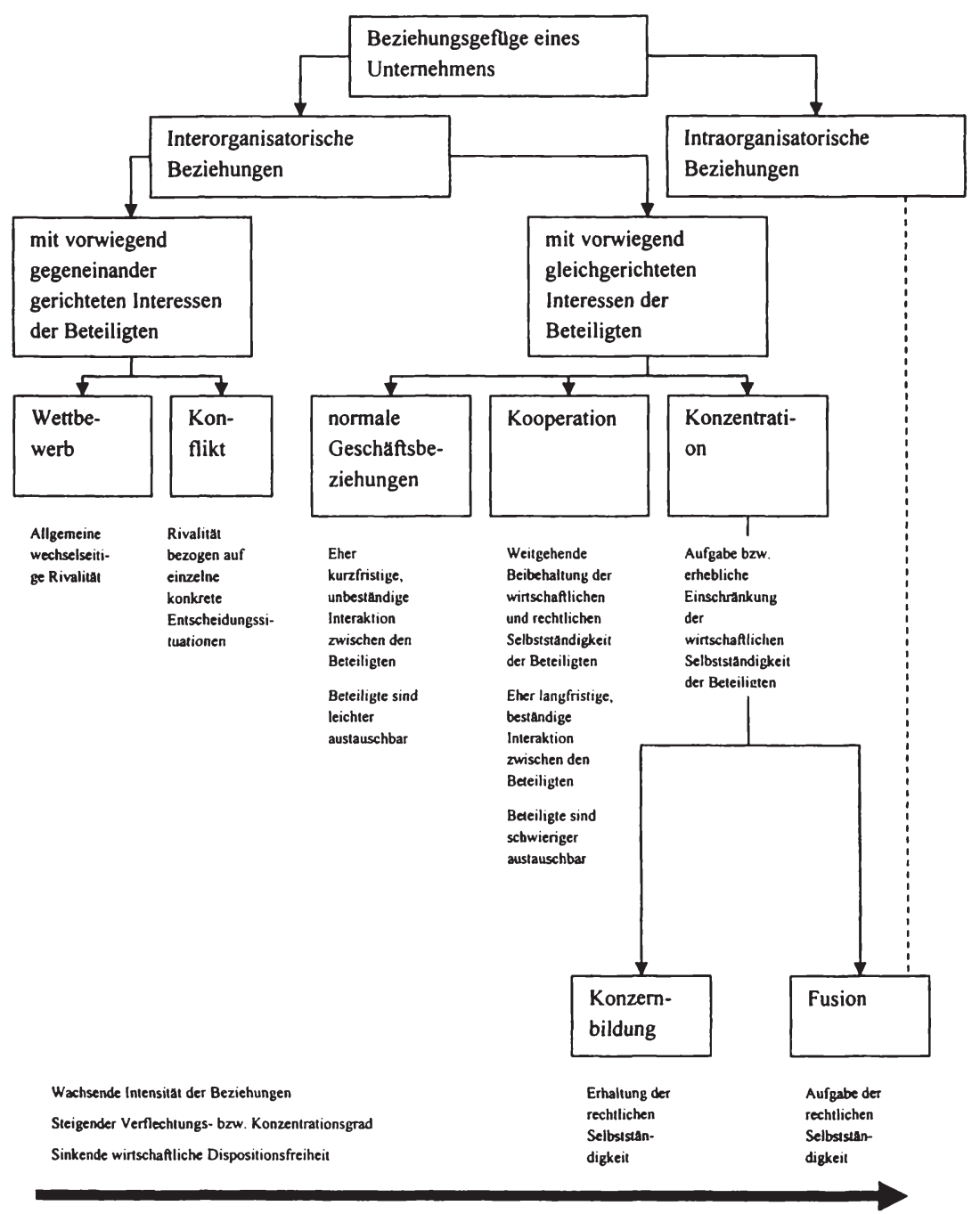

Abbildung 2-20: Beziehungsgefüge eines Unternehmens

Quelle: Pfohl (2004a), S. 311; basierend auf Freichel (1992), S. 54

Im Bereich der interorganisatorischen Beziehungen kann zunächst zwischen Beziehungen mit vorwiegend gleichgerichteten und vorwiegend gegeneinander gerichteten 
Interessen unterschieden werden. ${ }^{26}$ Vorwiegend gegeneinander gerichtete Interessen liegen im Rahmen von Wettbewerbsbeziehungen und Konfliktbeziehungen vor. Wettbewerb, hier interpretiert aus der Perspektive des einzelnen Unternehmens, zeichnet sich durch das Vorliegen einer allgemeinen, wechselseitigen Rivalität im Sinne des Konkurrenzgedankens aus. Als fundamentales Koordinierungsinstrument in einer Marktwirtschaft stellt er - unabhängig von einer konkreten Entscheidungssituation - sicher, dass der Preis seine ihm übertragenen Aufgaben optimal erfüllen kann. ${ }^{27}$ Konfliktbeziehungen hingegen beziehen sich stets auf einzelne konkrete Entscheidungssituationen.

Bei den interorganisatorischen Beziehungen mit vorwiegend gleichgerichteten Interessen lassen sich mit „normalen“ Geschäftsbeziehungen, der Kooperation und der Konzentration drei Hauptausprägungsformen unterscheiden, welche durch einen zunehmenden Verflechtungsgrad bzw. sinkende wirtschaftliche Dispositionsfreiheit gekennzeichnet sind. Bei der Konzentration letztlich differenziert man zwischen der Konzernbildung (Erhaltung der rechtlichen Selbstständigkeit der einzelnen Konzernunternehmen) und der Fusion (Aufgabe der rechtlichen Selbstständigkeit), wobei in beiden Fällen die wirtschaftliche Eigenständigkeit der Beteiligten stark eingeschränkt bzw. ganz aufgegeben wird. Die sog. „normalen“ Geschäftsbeziehungen sind angesichts ihres kurzfristigen, unbeständigen Charakters und angesichts der leichten Austauschbarkeit der Geschäftspartner Ausdruck von Beziehungen zur Leistungskoordination, welche in institutioneller Hinsicht deutliche Elemente rein-marktlicher Koordination im Sinne der Transaktionskostentheorie aufweisen und welche somit dem ursprünglichen Grundgedanken marktlicher Beziehungen entsprechen, so wie er im wettbewerblichen Prinzip nach traditionellem Verständnis verankert ist. ${ }^{28}$ Kooperationen hingegen sind Formen interorganisatorischer Beziehungen, welche sich durch gemeinschaftliches, zielgerichtetes, durch bewusste (vertragliche) Absprachen fixiertes Handeln bei wirtschaftlicher und rechtlicher Selbstständigkeit der Beteiligten auszeichnen. ${ }^{29}$ Kooperationen sind der Ausgangspunkt für das Entstehen metalogistischer Systeme. ${ }^{30}$ Kooperationen sind langfristig angelegte institutionelle Arrangements zur Leistungskoordination, da sie aufgrund der Ausgestaltung der sich hinter ihnen verbergenden vertraglichen Arrangements nicht ohne weiteres in "normale“ Ge-

\footnotetext{
26 Vgl. dafür und für das Folgende Pfohl (2004a), S. 310 ff; Freichel (1992), S. 53 ff.

$27 \mathrm{Vgl}$. Unterabschnitt 2.1.2.2.

28 Vgl. Freichel (1992), S. 56.

29 Vgl. für die Auseinandersetzung mit dem Kooperationsbegriff ausführlich Balling (1998), S. 12 ff., insb. S. 17.

Vgl. Pfohl (2004a), S. 312.
} 
schäftsbeziehungen überführt werden können, die Beteiligten nicht kurzfristig austauschbar sind. Obgleich die vertraglichen Arrangements dazu geeignet sind, die wirtschaftliche Entscheidungsfreiheit der Beteiligten unter Umständen einzuschränken, so bleibt die wirtschaftliche Selbstständigkeit der Beteiligten dennoch davon unberührt, da jedes Unternehmen aufgrund seiner rechtlichen Selbstständigkeit autonom über Verbleib oder Austritt aus der Kooperation entscheiden kann. Kooperationen sind im transaktionskostentheoretischen Sinne durch paralleles Wirken marktlicher und hierarchischer Elemente gekennzeichnet. ${ }^{31}$ Zwar dominieren in aller Regel die marktlichen Koordinationselemente und prägen somit den Umgang zwischen den Kooperationspartnern, je nach Intensität des Verflechtungsgrades innerhalb von Kooperationen kann das Ausmaß hierarchischer Koordinationselemente jedoch dennoch mitunter sehr hoch sein. ${ }^{32}$ Die Konzernbildung als Form der Konzentration markiert den nächst höheren Verflechtungsgrad im Spektrum interorganisatorischer Beziehungen. Die Konzernunternehmen behalten zwar de jure ihre rechtliche Selbstständigkeit, verlieren aber ihre wirtschaftliche Selbstständigkeit vollständig, da sie unter eine einheitliche Leitung gestellt werden. ${ }^{33}$ Die Fusion als weitere Form der Konzentration schließlich drückt den höchsten Verflechtungsgrad aus. Sie hat die am meisten einschneidenden Auswirkungen auf die beteiligten Unternehmen, da die Fusionspartner neben der wirtschaftlichen auch die rechtliche Selbstständigkeit verlieren. ${ }^{34}$ Die Fusion markiert somit den Übergang von interorganisatorischen $\mathrm{zu}$ intraorganisatorischen Beziehungen. ${ }^{35}$ Konzentrative Beziehungsgefüge sind dementsprechend durch deutliche Elemente streng hierarchischer, auf Anweisungen basierender Koordination im Sinne der Transaktionskostentheorie geprägt.

Was das Verhältnis zwischen den drei Hauptausprägungsformen der interorganisatorischen Beziehungen mit vorwiegend gleichgerichteten Interessen betriff - „normalen“ Geschäftsbeziehungen, kooperativen und konzentrativen Arrangements - so kann zunächst auf das in Unterabschnitt 2.5.2 Gesagte verwiesen werden. In Abhängigkeit der (zu erwartenden) Produktions- bzw. Beschaffungskostenstruktur, der (zu erwartenden) Transaktionskostenstruktur sowie den (zu erwartenden) Qualitätswirkungen einer angestrebten Logistiktransaktion/eines Logistiktransaktionsbündels kann auf Basis eines ökonomischen Kalküls die Entscheidung für ein vorteilhaftes, konkretes

\footnotetext{
Vgl. Stahl (1995), S. 34.

Vgl. Freichel (1992), S. 57.

Vgl. Koch, Czogalla (2004), S. 62.

Vgl. Bubik (2005), S. 8.
} 
organisatorisch-institutionelles Arrangement zur Koordination der betreffenden Transaktion herbeigeführt werden. Während die Frage nach der Vorteilhaftigkeit einzelner organisatorisch-institutioneller Arrangements für angestrebte Logistiktransaktionen also - zumindest theoretisch - durch einen ökonomischen Diagnoseprozess ausgearbeitet und zu einer Entscheidung gebracht werden kann, so schließt dies jedoch die Frage nach der konkreten Machbarkeit nicht mit ein. Ob ein als vorteilhaft diagnostiziertes Arrangement für ein entscheidendes Unternehmen auch mach- bzw. umsetzbar ist, ist nicht zuletzt eine Frage seiner finanziellen Leistungsfähigkeit bzw. seiner Ressourcenstärke. Hier erweisen sich insbesondere konzentrative Arrangements mit hoher Bindungsintensität in Anbetracht des damit verbundenen hohen Kapitalbedarfes als organisatorisch-institutionelle Entscheidungsoption, welche nur wenigen kapital- und ressourcenstarken Akteuren offen steht. ${ }^{36}$ Die Frage der konkreten Machund Umsetzbarkeit verwässert folglich im realen Wirtschaftsgeschehen bisweilen die theoretisch geleitete, ökonomische Vorteilhaftigkeitsdiagnose. Daher können insbesondere kooperative und konzentrative Arrangements im realen Wirtschaftsgeschehen oftmals als alternative, grundsätzliche Umsetzungswege zur Erreichung vergleichbarer Zielsetzungen interpretiert werden, welche allerdings - je nach ökonomischem Charakter der Logistiktransaktion - divergierende Zielerreichungsgrade aufweisen können. ${ }^{37}$ Dabei dienen Kooperationen häufig auch als (mit gegebener finanzieller und sonstiger Ressourcenausstattung machbare) Alternative zu bzw. Antwort auf konzentrative Arrangements. ${ }^{38}$ Derartige Überlegungen unterstreichen die schon mehrfach hervorgehobene Bedeutung von kooperativen Arrangements im Logistikmarkt: Zum einen können sie das First-Best-Ergebnis einer ökonomischen Vorteilhaftigkeitsanalyse sein, zum anderen dienen sie als Second-Best-Lösung für den Fall, dass die FirstBest-Lösung (bspw. Produktion der Logistikleistung im Rahmen eines konzentrativen Arrangements mit Kapitalverflechtung) aufgrund beschränkter Ressourcenausstattung oder aufgrund sonstiger Hemmnisse nicht umgesetzt werden kann. Darüber hinaus können Kooperationen als Vorstufe bzw. Ausgangspunkt für konzentrative Arrangements dienen. In solchen Kooperationen soll vorab geprüft werden, ob die potenziellen Akquisitions- oder Fusionspartner strategisch zueinander passen und eine spätere festere Verbindung Erfolg versprechend ist. ${ }^{39}$

Vgl. Pfohl (2004a), S. 312.

Vgl. Lieb, Lange (2003), S. 455.

Vgl. Baumgarten, Zadek, Keller (2001), S. 18; Held, Steckler (2007), S. 460.

Vgl. Held, Steckler (2007), S. 449.

Vgl. Held, Steckler (2007), S. 450. 
Insofern ist PFOHL zuzustimmen, welcher der effizienten kooperativen Abwicklung logistischer Prozesse in Netzwerken - und damit den kooperativen Arrangements im Logistikmarkt - eine Schlüsselrolle für den Erfolg der kollektiven Leistungserstellung innerhalb interorganisatorischer Beziehungsgefüge, welche durch aufgebrochene Wertschöpfungsketten und unternehmensübergreifende Leistungserstellungsprozesse gekennzeichnet sind, zuweist. ${ }^{40}$

Was die Trennlinien zwischen den drei Hauptausprägungsformen der interorganisatorischen Beziehungen mit vorwiegend gleichgerichteten Interessen betrifft, so lässt sich die Kooperation nach Ansicht von FrEICHEL gegen die "normale“ Geschäftsbeziehung über das Merkmal der Fristigkeit der Geschäftsbeziehung abgrenzen: in Kooperationen erfolgt eine langfristige, beständige Interaktion zwischen den Geschäftspartnern bezüglich der vertragsgemäß gemeinsam zu erfüllenden (Teil-)Aufgabe. ${ }^{41}$ Gegenüber den verschiedenen Formen der Konzentration wiederum ist das Merkmal der Selbstständigkeit das Hauptabgrenzungskriterium aus Sicht der Kooperation. ${ }^{42} \mathrm{Zu}$ einem ähnlichen Ergebnis kommt STAHL, der den Aspekt der Koordination über Kooperation im Rahmen der Analyse von internationalen Speditionsnetzwerken beleuchtet. Internationale Speditionsnetzwerke versteht er als logistikspezifische Ausprägungsform von strategischen Unternehmensnetzwerken im Sinne kooperativer interorganisatorischer Beziehungsgefüge. ${ }^{43}$ Er grenzt internationale Speditionsnetzwerke gegenüber Zusammenschlüssen von Speditionen (d. h. Koordination über Hierarchie) über das Merkmal der rechtlichen Selbstständigkeit und im Falle konzernartiger Verflechtungsstrukturen - dem Grenzfall zu hierarchischer Organisation also - zusätzlich über das Merkmal der wirtschaftlichen Selbstständigkeit der beteiligten Speditionen ab. ${ }^{44} \mathrm{Zu}$ marktlicher Koordination grenzt er internationale Speditionsnetzwerke über folgende Merkmale ab: ${ }^{45}$

- Zum Preismechanismus als marktlichem Instrument zur Ex-postKoordination treten Elemente der Ex-ante-Koordination (bspw. Abstimmung der Unternehmenspläne).

\footnotetext{
Vgl. Pfohl (2004b), S. 3.

Vgl. Freichel (1992), S. 57.

Vgl. Freichel (1992), S. 57.

Vgl. Stahl (1995), S. 32.

Vgl. Stahl (1995), S. 32.

Vgl. Stahl (1995), S. 33 f.
} 
- Etablierung von netzwerkinternen Sanktionsmechanismen bei Schlechtleistung oder Vertragsverletzung durch Netzwerkpartner sowie von vorher festgelegten Eskalationspfaden zur Konfliktbewältigung im Netzwerk.

- Entwicklung kontinuierlicher und zukunftsgerichteter Beziehungsstrukturen, welche die Netzwerkpartner leistungsmäßig und emotional dauerhaft aneinander binden und welche langfristig zu einer Atmosphäre des Vertrauens und zu gemeinsamen Wertvorstellungen führen können.

Was das Verhältnis zwischen interorganisatorischen Beziehungen mit vorwiegend gleichgerichteten Interessen und denen mit vorwiegend gegeneinander gerichteten Interessen betrifft, so schließen sich die beiden nicht aus:

- Wie auch in intraorganisatorischen Beziehungsgefügen nicht unüblich, sind Konflikte verschiedenster Art und Weise in interorganisatorischen Beziehungsgefugen, insbesondere in längerfristig angelegten kooperativen und konzentrativen, ein unvermeidbarer Bestandteil. Daher gilt es, in solchen längerfristigen Beziehungsgefügen ein geregeltes (in der Regel vertraglich fixiertes) Konfliktmanagement $\mathrm{zu}$ institutionalisieren, welches dazu geeignet ist, aufkommende Konflikte auf ihren jeweiligen Eskalationsstufen angemessen zu handhaben. ${ }^{46}$ Ein unzureichendes Konfliktmanagement könnte mittelfristig die Stabilität einer interorganisatorischen Beziehung gefährden.

- Ferner sind durchaus Konstellationen denkbar, in denen Unternehmen in Teilbereichen ihrer Wertschöpfungsaktivitäten gleichgerichtete Interessen aufweisen und kooperieren (bspw. in der Beschaffung), während sie in anderen Teilbereichen im Wettbewerb zueinander stehen (bspw. in der Distribution). ${ }^{47}$

Die These der Koexistenz mehrer alternativer Koordinationsmechanismen, welche in Unterabschnitt 2.1.2.2 dieser Arbeit schon aus der Perspektive der Gesamtmarktkoordination diskutiert wurde, lässt sich folglich sinngemäß auf das parallele Wirken mehrerer unterschiedlicher Koordinationsmechanismen aus der Perspektive interorga- 
nisatorischer Beziehungsgefüge aus Sicht der einzelnen Organisation übertragen bzw. erweitern. Gleichermaßen ist das in Unterabschnitt 2.1.2.2 Gesagte auf die Erörterungen dieses Unterabschnitts zu übertragen, was den wettbewerblichen Marktprozess als den wünschenswerten und überlegenen Marktprozess anbetrifft. Es sei auch hier nochmals betont, dass die Anerkennung der Existenz interorganisatorischer Beziehungen mit gleichgerichteten Interessen zwischen Wettbewerbern nicht den wettbewerblichen Marktprozess als den überlegenen und erwünschten Marktprozess infragestellt. Vielmehr sollen die denkbaren ökonomischen Beweggründe für das Eingehen kooperativer und konzentrativer Arrangements zur Marktkoordination im Logistikmarkt möglichst umfassend aufgezeigt werden, um darauf aufbauend unter Bezugnahme auf ihre jeweilige ökonomische Ratio zu beleuchten, ob und inwieweit sie in das wettbewerbstheoretische Gedankengebäude integriert werden können oder nicht.

Die interorganisatorischen Beziehungsgefüge wiederum sind in einem dritten Schritt als Grundlage dafür zu betrachten, metalogistische Systeme zu konstituieren ${ }^{48}$ und sie lassen sich insofern als organisatorisch-institutionelle Musterformen zur Lösung und Beherrschung von Koordinationsproblemen - und hier insbesondere von (logistischen) Schnittstellenproblemen - an und zwischen (logistischen) Systemgrenzen begreifen. Metalogistische Systeme wurden in Unterabschnitt 2.2.2.3.2 als diejenigen Logistiksysteme hervorgehoben, welche die Vorzüge des systemischen Logistikdenkens, nämlich die integrierte Perspektive auf alle am logistischen Prozess beteiligte Institutionen am besten abbilden. In Abhängigkeit der Ausgestaltung der ihnen zugrunde liegenden interorganisatorischen Beziehungsgefüge können metalogistische Systeme demnach das gesamte Spektrum zwischen kurzfristigen, wenig verflochtenen, marktlichen Systemen (bei „normalen“ Geschäftsbeziehungen), überdauernden, intensiven, stärker verflochtenen Systemen (bei kooperativen Beziehungsgefügen) oder stark verflochtenen, konzentrierten, hierarchischen Systemen (bei konzentrativen Beziehungsgefügen) abdecken. An ihrer marktlichen Grenzlinie können Metalogistiken einen derart kurzfristigen und sporadischen Charakter aufweisen, dass sie kaum als Metalogistiken wahrnehmbar sind. An ihrer hierarchischen Grenzlinie gehen die interorganisatorischen Beziehungen innerhalb der Metalogistiken in intraorganisatorische Beziehungen über. Metalogistische Systeme werden dann zu mikrologistischen Systemen. Metalogistische Systeme sind daher hauptsächlich im Bereich kooperativer Beziehungsgefüge evident. 
Mittels dieser stufenweise aufgebauten Argumentation lassen sich mehrere koordinationsrelevante, institutionelle Aspekte für den Logistikmarkt miteinander verknüpfen und zu einem integrierten Systematisierungsansatz verbinden. Es sind dies die Aspekte

1. des Leitgedankens der Logistikkonzeption, Güter-, Material- und Informationsflüsse auf der Grundlage des Systemgedankens unternehmens- bzw. schnittstellenübergreifend und gesamthaft zu optimieren ${ }^{49}$,

2. der transaktionskostentheoretisch fundierten Perspektive der institutionellen Koordination logistischer Systeme, deren Basiskategorien (Markt, Kooperation und Hierarchie) zur Koordination von Transaktionen der folgenden Darstellung ja als Systematisierungsbasis dienen sollen sowie

3. der (inter-)organisationstheoretisch fundierten Perspektive der institutionellen Koordination logistischer Systeme, wonach die konkrete Ausgestaltungsform der interorganisatorischen Beziehungen zwischen logistischen Teilsystemen die Art und Weise, wie mit logistischen Schnittstellenproblemen an den (Teil-) Systemgrenzen umgegangen wird - und damit die Qualität der Umsetzung des Leitgedankens der Logistikkonzeption - determiniert ${ }^{50}$.

Im Folgenden werden nun nacheinander Ausprägungsformen „normaler“ Geschäftsbeziehungen, kooperativer Arrangements und konzentrativer Arrangements als Ausprägungen der institutionellen Ausgestaltung der Leistungskoordination im Logistikmarkt vorgestellt und im Zuge dessen auch deren ökonomische Grundlegung erörtert.

\subsubsection{2 „Normale“ Geschäftsbeziehungen: Elemente rein-marktlicher Koordina- tion im Logistikmarkt}

Die rein-marktliche Koordination in ihrer idealtypischen Grundform nach neoklassischem Vorbild, welche ausschließlich auf Basis des anonymen Preismechanismus funktioniert, stellt angesichts der in realiter unerfüllbaren Bedingungen, an welche die Funktionsfähigkeit dieser Koordinationsform geknüpft ist (insb. vollständige Homogenität der Güter, vollständige Markttransparenz, unendlich hohe Anbieter- und Nachfragerzahl), sicherlich in jedem realen Markt einen theoretischen Grenzfall dar. 
Dennoch existieren im Logistikmarkt, insbesondere im Bereich der teilstandardisierten bis standardisierten Transportleistungen zur Raumüberwindung (z. B. in den Teilmärkten 2 oder 5$)^{51}$, reale Formen der Leistungskoordination, welche deutliche Elemente des Idealmodells rein-marktlicher Koordination aufweisen und welche daher als „normale" Geschäftsbeziehungen zumindest in dessen Nachbarschaft zu verorten sind. In diesem Kontext sind insbesondere Arrangements zu nennen, welche auf Basis kurzfristiger Frachtverträge oder Speditionsverträge zur Abwicklung (1) von logistischen Transaktionen mit geringer Faktorspezifität und mit häufiger Wiederholungszahl (wie standardisierte Transportleistungen im Ladungs- und Teilladungsverkehr) oder (2) von logistischen Transaktionen mit mittlerer Faktorspezifität in gelegentlicher Wiederholungszahl (wie spezielle Gelegenheitsverkehre) zustande kommen. ${ }^{52}$ Als markantes und hier allein vorzustellendes Beispiel für eine in diesem Zusammenhang entsprechend charakteristische und gleichsam ,moderne“ Realform eines institutionellen Arrangements ist die elektronische Frachtenbörse zu nennen.

\section{Elektronische Frachtenbörsen}

Mittels des Einsatzes von Frachtenbörsen wird von deren Nutzern versucht, die Allokation von verfügbaren Laderaumkapazitäten bei Straßengüterteilladungs- und Straßengüterladungsverkehren zu verbessern und über eine effektivere Transportdisposition Leerfahrtenanteile zu reduzieren. Hierbei geht es aus Sicht der Anbieter von Laderaumkapazität (d. h. Logistikdienstleister, bspw. Frachtführer oder Spediteure im Selbsteintritt, welche Transportfahrten durchführen) in erster Linie um

- das punktuelle, gezielte Auffüllen von Leerräumen in bereits disponierten Fahrzeugen oder

- das Akquirieren von Rück- oder Querladungen aus Zieldestinationen, in denen der Laderaumanbieter keine längerfristigen Verladerbeziehungen unterhält, entweder für Rücktransporte hin zum Standort des Fahrzeugs oder für Quertransporte hin zu einem neuen Beladeort des Fahrzeuges.

5I Vgl. Unterabschnitt 2.4.2.1.

52 Vgl. Pfohl, Large (1992), S. 34 f. 
Die Basisauslastung für die Fahrzeuge wird jedoch in der Regel nach wie vor über das traditionelle Chartergeschä $\mathrm{ft}^{53}$ abgewickelt oder im Rahmen längerfristiger VerladerLogistikdienstleister-Beziehungen vertraglich abgesichert. Da es sich bei Ladungsund Teilladungstransporten in der Regel um termingebundene Verkehre handelt, muss der Transport zu einem bestimmten Zeitpunkt durchgeführt werden, auch wenn das Fahrzeug nicht optimal ausgelastet ist. Elektronische Frachtbörsen nun bieten eine zweckmäßige Plattform, ohne viel Aufwand und zeitlichen Vorlauf Kontakt mit vielen potenziellen Verladern aufzunehmen und sie sind somit geeignet, kurzfristig „Löcher zu stopfen", um eine höhere Auslastung der Fahrzeuge zu erreichen. Für die Nachfrager nach Laderaumkapazitäten (bspw. Spediteure, welche im Auftrag die Organisation/Disposition von Transporten zu besorgen haben; Industrie- und Handelsunternehmen, welche ihre Ladungen in Eigenregie versenden wollen) bedeutet dies, dass die Preisvereinbarungen, welche über elektronische Frachtenbörsen zu erzielen sind, in der Regel sehr attraktiv sind. Dies ist darauf zurückzuführen, dass Laderaumanbieter sinnvollerweise auch Transportpreise akzeptieren, welche nur geringfügig über den durch die zusätzliche Ladung direkt anfallenden Zusatzkosten für den Laderaumanbieter (bspw. Kosten des Zeitverlustes oder Streckenkosten durch die zusätzlichen Ladeund Entladestellen) liegen, weil die zusätzliche Ladung dann einen zusätzlichen Deckungsbeitrag bezogen auf den gesamten Transport bringt.

Freilich werden auch die Nachfrager nach Laderaumkapazitäten nicht alle ihre Ladungen über elektronische Frachtenbörsen handeln, sondern nur die zeitlich unkritischen oder solche, die nicht in großen Häufigkeiten anfallen. Zeitkritische Transporte bzw. häufig in ähnlicher Ausprägung anfallende Transporte werden aufgrund des höheren Unsicherheitspotenzials bzw. angesichts des Häufigkeitsmerkmals in der Regel über längerfristig abgesicherte Verlader-LogistikdienstleisterBeziehungen abgewickelt.

Zur Funktionsweise von elektronischen Frachtenbörsen: Anbieter von freien Laderaumkapazitäten und Nachfrager nach freien Laderaumkapazitäten registrieren sich kostenpflichtig beim Betreiber der Frachtenbörse (wie z. B. Teleroute, TimoCom) und können nach erfolgter Registrierung a) auf sämtliche Informationen zu Laderaumangebot und -nachfrage zugreifen, welche andere Nutzer in das System eingestellt haben und welche vom Betreiber zentral verwaltet werden und b) dem System selbst Angebots- und/oder Nachfragepositionen nach Laderaum hinzufugen, welche von den

53 Das sind „normale“ Geschäftsbeziehungen zwischen Logistikdienstleistern und Verladern, welche bspw. mittels telefonischer Anmeldung der Ladung beim Logistikdienstleister durch den Verlader $\mathrm{zu}$ jeweiligen Tagespreisen abgewickelt werden. 
anderen registrierten Nutzern eingesehen werden können. Die Verwaltung und die Verbreitung der Informationen basiert auf der Nutzung der Netzwerktechnologie des Internets. Elektronische Frachtenbörsen sind daher Anwendungsformen der Netzwerkökonomik und dem Grunde nach den Geschäftsmodellen zuzuordnen, welche im Rahmen der netzwerkökonomischen Erörterungen als E-Commerce definiert wurden. ${ }^{54}$ Bei Anwahl einer Angebots-/Nachfrageposition stellt die Börse dem Interessenten die erforderlichen Daten zu - im Falle einer Angebotsposition - Laderaum (Anzahl verfügbare Lademeter/Ladevolumen, Art des Lademittels, Ort und Zeit der Verfügbarkeit) oder - im Falle einer Nachfrageposition - zu Ladung (Art, Gewicht, Volumen, Abmessung, Termin, Destination, Besonderheiten) sowie entsprechende Kontaktdaten der Anbieter oder Nachfrager bereit. Da in der Frachtenbörse in der Regel keine Informationen zu Preisen und Konditionen eingestellt werden, erfolgen Preisfindung und abschließende vertragliche Fixierung der Transaktion nicht über die Börse, sondern „traditionell“" über telefonische oder schriftliche Kontaktaufnahme und schriftliche bilaterale Verträge. Die Frachtenbörse nimmt als "neutraler Partner“ keinen Einfluss auf die Geschäftsverhandlungen. ${ }^{55}$ Frachtenbörsen sind folglich trotz ihres Charakters als E-Commerce-Anwendung keine Börsensysteme bzw. elektronische Märkte im engeren Sinne. Sie stellen vielmehr Informationssysteme dar, welche laderaum- und ladungsrelevante Informationen zentral und systematisch geordnet darstellen und verbreiten, sie funktionieren dabei wie ein virtuelles „schwarzes Brett“ ${ }^{56}$ Sie tragen demzufolge im Sinne einer „Virtual Community“ dazu bei, die Markttransparenz zu erhöhen ${ }^{57}$, indem sie marktliche Informationsdefizite und asymmetrien abbauen und damit die Kontaktaufnahme zwischen potenziellen Transaktionspartnern erleichtern.

Aus der Perspektive der Transaktionskostentheorie handelt es sich bei einer elektronischen Frachtenbörse um einen ökonomischen Ort, an welchem kurzfristige Frachtgeschäfte mit geringer Wiederholungshäufigkeit getätigt und kurzfristige Frachtverträge geschlossen werden. Das gehandelte Transaktionsobjekt sind Straßengütertransportleistungen (bzw. unter Einbeziehung des Zeitaspektes: Straßengüterverkehrsleistungen) aus dem allgemeinen Teilladungs- und dem Ladungsbereich. Für die Nachfragergruppe der Verlader aus Industrie und Handel stellen derartige Transportprozesse von einem bestimmten Versandort zu einem bestimmten Empfangsort zu einem bestimm-

Vgl. Unterabschnitt 2.3.3.1.4.

Vgl. Teleroute (2008).

Vgl. Florian (2000), S. 7.

Vgl. Krieger (2000), S. 102.
} 
ten Zeitpunkt - obwohl es sich dabei um weitgehend standardisierte Transportobjekte handelt, welche mit ebenso weitgehend standardisierten Transportmitteln abgewickelt werden können - zunächst hoch prozessspezifische Transaktionsobjekte dar. ${ }^{58}$ Demgegenüber haben Transportleistungen für die Verlader in der Regel untergeordnete strategische Bedeutung. Sie sind keine Kernkompetenz, sondern - in Abhängigkeit der Gewichtung, mit der Logistikprozesse innerhalb der Wertschöpfungskette der Verladerunternehmen versehen sind - allenfalls Komplementär- oder Peripherkompetenzen, welche gemäß der Theorie der Kernkompetenzen nicht unbedingt vom Unternehmen selbst beherrscht werden müssen. ${ }^{59}$ Angesichts der Kombination aus hoher Spezifität und geringer strategischer Bedeutung ist es daher aus ihrer Sicht eine sinnvolle Strategie, Transportleistungen nicht selbst zu produzieren, sondern sie an darauf spezialisierte Logistikdienstleister outzusourcen, um über die Änderung der Koordinationsform von Eigenproduktion („Make“, „Hierarchie“) zu Fremdbezug (,Buy“, ,Markt“) die Spezifität zu reduzieren. ${ }^{60}$

Aus Sicht des spezialisierten Logistikdienstleisters, welcher die Strategie einer standardbasierten, kundenbezogenen Individualisierung über transportorientierte, funktionale Spezialisierung verfolgt ${ }^{61}$, stellt die einzelne Transportleistung nämlich wiederum ein Transaktionsobjekt dar, für dessen Erstellung und Übertragung keine zusätzlichen Investitionen in spezifische Faktoren, weder Human- noch Sachkapital, notwendig sind. Termingebundene Transportleistungen in jedwede Destination gehören zum Basisleistungsprofil eines entsprechenden Logistikunternehmens. Aufgrund der Tatsache, dass am Logistikmarkt für alle Destinationen und für alle Teilladungs- und Ladungsgüter spezialisierte Dienstleister zur Verfügung stehen und die Logistikmärkte nun wettbewerblich sind, können die nachgefragten Transportleistungen stets von mehreren Dienstleistern in vergleichbarer Qualität und zu vergleichbaren Preisen erbracht werden. ${ }^{62}$

Vgl. Arnold, Eßig (2002), S. D3-21.

Vgl. dafür sowie allgemein zur Theorie der Kernkompetenzen und deren transaktionskostentheoretischer Interpretation Picot, Reichwald, Wiegand (2003), S. $291 \mathrm{ff}$.

Vgl. Picot, Reichwald, Wigand (2003), S. 51.

Vgl. Unterabschnitt 2.4.5.4.

Zu Regulierungszeiten hatten Verlader bei Vorliegen einer derartigen Konstellation nach Abwägung der Transaktions- und Produktionskosten bei Eigenerstellung oder Fremdbezug oftmals keine andere Alternative, als die anfallenden Transportleistungen mittels eines Werkverkehrs selbst zu produzieren. Grund für diese - aus heutiger Sicht - suboptimale Entscheidung pro Werkverkehr war das mangelhafte, nicht anforderungsadäquate Leistungsangebot der gewerblichen Logistikanbieter, was dazu geführt hat, dass die Transaktionskosten (Suchkosten für einen geeigneten Dienstleister, Kontrollkosten zu Überwachung der Qualität der Leistungserstellung) 
Um bestehende (Verhaltens-)Unsicherheiten (bspw. hinsichtlich Bonität oder Geschäftsgebaren potenzieller, unbekannter Transaktionspartner) abzubauen, welche mit den über Frachtenbörsen angestoßenen Transaktionen für die Börsenteilnehmer systembedingt verbunden sind, und insbesondere um das Risiko opportunistischer Verhaltensweisen einzelner Transaktionsbeteiligter nach erfolgter Transaktion einzudämmen, bieten Frachtenbörsen entsprechende Zusatzservices an, welche diesbezüglich zur Risikominderung beitragen sollen. Solche Zusatzservices sind bspw.:

- die Vorab-Überprüfung der Teilnehmer der Börse über Wirtschaftsauskunftsdateien,

- die Möglichkeit für geschädigte Nutzer der Börse, Warnmitteilungen an die Nutzergemeinschaft („Community“) über ein Fehlverhalten von bestimmten Teilnehmern abzusetzen,

- die Gründung von „Inkassoabteilungen“ innerhalb der Börsenbetreiberorganisation, welche in der Lage sind, berechtigte Forderungen nötigenfalls mithilfe darauf spezialisierter, eigener Anwälte durchsetzen. ${ }^{63}$

Demzufolge besteht aus Sicht der Verlader per saldo keine Veranlassung, eigene Investitionen in spezifische Faktoren vorzunehmen oder die Vertragsbeziehung über den kurzfristigen Frachtvertrag hinausgehend weiter abzusichern. Kurzfristige Markttransaktionen über elektronische Frachtenbörsen stellen folglich aus der Perspektive der Transaktionskostentheorie eine effiziente Form der Marktkoordination für teilstandardisierte bzw. standardisierte Transportleistungen dar. Dies gilt vor allem auch deshalb, weil die Möglichkeiten, welche die Anwendung von Netzwerktechnologien bieten, die Partnersuche und -kontaktaufnahme für Laderaumanbieter oder -nachfrager zu niedrigen Transaktionskosten über die Spotmarkt-Strukturen, wie sie über elektronische Frachtenbörsen bereitgestellt werden, gestatten. ${ }^{64}$

für die Verlader bei Fremdvergabe der Transportleistungen an einen Dienstleister noch höher als bei Eigenproduktion gewesen wären.

Vgl. Klaus (2003), S. 28 f. 


\subsubsection{Kooperative Arrangements: Elemente hybrider Koordination im Logistikmarkt}

\subsection{Beziehungsebenen und Beziehungsrichtungen von Kooperationen}

Kooperationen jedweder Form folgen in der Logistik einer langen Tradition. Diese Kooperationen hatten zum Teil den Charakter staatlich initiierter Zwangskartelle, wie bspw. der Reichs-Kraftwagen-Betriebsverband (RKB) ${ }^{65}$ Bereits vor Jahrzehnten - in den 1970er Jahren - haben die Akteure im Logistikmarkt aber auch die Notwendigkeit zur kooperativen Zusammenarbeit auf freiwilliger Basis erkannt, um dadurch logistische Rationalisierungsreserven zu nutzen oder um mithilfe logistischer Optimierung marktwirksame Leistungsverbesserungen $\mathrm{zu}$ realisieren. ${ }^{66}$ Wie insbesondere in den Ausführungen zu Netzwerkökonomik und Strukturwandel zum Ausdruck gekommen sein dürfte, sind kooperative interorganisatorische Beziehungsgefuge aber gerade in der „modernen“ Logistik von immer größerer quantitativer und qualitativer Relevanz, weil sich verladende Unternehmen aus Industrie und Handel, aber auch Logistikunternehmen in zunehmendem Maße tief greifenden Reorganisationsprozessen gegenübersehen, welche die unternehmensbezogenen und die unternehmensübergreifenden Organisations- und Produktionsstrukturen verändern. Umfassende arbeits- und standortteilig organisierte Gestaltungsformen industrieller Fertigung sowie des Handeltreibens auf der Grundlage technologischer Integration und organisatorischer Verflechtung führen dazu, dass sich die Anzahl koordinierungsintensiver Schnittstellen in und zwischen den Unternehmen stark erhöht. Damit verbunden ergibt sich die Notwendigkeit, die aus diesen Reorganisationsprozessen resultierende neue Koordinationskomplexität logistischer Transaktionen in den Wertschöpfungsketten der beteiligten Unternehmen zu beherrschen, was ein entsprechend kooperatives Verhalten aller Wertschöpfungspartner voraussetzt. ${ }^{67}$ Insofern ist das kooperative Wirken zur Beherrschung von logistischen Schnittstellenproblemen als zentrale Aufgabe der Logistik zu bezeichnen und ist damit wichtiger Bestsandteil ihres Selbstverständnisses. ${ }^{68}$ Kooperationen in der Logistik können sich dabei grundsätzlich auf überbetrieblicher oder auf zwischenbetrieblicher Ebene vollziehen.

\footnotetext{
65 Vgl. Köberlein (1997), S. 84; vgl. auch Unterabschnitt 2.3.2.2.1.

66 Vgl. bspw. Vogel (1979), S. $333 \mathrm{ff}$.

67 Vgl. Pfohl (2004a), S. 314.

68 Vgl. Arnold, Eßig (2002), S. D3-18.
} 


\section{Überbetriebliche Kooperation}

Überbetriebliche Kooperationen zeichnen sich dadurch aus, dass Logistikaufgaben in einer gemeinsam getragenen Institution koordiniert bzw. in diese ausgegliedert werden. ${ }^{69} \mathrm{Zu}$ diesem $\mathrm{Zwecke}$ wird alternativ eine neue Institution gegründet oder es erfolgt eine Beteiligung an einer bereits bestehenden Institution mit überbetrieblichem Charakter. ${ }^{70}$ Dabei ist es ein wesentliches Kennzeichen der überbetrieblichen Kooperation, dass größere Unternehmensgruppen oder Branchen auf der Basis kollektiver Abstimmung und mittels konzertierter Handlungen eine gemeinsame logistische Optimierung anstreben." Überbetriebliche Kooperation dokumentiert sich in der Logistik in Form gewerbewirtschaftlicher oder gewerbepolitischer Zusammenarbeit. Gewerbewirtschaftliche Zusammenarbeit hat in der Regel zum Ziel, bestimmte operative, administrative oder IuK-technische Komponenten des logistischen Leistungserstellungsprozesses für die jeweilige Gruppe der Kooperationsteilnehmer zu optimieren. Beispiele sind Straßenverkehrsgenossenschaften, welche Versorgungseinrichtungen wie Autohöfe unterhalten, Laderaumbörsen betreiben, gemeinsame Beschaffungsprozesse organisieren oder den Mitgliedsunternehmen Hilfestellung bei betriebswirtschaftlichen und IuK-technischen Problemstellungen geben. ${ }^{72}$ Ferner sind Speditionskooperationen im allgemeinen Stückgutmarkt zu nennen, welche unter dem Dach eines Gemeinschaftsunternehmens operieren (IDS Logistik GmbH, System Alliance $\mathrm{GmbH}$ ). Gewerbepolitische Zusammenarbeit hingegen hat in der Regel zum Ziel, die Interessen der Kooperationsmitglieder auf dem politischen Parkett zu vertreten oder ökonomische Vorteile durch Normierung, Typisierung und Standardisierung zu verwirklichen, welche letztlich an alle Marktakteure weitergegeben werden. Beispiele für derartige Kooperationen sind Fachvereinigungen und Branchenverbände der Logistikwirtschaft (aber durchaus auch anderer Branchen), sowie insbesondere deren logistikthemenspezifische Fachausschüsse. ${ }^{73}$ Hier konnten in der Vergangenheit große transaktionskostensenkende Fortschritte im Bereich der Normung (bspw. diverse DIN-Normen zur Klassifizierung von Gütern oder Materialien sowie deren logistischer Eigenschaften, das europäische Artikel-Nummern-System EAN) oder im Bereich der Standardisierung (bspw. die im Rahmen des UN/EDIFACT-Systems

Vgl. Pfohl (2004a), S. 314.

Vgl. Freichel (1992), S. 63.

Vgl. Arnold, Eßig (2002), S. D3-19.

Vgl. Aberle (2003a), S. 82.

Vgl. Pfohl (2004a), S. 316. 
erarbeiteten Kommunikationsstandards innerhalb einer Logistikkette) realisiert werden. $^{74}$

\section{Zwischenbetriebliche Kooperation}

Zwischenbetriebliche Kooperationen zeichnen sich durch direkte Leistungsbeziehungen zwischen zwei oder mehr Kooperationspartnern aus. In Abhängigkeit der Richtung, in der kooperative interorganisatorische Beziehungsgefuge auftreten, kann zwischen horizontalen, vertikalen und diagonalen Kooperationen unterschieden werden. ${ }^{75}$ Horizontale Kooperationen betreffen Beziehungen zwischen Unternehmen, welche auf derselben Wertschöpfungsstufe bezogen auf den Logistikkanal agieren (Kooperation zwischen Versender und Empfänger, Versand- und Empfangsspedition). Vertikale Kooperationen vollziehen sich zwischen Unternehmen, welche Leistungen auf verschiedenen Wertschöpfungsstufen des Logistikkanals erbringen (Kooperation zwischen Versender und Spedition, Spedition und Frachtführer, Spedition und Empfänger). Nicht selten sind vertikale Kooperationen das Ergebnis der vertraglichen Festigung von Leistungsbeziehungen, welche schon vor dem Eingehen der Kooperation als kurzfristig angelegte „normale“ Geschäftsbeziehungen - oftmals mit geringerem Leistungsumfang - zwischen den Beteiligten bestanden haben. ${ }^{76}$ Diagonale Kooperationen umfassen insbesondere die Zusammenarbeit verschiedener Verkehrstechniken bzw. Verkehrsträger. Vergleiche dazu Abbildung 2-21.

Vgl. Pfohl (2004a), S. 316; Arnold, Eßig (2002), S. D3-22.

Vgl. dafür und für das Folgende Freichel (1992), S. 62.

Vgl. Pfohl (2004a), S. 317. 


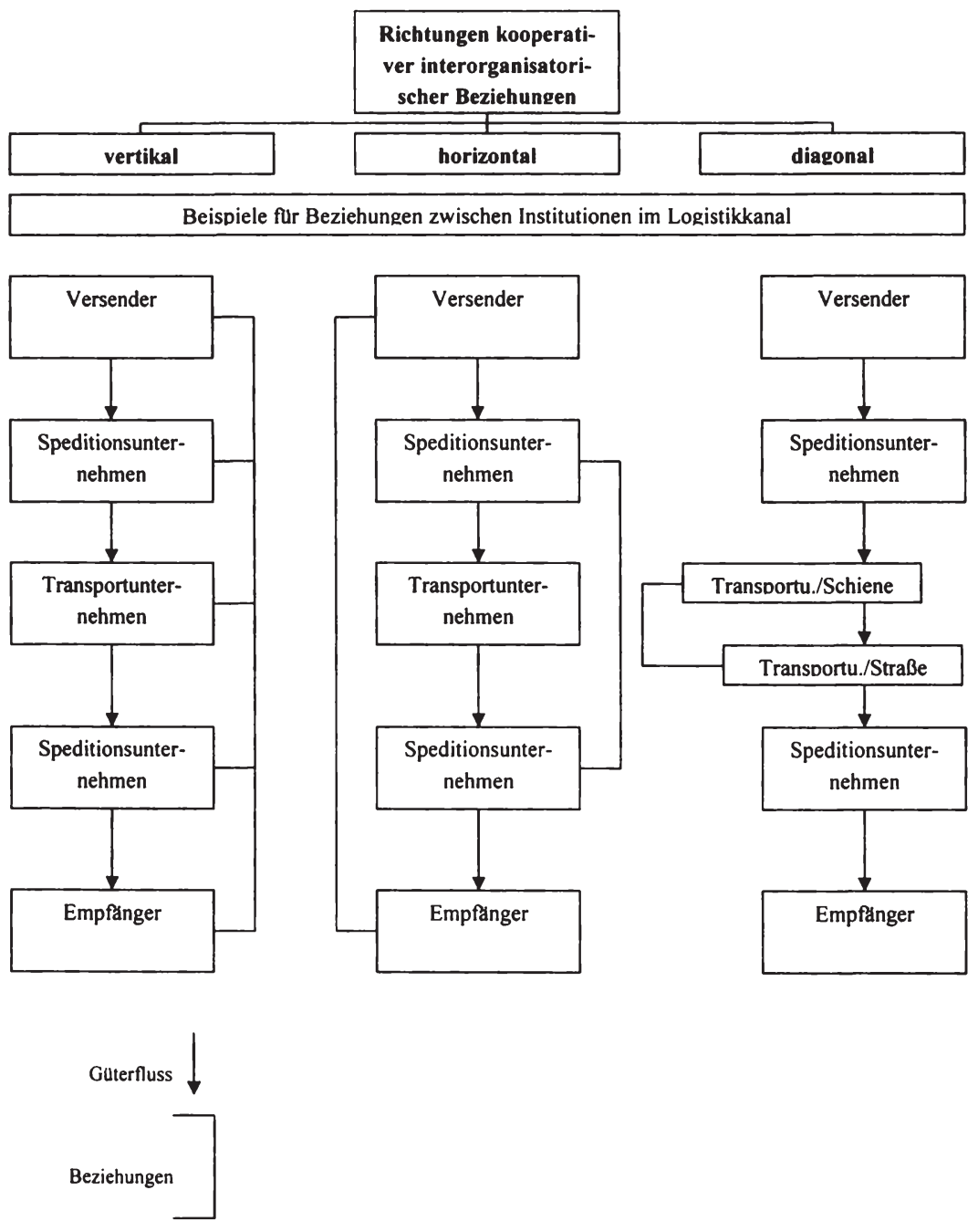

\section{Abbildung 2-21: Richtungen kooperativer interorganisatorischer Beziehungen}

Quelle: Freichel (1992), S. 61 
Zum Verhältnis zwischen überbetrieblichen und zwischenbetrieblichen Kooperationen

Die beiden Kooperationsformen können nicht trennscharf voneinander abgegrenzt werden, da eine gemeinsam getragene Institution im Rahmen einer per definitionem uberbetrieblichen Kooperation (bspw. ein Gemeinschaftsunternehmen) der Zusammenarbeit je nach ihrer Ausgestaltungsform schwerpunktmäßig sowohl zwischen- als auch überbetrieblichen Charakter geben kann. ${ }^{77}$ Daher wird alternativ vorgeschlagen, zur Charakterisierung unterschiedlicher Beziehungsebenen von interorganisatorischen Beziehungsgefügen mit und ohne Zentralorgan zu sprechen, wobei - sofern vorhanden - das Wesen des Zentralorgans (und damit mittelbar auch das Wesen des gesamten Beziehungsgefüges) über Art, Umfang und Intensität der ihm zugedachten Entscheidungs- und Ausführungsfunktionen und -aufgaben oder uber den Typus dessen institutionell-organisatorischer Verankerung im Beziehungsgefüge konkretisiert werden kann. ${ }^{78}$ Mögliche Ausprägungsformen interorganisatorischer Beziehungen ergeben sich dann zum einen auf der Ebene zwischen den Kooperationspartnern untereinander, auf der Ebene zwischen den Kooperationspartnern und dem Zentralorgan sowie ggf. auf der Ebene zwischen mehreren Zentralorganen. Die konkrete Ausgestaltung der Beziehungen auf den jeweiligen Ebenen in Bezug auf koordinationsrelevante Parameter (bspw. vertragliche Zementierung, leistungsmäßige Intensität, Funktionsumfang, Verflechtungsgrad oder Dauerhaftigkeit der Beziehungen) ist Ausdruck der Gewichtung, mit welcher die Elemente dezentraler (rein-marktlicher) und zentraler (hierarchischer) Koordination im betreffenden Kooperationsgebilde versehen sind und bestimmt somit den Charakter des gesamten kooperativen Beziehungsgefüges.

\subsection{Horizontale kooperative Arrangements im Logistikmarkt, dargestellt am Beispiel der System-Kooperationen im nationalen allgemeinen Stïckgutmarkt}

Relevanz und organisatorisch-institutionelle Grundkonstruktion von SystemStückgutkooperationen

Die Stückgutnetzwerke der System-Stückgutkooperationen mittelständischer Speditionen spielen im nationalen allgemeinen Stückgutmarkt eine wichtige Rolle, sie bilden 
das Gegengewicht zu den Netzwerken der großen, integrierten Konzerndienstleister und der sonstigen, konzernähnlichen Unternehmen. Angesichts der kundenseitigen Leistungsanforderungen hinsichtlich der Produktion und der Überwachung einer entsprechenden Servicequalität sowie angesichts der daraus resultierenden Anforderungen an den Leistungserstellungsprozess hinsichtlich

- durchgängiger Flächendeckung,

- Standardisierung der Abläufe,

- Optimierung der administrativen Abwicklungsprozesse und der

- Realisierung von Größenvorteilen

sind nur diese drei genannten Akteursgruppen in der Lage, die Leistung in anforderungsadäquater Form zu erbringen. ${ }^{79,80}$ Für mittelständische Speditionen ist der Beitritt zu einer System-Stückgutkooperation folglich die einzige Möglichkeit, erfolgreich am nationalen Stückgutmarkt teilnehmen zu können, da die Reichweite ihres eigenen unternehmensweiten Netzwerkes den kundenseitigen Leistungsanforderungen nicht genügen kann. ${ }^{81}$ Erst die horizontale Kooperation miteinander versetzt die Gruppe der mittelständischen Speditionen in die Lage, die Nachteile ihrer Kleinheit zu überwinden. ${ }^{82}$ So können sie ihr - durchaus vorhandenes - entsprechendes Prozess-Know-how marktfähig umsetzen ${ }^{83}$ und in das neue Marktfeld der nationalen Stückgutverkehrsleistung eindringen ${ }^{84}$. Im Jahr 2002/03 wurden knapp 40\% des gesamten Marktvolumens (ca. 5 Mrd. $€$ ) bzw. knapp 50\% des outgesourcten Marktvolumens (ca. 4 Mrd. $€$ ) des nationalen allgemeinen Stückgutmarktes über System-Stückgutkooperationen abgewickelt. ${ }^{85}$ System-Stückgutkooperationen bilden damit diejenige Akteursgruppe mit dem größten Umsatzanteil. ${ }^{86}$

Vgl. Tripp (2003), S. 17.

$\mathrm{Vgl}$. zu Leistungserstellungsprozess sowie zu den kritischen Erfolgsfaktoren im nationalen allgemeinen Stückgutmarkt auch Unterabschnitt 2.4.5.4.2.

Vgl. Wendlandt, Böttiger (2007), S. 18.

Vgl. Bjelicic (2003), S. 305.

Vgl. Kremer (2000), S. 77.

Vgl. Aberle (2003a), S. 85.

Vgl. Klaus (2003), S. 105.

Vgl. Tripp (2003), S. 17. 
Die organisatorisch-institutionelle Grundkonstruktion der System-Stückgutkooperationen weist im Grundsatz immer eine ähnliche Musterform auf: Es handelt sich stets um eine mehr oder weniger homogene Menge von mittelständischen Speditionsunternehmen, welche zum Zwecke der gemeinschaftlichen Organisation von nationalen Stückgutverkehren eine Interessengemeinschaft gründen und sich unter dem Dach einer gemeinsamen Systemzentrale zusammenschließen. Die Systemzentrale hat in der Regel die Rechtsform einer Kapitalgesellschaft ( $\mathrm{GmbH}$, selten auch $\mathrm{AG}$ ) oder einer GmbH \& Co. KG. In den als GmbH organisierten System-Kooperationen - der am weitesten verbreiteten formalrechtlichen Konstruktion - fungieren bspw. ausgewählte Partnerunternehmen als Gesellschafter und leisten eine Gesellschaftereinlage, aus deren Summe sich das Stammkapital der GmbH ergibt. Die Gesellschafter sind als Franchisegeber (in ihrer Eigenschaft als $\mathrm{GmbH}-$ Gesellschafter) und gleichzeitig als Franchisenehmer (in ihrer Eigenschaft als Speditionsunternehmen) tätig, mit weiteren Franchisenehmern werden Dienstleistungsverträge abgeschlossen. Aus der Summe der Gesellschafter (Franchisegeber) und der weiteren Franchisenehmer ergibt sich die Gesamtanzahl der Partnerunternehmen einer System-Stückgutkooperation. ${ }^{87}$

Der Systematik des vorangehenden Unterabschnitts folgend handelt es sich folglich um horizontale interorganisatorische Beziehungsgefuge mit Zentralorgan. Die SystemStückgutkooperationen in ihren verschiedenen real-marktlichen Ausprägungsformen unterscheiden sich nun sowohl was die Ausgestaltung der Beziehungen zwischen den Partnerunternehmen, als auch was die Ausgestaltung der Beziehungen zwischen Partnerunternehmen und dem Zentralorgan (d. h. der Systemzentrale) angeht. Eine grobe Charakterisierung dieser unterschiedlichen Beziehungsstrukturen zwischen den Kooperationsakteuren kann anhand der alternativen Geschäftsmodelle, auf deren Grundlage die System-Stückgutkooperationen sich bilden können, vorgenommen werden. Eine detailliertere Spezifizierung ließe sich allerdings nur anhand der Analyse der konkreten Strategien der am Markt aktiven System-Stückgutkooperationen hinsichtlich des Umganges mit aufbau- und ablauforganisatorischen Fragestellungen zur Gestaltung ihrer Stückgutverkehrsnetzwerke erreichen. ${ }^{88}$

\footnotetext{
87 Vgl. dazu Tripp (2003), S. 23 f. Vgl. für die Konstruktion der System-Kooperationen als Franchisesysteme und daraus etwaig resultierende doppelte Prinzipal-Agenten-Beziehungen Wendlandt, Böttiger (2007), S. $18 \mathrm{f}$.

Vgl. ausführlich Tripp (2003), S. 27 ff. und S. $30 \mathrm{ff}$.
} 


\section{Geschäftsmodelle zur Bildung von System-Kooperationen}

TRIPP unterscheidet mit der Produktions-Kooperation, der Marketing-Kooperation und der Risiko-Kooperation drei prinzipiell mögliche Geschäftsmodelle. ${ }^{89}$

Die Produktions-Kooperation stellt eine vergleichsweise offene und lose Form der am Markt praktizierten System-Stückgutkooperationen dar. Der Fokus liegt auf der Abwicklung der operativen Erstellung der Stückgutverkehrsleistung und auf der Abwicklung der dazugehörigen transportbezogenen Informations- und Zahlungsströme. Die Systemzentrale hat die Aufgabe, die Umschlagsprozesse im Zentralhub und, sofern vorhanden, in den Regionalhubs zu organisieren. Ferner entwickelt sie Empfehlungen für die Gestaltung der Verrechnungspreisstruktur für die Verteilung (,Delivery“) im Sammelguteingang, von denen die Partnerunternehmen allerdings im Rahmen bilateraler Einzelvereinbarungen abweichen können. Sämtliche Aufgaben im Bereich des Marketing und des Vertriebs hingegen obliegen allein den Partnerunternehmen und nicht der Systemzentrale. Vorteile der Produktions-Kooperation liegen in den großen Freiheitsgraden, die jedem Partnerunternehmen bei den eigenen unternehmerischen Entscheidungen zugestanden werden. Produktions-Kooperationen sind in der Regel offen für Unternehmen, welche schon in anderen Kooperationen Mitglied sind, Kooperationsmitglieder haben weitestgehend keine Einspeisungspflicht von Sendungen in das Systemnetzwerk. Nachteilig wirkt sich der extrem offene Charakter der Kooperation auf den Erfolg bei der Umsetzung von Maßnahmen zu Systemintegration, Standardisierung und Rationalisierung aus; Vorteile, welche aus derartigen Maßnahmen zu erwarten wären, können nicht voll umfänglich genutzt werden. Da das koordinierende Zentralorgan (die Systemzentrale also) in Produktions-Kooperationen systembedingt bewusst wenig Einfluss auf die Entscheidungsprozesse der Partnerunternehmen nimmt, stößt das System aufgrund der - oftmals konkurrierenden Einzelinteressen der Partnerunternehmen folgerichtig schnell an seine Systemgrenzen. Die Funktionsfähigkeit der Produktions-Kooperation ist eng an das Vorhandensein klarer Entscheidungskompetenzen und die Funktionsfähigkeit von Entscheidungsstrukturen innerhalb der Kooperation gekoppelt.

Das der Produktions-Kooperation entgegenstehende Geschäftsmodell ist das der Risiko-Kooperation. Risiko-Kooperationen sind dadurch gekennzeichnet, dass die Partnerunternehmen der Systemzentrale deutlich mehr Entscheidungskompetenzen übertragen und damit das Zentralorgan gestärkt wird. Die Vorteile des Modells einer 
Risiko-Kooperation liegen in den klaren Entscheidungsstrukturen und den bindenden Entscheidungsvorgaben der Systemzentrale. Sie zeichnet sich ferner durch ein straffes Key-Account-Management sowie klare Regelungen zu Fragen des Gebietsschutzes, der Partnerauswahl und der Gestaltung der Verrechnungspreise aus. Integrations- und Standardisierungsvorhaben sind bei Risiko-Kooperationen leichter und schneller durch- und umsetzbar - auf Kosten einer nicht unerheblichen Einschränkung der unternehmerischen Freiheit der einzelnen Partnerunternehmen aufgrund der Übertragung von Entscheidungskompetenzen in sämtlichen wesentlichen Fragestellungen auf die Systemzentrale. Zwar ist die Risiko-Kooperation im Stückgutmarkt bislang ein theoretisches Konstrukt, welches am Markt noch keine Umsetzung gefunden hat. Es ist aber durchaus denkbar, dass dieses Geschäftsmodell in Zukunft Realität werden könnte, da hier die Vorteile der Koordination durch Kooperation mit den Vorteilen der Koordination durch Hierarchie gekoppelt werden könnten. Insbesondere die bekannten Risiken wie Netzwerkunsicherheit oder Finanzierungsschwierigkeiten, mit denen sich traditionelle mittelständisch geprägte System-Stückgutkooperationen konfrontiert sehen, könnten abgemildert werden. In jedem Fall würde eine Kooperation nach diesem Muster aufgrund ihrer konzernähnlichen Organisation in die Nähe eines konzentrativen Beziehungsgefüges rücken.

Zwischen den beiden vorgenannten Kooperationskonstrukten ist die MarketingKooperation angesiedelt. Sie stellt einen gangbaren Mittelweg dar, welcher am Markt auch praktiziert wird. Die Zusammenarbeit ist hier breiter angelegt als in der Produktions-Kooperation, da auch bestimmte Fragen des Marketing (einheitlicher Marken- und Kommunikationsauftritt mittels Corporate Identity, Corporate Design) und des Vertriebs (Key-Account-Management) zentralisiert über die Systemzentrale als Vermarktungs- und Kommunikationsplattform gelöst werden. Ferner bestehen mehr oder weniger strikte Vorgaben der Systemzentrale hinsichtlich der Regelungen zu Gebietsschutz, Partnerauswahl, Verrechnungspreisgestaltung etc., ohne dass jedoch die ökonomische Selbstständigkeit der Partnerunternehmen in dem Ausmaß beschränkt wird, wie das in der Risiko-Kooperation der Fall ist. Real-marktliche Ausprägungsformen von Marketing-Kooperationen können im Detail allerdings sehr vielfältig sein und sich in Einzelheiten tendenziell entweder in unmittelbarer Nähe zur sehr losen Produktions-Kooperation bewegen, oder aber an der Schwelle zur konzernähnlichen Risiko-Kooperation stehen. 
Kooperationsmotive und -hemmnisse: Stärken, Schwächen, Chancen und Bedrohungen von System-Stückgutkooperationen

Das Arrangement aus Kooperationsmotiven und -hemmnissen ergibt sich aus dem Bestreben der Speditionsunternehmen, Potenziale bzw. Stärken und Chancen der Kooperation zu nutzen und gleichzeitig deren Schwächen möglichst zu kompensieren und deren Risiken zu vermeiden. TRIPP kommt im Vergleich zu Stückgutnetzwerken von Konzernunternehmen oder konzernähnlichen Unternehmen zu folgenden Schlussfolgerungen bezüglich der Stärken und Schwächen von, sowie Chancen und Bedrohungen für System-Stückgutkooperationen: ${ }^{90}$

Zu den Stärken der mittelständisch geprägten System-Stückgutkooperationen gehören sicherlich die lokale bzw. regionale Marktpräsenz und Marktstärke der Partnerunternehmen und - damit verbunden - die Möglichkeit zu nachhaltiger, intensiver Kundenbindung durch persönliche Kontakte und räumliche Nähe zwischen den Entscheidungsträgern aus Spedition und Verladerschaft. Ferner wird in SystemStückgutkooperationen ein hohes $\mathrm{Ma} ß$ an Einheitlichkeit und Geschlossenheit erreicht, sowohl was die Flächendeckung des Leistungsangebots betrifft, als auch was die Definition, Einhaltung und Überwachung von Leistungsqualität und Qualitätsstandards (Liefer- und Termintreue, Sendungsverfolgungssysteme, durchgängige operative und administrative IuK-Systeme) anbelangt. Darüber hinaus sind System-Stückgutkooperationen in der Lage, gemeinsam dasjenige kritische Sendungsvolumen - bzw. die „kritische Masse“ - zu generieren, welche/s notwendig ist, Größeneffekte bzw. Netzeffekte zu realisieren.

Schwächen der System-Stückgutkooperationen ergeben sich hauptsächlich aus dem bereits oben zitierten Spannungsfeld zwischen Autonomie und Interdependenz bei kooperativer Zusammenarbeit - dem Zielkonflikt, welcher sich zwischen individuellen Zielen der Partnerunternehmen und den Zielen des Gesamtnetzwerks auftut. Dabei zeigt sich die Kooperation gegenüber der Konzernunternehmung insbesondere dadurch im Nachteil, dass in Kooperationen jedes Partnerunternehmen eigenwirtschaftlich planen und Gewinne erwirtschaften muss, wohingegen in Konzernunternehmen nicht gewinnbringende Niederlassungen quersubventioniert werden können, da das betriebswirtschaftliche Ergebnis der Gesamtunternehmung im Vordergrund steht. Zudem wäre in diesem Kontext die mangelnde Zielkongruenz der Zielsysteme der einzelnen Partnerunternehmen zu nennen. Ein weiterer Schwachpunkt ist die inhärente Netzwerkinstabilität, welche sich bspw. aufgrund der ständigen Gefahr von Insolven- 
zen $^{91}$ oder aufgrund ungelöster Unternehmensnachfolgeprobleme einzelner Partner ergibt. Ferner behindert eine durch etwaige Finanzierungs- oder Liquiditätsprobleme verursachte Investitionsunfähigkeit einzelner Partnerunternehmen die Entwicklung des Gesamtnetzwerks. Auch die Komplexität der Entscheidungsstrukturen innerhalb der Führungsgremien in System-Stückgutkooperationen schaffen Probleme: Entscheidungsfindungsprozesse sind transaktionskostenintensiv und fuihren nicht selten zu ineffizienten, suboptimalen Entscheidungen. ${ }^{92}$ Dies gilt insbesondere dann, wenn im Rahmen von Entscheidungsfindungsprozessen auf Partialinteressen Rücksicht genommen werden muss.

Chancen für System-Stückgutkooperationen, welche sich aus den Veränderungen der Rahmenbedingungen der Logistikmärkte ergeben, liegen vor allem im Mittelstandscharakter der Kooperationen begründet. System-Stückgutkooperationen werden von der (insbesondere mittelständischen) Verladerschaft ausdrücklich als alternatives Konstrukt zu Konzerndienstleistern und konzernähnlichen Dienstleistungsunternehmen begrüßt. Zudem versetzt das gemeinsame Stückgutnetzwerk die Partnerunternehmen in die Lage, auch in anderen Logistikleistungsbereichen miteinander $\mathrm{zu}$ kooperieren und ihr gemeinsames Angebotsportfolio bspw. um Kontraktlogistikdienstleistungen zu erweitern. Ferner können die System-Stückgutkooperationen ihr nationales Netzwerk sowie die Erfahrungen, die im nationalen Stückgutmarkt gesammelt worden sind dazu nutzen, um gemeinsame europäische Netzwerke aufzubauen.

Bedrohungen ergeben sich für die Kooperationen insbesondere durch die Stärke, mit der die Konzernunternehmen am Markt agieren, sowohl was deren operative und IuKtechnische, als auch was deren finanzielle Leistungsfähigkeit anbelangt. Auch das weit fortgeschrittene Stadium, in welchem sich die Umsetzung der Europastrategien der Konzernunternehmen befindet, begründet bei den Kooperationen schnellen Handlungsbedarf - insbesondere auch deshalb, weil die Verladerschaft die europäische Netzabdeckung im Bereich der Stückgutverkehre immer vehementer nachfragt. Zudem sehen sich viele mittelständische Kooperationsverbünde zunehmend der Situation gegenübergestellt, dass die großen netzlosen Konzern-Logistikdienstleister, welche vorwiegend nicht-netzgebundene Logistikleistungen erbringen (bspw. hochwertige Kontraktlogistikleistungen, Supply Chain Management), versuchen, durch Akquisition einzelner Kooperationspartnerunternehmen Zugang zu deren Stückgutnetzwerk zu

91 Vgl. ähnlich auch Bretzke (2006), S. 1.

92 Vgl. ähnlich auch Bretzke (2006), S. 1. 
erlangen. ${ }^{93}$ Diese Strategie ist ein Ausdruck der erkannten Notwendigkeit seitens der netzlosen Konzern-Logistikdienstleister, ihr Leistungsportfolio um diverse Netzwerkkomponenten zu erweitern, um ihre „strategische Lücken“ aufzufüllen. ${ }^{94} \mathrm{Ihr}$ strategisches Ziel ist es dabei, sich in Richtung eines „Vollsortimenters" zu bewegen, welcher in der Lage ist, SCM-Kompetenzen und Netzwerkkompetenzen zusammenzufuhren und dadurch alle Logistiksegmente in integrierter Form anzubieten. ${ }^{95}$

Angesichts der soeben skizzierten Entwicklungen wirft KLAUS die Frage auf, ob die System-Stückgutkooperationen auf Dauer bestehen können, oder ob sie früher oder später in Konzernorganisationen eingegliedert werden, ${ }^{96}$ wie das im KEP-Markt bereits geschehen ist. ${ }^{97}$

\section{Exkurs: Marktstrukturentwicklung KEP-Markt}

Der Teilmarkt 11 (KEP - Paket, echte Kurier- und spezialisierte Expressdienste) und hier wiederum insbesondere der Markt für integrierte, standardisierte Paketfrachtsysteme als das umsatz- und mengenmäßig bedeutendste Teilmarktsegment des Teilmarktes 11 , ist durch eine außerordentlich hohe Marktkonzentration gekennzeichnet. ${ }^{98}$ Nachdem in den frühen 1990er Jahren neben den großen Integrators auch einige mittelständisch geprägte Kooperationen wie bspw. der Deutsche Paketdienst (DPD) oder German Parcel (GP) zu den dominierenden Marktakteuren zählten, hat sich die Anbieterlandschaft im KEP-Markt bis heute fundamental verändert. ${ }^{99}$ Dies ist im Wesentlichen auf die Aktivitäten der großen nationalen Postgesellschaften zurückzuführen, welche seit Mitte der 1990er Jahre mittels umfangreicher Akquisitionstätigkeiten - oftmals ausgerichtet auf nationale Konkurrenten - in den KEP-Markt eingedrun-

Als markantes Beispiel dafür kann die System-Stückgutkooperation IDS dienen, welche ursprünglich als nationale mittelständische Kooperation gegründet wurde und sich in der Folgezeit zu einer führenden Mittelstandkooperation im deutschen Markt entwickelt hat. Heute wird die IDS mit dem schweizerischen Logistikunternehmen Kühne \& Nagel sowie der dänischen DFDS Transport Group von zwei konzernartigen Logistikdienstleistern dominiert, welche jeweils einen Transportanteil von rund $30 \%$ - zusammen also rund $60 \%$ - innehaben. Die mittelständischen IDS-Gesellschafter sind mit rund 40\% Transportanteil demnach bereits in der Minderheit. Kühne \& Nagel sowie DFDS haben seit 2003 mehrere IDS-Gesellschafterunternehmen mit der Zielsetzung aufgekauft, ihre jeweilige Netzwerkkompetenz auszuweiten. Vgl. Held, Steckler (2007), S. 458; Klaus, Kille (2006), S. 114.

94 Lieb, Lange (2003), S. 455.

95 Vgl. Lieb, Lange (2003), S. 455.

96 Vgl. Klaus (2003), S. $105 \mathrm{f}$.

97 Vgl. Klaus, Kille (2006), S. 114.

98 Vgl. Klaus (2003), S. 130.

99

Vgl. Klaus, Müller-Steinfahrt (2000), S. 133; Helmke (2006), S. 1. 
gen sind ${ }^{100}$ Seither beherrschen die Integrators und die nationalen Postgesellschaften uber ihre Tochterunternehmen und Beteiligungen den KEP-Markt maßgeblich. Neben den Integrators UPS (United Parcel Service) und FedEx (Federal Express) sind die Deutsche Post World Net/DHL Worldwide, die Niederländische Post mit TNT (Thomas Nationwide Transport), die Französische Post mit dem DPD und die Britische Post mit GLS (General Logistics System) - vormals GP - auf dem KEPMarkt aktiv, wobei UPS, FedEx, TNT und DHL weltweit agieren und die Französische (DPD) sowie die Britische Post (GLS) sich auf den europäischen Markt konzentrieren. ${ }^{101}$ Bezogen auf den nationalen, deutschen KEP-Markt sind in diesem Zusammenhang vornehmlich die Integration der Paketnetzwerke der mittelständischen Speditionskooperationen DPD und GP in die Konzernstrukturen der Französischen und der Britischen Post durch Akquisition sowie die Zusammenführung der Netzwerke der Deutschen Post und des Integrators DHL als relevante Entwicklungen zu betrachten.

\section{Exkurs Ende}

\subsection{Vertikale kooperative Arrangements im Logistikmarkt, dargestellt am Beispiel des Konzeptes des Supply-Chain-Managements}

\section{Zu Begriff und konzeptionellen Grundlagen des Supply-Chain-Managements}

Das Konzept des Supply-Chain-Managements (SCM-Konzept) stellt einen vertikalkooperativen Lösungsansatz zur unternehmensübergreifenden Optimierung von „Supply Chains" dar. ${ }^{102}$ In der Definition von KLAUS umfasst der Begriff der Supply Chain dabei die Abfolge von Aktivitäten, welche notwendig sind, um Kunden bzw. Märkte erfolgreich zu versorgen. ${ }^{103}$ Diese Definition macht deutlich, dass sich das SCM-Konzept nicht auf die bloße Abarbeitung klassischer logistischer Fragestellungen verengen lässt, sondern sowohl in Fragen der Dimensionierung und Intensität institutionell-organisatorischer Verflechtungsstrukturen als auch in Fragen der inhaltlichen Tiefe und Breite der Zusammenarbeit zwischen den Beteiligten in der Supply Chain weit darüber hinausgeht. Nichtsdestotrotz jedoch bilden logistische

\footnotetext{
100 Vgl. Helmke (2006), S. I.

101 Vgl. Helmke (2006), S. 1.

102 Vgl. Zentes, Janz (2002), S. D3-31.

103 Vgl. Klaus (2000b), S. 449.
} 
Fragestellungen den zentralen Ausgangs- und Bezugspunkt vieler SCM-Aktivitäten. ${ }^{104}$ Dies ist auch einleuchtend, wenn man sich vergegenwärtigt, dass sich sämtliche SCMAktivitäten doch offenkundig auf der Grundlage logistischer Basisprinzipien (Flussbzw. Prozessorientierung, Ganzheitlichkeit des Denkansatzes) vollziehen. ${ }^{105}$ Das SCM-Konzept kann somit vor diesem Hintergrund als umfassendere, auch nichtlogistische Aktivitäten beinhaltende konzeptionelle Deutung und Fortführung der ganzheitlichen, systemischen Perspektive und der Güterflussorientierung aufgefasst werden - derjenigen Grundgedanken also, welche in Unterabschnitt 2.2.2.2.3 als wesentliche Konzeptmerkmale der Logistik hervorgehoben wurden. ABERLE interpretiert das SCM-Konzept daher auch als höhere Entwicklungsstufe einer modernen Logistikkonzeption, deren Zielsetzung die Optimierung der gesamten Wertschöpfungsprozesse im Netzwerk von Hersteller, Handel und Logistikdienstleister auf der Basis kooperativer Arrangements im Logistik- bzw. Wertschöpfungsnetzwerk ist. ${ }^{106}$ Ein Industrie- oder Handelsunternehmen, welches SCM einführt, koppelt dabei seine Geschäftsprozesse mit denen eines Lieferantennetzwerks sowie mit denen eines Kundennetzwerks, wobei die Logistikaktivitäten des so entstandenen Wertschöpfungsnetzwerkes wiederum innerhalb einer Kooperationsbeziehung zu einem Netzwerk von Logistikdienstleistern koordiniert und abgewickelt werden. ${ }^{107}$

Dementsprechend besteht der zentrale Ansatzpunkt von SCM darin, sämtliche Aktivitäten und Geschäftsprozesse der Unternehmen entlang der Supply Chain auf der prozessualen Ebene dergestalt zu synchronisieren, dass die typischen Schnittstellenprobleme, welche sich im Zuge (1) der dezentralen Entscheidungsstrukturen - jedes Unternehmen in der Supply Chain trifft prinzipiell seine Logistikentscheidungen eigenständig und isoliert von den anderen Beteiligten in der Supply Chain - und (2) des diesen Entscheidungen zwangsläufig zugrunde liegenden asymmetrisch verteilten, unvollständigen Bestandes an Informationen ergeben, überwunden werden. Im SCM ist daher die Suche nach unter diesen spezifischen Rahmenbedingungen vorteilhaften Ausgestaltungsformen der Leistungskoordination - insbesondere bezogen auf deren institutionelle Verankerung - zwischen den Beteiligten in der Supply Chain von großer Relevanz. ${ }^{108}$ Dem kooperativen Charakter des SCM-Ansatzes und der darauf ausgerichteten Synchronisation auf der Prozessebene entsprechend werden für die Gestaltung des SCM auf institutioneller Ebene gleichfalls kooperative Arrangements 
gewählt. Diese allerdings können im konkreten Fall ein unterschiedliches Kooperationsausmaß, d. h. unterschiedliche Kooperationsintensität (gemessen an der Kooperationsbreite und -tiefe zwischen den Kooperationspartnern) und unterschiedlichen Kooperationsumfang (gemessen am Anteil des gesamten Güterflusses eines Kooperationspartners, den dieser an einen anderen Kooperationspartner outsourct) ${ }^{109}$ annehmen. Eine wesentliche Entscheidungsgrundlage für die diesbezüglich zu installierende konkrete Ausgestaltungsform der kooperativen Arrangements zwischen Supply-ChainPartnern sind im Vorfeld der vertraglichen Fixierung der Kooperationsbeziehungen angestrengte kollektive Effizienzüberlegungen. Eine wichtige Komponente dieser Effizienzüberlegungen bilden Überlegungen zur Supply-Chain-übergreifenden (Re-) Konfiguration und Optimierung von Leistungstiefenstrukturen (anders formuliert: Supply-Chain-weite Make-or-Buy-or-Cooperate-Entscheidungsfindungsprozesse) der Supply-Chain-Beteiligten. Ziel der schlussendlich zustande gekommenen kooperativen Arrangements muss es sein, das kategorische Denken in bereichsbezogenen und institutionell abgegrenzten Verantwortlichkeiten für einzelne Teile der Supply Chain zu überwinden und in ein übergreifendes Denken in Prozessverantwortlichkeiten für die gesamte Supply Chain zu überführen. ${ }^{110}$ Die erfolgreiche Umsetzung des SCMKonzeptes erfordert hohe Kooperations- und Logistikkompetenz der in das jeweilige SCM-Projekt involvierten Parteien - insbesondere vor dem Hintergrund der bereits mehrfach hervorgehobenen ständig wachsenden institutionellen und materiellen Komplexität, welche durch vielgestaltige, outsourcinggetriebene Ausgestaltungsformen arbeitsteiliger Leistungserstellungsprozesse sowie durch die räumliche Ausdehnung der Supply Chains in das Logistiksystem hineingetragen wird. ${ }^{\prime \prime}$

Der SCM-Gedanke wurde und wird im Logistikmarkt bereitwillig adaptiert und greift in Form vielfältiger realer Ausprägungen vertikaler kooperativer Arrangements Platz, wobei sich die realen Ausprägungsformen des SCM-Konzeptes auf unterschiedlichen Umsetzungsstufen hinsichtlich der Durchgängigkeit und des Ausmaßes der Kooperationsbeziehungen in der Supply Chain befinden. Dabei sind insbesondere konzeptionelle Vorstufen von SCM in Form von Kontraktlogistikpartnerschaften im Logistikmarkt seit Längerem gebräuchliche Unternehmenspraxis. ${ }^{12}$ Daneben existieren jedoch auch neuere Konzepte in weiter fortgeschritten€n Umsetzungsstadien. Zu nennen ist hier bspw. das Konzept des Efficient Consumer Response (ECR) im Konsumgütersektor,

\footnotetext{
108

Vgl. Jammernegg, Trcka (1999), S. 209; Ihde (2001), S. 17.

Vgl. zum Begriff des Kooperationsausmaßes ausführlich Pfohl (2004a), S. 320 ff.

Vgl. Ihde (2001), S. 313.

111 Vgl. Eisenkopf et al. (2002), S. 41.
} 
welches auf die kooperative Zusammenarbeit zwischen Hersteller und Handel zur auf Verbraucherbedürfnisse ausgerichteten und an Effizienzzielen orientierten Optimierung der gemeinsamen Wertschöpfungskette ausgerichtet ist. ${ }^{113}$ Das konzeptionelle Rückgrat eines funktionsfähigen ECR bilden (1) ein ausgereiftes SCM auf der Ebene der Logistikprozesse sowie (2) eine kooperative Zusammenarbeit im Marketing. ${ }^{114} \mathrm{Der}$ Fokus von ECR liegt dabei auf der IuK-technischen Integration der Geschäftsprozesse der Industrie- und Handelsunternehmen zum Zwecke der Optimierung der Distributionslogistik. $^{115}$

Aufgrund der Tatsache, dass ein funktionsfähiges SCM inhaltlich-konzeptionell auf der Adaption der Basisprinzipien der Logistikkonzeption beruht und institutionellorganisatorisch betrachtet auf einem stabilen und dauerhaften vertikal-kooperativen interorganisatorischen Beziehungsgefüge fußt, kann das SCM-Konzept in allen seinen Umsetzungsstadien sowie mit allen seinen Vorstufen folgerichtig in den Objektbereich der vertikalen metalogistischen Systeme verortet werden. ${ }^{116}$ In SCM-Partnerschaften fungiert in der Regel ein Unternehmen, meist ein Logistikdienstleister, als Koordinator in der Supply Chain. Dieser Supply-Chain-Koordinator hat die Aufgabe, die operativen und IuK-technischen Leistungserstellungssysteme und die Supply Chain zu gestalten, zu steuern und zu kontrollieren. Dieser Supply-Chain-Koordinator wird bisweilen mit dem Begriff des 4 PL assoziiert, welcher als vierte Kraft neben Versender, Empfänger und ausführenden Logistikunternehmen agiert. ${ }^{17}$ Der 4 PL hat im Rahmen eines SCM-Projektes die Aufgabe, die gesamte Supply Chain vertikal zu integrieren und gesamthaft zu planen und zu steuern. ${ }^{118}$

Im Folgenden werden vertikale kooperative Arrangements zwischen verladenden Unternehmen aus Industrie und Handel sowie Logistikunternehmen, welche eine zentrale Komponente innerhalb des SCM-Ansatzes sowie innerhalb aller seiner konzeptionellen Vorstufen darstellen, betrachtet und Kooperationsmotive aus Sicht der beiden Kooperationsparteien beleuchtet.

Vgl. Lieb, Lange (2003), S. 455.

Vgl. Tucher, Frhr. v., Wiezorek (2000), S. 104; Kotzab (1999), S. 227 ff.; Pfohl (2004a), S. 214.

Vgl. Aberle (2003a), S. 514; Tucher, Frhr. v., Wiezorek (2000), S. 104.

Vgl. Arnold, Eßig (2002), S. D3-24.

Vgl. Kotzab (1999), S. 220.

Vgl. Klaus (2003), S. 110; Vgl. zum 4PL ausführlich auch Unterabschnitt 2.4.5.2.4.

Vgl. Pfohl (2004b), S. 27. 


\section{Motive für die Bildung vertikaler kooperativer Arrangements in der Kontraktlogistik bzw. im SCM aus Sicht der verladenden Unternehmen aus Industrie und Handel}

Motive für das Einrichten längerfristiger, vertikaler kooperativer Arrangements mit Logistikunternehmen gründen aus Sicht der Verlader auf folgenden Argumenten, welche typischerweise als Vorteile derartiger Arrangements vorgebracht werden: ${ }^{19}$

- Die Verladerunternehmen erhalten die Möglichkeit, die Nutzung ihrer unternehmenseigenen Ressourcen und Kräfte auf die eigenen Kernkompetenzen zu konzentrieren. Sie erreichen dadurch eine Fokussierung ihrer Geschäftsprozesse auf - aus ihrer Sicht - wertschöpfende Prozesse und reduzieren gleichsam die Systemkomplexität in ihren Unternehmen.

- Die Verladerunternehmen erreichen (strategische) Kostensenkung bei gleichzeitiger Leistungsverbesserung durch das Ausnutzen von Spezialisierungsvorteilen auf Seiten des Logistikunternehmens. Diese Spezialisierungsvorteile äußern sich in Größen- und Verbundvorteilen, welche sich bspw. aus der parallelen Übernahme ähnlicher Leistungen für unterschiedliche Verlader, aus der Häufigkeit der Dienstleistungserstellung ${ }^{120}$ oder aus einer Reduktion der Verweildauer der Güter im Logistiksystem durch den Einsatz entsprechender Produktionstechnologien und Kompetenzen ergeben. Spezialisierungsvorteile ergeben sich sowohl im Bereich der operativen Logistikleistungserstellung als auch im Bereich der die Logistikabwicklung unterstützenden IuK-Technologien. Beide Bereiche gehören zu den Kernkompetenzen entsprechend spezialisierter Logistikunternehmen. Je spezifischer, individueller und komplexer die Logistikleistung eines Logistikunternehmens ist, welche es für ein Verladerunternehmen bereitstellt, desto eher wird der Verlader bereit sein, das Investitionsrisiko des Logistikunternehmens über einen längerfristigen Kooperationsvertrag abzusichern, weil das Logistikunternehmen dann aus Sicht des Verladers weniger austauschbar ist. ${ }^{121}$ Folglich determiniert der Grad der Spezifität der Logistikleistung den Bindungsgrad des jeweiligen institutionellen Arrangements. ${ }^{122}$

- Die Verladerunternehmen können bei Kooperation mit entsprechend spezialisierten Logistikunternehmen in SCM-Projekten die transaktions- und produkti-

Vgl. für das Folgende Stein (2000), 244; Tripp (2004), S. 10; Kersten, Koch (2007), S. $117 \mathrm{ff.}$

Pfohl (2007), S. 65.

Vgl. Wendlandt, Böttiger (2007), S. 24.

Vgl. Wendlandt, Böttiger (2007), S. 24. 
onskostensenkende Integrationskompetenz und -fähigkeit derjenigen Logistikunternehmen nutzen, deren Kernkompetenzen in der Integration der an der Supply Chain beteiligten Unternehmen, in der Beherrschung der Komplexität logistischer Prozesse sowie in der Bewältigung von Koordinationsproblemen an den Unternehmensschnittstellen liegen. ${ }^{123}$

- Zudem kann sich die Serviceleistung, gemessen in Logistikprozessqualität und Logistikprozesssicherheit, durch eine Kooperationspartnerschaft mit einem entsprechend spezialisierten Logistikunternehmen verbessern.

- Ferner ergibt sich (kurzfristiges) Kostensenkungspotenzial durch die Möglichkeiten zur Branchenarbitrage, d. h. die Möglichkeiten zur Ausnutzung branchenbezogener Unterschiede bezüglich Lohnkosten, Arbeitszeiten oder Arbeitsproduktivitäten zwischen dem Industrie- und Dienstleistungssektor.

- Ein weiterer Vorteil ist die Möglichkeit zur Variabilisierung von Logistikkosten, welche unabhängig von der Inanspruchnahme von Leistungen sind und bei Eigenproduktion folglich Fixkostenblöcke darstellen würden. Diese Fixkostenblöcke würden zudem wahrscheinlich aufgrund von minderauslastungsbedingten Größennachteilen ein vergleichsweise höheres absolutes Kostenniveau haben.

- Als Nebeneffekt ergibt sich schließlich im Falle einer Partnerschaft zwischen Verlader und Logistikunternehmen eine Erhöhung der Logistikkostentransparenz.

\section{Motive für die Bildung vertikaler kooperativer Arrangements in der Kontraktlogistik bzw. im SCM aus Sicht der Logistikunternehmen}

Aus Sicht der Logistikunternehmen werden folgende Argumente als Vorteile für vertikale kooperative Arrangements vorgetragen: ${ }^{124}$

- Logistikunternehmen profitieren von der höheren Bindungsfestigkeit kooperativer Arrangements im Vergleich zu „normalen“ Geschäftsbeziehungen. Diese höhere Bindungsfestigkeit ergibt sich zum einen aus der Notwendigkeit zur intensiveren Interaktion und zum intensiveren Informationsaustausch mit den 
Verladern, um kundenindividuelle SCM-Projekte in anforderungsgerechter Leistungsqualität umsetzen zu können. ${ }^{125}$ Zum anderen ergibt sie sich aus der Notwendigkeit für die Logistikunternehmen, ihre - in aller Regel anfallenden spezifischen Investitionen in das gemeinsame SCM-Projekt aufgrund der damit einhergehenden (oft gegenseitigen) investitionsrisikobedingten Abhängigkeit über längerfristige Kooperationsverträge abzusichern. ${ }^{126}$ In diesem Zuge werden Logistikunternehmen, verglichen mit Spotmarkt-Transaktionen, weniger leicht austauschbar.

- Die fortdauernde Integration in die Geschäftsprozesse der Verlader, welche die gemeinsame Logistikaufgabenerfüllung bedingt, erlaubt es dem Logistikunternehmen zum einen, Folgegeschäfte zu akquirieren. Zum anderen nimmt der Grad der Austauschbarkeit für die Logistikunternehmen mit zunehmender Dauer und Intensität der Kooperationsbeziehung weiter ab, weil die kontinuierliche Integration in die Geschäftsprozesse der Verlader über eine Anpassung des Dienstleistungsangebotes zusätzliche Kundennutzen schafft und gleichzeitig aufgrund von Wissensnachteilen die Eintrittsbarrieren in die Kooperationsbeziehung für Wettbewerber exorbitant hoch werden.

- Ferner realisieren Logistikunternehmen in vertikalen kooperativen Beziehungen, welche höherwertige Logistikleistungen zum Gegenstand haben, in der Regel höhere Renditen als dies mit dem Angebot von Basisleistungen (Transportieren, Umschlagen, Lagern) möglich ist. ${ }^{127}$ Die Wertschöpfungspartnerschaften sind vor allem dann nachhaltig, wenn sich zwischen den Kooperationspartnern eine Win-Win-Situation einstellt, d. h. dass die Logistikunternehmen ihre überdurchschnittlichen Renditen bei gleichzeitiger Leistungsverbesserung und Kostenreduktion auf Seiten der Verlader realisieren. 
Hemmnisse für die Bildung vertikaler kooperativer Arrangements in der Kontraktlogistik bzw. im SCM aus Sicht der verladenden Unternehmen aus Industrie und Handel und aus Sicht der Logistikunternehmen

Aus Sicht der Verlader werden folgende Faktoren vorgetragen, welche die Bildung von vertikalen Kontraktlogistik- und SCM-Kooperationen beeinträchtigen: ${ }^{128}$

- Verlader verlieren die Kontrolle über die Logistik. Dies ist insbesondere deshalb problematisch, da es sich bei Logistikprozessen um Prozesse handelt, welche stets eine hohe Relevanz für die Kundenzufriedenheit haben und welche bei Schlechtleistung sofort negativ vom Kunden wahrgenommen werden.

- Verlader heben einen Abfluss von Logistikkompetenz zu fürchten, welcher je nach Umfang und Tiefe der kooperativen Zusammenarbeit - die operativen Logistikprozesse oder gar die Planungs- und Kontrollprozesse umfassen kann.

- Für die Verlader verringert sich das Ausmaß der Kundenbindung. Insbesondere die Kooperation mit Logistikunternehmen im Bereich der Distributionslogistik, welche ja unmittelbaren Kontakt mit dem Kunden impliziert, kann dazu führen, dass sowohl die emotionale Kundenbindung leidet als auch dass dem Verladerunternehmen wichtige Kundeninformationen verloren gehen.

- Die Abhängigkeit vom Logistikunternehmen wächst für den Verlader. Dies ist vor allem deshalb kritisch, weil der Verlader ja wissentlich die Logistikkompetenz aus der Hand gibt und aufgrund der hohen Spezifität der Kontraktlogistik- bzw. SCM-Transaktionen bei Schlecht- oder Nichtleistung des Dienstleisters in der Regel nicht oder nur mit hohem Aufwand korrigierend eingreifen kann. Darüber hinaus ist der Logistikdienstleister selbst bei Schlechtleistung aufgrund der hohen Spezifität der kundenindividuellen Kontraktlogistik- oder SCM-Leistungen nur schwer auswechselbar.

Auch aus Sicht der Logistikunternehmen ergeben sich Problempunkte beim Eingehen von Kontraktlogistik- bzw. SCM-Kooperationen: ${ }^{129}$ 
- Der hohe Spezifitätsgrad der Kontraktlogistik- bzw. SCM-Leistung erfordert in der Regel bereits in einer sehr frühen Phase der Kooperation Investitionen in das Kooperationsprojekt seitens der Logistikunternehmen.

- Insbesondere in der Phase der Projektausschreibung besteht für das Logistikunternehmen die Gefahr, dass eigene Logistikkompetenz an den potenziellen Kooperationspartner oder - durch Offenlegung von Logistikangeboten - auch an konkurrierende Logistikunternehmen abfließt.

Die hier angesprochenen Problempunkte dokumentieren sich per saldo in einem wechselseitigen Abhängigkeitsverhältnis. Um dieses wechselseitige Abhängigkeitsverhältnis handhaben zu können und die daraus erwachsenden Gefahren für die Kooperation zu beherrschen, ist es unbedingt erforderlich, dass beide Seiten vertrauensbildende Signale aussenden und dass die Gestaltung des Kooperationsvertrages geeignet ist, (1) potenziell opportunistische Verhaltensweisen der Kooperationspartner ausreichend zu sanktionieren und (2) finanzielle Risiken ausreichend abzusichern. Nur wenn die Kooperationshemmnisse überwunden werden, können die Wirkungspotenziale der Kooperation auch realisiert werden.

\subsubsection{Konzentrative Arrangements: Elemente hierarchischer Koordination im Logistikmarkt}

\subsection{Ausprägungsformen und Beziehungsrichtungen unternehmerischer Konzentrationsstrategien}

Hohe Konzentrationsgrade sind das Ergebnis von Konzentrationsprozessen. Konzentrationsprozesse wiederum können sowohl durch externe als auch durch interne Wachstums- und Konzentrationsstrategien von Unternehmen angestoßen werden. ${ }^{130}$ Dabei steht das externe Unternehmenswachstum im Zentrum wettbewerbspolitischer Betrachtungen, da es sich - im Vergleich zum internen Wachstum - wesentlich schneller vollzieht und seine Auswirkungen folglich schneller evident sind. ${ }^{131}$

130 Vgl. Herdzina (1999), S. 184; Koch, Czogalla (2004), S. 62.

131 Vgl. Schmidt, Röhrich (1992), S. 179. 


\section{Externes Unternehmenswachstum}

Konzentrationsprozesse in einem Markt sind dann dem externen Unternehmenswachstum zuzurechnen, wenn sie das Ergebnis des Zusammenschlusses vormals selbstständiger Unternehmen zu einer rechtlichen und wirtschaftlichen Einheit sind. ${ }^{132}$ Während die mehr oder weniger starke Beschränkung der wirtschaftlichen Dispositionsfreiheit der beteiligten Unternehmen dabei regelmäßig das Ergebnis eines Zusammenschlusses ist, wird deren rechtliche Selbstständigkeit nicht notwendigerweise tangiert. ${ }^{133}$ Der Komplettverlust der rechtlichen Selbstständigkeit erfolgt lediglich bei der bindungsintensivsten Zusammenschlussform der Fusion. ${ }^{134}$ In dieser Interpretation umfasst der Begriff des Zusammenschlusses folglich im Grunde genommen auch sämtliche Formen kooperativer Arrangements. Dies wiederum kann als abermaliger Beleg dafür interpretiert werden, dass kooperative und konzentrative Arrangements fließend ineinander übergehen können. Konkrete interorganisatorische Arrangements lassen sich dabei dennoch anhand des Grades ihrer ökonomischen und juristischen Bindungsintensität und anhand ihrer Fristigkeit - mit anderen Worten: anhand der Gewichtung und des Zusammenwirkens ihrer marktlichen und hierarchischen Elemente - in der Regel hinlänglich eindeutig einer der beiden Alternativen zuordnen. Den Übergang von einem kooperativen Arrangement zu einem konzentrativen Arrangement markiert das Unterscheidungskriterium der ,einheitlichen Leitung““: ${ }^{135}$ Die einheitliche Leitung, unter welche die beteiligten Unternehmen bei einem Zusammenschluss mit konzentrativem Charakter definitionsgemäß gestellt werden, impliziert, dass bei konzentrativen Arrangements - im Gegensatz zu kooperativen Arrangements - die Zusammenarbeit (1) auf umfassende wirtschaftliche Integration ausgelegt, d. h. nicht auf bestimmte Funktionsbereiche oder Projekte beschränkt und (2) zeitlich nicht begrenzt ist. ${ }^{136}$ Ferner sind konzentrative Arrangements - wieder im Gegensatz zu kooperativen Arrangements - in der Regel durch Kapitalverflechtung bzw. Kapitalbeteiligungsstrukturen zwischen den beteiligten Unternehmen gekennzeichnet. Der prozentuale Umfang der finanziellen Beteiligung eines erwerbenden Unternehmens an einem erworbenen Unternehmen determiniert dabei den Umfang der Beschränkung der wirtschaftlichen und der juristischen Selbstständigkeit des erworbenen Unternehmens. ${ }^{137}$ Eine Fusion (der Komplettverlust der rechtlichen Selbstständigkeit also) ist

Vgl. Bubik (2005), S. 9.

Vgl. Bubik (2005), S. 4.

Vgl. Unterabschnitt 2.5.3.1.

135 Vgl. Unterabschnitt 2.5.3.1.

136 Vgl Bubik (2005), S. 7 ff.

137 Vgl. Bubik (2005), S. 8 f.
} 
nach dem deutschen Aktiengesetz ab einem Beteiligungsanteil von $75 \%$ möglich, da das erwerbende Unternehmen dann in der Lage ist, den Verschmelzungsprozess durch den Abschluss von Unternehmensverträgen einzuleiten. ${ }^{138}$

Zunächst sinkt durch Zusammenschlüsse die Anzahl unabhängig handelnder Unternehmen am Markt, eventuell verändern sich auch die Marktanteile der Marktteilnehmer. Dies hat die Erhöhung der absoluten und u. U. auch der relativen Konzentration zur Folge (primäre Konzentrationseffekte der Zusammenschlüsse). Initiieren die großen Marktteilnehmer in der Fortsetzung Verdrängungsstrategien und bewirken im Extremfalle Marktaustritte kleiner Marktteilnehmer, so kann dies die absolute und die relative Marktkonzentration abermals erhöhen (sekundäre Konzentrationseffekte der Zusammenschlüsse). ${ }^{139}$ Hinsichtlich des externen Unternehmenswachstums können zum Zwecke einer differenzierten Analyse in Abhängigkeit des leistungswirtschaftlichen Zusammenhanges zwischen den am Zusammenschluss beteiligten Unternehmen - in Analogie zu den kooperativen Arrangements - mit

- horizontalen Zusammenschlüssen,

- vertikalen Zusammenschlüssen und

- diagonalen (konglomeraten) Zusammenschlüssen

drei Richtungen unterschieden werden, in denen Zusammenschlüsse stattfinden. ${ }^{140}$ Diese drei Hauptformen von Zusammenschlüssen sind auch für den Logistikmarkt die relevanten Formen, wobei die horizontalen Zusammenschlüsse dominieren. ${ }^{141}$

Horizontale Zusammenschlüsse sind Zusammenschlüsse vormals selbstständiger Unternehmen, die auf dem gleichen sachlich und räumlich relevanten Markt tätig sind. ${ }^{142}$ Prinzipiell können sie die Realisierung von Economies of Scale, der Etablierung marktstrategischer Zielsetzungen (Marktbeherrschung, Errichtung von Marktzutrittsschranken) oder die Durchsetzung von Managementinteressen (bspw. die Politik

\footnotetext{
138 Vgl. Bubik (2005), S. 9.

139 Vgl. Herdzina (1999), S. 185.

140 Vgl. Schmidt (1999), S. 138

$141 \mathrm{Vgl}$. Aberle (2003a), S. 87.

142 Vgl. Schmidt (1999), S. 138.
} 
des sog. Empire Building ${ }^{143}$ ) zum Ziel haben; jedoch birgt das Überschreiten der optimalen Unternehmensgröße gleichermaßen die Gefahr von Diseconomies of Scale oder von X-Inefficiencies im Sinne LEIBENSTEINs ${ }^{144}{ }^{145}$

Horizontale Zusammenschlüsse haben die direkte Reduktion der Anzahl unabhängig voneinander agierender Wirtschaftssubjekte auf dem Markt zur Folge und nehmen somit unmittelbar Einfluss auf den absoluten und den relativen Konzentrationsgrad. Die primären Konzentrationseffekte treten hier sogleich auf, die sekundären Konzentrationseffekte folgen $u$. U. sehr rasch. ${ }^{146}$ Wegen der Unmittelbarkeit ihrer Wirkungen und den damit verbundenen marktstrategischen Optionen sind horizontale Zusammenschlüsse wettbewerbspolitisch am Besten greif- und handhabbar. ${ }^{147}$

Als vertikale Zusammenschlüsse gelten Zusammenschlüsse vormals selbstständiger Unternehmen aufeinander folgender Wirtschaftsstufen, wobei die Zusammenschlussbeteiligten in einer Käufer-Verkäufer-Beziehung stehen. ${ }^{148}$ Dabei kann zwischen einer Vorwärts- und einer Rückwärtsintegration unterschieden werden, je nachdem, ob eine vor- oder eine nachgelagerte Wirtschaftsstufe in ein Unternehmen eingegliedert wird. ${ }^{149}$ Mit vertikalen Zusammenschlüssen können Transaktionskostenersparnisse beabsichtigt sein, aber auch marktstrategische Zielsetzungen sind denkbar. ${ }^{150}$ Für eine Beurteilung der Effizienz müssen die Transaktionskostenersparnisse, welche möglicherweise mit einem vertikalen Zusammenschluss verbunden sind, allerdings den steigenden Organisationskosten bei vertikaler Integration gegenübergestellt werden. ${ }^{151}$

Diagonale oder konglomerate Zusammenschlüsse können negativ definiert werden als Zusammenschlüsse, welche weder unter die Kategorien der horizontalen noch der vertikalen Zusammenschlüsse fallen. Im Allgemeinen dienen derartige Zusammenschlüsse der Risikostreuung ${ }^{152}$ oder erfolgen aus marktstrategischen Gründen (wie etwa die Etablierung von Marktzutrittsschranken durch reciprocal dealing oder

Vgl. dazu genauer Schmidt, Röhrich (1992), S. $180 \mathrm{f}$.

$\mathrm{X}$-Inefficiencies entstehen durch fehlenden Wettbewerbsdruck und mangelnde Motivation des Managements, Diseconomies of Scale hingegen sind technologisch bedingt. Vgl. dazu Leibenstein (1966); Schmidt, Röhrich (1992), S. 180.

Vgl. Schmidt (1999), S. 138; Schmidt, Röhrich (1992), S. 181 f.

Vgl. Bubik (2005), S. 10; Herdzina (1999), S. 185.

Vgl. Bubik (2005), S. 10.

Vgl. Schmidt (1999), S. 139.

Vgl. Bubik (2005), S. 11.

Vgl. Monopolkommission (1984), Tz. 711.

Vgl. Schmidt (1999), S. $139 \mathrm{f}$.

Vgl. Schmidt, Röhrich (1992), S. 180. 
predatory pricing). ${ }^{153}$ Ein weiterer Beweggrund für konglomerate Zusammenschlüsse, nämlich die Realisierung von Economies of Scope, ist vor allem im Forschungs- und Entwicklungsbereich sowie im administrativen Bereich von Bedeutung. ${ }^{154}$ Allerdings ist auch hier wieder der Umstand zu beachten, dass den potenziellen Economies of Scope die Gefahr von Diseconomies of Scope entgegensteht, welche sich als steigende Koordinationskosten im Rahmen des Leistungserstellungsprozesses für unterschiedliche Produkte auf verschiedenen Märkten niederschlagen. ${ }^{155}$

Vertikale und konglomerate Zusammenschlüsse haben nicht die direkte Reduktion der Anzahl unabhängig voneinander agierender Wirtschaftssubjekte auf dem Markt zur Folge. Daher verändert sich das Ausmaß der horizontalen Markt- bzw. Angebotskonzentration oftmals wenig oder überhaupt nicht; die herkömmlich angewendeten Konzentrationsmaße vermögen die von vertikalen und konglomeraten Zusammenschlüssen ausgehenden Gefahren (zunächst) nicht adäquat zu erfassen. Die primären Konzentrationseffekte bleiben aus. Allerdings sind die später auftretenden, oft sehr weit reichenden Sekundäreffekte umso bedeutungsvoller. ${ }^{156}$ Dies gilt insbesondere für die konglomeraten Zusammenschlüsse, welchen zunächst nur wenig Aufmerksamkeit geschenkt worden ist. ${ }^{157}$ KRUSE weist auf die wettbewerbsschädlichen Wirkungen vertikaler Integration hin und ist der Meinung, dass die Gefahren für den Wettbewerb, die von vertikaler Integration ausgehen, in der deutschen Wettbewerbs- respektive Deregulierungspolitik offenkundig unterschätzt werden. ${ }^{158}$

\section{Internes Unternehmenswachstum}

Konzentrationsprozesse in einem Markt sind dann dem internen Unternehmenswachstum zuzurechnen, wenn sie durch überproportionales Wachstum einzelner Unternehmen aufgrund von Investitionstätigkeit in Produktionshöhe, Produktionstiefe oder Produktionsbreite und somit durch divergierendes Unternehmenswachstum angestoßen wurden. ${ }^{159}$ Dieses divergierende Größenwachstum hat eine Verschiebung der Marktanteile zwischen den Marktakteuren und damit eine Erhöhung der relativen horizontalen 
Konzentration zur Folge (primärer Konzentrationseffekt des internen Wachstums). ${ }^{160}$ Im Falle von Marktaustritten von Unternehmen, welche relativ weniger gewachsen sind, stellt sich zusätzlich absolute horizontale Konzentration und u. U. weitere relative Konzentration ein (sekundärer Konzentrationseffekt des internen Wachstums). ${ }^{161}$

\subsection{Motive für die Bildung konzentrativer Arrangements im Logistikmarkt}

Die Frage nach den Motiven für die Bildung konzentrativer Arrangements im Logistikmarkt wurde in dieser Arbeit bereits an mehreren Stellen angerissen: In Unterabschnitt 2.4.4.1 wurde im Zuge einer Konzentrationsanalyse des Logistikmarktes die Praktizierung wettbewerbsbeschränkender Verhaltensweisen als Konzentrationsmotiv diskutiert. Im vorangehenden Unterabschnitt wurden in der Fallgruppe des externen Unternehmenswachstums einige mögliche ökonomische und außerökonomische Motive für Unternehmenszusammenschlüsse angedeutet. In diesem Unterabschnitt nun sollen die Motive, welche ursächlich für das Eingehen konzentrativer Arrangements im Logistikmarkt sind, zusammenfassend aufbereitet werden.

\section{Allgemeines Schema der Konzentrationsursachen gemäß MONOPOLKOMMISSION}

Anfangs der 1980er Jahre wurde von der MONOPOLKOMMISSION der Versuch unternommen, Konzentrationsursachen in einem allgemeinen Schema zu erfassen. Ursachen, die Umfang und Ausmaß der ökonomischen Konzentration und deren Entwicklung im Zeitablauf determinieren, können nach dem Entwurf der MONOPOLKOMMISSION in ihrem vierten Hauptgutachten auf unterschiedlichen Ebenen bzw. Stufen untersucht werden. Auf abstrakter Ebene sind Veränderungen von Konzentrationstatbeständen zunächst das sichtbare Resultat von Vorgängen wie

- Marktzutritten,

- Marktaustritten,

- Fusionen oder

- internem Unternehmenswachstum. 
Diese Vorgänge bezeichnet die MONOPOLKOMMISSION als Konzentrationsursachen der 2. Stufe. ${ }^{162}$ Die Konzentrationsursachen der 2. Stufe wiederum sind das Resultat konkreter, strategischer Unternehmensentscheidungen und marktlicher Gegebenheiten. Diese originären Konzentrationsmotive, diejenigen Faktoren also, welche Konzentration vorteilhaft, notwendig oder möglich machen und Marktzu- bzw. Marktaustritte, externes oder internes Wachstum zur Folge haben, werden Konzentrationsursachen der 1. Stufe genannt. ${ }^{163} \mathrm{Zu}$ den Konzentrationsursachen der 1. Stufe zählen nach Ansicht der MONOPOLKOMMISSION ökonomische und außerökonomische Motive wie bspw.

- staatliche Rahmenbedingungen,

- unvollständige Kapitalmärkte,

- Größenvorteile,

- wettbewerbsbeschränkende Verhaltensweisen,

- Patente,

- Forschung und Entwicklung sowie

- Werbung. ${ }^{164}$

Die Konzentrationsursachen der 1. Stufe sind auch deshalb von entscheidender Bedeutung, da sie als Ausdruck konkreter unternehmerischer Aktionen der zentrale Anknüpfungspunkt für jegliche Maßnahmen zu Konzentrationsbekämpfung sein sollten. $^{165}$

\section{Motive für konzentrative Arrangements im Logistikmarkt}

Das allgemeine, mehrstufige Schema, welches die MONOPOLKOMMISSION im Rahmen ihres vierten Hauptgutachtens erarbeitet hat, wurde für den Logistikmarkt von zahlreichen Autoren konkretisiert und inhaltlich ausgefültt. Dabei beziehen sich die Ausführungen und Systematiken der Autoren stets auf die Stufe der konkreten Unternehmensentscheidungen bzw. der originären Konzentrationsmotive.

\footnotetext{
162 Vgl. Monopolkommission (1982), Tz. 708. 
BJELICIC beschäftigt sich mit externem Unternehmenswachstum von Verkehrs- bzw. Logistikunternehmen, welches sich im Logistikmarkt durch Fusionen (,Mergers“) und Übernahmen („Acquisitions“) vollzieht. ${ }^{166} \mathrm{Er}$ identifiziert u. a. folgende zentrale Unternehmensstrategien und Umstände als Motive für die M\&A-Aktivitäten, welche steigende Unternehmenskonzentration im Logistikmarkt bewirken:

- Realisierung von Economies of Scale,

- Marktanteilserweiterung zum Zwecke der Errichtung von Marktzutrittsbarrieren für potenzielle Konkurrenten,

- Kontrolle von mehrgliedrigen Leistungsketten im Rahmen einer vertikalen Integration, um Verladern anforderungsgemäß ein komplettes Leistungsangebot anbieten zu können,

- Risikostreuung,

- Umsetzung reiner Managementinteressen („Empire Building“),

- geografische Ausdehnung netzwerkbasierter Logistikleistungen und Ausweitung der Gesamt-Leistungspalette gemäß der Verladeranforderungen,

- Reaktion auf M\&A-Aktivitäten in Verladerbranchen,

- Ungelöste Nachfolgeprobleme, die v. a. in mittelständischen Unternehmen zu Unternehmensverkäufen führen,

- Anpassungsreaktionen auf regulierungsbedingt unterbliebene Marktauslese und daraus resultierende suboptimale Marktstrukturen sowie

- Privatisierung einstmals staatlicher Unternehmen. ${ }^{167}$

Ebenfalls speziell auf die Ursachen für die strategische Unternehmensentscheidung zum Eingehen eines konzentrativen Arrangements im Logistikmarkt ausgerichtet habén KLAUS und MÜLLER-STEINFAHRT eine umfassende und systematische Zusammenstellung möglicher Fusionstreiber erarbeitet, welche sowohl ökonomische als auch

Vgl. Bjelicic (2003). Zur begrifflichen Auseinandersetzung mit den Anglizismen Mergers \& Acquisitions vgl. Bubik (2005), S. 5 f.

167 Vgl. Bjelicic (2003), S. 292 f. Ähnliche, mit der Systematik von Bjelicic korrespondierende Faktoren, wenngleich nicht in vergleichbarer Ausführlichkeit, identifiziert Aberle. Vgl. Aberle 
außerökonomische Fusionsmotive mit berücksichtigt. ${ }^{168}$ Der Terminus „Fusion“ wird von KLAUS und MÜLLER-STEINFAHRT in diesem Zusammenhang nicht ausschließlich für Fusionstatbestände im engeren Sinne - nämlich die Aufnahme oder Neubildung eines Unternehmens unter Aufgabe der wirtschaftlichen und der rechtlichen Selbstständigkeit der Fusionspartner ${ }^{169}$ - benutzt, sondern stellvertretend für verschiedene, auch schwächere Formen konzentrativer Arrangements verwendet. ${ }^{170}$ Vergleiche zur Logik von Motiven für konzentrative Arrangements im Logistikmarkt folgende Abbildung 2-22.

Die Ausfuhrungen dieses Unterabschnittes haben gezeigt, dass sich die Motive für konzentrative Arrangements im Logistikmarkt augenscheinlich nicht merklich von den Motiven für kooperative Arrangements zu unterscheiden scheinen.

(2003a), S. 88. Auch Baumgarten, Zadek und Keller gelangen zu ähnlichen Einschätzungen. Vgl.

170 Vgl. Klaus, Müller-Steinfahrt (2000), S. 16. Der Begriff der Fusion entspricht in diesem Kontext folglich vielmehr dem Begriff des Zusammenschlusses in der Form, wie er in dieser Arbeit definiert wurde. 


\section{Fusionstreiber}

ausgeprägt als...

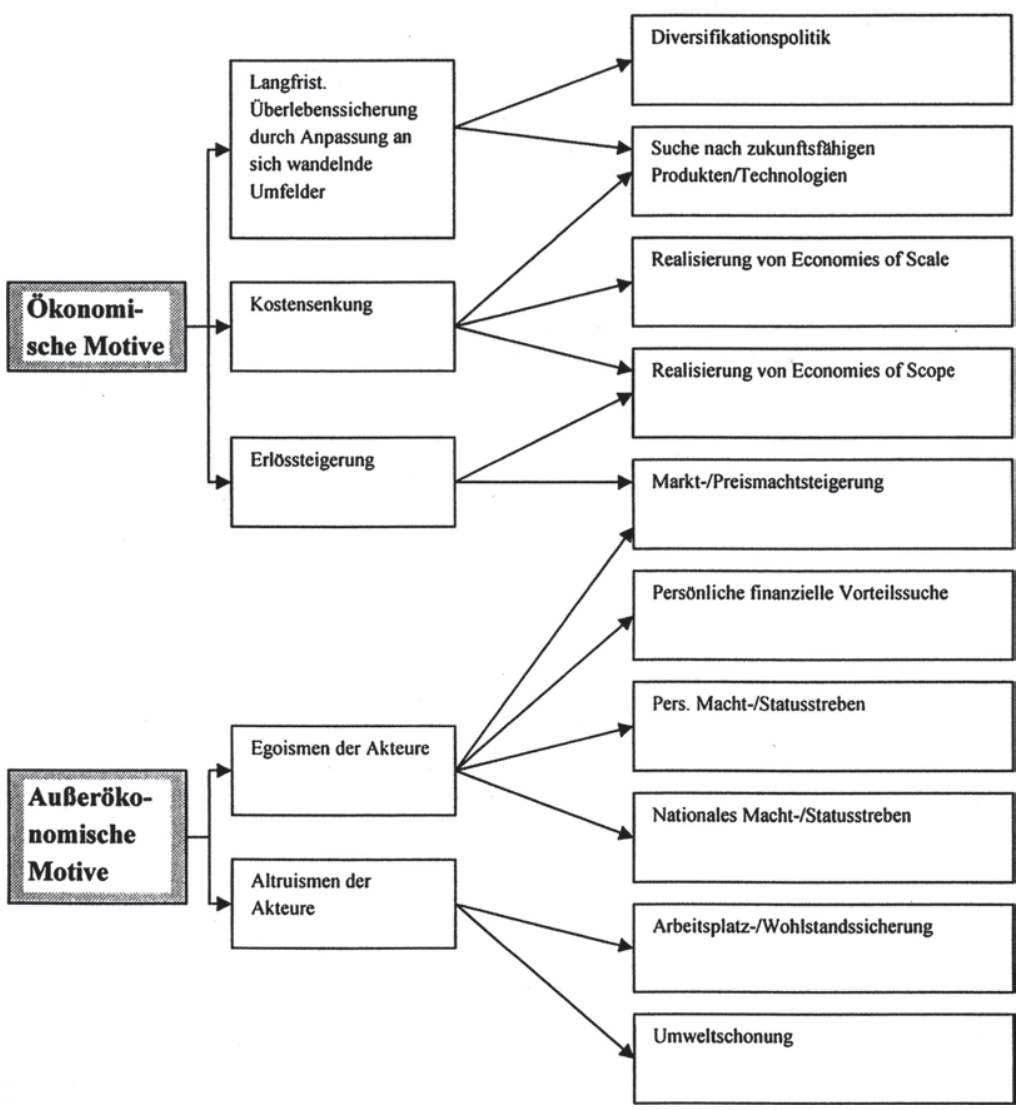

\section{Abbildung 2-22: Logik von Motiven für konzentrative Arrangements im Logis- tikmarkt}

Quelle: in Anlehnung an Klaus, Müller-Steinfahrt (2000), S. 17 


\subsection{Konzentrative Arrangements im Logistikmarkt, dargestellt am Beispiel der akquisitionsgetriebenen Expansionsstrategien von Konzernlogistik- unternehmen}

\section{Deutsche Post World Net (DPWN)}

Seit Mitte der 1990er Jahre tritt im Logistikmarkt eine neue ressourcenstarke Anbietergruppe auf. Es handelt sich hierbei um eine Reihe nationaler Postgesellschaften, welche nach dem deregulierungsbedingten Wegfall ihres behördenbetrieblichen Monopolstatus im Bereich der Kurier-, Express- und Paketdienstleistungen im europäischen, landseitigen Verkehr (gezwungenermaßen) in marktaktive Post- und Logistikunternehmen umstrukturiert worden sind. ${ }^{171}$ Zentraler Bestandteil dieser Umstrukturierungsmaßnahmen war häufig die teilweise, schrittweise oder vollständige Privatisierung der ehemals staatlich-behördlichen Postgesellschaften. ${ }^{172}$ Im Zuge dieser Umstrukturierungsmaßnahmen resultierte ferner eine Veränderung in der Geschäftsstrategie und -philosophie dieser Unternehmen. Sie betrachteten sich seither als Logistikpartner der Wirtschaft und strebten und streben sowohl in räumlicher als auch in sachlicher Hinsicht eine Expansion ihrer Tätigkeitsfelder an. Zentrales Ziel hierbei ist der Ausbau der Marktposition und damit die Stabilisierung bzw. Erhöhung des Unternehmenswertes. ${ }^{173}$ Eine mögliche strategische Option, dieses Ziel zu erreichen, besteht in einer akquisitionsgetriebenen Expansionsstrategie, d. h. dem Begründen konzentrativer Arrangements mit national oder regional agierenden Logistikunternehmen. Als Beispiel hierfür kann die strategische Orientierung des aus der Deutschen Bundespost hervorgegangenen Logistikkonzerns DPWN ins Feld geführt werden.

Die DPWN verfolgt eine global ausgerichtete Expansionsstrategie mit dem Ziel der Weltmarktführerschaft in jedem Marktsegment. ${ }^{174}$ Die Geschäftstätigkeit der DPWN gliedert sich aufbauorganisatorisch in die vier Unternehmensbereiche Brief, Express, Logistik und Finanzdienstleistungen auf und wird unter den Marken Deutsche Post (Brief), DHL (Express und Logistik) und Postbank (Finanzdienstleistungen) abgewickelt. Mit dieser Aufstellung deckt der Konzern das gesamte Spektrum an Logistikleistungen zur integrierten Abwicklung von Briefverkehren sowie Waren-, Informationsund Finanzströmen ab. In jedem der vier Unternehmensbereiche unternahm die

\footnotetext{
171 Vgl. Aberle (2003b), S. $282 \mathrm{f}$.

172 Vgl. Aberle (2003b), S. 282.

173 Vgl. Baumgarten, Zadek, Keller (2001), S. 14.

174 Vgl. Deutsche Post World Net (2008a), S. 30.
} 
DPWN in den letzten Jahren umfassende Akquisitions- und Beteiligungsaktivitäten, welche (1) ihr Produktportfolio kontinuierlich in Richtung anspruchsvoller Kontraktlogistik- bzw. SCM-Leistungen erweitern, (2) eine Stabilisierung und Erweiterung ihres Produktportfolios und der räumlichen Reichweite im Bereich der netzwerkbasierten Logistikleistungen bewirken und (3) die räumliche Netzabdeckung und die Netzdichte in den netzwerkbasierten Stammgeschäftsfeldern (bspw. KEP) verbessern sollten. Einen Überblick über Akquisitionstätigkeit der DPWN in den letzten Jahren gibt die folgende Tabelle 2-10.

Aus der Vielzahl der durchgeführten Akquisitionen sind folgende Fälle von besonderer strategischer Bedeutung und daher hervorzuheben: ${ }^{175}$ Mit dem Kauf der schweizerischen Danzas Gruppe im Jahr 1999 wurde die Logistiksparte des DPWN-Konzerns begründet. Von großer Bedeutung ist die Integration des See- und Luftrachtgeschäftes von Danzas in die DPWN. Eine wichtige Maßnahme von großer strategischer Tragweite für den Unternehmensbereich Express war die Akquisition des Integrators DHL im Jahr 2002. Hierdurch konnte der Unternehmensbereich gestärkt und die räumliche Ausweitung des Expressgeschäftes in die Vereinigten Staaten erreicht werden. Mit dem Kauf des US-amerikanischen Paketzustellers Airborne, welcher im Jahr 2003 abgeschlossen wurde, verband DPWN das internationale Netzwerk und die Netzwerkkompetenz im grenzüberschreitenden Expressgeschäft von DHL mit dem US-nationalen Luft- und Landnetzwerk von Airborne mit dem Ziel, auf dem US-Markt eine starke Wettbewerbsposition einzunehmen. Mit der Übernahme des britischen Logistikunternehmens Exel im Jahr 2005 konnte die Marktposition des DPWNKonzerns auf globalem Parkett in der Luft- und Seefracht sowie in der Kontraktlogistik nochmals deutlich gestärkt werden.

Mit dem umfassenden, weltweiten Netzwerk von Tochtergesellschaften und Beteiligungen hat es die DPWN innerhalb eines guten Jahrzehnts geschaff, sich als leistungsstarker Anbieter ganzheitlicher, integrierter Logistikleistungen mit globaler Netzverfügbarkeit im Logistikmarkt zu positionieren und zu etablieren. Die DPWN ist damit in der Nähe eines multimodalen Vollsortimenters im Sinne von LIEB und LANGE $\mathrm{zu}$ verorten, welcher sich dadurch auszeichnet, dass er Netzwerkkompetenzen und Kompetenzen im Bereich der Kontraktlogistik- bzw. SCM-Logistikleistungen in sich vereinigt und deren Nutzenpotenziale miteinander zu verbinden in der Lage ist. ${ }^{176}$ 


\begin{tabular}{|c|c|c|c|}
\hline Akquisitionen & Land & $\begin{array}{r}\text { Jahr / } \\
\text { Zeitraum }\end{array}$ & $\begin{array}{l}\text { Kapitalanteile und } \\
\text { Stimmrechtsanteile }\end{array}$ \\
\hline \multicolumn{4}{|l|}{ BRIEF } \\
\hline Global Mail Ltd & USA & 2002 & $100,00 \%$ \\
\hline Interlanden & Niederlande & 2004 & $100,00 \%$ \\
\hline SmartMail & USA & 2004 & $100,00 \%$ \\
\hline Mail Merge & Niederlande & 2005 & $70,00 \%$ \\
\hline Unipost & Spanien & 2004 & $38,00 \%$ \\
\hline Koba & Frankreich & 2005 & $100,00 \%$ \\
\hline Williams Lea & Großbritannien & 2006 & $67,00 \%$ \\
\hline The Stationery Office & Großbritannien & 2007 & $100,00 \%$ \\
\hline \multicolumn{4}{|l|}{ EXPRESS } \\
\hline DHL International GmbH & Deutschland & 2002 & $100,00 \%$ \\
\hline Ducros Services Rapides & Frankreich & 2000 & $100,00 \%$ \\
\hline Van Gend \& Loos & Niederlande & 1999 & $100,00 \%$ \\
\hline Securior Omega Holdings & Großbritannien & 2003 & $100,00 \%$ \\
\hline Narrondo Desarrollo SL & Spanien & 2004 & $100,00 \%$ \\
\hline $\begin{array}{l}\text { DHL Express (Canada) Ltd, } \\
\text { former Mayne Logistics Loomis }\end{array}$ & Kanada & 2003 & $100,00 \%$ \\
\hline DHL Sinotrans International Air & & 2003 & $5,00 \%$ \\
\hline Airborne Inc & USA & 2003 & $100,00 \%$ \\
\hline Blue Dart Express plc & Indien & 2005 & $81,03 \%$ \\
\hline PPL & Tschechien & 2006 & $100,00 \%$ \\
\hline ASTAR Air Cargo Holdings LLC & USA & 2007 & $49,00 \%$ \\
\hline Polar Air Cargo Worldwide Inc. & USA & 2007 & $49,00 \%$ \\
\hline AeroLogic GmbH & Deutschland & 2007 & $50,00 \%$ \\
\hline \multicolumn{4}{|l|}{ LOGISTIK } \\
\hline DANZAS Holding AG & Schweiz & 1999 & $100,00 \%$ \\
\hline Nedlloyd Logistics Group & Niederlande & 1999 & $100,00 \%$ \\
\hline ASG AB & Schweden & 2000 & $100,00 \%$ \\
\hline Air Express International AEI & USA & 2000 & $100,00 \%$ \\
\hline Exel plc & Großbritannien & 2005 & $100,00 \%$ \\
\hline $\begin{array}{l}\text { FC (Flying Cargo) International } \\
\text { Transportation Ltd. }\end{array}$ & Israel & 2007 & $100,00 \%$ \\
\hline \multicolumn{4}{|c|}{ FINANZ DIENSTLEISTUNGEN } \\
\hline Deutsche Postbank & Deutschland & 2006 & $50 \%$ plus 1 Aktie \\
\hline PB Capital & USA & 2001 & $100,00 \%$ \\
\hline DSL Bank & Deutschland & 2000 & $100,00 \%$ \\
\hline BHW & Deutschland & 2006 & $98,43 \%$ \\
\hline $\begin{array}{l}\text { Postbank Versicherungsvermitt- } \\
\text { lung GmbH }\end{array}$ & Deutschland & 2007 & $100.00 \%$ \\
\hline
\end{tabular}

Tabelle 2-10: Akquisitionstätigkeit der Deutsche Post World Net in den Jahren $1999-2007$

Quelle: Deutsche Post World Net (2008b) 
Eigene Netzwerke im Bereich KEP, Land-, Luft- und Seefracht mit möglichst weltweiter Netzabdeckung bilden die Plattform für Kontraktlogistik- bzw. SCMLeistungen, wobei die beiden Leistungskomponenten in einer starken Wechselbeziehung zueinander stehen: Stabile und umfassende Netzwerke ermöglichen und verbessern das Angebot komplexer, netzwerkbasierter SCM-Leistungen, die steigenden Anforderungen seitens der SCM-Leistungen an die Netzwerke hinsichtlich Flächenabdeckung, Netzfrequenz und verbesserter zeitlicher Taktung von Güterströmen können wiederum dazu benutzt werden, die Qualität der eigenen Netzwerke weiterzuentwickeln. ${ }^{177}$ Seine strategischen Lücken schloss und schließt der DPWNKonzern stark akquisitionsgetrieben mit Hilfe konzentrativer Arrangements in Form horizontaler, vertikaler und konglomerater/diagonaler Unternehmenszusammenschlüsse. Dabei werden diejenigen Wirkungspotenziale freigesetzt, welche im vorangehenden Unterabschnitt diskutiert wurden:

Bei den Akquisitionen im Bereich der netzgebundenen Logistikleistungen (KEP, Land, Luft- und Seefracht), welche in erster Linie horizontale (gleicher sachlicher und räumlicher Markt) und konglomerate/diagonale (verschiedene räumlich relevante Märkte) Elemente aufweisen, lag der Fokus auf der Realisierung von Economies of Scale und Economies of Scope. Es sollten möglichst standardisierte Transport- und Verkehrsleistungserstellungsprozesse mit interkontinentaler Reichweite etabliert werden, welche durch eine möglichst hohe räumliche Netzdichte (Anzahl und räumliche Verteilung der Betriebsstätten), enge Netzvermaschung (Anzahl der Verkehrslinien und das gewählte Bündelungssystem) und hohe Netzwerkfrequenz (Anzahl der Abfahrten pro Zeiteinheit je Relation) gekennzeichnet sind. Ferner dürften marktstrategische Überlegungen eine Rolle gespielt haben (Marktanteilssteigerung, Errichtung von Marktzutrittsbarrieren für potenzielle Konkurrenten). Bei den Akquisitionen im Bereich der Kontraktlogistik- bzw. SCM-Leistungen, welche vorrangig vertikale und konglomerate/diagonale Elemente aufweisen, war die Hauptintention wohl die Realisierung von produktionskosten-, transaktionskosten- und nutzenbasierten Vorteilen aus der vertikalen Leistungsintegration sowie die Diversifizierung des Leistungsangebotes in Richtung anspruchsvoller Kontraktlogistik ${ }^{178}$ mit dem Ziel, Kontrolle über vielgliedrige Leistungsketten zu bekommen, um den Verlader gemäß seines logistischen Bedarfes möglichst mit einem lückenlosen Komplettleistungsangebot bedienen zu können. Auch bei diesen Akquisitionen kamen wohl marktstrategische Zielsetzungen zum Tragen. 
Ob die angestrebten Ziele, welche mit den Akquisitionen verbunden waren, tatsächlich umgesetzt werden können, hängt mit der Fähigkeit des Konzerns zusammen, die in den Konzern eingegliederten Unternehmen, welche bislang in der Regel selbstständig in unterschiedlichen räumlichen und/oder sachlichen Märkten agiert haben, in den Konzern zu integrieren. Wenn der mit schnellem akquisitionsbasierten, externem Unternehmenswachstum verbundene Integrationsaufwand unterschätzt würde, könnten „schnell eher Werte vernichtet denn hinzugewonnen werden“. ${ }^{179}$ Angestrebte Kostensenkungs- und Leistungsverbesserungspotenziale könnten sich in diesem Fall gegenteilig auswirken; Diseconomies of Scale/Scope und X-Inefficiencies könnten das Resultat sein. Die Strategie der DPWN scheint allerdings erfolgreich zu sein, der Logistikkonzern hat sich als leistungsstarker Global Player am Logistikmarkt etabliert.

Der Markterfolg des Logistikkonzerns DPWN ist - neben seiner operativen und strategischen Leistungsfähigkeit und seiner Integrationskompetenz - in erster Linie auf seine immense finanzielle Ressourcenstärke zurückzuführen. Wettbewerbspolitisch problematisch dabei ist der Umstand, dass Postunternehmen die Gewinne aus monopolistisch beherrschten Marktsegmenten (bspw. aus den Briefpostdiensten) zur Quersubventionierung wettbewerblich strukturierter Unternehmensbereiche (wie KEPund Speditionsmärkte) benutzen können. ${ }^{180}$ Obwohl dies wettbewerbsrechtlich unzulässig ist, gestaltet sich die Nachweisführung für den Einsatz derartiger Praktiken als außerordentlich schwierig. ${ }^{181}$ ABERLE führt als Beleg für die Virulenz dieser Konstellation einen Fall an, in dem die EU-Kommission zu der Auffassung gelangt ist, dass die DPWN Einnahmen aus Monopolmärkten (Briefpost) zur Quersubventionierung benutzt hat (nämlich für die Restrukturierung des Paketgeschäftes durch den Bau moderner, IuK-gestützter Umschlags- und Kommissioniersysteme in den Postfrachtzentren). Die EU-Kommission hat die DWPN daraufhin am 19. Juni 2002 mit einem Bußgeld in Höhe von 752 Mio. EUR belegt. ${ }^{182}$

Aus der Öffnung der KEP-Dienste, verbunden mit den damals zu konstatierenden beträchtlichen Mängeln in der Leistungsqualität bei den staatlichen Postunternehmen, ergab sich folglich zunächst Eindringungspotenzial für neue Anbieter in die entsprechenden Logistikteilmärkte, mit welchen sich die Postunternehmen nun auf wettbewerblicher Basis auseinanderzusetzen hatten. In der Folgezeit kam es bedingt durch den neu installierten wettbewerblichen Regelungsmechanismus - nicht zuletzt

Lieb, Lange (2003), S. 455.

Vgl. Aberle (2003a), S. 533 f.

Vgl. Aberle (2003a), S. 534.

Vgl. Aberle (2003b), S. 283.
} 
aufgrund der spezifischen produktionstechnischen Anforderungen bei der netzgebundenen Produktion von KEP-Dienstleistungen sowie aufgrund der Kundenanforderungen ${ }^{183}$ - zu einer konzentrativen Entwicklung im Bereich der Marktstruktur auf dem KEP-Markt.

\subsubsection{Zusammenfassung}

Dieser letzte Teil der Marktanalyse hatte die Untersuchung und zusammenfassende Darstellung zentraler Aspekte der Leistungskoordination auf dem Logistikmarkt zum Gegenstand. Die Kernthese, welche hier vertreten wurde und welche das konzeptionelle Fundament der gesamten Koordinationsanalyse bilden sollte, besagt, dass die Leistungskoordination auf dem Logistikmarkt - verstanden als das Zusammen- und Wechselwirken von Angebot und Nachfrage bzw. als die Organisation der Transaktionsbeziehungen zwischen Anbietern und Nachfragern nach Logistikleistungen maßgeblich von der institutionellen Verankerung der Leistungserstellung bestimmt wird. Diese These leitet sich aus dem unternehmensübergreifenden, systembindenden und -koppelnden Charakter der Logistikkonzeption ab, welcher impliziert, dass die Güte der Organisation von Transaktionsbeziehungen in einem Logistiksystem eng an die Qualität der Koordinations- und Strukturierungsleistung gekoppelt ist, die von den am jeweiligen Logistiksystem beteiligten Institutionen ausgeht. Vor dem Hintergrund dieser Überlegungen erwies sich die Untersuchung der Prinzipien und Bestimmungsgründe für Existenz, Auswahl und Umgestaltung bestimmter institutioneller Arrangements zwischen den Anbietern und Nachfragern von Logistikleistungen innerhalb von Logistiksystemen als geeigneter Rahmen für die weitere Analyse der Leistungskoordination im Logistikmarkt.

Ausgangspunkt der Koordinationsanalyse war die Erörterung der für die institutionelle Organisation von Logistiksystemen grundlegenden Fragestellung des „Make or Buy“, d. h. der Gestaltung der individuellen logistischen Leistungstiefe im Spannungsfeld zwischen den beiden institutionellen Grundsatzalternativen, Logistikleistungen selbst zu produzieren oder sie einzukaufen. Es wurde festgestellt, dass die Optimierung der logistischen Leistungstiefe, welche mittels Maßnahmen zu Verringerung (Outsourcing) oder Erhöhung (Insourcing) der Leistungstiefe im Rahmen eines Make-or-BuyEntscheidungsprozesses angedacht wird, stets eine strategische Nutzensteigerung im Logistiksystem der Wertschöpfungskette des Entscheiders bewirken sollte. Mit der Produktions- und Beschaffungskosten-, der Transaktionskosten- und der Qualitätsper- 
spektive wurden drei Perspektiven vorgestellt, aus welchen sich Potenziale zu möglichen strategischen Nutzensteigerungen - interpretiert als realisierte Synergiepotenziale auf der Basis diverser Bündelungseffekte - herleiten lassen. Die besagten Perspektiven stellen damit gleichzeitig Bewertungsdimensionen dar, auf Basis derer die Güte alternativer logistischer Leistungstiefen diagnostiziert werden kann. Es wurde ferner festgestellt, dass sich die Frage der Gestaltung der logistischen Leistungstiefe als komplexe Optimierungsaufgabe inmitten eines breiten Spektrums an Möglichkeiten präsentiert, welches weitaus mehr Gestaltungsoptionen umfasst als lediglich das idealtypische „Make“ oder „Buy“ von Logistikleistungen. Vielmehr existieren - im Lichte der Transaktionskostentheorie betrachtet - zwischen den Extrempunkten „Make“ und „Buy“ zahlreiche Ausprägungsformen institutioneller Arrangements zur Leistungskoordination, welche, fixiert in Form vertraglicher Arrangements mit unterschiedlicher Bindungsintensität, entlang eines Kontinuums zwischen den beiden Extermpunkten zu verorten sind. Vor diesem Hintergrund wurde befunden, dass die anfangs eingefürte Fragestellung des "Make or Buy“ auch einer terminologischen Erweiterung in „Make or Buy or Cooperate“ bedurfte, welche diesen Überlegungen Rechnung trägt.

Die Relevanz der bis hierhin vorgetragenen Überlegungen ist auch im realen Logistikmarktgeschehen deutlich abzulesen. Es zeigte sich, dass sich die Marktakteure - Industrie- und Handelsunternehmen gleichermaßen wie Logistikunternehmen angesichts der beobachtbaren Veränderungen im relevanten rechtlichen, technologischen und ökonomischen Umfeld des Logistikmarktes zunehmend dazu veranlasst sehen, die gegenwärtige Ausgestaltung der Arbeitsteilung in und zwischen logistischen Systemen gründlich und von strategischen Kosten- und Qualitätsüberlegungen geleitet $\mathrm{zu}$ hinterfragen. Auf Basis von Make-or-Buy-or-Cooperate-Entscheidungsprozessen werden Suchprozesse in Bezug auf die effiziente Gestaltung und Veränderung der logistischen Leistungstiefe in Gang gebracht, welche die Arbeitsteilung im Logistikmarkt neu organisieren und deren Resultate in Gestalt unterschiedlichster Ausprägungsformen institutioneller Leistungskoordination sichtbar werden.

Die systematisierte Darstellung und ökonomische Beurteilung eben dieser unterschiedlichen Ausprägungsformen institutioneller Leistungskoordination im Logistikmarkt war Gegenstand der weiteren Analyse. Der Rahmen für die Systematisierung der Darstellung wurde auf der Grundlage einer in drei Argumentationsschritten aufgebauten Logik entworfen: 
- Die Ausgangsbasis bildeten in einem ersten Schritt die der Transaktionskostentheorie entlehnten, grundsätzlichen institutionellen Abwicklungsalternativen, welche sich auf der logistikmarktlichen Betrachtungsebene als rein-marktliche Koordination, als Koordination über Kooperation sowie als Koordination über die reine Hierarchie manifestieren.

- Die transaktionskostentheoretisch hergeleiteten institutionellen Arrangements wurden in einem zweiten Schritt auf die Betrachtungsebene der einzelnen Organisation projiziert und als organisatorisch-institutionelle Koordinationsmuster auf der Grundlage interorganisatorischer Beziehungsgefüge aufgefasst. Solche Beziehungsgefuige umfassen interorganisatorische Beziehungen mit vorwiegend gegeneinander gerichteten Interessen (Wettbewerb, Konflikte) und vorwiegend gleichgerichteten Interessen der Beteiligten (normale Geschäftsbeziehungen, Kooperation und Konzentration).

- Interorganisatorische Beziehungsgefüge wiederum - und hier insbesondere die Kooperation - wurden in einem dritten Schritt als konstitutive Grundlage für metalogistische Systeme dargestellt und insofern als organisatorisch-institutionelle Musterformen zur Lösung und Beherrschung von (logistischen) Koordinations- bzw. Schnittstellenproblemen an und zwischen (logistischen) Systemgrenzen begriffen.

Gerade der dritte Argumentationsschritt ist deshalb von zentraler Bedeutung, weil metalogistische Systeme als diejenigen Logistiksysteme gelten, in welchen der unternehmensübergreifende, systembindende und -koppelnde Charakter der Logistikkonzeption seine evidenteste Entsprechung findet. Somit gelang es mittels der stufenweise in drei Schritten aufgebauten Argumentation, die transaktionskostentheoretisch fundierte Perspektive und die (inter-)organisationstheoretisch fundierte Perspektive der institutionellen Koordination logistischer Systeme sowie den Leitgedanken der Logistikkonzeption, Güter-, Material- und Informationsflüsse auf der Grundlage des Systemgedankens unternehmens- bzw. schnittstellenübergreifend zu optimieren, zu einem integrierten Systematisierungsansatz zu verbinden. Diesem Systematisierungsansatz folgend wurden anschließend nacheinander Ausprägungsformen „normaler“ Geschäftsbeziehungen, kooperativer Arrangements und konzentrativer Arrangements als Ausprägungsformen institutioneller Leistungskoordination im Logistikmarkt dargestellt und ökonomisch bewertet. Dies geschah mittels der Verknüpfung modellhafter Erörterung anhand abstrakter organisatorisch-institutioneller Musterformen und exemplarischer Erörterung anhand konkreter Beispiele. 
Im Vordergrund stand dabei die Analyse der kooperativen Arrangements, deren Relevanz bereits an verschiedener Stelle hervorgehoben wurde. Zunächst erfolgten grundlegende Erörterungen $\mathrm{zu}$ den diversen möglichen Beziehungsebenen und Beziehungsrichtungen von Kooperationen. Darauf aufbauend wurden anschließend die Charakteristika horizontaler kooperativer Arrangements im Logistikmarkt am Beispiel der System-Kooperationen im nationalen allgemeinen Stückgutmarkt dargelegt sowie die Motive und Hemmnisse für das Eingehen derartiger Kooperationen aus Sicht der potenziellen Kooperationspartner erläutert. Danach wurden die Charakteristika vertikaler kooperativer Arrangements im Logistikmarkt am Beispiel des Konzeptes des Supply-Chain-Managements demonstriert sowie die Motive und Hemmnisse für das Eingehen derartiger Kooperationen aus Sicht der verladenden Unternehmen sowie aus Sicht der Logistikunternehmen dargelegt.

Die Ausführungen zu den kooperativen Arrangements, welche die Elemente hybrider Koordination im Logistikmarkt herausgestellt haben, wurden flankiert von Darlegungen zu „normalen“ Geschäftsbeziehungen, illustriert am Beispiel der elektronischen Frachtenbörsen sowie zu konzentrativen Arrangements, illustriert am Beispiel der akquisitionsgetriebenen Expansionsstrategie der Deutsche Post World Net. Hier wurde deutlich, dass im Logistikmarkt durchaus auch in spürbarem Umfang Elemente reinmarktlicher und hierarchischer Koordination existieren. 


\section{Berührungspunkte zwischen den Konzeptionen des Wettbewerbs und der Logistik}

\subsection{Vorbemerkungen}

Im Kapitel 1 wurde das Prozessphänomen des wirtschaftlichen Wettbewerbs untersucht, Kapitel 2 befasste sich mit dem Prozessphänomen der logistischen Reorganisation. Beiden Kapiteln lag die eingangs eingeführte Argumentationssequenz „Prozessdeterminanten bedingen den Prozessablauf; der Prozessablauf zeitigt bestimmte Wirkungen" als Analysebasis zugrunde.

Bei der Analyse des Wettbewerbs fand diese Argumentationssequenz ummittelbar und in expliziter Form Verwendung: mittels der Integration von wettbewerbstheoretischen Ansätzen resp. deren jeweiligen Denkhaltungen hinsichtlich der Wettbewerbsdeterminanten, des wettbewerblichen Prozessverlaufes und der Wettbewerbswirkungen zu einer umfassenderen Wettbewerbskonzeption konnten auf Basis der Kausalität „Determinanten - Prozess - Wirkungen“ z. T. erhebliche konzeptionelle Divergenzen zwischen einzelnen Ansätzen entschärft und voneinander abweichende Einzelaussagen kanalisiert werden.

Bei der Untersuchung der logistischen Reorganisation war die Argumentationssequenz mittelbare Analysegrundlage: obwohl die Gliederungssystematik für die industrieökonomisch basierte Marktanalyse des Logistikmarktes bewusst vom SVE-Paradigma entkoppelt wurde, so rekurrierte die Marktanalyse in inhaltlichen und konzeptionellen Fragen dennoch im Wesentlichen auf dessen Implikationen. Die dem SVE-Paradigma entspringende grundsätzliche Kausalität Struktur - Verhalten - Ergebnis wiederum kann als verunglückte Deutung der logisch richtigen Kausalbeziehung „Determinanten - Prozess - Wirkungen“ interpretiert werden wodurch sich die vorliegende Logistikmarktanalyse als geeignetes Instrument zur Vermehrung des Wissens über Determinanten, Prozessverlauf und Wirkungen des Prozesses der logistischen Reorganisation erwies.

Im Folgenden sollen die Berührungspunkte zwischen den beiden Konzepten des Wettbewerbs und der Logistik aufgezeigt werden. Es wird folgende Vorgehensweise gewählt: Zunächst wird (1) die Stellung des Wettbewerbs als Ordnungsprinzip in einem marktwirtschaftlich organisierten Wirtschaftssystem und (2) die Stellung der Logistik bzw. des Logistiksystems im Systemverbund der Gütertransformation zusammenfassend erörtert (Unterabschnitte 3.2.1 und 3.2.2). Hierzu wird auch auf diesbezügliche Anhaltspunkte und Aspekte, welche bereits an verschiedenen Stellen 
dieser Abhandlung formuliert worden sind, Bezug genommen. Danach wird als inhaltlicher Schwerpunkt des dritten Kapitels das Konzept der Logistik in die Wettbewerbskonzeption eingearbeitet (Abschnitt 3.3). Den entsprechenden wettbewerbstheoretischen Bezugsrahmen hierfür bildet das umfassendere Wettbewerbskonzept, welches in Abschnitt 1.3 erarbeitet worden ist. Die zugrunde liegende analytische Basis ist wiederum die Kausalität „Determinanten - Prozess - Wirkungen“. Eine Zusammenfassung der wesentlichen Ergebnisse beschließt das Kapitel (Abschnitt 3.4). 


\subsection{Ausgangspunkt: Zusammenfassende Standortbestimmung der Konzeptio- nen des Wettbewerbs und der Logistik}

\subsubsection{Der Wettbewerb als Ordnungsprinzip innerhalb eines marktwirtschaftlich organisierten Wirtschaftssystems}

Grundintention allen ökonomischen Handelns ist es, Wohlstand zu mehren. Das Streben nach Wohlstandsmehrung wiederum kann auf das Ziel der Knappheitsreduktion, d. h. der Verringerung der Diskrepanz zwischen gewünschter und vorhandener Gütermenge konkretisiert werden. Ökonomisches Handeln bzw. Wirtschaften wird daher auch als ,planmäßige Disposition über knappe Güter zur Befriedigung von Bedürfnissen" umschrieben. ${ }^{1}$ Unter Bezugnahme auf die prinzipiell denkbaren theoretischen Ansatzpunkte zur Knappheitsreduktion, nämlich die Erweiterung des Gütervolumens, die Verbesserung der Güterstruktur und die Verbesserung der Güterverteilung, lässt sich die Zielsetzung der Knappheitsreduktion, welche anfangs noch in vergleichsweise abstrakter Formulierung auf den gesellschaftlichen Grundwert „Wohlstand“ rekurriert, auf die Ebene der allgemeinen wirtschaftspolitischen Zielsetzungen Wirtschaftswachstum, optimale Güterallokation und Verteilungsgerechtigkeit präzisieren. Um diese Zielsetzungen zu verwirklichen, ist zuvor allerdings die Lösung von folgenden drei Problemen notwendig: ${ }^{2}$

- Das Informationsproblem: es werden Informationen über das jeweilige Ausmaß der Güterknappheit benötigt.

- Das Lenkungsproblem: es wird ein Mechanismus benötigt, welcher die Produktionsfaktoren bzw. Aktivitäten in jene Verwendungs- bzw. Aktivitätsbereiche lenkt, in denen Knappheit besonders groß ist.

- Das Ausgleichsproblem: es wird ein Mechanismus benötigt, welcher die Diskrepanz zwischen Nachfrage (Bedürfnissen) und Angebot (vorhandenen Mitteln) überbrückt.

Als ein Erfolg versprechendes, greifbares Instrument zur Knappheitsreduktion wurde bereits im 18. Jahrhundert die Arbeitsteilung und Spezialisierung mit ihrer produktivi- 
tätssteigernden Wirkung identifiziert. Arbeitsteilung wurde und wird seither in der Wirtschaftspraxis entsprechend nachdrücklich gepflegt. Neben den nachweislich produktivitätssteigernden Effekten begründet die Arbeitsteilung jedoch auch einen zentralen gesamtwirtschaftlichen Problempunkt: ${ }^{3}$ Sie erschwert die Lösung der drei oben genannten Probleme, da der volkswirtschaftliche Produktionsprozess nicht mehr direkt überschaubar ist. Eine im Einzelnen nicht mehr erfassbare Vielzahl in sich zerlegter, aber gleichzeitig wechselseitig voneinander abhängiger und miteinander verflochtener Produktionsprozesse in Millionen von Produktionsstätten potenziert die gesamtwirtschaftliche Koordinationskomplexität. Zur Beherrschung dieser Koordinationskomplexität ist die Existenz eines Ordnungsrahmens im Sinne eines Koordinationsmechanismus erforderlich, welcher geeignet ist, die drei Probleme in einer arbeitsteilig organisierten Volkswirtschaft zu lösen und die einzelnen Pläne der Unternehmen untereinander und bezogen auf die Planungsvorhaben der Haushalte abzustimmen. Damit ist die Frage nach dem geeigneten System der Wirtschaftsplanung, dem Wirtschaftssystem aufgeworfen. ${ }^{4}$

Zum Zwecke der Organisation systematischer Wirtschaftsplanung haben sich in der einschlägigen ökonomischen Auseinandersetzung verschiedene mögliche Ordnungssysteme bzw. Koordinationsmechanismen herauskristallisiert. Zu nennen wären hier insbesondere

- die Koordination durch eine Zentralbehörde (Zentralplanwirtschaft),

- die Koordination durch die Preisbildung auf Märkten (Marktwirtschaft),

- die Koordination durch Nächstenliebe, Humanität und Solidarität (Karitas),

- die Koordination durch Verhandlungen,

- die Koordination durch Wahlen sowie

- die Koordination durch Netzwerke.

Dabei werden für gewöhnlich die reinen Prinzipien bzw. idealtypischen Wirtschaftssysteme der Zentralplanwirtschaft und der Marktwirtschaft als Ausdruck organisatorischer Grundsatzpositionen gegenübergestellt, wobei die übrigen genannten Koordinationsmechanismen diesen beiden als partielle Koordinationsmechanismen zugeordnet

Vgl. für das Folgende Herdzina (2005), S. 28. 
werden können: die Koordination über Netzwerke, Verhandlungen und Karitas werden unter der Marktwirtschaft, Koordination über Wahlen unter der Zentralplanwirtschaft subsumiert.

Marktwirtschaft und Zentralplanwirtschaft können in Anlehnung an die drei zu lösenden Probleme anhand folgender Merkmale voneinander abgegrenzt werden:

\begin{tabular}{|l|l|l|}
\hline Abgrenzungsmerkmale & Zentralplanwirtschaft & Marktwirtschaft \\
\hline 1. Entscheidungskompetenz & $\begin{array}{l}\text { Zentrale Planung: Planungsbehठ̈- } \\
\text { de legt Produktions- und } \\
\text { Konsummengen fest }\end{array}$ & $\begin{array}{l}\text { Dezentrale Planung: Unternehmen planen } \\
\text { u. a. Produktion und Investition, } \\
\text { Haushalte planen u. a. Konsum und } \\
\text { Ersparnis }\end{array}$ \\
\hline 2. Informationsmechanismus & $\begin{array}{l}\text { alternativ: } \\
\text { Befragung der Produktionsstătten } \\
\text { und der Haushalte oder autorităre } \\
\text { Festlegung }\end{array}$ & $\begin{array}{l}\text { Preise auf Mărkten als Knappheitsanzei- } \\
\text { ger (Informationsfunktion des Preises) }\end{array}$ \\
\hline 3. Koordinationsmechanismus & $\begin{array}{l}\text { Planungsbehörde organisiert die } \\
\text { Koordination von Produktion und } \\
\text { Nachfrage auf allen Produktions- } \\
\text { stufen ex ante mit Hilfe von } \\
\text { Bezugsscheinen }\end{array}$ & $\begin{array}{l}\text { Preise auf Mărkten gleichen Angebot und } \\
\text { on des Preises) }\end{array}$ \\
\hline 4. Lenkungsmechanismus & $\begin{array}{l}\text { Planungsbehörde lenkt die } \\
\text { Produktionsfaktoren und legt die } \\
\text { Produktionssolls fest }\end{array}$ & $\begin{array}{l}\text { Preise auf Mărkten lenken die } \\
\text { Produktionsfaktoren (Lenkungsfunktion } \\
\text { des Preises) }\end{array}$ \\
\hline 5. Eigentumsordnung & Kollektiveigentum & Privateigentum \\
\hline
\end{tabular}

\section{Tabelle 3-1: Abgrenzung von Marktwirtschaft und Zentralplanwirtschaft}

Quelle: Herdzina (2005), S. 32

Diese reinen Prinzipien der systematischen Wirtschaftsplanung allerdings, wie sie sich in der Zentralplanwirtschaft und in der Marktwirtschaft verankert finden, sind in keiner real existierenden Volkswirtschaft vollständig umgesetzt. Vielmehr zeichnet sich die ökonomische Realität regelmäßig durch die Existenz realtypischer Wirtschaftssysteme aus, welche durch das Zusammenwirken der reinen Prinzipien gekennzeichnet sind, wobei aber in der Regel eines der beiden reinen Prinzipien dominiert. 
Wie bereits in Unterabschnitt 2.1.2.2, Fn. 25 angedeutet wurde, handelt es sich bei der Diskussion um die Wirtschaftssysteme also um eine auf die gesamtwirtschaftliche Analyseebene übertragene, inhaltlich kongruente Ausgestaltungsform der ökonomischen Grundsatzdebatte um Relevanz und Konfiguration alternativer Koordinationsmechanismen zur Steuerung wirtschaftlicher Aktivität. Diese Grundsatzdebatte hat ihren Ausgangspunkt auf der Analyseebene singulärer Organisationen (bspw. in Gestalt der Diskussion abstrakter sozialer Handlungsoptionen und Interaktionsprinzipien von Individuen im Sinne von MANTZAVINOS) und wird auch auf der marktlichen, industriestrukturellen Analyseebene (bspw. in Gestalt des institutionenökonomischen „Governance-Ansatzes") geführt.

Die realen Wirtschaftssysteme der modernen, westlichen Ökonomien - so auch das Wirtschaftssystem der Bundesrepublik Deutschland - werden maßgeblich determiniert durch die gesellschaftspolitische Grundsatzentscheidung für das marktwirtschaftliche Prinzip. Diese Grundsatzentscheidung fußt auf der Einschätzung, dass eine Marktwirtschaft größere Freiheitsspielräume eröffnet als andere Wirtschaftssysteme und dass der marktwirtschaftliche Preisbildungsmechanismus einen den übrigen denkbaren Organisations- bzw. Koordinationsmechanismen der Wirtschaftsplanung überlegenen Ansatz zur Lösung des Informations-, des Ausgleichs- und des Lenkungsproblems darstellt. Eine wesentliche, vielleicht die wichtigste Voraussetzung für das ungehinderte Funktionieren des marktwirtschaftlichen Preismechanismus ist das Vorliegen von Wettbewerb bzw. die Abwesenheit von Wettbewerbsbeschränkungen. Wirtschaftlicher Wettbewerb zwischen unabhängig voneinander agierenden Konkurrenten nämlich begründet Anreize zur permanenten Leistungsverbesserung, da die Wirtschaftsakteure bei den Versuchen, ihre persönlichen Ziele durchzusetzen, stets auf die Anstrengungen anderer Wirtschaftsakteure stoßen, welche genau dasselbe versuchen, wobei der höhere Zielerreichungsgrad des einen Akteurs einen geringeren Zielerreichungsgrad für andere Akteure nach sich zieht. ${ }^{5}$ Wettbewerb setzt die Konkurrenten folglich dem uneingeschränkten Zwang zum aktiven Wirtschaften aus und verlangt ihnen in diesem Zuge eine dauerhafte Reflexion von Möglichkeiten zur Knappheitsreduzierung ab. Das Wettbewerbsprinzip basiert folglich auf einem System dezentraler Planungs- und Entscheidungsstrukturen und darauf aufbauend auf der Strategie, das individuelle Maximierungsstreben des einzelnen Wirtschaftssubjektes als Grundlage für die Realisierung eines kollektiven Optimums zu instrumentalisieren. Die Einzigartigkeit dieses Ansatzes liegt darin begründet, dass die Gesamtheit der individuellen Kalküle, geleitet durch den Wettbewerbsprozess, sich zur kollektiven Ratio vereinigen. 
Wettbewerb leistet - sofern sich ihm kein Wirtschaftsakteur entziehen kann - damit einen wichtigen Beitrag dazu, dass der Preis eine akzeptable Planungs- und Steuerungsleistung hinsichtlich der Bestimmung der gesamtwirtschaftlichen Bedürfnisrangordnung und hinsichtlich des Einsatzes der zur Bedürfnisbefriedigung zur Verfügung stehenden Ressourcen produziert. M. a. W kommt dem Wettbewerb in der Rolle des fundamentalen Koordinations- und Ordnungsprinzips in einem marktwirtschaftlichen, arbeitsteilig organisierten Wirtschaftssystem die Aufgabe zu, als Voraussetzung für das Funktionieren des marktwirtschaftlichen Preismechanismus einen Beitrag zur Reduzierung von Knappheit zu leisten. ${ }^{6}$ Akzeptiert man diesen Zusammenhang, so erhellt daraus, dass die Entscheidung für den Primat des Ordnungsprinzips des Wettbewerbs maßgeblich mit der Grundsatzentscheidung für den Primat der Plankoordination über die Marktpreisbildung als reinem Prinzip der systematischen Wirtschaftsplanung korrespondiert.

Doch auch das reale Wirtschaftssystem der Bundesrepublik Deutschland ist - bei aller Dominanz des marktwirtschaftlichen Prinzips - als Mischsystem konzipiert und enthält Elemente zentraler Planung (zunächst bereits innerhalb von Unternehmen in Form der „einfachen zentralgeleiteten Wirtschaft“ im Sinne von EUCKEN sowie entscheidend dann als „Zentralverwaltungswirtschaft“ seitens des Staates im Falle nachgewiesenen Marktversagens), Elemente von Koordination durch Wahlen (bspw. bei der Zusammensetzung von Parlamenten und Regierungen, Bereitstellung von öffentlichen Gütern), Elemente von Koordination durch Verhandlungen (bspw. Tarifverhandlungen), Elemente von Koordination durch Netzwerke (bspw. langfristige Lieferanten-Kunden-Beziehungen) oder Elemente von Koordination durch Karitas (bspw. Stiftungen, Schenkungen). Der Set der Koordinationsmechanismen ist in seiner hier vorliegenden Konfiguration zwar zum einen das Resultat unabänderlicher gesellschaftspolitischer Grundsatzentscheidungen, spiegelt zum anderen aber natürlich auch aus ökonomischen Notwendigkeiten heraus getroffene Effizienzüberlegungen und machtpolitische Erwägungen wider.

Aus der beschriebenen Koexistenz mehrerer Koordinationsmechanismen ergibt sich aber nun zwangsläufig die möglicherweise problematische Konstellation, dass das Ordnungsprinzip Wettbewerb, welches ja auf die Erhaltung der Funktionsfähigkeit des Prozesses der Marktpreisbildung ausgerichtet und an die Durchsetzung der dazu erforderlichen organisationssystematischen Voraussetzungen gekoppelt ist, zwangsläufig mit den organisationssystematischen Voraussetzungen der übrigen Koordinations-

Vgl. Herdzina (1999), S. 18. 
mechanismen kollidieren muss. Insbesondere Ansätze zur ex-ante-Verhaltenskoordination bzw. zur kollektiven Wirtschaftsplanung, welche dem marktwirtschaftlichen Postulat der totalen Dezentralität der Wirtschaftsplanung entgegenstehen und welche die gemeinschaftiche Beseitigung von Unsicherheit zum Gegenstand haben, widersprechen im Grundsatz auch dem Wettbewerbsgedanken.

Vor diesem Hintergrund ist es erforderlich, sich mit Fragen der Zulässigkeit von Abweichungen vom marktwirtschaftlichen Koordinationsmechanismus und deren Grenzen auseinanderzusetzen. Derartige Abweichungen müssen sich stets an ihrer Kompatibilität mit dem Wettbewerbsprinzip messen lassen, weil dieses in seiner Eigenschaft als zentrales Ordnungsprinzip in einem marktwirtschaftlichen Wirtschaftssystem als Referenzmaßstab für Abweichungen fungiert. Die Prüfung und Legitimierung von erforderlichen Abweichungen vom Wettbewerbsprinzip auf der Basis zuvor festgelegter Prüf- und Bewertungskriterien ist folglich eine zentrale Aufgabenstellung in einem realtypischen, wettbewerbsbasierten, marktwirtschaftlichen Wirtschaftssystem, die Festlegung geeigneter Prüf- und Bewertungskriterien eine unabdingbare Voraussetzung dafür.

\subsubsection{Logistik als Koordinationsprinzip im Systemverbund der gesamtwirt- schaftlichen Gütertransformation}

Wie im vorangehenden Unterabschnitt ausgeführt wurde, wird die produktivitätssteigernde Wirkung arbeitsteiligen Wirtschaftens um den Preis einer immens erhöhten gesamtwirtschaftlichen Koordinationskomplexität erkauft. Diese Feststellung zog die Erkenntnis nach sich, dass die zentralen Planungs- und Steuerungsfragen auf gesamtwirtschaftlicher Ebene - das Informations-, das Lenkungs- und das Ausgleichsproblem - nur dann einer befriedigenden Lösung zugeführt werden können, wenn die einzelnen Beiträge der Wirtschaftssubjekte zur Problemlösung durch die Grundsätze eines gemeinsamen, übergeordneten Ordnungsprinzips und -rahmens zielgerichtet miteinander verknüpft und koordiniert werden.

Aus der Perspektive der Logistik dokumentiert sich die Koordinationskomplexität, welche sich aus dem arbeitsteiligen Wirtschaften ergibt, in Form eines Geflechts komplexer Güter-, Material und Informationsaustauschbeziehungen zwischen den Wirtschaftsakteuren. Diese Austauschbeziehungen sind Ausdruck der Überbrückungsbedarfe, welche sich unmittelbar aus der räumlichen Trennung, der zeitlichen Entkoppelung sowie aus der art- und mengenmäßigen Aufspaltung von Güterbereitstellungs- bzw. Produktions- und Güterverwendungs- bzw. Konsumtionsprozessen 
ergeben. Transfer- bzw. Logistiksysteme produzieren als funktionale Subsysteme arbeitsteilig organisierter Wirtschaftssysteme Lösungsansätze zu den Fragestellungen der Raumüberwindung, der Zeitüberbrückung und der Güterordnung, welche diese Austauschbeziehungen gleichermaßen organisatorisch-institutionell kleiden wie inhaltlich ausfüllen und dadurch die Güterbereitstellungs- und die Güterverwendungsprozesse entsprechend dem logistischen Bedarf der Volkswirtschaft in organisatorischinstitutioneller und inhaltlicher Hinsicht zu Wertschöpfungsketten verknüpfen. Sie tragen den Prozess der logistischen Reorganisation und treiben ihn voran. Dabei zielt die konzeptionelle Ausrichtung der Logistik ausdrücklich auf eine institutionen- bzw. schnittstellenübergreifende, gesamthafte Optimierung dieser Austauschbeziehungen ab, sodass Logistiksysteme angesichts vielstufiger Aufeinanderfolgen von Transferund Transformationsprozessen interorganisatorische Güterflusssysteme konstituieren. Diese Güterflusssysteme können institutionell als metalogistische Systeme im Sinne der Verknüpfung von mikrologistischen Systemen (Logistikunternehmen und logistischen Subsystemen von Industrie- und Handelsunternehmen) beschrieben werden und sind dementsprechend schwerpunktmäßig durch interorganisatorische Beziehungsgefüge mit kooperativem Charakter gekennzeichnet. Inhaltlich bestehen die Güterflusssysteme aus einem Netzwerk von Güter-, Material- und Informationsströmen, welches in seiner Gesamtheit die Planungssphäre eines einzelnen Unternehmens übersteigt und dessen Optimierung folglich auch jenseits der Beherrschbarkeit durch ein einzelnes Unternehmen liegt.

Was die Form des Zusammenwirkens von Logistik- und Transformationsprozessen betrifft, so können Logistikprozesse bezogen auf die Organisation von Produktion und Konsumtion sowohl resultierenden als auch bedingenden Charakter haben: Zum einen determinieren art- und mengenmäßige sowie räumliche und zeitliche Zerklüftungen arbeitsteilig organisierter Produktions- und Konsumtionsstrukturen das Wesen der Überbrückungsbedarfe und damit auch der Austauschbeziehungen. Zum anderen kann die Güte der Transferbedingungen im Logistiksystem die Ausgestaltung und Organisation der räumlichen, zeitlichen und art-/mengenmäßigen Strukturierung der Gütertransformation bestimmen.

Der Logistik kommt im Systemverbund der gesamtwirtschaftlichen Gütertransformation demnach in Gestalt eines übergeordneten Koordinationsprinzips die Aufgabe zu, unternehmensübergreifende Leistungsverflechtungen zwischen den Güterbereitstellungs- und den Güterverwendungssystemen zu koordinieren. Die Logistik stellt dafür spezifische Koppelungselemente zur Verfügung, da die unmittelbare, direkte Kopplung von Güterbereitstellungs- und Güterverwendungssystemen aufgrund räumlicher 
und zeitlicher Friktionen nicht möglich wäre. ${ }^{7}$ Die Logistik ist dabei aufgrund ihrer unternehmensübergreifenden, gesamthaften Orientierung in der Position, auf gesamtwirtschaftliche Größen wie die Organisation der Arbeitsteilung oder den ökonomischen Vernetzungsgrad einwirken zu können, genauso wie sie ihrerseits von eben diesen Größen maßgeblich beeinflusst wird. ${ }^{8}$ Logistische Reorganisation führt damit in Erfüllung ihres Koordinationsauftrages angesichts ihrer spezifisch netzwerkbildenden Ausrichtung tendenziell zu einer Verschiebung des Sets an Koordinationsmechanismen: interorganisatorische Beziehungsstrukturen mit längerfristigem kooperativem Charakter zwischen Wirtschaftssubjekten werden begünstigt - sogar benötigt, Koordination durch Netzwerke gewinnt folglich an Bedeutung. Die Koordination durch Netzwerke beruht nun auf der Grundidee der kooperativen Planabstimmung zwischen einzelnen Wirtschaftssubjekten, $d$. h. der ex-ante-Verhaltenskoordination bzw. der kollektiven Wirtschaftsplanung. Das Logistikprinzip als Auslöser für die Netzwerkbildung und der damit einhergehenden Beziehungsgefüge geht somit zunächst prinzipiell nicht konform mit dem Wettbewerbsprinzip, welches ja grundsätzlich den Idealzustand der totalen Dezentralität der Entscheidungsfindung bzw. der Wirtschaftsplanung postuliert. Um nun die Frage zu beantworten, wie die durch die logistische Reorganisation initiierte Abweichung vom reinen marktwirtschaftlichen Koordinationsmechanismus zugunsten der Koordination durch Netzwerke zu bewerten ist, muss das Beziehungsverhältnis zwischen dem Wettbewerb als übergeordnetem Ordnungs- und der Logistik als unternehmensübergreifendem Koordinationsprinzip geklärt werden. Hierzu wird nun untersucht, wie sich die Logistikkonzeption in die Wettbewerbskonzeption einpassen lässt und welche Impulse im Rahmen dieser konzeptionellen Zusammenführung von der logistischen Reorganisation auf Determinanten, Prozessverlauf und Wirkungen des Wettbewerbs ausgehen.

Vgl. Möhlmann (1984), S. 26.

Vgl. dazu auch die Ausführungen in den Unterabschnitten 2.3.3.1 für den Bereich der Netzwerkökonomik und 2.3.3.2 für den Bereich der Arbeitsteilung. 


\subsection{Integration der Logistikkonzeption in die Wettbewerbskonzeption}

\subsubsection{Logistische Reorganisation und die Wettbewerbsdeterminanten}

\subsubsection{Logistische Reorganisation und die mittelbaren Wettbewerbsdeterminan- ten}

\subsection{Logistische Reorganisation und interne Unternehmensstruktur}

Was die Beziehung der Logistik $\mathrm{zu}$ den mittelbaren Wettbewerbsdeterminanten angeht, so ist zunächst der Einfluss der logistischen Reorganisation auf die interne Unternehmensstruktur und deren Komponenten hervorzuheben, welcher im Rahmen der Analyse der logistischen Reorganisation an zahlreichen Stellen belegt werden konnte. Diesbezügliche Anknüpfungspunkte ergaben sich insbesondere bei (1) der Untersuchung logistikrelevanter Strukturwandelphänomene sowie bei (2) der Erörterung logistischer Fragestellungen vor netzwerkökonomischem Hintergrund.

\section{Ad (1)}

Ausgehend von den veränderten Anforderungen an das gesamtwirtschaftliche Logistiksystem - und hier insbesondere an das Verkehrssystem - durch die mengenmäßigen Umschichtungen in der gesamtwirtschaftlichen Güter- bzw. Produktionsstruktur in Richtung heterogener Stückgüter der Konsum- und Investitionsgüterindustrien zulasten der homogenen Massengüter der Grundstoffindustrien konnte unter Rückgriff auf diverse Wirkungseffekte (Logistik-Güterstruktureffekt, Logistikeffekt) ein inhaltlicher Bezug zu logistikdeterminierten Veränderungen in der Unternehmensstruktur bzw. der einzelwirtschaftlichen Produktionsstruktur in den Transformationssystemen hergestellt werden. Letztere sind dabei als Ausdruck unternehmerischer Anpassungsprozesse zu werten. Diese tragen dem veränderten logistischen Bedarf der Unternehmen, wie er sich aus den Veränderungen in der gesamtwirtschaftlichen Güter- bzw. Produktionsstruktur ableiten lässt, bezogen auf Kontinuität, Präzision und Flexibilität bei der raum-zeitlichen Eintaktung von Güter-, Material- und Informationsströmen Rechnung. Folglich erweisen sich aus der Vielzahl möglicher unternehmensbezogener Strukturvariabler insbesondere diejenigen Komponenten des unternehmerischen Organisationssystems als Veränderliche von logistischem Interesse, welche in der Funktion eines Bindegliedes zum Transfersystem die Gestaltung der 
raum-zeitlichen Komponenten der unternehmerischen Leistungserstellungsprozesse zum Gegenstand haben. Eine wesentliche Komponente in dieser Hinsicht ist die Ausgestaltung der zwischen- und überbetrieblichen Arbeitsteilung und hier insbesondere jene Formen, welche mit einer räumlichen Trennung der einzelnen Leistungserstellungsprozesse sowie der diese Prozesse ausführenden ökonomischen Institutionen einhergehen. Die Entscheidung über die Ausgestaltung der Arbeitsteilung ist in hohem Maße logistikdeterminiert, da die Leistungsfähigkeit des Logistiksystems und dessen institutioneller Elemente maßgeblich darüber entscheidet, inwieweit in den Transformationssystemen (Re-)Organisationsgewinne aus der räumlichen (Re-)Strukturierung der Arbeitsteilung realisiert werden können. Diese (Re-)Organisationsgewinne präsentieren sich in Form möglicher Rationalisierungsvorteile durch Spezialisierung (bei standortteiliger Produktion im Rahmen des Entscheidungsprozesses pro/contra Artteilung) oder in Form möglicher produktions- und raumbezogener Größen- und Verbundeffekte (bei zentraler Produktion im Rahmen des Entscheidungsprozesses pro/contra Mengenteilung). Die Leistungsfähigkeit des Logistiksystems bestimmt folglich fur die Transformationssysteme den Umfang

- zentralisierter sowie standortteiliger Produktionsstrukturen,

- der Erschließung des Potenzials standortbezogener Vorteile von Produktionsfaktoren, welches sich aus der raumdifferenzierenden Auflösung bzw. Trennung bisher vertikal integrierter Wertschöpfungsketten ergibt,

- der Zunahme der vertikalen Arbeitsteilung, d. h. den Umfang der Reduktion der eigenen Fertigungstiefe bei gleichzeitigem Outsourcing von Logistikaufgaben an Logistikunternehmen mit dem Ziel, Systemkomplexität und deren Kosten innerhalb der eigenen Unternehmensgrenzen zu verringern.

Damit wirkt der Grad der logistischen Reorganisation unmittelbar auf die Anzahl der Betriebe pro Unternehmung und die Anzahl der Produktionsstufen im Unternehmen ein, beides Komponenten der internen Unternehmensstruktur.

Ad (2)

In eine ähnliche Richtung wies die Analyse der Netzwerkökonomik. Hier konnte als wichtiges Ergebnis festgehalten werden, dass es sich bei der Logistik und der Netzwerkökonomik um zwei komplementäre, sich bedingende und sich positiv 
verstärkende Denk- und Gestaltungsansätze zur Beherrschung horizontaler und vertikaler real-marktlicher Koordinationserfordernisse auf hohem Komplexitätsniveau handelt. Logistik greift auf netzwerkökonomische Technologien und Vernetzungspotenziale als Inputfaktoren zur Aufgabenerfüllung zurück, die Netzwerkökonomik ihrerseits ist auf eine funktions- und leistungsfähige physische logistische Abwicklung angewiesen, um ihre Potenziale zur Realisierung einer möglichst umfänglichen qualitativen und quantitativen Vernetzung von Akteuren, Prozessen und Informationen umsetzen zu können. Ein zweckgerichtet gekoppeltes Zusammenwirken der Potenziale von Logistik und Netzwerkökonomik bedingt zunächst tendenziell eine Zunahme der vertikalen Arbeitsteilung in den Transformationssystemen, d. h. die Reduzierung der (logistischen und nicht logistischen) Leistungstiefe bei den verladenden Unternehmen. Dies wiederum zieht folgerichtig einen veränderten logistischen Bedarf auf Seiten der Verladerunternehmen nach sich. Die Integration neuer, netzwerkökonomischer Technologien in die traditionellen Leistungserstellungsprozesse und die Etablierung netzwerkökonomisch basierter, institutioneller Gestaltungsoptionen können dazu beitragen, diesem veränderten logistischen Bedarf sowohl auf der inhaltlichen Ebene der Gestaltung der Leistungserstellung als auch auf der Ebene der institutionellen Leistungskoordination besser gerecht $\mathrm{zu}$ werden. Logistische Reorganisation beeinflusst die interne Unternehmensstruktur demnach auch aus netzwerkökonomischer Perspektive.

- Diese Beeinflussung vollzieht sich zum einen dadurch, dass die Leistungsfähigkeit der Logistiksysteme den Grad der Befriedigung des netzwerkökonomisch basierten veränderten logistischen Bedarfes hinsichtlich der Gestaltung der vertikalen Arbeitsteilung determiniert.

- Zum anderen vollzieht sie sich auch dadurch, dass die Integration der netzwerkökonomischen Technologien als Inputfaktoren in die logistische Leistungserstellung das grundsätzliche Leistungspotenzial der Logistiksysteme um IuK-technische Komponenten erweitert und die Stellung der Logistik als ausschlaggebendes Koordinationsprinzip im Systemverbund der Gütertransformation somit auch entkoppelt vom netzwerkökonomischen Kontext festigt.

Auch im netzwerkökonomischen Kontext wirkt der Grad der logistischen Reorganisation folglich auf Komponenten der internen Unternehmensstruktur, insbesondere auf die Anzahl der Produktionsstufen im Unternehmen ein. 
Die hier beschriebenen, auf die logistische Reorganisation zurückzuführenden Änderungen in der internen Unternehmensstruktur bzw. der unternehmensinternen Produktionsstruktur sind jedoch lediglich ein Zwischenschritt. Die damit realisierbaren (Re-)Organisationsgewinne auf Unternehmensebene durch die (Re-)Strukturierung der vertikalen Arbeitsteilung bilden den Anknüpfungspunkt für weitere Reorganisationsprozesse, welche sich nun auf einer Ebene jenseits der Unternehmensgrenzen vollziehen. Denn die möglichst weit reichende Umsetzung des in der Logistikkonzeption verankerten Prinzips, Güterflusssysteme unternehmensübergreifend zu optimieren, gebietet es, zur Ermittlung diesbezüglich möglicherweise zweckdienlicher (Re-) Strukturierungsmaßnahmen auch diejenigen Abschnitte der Wertschöpfungskette des betreffenden Unternehmens in das Optimierungskalkül einzubeziehen, welche dem unternehmensinternen Leistungserstellungsprozess vor- und nachgelagert sind. Eine Einschränkung des Optimierungskalküls auf die unternehmensinterne Ebene entspräche allenfalls einem Logistikverständnis der dritten Entwicklungsphase nach BAUMGARTEN („Logistik integriert Funktionen zu Prozessketten“) bzw. Rangstufe 3 nach WEBER ET AL.' Ein Logistikverständnis der vierten Entwicklungsphase nach BAUMGARTEN („Logistik integriert Unternehmen zu Wertschöpfungsketten“) bzw. der Rangstufe 4 nach WEBER ET AL. impliziert im Gegensatz dazu zwingend eine Ausweitung des Anwendungsbereiches logistikbasierter Gestaltungsansätze auf die unternehmensübergreifende Ebene zum Zwecke der Optimierung der gesamten Wertschöpfungskette. Wenn man nun in Rechnung stellt, dass die verladenden Unternehmen in Deutschland noch deutliches Entwicklungspotenzial und auch den Entwicklungswillen in Richtung dieser vierten und (vorerst) letzten Entwicklungsphase der logistischen Reorganisation aufweisen ${ }^{2}$, so erhellt daraus, dass sich die Einflusssphäre der logistischen Reorganisation in Fragen der (Re-)Strukturierung der arbeits- und standortteiligen Organisation der Leistungserstellungsprozesse in den Transformationssystemen in Zukunft zunehmend auf die unternehmensübergreifende Ebene ausdehnen wird.

Daraus lässt sich nun im Ergebnis ableiten, dass die Beeinflussung entsprechender Komponenten der internen Unternehmensstruktur durch die logistische Reorganisation als Plattform für eine weiter reichende Einflussnahme auf die raum-zeitliche Strukturierung von Wertschöpfungsketten bzw. Wertschöpfungssystemen in organisatorischinstitutioneller und in inhaltlicher Hinsicht zu bewerten ist. Diese weiter reichende Einflussnahme gewinnt in dem Ausmaß und mit der Geschwindigkeit an Bedeutung,

Vgl. Unterabschnitt 2.2.2.2.3.

Vgl. dazu Abbildung 2-8. 
in dem die vierte und vorerst höchste Entwicklungsstufe logistischer Reorganisation - und damit der unternehmensübergreifende logistische Optimierungsansatz - die Transformationssysteme durchdringt und in den verladenden Unternehmen umgesetzt werden kann. Die dann zu realisierenden (Re-)Organisationsgewinne in Gestalt von Rationalisierungsvorteilen durch Spezialisierung oder in Gestalt produktions- und raumbezogener Größen- und Verbundeffekte umfassen prinzipiell dieselben ökonomischen Kategorien wie bei der Optimierung der internen Unternehmensstruktur. Jedoch berücksichtigt ein Optimierungsansatz, welcher die gesamte Wertschöpfungskette zum Gegenstand hat, unternehmensübergreifende kosten- und leistungsmäßige Wirkungsinterdependenzen zwischen den Beteiligten der Wertschöpfungskette und beseitigt damit Suboptimalitäten, welche bei der isolierten Optimierung der unternehmensinternen Leistungserstellung unabwendbar wären. Im Ergebnis zieht der unternehmensübergreifende Optimierungsansatz der Logistik Anpassungsreaktionen der an der Wertschöpfungskette beteiligten Unternehmen nach sich. Er manifestiert sich nicht selten in der Auflösung und Trennung bisher vertikal integrierter Fertigungsketten und führt oftmals zu einer Reduzierung der Fertigungstiefe oder anders ausgedrückt: zu einer Fokussierung auf Kernkompetenzen im Leistungserstellungsprozess.

Untrennbar verbunden mit der unternehmensübergreifenden Optimierung von Wertschöpfungsketten jedoch ist auch die Verlagerung von Koordinationskomplexität aus den Transformationssystemen auf logistische Transaktionen, welche das unabwendbare Resultat der wachsenden Anzahl koordinierungsintensiver logistikrelevanter Schnittstellen entlang der Wertschöpfungskette sind. Daher bedingt ein logistikbasierter Optimierungsansatz auf Wertschöpfungskettenebene erhebliche Anstrengungen zur Beherrschung der erhöhten Koordinationskomplexität logistischer Transaktionen, insbesondere was die Gestaltung der organisatorisch-institutionellen Ausgestaltungsformen von Beziehungsgefügen zur Leistungskoordination zwischen Beteiligten der Wertschöpfungskette betrifft. Der Umfang, in dem das logistische System diese erhöhte Koordinationskomplexität $\mathrm{zu}$ beherrschen in der Lage ist, determiniert maßgeblich die raum-zeitliche Strukturierung von Wertschöpfungsketten. Die diesbezügliche Leistungsfähigkeit des logistischen Systems bestimmt nämlich das Ausmaß, in welchem mögliche (Re-)Organisationsgewinne in den Transformationssystemen aus der (Re-)Strukturierung von Wertschöpfungsketten realisierbar sind.

Summa summarum wirkt der Grad der logistischen Reorganisation also auch auf die raum-zeitliche Strukturierung von Wertschöpfungsketten in institutioneller und in inhaltlicher Hinsicht ein. $\mathrm{Da}$, wie noch zu zeigen sein wird, die raum-zeitliche Strukturierung von Wertschöpfungsketten bzw. Wertschöpfungssystemen bedeutsam 
für das Marktverhalten ist, soll die Wertschöpfungskettenstruktur neben der internen Unternehmensstruktur als zusätzliche logistikbedingte mittelbare Wettbewerbsdeterminante in die Wettbewerbskonzeption aufgenommen werden.

\subsection{Logistische Reorganisation und die gesamtwirtschaftliche Produktivi- tätsstruktur}

Die bisherigen Ausführungen haben gezeigt, dass der Grad der logistischen Reorganisation die Ausgestaltung der - insbesondere räumlichen - Arbeitsteilung, sowohl auf unternehmensinterner als auch auf unternehmensübergreifender Ebene in den Transformationssystemen beeinflusst. Damit können der logistischen Reorganisation produktivitätssteigernde Effekte in dem Umfang zugeschrieben werden, in dem sie zur Realisierung neuer, produktivitätssteigernder Formen der Arbeitsteilung und zur Realisierung entsprechender Reorganisationsgewinne beiträgt. Da die Logistikaffinität der Leistungserstellungsprozesse innerhalb der Transformationssysteme naturgemä $\beta$ nicht gleich verteilt, sondern vielmehr in Abhängigkeit der unternehmens-, branchenoder sektorspezifischen Produktionsbedingungen unterschiedlich ausgeprägt ist, kommen die produktivitätssteigernden Potenziale logistischer Reorganisation entsprechend in unterschiedlichem Ausma $\beta$ zum Tragen. Dies wiederum bedeutet, dass die logistische Reorganisation möglicherweise zu divergierenden Produktivitätsentwicklungen in verschiedenen Bereichen der Volkswirtschaft und damit zur Veränderung der Produktivitätsstruktur beitragen kann: Logistikaffine Unternehmen, Branchen oder Sektoren erfahren einen Produktivitätsschub, weniger logistikaffine dagegen partizipieren in geringerem Umfang. Entsprechend reagieren diejenigen Unternehmen, Branchen und Sektoren, welche aufgrund gegebener Logistikaffinität und einer damit einhergehenden stärkeren Logistikdurchdringung ihrer Leistungserstellungsprozesse auch eine stärkere Abhängigkeit von der Funktionsfähigkeit ihrer Logistiksysteme aufweisen, auch stärker auf Ineffizienzen in den eigenen Logistiksystemen und im gesamtwirtschaftlichen Logistiksystem: derartige Ineffizienzen können gravierende Auswirkungen auf die Wettbewerbssituation einzelner Unternehmen oder Wirtschaftsbereiche haben.

In diesem Sinne kann der logistischen Reorganisation attestiert werden, dass sie auch die gesamtwirtschaftliche Produktivitätsstruktur, eine weitere mittelbare Wettbewerbsdeterminante, beeinflusst. 


\subsection{Logistische Reorganisation und Marktwachstum}

Akzeptiert man die Feststellung, dass die logistische Reorganisation möglicherweise produktivitätssteigernde Effekte besitzt und zudem die divergierende Produktivitätsentwicklung zwischen verschiedenen Bereichen der Volkswirtschaft begünstigt, so ist in einem nächsten Schritt zu untersuchen, ob sie möglicherweise auch die Entwicklung von Marktwachstum tangiert. In der Tat lässt sich über das Produktivitätsargument ein Zusammenhang zwischen logistischer Reorganisation und der Entwicklung der Wachstumsrate eines einzelnen Marktes im Zeitablauf sowie divergierender Wachstumsraten verschiedener Märkte in derselben Zeitperiode - also wirtschaftlichem Strukturwandel - herleiten. Ausgehend von der These, dass der Fortlauf expansiver und kontraktiver Marktprozesse u. a. von der Ausprägung angebotsseitig wirkender Komponenten wie dem technologischen Potenzial sowie der Mobilität und Verfügbarkeit geeigneter Produktionsfaktoren bestimmt wird ${ }^{3}$, so ist hinsichtlich einer denkbaren Verknüpfung von Logistik und Marktwachstumsentwicklung folgendes zu konstatieren: Logistische Reorganisation erweitert aufgrund ihrer produktivitätssteigernden Effekte tendenziell das technologische Potenzial. Logistik ist selbst Gegenstand von Verfahrensfortschritten in den Leistungserstellungsprozessen („Logistikinnovationen“) bzw. trägt dazu bei, nicht-logistische Verfahrensfortschritte umzusetzen. Verfahrensfortschritte setzen dann über Preis- und Nutzeneffekte weitere Expansionskräfte für den betreffenden Markt frei. Änderungen im technologischen Potenzial eines Marktes wiederum erfordern Verschiebungen in der Produktionsfaktorenstruktur. Die geeigneten Produktionsfaktoren müssen schnell und in entsprechender Menge und Qualität zur Ausdehnung der Produktion in potenziell expandierenden Märkten verfügbar sein, damit Expansionschancen im Markt vollständig und ohne Zeitverzögerung genutzt werden können, d. h. die Erweiterung des technologischen Potenzials erfordert Faktormobilität. Der Grad der Leistungsfähigkeit der logistischen Systeme nun beeinflusst die Möglichkeiten zur Beschaffung geeigneter Produktionsfaktoren maßgeblich mit, logistische Reorganisation ist folglich eine wichtige Voraussetzung für die physische Mobilität der Produktionsfaktoren.

Bezogen auf die Wachstumsentwicklung eines einzelnen Marktes im Zeitablauf bedeutet dieser Zusammenhang, dass logistische Reorganisation tendenziell expansive Marktkräfte freisetzt und damit dazu beiträgt - stets natürlich in Abhängigkeit der Nachfrageentwicklung - zumindest kontraktive Marktentwicklungen zu bremsen oder gar in expansive Marktentwicklung umzuwandeln. Dieser Zusammenhang ist insbesondere in Märkten bedeutsam, welche sich bereits in einer späten Marktphase 
befinden und in denen dort entsprechend typische Wettbewerbsverhältnisse herrschen. ${ }^{4}$ In solchen Märkten bietet die logistische Reorganisation Möglichkeiten, kontraktive Marktentwicklungstendenzen zu bremsen und die Wettbewerbskräfte zu stimulieren. Bezogen auf die vergleichende Wachstumsentwicklung mehrerer Märkte in einer bestimmten Zeitperiode bedeutet dieser Zusammenhang, dass diejenigen Märkte, deren Produktionsbedingungen eine Logistikaffinität aufweisen und welche somit die produktivitätssteigernden Effekte logistischer Reorganisation nutzen können, auch an den tendenziell expansiven Kräften, welche die logistische Reorganisation freisetzt, partizipieren können. Den weniger logistikaffinen Märkten bleiben derartige Verbesserungspotenziale hingegen verschlossen.

Diese beschriebenen Zusammenhänge lassen nun die Schlussfolgerung zu, dass die Leistungsfähigkeit logistischer Systeme möglicherweise dazu beiträgt,

- divergente Wachstumsentwicklungen verschiedener Märkte zu begründen, beschleunigen oder abzuschwächen,

- deren Umfang mitzubestimmen und somit auch

- den sektoralen Strukturwandel zu gestalten.

Insofern kann der logistischen Reorganisation Einflusspotenzial auf das technologische Potenzial sowie auf die physische Mobilität und Verfügbarkeit geeigneter Produktionsfaktoren bzw. die Produktionsfaktorenstruktur zugestanden werden. Beide sind Komponenten des Marktwachstums, einer weiteren mittelbaren Wettbewerbsdeterminante.

\subsubsection{Logistische Reorganisation und die unmittelbaren Wettbewerbsdetermi- nanten}

Nachdem im vorangehenden Unterabschnitt Anknüpfungspunkte für die Integration der logistischen Reorganisation in einige entscheidende mittelbare Wettbewerbsdeterminanten diskutiert worden sind, gilt es nun im nächsten Schritt zu untersuchen, wie diese mittelbaren Wettbewerbsdeterminanten unter dem Einfluss der logistischen

Vgl. dazu Unterabschnitt 1.2.4.1.

Vgl. Unterabschnitt 1.2.4.2. 
Reorganisation auf die Möglichkeit und die Neigung zu wettbewerblichem Marktverhalten - auf die unmittelbaren Wettbewerbsdeterminanten also - wirken.

Was die Möglichkeit zum wettbewerblichen Marktverhalten betriff, wurde in Unterabschnitt 1.3.3.1 dargelegt, dass diese für ein Unternehmen gegeben ist, wenn es über Markttransparenz verfügt, wenn Wettbewerbsfreiheit gegeben ist und wenn es die Fähigkeit zu Wettbewerbsverhalten besitzt. In diesem Kontext ist zunächst auf die positiven Effekte der logistischen Reorganisation auf die Produktivität und darauf aufbauend auf das technologische Potenzial sowie die physische Faktormobilität hinzuweisen. Diese positiven Effekte tragen dazu bei, dass die Spielräume für kreatives und adaptives Marktverhalten für diejenigen Unternehmen erweitert werden, welche auf die logistischen Handlungsoptionen zurückgreifen (können). Sie wirken demnach positiv auf die Fähigkeit, ein gewünschtes wettbewerbliches Marktverhalten auch durchzuführen. Der logistische Ansatz als unternehmensübergreifender Optimierungsansatz ist darauf ausgerichtet, unternehmensinterne Wertschöpfungsprozesse und unternehmensübergreifende Wertschöpfungssysteme auf institutioneller und prozessualer Ebene in räumlicher und zeitlicher Hinsicht neu zu strukturieren. Die Durchsetzung des unternehmensübergreifenden Ansatzes zieht, wie bereits mehrfach erwähnt, eine Erhöhung der Systemkomplexität logistischer Transaktionen und organisatorischinstitutioneller Beziehungsgefüge zwischen den Transaktionsbeteiligten im Logistiksystem nach sich. Diese Systemkomplexität ist Ausdruck realwirtschaftlicher kostenund leistungsmäßiger Wirkungsinterdependenzen zwischen den Beteiligten der Wertschöpfungskette, welche im Rahmen des unternehmensübergreifenden Optimierungsansatzes auf prozessualer und institutioneller Ebene als Leistungsverflechtungen abgebildet werden. Aus dem Gesagten ergibt sich nun die vordergründig erstaunlich anmutende Konsequenz, dass logistische Reorganisation die Systemkomplexität erhöht, aber genau dadurch viele bei der Prozessmodellierung bislang im Verborgenen gebliebene, deshalb jedoch nicht minder existente und relevante Leistungszusammenhänge offen legt und somit den gesamten Leistungserstellungsprozess transparenter gestaltet. Insofern wirkt logistische Reorganisation tendenziell positiv auf die gesamtwirtschaftliche Markttransparenz und erhöht somit die Möglichkeit für ein Unternehmen, gegebene Chancen zu wettbewerblichen Aktionen zu erkennen. Der Vollständigkeit halber darf hinsichtlich des Zusammenhanges zwischen logistischer Reorganisation und Markttransparenz auch jener Argumentationsstrang nicht unerwähnt bleiben, welcher schon in Unterabschnitt 2.2.2.4.2 vorgetragen wurde: Die hohe Systemkomplexität logistischer Transaktionen sowie deren organisatorischinstitutioneller Verankerung bedingt nun, dass Maßnahmen zur logistischen Reorganisation von unternehmensexternen Betrachtern, also auch von den Konkurrenten, als 
vergleichsweise schwer nachzuvollziehende und zu vergleichende Aktionen wahrgenommen werden. Logistikbasierter Verfahrensfortschritt, d. h. eine produktivitätsbasierte Erhöhung des technologischen Potenzials im Logistiksystem kann von Konkurrenten dementsprechend nur mit großen Anstrengungen und mit erheblichem Zeitverzug imitiert werden, wodurch dem logistik-innovierenden Unternehmer genug Zeit verbleibt, um Vorsprungsgewinne zu realisieren. Überlegene Logistiksysteme weisen folglich, bezogen auf den Parallelprozess zwischen Konkurrenten, gleichsam Tendenzen auf, die Markttransparenz zu reduzieren. Diese Reduktion der Markttransparenz allerdings ist nicht wettbewerbsschädlich, sondern wirkt diesbezüglich vielmehr stimulierend.

Dieser zweite Argumentationsstrang zur Herleitung einer denkbaren Beziehung zwischen logistischer Reorganisation und Markttransparenz leitet über zur zweiten unmittelbaren Wettbewerbsdeterminante, der Neigung zu wettbewerblichem Marktverhalten. In Bezug auf die Neigung zu wettbewerblichem Marktverhalten wurde in Unterabschnitt 1.3.3.1 dargelegt, dass diese abhängig ist von der Wirtschaftsmentalität, von den relativen Expansionschancen sowie vom Ausmaß des Wettbewerbszwanges. Wenn nun Maßnahmen zur logistischen Reorganisation von außerhalb des agierenden Unternehmens als intransparent und daher als nur schwer imitierbar betrachtet werden, so scheint eine wettbewerbliche Vorstoßaktion, welche auf der Optimierung unternehmensinterner oder -übergreifender Logistiksysteme fußt, von guten Erfolgsaussichten in Bezug auf die Realisierung der beabsichtigten Wettbewerbsvorteile zu sein. Das agierende Unternehmen muss keine zeitnahen Anpassungsreaktionen der Wettbewerber fürchten, welche seine Vorsprungsposition vor Ablauf einer angemessenen Zeit erodieren würden. Insofern kann der logistischen Reorganisation ein positiver Einfluss auf die sich im Markt bietenden relativen Expansionschancen bescheinigt werden. Dies wiederum beeinflusst die Neigung, wettbewerbliches Marktverhalten zu praktizieren tendenziell positiv, was gerade in denjenigen Märkten positiv auf die Wettbewerbskräfte wirken dürfte, welche sich bereits in einer späten Marktphase befinden. ${ }^{5}$ In solchen Märkten, welche gemeinhin weit bis eng oligopolistisch strukturiert sind, wurden kostensenkende und produktivitätserhöhende Verfahrensfortschritte in den Leistungserstellungsprozessen, welche direkt am Produktionsbereich - am Transformationssystem also - ansetzen, in der Regel bereits bis an die

5 Vgl. für die Darstellung der Charakteristika und der Wettbewerbsverhältnisse in Märkten, welche sich in einer späten Marktphase befinden Unterabschnitt 1.2.4.2. 
Rationalisierungsgrenzen getätigt. ${ }^{6}$ Neue Möglichkeiten für Verfahrensfortschritt, welche am Logistiksystem - am Transfersystem also - ansetzen, bieten gerade hier neuen Spielraum für wettbewerbliche Vorstoßaktionen und stellen aufgrund ihrer von außerhalb schweren Nachvollziehbarkeit dienliche Anknüpfungspunkte dar, um die allgegenwärtige oligopolistische Reaktionsinterdependenz zu durchbrechen. Damit einher geht die Stärkung der Wettbewerbskräfte im Markt.

\subsubsection{Logistische Reorganisation und Marktverhalten}

Im vorangehenden Unterabschnitt wurden Argumente für eine mögliche Einflussnahme der logistischen Reorganisation auf jenen Gesamtkomplex von Anreizen und Möglichkeiten, welcher das Zustandekommen des wettbewerblichen Marktprozesses determiniert, sowie auf deren Bestimmungsfaktoren vorgetragen und in die Systematik der Wettbewerbsdeterminanten eingeordnet. Nun gilt es, die gewonnenen Erkenntnisse auf die Marktprozessebene zu projizieren und zu eruieren, wie sich die Integration der logistischen Reorganisation auf das Gefüge der von den Unternehmen praktizierten Marktverhaltensweisen und damit auf die Ausgestaltung realer Marktprozesse auswirkt. Für die folgenden Ausführungen wird auf die in Unterabschnitt 1.3.2.2 erarbeitete Systematik von Marktverhaltenstypen zurückgegriffen.

\subsubsection{Logistische Reorganisation und wettbewerbliches (kreatives/adaptives) Marktverhalten}

Der vorangehende Unterabschnitt förderte Anhaltspunkte dafür zutage, dass die logistische Reorganisation offenkundig tendenziell positiv auf mehrere Komponenten der unmittelbaren Wettbewerbsdeterminanten, d. h. auf die Möglichkeit und die Neigung der Unternehmen, wettbewerbliches Marktverhalten zu praktizieren, einwirkt. Als unbedingt wettbewerbliches Marktverhalten wurden in Unterabschnitt 1.3.2.2 das (1) kreative und das (2) adaptive Marktverhalten hervorgehoben.

Ad (1)

Maßnahmen zur logistischen Reorganisation dienen den Wirtschaftsakteuren als ein Instrument, um sich einen Wettbewerbsvorsprung gegenüber ihren Konkurrenten zu 
verschaffen. Die positiven Effekte logistikbasierter Optimierungsansätze hinsichtlich der Erhöhung der Faktorproduktivität sowie hinsichtlich der Erweiterung des technologischen Potenzials begründen neue Möglichkeiten zum Verfahrensfortschritt in den Leistungserstellungsprozessen. In Verbindung mit den positiven Effekten, welche ein leistungsfähiges Logistiksystem auf die physische Faktormobilität zeitigt, fördern die Möglichkeiten der logistischen Reorganisation die unternehmerische Beweglichkeit im Sinne kreativen Marktverhaltens in doppelter Hinsicht:

- Zum einen dokumentiert sich logistische Reorganisation in Gestalt von Verfahrensfortschritten zur Optimierung von Güter-, Material- und Informationsströmen und trägt damit dazu bei, die Leistungserstellungsprozesse weiterzuentwickeln und zu verbessern (Fortschrittsaktivitäten im engeren Sinne). ${ }^{?}$

- Zum anderen vergrößern die im Logistikansatz verankerten Optionen zur Verbesserung der räumlichen und zeitlichen Güter-, Material- und Informationsverfügbarkeit zu jedem Zeitpunkt und auf jeder beliebigen Stufe der Wertschöpfungskette - m. a. W.: Optionen zur Verbesserung des Grades der logistischen Effizienz - auch die Möglichkeiten für das Unternehmen zur spontanen Anpassung an Änderungen der Nachfragestruktur. Die dazu erforderlichen Maßnahmen zu Erweiterung, Verkleinerung oder Umstellungen des Produktionsprogrammes können bei Rückriff auf ein leistungsfähiges Logistiksystem leichter bewerkstelligt werden. Dieses Argument ist insbesondere vor dem Hintergrund der in Unterabschnitt 2.2.2.4.2 beschriebenen Veränderungen auf den Produktmärkten (räumlich und zeitlich flüchtige Nachfrage, bedingt bspw. durch Angebotsüberhänge auf den Produktmärkten, verbesserte Markttransparenz für die Konsumenten sowie beschleunigte Diffusion und Imitation der Produkte) relevant, da derartige Veränderungen die Relevanz der Logistikqualität bei der Entscheidungsfindung der Nachfrager hinsichtlich ihres Konsumverhaltens bekräftigen. ${ }^{8}$

Vgl. auch die Ausführungen in Unterabschnitt 2.2.2.4.2 zum logistischen Rationalisierungspotenzial.

Vgl. auch die Ausführungen in Unterabschnitt 2.2.2.4.2 zum logistischen Wettbewerbspotenzial. 
Ad (2)

Maßnahmen zur logistischen Reorganisation können ebenso als ein Instrument dazu dienen, die Vorsprungspositionen, welche sich Wettbewerber durch kreatives Marktverhalten erarbeitet haben, wieder abzubauen. Im gleichen Ausmaß, in dem die positiven Effekte logistikbasierter Optimierungsansätze auf Faktorproduktivität, auf Faktormobilität sowie auf das technologische Potenzial Möglichkeiten zu kreativem Marktverhalten eröffnen, stellen sie auch die ökonomische Grundlage zum Abbau der Lücken zwischen vorstoßenden und nachfolgenden Unternehmen dar. Mit der Imitation und der Entwicklung neuer Produkte und Produktionsverfahren bieten sich hierzu prinzipiell zwei grundsätzliche Strategien.

- Obwohl Logistiksysteme selten direkter Ansatzpunkt für Imitationshandlungen sind - auf die Schwierigkeiten bei der Imitation überlegener Logistiksysteme wurde bereits hingewiesen -, können Maßnahmen zur logistischen Reorganisation dennoch indirekt dazu beitragen, Imitationshandlungen auf der Produktebene auf den Weg zu bringen bzw. zu beschleunigen, weil sie an der Optimierung von Stoff- und Informationsströmen und damit der zeitlichen und räumlichen Verfügbarkeit der für solche Imitationshandlungen wichtigen Inputfaktoren ansetzen.

- Werden Maßnahmen zur logistischen Reorganisation für adaptives Marktverhalten in Gestalt von (nicht imitierenden) Verfahrensfortschritten zur Optimierung von Güter-, Material- und Informationsströmen instrumentalisiert, so gelten die unter ad (1) zum kreativen Marktverhalten gemachten Ausführungen entsprechend.

\subsubsection{Logistische Reorganisation und kollektives Marktverhalten}

\subsection{Zur Kompatibilität von logistikbezogenen kooperativen Beziehungsge- fuigen und wettbewerblichem Marktverhalten}

Die Analyse in Kapitel 2 hat gezeigt, dass die positiven Effekte, welche mit logistischer Reorganisation einhergehen, voll umfänglich nur durch das kooperative Zusammenwirken zwischen den am jeweiligen Logistiksystem beteiligten Wirtschaftsakteuren realisiert werden können. Diese Schlussfolgerung liegt in der unternehmensübergreifenden, auf die Optimierung von Wertschöpfungsketten ausgerichte- 
ten Orientierung des Logistikansatzes begründet und hat zur Konsequenz, dass Maßnahmen zur logistischen Reorganisation mit dem Zweck, vorstoßende oder nachfolgende Wettbewerbshandlungen durchzuführen, notwendigerweise in nicht unwesentlichem Umfang auf kooperativen Beziehungsgefügen fußen. Diese können sich sowohl zwischen Marktteilnehmern derselben Marktstufe (horizontale Kooperation) als auch zwischen Marktteilnehmern unterschiedlicher Marktstufen (vertikale Kooperation) vollziehen und gründen auf der Absicht, Marktabläufe und Verhaltensweisen umfassend im Vorhinein festzulegen bzw. vertraglich zu regeln. Sie tendieren dazu, Unsicherheitsfaktoren, welche dem System marktlicher ex-post-Koordination anhaften, zugunsten eines Systems der ex-ante-Verhaltenskoordination auszuschalten. Kooperative Beziehungsgefüge können folglich als die organisatorisch-institutionelle Ausgestaltungsform des kollektiven Marktverhaltens interpretiert werden, welches aufgrund seiner Tendenz, die Handlungsspielräume der beteiligten Wirtschaftsakteure $\mathrm{zu}$ reduzieren, zu den potenziell wettbewerbsbeschränkenden Marktverhaltensweisen zu zählen ist.

Im Falle der logistikbezogenen kooperativen Beziehungsgefüge war allerdings festzustellen, dass diese aufgrund der Spezifika der Logistiktransaktionen und aufgrund des übergreifenden Charakters des logistischen Optimierungsansatzes unabdingbare Voraussetzung dafür sind, Rationalisierungs- und Produktivitätsreserven, welche die logistische Reorganisation bereit hält, umfänglich auszuschöpfen und im Rahmen von vorstoßenden und nachfolgenden Wettbewerbshandlungen zu instrumentalisieren. Die Analyse in Kapitel 2 lässt hinsichtlich der positiven Impulse, welche von den logistikbezogenen kooperativen Beziehungsgefügen auf die ökonomische Performance logistischer Reorganisation erwartet werden können, nachstehende Schlussfolgerungen zu. Diese Schlussfolgerungen belegen die ökonomische Ratio kooperativer Leistungserstellung im Logistikmarkt und stützen darauf aufbauend die These der prinzipiellen Kompatibilität von logistikbezogenen kooperativen Beziehungsgefügen und wettbewerblichem Marktverhalten.

\subsection{Wirkungspotenziale logistikbezogener kooperativer Beziehungsgefüge}

\section{Wirkungspotenziale horizontaler kooperativer Arrangements}

Aus der Analyse des allgemeinen, nationalen Stückgutmarktes (Unterabschnitt 2.4.5.4.2) sowie aus den Ausführungen zu horizontalen kooperativen Arrangements (Unterabschnitt 2.5.3.3.2) ergeben sich zusammenfassend nachstehende Folgerungen: 
- Die Bildung horizontaler Kooperationen befähigt die Kooperationspartner in erster Linie, produktionskosten-, transaktionskosten- und leistungsbezogene Vorteile zu realisieren, welche sich im Rahmen von Standardisierungsstrategien ergeben. Standardisierung kann sich dabei sowohl auf der Ebene der operativen als auch auf der Ebene der administrativen Leistungserstellungsprozesse vollziehen.

- Die erfolgreiche Umsetzung von Strategien zur Standardisierung operativer Leistungserstellungsprozesse in der Logistik fußt im Wesentlichen auf dem Vorhandensein der Möglichkeit, diejenigen logistischen Objekte zu vereinheitlichen, welche Gegenstand der jeweiligen logistischen Leistungserstellungssysteme sind. Diese Vereinheitlichung logistischer Objekte wiederum ist insbesondere im Bereich bestimmter netzwerkbasierter Transportlogistiksysteme ausschlaggebend für die Effizienz der Leistungserstellung (so bspw. im allgemeinen, nationalen Stückgutmarkt oder im KEP-Markt). Einheitlichkeit der systemweit transportierten Güter - bezogen auf Gewicht, Volumen, Haltbarkeit oder sonstige relevante physische Gütercharakteristika - zieht (1) insbesondere die Möglichkeit der Erhöhung des logistischen Automatisierungsgrades nach sich, bewirkt folglich (2) die Möglichkeit zur effizienten Abwicklung großer Transportvolumina und schafft damit (3) die Voraussetzungen zur Erzielung von Größeneffekten.

- Auf der Ebene der administrativen Leistungserstellungsprozesse sind Standardisierungsstrategien vor allem auf die Durchsetzung systemweiter informationstechnischer Standards zur Datengenerierung, zur Datenverwaltung und zum Datenaustausch angelegt. Durch die Etablierung solcher Standards wird (1) ein Beitrag zur Erhöhung der Daten- und damit der Leistungsqualität geleistet und (2) der kostenverursachende Aufwand für die systemweite Abwicklung transportübergreifender Dokumenten- und Informationsflüsse reduziert.

Die Standardisierung operativer und administrativer Leistungserstellungsprozesse bewirkt demnach, dass große Gütermengen effizient durch logistische Leistungserstellungssysteme geschleust werden können. Dies begründet die Möglichkeit, Größeneffekte bzw. umfassender formuliert: Netzwerkeffekte im Sinne von kosten- und nutzenbasierten Größen- und Dichteeffekten zu realisieren. 
- Ferner bieten horizontale Kooperationen mittelständischen Logistikunternehmen die Möglichkeit, netzwerkbasierte Transportlogistikleistungen in anforderungsgerechter Leistungsqualität anzubieten - und damit in Marktsegmente vorzudringen, welche ihnen ohne Kooperation mit anderen Logistikunternehmen verschlossen bleiben würden. Horizontale Kooperationen haben folglich die Funktion eines Gegengewichts zu konzentrativen Tendenzen. ${ }^{9}$

In welchem Umfang Produktionskosten- und Transaktionskostenersparnisse in horizontalen Kooperationen jedoch erzielt werden können, hängt von der konkreten Ausgestaltung des kooperativen Beziehungsgefüges ab. Für den Fall der SystemStückgutkooperationen bedeutet dies bspw., dass Standardisierungsvorteile, Transaktionskostenersparnisse und eine hinreichend wettbewerbsfähige Leistungsqualität nur dann realisiert werden können, wenn sich die Kooperationen durch eine entsprechende Bindungsfestigkeit auszeichnen. Andernfalls würden die Kosten- und Leistungspotenziale dieser Ausprägungsform zur Leistungskoordination nicht zum Tragen kommen können, die Kooperation würde an ihrer inneren Disharmonie, an der Interessenheterogenität ihrer Mitglieder scheitern. Ein Mehr an Transaktionskosten und realisierte Größen- bzw. Netzwerkeffekte in allenfalls reduziertem Umfang wären die Folge. Daher ist es für den diesbezüglichen Erfolg der Kooperation unabdingbar wichtig, dass sie durch eine möglichst umfassende Kooperationsvereinbarung abgesichert wird, welche dem Zentralorgan die Koordination der Kooperationsaktivitäten in maßgeblichem Umfang überträgt. Nur so sind transaktionskosteneffiziente Entscheidungsfindungsprozesse und funktionsfähige Sanktionsmechanismen gegen opportunistisches Verhalten einzelner Mitglieder möglich, nur so ist effiziente Beherrschung und Überwachung der Leistungsprozesse denkbar. Daraus erhellt aber auch, dass sich horizontale kooperative Beziehungsgefüge stets am Rande konzentrativer Beziehungsgefuge bewegen und damit Gefahr laufen, zu Vorstufen bzw. zum Ausgangspunkt für letztere zu werden.

\section{Wirkungspotenziale vertikaler kooperativer Arrangements}

Aus der Analyse der Teilmärkte für Kontraktlogistik (Unterabschnitt 2.4.5.4.3) sowie aus den Ausführungen zu vertikalen kooperativen Arrangements (Unterabschnitt 2.5.3.3.3) ergeben sich zusammenfassend nachstehende Folgerungen: 
- Vertikale Logistikkooperationen tragen in erster Linie dazu bei, produktionskosten-, transaktionskosten- und leistungsbezogene Vorteile aus der produktivitätssteigernden Wirkung von Arbeitsteilung und Spezialisierung zu generieren. Insbesondere verladende Unternehmen aus Industrie und Handel können ihre Aktivitäten im Rahmen vertikaler kooperativer Beziehungsgefüge mit Logistikunternehmen auf ihre Kernkompetenzen ausrichten und die Gesamtkomplexität ihrer intraorganisatorischen Geschäftsprozesse um deren nichtwertschöpfende Komponenten reduzieren. Gleichzeitig können sie das logistikthemenspezifische Fach-Know-how entsprechend spezialisierter Logistikunternehmen in ihre eigenen Wertschöpfungsprozesse integrieren. Der Austausch von Planungsinformationen zwischen den kooperativ verbundenen Unternehmen reduziert dabei (1) den sich zwangsläufig ergebenden transaktionskostenverursachenden Abstimmungs- und Koordinationsaufwand an den Schnittstellen zwischen den einzelnen mikrologistischen Systemen, die zu einem unternehmensübergreifenden Wertschöpfungssystem zusammengeführt werden. Ferner begründen vertikale kooperative Arrangements (2) produktionskostenbezogene Spezialisierungsvorteile, welche in Form von Größen- und Verbundeffekten von der Integration spezialisierter Logistikunternehmen in die Wertschöpfungsprozesse ausgehen.

Demzufolge begründet eine möglichst umfassende Neuausrichtung des Betrachtungshorizontes logistischer Problemstellungen von einer rein intraorganisatorischen mikrologistischen Perspektive auf die Ebene interorganisatorischer vertikaler metalogistischer Systeme (Supply Chains) Potenziale zur Produktionsund Transaktionskostensenkung sowie zur Leistungsverbesserung.

- Vertikale Logistikkooperationen eröffnen Möglichkeiten zur Rationalisierung innerhalb von Güterflusssystemen. Sie leisten folglich einen Beitrag, produktionskosten- und transaktionskostenbezogene Rationalisierungsvorteile zu realisieren.

- Rationalisierungspotenzial resultiert zum einen aus der Möglichkeit zur güterflusssystemweiten Integration von Informationsflüssen. Datenverluste, Intransparenzen in den Leistungserstellungsprozessen, Datenredundanzen und, damit einhergehend, eine unnötige Duplizierung logistischer Aktivitäten können vermieden werden. Hierdurch sinken zum einen die Produktionskosten im Bereich operativer und administrativer Leistungserstellungsprozesse, zum anderen aber auch die Transaktionskosten (Kontroll- und Überwachungskosten, Informationskosten, Redu- 
zierung von Möglichkeiten zu opportunistischen Verhaltensweisen durch einen Zugewinn an Transparenz) .

- Ferner resultiert Rationalisierungspotenzial aus dem güterflusssystemweiten Einsatz bestimmter physischer logistischer Produktionstechnologien (bspw. Container oder Paletten, welche mit entsprechenden Flurförderfahrzeugen, Um- und Verladeeinrichtungen oder Lagersystemen bedient werden müssen). Die Verwendung derartiger Technologien erfordert die güterflusssystemweite Abstimmung zwischen den mikrologistischen Systemen. Da die Kosten, welche die Technologien verursachen, das gesamte Güterflusssystem betreffen, können sie auch nur gemeinsam in Kooperation von allen am Güterflusssystem beteiligten Parteien beeinflusst werden. ${ }^{10}$

Insofern scheint im Logistikmarkt der institutionell-organisatorische Wandel von Logistiksystemen in Richtung interorganisatorischer kooperativer Beziehungsgefüge die Ausgestaltung des technologischen Wandels wesentlich mitzubestimmen.

\section{Zum Verhältnis horizontaler und vertikaler kooperativer Beziehungsstrukturen}

Horizontale und vertikale Logistikkooperationen treten in der Wirtschaftspraxis selten gänzlich isoliert voneinander auf. Erzeugen eine Ansammlung von Industrie-, Handels- und Logistikunternehmen ein vertikales kooperatives Beziehungsgefüge zur gemeinschaftlichen Optimierung einer unternehmensübergreifenden Supply Chain, dann sind im Zuge dieses Optimierungsvorhabens in aller Regel auch netzwerkbasierte Logistikleistungen wie bspw. Transport- und Verkehrsleistungen erforderlich. Derartige netzwerkbasierte Logistikleistungen können, wie gezeigt, allenfalls von Konzernlogistikunternehmen bzw. konzernähnlichen Logistikunternehmen mit Netzwerkkompetenz allein in Eigenproduktion erbracht werden. Alle anderen, insbesondere die mittelständischen Logistikunternehmen sind für die anforderungsadäquate Produktion netzwerkbasierter Logistikleistungen auf horizontale Logistikkooperationen angewiesen. Vertikale Logistikkooperationen greifen folglich in aller Regel auf horizontale kooperative Beziehungsgefüge zurück, um Teile der geforderten Kontaktlogistikleistungen bzw. der SCM-Leistungen zu produzieren. Ähnliches ist für den Bereich horizontaler Logistikkooperationen zu konstatieren. Originär als horizontale 
Logistikkooperationen einzuordnende Arrangements fußen in aller Regel auf vertikalen Beziehungsgefügen oder können die Basis für vertikale Beziehungsgefüge sein. So bieten bspw. die mittelständisch geprägten kooperativen Beziehungsgefüge in SystemStückgutkooperationen den Partnerunternehmen die Option, auch in anderen Logistikleistungsbereichen miteinander zu kooperieren und ihr Leistungsspektrum für einzelne Stückgut-Kunden zusätzlich um Kontraktlogistikleistungen im Rahmen vertikaler Kooperationen zu erweitern. In solchen Fällen überschneiden sich Elemente horizontaler und vertikaler Logistikkooperation. " Ferner werden in System-Stückgutkooperationen die physischen Transportleistungen im Allgemeinen an spezialisierte Transportunternehmen outgesourct. Diese Unternehmer-Subunternehmerbeziehungen werden dann in Form längerfristiger vertikaler Logistikkooperationen institutionalisiert.

Daraus erhellt, dass auf Kooperation ausgerichtete institutionelle Arrangements im realen Logistikmarktgeschehen - unabhängig davon, welche Richtung der ursprüngliche Beweggrund für die Kooperation aufwies - in aller Regel sowohl Komponenten horizontaler als auch vertikaler interorganisatorischer Beziehungsgefüge beinhalten. Dementsprechend treten in Logistikkooperationen auch die Wirkungskomponenten beider Kooperationsformen miteinander vermengt auf. Wichtig dabei ist die Erkenntnis - und das ist das verbindende Moment zwischen den einzelnen Wirkungskomponenten -, dass sich die zu realisierenden Potenziale nicht auf einzelne Mikrologistiken beziehen, sondern auf metalogistische Systeme, auf gesamte Supply Chains oder Wertschöpfungsketten. Um die vorhandenen positiven Wirkungspotenziale der horizontalen und vertikalen kooperativen Beziehungsgefüge auch tatsächlich realisieren zu können, ist es unbedingt erforderlich, dass die Kooperationsparteien eine Atmosphäre gegenseitigen Vertrauens schaffen und dass der Kooperationsvertrag möglichst umfassend sämtliche Formen opportunistischer Verhaltensweisen der Kooperationspartner ausschließt bzw. sanktioniert sowie die aus den Charakteristika der betreffenden Logistikleistung resultierenden Regelungsanforderungen (bspw. hinsichtlich der Minderung finanzieller Risiken) adäquat erfasst. Nur wenn jeder potenzielle Kooperationspartner aufgrund der Gestaltung des Kooperationsvertrages und der Kooperationsatmosphäre erwarten darf, einen positiven Nutzen aus der Kooperation ziehen zu können - also dass sich eine sog. „Win-Win-Beziehung“ einstellt - kann die Kooperation erfolgreich sein und ihre Wirkungspotenziale entfalten. Bei entsprechender Komplexität und/oder Spezifität der Logistikleistung, welche kooperativ erstellt werden soll, sind dazu unter Umständen umfassende 
vertragliche Regelungen notwendig. Das bedeutet, dass sich das angestrebte kooperative Arrangement aufgrund seiner Bindungsintensität spürbar deutlich in Richtung der institutionellen Sphären der konzentrativen Arrangements orientiert.

\subsubsection{Logistische Reorganisation und Wettbewerbswirkungen}

\subsubsection{Logistische Reorganisation und die ökonomischen Wettbewerbsfunktio- nen}

In Unterabschnitt 1.3.1.1 wurden die folgenden ökonomischen Wettbewerbsfunktionen im Sinne „allgemein formulierbarer Erwartungen“ bezüglich der Wirkungen des Wettbewerbs beschrieben, welche als musterhafte Voraussagen die positiven Steuerungseigenschaften des Wettbewerbs innerhalb eines marktwirtschaftlichen Wirtschaftssystems widerspiegeln. Es sind dies

- die Anpassungs- bzw. Allokationsfunktion des Wettbewerbs,

- die Entdeckungs- bzw. Fortschrittsfunktion des Wettbewerbs sowie

- die Verteilungsfunktion des Wettbewerbs.

Im Folgenden soll nun nicht die prinzipielle Kompatibilität der logistischen Reorganisation mit den ökonomischen Wettbewerbswirkungen bewiesen werden - diese ergibt sich bereits aus der Tatsache, dass sich die logistische Reorganisation positiv in die Wettbewerbsdeterminanten einbringt und in ihrer Rolle als Instrument fur wettbewerbliches Marktverhalten in jedem Fall einen positiven Zielbeitrag zu den erwarteten Wettbewerbswirkungen zu leisten in der Lage ist. Die Frage, die an dieser Stelle zu klären ist, betrifft vielmehr die Ebene des Beziehungsverhältnisses zwischen der Logistik- und der Wettbewerbskonzeption: es gilt zu prüfen, ob die Logistikkonzeption - analog der Wettbewerbskonzeption - das individuelle Maximierungsstreben Einzelner in Richtung eines kollektiven Optimums kanalisiert und ob darauf aufbauend die These einer über die instrumentale Rolle der logistischen Reorganisation hinausgehende Wirkungsbeziehung zwischen den beiden Konzeptionen auf der Ebene übergeordneter Prinzipien für Koordination und Ordnung innerhalb komplexer Wirtschaftssysteme gestützt wird. Nach dieser Maßgabe werden nun anschließend die 
Wirkungen der logistischen Reorganisation in Beziehung zu den einzelnen Wettbewerbsfunktionen gesetzt.

\subsection{Logistische Reorganisation und die Anpassungs- bzw. Allokationsfunk- tion des Wettbewerbs}

Die Anpassungs- bzw. Allokationsfunktion bringt zum Ausdruck, dass Wettbewerb die Anpassung der Zusammensetzung der Güterproduktion an die Änderungen der Nachfragestruktur bewirkt und den dafür erforderlichen Reallokationsprozess der Produktionsfaktoren in Gang setzt.

Logistik wiederum befasst sich mit der Optimierung von Güter-, Material- und Informationsströmen. Diese Optimierung vollzieht sich in der (vorläufigen) Endausbaustufe der Logistikkonzeption auf der unternehmensübergreifenden Ebene. Ausgangspunkt für das logistische Optimierungsstreben ist allerdings regelmäßig das individuelle Optimierungskalkül von einzelnen Unternehmen. Angestrebtes Ergebnis logistischer Reorganisation ist zunächst der individuelle Unternehmenserfolg. Da die rein unternehmensbezogene Optimierung von Stoff- und Informationsströmen jedoch erkanntermaßen lediglich Suboptima bezogen auf den gesamten, wertschöpfungskettenbezogenen Güterfluss produziert, wird im Rahmen der Logistik versucht, unternehmensübergreifende kosten- und leistungsbezogene Wirkungsinterdependenzen offenzulegen und gesamthaft zu optimieren.

Das verbindende Element zwischen der Wettbewerbs- und der Logistikkonzeption, in Bezug auf die Anpassungs- bzw. Allokationsfunktion, ist folglich in deren gemeinsamer Intention zu sehen, erforderliche Bewegungen von Produktionsfaktoren resp. Gütern, Materialien und Informationen, wie sie das interaktive Zusammenwirken konsumtiver und produktiver Prozesse mit sich bringt, zu veranlassen und zu bewältigen. Wettbewerb veranlasst und bewältigt diese Stoff- und Informationsbewegungen in Abstraktion von räumlichen und zeitlichen Friktionen realen ökonomischen Handelns auf der Basis von Preissignalen. Demgegenüber hat sich die Logistik im realen Wirtschaftsgeschehen mit der konkreten Ausgestaltung der Veranlassung und mit den konkreten Anforderungen an die Bewältigung dieser Bewegungen auseinanderzusetzen - sie hat demgemäß räumliche und zeitliche Friktionen der ökonomischen Realität, logistikrelevante unternehmensübergreifende Wirkungsinterdependenzen und die damit einhergehende Koordinationskomplexität explizit zum Gegenstand ihres Wirkens zu machen. 
Ein zentraler Hebel für die Logistik, ihren Auftrag zu erfüllen ist die Bildung von horizontalen und vertikalen metalogistischen Systemen, welche auf kooperativen interorganisatorischen Beziehungsgefügen gründen. Derartige Systeme bilden einen geeigneten, institutionellen Rahmen für die Verknüpfung unternehmensübergreifender Stoff- und Informationsströme.

Vertikale metalogistische Systeme fußen in der Regel auf der Idee, Stoff- und Informationsströme entlang einer Wertschöpfungskette unter Berücksichtigung existenter unternehmensübergreifender kosten- und leistungsbezogener Verflechtungen zwischen den Wertschöpfungspartnern zu optimieren. Der damit korrespondierende strategische Ansatz der gewerblichen Anbieter von Logistikleistungen ist der der kundenbezogenen Individualisierung ihres Leistungsangebotes. ${ }^{12}$ Im Rahmen dieses Ansatzes wird intendiert, durch ein tiefes Eindringen in die Leistungserstellungsprozesse des Kunden ein möglicht umfangreiches branchen- oder kundenspezifisches Logistikwissen aufzubauen, um darauf aufbauend die Stoff- und Informationsströme möglichst genau abbilden, steuern und letztlich optimieren zu können.

Horizontale metalogistische Systeme basieren hingegen in der Regel auf der Idee, die logistische Abwicklung von Güter-, Material- und Informationsströmen unabhängig von einzelnen Kunden oder Wertschöpfungsketten optimal zu gestalten. Der damit korrespondierende strategische Ansatz der gewerblichen Anbieter von Logistikleistungen ist der der kundenunabhängigen, produktionsprozessbezogenen Standardisierung und findet häufig im Bereich der netzwerkbasierten Logistikleistungskomponenten Anwendung. ${ }^{13}$ Dieser Ansatz ist darauf ausgerichtet, durch einen möglichst hohen Grad von Systemstandardisierung und - wenn möglich - Automatisierung der operativen und administrativen Leistungserstellungsprozesse, verbunden mit der Standardisierung der im Logistiksystem abgewickelten logistischen Güter, die Abwicklung von Stoff- und Informationsströmen netzwerkweit zu optimieren.

Vertikale und horizontale metalogistische Systeme überlappen sich im realen Wirtschaftsgeschehen, Metalogistiken beinhalten folglich in aller Regel sowohl Komponenten vertikaler als auch horizontaler Beziehungsstrukturen. ${ }^{14}$ Daraus erhellt, dass sich auch die Effizienzwirkungen der vertikalen und horizontalen metalogistischen Systeme im realen Wirtschaftsgeschehen überlappen und sich die jeweiligen strategischen Ansätze der Anbieter von Logistikleistungen dementsprechend ergänzen

12 Vgl. die Unterabschnitte 2.4.5.4.1 und 2.4.5.4.3.

13 Vgl. die Unterabschnitte 2.4.5.4.1 und 2.4.5.4.2.

14 Vgl. Unterabschnitt 3.3.2.2.2. 
müssen, um die Potenziale zur Optimierung der jeweiligen Stoff- und Informationsströme auch zu nutzen. Der entsprechende strategische Ansatz kann als standardbasierte, kundenbezogene Individualisierung formuliert werden ${ }^{15}$ und ist auf die modulare Verknüpfung der beiden Perspektiven der

- kunden- bzw. wertschöpfungskettenbezogenen Stoff- und Informationsströme und der

- kundenunabhängigen (leistungserstellungsnetzwerkweiten) Stoff- und Informationsströme

sowie der damit jeweils verbundenen Optimierungspotenziale ausgerichtet. Zur Verdeutlichung dieser Zusammenhänge vergleiche folgende Abbildung 3-1. 
(1)

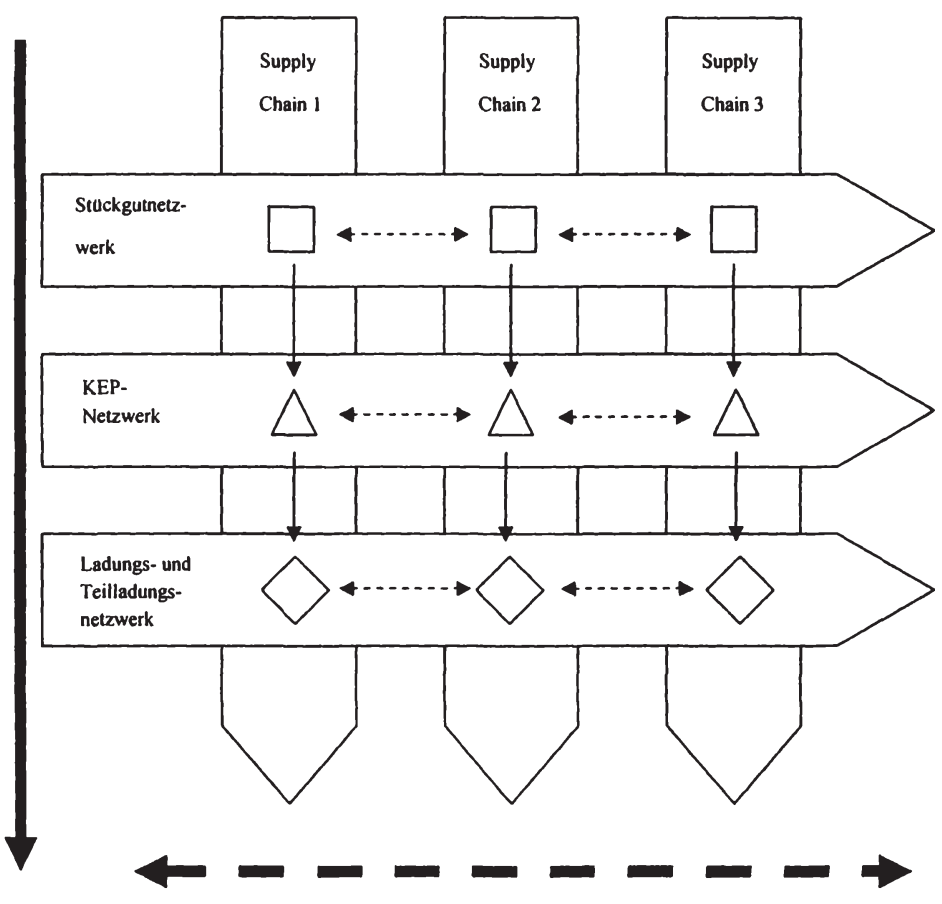

(2)

(1) Wertschopfungskettenbezogene Optimierung von Guter-, Material- und Informationsstromen in vertikalen metalogistischen Systemen

Strategie: kundenbezogene Individualisierung

(2) Netzwerkbezogene Optimierung von Guter-, Material- und Informationsstromen in horizontalen metalogistischen Systemen

Strategie: kundenunabhangige, produktionsprozessbezogene Standardisierung

$\square$ Stuckguter

$\bigwedge \quad$ KEP-Guter

Ladungs- und Teilladungsguter

\section{Abbildung 3-1: Optimierungspotenzial metalogistischer Systeme}

Quelle: eigene Erstellung 
Damit ist hinsichtlich der Ausgestaltung und Dimensionierung der Optimierungspotenziale logistischer Reorganisation auf der institutionellen Basis metalogistischer Systeme folgendes festzuhalten:

- Metalogistische Systeme basieren auf einem einzelwirtschaftlichen Optimierungskalkül.

- Dieses einzelwirtschaftliche Optimierungskalkül schlägt sich in vertikalen metalogistischen Systemen in Form des Bestrebens des Wertschöpfungskettenleaders nieder, alle die Wertschöpfungskette betreffenden Güter-, Material- und Informationsströme zu optimieren. Hierzu wird sehr oft ein auf diese Optimierungsaufgabe spezialisiertes Logistikunternehmen als führende Integrationsfigur beauftragt.

- In horizontalen metalogistischen Systemen manifestiert sich das einzelwirtschaftliche Optimierungskalkül in dem Bestreben einzelner Unternehmen, eine - meist netzwerkbasierte - Logistikleistung (1) in kundenanforderungsgerechter Leistungsqualität und (2) möglichst rationell produzieren zu können.

- Dieses einzelwirtschaftliche Optimierungskalkül führt letzten Endes dazu, dass die Güter-, Material- und Informationsströme entsprechend ihres jeweiligen leistungswirtschaftlichen Zusammenhanges gesamthaft optimiert werden.

- Diese gesamthafte Optimierung erstreckt sich im Falle vertikaler metalogistischer Systeme auf Ströme von heterogenen Gütern mit verschiedenen logistischen Handlingeigenschaften (bspw. KEP-Güter, Stückgüter oder Ladungsgüter), welche dem Ziel dienen, die Produktionsfaktoren über sequenzielle und/oder parallele Produktions- und Konsumtionsvorgänge in einen konsumnäheren Zustand zu überführen.

- Im Falle der horizontalen metalogistischen Systeme erfolgt die gesamthafte Optimierung netzwerkbezogen und auf Ströme mit relativ homogenen Gütern ausgerichtet. Hier werden folglich Ströme von bspw. KEPGütern, Stückgütern oder Ladungsgütern optimiert, welche aus verschiedenen Wertschöpfungsketten stammen.

- Die wertschöpfungskettenübergreifende optimierende Güter- und Informationskoordination in horizontalen metalogistischen Systemen trägt 
folglich zum Erfolg von wertschöpfungskettenbezogenen Optimierungsvorhaben im Rahmen vertikaler metalogistischer Systeme bei.

- Damit ist zu konstatieren, dass auch das Logistikprinzip als unternehmensübergreifendes Koordinationsprinzip einzelwirtschaftliches Maximierungsstreben in Richtung eines kollektiven Optimums kanalisiert, welches sich allerdings nicht wie bei der Wettbewerbskonzeption auf die gesamte Volkswirtschaft, sondern lediglich auf Teilbereiche erstreckt. Diese Teilbereiche umfassen diejenigen Ausschnitte des realen Wirtschaftsgeschehens, in welchen aufgrund logistikbasierter Analyse entsprechende konkrete güterwirtschaftliche Zusammenhänge aufgedeckt wurden, die dann zum Gegenstand logistischer Optimierungsansätze gemacht werden können.

Hinsichtlich des Verhältnisses der Wettbewerbs- und der Logistikkonzeption auf der Ebene übergeordneter Prinzipien für Koordination und Ordnung innerhalb komplexer Wirtschaftssysteme ist im Ergebnis daher folgendes zu konstatieren:

- Die Logistikkonzeption kann als eine Form der Operationalisierung der wettbewerblichen Anpassungs- bzw. Allokationsfunktion interpretiert werden: Wettbewerb bewirkt, dass Produktionsfaktoren auf Basis der Verknüpfung dezentraler Unternehmens- und Haushaltsentscheidungen mittels Preissignalen in ihre produktivste Verwendung im Produktionsprozess gelenkt werden. Im realen Wirtschaftsgeschehen konkretisiert sich die Lenkung von Produktionsfaktoren in Gestalt eines komplexen raum-zeitlich strukturierten Geflechts, bestehend aus physischen Güter- und Materialbewegungen sowie aus Informationsströmen. Im Prozess der logistischen Reorganisation wird nach Möglichkeiten gesucht, diese physischen Güter- und Materialbewegungen sowie die Informationsströme möglichst effizient zu bewältigen.

- Logistikeffizienz in Gestalt leistungsfähiger Logistiksysteme trägt dazu bei, dass

o die Produktionsfaktoren mit zunehmender Effektivität unter Berücksichtigung und Beherrschung der Beschränkungen durch die raumzeitliche Strukturierung der Produktions- und Konsumtionsprozesse physisch gelenkt werden, dass 
0 die dezentralen Planungsentscheidungen der Unternehmen und Haushalte effektiver umgesetzt werden und dass folglich

○ der Wettbewerb die Anpassungs- bzw. Allokationsfunktion besser erfüllen kann.

Der Grad der Logistikeffizienz berührt folglich in jedem Fall die Effektivität der wettbewerblichen Steuerungsleistung.

- In dem Ausmaß, in dem Logistik aus der Rolle des resultierenden Faktors der Organisation von Produktion und Konsumtion in die Position eines Faktors avanciert, welcher die Organisation von Produktion und Konsumtion bedingt, steigt auch das Ausmaß der Einflussnahme logistischer Reorganisation auf die Entscheidungsfindung bei den Unternehmen und Haushalten bezüglich ihrer Produktions- bzw. Konsumplanung. Unter diesen Umständen berührt der Grad der Leistungsfähigkeit der logistischen Systeme auch die Güte der Entscheidungsfindung hinsichtlich der individuellen Wirtschaftsplanung und trägt infolgedessen nicht nur dazu bei, den Prozess der Faktorallokation operativ abzuwickeln, sondern darüber hinaus Richtung und Intensität dieses Prozesses zu gestalten.

Insofern tangiert der Grad der Logistikeffizienz zudem auch, zumindest mittelbar, die Effizienz der wettbewerblichen Steuerungsleistung.

\subsection{Logistische Reorganisation und die Entdeckungs- bzw. Fortschrittsfunk- tion des Wettbewerbs}

In der Entdeckungs- bzw. Fortschrittsfunktion des Wettbewerbs manifestiert sich die Auffassung, dass Wettbewerb die Vermehrung und die Verbreitung des technischen Wissens bewirkt. Wettbewerb sorgt demgemäß dafür, dass Produktionsfaktoren in den Bereich der Forschung und Entwicklung gelenkt werden, um neue Mechanismen und Verfahren der Problemlösung zu entdecken, d. h. Produktinnovationen, Produktdiffusion und Verfahrensinnovationen in den Produktionsprozessen anzustoßen. Auch der in der Logistikkonzeption verankerte Optimierungsansatz begründet die Notwendigkeit innovativer Aktivitäten im Logistiksystem und impliziert damit eine ausgeprägte Fortschrittsorientierung im Prozess der logistischen Reorganisation. Sichtbaren Niederschlag findet diese ausgeprägte Fortschrittsorientierung in der raschen konzeptionellen Evolution der Logistik in der akademischen Forschung und Lehre sowie in der bereitwilligen Regsamkeit der Unternehmen in der Wirtschaftspraxis, an den 
Potenzialen dieser konzeptionellen Evolution zu partizipieren und eine möglichst hohe Rangstufe logistischer Entwicklung zu erreichen. ${ }^{16}$

Das verbindende Element zwischen der Wettbewerbs- und der Logistikkonzeption, in Bezug auf die Entdeckungs- bzw. Fortschrittsfunktion, ist folglich in deren gemeinsamer Intention zu sehen, technisches Wissen zu vermehren und zu verbreiten. Was dabei die Art der Beziehung zwischen den beiden Konzeptionen angeht, kann die Logistikkonzeption zunächst in einem ersten Schritt als Beleg für die Funktionsfähigkeit des wettbewerblichen Suchprozesses gedeutet werden: Möglicherweise hat der Wettbewerb als Such- und Informationsverfahren dazu beigetragen, die Logistikkonzeption zu entdecken, zu verbreiten und im Rahmen des Prozesses der logistischen Reorganisation permanent weiterzuentwickeln. Dennoch gebieten zumindest zwei Argumente, die Logistikkonzeption nicht auf die Rolle eines bloßen Anwendungsbereiches der Wettbewerbskonzeption zu reduzieren, sondern sie aus der allgemeinen Phalanx der im Rahmen des wettbewerblichen Suchprozesses gemachten Entdeckungen hervorzuheben. Erstens wird in diesem Zusammenhang nochmals auf die Exponiertheit der Stellung des Logistiksystems im gesamten Wirtschaftsprozess verwiesen. Die Exponiertheit ergibt sich aus dem Umstand, dass sich im Logistiksystem als Scharnier bzw. Bindeglied zwischen praktisch allen denkbaren Wirtschaftsbereichen die Möglichkeiten zur Einflussnahme auf eine Vielzahl ökonomischer Prozesse auf eine vergleichsweise geringe Anzahl von Wirtschaftsakteuren konzentrieren. ${ }^{17}$ Insofern bleiben auch die Wirkungen von Innovationsaktivitäten im Logistiksystem nicht auf das Logistiksystem beschränkt, sondern sind ausschlaggebend für das gesamte Wirtschaftsgeschehen. Zweitens wird darauf hingewiesen, dass die Wettbewerbskonzeption die mit der Generierung von Innovationen zwangsläufig verbundenen Stoff- und Informationsbewegungen in den Bereich der Forschung und Entwicklung in Abstraktion von räumlichen und zeitlichen Friktionen der ökonomischen Realität allein auf der Basis von Preissignalen veranlasst und bewältigt. Demgegenüber ist die Suche nach neuen Möglichkeiten zur Überwindung eben dieser räumlichen und zeitlichen Friktionen zentraler Gegenstand des Prozesses der logistischen Reorganisation und somit zentraler Bestandteil der Innovationsleistung des Logistiksystems.

Was nun Umfang und Wertigkeit des Beitrages der logistischen Reorganisation zur wettbewerblichen Innovationsleistung betrifft, ist zunächst auf die Ausführungen in Unterabschnitt 2.2.2.4.1 zu verweisen. An dieser Stelle wurde die zunehmende

Vgl. Unterabschnitt 2.2.2.2.3 
Relevanz von logistikbasierten Innovationen („Logistikinnovationen“) im Rahmen einer Innovationsdiskussion hervorgehoben, welche bislang überwiegend auf Sachgüterinnovationen und von mit der Produktion von Sachgütern unmittelbar verbundenen (Produktions-)Verfahrensinnovationen fokussiert war. Die zunehmende Relevanz von Logistikinnovationen wurde auf den Umstand zurückgeführt, dass die Reflexion ihrer Leistungserstellungsprozesse unter Berücksichtigung der Potenziale logistischer Reorganisation von den Unternehmen als wettbewerbswirksamer Gestaltungsparameter erkannt worden ist. Die relative Wertigkeit von Logistikinnovationen in der Innovationskultur im Vergleich zu den Sachgüterinnovationen spiegelt dabei die relative Wertigkeit bzw. die Stellung des Logistiksystems im gesamtwirtschaftlichen Systemverbund der Gütertransformation wider. Sie ist dementsprechend davon abhängig, ob das Logistiksystem primär die Rolle eines resultierenden Faktors der Organisation von Produktion und Konsumtion, oder vielmehr die Position eines die Organisation von Produktion und Konsumtion bedingenden Faktors wahrnimmt. ${ }^{18}$ Es sind daher hinsichtlich der relativen Wertigkeit der Logistikinnovationen die beiden folgenden Grundsatzalternativen denkbar:

- Bekleidet die Logistik im Systemverbund der Gütertransformation überwiegend die Funktion einer resultierenden Größe, dann sind Logistikinnovationen folglich ebenfalls überwiegend resultierende Größen, welche sich aus den Notwendigkeiten der Organisation von Produktion und Konsumtion und den damit verbundenen Produkt- und Verfahrensinnovationen ableiten lassen.

Logistikinnovationen folgen in diesem Fall mehrheitlich den Produktbzw. (Produktions-)Verfahrensinnovationen.

- Ist die Logistik hingegen überwiegend in der Position eines bedingenden Faktors, so wirken die im Logistiksystem produzierten Innovationen bedingend auf die Organisation produktiver und konsumtiver Prozesse ein. Logistikinnovationen könnten dann unter Umständen sogar die Basis für Produktund (Produktions-)Verfahrensinnovationen sein und diese anstoßen. In diesem Fall nehmen Logistikinnovationen eine Impulsgeberrolle für Innovationsaktivitäten in vielen unterschiedlichen Bereichen der produzierenden und

Vgl. Unterabschnitt 2.1.1.

Vgl. dazu auch die Ausführungen zum Charakter der Nachfrage nach Logistikleistungen als abgeleitete Nachfrage in Unterabschnitt 2.2.3.2, insbesondere Fn. 147. 
handeltreibenden Wirtschaft ein und strahlen folglich in die Transformationssysteme aus.

Produkt- bzw. (Produktions-)Verfahrensinnovationen folgen in diesem Fall mehrheitlich den Logistikinnovationen.

Für das Verhältnis zwischen der Wettbewerbs- und der Logistikkonzeption, bezogen auf die Entdeckungs- bzw. Fortschrittsfunktion des Wettbewerbs, ergeben sich daraus nachstehende Schlussfolgerungen:

- Folgen Logistikinnovationen mehrheitlich den Produkt- bzw. (Produktions-) Verfahrensinnovationen, so dient die Produktion von Innovationen im Logistiksystem dem Wettbewerb offensichtlich primär als ein Instrument, mit Hilfe dessen er den Erfüllungsgrad der ihm zugeschriebenen Entdeckungsbzw. Fortschrittsfunktion verbessern kann: Logistikinnovationen, welche im Rahmen des Prozesses der logistischen Reorganisation hervorgebracht werden, tragen dazu bei, dass das Logistiksystem den gütertransferbezogenen Anforderungen, welche aus Sicht der Transformationssysteme an die erfolgreiche Realisierung von Produkt- und Verfahrensinnovationen sowie an die Produktdiffusion geknüpft sind, besser entspricht.

- Der Grad, in dem das Logistiksystem den diesbezüglichen gütertransferbezogenen Anforderungen entspricht, wird wiederum von den Bedingungen zur ökonomischen Beherrschung der jeweiligen raum-zeitlichen Friktionen, welche sich im Rahmen real-wirtschaftlicher Leistungserstellungsprozesse ergeben - den logistischen Bedingungen also -, determiniert.

- Die Güte der Innovationsleistung im Prozess der logistischen Reorganisation nimmt Einfluss auf die Gestaltung dieser logistischen Bedingungen. Sie bestimmt den Umfang mit, in welchem sich die logistischen Bedingungen den innovationsbezogenen Anforderungen der Transformationssysteme annähern und wirkt somit auf die Möglichkeiten zur physischen Umsetzung und damit den Umsetzungserfolg der Innovationsaktivitäten in den Transformationssystemen ein.

Insofern tangiert der Grad der Logistikeffizienz auf jeden Fall die Effektivität der wettbewerblichen Innovationsleistung. 
- Folgen Produkt- bzw. (Produktions-)Verfahrensinnovationen mehrheitlich den Logistikinnovationen, so hat Innovationsproduktion im Logistiksystem nicht mehr lediglich instrumentalen Charakter mit der Folgewirkung, dass die Effektivität der wettbewerblichen Innovationsleistung berührt wird. Vielmehr beeinflussen Logistikinnovationen dann neben den Möglichkeiten zur physischen Umsetzung der Innovationsaktivitäten in den Transformationssystemen auch die Intensität und die Richtung, mit welcher bzw. in welcher Innovationsaktivitäten in den Transformationssystemen überhaupt erst angestoßen werden. Das bedeutet, dass die Güte der Innovationsleistung im Prozess der logistischen Reorganisation ursächlich auf den Prozess der Lenkung von Produktionsfaktoren in den Bereich der Forschung und Entwicklung einwirkt.

Somit tangiert der Grad der Logistikeffizienz unter Umständen zudem auch die Effizienz der wettbewerblichen Innovationsleistung.

\subsection{Logistische Reorganisation und die Verteilungsfunktion des Wettbe- werbs}

Die Verteilungsfunktion des Wettbewerbs hebt auf den Aspekt der (Leistungs-) Gerechtigkeit ab. Hier wird dem Wettbewerb die Aufgabe übertragen, funktionslose, d. h. nicht leistungsbezogene Einkommen auf den Gütermärkten - insbesondere funktionslose Unternehmergewinne - zu verhindern bzw. zügig abzubauen. Berührungspunkte zwischen der Wettbewerbs- und der Logistikkonzeption in ähnlicher Wirkungsstärke, wie sie bei den beiden anderen ökonomischen Wettbewerbsfunktionen herausgearbeitet werden konnten, sind bei der Verteilungsfunktion des Wettbewerbs auf den ersten Blick nicht zu beobachten.

Dennoch gilt jedoch auch hier - analog zu den beiden anderen ökonomischen Wettbewerbsfunktionen - dass, in Abhängigkeit des Ausmaßes, in welchem die Erfüllung der Verteilungsfunktion an die Überwindung und Beherrschung räumlicher und zeitlicher Friktionen geknüpft ist, die logistische Reorganisation auch in diesem Zusammenhang einen spezifischen Beitrag leisten kann. Denn gerade die von der Wettbewerbskonzeption gepflegte Abstraktion von Raum und Zeit und von den damit einhergehenden Notwendigkeiten und Beschränkungen im realen Wirtschaftsgeschehen bildete in den vorangehenden beiden Unterabschnitten ja den argumentativen Anknüpfungspunkt für die Integration der logistischen Reorganisation in den Themenbereich der Wettbe- 
werbswirkungen. Natürlich sind auch der wettbewerbliche Gewinndifferenzierungssowie der wettbewerbliche Gewinnerosions- bzw. Gewinneliminierungsprozess ${ }^{19}$, deren zweckgerichtete Aufeinanderfolge die mit der Verteilungsfunktion angestrebte akzeptable, auf Leistungsgerechtigkeit basierende Primärverteilung gewährleisten soll, den räumlichen und zeitlichen Friktionen realen Wirtschaftsgeschehens unterworfen. Sowohl die (gewinndifferenzierenden) Vorstoßhandlungen der Pioniere als auch die (gewinnerodierenden bzw. gewinneliminierenden) Verfolgungshandlungen der Nachahmer sind in ihrer Dynamik und in ihrer ökonomischen Beweglichkeit an den Grad der Faktormobilität im Sinne einer ausreichenden physischen Beweglichkeit der Produktionsfaktoren gebunden. Die Gestaltung der Möglichkeiten zur zielgerichteten, physischen Bewegung von Produktionsfaktoren (Güter und Material) sowie zur Verfügbarkeit von entsprechenden Informationen unterliegt wiederum der produktiven Einflusssphäre des Prozesses der logistischen Reorganisation. Insofern muss der logistischen Reorganisation, auch bezogen auf die Verteilungsfunktion, Einflusspotenzial zugestanden werden.

Umfang und Wertigkeit dieses Beitrages ist davon abhängig - wiederum analog zu den beiden anderen ökonomischen Wettbewerbsfunktionen -, welcher Stellenwert dem Logistiksystem im Systemverbund der Gütertransformation beigemessen wird:

- Logistikeffizienz in Gestalt leistungsfähiger Logistiksysteme trägt zumindest dazu bei, dass unter Wettbewerb getroffene unternehmerische Planungsentscheidungen zu gewinndifferenzierenden Vorstoß- oder gewinnerodierenden/gewinneliminierenden Verfolgungshandlungen effektiver umgesetzt werden können und nicht an der Komplexität des raum-zeitlichen Geflechts aus physischen Güter- und Materialbewegungen sowie aus Informationsströmen scheitern (Logistik als resultierender Faktor der Organisation von Produktion und Konsumtion).

Der Grad der Logistikeffizienz berührt folglich die Effektivität der wettbewerblichen Verteilungsleistung.

- Steigert sich das Ausmaß der Einflussnahme logistischer Reorganisation auf die Entscheidungsfindung bei den Unternehmen und Haushalten bezüglich ihrer Produktions- bzw. Konsumplanung, dann berührt der Grad der Leistungsfähigkeit der logistischen Systeme auch die Güte der individuellen

19 Vgl. zur Charakterisierung des Wettbewerbsprozesses die Ausführungen in Unterabschnitt 
Entscheidungsfindung, auf Basis derer die wettbewerblichen Vorstoß- und Verfolgungshandlungen vollzogen werden und damit einhergehend der Abbau funktionsloser Einkommen eingeleitet wird. In diesem Fall trägt die Leistungsfähigkeit der logistischen Systeme dazu bei, neben der operativen Abwicklung auch Richtung und Intensität des Prozesses des Abbaus funktionsloser Einkommen zu gestalten.

Insofern berührt der Grad der Logistikeffizienz auch die Effizienz der wettbewerblichen Verteilungsleistung.

Allerdings vollziehen sich wettbewerbliche Gewinndifferenzierungs- und Gewinneliminierungsprozesse nicht selten auf der Basis von Innovationshandlungen und sind darüber hinaus entweder Resultat oder Grundlage von Anpassungs- bzw. Faktorreallokationsprozessen. Offensichtlich überlagern, verstärken oder bedingen sich die Verteilungsfunktion sowie die Fortschritts- und Anpassungsfunktion also bisweilen hinsichtlich ihrer Anforderungsprofile an die Logistiksysteme, bessere Möglichkeiten zur Überwindung räumlicher und zeitlicher Beschränkungen zur effektiveren oder effizienteren Erfüllung ihrer Aufgabe zu schaffen. Daher kann das Einflusspotenzial logistischer Reorganisation auf die Verteilungsfunktion des Wettbewerbs kaum isoliert betrachtet werden. Vielmehr muss es in Beziehung zum Einflusspotenzial der logistischen Reorganisation auf die beiden anderen ökonomischen Wettbewerbsfunktionen gesetzt werden.

\subsubsection{Logistische Reorganisation und die Freiheitsfunktion des Wettbewerbs}

\subsection{Freiheitsfunktion des Wettbewerbs, Beschränkungen des Handlungs- spielraumes und Wettbewerbsbeschränkungen}

In der Freiheitsfunktion dokumentiert sich die Auffassung, dass Wettbewerb Freiheit bewirkt. ${ }^{20}$ Die Freiheitsfunktion des Wettbewerbs gründet auf der Annahme, dass das dezentrale, marktwirtschaftliche Planungssystem generell größere Handlungsspielräume und Wahlmöglichkeiten aufweist als alternative Ordnungssysteme zur Organisation der Wirtschaftsplanung. Wettbewerbliches Marktverhalten wiederum ist eine unabdingbare Voraussetzung für die Funktionsfähigkeit des marktwirtschaftlichen

1.3.2.1.

VgI. Unterabschnitt 1.3.1.2. 
Systems. Insofern kann Wettbewerb als ein Instrument zur Sicherung von Freiheit betrachtet werden.

Wettbewerbliche Marktprozesse gewährleisten jedoch keinesfalls, dass in jedem Einzelfall die ökonomischen Handlungsspielräume und Wahlmöglichkeiten aller Wirtschaftsakteure vergrößert werden. Eine durch wettbewerbliche Marktprozesse initiierte Erweiterung des Handlungsspielraums eines Marktteilnehmers kann durchaus zu einer Verringerung des Handlungsspielraumes eines anderen Marktteilnehmers führen. Wettbewerbsfreiheit ist folglich eine relativ zu betrachtende Größe. ${ }^{21}$ Daraus erhellt, dass es für das Verständnis der Freiheitsfunktion des Wettbewerbs unabdingbar notwendig ist, zunächst die in einem dem wettbewerblichen Ordnungsprinzip überantworteten Ordnungssystem legitimen von den illegitimen Beschränkungen der ökonomischen Wahl- bzw. Handlungsmöglichkeiten zu separieren. Illegitime Beschränkungen der ökonomischen Wahl- bzw. Handlungsmöglichkeiten sind unangemessene bzw. unbillige Beschränkungen der Wettbewerbsfreiheit im Sinne von Wettbewerbsbeschränkungen.

Hierzu ist zunächst auf den Ansatz von HOPPMANN zu verweisen. Er unterscheidet zwischen natürlichen und künstlichen Einschränkungen der Wettbewerbsfreiheit. Künstliche Einschränkungen können durch staatliche bzw. unternehmerische Praktiken verursacht und somit durch wirtschaftspolitische Maßnahmen beeinflusst werden, sind also korrigierbar. ${ }^{22}$ Natürliche Einschränkungen hingegen stellen prinzipiell nicht korrigierbare Beschränkungen des Handlungsspielraumes von Marktteilnehmern dar, wie bspw. Größenvorteile oder unterschiedliche Ressourcenausstattung. ${ }^{23}$ Dieser Ansatz wird später von HERDZINA aufgegriffen. Da man allerdings zumindest bei den natürlichen Beschränkungen des Handlungssielraumes von Marktteilnehmern schwerlich von Wettbewerbsbeschränkungen sprechen kann, wählt dieser für seinen Systematisierungsansatz zur Herleitung von Wettbewerbsbeschränkungen zunächst die terminologisch neutral gefasste Formulierung der „Beschränkungen des Handlungsspielraumes" von Marktteilnehmern. Er unterscheidet also zwischen natürlichen, nicht korrigierbaren sowie künstlichen, korrigierbaren Beschränkungen des Handlungsspielraumes von Marktteilnehmern. ${ }^{24}$

Künstliche Beschränkungen des Handlungsspielraumes wiederum können entweder nicht willkürlich (i. S. v. nicht durch Maßnahmen von Marktteilnehmern oder

Vgl. Herdzina (1999), S. 113 f. sowie Hoppmann (1968a), S. 31 f.

Vgl. Hoppmann (1968a), S. 32.

Vgl. Berg (1977); Herdzina (1999), S. 84 f.

Vgl. Herdzina (1999), S. 85.
} 
Institutionen herbeigeführt wie bspw. ein Mangel an Markttransparenz oder Mobilität) oder willkürlich (i. S. v. durch Maßnahmen von Marktteilnehmern oder Institutionen herbeigeführt) sein. Die Kategorie der künstlichen, nicht willkürlichen Beschränkungen allerdings ist nur schwer von den natürlichen Beschränkungen $(\rightarrow$ mangelnde Mobilität kann auch Folge unzureichenden Know-hows bzw. unzureichender Begabungen der Wirtschaftssubjekte sein) und von den künstlichen, willkürlichen Beschränkungen ( $\rightarrow$ mangelnde Markttransparenz kann auch das Resultat einer bewusst praktizierten unternehmerischen Strategie sein) zu unterscheiden. ${ }^{25}$

Künstliche, willkürliche Beschränkungen letztlich können marktleistungsbedingt oder nicht marktleistungsbedingt sein. Marktleistungsbedingte Beschränkungen sind das Resultat wettbewerblicher Marktprozesse in Form kreativer oder adaptiver Marktverhaltensweisen und infolgedessen (wettbewerbs-)systemimmanent. Sie können daher nicht als Wettbewerbsbeschränkungen abqualifiziert werden. Lediglich die nicht marktleistungsbedingten Beschränkungen stellen unbillige Beschränkungen des Handlungsspielraumes anderer Marktteilnehmer dar, sind also als Freiheits- bzw. Wettbewerbsbeschränkungen zu bezeichnen. ${ }^{26}$ Vergleiche dazu auch die folgende Abbildung 3-2.

Es bleibt somit festzuhalten, dass die

- natürlichen, die

- künstlichen, nicht willkürlichen und die

- künstlichen, willkürlichen, marktleistungsbedingten

Beschränkungen des Handlungsspielraumes legitime Beschränkungen der ökonomischen Wahl- bzw. Handlungsmöglichkeiten in einem dem wettbewerblichen Ordnungsprinzip überantworteten Ordnungssystem darstellen. Lediglich die künstlichen, willkürlichen Beschränkungen des Handlungsspielraumes, welche nicht marktleistungsbedingt sind, werden als illegitime, weil unangemessene Beschränkungen der ökonomischen Wahl- bzw. Handlungsmöglichkeiten in einem dem wettbewerblichen Ordnungsprinzip überantworteten Ordnungssystem behandelt. 


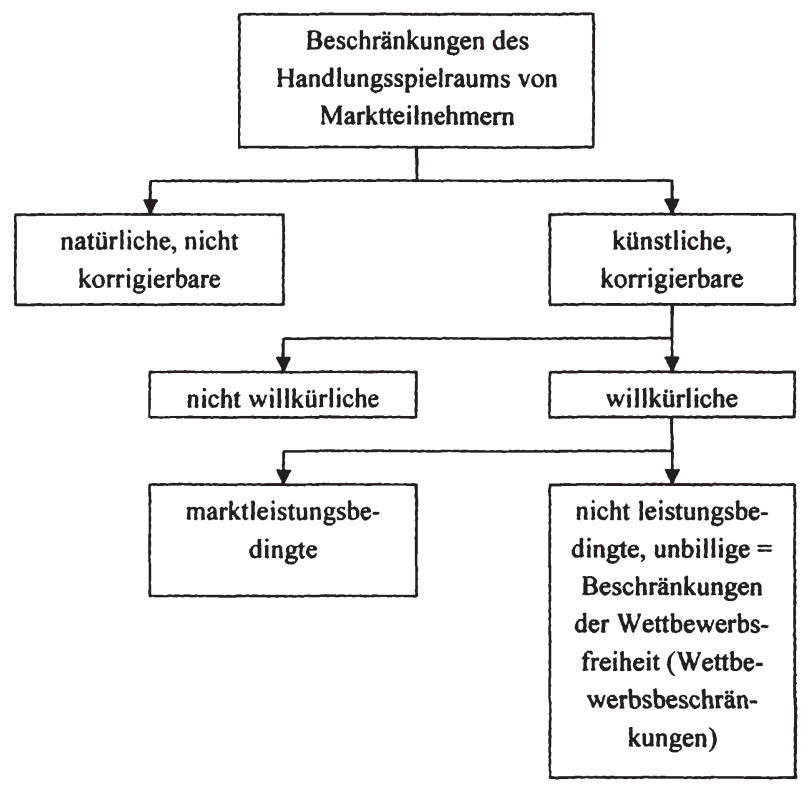

\section{Abbildung 3-2: Beschränkungen des Handlungsspielraumes und Wettbewerbsbe- schränkungen \\ Quelle: Herdzina (1999), S. 85}

Was nun die Frage nach möglichen Berührungspunkten zwischen der logistischen Reorganisation und der Freiheitsfunktion des Wettbewerbs angeht, so kann unter Bezugnahme auf die Ausführungen zu den legitimen Beschränkungen der ökonomischen Wahl- bzw. Handlungsmöglichkeiten und zu den illegitimen Beschränkungen der Wettbewerbsfreiheit im Sinne von Wettbewerbsbeschränkungen folgendes feststellt werden.

\subsection{Logistische Reorganisation und Beschränkungen der Handlungsspiel- räume}

Grundlage der folgenden Argumentation sollen nachstehende Fakten bilden, welche im Zuge der bisherigen Analyse in Kapitel 3 zutage gefördert werden konnten: 
1. In den vorangehenden Unterabschnitten ist mehrfach die Bedeutung leistungsfähiger Logistiksysteme für die Möglichkeiten zur Beschaffung geeigneter Produktionsfaktoren hervorgehoben worden, woraufhin der logistischen Reorganisation die Rolle als eine wichtige Voraussetzung für die physische Mobilität und Verfügbarkeit von Produktionsfaktoren zugedacht wurde.

2. Ferner wurden die tendenziell positiven Wirkungspotenziale der logistischen Reorganisation auf die gesamtwirtschaftliche Markttransparenz angemerkt. Diese resultieren aus der Tatsache, dass im Zuge der Durchsetzung des unternehmensübergreifenden Optimierungsansatzes der Logistik bislang verborgene aber dennoch existente kosten- und leistungsmäßige Wirkungsinterdependenzen in realen Leistungserstellungsprozessen identifiziert und diese in prozessualer und institutioneller Hinsicht visualisiert werden.

3. In einem alternativen, zweiten Argumentationsstrang für die Herleitung einer Beziehung zwischen logistischer Reorganisation und Markttransparenz wurde auf Tendenzen zur Reduktion der Markttransparenz, bezogen auf den Parallelprozess zwischen Konkurrenten, hingewiesen. Diese Tendenzen resultieren aus der Tatsache, dass Maßnahmen zur logistischen Reorganisation aufgrund der hohen Systemkomplexität logistischer Transaktionen sowie deren organisatorisch-institutioneller Verankerung von unternehmensexternen Betrachtern als außerordentlich undurchsichtige und vergleichsweise schwer nachzuvollziehende Aktionen wahrgenommen werden. Überlegene Logistiksysteme reduzieren folglich, bezogen auf den Parallelprozess zwischen Konkurrenten, tendenziell die Markttransparenz. Dadurch ist logistikbasierter Verfahrensfortschritt im Sinne einer produktivitätsbasierten Erhöhung des technologischen Potenzials im Logistiksystem von Konkurrenten nur schwer und mit entsprechender Zeitverzögerung zu imitieren. Das innovierende Unternehmen kann sich folglich mithilfe logistikbasierten Verfahrensfortschritts eine temporäre Vorsprungsposition herausarbeiten, welche ihm die Realisierung möglicher Pioniergewinne erlaubt, bevor diese Vorsprungsposition nach Ablauf einer angemessenen Zeitspanne durch Imitationshandlungen der Konkurrenten wieder erodiert wird.

4. Ferner wurde wiederholt auf die große Bedeutsamkeit hingewiesen, welche kooperatives Zusammenwirken zwischen den am jeweiligen Logistiksystem beteiligten Wirtschaftsakteuren dafür hat, die zu erwartenden positiven Effekte logistischer Reorganisation möglichst umfassend zu realisieren. Interorganisatorische, kooperative Beziehungsgefüge wurden dementsprechend als dasjenige 
zentrale institutionelle Fundament benannt, auf Basis dessen sich Handlungen zur logistischen Reorganisation vollziehen. Logistikbezogene kooperative Beziehungsgefüge tragen nämlich angesichts der Spezifika der Logistiktransaktionen und aufgrund des übergreifenden Charakters des logistischen Optimierungsansatzes maßgeblich dazu bei, dass logistikbezogene Rationalisierungsund Produktivitätsreserven ausgeschöpft und im Rahmen vorstoßender und nachfolgender Wettbewerbshandlungen instrumentalisiert werden können.

\section{Ad 1. - 3.: Mobilität und Markttransparenz}

Beide, Mobilität von Produktionsfaktoren und Markttransparenz, wiederum zählen auch zu denjenigen Merkmalen, welche auf die Handlungsspielräume der Marktteilnehmer Einfluss nehmen - Beschränkungen der Faktormobilität oder der Markttransparenz beschränken Handlungsspielräume, ein Zuwachs an Faktormobilität oder Markttransparenz erweitert sie.

Wenn also die logistische Reorganisation positiv auf die physische Mobilität und Verfugbarkeit von Produktionsfaktoren (siehe 1.) und auf die gesamtwirtschaftliche Markttransparenz (siehe 2.) einwirkt, erweitert sie damit prinzipiell auch die Gesamtheit der Handlungsspielräume der Wirtschaftssubjekte. Ob die logistikbedingten, auf der Erhöhung von Transparenz oder Mobilität basierenden Erweiterungen von Handlungsspielräumen dabei als Reduzierung künstlicher, nicht willkürlicher Beschränkungen oder als Reduzierung natürlicher Beschränkungen der Handlungsspielräume $(\rightarrow$ mangelnde Mobilität als Folge unzureichenden Know-hows bzw. unzureichender Begabungen der Wirtschaftssubjekte) klassifiziert werden, ist von nachrangiger Bedeutung. Bedeutsam jedoch ist die Erkenntnis, dass die logistische Reorganisation in diesem Fall offensichtlich dazu beiträgt, solche Beschränkungen von Handlungsspielräumen zu reduzieren, welche nicht durch aktive Maßnahmen von Marktteilnehmern oder Institutionen herbeigeführt worden sind. Insoweit ist logistische Reorganisation auch aus der Perspektive der Freiheitsfunktion des Wettbewerbs als Werkzeug zu begreifen, welches die Rahmenbedingungen und Möglichkeiten für wettbewerbliches Marktverhalten verbessert und somit wettbewerbliches Marktverhalten fördert.

Doch wie beschrieben bewirkt logistische Reorganisation unter Umständen auch die Reduktion von Markttransparenz (siehe 3.). Hier handelt es sich um eine künstliche, willkürliche Beschränkung der Handlungsfreiheit für eine Gruppe von Wirtschaftsakteuren, d. h. sie ist das Resultat einer bewusst praktizierten unternehmerischen 
Strategie. Die logistikbedingte Reduktion der Markttransparenz ist allerdings dem Grunde nach marktleistungsbedingt - also aus einem kreativen Marktverhalten heraus entstanden - und ist insofern Ausdruck eines wettbewerblichen Marktgeschehens. Die Komplexität und die daraus resultierende schwere Imitierbarkeit von kreativen Wettbewerbshandlungen, welche sich auf Basis von Maßnahmen zur logistischen Reorganisation vollziehen, bedingen dabei, dass sich im Zustand reduzierter Markttransparenz eine Situation mit Potenzial zur temporären Gewinndifferenzierung zugunsten des innovierenden Unternehmens ergibt. Somit setzt die logistische Reorganisation prinzipiell Anreize zur Durchführung wettbewerblichen Marktverhaltens. Vor diesem Hintergrund können Maßnahmen zur logistischen Reorganisation insbesondere dazu beitragen, dem Marktgeschehen in engen Oligopolmärkten, welche durch oligopolistische Reaktionsinterdependenzen gekennzeichnet sind, neue wettbewerbliche Impulse zu geben. Auch in diesem Fall ist der logistischen Reorganisation folglich zu attestieren, dass sie einen Beitrag zur Förderung wettbewerblichen Marktverhaltens leistet.

\section{Ad 4.: Kooperative Beziehungsgefüge}

Erklärte Absicht bei der Bildung logistikbezogener kooperativer Beziehungsgefüge ist es, die Abläufe in Logistiksystemen umfassend im Vorhinein zu planen und die Ausgestaltung logistischer Transaktionen vertraglich, in der Regel auch längerfristig, zu zementieren. Sie neigen also dazu, das System der marktlichen ex-postKoordination zugunsten eine Systems der ex-ante-Verhaltenskoordination auszuschalten. Aus Perspektive der Freiheitsfunktion des Wettbewerbs sind derartige kooperative Beziehungsgefüge dementsprechend als organisatorisch-institutionelle Ausgestaltungsform des kollektiven Marktverhaltens zu interpretieren.

Kollektives Marktverhalten wiederum wird aufgrund seiner Tendenz, die Handlungsspielräume und unter Umständen auch die Wahlmöglichkeiten sowohl der unmittelbar beteiligten als auch der mittelbar betroffenen Parteien (wie bspw. Kooperationspartner, Konkurrenten, welche nicht Kooperationspartner sind, Akteure der Marktgegenseite, Akteure vor- oder nachgelagerter Marktstufen) zu beschränken, prinzipiell zu den nichtwettbewerblichen Marktverhaltensweisen gezählt. ${ }^{27}$ Allerdings können auch Konstellationen beschrieben werden, in welchen der prinzipiell wettbewerbsbeschränkende Charakter kollektiven Marktverhaltens durch positive, wettbewerbsfördernde Effekte des Kollektivverhaltens (über-)kompensiert wird. So sind bspw. Formen des 
Kollektivverhaltens denkbar, welche die Handlungsspielräume anderer einschränken, gleichzeitig aber Handlungsspielräume für andere erhalten bzw. neue Handlungsspielräume schaffen. Ferner sind Formen des Kollektivverhaltens vorstellbar, welche die ökonomische Marktperformance unter billigender Inkaufnahme einer Beschränkung von Handlungsspielräumen für Marktteilnehmer verbessern. ${ }^{28} \mathrm{Im}$ Folgenden gilt es nun zu untersuchen, wie die Beschränkungen der Handlungsspielräume und der Wahlfreiheit durch logistikbezogene kooperative Beziehungsgefüge aus Sicht der Freiheitsfunktion des Wettbewerbs zu bewerten sind.

Hierzu sind zunächst die beiden folgenden, im Vorfeld bereits ausführlich dargestellten Gegebenheiten nochmals in Erinnerung zu rufen: ${ }^{29}$

- Die Bildung metalogistischer Systeme auf der organisatorischinstitutionellen Basis kooperativer Beziehungsgefüge wurde aufgrund der Spezifika logistischer Transaktionen und aufgrund des unternehmensübergreifenden Charakters des logistischen Optimierungsansatzes als systembedingt begriffen, da sie angezeigt sind, um die ökonomischen Potenziale aus der logistischen Reorganisation möglichst umfänglich auszuschöpfen.

- Die kooperative Leistungserstellung im Logistikmarkt fußt insoweit erkennbar auf einer ökonomischen Ratio, als von logistikbezogenen kooperativen Beziehungsgefügen nachgewiesenermaßen deutlich positive Impulse auf die ökonomische Performance logistischer Reorganisation ausgehen. Dementsprechend konnte - argumentiert aus rein ökonomischer Perspektive - die These der prinzipiellen Kompatibilität von logistikbezogenen kooperativen Beziehungsgefügen und wettbewerblichem Marktverhalten erhärtet werden.

Die Existenz kooperativer Beziehungsgefüge in der Logistik ist folglich das Resultat einer ökonomischen Auseinandersetzung der Marktteilnehmer mit faktischen Handlungsanforderungen, welche sich unmittelbar aus dem Charakter der Logistikkonzeption ergeben. Kooperative Beziehungsgefüge sind in der Logistikkonzeption somit systembedingt verankert. Daraus erhellt: Die Auseinandersetzung mit der Frage, wie die Beschränkungen der Handlungsspielräume und der Wahlfreiheit, welche zwangsläufig mit solchen kooperativen Beziehungsgefügen einhergehen, im Sinne der 
Freiheitsfunktion des Wettbewerbs zu bewerten sind, ist untrennbar mit der Frage nach der Wettbewerbskonformität der Leitgedanken der Logistikkonzeption verbunden. Wenn kooperative Beziehungsgefüge nämlich unerlässlich dafür sind, die ökonomischen Potenziale, welche die Logistikkonzeption birgt, umfänglich auszuschöpfen, dann ist die Qualität der Beschränkungen der Handlungsspielräume und der Wahlfreiheit, welche von derartigen Beziehungsgefügen ausgehen, unter Bezugnahme auf die diesen Beziehungsgefügen ursächlich zugrunde liegende Logistikkonzeption zu beurteilen. Diese Erkenntnis wiederum führt zu der Frage, ob der unternehmensübergreifende logistische Optimierungsansatz und das Denken in Wertschöpfungsketten bzw. -systemen, auf welchem die moderne Logistikkonzeption ja fußt, wettbewerbskonform ist. In der Tat scheint es sowohl intuitiv einleuchtend als auch argumentativ belegbar, dass die Entdeckung und die fortdauernde Weiterentwicklung der modernen Logistikkonzeption bis in ihr gegenwärtiges Stadium maßgeblich dem Wettbewerb in seiner Funktion als Such- und Informationsverfahren zu verdanken ist. ${ }^{30}$

Insofern kann im Ergebnis Folgendes festgehalten werden:

- Kooperative Beziehungsgefüge in der Logistik produzieren als organisatorisch-institutionelle Ausgestaltungsform kollektiver Marktverhaltensweisen Beschränkungen der Handlungsspielräume und der Wahlfreiheit für Marktteilnehmer, welche prinzipiell

$\circ$ die Entdeckung der besten Marktergebnisse in einem Wettbewerbsprozess durch die ex-ante-Verhaltenskoordination der Beteiligten verhindern,

○ bestimmte Marktergebnisse im Vorhinein festlegen bzw. diese präjudizieren und damit

○ die Ungewissheit, welche dem Wettbewerbsprozess eigen ist, reduzieren.

Damit sind bei den logistikbezogenen kooperativen Beziehungsgefügen diejenigen Problempunkte zu beobachten, welche typischerweise allen Kooperationen anhaften. Infolgedessen sind logistikbezogene kooperative Beziehungsgefüge aus Perspektive der Freiheitsfunktion des Wettbewerbs zu- 
nächst kritisch zu beurteilen, da mit ihnen auch nicht marktleistungsbedingte Beschränkungen der Handlungsspielräume einhergehen können.

- Allerdings müssen die Beschränkungen der Handlungsspielräume und der Wahlfreiheit in logistikbezogenen kooperativen Beziehungsgefügen auch unter Berücksichtigung der folgenden Zusammenhänge beurteilt werden:

- Der Zustand reduzierten Wettbewerbs innerhalb der kooperativen Beziehungsgefüge ist die direkte Folge der organisatorischinstitutionellen Umsetzung der Logistikkonzeption, deren Entdeckung und Verbreitung wiederum maßgeblich auf die wettbewerbliche Such- und Informationsleistung zurückzuführen ist.

Bei einer freiheitsbezogenen Beurteilung der kooperativen Beziehungsgefüge sind demnach die Ausstrahlungseffekte der konzeptionellen Ebene zu berücksichtigen.

- Kooperative Beziehungsgefüge bewirken nicht nur die Reduzierung von Handlungsspielräumen und Wahlfreiheiten, sondern tragen auch dazu bei, diese zu erhalten bzw. neue Handlungsspielräume und Auswahlalternativen zu eröffnen:

- So sorgen System-Stückgutkooperationen, also kooperative Beziehungsgefüge im Rahmen horizontaler metalogistischer Systeme, dafür, dass mittelständische Logistikunternehmen überhaupt erst am Stückgut-Marktgeschehen teilnehmen können.

- Desgleichen eröffnen Supply-Chain-Management-Kooperationen, also kooperative Beziehungsgefüge im Rahmen vertikaler metalogistischer Systeme, den Beteiligten neue Handlungsoptionen, welche sie ohne die Bildung des kooperativen Arrangements nicht hätten.

Damit ist eine freiheitsbezogene Beurteilung der kooperativen Beziehungsgefüge auch durch die Notwendigkeit von Abwägungsentscheidungen zwischen freiheitsbeschränkenden und freiheitsschaffenden Komponenten gekennzeichnet.

- Die Abwicklung logistischer Transaktionen innerhalb kooperativer Beziehungsgefüge verbessert die ökonomische Performance in Logistiksystemen nicht nur, sondern ist oftmals deren unentbehrliche orga- 
nisatorisch-institutionelle Grundlage. Die damit einhergehenden Beschränkungen der Handlungs- und Wahlfreiheit müssen bei der Durchsetzung des übergreifenden logistischen Optimierungsansatzes in Kauf genommen werden.

Bei diesem Zusammenhang handelt es sich im Übrigen um die besonders ausgeprägte Form einer Dilemmakonstellation: Ökonomische Performance in Logistiksystemen im Sinne der Erfüllung der ökonomischen Wettbewerbsfunktionen ist ursächlich und unabdingbar an eine teilweise Nichterfüllung der Freiheitsfunktion geknüpft.

- Die freiheitsbezogene Beurteilung der logistikbezogenen kooperativen Beziehungsgefüge bewegt sich folglich in einem Spannungsfeld zwischen dem prinzipiell freiheitsbeschränkenden, also illegitimen Charakter der $\mathrm{Be}$ schränkungen und den relativierenden Zusammenhängen, welche auf eine Kompensation dieser Freiheitsbeschränkungen hinwirken. Dieses Spannungsfeld kann aber möglicherweise dadurch überwunden werden, dass die Frage nach der geeigneten logistischen Systemebene, welche als Grundlage für die Beurteilung der Wettbewerbskonformität der kooperativen Beziehungsgefüge in Bezug auf die Freiheitsfunktion herangezogen werden soll, in die Betrachtung einbezogen wird. Während nämlich die freiheitsbeschränkenden Effekte vor allem auf der mikrologistischen Systemebene wirken, wirken die relativierenden Effekte auf der metalogistischen Systemebene. Neigt man nun dazu, dem Kerngedanken der Logistikkonzeption entsprechend, die produktive Leistung der metalogistischen Systemebene in den Mittelpunkt zu rücken, dann bedeutet dies, dass Freiheitsbeschränkungen mikrologistischer Systeme (d. h. einzelner Marktteilnehmer) bewusst zugunsten eines Wettbewerbs auf Basis horizontaler metalogistischer Systeme (bspw. zwischen System-Stückgutkooperationen) bzw. auf Basis vertikaler metalogistischer Systeme (zwischen Supply Chains oder Wertschöpfungsketten) in Kauf genommen werden müssen. Eine solche Argumentation wird zudem durch die mobilitäts- und transparenzerhöhenden Effekte logistischer Reorganisation - dargestellt in diesem Unterabschnitt unter Ad 1.3.: Mobilität und Markttransparenz - gestützt, welche ja prinzipiell eine Erweiterung der Handlungsspielräume der Marktteilnehmer bewirken und welche sich oftmals erst auf der Basis metalogistischer Systeme entfalten können. 
Insoweit findet sich hier an dieser Stelle auch die Entscheidung bestätigt, die Wertschöpfungskettenstruktur als zusätzliche logistikbedingte mittelbare Wettbewerbsdeterminante in die Wettbewerbskonzeption aufzunehmen. ${ }^{31}$ In logistischer Interpretation finden Wertschöpfungsketten ihre begriffliche und konzeptionelle Entsprechung in den Supply Chains. Die raum-zeitliche Strukturierung von Wertschöpfungsketten unterliegt aus Logistiksicht folglich den Grundgedanken des SCM-Konzeptes, welches in dieser Arbeit an entsprechender Stelle als umfassendere, auch nicht-logistische Aktivitäten beinhaltende konzeptionelle Deutung und Fortführung der ganzheitlichen, systemischen Perspektive und der Güterflussorientierung - und damit der wesentlichen Konzeptmerkmale der Logistik - hervorgehoben wurde. ${ }^{32}$ Der SCM-Gedanke wiederum greift im Logistikmarkt in Form vielfältiger Ausprägungsformen vertikaler kooperativer Arrangements Platz und wird in aller Regel von horizontalen kooperativen Arrangements zum Zwecke der Erbringung netzwerkbasierter Logistikleistungen flankiert. ${ }^{33}$ Die mit dem SCM-Konzept korrespondierende logistische Gestaltungsebene, auf Basis derer sich die raum-zeitliche Strukturierung von Supply Chains bzw. Wertschöpfungsketten in institutioneller und in inhaltlicher Hinsicht vollzieht, ist demzufolge die (vertikale und die horizontale) metalogistische Systemebene. Auf der Grundlage dieser Zusammenhänge lassen sich die beiden nachstehenden Schlussfolgerungen ziehen:

(1) Die institutionelle und inhaltliche Ausgestaltung der gesamtwirtschaftlichen Wertschöpfungskettenstruktur ist ein Gradmesser für den Durchdringungsgrad der gesamtwirtschaftlichen Leistungserstellung mit dem unternehmensübergreifenden Optimierungsansatz der Logistik und infolgedessen auch für das Umsetzungsstadium der Logistikkonzeption in einer Volkswirtschaft.

(2) Die institutionelle Ausgestaltung der gesamtwirtschaftlichen Wertschöpfungskettenstruktur lässt Rückschlüsse auf das Ausmaß an potenziellen Freiheitsbeschränkungen für einzelne Mikrologistiken sowie auf das Aus$\mathrm{ma}$ an Möglichkeiten und Neigung zu wettbewerblichen Marktverhaltensweisen innerhalb und zwischen Metalogistiken zu. 


\subsection{Zusammenfassung der wesentlichen Ergebnisse}

In Unterabschnitt 3.2.2 wurde festgestellt, dass die logistische Reorganisation in Erfüllung ihres Koordinationsauftrages angesichts ihrer spezifisch netzwerkbildenden Ausrichtung tendenziell zu einer Verschiebung des Sets an Koordinationsmechanismen in Richtung der Koordination durch Netzwerke führt. Dieser Umstand ist auf ihre konzeptionell bedingte Affinität $\mathrm{zu}$ interorganisatorischen Beziehungsstrukturen mit längerfristigem kooperativem Charakter als organisatorisch-institutioneller Grundlage der Leistungserstellung zurückzuführen. Da jedoch die Koordination durch Netzwerke auf der Grundidee der ex-ante-Verhaltenskoordination bzw. der kollektiven Wirtschaftsplanung fußt, geht das Logistikprinzip als Auslöser der Netzwerkbildung zunächst prinzipiell nicht konform mit dem Wettbewerbsprinzip. Dieses postuliert nämlich grundsätzlich den Idealzustand der totalen Dezentralität der Entscheidungsfindung bzw. Wirtschaftsplanung. Dementsprechend musste die Frage aufgeworfen werden, wie die durch die logistische Reorganisation initiierte Abweichung vom reinen marktwirtschaftlichen Koordinationsmechanismus in Richtung der Koordination durch Netzwerke zu bewerten ist. Zur Beantwortung dieser Frage war es vonnöten, zunächst Aufschluss über das Beziehungsverhältnis zwischen dem Wettbewerb als übergeordnetem Ordnungsprinzip in einem marktwirtschaftlichen System und der Logistik als unternehmensübergreifendem Koordinationsprinzip im Systemverbund der gesamtwirtschaftlichen Gütertransformation zu erlangen und die Berührungspunkte zwischen der Logistikkonzeption und der Wettbewerbskonzeption aufzuzeigen.

Dies war Gegenstand des Abschnittes 3.3. Die Untersuchung konzentrierte sich hierzu auf die Beantwortung der Frage, welche Impulse im Rahmen einer konzeptionellen Zusammenführung von Logistik und Wettbewerb von der logistischen Reorganisation auf Determinanten, Prozessverlauf und Wirkungen des Wettbewerbs ausgehen.

Zuerst wurde das Beziehungsverhältnis zwischen der logistischen Reorganisation und den mittelbaren Wettbewerbsdeterminanten untersucht. Hier konnten folgende Ergebnisse zutage gefördert werden:

1. Der Grad der logistischen Reorganisation wirkt unmittelbar auf die Anzahl der Betriebe pro Unternehmung und die Anzahl der Produktionsstufen im Unternehmen, beides Komponenten der internen Unternehmensstruktur, ein.

2. Die logistische Reorganisation beeinflusst die gesamtwirtschaftliche Produktivitätsstruktur. 
3. Die logistische Reorganisation beeinflusst das technologische Potenzial sowie die physische Mobilität und Verfügbarkeit geeigneter Produktionsfaktoren bzw. die Produktionsfaktorenstruktur positiv - beides Komponenten des Marktwachstums.

4. Der Grad der logistischen Reorganisation wirkt sowohl in institutioneller als auch in inhaltlicher Hinsicht auf die raum-zeitliche Strukturierung von Wertschöpfungsketten bzw. die Wertschöpfungskettenstruktur ein. Da die raum-zeitliche Strukturierung von Wertschöpfungsketten bzw. Wertschöpfungssystemen als bedeutsam für das Marktverhalten eingeschätzt wurde, wurde sie als eine zusätzliche logistikbedingte mittelbare Wettbewerbsdeterminante in die Wettbewerbskonzeption aufgenommen.

\begin{abstract}
Als nächster Schritt erfolgte die Untersuchung der Frage, wie die mittelbaren Wettbewerbsdeterminanten unter dem Einfluss der logistischen Reorganisation auf die Möglichkeit und die Neigung zu wettbewerblichem Marktverhalten - auf die unmittelbaren Wettbewerbsdeterminanten also - wirken. Hier waren folgende Ergebnisse zu vermerken:
\end{abstract}

5. Hinsichtlich der Effekte logistischer Reorganisation auf die Möglichkeit zu wettbewerblichem Marktverhalten war folgendes zu konstatieren: Die positiven Effekte der logistischen Reorganisation auf die Produktivität und darauf aufbauend auf das technologische Potenzial sowie die physische Faktormobilität tragen dazu bei, dass die Spielräume für kreatives und adaptives Marktverhalten für diejenigen Marktteilnehmer erweitert werden, welche von den Handlungsoptionen, welche die logistische Reorganisation bereithält, profitieren (können). Damit wirken sie positiv auf die Fähigkeit, gewünschtes wettbewerbliches Marktverhalten zu praktizieren. Ferner wurde festgestellt, dass die logistische Reorganisation über ihr Einflusspotenzial auf die raum-zeitliche Strukturierung von Wertschöpfungsketten in institutioneller und in inhaltlicher Hinsicht die Systemkomplexität logistischer Transaktionen und der sich dahinter verbergenden organisatorisch-institutionellen Beziehungsgefüge erhöht. Gleichermaßen werden in den (im Lichte des unternehmensübergreifenden Optimierungsansatzes) neu strukturierten Wertschöpfungsketten bislang im Verborgenen gebliebene kosten- und leistungsmäßige Wirkungszusammenhänge auf der institutionellen und der prozessualen Ebene offen gelegt. Damit wird 
summa summarum der gesamte Leistungserstellungsprozess durch die logistische Reorganisation zwar wesentlich komplexer, aber dennoch transparenter gemacht. Insofern wirkt logistische Reorganisation tendenziell positiv auf die gesamtwirtschaftliche Markttransparenz, weil sie die Möglichkeit für die Unternehmen erhöht, Chancen zu wettbewerblichen Aktionen zu erkennen.

6. Hinsichtlich der Effekte logistischer Reorganisation auf die Neigung zu wettbewerblichem Marktverhalten konnte folgendes festgehalten werden: Mit demselben Argument, mit welchem die positiven Effekte der logistischen Reorganisation auf die gesamtwirtschaftliche Markttransparenz betont wurde, kann auch eine Reduktion der Marktransparenz durch logistische Reorganisation diesmal allerdings im Einzelfall aus Sicht der unmittelbaren Konkurrenten des seine Logistiksysteme reorganisierenden Unternehmens - hergeleitet werden. Die hohe Systemkomplexität logistischer Transaktionen und deren organisatorisch-institutioneller Verankerung führt nämlich dazu, dass Maßnahmen zur logistischen Reorganisation für unternehmensexterne Betrachter (also auch die Konkurrenten) als vergleichsweise schwer nachzuvollziehende Aktionen wahrgenommen werden. Daher können überlegene Logistiksysteme von Konkurrenten nur mit großen Anstrengungen und mit erheblichem Zeitverzug imitiert werden. Überlegene Logistiksysteme weisen somit, bezogen auf den Parallelprozess zwischen Konkurrenten, eine Tendenz zur Reduzierung von Markttransparenz auf. Diese Reduktion der Markttransparenz allerdings wirkt stimulierend auf den Wettbewerbsprozess, da sie dem logistik-innovierenden Unternehmen ausreichend Zeit verschaff, Vorsprungsgewinne zu realisieren, ohne dass zeitnahe Anpassungsreaktionen der Konkurrenten gefürchtet werden müssen, welche die Vorsprungsposition vor Ablauf einer angemessenen Zeit erodieren. Wettbewerbliche Vorstoßaktionen, welche auf der Optimierung unternehmensinterner und unternehmensübergreifender Logistiksysteme basieren, scheinen insofern gute Erfolgsaussichten in Bezug auf die Realisierung der beabsichtigten Wettbewerbsvorteile zu haben. Logistischer Reorganisation kann folglich ein positiver Einfluss auf die sich im Markt bietenden relativen Expansionschancen attestiert werden. Dies wiederum beeinflusst die Neigung, wettbewerbliches Marktverhalten zu praktizieren, tendenziell positiv. Gerade in oligopolistischen Märkten, welche sich möglicherweise bereits in einer späten Marktphase befinden, eröffnen die Optionen zur logistikbasierten Verfahrensinnovation neue Spielräume für wettbewerbliche Vorstoßaktionen, welche zum einen die Wettbewerbskräfte im Markt stärken und welche ferner dienliche An- 
knüpfungspunkte bereit stellen, die allgegenwärtige oligopolistische Reaktionsinterdependenz zu durchbrechen.

Anschließend wurden die in der bisherigen Analyse gewonnenen Erkenntnisse auf die Marktprozessebene projiziert und es wurde ergründet, wie sich die Integration der logistischen Reorganisation auf das Gefüge der von den Unternehmen praktizierten Marktverhaltensweisen und damit auf die Ausgestaltung der realen Marktprozesse auswirkt. Hier zeigten sich folgende Ergebnisse:

7. Die positiven Effekte logistikbasierter Optimierungsansätze hinsichtlich der Erhöhung der Faktorproduktivität sowie der Erweiterung des technologischen Potenzials fördern in Verbindung mit den positiven Effekten leistungsfähiger Logistiksysteme auf die physische Faktormobilität kreatives Marktverhalten in doppelter Hinsicht:

Zum einen dokumentiert sich logistische Reorganisation in Gestalt von Verfahrensfortschritten mit dem Ziel, Güter-, Material- und Informationsströme zu optimieren.

Zum anderen vergrößert logistische Reorganisation auch die Möglichkeiten der Unternehmen zur spontanen Anpassung an Veränderungen der Nachfragestruktur. Die dazu erforderlichen Maßnahmen zu Erweiterung, Verkleinerung oder Umstellungen des Produktionsprogrammes können leichter bewerkstelligt werden, wenn auf ein leistungsfähiges Logistiksystem zurückgegriffen werden kann.

8. Maßnahmen zur logistischen Reorganisation können ebenso als Instrument dazu dienen, ökonomische Abstände zwischen vorstoßenden und nachfolgenden Unternehmen, welche sich durch kreative Marktverhaltensweisen aufgetan haben, durch adaptives Marktverhalten wieder zu verringern.

Zum einen können Maßnahmen zur logistischen Reorganisation Grundlage dafür sein, Imitationshandlungen auf der Produktebene zu begründen bzw. zu beschleunigen, weil sie über die Optimierung von Stoff- und Informationsströmen positiv auf die räumliche und zeitliche Verfügbarkeit von Inputfaktoren wirken, welche für jegliche Imitationshandlung essenziell wichtig sind. Logistiksysteme selbst sind - aus den genannten Gründen - eher selten Gegenstand von Imitationshandlungen. 
Zum anderen können Maßnahmen zur logistischen Reorganisation in Gestalt von - nicht auf Imitation ausgerichteten - Verfahrensfortschritten mit dem Ziel, Güter-, Material- und Informationsströme zu optimieren, ebenfalls Gegenstand adaptiver Marktverhaltensweisen sein.

9. Maßnahmen zur logistischen Reorganisation mit dem Zweck, kreatives oder adaptives Marktverhalten zu praktizieren, fußen in nicht unwesentlichem Umfang auf kooperativen Beziehungsgefügen. Kooperatives Zusammenwirken zwischen den am jeweiligen Logistiksystem beteiligten Wirtschaftsakteuren nämlich ist unabdingbar dafür, die positiven Effekte logistischer Reorganisation voll umfänglich zu realisieren. Kooperative Beziehungsgefüge wiederum können als organisatorisch-institutionelle Ausgestaltungsform des kollektiven Marktverhaltens interpretiert werden, welches aufgrund seiner Tendenz, die Handlungsspielräume der beteiligten Wirtschaftsakteure zu reduzieren, zu den nichtwettbewerblichen Marktverhaltensweisen zu zählen ist. Für den Fall der logistikbezogenen kooperativen Beziehungsgefüge ergab sich allerdings eine prinzipielle Kompatibilität zum wettbewerblichen Marktverhalten. Diese Beurteilung wurde damit begründet, dass kooperative Beziehungsgefüge in der Logistik die Voraussetzung dafür sind, logistikbezogene Rationalisierungs- und Produktivitätsreserven voll umfänglich auszuschöpfen und im Rahmen von vorstoßenden und nachfolgenden Wettbewerbshandlungen zu instrumentalisieren. Folglich unterliegt die kooperative Leistungserstellung im Logistikmarkt im Grundsatz einer ökonomischen Ratio, welche sich auch anhand vielfältiger positiver Wirkungspotenziale logistikbezogener kooperativer Beziehungsgefüge auf die ökonomische Performance der logistischen Reorganisation belegen lässt.

Auf den Ergebnissen der bisherigen Analyse aufbauend wurden anschließend die Wirkungen der logistischen Reorganisation in Beziehung zu den einzelnen ökonomischen Wettbewerbsfunktionen gesetzt. Ziel war es, die These einer über die instrumentale Rolle der logistischen Reorganisation hinausgehende Wirkungsbeziehung zwischen den beiden Konzeptionen auf der Ebene übergeordneter Prinzipien für Koordination und Ordnung innerhalb komplexer Wirtschaftssysteme zu überprüfen. Hier konnten die folgenden Ergebnisse zutage gefördert werden: 
10. Die logistische Reorganisation beeinflusst alle drei ökonomischen Wettbewerbsfunktionen, namentlich die Anpassungs- bzw. Allokationsfunktion, die Entdeckungs- bzw. Fortschrittsfunktion sowie die Verteilungsfunktion. Dieses Einflusspotenzial fußt auf dem Umstand, dass die Logistikkonzeption mit den Fragestellungen hinsichtlich der Bewältigung räumlicher und zeitlicher Friktionen ökonomischen Handelns genau jene Gegebenheiten thematisiert, welche im realen Wirtschaftsgeschehen erkanntermaßen von höchster Relevanz sind, von denen die Wettbewerbskonzeption jedoch abstrahiert. Die Tragweite des Einflusses ist dabei davon abhängig, welchen Stellenwert sich das Logistiksystem im Systemverbund der Gütertransformation eines konkreten Wirtschaftssystems erarbeitet hat.

Bekleidet die Logistik hier tendenziell eher die Rolle eines resultierenden Faktors der Organisation von Produktion und Konsumtion, dann beeinflussen die Bedingungen im Logistiksystem hinsichtlich der Bewältigung räumlicher und zeitlicher Friktionen ökonomischen Handelns die Umsetzungsqualität bzw. den Umsetzungserfolg der bereits vollzogenen dezentralen Produktions- und Konsumplanungsentscheidungen der Unternehmen und Haushalte. In diesem Fall tangiert der Grad der Logistikeffizienz im Sinne der Leistungsfähigkeit der Logistiksysteme die Effektivität der wettbewerblichen Steuerungs-, Fortschrittsund Verteilungsleistung.

In dem Ausmaß, in dem der Logistik hingegen eher die Rolle eines bedingenden Faktors der Organisation von Produktion und Konsumtion zukommt, beeinflussen die Bedingungen im Logistiksystem hinsichtlich der Bewältigung räumlicher und zeitlicher Friktionen ökonomischen Handelns auch das Zustandekommen von Entscheidungen zur individuellen Wirtschaftsplanung in Intensität und Richtung mit. In diesem Fall berührt der Grad der Logistikeffizienz auch die Effizienz der wettbewerblichen Steuerungs-, Fortschritts- und Verteilungsleistung.

11. Vor allem bei der Analyse der Beziehung zwischen logistischer Reorganisation und der Anpassung- bzw. Allokationsfunktion des Wettbewerbs wurde deutlich, dass die Logistikkonzeption in der Lage ist, individuelles Maximierungsstreben einzelner in Richtung eines kollektiven Optimums zu kanalisieren. Freilich erstreckt sich das kollektive Optimum, welches aus der Anwendung des Logistikprinzips resultiert - anders als bei Anwendung der Wettbewerbskonzeption - nicht auf die gesamte Volkswirtschaft, sondern lediglich auf Teilbereiche. Diese Teilbereiche umfassen diejenigen Ausschnitte des realen Wirt- 
schaftsgeschehens, für welche aus logistischer Analyseperspektive tatsächliche güterwirtschaftliche Zusammenhänge aufgedeckt wurden, welche dann zum Ausgangspunkt für logistische Optimierungsvorhaben gemacht werden können. Unbeschadet dieser Einschränkung bei der Reichweite des Optimierungsraumes erfüllt die Logistikkonzeption damit dennoch die Bedingung dafür, dass sie als übergeordnetes Koordinationsprinzip von gesamtwirtschaftlicher Relevanz eingeordnet werden kann.

\begin{abstract}
Abschließend wurde die Beziehung zwischen der logistischen Reorganisation und der Freiheitsfunktion des Wettbewerbs untersucht. Auf der Grundlage einführender Anmerkungen zur Unterscheidung zwischen legitimen Beschränkungen der ökonomischen Wahl- bzw. Handlungsmöglichkeiten und illegitimen Beschränkungen der Wettbewerbsfreiheit im Sinne von Wettbewerbsbeschränkungen ergaben sich folgende Resultate:
\end{abstract}

12. Logistische Reorganisation wirkt positiv auf die physische Mobilität und Verfügbarkeit von Produktionsfaktoren und auf die gesamtwirtschaftliche Markttransparenz ein. Ein Zuwachs an Faktormobilität und Markttransparenz erweitert die Handlungsspielräume von Wirtschaftsakteuren. Insofern erweitert die logistische Reorganisation die Gesamtheit der Handlungsspielräume der Wirtschaftsakteure und stellt somit aus der Perspektive der Freiheitsfunktion des Wettbewerbs ein Werkzeug dar, welches die Rahmenbedingungen und Möglichkeiten für wettbewerbliches Marktverhalten verbessert und somit wettbewerbliches Marktverhalten fördert. Ferner bewirkt die logistische Reorganisation unter Umständen jedoch auch eine temporäre Reduktion der Markttransparenz aus Sicht der unmittelbaren Konkurrenten. Diese ergibt sich wiederum aus der Komplexität logistischer Transaktionen sowie aus der Komplexität der organisatorisch-institutionellen Verankerung logistischer Transaktionen. Diese Komplexität bewirkt nämlich, dass Maßnahmen zur logistischen Reorganisation (1) für den unternehmensexternen Beobachter, also auch den Konkurrenten, eine undurchdringliche und folglich schwer zu imitierende Materie sind und (2) im Zustand reduzierter Markttransparenz eine Situation mit Potenzial zur temporären Gewinndifferenzierung zugunsten des innovierenden Unternehmens begründen. Eine solche Reduktion der Markttransparenz ist folglich Ausgangspunkt für kreative Marktverhaltensweisen bzw. deren marktleistungsbedingtes Resultat und somit in jedem Fall Ausdruck eines wettbewerblichen 
Marktgeschehens. Auch hier setzt die logistische Reorganisation prinzipiell positive Anreize zur Praktizierung wettbewerblicher Marktverhaltensweisen, obwohl faktisch Handlungsspielräume für einzelne Wirtschaftsakteure eingeschränkt werden.

13. Ferner wurde nochmals auf die Relevanz kooperativer Beziehungsgefüge im Sinne organisatorisch-institutioneller Ausgestaltungsformen des kollektiven Marktverhaltens für die Qualität der Leistungserstellung im Logistikmarkt abgehoben. Bei der Beurteilung dieser logistikbezogenen kooperativen Beziehungsgefüge in Bezug auf die Freiheitsfunktion des Wettbewerbs wurden sowohl Beschränkungen des Handlungsspielraumes mit freiheitsbeschränkendem, also illegitimem Charakter als auch Zusammenhänge, welche auf eine Kompensation dieser Freiheitsbeschränkungen hinwirken, identifiziert. Ferner zeigte sich, dass die Freiheitsbeschränkungen durch logistikbezogene kooperative Beziehungsgefüge primär auf der mikrologistischen Ebene zu beobachten sind, während die die Freiheitsbeschränkungen kompensierenden Effekte primär auf der metalogistischen Ebene wirken. Tendiert man dazu, in Reflexion des Kerngedankens der Logistikkonzeption, die produktive Leistung der metalogistischen Systemebene zu priorisieren, dann bedeutet dies, dass Freiheitsbeschränkungen auf der mikrologistischen Systemebene (d. h. der Ebene einzelner Marktteilnehmer) bewusst in Kauf genommen werden müssen, um damit ein durch logistische Reorganisation begründetes wettbewerbliches Marktgeschehen auf Basis horizontaler metalogistischer Systeme (bspw. zwischen SystemStückgutkooperationen) bzw. auf Basis vertikaler metalogistischer Systeme (bspw. zwischen Supply Chains oder Wertschöpfungsketten) zu initialisieren. Für diese Argumentation spricht auch der Umstand, dass die bereits unter Punkt 12. diskutierten mobilitäts- und transparenzerhöhenden Effekte logistischer Reorganisation, welche prinzipiell eine Erweiterung von Handlungsspielräumen der Marktteilnehmer bewirken, oftmals erst auf der Basis metalogistischer Systeme zum Tragen kommen.

Als Ergebnis dieses Abschnittes 3.3 kann somit festgehalten werden, dass sich die einleitend formulierte These der Existenz konzeptioneller Parallelen und von Wirkungsinterdependenzen zwischen Wettbewerb und logistischer Reorganisation auf der Ebene übergeordneter Prinzipien für Koordination und Ordnung innerhalb komplexer Wirtschaftssysteme bestätigt findet. In einer vergleichenden Analyse auf Basis der Kausalität „Prozessdeterminanten - Prozessverlauf - Prozesswirkungen“ konnten 
diese konzeptionellen Parallelen und Wirkungsinterdependenzen aufgedeckt, systematisiert und bezüglich ihrer Ausgestaltungsform sowie bezüglich ihrer Wirkungsrichtung konkretisiert werden.

Nun gilt es, die Frage, welche in Unterabschnitt 3.2.2 aufgeworfen wurde, nämlich wie die durch die logistische Reorganisation initiierte Abweichung vom reinen marktwirtschaftlichen Koordinationsmechanismus zugunsten der Koordination durch Netzwerke zu bewerten ist, unter Bezugnahme auf die Analyseergebnisse von Abschnitt $3.3 \mathrm{zu}$ erörtern. Vor dem Hintergrund der bis hierhin gewonnenen Erkenntnisse können nachstehende finale Schlussfolgerungen gezogen werden:

\section{Finale Schlussfolgerung 1:}

Das Wettbewerbs- und das Logistikprinzip sind angesichts der Ergebnisse der konzeptionellen Zusammenfühung von Wettbewerb und Logistik als zwei im Grundsatz kompatible Prinzipien zu betrachten:

- Der Wettbewerb erfüllt seine Funktion als übergeordnetes Ordnungsprinzip in Abstraktion von räumlichen und zeitlichen Friktionen ökonomischen Handelns. Solche Friktionen ergeben sich aber im realen Wirtschaftsgeschehen zwangsläufig im Zuge der operativen Notwendigkeit, eine Vielzahl räumlich und zeitlich getrennter Produktions- und Konsumtionsprozesse zweckgerichtet aufeinander abstimmen zu müssen. Die Auseinandersetzung mit raum-zeitlichen Komponenten des ökonomischen Handelns ist für das reale Wirtschaftsgeschehen demnach offensichtlich von höchster Relevanz, die Bewältigung räumlicher und zeitlicher Friktionen ist für die Abwicklung tatsächlich anfallender Güter-, Material- und Informationsströme unabdingbar. Die Logistik in ihrer Funktion als übergeordnetes Koordinationsprinzip thematisiert genau diese raum-zeitlichen Gegebenheiten. Mittels der Integration der Logistikkonzeption in die Wettbewerbskonzeption wird die raumzeitliche Dimension in die wettbewerbsbezogenen Überlegungen eingebracht und damit die diesbezügliche Abstraktion aufgegeben.

- Ausgehend von der Reduktion des Abstraktionsgrades um räumliche und zeitliche Komponenten kann eine positive Einflussnahme seitens des Prozesses der logistischen Reorganisation auf mehrere mittelbare Wettbewerbsdeterminanten und deren Komponenten, auf mehrere unmittelbare Wettbewerbsdeterminanten, auf den wettbewerblichen Prozessverlauf sowie darauf 
aufbauend auf die Effektivität und - je nach Stellenwert des Logistiksystems - auch auf die Effizienz der ökonomischen Wettbewerbsleistung im Sinne der wettbewerblichen Steuerungs-, Fortschritts- und Verteilungsleistung aufgezeigt werden.

- Angesichts der ökonomischen Spezifika logistischer Transaktionen erweist sich die Logistikleistungserstellung innerhalb kooperativer Beziehungsgefüge als eine direkte und unausweichliche Folge in einer auf ökonomische Belange ausgerichteten Durchführungspraxis bei der organisatorischinstitutionellen Umsetzung der Logistikkonzeption. Dies birgt jedoch möglicherweise Problempotenzial in Bezug auf die Beziehung zwischen logistischer Reorganisation und der Freiheitsfunktion des Wettbewerbs.

- Allerdings kann auch aus Perspektive der Freiheitsfunktion des Wettbewerbs prinzipielles Einvernehmen mit dem Prozess der logistischen Reorganisation konstatiert werden. Zwar offenbart sich hier fast zwangsläufig die klassische Dilemmakonstellation in Gestalt der konfliktären Beziehung zwischen der freiheitsorientierten Betrachtungsperspektive (mit dem Ziel der Erhaltung von Handlungsspielräumen) und der ökonomischen Betrachtungsperspektive (mit dem Ziel der größten ökonomischen Vorteilhaftigkeit), welche aufzulösen die Wettbewerbstheorie und auch die Wettbewerbspolitik schon lange Zeit beschäftigt. Diese Dilemmakonstellation kann jedoch für den Fall logistikbezogener kooperativer Arrangements dadurch überwunden werden, dass - in Reflexion des Kerngedankens der Logistikkonzeption - der produktiven, freiheitsschaffenden Leistung der metalogistischen Systemebene gegenüber den freiheitsbeschränkenden Effekten auf der mikrologistischen Systemebene Priorität eingeräumt wird. Wird dieser dargestellte Zusammenhang zudem unter Berücksichtigung der übrigen freiheitsschaffenden Effekte logistischer Reorganisation (insbesondere durch den Zugewinn an physischer Mobilität und Verfügbarkeit von Produktionsfaktoren sowie an gesamtwirtschaftlicher Markttransparenz) bewertet, welche sich ebenfalls erst auf der metalogistischen Systemebene voll entfalten können, dann folgt daraus das oben zitierte prinzipielle Einvernehmen zwischen der Freiheitsfunktion des Wettbewerbs und logistischer Reorganisation. 


\section{Finale Schlussfolgerung 2:}

Wenn es sich beim Wettbewerbs- und dem Logistikprinzip um zwei im Grundsatz kompatible Prinzipien handelt, dann kann eine durch den Prozess der logistischen Reorganisation initiierte Abweichung vom reinen marktwirtschaftlichen Koordinationsmechanismus in Richtung der Koordination durch Netzwerke aus Sicht des Wettbewerbs, welcher ja dem marktwirtschaftlichen System als Ordnungsprinzip zugrunde liegt, nicht beanstandet werden. Die Koordination durch Netzwerke auf der Basis kooperativer Logistikleistungserstellung ist als eine organisatorischinstitutionelle Begleiterscheinung der ökonomischen Auseinandersetzung mit den räumlichen und zeitlichen Friktionen realen Wirtschaftsgeschehens zu betrachten. Bei den räumlichen und zeitlichen Friktionen realen Wirtschaftsgeschehens handelt es sich um Problemstellungen, welche auf der Betrachtungsebene der gesamtwirtschaftlichen Koordinationsmechanismen bislang nicht explizit thematisiert wurden, was angesichts der unstrittigen Tatsache, dass sich keine Ökonomie der Notwendigkeit entziehen kann, raum-zeitliche Problemstellungen im Rahmen der gesamtwirtschaftlichen Gütertransformation zu bewältigen, sehr erstaunlich ist. 
Carsten Wander - 978-3-631-75390-3

Downloaded from PubFactory at 01/11/2019 05:34:40AM

via free access 


\section{Schlussbetrachtungen}

Die vorliegende Arbeit befasste sich mit der Rolle logistischer Reorganisation wirtschaftlicher Aktivität innerhalb eines wettbewerbsbasierten marktwirtschaftlichen Systems. Motivation und Ausgangspunkt der Untersuchung war die einleitend formulierte These, dass die beiden ökonomischen Prozessphänomene des Wettbewerbs und der logistischen Reorganisation, welche prima facie in scheinbar beiderseitiger Unabhängigkeit voneinander verschiedene Ausschnitte der Ökonomik beleuchten, dennoch konzeptionelle Parallelen und vielfältige Wirkungsinterdependenzen aufweisen. Ziel der Arbeit war es im Anschließenden, diese konzeptionellen Parallelen und Wirkungsinterdependenzen zu identifizieren, zu analysieren und zu systematisieren. $\mathrm{Zu}$ diesem Zweck mussten die beiden in Rede stehenden Prozessphänomene zunächst einzeln inhaltlich durchdrungen und in eine Form gebracht werden, welche eine vergleichende Analyse der beiden erlaubt. Als gemeinsame analytische Grundlage für die Untersuchung von Wettbewerb und logistischer Reorganisation sowie der Interdependenzen zwischen den beiden erwies sich hierzu der Rückgriff auf die kausale Beziehung „Prozessdeterminanten - Prozessverlauf - Prozesswirkungen“ als nützlicher Anknüpfungspunkt. Die darin enthaltene Argumentationssequenz: „Die Prozessdeterminanten bedingen den Prozessablauf; der Prozessablauf zeitigt bestimmte Prozesswirkungen" zog sich als roter Faden durch die gesamte Arbeit und bildete somit deren analytische Klammer.

Als Ergebnis der vergleichenden Analyse von Wettbewerb und logistischer Reorganisation kann festgehalten werden, dass sich die These der Existenz konzeptioneller Parallelen und von Wirkungsinterdependenzen zwischen den beiden Phänomenen bestätigt findet. Zudem konnten die aufgezeigten konzeptionellen Parallelen und Wirkungsinterdependenzen im Rahmen der Analyse hinsichtlich ihrer Ausgestaltungsform sowie hinsichtlich ihrer Wirkungsrichtung in einem Umfang spezifiziert werden, welcher die finale Schlussfolgerung 1 erlaubte, in welcher das Wettbewerbs- und das Logistikprinzip als zwei im Grundsatz kompatible Prinzipien bezeichnet wurden. Diese Auffassung wiederum war wegbereitend für die Beurteilung, dass die zu beobachtende Umgewichtung im Set der gesamtwirtschaftlichen Koordinationsmechanismen in Richtung der Koordination durch Netzwerke, welche die Reorganisation produktiver und konsumtiver Prozesse nach den Grundsätzen des Logistikprinzips nach sich zieht, mit dem Wettbewerb als Ordnungsprinzip und damit auch mit dem marktwirtschaftlichen System grundsätzlich verträglich ist.

Als der inhaltliche Dreh- und Angelpunkt der vergleichenden Analyse von Wettbewerb und logistischer Reorganisation kristallisierte sich die Frage nach dem Umgang 
mit den räumlichen und zeitlichen Friktionen realen Wirtschaftsgeschehens heraus. Mit dieser Frage ist die Art und Weise der Auseinandersetzung mit jenen Problemstellungen angesprochen, welche sich aus der Existenz physischer Güter-, Material- sowie von begleitenden Informationsströmen zwischen denjenigen Institutionen ergeben, die Transferprozesse zwischen räumlich verteilten und zeitlich zerklüfteten Produktionsund Konsumtionsprozessen abwickeln. Wird in der wettbewerbstheoretischen Historie traditionell die Abstraktion von raum-zeitlichen Problemstellungen gepflegt, verhalf doch gerade die Berücksichtigung derartiger Problemstellungen in Fragen hinsichtlich der Ausgestaltung der gesamtwirtschaftlichen Leistungskoordination ${ }^{1}$ zu neuen Einsichten. Diese Einsichten wurden zu entsprechender finaler Schlussfolgerung 2 verdichtet, dass - in Abweichung zur marktwirtschaftlichen Koordination - die Koordination durch Netzwerke auf der Basis logistikbezogener kooperativer Leistungserstellung als eine organisatorisch-institutionelle Begleiterscheinung der ökonomischen Auseinandersetzung mit den räumlichen und zeitlichen Friktionen realen Wirtschaftsgeschehens zu betrachten ist.

Angesichts der Allgegenwärtigkeit räumlicher und zeitlicher Friktionen im realen Wirtschaftsgeschehen und der damit verbundenen immensen ökonomischen Tragweite der Logistikkonzeption, bezogen auf den gesamtwirtschaftlichen Leistungserstellungsprozess, strahlen diese beiden finalen Schlussfolgerungen möglicherweise auch auf die grundsätzliche - fast schon klassische - Frage nach dem Umgang der Wettbewerbstheorie mit alternativen, originär nicht-marktwirtschaftlichen Koordinationsmechanismen, und hier insbesondere mit der Kooperations- bzw. Netzwerkthematik aus. Sie implizieren nämlich, dass sich in dem Maße, in dem die Wettbewerbskonzeption auf dem unwegsamen Terrain eines - in diesem Fall um die logistischen Aspekte reduzierten Abstraktionsniveaus operiert, die Maßstäbe für die Bewertung von gesamtwirtschaftlichen Koordinationsmechanismen - in diesem Fall der Netzwerkkoordination - grundlegend ändern können und somit die Kriterien für deren Begutachtung neu definiert werden müssen. Insofern könnten sich die Ergebnisse und Schlussfolgerungen dieser Arbeit auch für die Wettbewerbspolitik als dienlicher Anknüpfungspunkt dazu erweisen, die Qualität ihrer materiellen Beurteilungs- bzw. Diagnoseleistung zu verbessern. 


\section{Literaturverzeichnis}

Abels, H.-W. (1980), Organisation von Kooperationen kleiner und mittlerer Unternehmen mittels Ausgliederung. Eine Untersuchung auf der Grundlage des situativen Ansatzes, Frankfurt a. M.

Aberle, G. (1992), Wettbewerbstheorie und Wettbewerbspolitik, 2. Auflage, Stuttgart

Aberle, G. (2003a), Transportwirtschaft: einzelwirtschaftliche und gesamtwirtschaftliche Grundlagen, 4. Auflage, München

Aberle, G. (2003b), Volkswirtschaftliche Bedeutung des Logistiksektors: Strategien der Verkehrsunternehmen und ihr Wandel zu Logistikdienstleistern, in: Merkel, H., Bjelicic, B. (Hrsg.), Logistik und Verkehrswirtschaft im Wandel: Unternehmensübergreifende Versorgungsnetzwerke verändern die Wirtschaft, München, S. $275-290$

Aberle, G. (2005), Zukünftige Entwicklung des Güterverkehrs: Sind Sättigungstendenzen erkennbar?, Diskussionsbeitrag Institut für Verkehrswissenschaft und Regionalpolitik Nr. 106, Freiburg

Abramovitz, M. (1937/38), Monopolistic Selling in a Changing Economy, in: Quarterly Journal of Economics, Jg. 52, S. 191-214

Akerman, J. (1960), Theory of Industrialism: Causal Analysis and Economic Plans, Lund

Alt, R. (2000), Electronic Commerce, in: Klaus, P., Krieger, W. (Hrsg.), Gabler Lexikon Logistik, 2. Auflage, Wiesbaden, S. 112-113

Alt, R., Schmid, B. (2000), Logistik und Electronic Commerce - Perspektiven durch zwei sich wechselseitig ergänzende Konzepte, in: Zeitschrift für Betriebswissenschaft, Jg. 70, Heft 1, S. 75-99

Arndt, H. (1966), Mikroökonomische Theorie, 2. Bd.: Marktprozesse, Tübingen

Arndt, H. (1976), Kapitalismus, Sozialismus, Konzentration und Konkurrenz, Tübingen

Arnold, U., Eßig, M. (2002), Kapitel D 3.3: Vertikale Kooperationen in der Logistik, in: Arnold, D., Isermann, H., Kuhn, A., Tempelmeier, H. (Hrsg.), Handbuch Logistik, Berlin, S. D3-18 - D3-26 
Arrow, K. J. (1969), The Organization of Economic Activity: Issues Pertinent to the Choice of Market Versus Nonmarket Allocation, in: Joint Economic Committee of U.S. Congress (Hrsg.), The Analysis and Evaluation of Public Expenditures: The PBB System, Bd. 1, Washington D.C., S. 47-64

BAG (Bundesamt für Güterverkehr) (1999a), Marktbeobachtung Güterverkehr, Jahresbericht 1998, Köln

BAG (Bundesamt für Güterverkehr) (1999b), Marktbeobachtung Güterverkehr, Sonderbericht: Die Auswirkungen der weiteren Liberalisierung des europäischen Verkehrsmarktes im Jahr 1998 auf die Unternehmen des gewerblichen Güterkraftverkehrs, Köln

BAG (Bundesamt für Güterverkehr) (2000), Marktbeobachtung Güterverkehr, Jahresbericht 1999, Köln

BAG (Bundesamt für Güterverkehr) (2001), Marktbeobachtung Güterverkehr, Jahresbericht 2000, Köln

BAG (Bundesamt für Güterverkehr) (2002), Marktbeobachtung Güterverkehr, Jahresbericht 2001, Köln

BAG (Bundesamt für Güterverkehr) (2003), Marktbeobachtung Güterverkehr, Jahresbericht 2002, Köln

BAG (Bundesamt für Güterverkehr) (2004), Marktbeobachtung Güterverkehr, Jahresbericht 2003, Köln

BAG (Bundesamt für Güterverkehr) (2005a), Marktbeobachtung Güterverkehr, Jahresbericht 2004, Köln

BAG (Bundesamt für Güterverkehr) (2005b), Marktbeobachtung Güterverkehr, Sonderbericht zum Strukturwandel im Güterkraftverkehrsgewerbe, Köln

BAG (Bundesamt für Güterverkehr) (2006), Marktbeobachtung Güterverkehr, Jahresbericht 2005, Köln

BAG (Bundesamt für Güterverkehr) (2007), Marktbeobachtung Güterverkehr, Jahresbericht 2006, Köln

Bain, J. S. (1948), Price and Production Policies, in: Ellis, H. (Hrsg.), A Survey of Contemporary Economics, Homewood/III., S. 129-173 
Bain, J. S. (1951), Relation of Profit Rate to Industry Concentration: American Manufacturing 1936-1940, in: The Quarterly Journal of Economics, Bd. 65, S. 293-324

Bain, J. S. (1956), Barriers to New Competition, Cambridge, MA

Bain, J. S. (1968), Industrial Organization, 2. Auflage, New York

Balling, R. (1998), Kooperation: strategische Allianzen, Netzwerke, Joint Ventures und andere Organisationsformen zwischenbetrieblicher Zusammenarbeit in Theorie und Praxis, 2. Auflage, Frankfurt a. M.

Bartling, H. (1997), Von der Wettbewerbstheorie zur Theorie der Wettbewerbspolitik, in: Kruse, J., Stockmann, K., Vollmer, L. (Hrsg.), Wettbewerbspolitik im Spannungsfeld nationaler und internationaler Kartellrechtsordnungen, Baden-Baden, S. 17-31

Baßeler, U., Heinrich, J., Utecht, B. (2006), Grundlagen und Probleme der Volkswirtschaft, 18. Auflage, Stuttgart

Bauer, H. (1989), Marktabgrenzung: Konzeption und Problematik von Ansätzen und Methoden zur Abgrenzung und Strukturierung von Märkten unter besonderer Berücksichtigung von markttheoretischen Verfahren, Berlin

Bauer, H. (1995), Marktabgrenzung, in: Tietz, B. (Hrsg.), Handwörterbuch des Marketing, 2. Auflage, Stuttgart, Sp. 1709-1721

Baum, H. (1997), Der volkswirtschaftliche Nutzen des Verkehrs, in: Zeitschrift für Verkehrswissenschaft, Jg. 68, Heft 1, S. 27-52

Baum, H., Esser, K., Höhnscheid, K.-J. (1998), Volkswirtschaftliche Kosten und Nutzen des Verkehrs, Forschungsarbeiten aus dem Straßen- und Verkehrswesen, Heft 108, Bonn

Baumgarten, H. (2001), Trends und Strategien in der Logistik: Die Entwicklung und die Zukunft der Logistik, in: Baumgarten, H. (Hrsg.), Logistik im E-Zeitalter: Die Welt der globalen Logistiknetzwerke, Frankfurt a. M., S. 9-32

Baumgarten, H., Zadek, H., Keller, T. (2001), Mergers \& Acquisitions - Logistik als Erfolgsfaktor, in: Hossner, R. (Hrsg.), Jahrbuch der Logistik 2001, Düsseldorf, S. 14-18 
Baumgarten, H., Zadek, H., Kieffer, D. (2003), Logistikdienstleistung - Richtig im Markt positioniert?, in: Logistik Heute, Jg. 25, Heft 11, S. 26-29

Baumol, J., Panzar, C, Willig, R. D. (1982), Contestable Markets and the Theory of Market Structure, San Diego/New York

Berg, H. (1977), Probleme einer Bestimmung der Funktionsfähigkeit des Wettbewerbs, in: Pfohl, H.-C., Rürup, B. (Hrsg.), Wirtschaftliche Messprobleme, Materialien zur Volks- und Betriebswirtschaft, Bd. 2, Köln

Berkelova, M. (1992), Die Vollendung des europäischen Binnenverkehrsmarktes und der Reformbedarf der deutschen Verkehrspolitik dargestellt am Beispiel des Straßengüterverkehrs, Bochum

Bester, H. (2004), Theorie der Industrieökonomik, 3. Auflage, Berlin

Bickenbach, F., Kumkar, L., Soltwedel, R. (2002), Wettbewerbspolitik und Regulierung - Die Sichtweise der Neuen Institutionenökonomik, in: Zimmermann, K. (Hrsg.), Neue Entwicklungen in der Wirtschaftswissenschaft, Heidelberg, S. 217275

Bjelicic, B. (2003), Der Wandel der Unternehmensstrukturen in der globalen Verkehrswirtschaft, in: Merkel, H., Bjelicic, B. (Hrsg.), Logistik und Verkehrswirtschaft im Wandel: Unternehmensübergreifende Versorgungsnetzwerke verändern die Wirtschaft, München, S. 291-306

Blankart, C., Knieps, G. (1992), Netzökonomik, in: Jahrbuch für neue Politische Ökonomie, 11 Jg., S. 73-87

Böbel, I. (1978), Industrial Organization, Tübingen

Böbel, I. (1984), Wettbewerb und Industriestruktur: Industrial Organization-Forschung im Überblick, Berlin

Boecker, E. (2002), Wandel im Transportmarkt, in: Logistik Heute, Jg. 24, Heft 11, S. 28-29

Bölsche, D. (2002), Kapitel D 3.1: Gestaltung der Logistiktiefe, in: Arnold, D., Isermann, H., Kuhn, A., Tempelmeier, H. (Hrsg.), Handbuch Logistik, Berlin, S. D3-1 - D3-8

Bombach, G. (1964), Der Strukturbegriff in der Ökonomie, in: Neumark, F. (Hrsg.), Strukturwandlungen einer wachsenden Wirtschaft, Berlin, S. 10-17 
Borchert, M., Grossekettler, H. (1985), Preis- und Wettbewerbstheorie: Marktprozesse als analytisches Problem und ordnungspolitische Gestaltungsaufgabe, Stuttgart

Boss, A., Laaser, C.-F., Schatz, K.-W. et al. (1996), Deregulierung in Deutschland: eine empirische Analyse, Tübingen

Bowersox, D. J., Closs, D. J. (1996), Logistical Management: the Integrated Supply Chain Process, 1. Auflage, New York

Brauer, K. (1979), Betriebswirtschaftslehre des Verkehrs, Erster Teil: Tätigkeitsbedingungen der Verkehrsbetriebe, Berlin

Brauer, K. (1980), Betriebswirtschaftslehre des Verkehrs, Zweiter Teil: Leistungsbereitschaft der Verkehrsbetriebe, Berlin

Bresnahan, T. F., Schmalensee, R. (1987), The Empirical Renaissance in Industrial Economics: An Overview, in: Journal of Industrial Economics, Bd. 35, S. 371378

Bretzke, W.-R. (1999), Überblick über den Markt an Logistik-Dienstleistern, in: Weber, J., Baumgarten, H. (Hrsg.), Handbuch Logistik: Management von Material- und Warenflussprozessen, Stuttgart, S. 219-225

Bretzke, W.-R. (2000), Logistikdienstleistungen, in: Klaus, P., Krieger, W. (Hrsg.), Gabler Lexikon Logistik, 2. Auflage, Wiesbaden, S. 314-320

Bretzke, W.-R. (2006), Netzwerkkooperationen im Stückgutmarkt: Krise einer Geschäftsidee?, URL http://www.mylogistics.net/de/news/themen.jsp?key=news 463024\&suchfeld $=$ st\%FCckgutbereich\&typ=search\&typ=search, Zugriff am 23.05.2008

BSL (Bundesverband Spedition und Logistik e.V.) (2000), Zahlen, Daten, Fakten aus Spedition und Logistik 2000, Bonn

Bubik, M. (2005), Erfolgskriterien für Unternehmenszusammenschlüsse - Eine theoretische und exemplarische Analyse, Frankfurt a. M.

Bühler, S., Jäger, F. (2002), Einführung in die Industrieökonomik, Berlin

Button, K. (1993), Transport Economics, 2. Auflage, Cambridge

Cardeneo, A. (2002), Kapitel C 3.2: Straßengüterverkehr, Speditionen, Logistikdienstleistungen, in: Arnold, D., Isermann, H., Kuhn, A., Tempelmeier, H. (Hrsg.), Handbuch Logistik, Berlin, S. C3-1 - C3-11 
Carlton, D., Perloff, J. (1990), Modern Industrial Organization, London

Chamberlin, E. (1933), The Theory of Monopolistic Competition, Cambridge/Mass.

Chamberlin, E. (1950), Product Heterogeneity and Public Policy, in: American Economic Review (Papers and Proceedings), Jg. 40, S. 85-92

Clark, J. M. (1940), Toward a Concept of Workable Competition, in: The American Economic Review, Jg. 30, S. 241-256

Clark, J. M. (1954), Competition and the Objectives of Government Policy, in: Chamberlin, E. (Hrsg.), Monopoly and Competition and their Regulation, London, S. 317-337

Clark, J. M. (1955), Competition: Static Models and Dynamic Aspects, in: The American Economic Review, Jg. 45, 450-462

Clark, J. M. (1961), Competition as a Dynamic Process, Washington

Clasen, S. (1966), Die Flexibilität der volkswirtschaftlichen Produktionsstruktur, Göttingen

CLM (Council of Logistics Management) (2004), URL http://clm1.org/Website/ AboutCLM/Definitions/Definitions.asp, Zugriff am 18.11.2004

Coase, R. (1937), The Nature of the Firm, in: Economica, 4 Jg., S. 386-405

Cournot, A. (1924), Untersuchungen über die mathematischen Grundlagen der Theorie des Reichtums, Jena

Commons, J. (1931), Institutional Economics, in: The American Economic Review, Jg. 21, S. 648-657

Christaller, W. (1933), Die zentralen Orte in Süddeutschland, Darmstadt

Daduna, J. (2003), Betriebliche Informationstechnologien am Beispiel des Straßengütertransports, in: Das Wirtschaftsstudium, Jg. 32, Heft 6, S. 752-755

Dehler, M. (2001), Entwicklungsstand der Logistik: Messung - Determinanten Erfolgswirkungen, Wiesbaden

Delfmann, W (2000a), Logistikkonzeption, Kernelemente der, in: Klaus, P., Krieger, W. (Hrsg.), Gabler Lexikon Logistik, 2. Auflage, Wiesbaden, S. 322-326 
Delfmann, W. (2000b), Integration, logistische, in: Klaus, P., Krieger, W. (Hrsg.), Gabler Lexikon Logistik, 2. Auflage, Wiesbaden, S. 212-214

Delfmann, W. (2000c), Standardisierungsstrategien, in: Klaus, P., Krieger, W. (Hrsg.), Gabler Lexikon Logistik, 2. Auflage, Wiesbaden, S. 431-433

Denkhaus, I. (1995), Verkehrsinformationssysteme - Durchsetzbarkeit und Akzeptanz in der Bundesrepublik Deutschland, Deutscher Universitätsverlag

Deutsche Post World Net (2008a), Geschäftsbericht 2007, Bonn

Deutsche Post World Net (2008b), Site: Akquisitionen, Internetauftritt der Deutsche Post World Net, URL http://investors.dpwn.de/de/investoren/der_konzern/akquisitionen/index.html, Zugriff am 20.3.2008

Diederich, H. (1977), Verkehrsbetriebslehre, Wiesbaden

Dohse, D., Laaser, C.-F., Schrader, J.-V., Soltwedel, R. (2005), Raumstruktur im Internetzeitalter: Tod der Distanz? - Eine empirische Analyse, Institut für Weltwirtschaft Kiel (Hrsg.), Kieler Diskussionsbeiträge Nr. 416/417, Kiel

Drechsler, W. (1988), Markteffekte logistischer Systeme: Auswirkungen von Logistikund unternehmensübergreifenden Informationssystemen im Logistikmarkt, Göttingen

Durth, R. (2000), Transaktionskosten und „Neue Ökonomie“, in: Wirtschaftswissenschaftliches Studium (WiSt), Jg. 29, Heft 11, S. 637-639

Eckey, H.-F., Kosfeld, R., Dreger, C. (2000), Statistik, 2. Auflage, Wiesbaden

Eckey, H.-F., Stock, W. (2000), Verkehrsökonomie - Eine empirisch orientierte Einführung in die Verkehrswissenschaften, Wiesbaden

Eckstein, W. (1985), Kooperative Systembildung in der Transportwirtschaft Innovationschancen mittelständischer Betriebe, Karlsruher Beiträge zur Wirtschaftspolitik und Wirtschaftsforschung, Heft 11, Karlsruhe

Edgeworth, F. (1881), Mathematical Psychics, London

Eickhof, N. (1993), Verkehrspolitische Reformerfordernisse, in: Das Wirtschaftsstudium, Jg. 22, Heft 5, S. 453-459

Eickhof, N., Berkelova, M. (1990), Verkehrspolitik in Deutschland und der EG, in: Wirtschaftswissenschaftliches Studium (WiSt), Jg. 19, Heft 12, S. 594-599 
Eisenkopf, A., Frank, H.-J., Heng, S., Heymann, E. (2002), Verkehr in Europa Privatisierung und Wettbewerb unverzichtbar, in: Frank, H.-J. (Hrsg.), Sonderbericht der Deutsche Bank Research, Frankfurt a. M.

Engelsleben, T., Niebuer, A. (1997), Entwicklungslinien der LogistikKonzeptionsforschung, Arbeitsbericht Nr. 93 des Seminars für Allgemeine Betriebswirtschaftlehre, Betriebswirtschaftliche Planung und Logistik der Universität zu Köln, Köln

Engerer, H., Voigt, S. (2002), Institutionen und Transformation - Mögliche Politikimplikationen der Neuen Institutionenökonomik, in: Zimmermann, K. (Hrsg.), Neue Entwicklungen in der Wirtschaftswissenschaft, Heidelberg, S. 149-215

Erber, G., Hagemann, H. (2002), Netzwerkökonomie, in: Zimmermann, K. (Hrsg.), Neue Entwicklungen in der Wirtschaftswissenschaft, Heidelberg, S. 277-319

Erber, G., Voigt, U., Klaus, P. (2001), Wandel der Logistik- und Verkehrssysteme durch E-Commerce - Informationsdefizite abbauen und Regulierungsrahmen schaffen, DIW-Wochenbericht 34/01, URL http://ww.diw-berlin.de/deutsch/publikationen/wochenberichte/docs/01-34-1.htm, Zugriff am 6.8.2002

Ernst, M. (2000), Telematik als Instrument einer flexiblen Verkehrspolitik - Potentiale und Grenzen, in: Zeitschrift für Verkehrswissenschaft, Jg. 71, Heft 1, S. 40-75

Ernst, M., Walpuski, D. (1993), Verkehrswissenschaftliche Implikationen der Telekommunikation, in: Ernst, M., Kopf, J. (Hrsg.), Elemente volkswirtschaftlicher Forschung und Lehre, Berlin, S. 99-122

Ernst, M., Walpuski, D. (1997), Telekommunikation und Verkehr, München

Eucken, W. (1959), Die Grundlagen der Nationalökonomie, 7. Auflage, Berlin

Ewers, H. J. (1973), Systemorientierte Integration von Transportabläufen im Güterverkehr, in: Seidenfus, H. (Hrsg.), Systemorientierte Verkehrspolitik, Göttingen, S. 33-57

Faller, P. (1999), Logistik und Verkehrsbetriebslehre, in: Weber, J., Baumgarten, H. (Hrsg.), Handbuch Logistik: Management von Material- und Warenflussprozessen, Stuttgart, S. 77-101

Fehl, U. (1987), Unternehmertheorie, Unternehmertypen und Marktanalyse, in: Borchert, M., Fehl, U., Oberender, P. (Hrsg.), Markt und Wettbewerb, Bern, Stuttgart, S. 17-37 
Femerling, C. (2003), B to B- und B to C-Logistik als Erfolgsfaktor der New Economy, in: Merkel, H., Bjelicic, B. (Hrsg.), Logistik und Verkehrswirtschaft im Wandel: Unternehmensübergreifende Versorgungsnetzwerke verändern die Wirtschaft, München, S. 205-221

Fiege, H. (1998), Komplexitätsreduktion durch Einschaltung logistischer Dienstleister, in: Hossner, R. (Hrsg.), Jahrbuch der Logistik 1998, Düsseldorf

Florian, M. (2000), Vorschläge für ein Szenario „Tauschbörse und E-Commerce“, Working Papers zur Modellierung sozialer Organisationsformen in der Sozionik (WP 10), Technische Universität Hamburg-Harburg, Arbeitsbereich Technikbewertung und Technikgestaltung, Hamburg

Fonger, M. (1992), Make-or-Buy-Strategien im Straßengüterfernverkehr aus transaktionskostentheoretischer Sicht, in: Seidenfus, H. (Hrsg.), Make or Buy: Transaktionskostentheorie als Entscheidungshilfe für die Verkehrswirtschaft, Göttingen, S. $51-93$

Frahm, E., Klaus, P. (2000), Verkehrspolitische und volkswirtschaftliche Rahmenbedingungen, in: Klaus, P., Krieger, W. (Hrsg.), Gabler Lexikon Logistik, 2. Auflage, Wiesbaden, S. 511-515

Freichel, S. (1992), Organisation von Logistikservice-Netzwerken: Theoretische Konzeption und empirische Fallstudien, Berlin

Freytag, A. (2000), Was ist wirklich neu an der New Economy?, in: Zeitschrift für Wirtschaftspolitik, 49 Jg., Heft 3, S. 303-312

Fritsch, M., Wein, T., Ewers, H.-J. (1999), Marktversagen und Wirtschaftspolitik: mikroökonomische Grundlagen staatlichen Handelns, 3. Auflage, München

Fritz, A. (2000), Die Entsorgungswirtschaft im Spannungsfeld zwischen Abfallpolitik und Kartellrecht: eine industrieökonomische Branchenstudie, Frankfurt a. M.

Gahlen, B., Rahmeyer, F. (1982), Die Strukturberichterstattung der Wirtschaftsforschungsinstitute, in: Zeitschrift für Wirtschafts- und Sozialwissenschaften, Jg. 102, Berlin, S. 173-194

Gatzke, E. (2001), Der KEP-Markt wandelt sich zu KEAV: Kurier, Express und Added Value, in: Baumgarten, H. (Hrsg.), Logistik im E-Zeitalter: Die Welt der globalen Logistiknetzwerke, Frankfurt a. M., S. 236-246 
Giersch, H. (1986), Die Ethik der Wirtschaftsfreiheit, in: Vaubel, R., Barbier, H. (Hrsg.), Handbuch Marktwirtschaft, Pfullingen, S. 12-22

Giesel, H. (1975), Unternehmungswachstum und Wettbewerb, Baden-Baden

Göpfert, I. (2000), Logistik Führungskonzeption: Gegenstand, Aufgaben und Instrumente des Logistikmanagements und -controllings, München

Greer, D. (1984), Industrial Organization and Public Policy, 2. Auflage, New York

Grether, E. T. (1970), Industrial Organization: Past History and Future Problems, in: The American Economic Review, Jg. 60, S. 83-89

Griesshaber, H. (2000), Logistikverträge mit Spediteuren, in: Klaus, P., Krieger, W. (Hrsg.), Gabler Lexikon Logistik, 2. Auflage, Wiesbaden, S. 345-348

Grüner, A. (1997), Zwischenbetriebliche Logistikleistungen in der Industrie: Produktion und Absatz investiver Dienstleistungen, Wiesbaden

Hamm, W. (1989), Deregulierung im Verkehr als politische Aufgabe, München

Hamm, W. (1994), Deregulierung - auch im Werkfernverkehr?, in: Internationales Verkehrswesen, Jg. 46, Heft 4, S. 177-180

Haubold, V. (1994), Die informationstechnisch gestützte Restrukturierung der industriellen Arbeitsteilung und ihre Folgen für den Güterverkehr, in: Ewers, H.J. (Hrsg.), Die Bedeutung von Informations- und Kommunikationstechnologien für den Verkehr, Göttingen, S. 59-130

Haubrock, M. (1994), Konzentration und Wettbewerbspolitik: Die Funktion der Monopolkommission im Zusammenhang mit der Konzentrationsentwicklung und ihre Bedeutung in der wettbewerbspolitischen Auseinandersetzung in der Bundesrepublik Deutschland, Frankfurt a. M.

Hauptmann, S. (2007), Gestaltung des Outsourcings von Logistikleistungen - Empfehlungen zur Zusammenarbeit zwischen verladenden Unternehmen und Logistikdienstleistern, Wiesbaden

v. Hayek, F. (1952), Die Verwertung des Wissens in der Gesellschaft, in: v. Hayek, F., Individualismus und wirtschaftliche Ordnung, Erlenbach-Zürich, S. 103-121

v. Hayek, F. (1969), Der Wettbewerb als Entdeckungsverfahren, in: v. Hayek, F., Freiburger Studien: Gesammelte Aufsätze, Tübingen, S. 249-265 
Heger, D. (2003), Nachhaltige Wettbewerbsvorteile in der Net Economy: Die Rolle von Handelsintermediären im B-to-B Electronic Commerce, Wiesbaden

Heiserich, O.-E. (2002), Logistik, 3. Auflage, Wiesbaden

Held, T., Steckler, N. (2007), Kapitel 4.3: Kooperationen zwischen Logistikdienstleitern, in: Stölzle, W., Weber, J., Hofmann, E., Wallenburg, C. (Hrsg.), Handbuch Kontraktlogistik - Management komplexer Logistikdienstleistungen, Weinheim, S. $447-461$

Helmke, C. (2006), Der Markt für Paket- und Expressdienste - Eine Studie zu Kundenzufriedenheit und Kundenbindung im Markt für Paket- und Expressdienste, URL https://kobra.bibliothek.uni-kassel.de/bitstream/urn:nbn:de:hebis: 34-2006112215835/6/Christoph_Helmke_Diss.pdf, Zugriff am 6.1.2008

Helmstädter, E. (1958), Produktionsstruktur und Wachstum, in: Jahrbücher für Nationalökonomie und Statistik (Teil 1), Jg. 169, S. 173-207

Helmstädter, E. (1990), Marktstruktur und dynamischer Wettbewerb - Theoretische Grundlagen der Schumpeter-Hypothesen, in: Gahlen, B. (Hrsg.), Marktstruktur und gesamtwirtschaftliche Entwicklung, Berlin, S. 159-174

Heng, S. (2004), Verkehr und Informationstechnologien - Stau ade?, in: Wirtschaftswissenschaftliches Studium (WiSt), Jg. 33, Heft 6, S. 373-376

Henning, R., Janz, O., Schröder, M., Janowski, J. (2003), Economies in der Verkehrswirtschaft, in: Merkel, H., Bjelicic, B. (Hrsg.), Logistik und Verkehrswirtschaft im Wandel: Unternehmensübergreifende Versorgungsnetzwerke verändern die Wirtschaft, München, S. 399-417

Herchenhein, N. (2003), Koordination in der Logistik: Merkmale, Gestaltungsmöglichkeiten und Integrationspotenziale offener und geschlossener Netzwerke, Göttingen

Herdzina, K. (1973), Marktstruktur und Wettbewerb, in: Zeitschrift für Wirtschaftsund Sozialwissenschaften, Jg. 93, S. 267-284

Herdzina, K. (1975), Zur historischen Entwicklung der Wettbewerbstheorie, in: Herdzina, K. (Hrsg.), Wettbewerbstheorie, Köln, S. 15-28

Herdzina, K. (1981), Wirtschaftliches Wachstum, Strukturwandel und Wettbewerb, Berlin 
Herdzina, K. (1985), Marktentwicklung und Wettbewerbsverhalten, in: Bombach, G., Gahlen, B., Ott, A. (Hrsg.), Industrieökonomik: Theorie und Empirie, Tübingen, S. $105-120$

Herdzina, K. (1989), Bemerkungen zur wettbewerbspolitischen Konzeption des GWB, in: Andreae, C.-A., Kirchhoff, J., Pfeiffer, G. (Hrsg.), Wettbewerb als Herausforderung und Chance, S. 3-15

Herdzina, K. (1990), Marktstruktur und dynamischer Wettbewerb - Theoretische Grundlagen der Schumpeter-Hypothesen, Korreferat zum Referat von E. Helmstädter, in: Gahlen, B. (Hrsg.), Marktstruktur und gesamtwirtschaftliche Entwicklung, Berlin, S. 175-180

Herdzina, K. (1999), Wettbewerbspolitik, 5. Auflage, Stuttgart

Herdzina, K. (2005), Einführung in die Mikroökonomik, 10. Auflage, München

Herdzina, K., Wander, C. (2004), Volkswirtschaftliche Analyse [der deutschen Transportbetonindustrie], in: Herdzina, K., Müller, C., Vollmer, L. (Hrsg.), Die deutsche Transportbetonindustrie - eine betriebswirtschaftliche, volkswirtschaftliche und kartellrechtliche Untersuchung -, Gutachten der Universität Hohenheim, Stuttgart, S. 77-129

Hess, T. (2000), Netzeffekte: Verändern neue Informations- und Kommunikationstechnologien das klassische Marktmodell?, in: Wirtschaftswissenschaftliches Studium (WiSt), Jg. 29, Heft 2, S. 96-98

Hesse, M. (1998), Raumentwicklung und Logistik, in: Raumforschung und Raumordnung, Jg. 56, Heft 2-3, S. 125-135

Heuß, E. (1965), Allgemeine Markttheorie, Tübingen

Heuß, E. (1968), Die Wettbewerbs- und Wachstumsproblematik des Oligopols, in: Schneider, H. K. (Hrsg.), Grundlagen der Wettbewerbspolitik, Schriften des Vereins fưr Socialpolitik, Bd. 48, Berlin, S. 50-70

Hoffmann, A., Stölzle, W. (2005), Vernetzte Logistik - Netzeffekte im Kombinierten Verkehr, in: Verkehrsforschung online, Ausgabe $1-2005$, URL http://www.verkehrsforschung-online.de/ausgabe/ausgabe_pdf.php?\&artikel_id $=28$, Zugriff am 11.1.2008

Hofmann, H.-J. (1982), Die Evolution von Marktstrukturen, Bern 
Hofmann, U. (2001), Netzwerk-Ökonomie, Heidelberg

Hoppmann, E. (1966), Preismeldestellen und Wettbewerb, in: Wirtschaft und Wettbewerb, Jg. 16, S. 97-121

Hoppmann, E. (1967), Wettbewerb als Norm der Wettbewerbspolitik, in: Ordo, Jg. 18, S. $77-94$

Hoppmann, E. (1968a), Zum Problem einer wirtschaftspolitisch praktikablen Definition des Wettbewerbs, in: H. K. Schneider (Hrsg.), Grundlagen der Wettbewerbspolitik, Berlin, S. 9-49

Hoppmann, E. (1968b), Zum Schutzobjekt des GWB, in: E.-J. Mestmäcker (Hrsg.), Wettbewerb als Aufgabe - nach zehn Jahren Gesetz gegen Wettbewerbsbeschränkungen, Bad Homburg, S. 61-104

Hoppmann, E. (1970), „Neue Wettbewerbspolitik“: Vom Wettbewerb zur staatlichen Mikro-Steuerung, in: Jahrbücher für Nationalökonomie und Statistik, Bd. 184, Heft 4-5, S. 397-416

Hoppmann, E. (1972), Fusionskontrolle, Tübingen

Hoppmann, E. (1974a), Die Abgrenzung des relevanten Marktes im Rahmen der Missbrauchsaufsicht über marktbeherrschende Unternehmen, Baden-Baden

Hoppmann, E. (1974b), Noch einmal zur ökonomischen Begründung von Ausnahmebereichen, in: Jahrbücher für Nationalökonomie und Statistik, Bd. 188, Heft 3, S. 256-267

Hoppmann, E. (1977), Marktmacht und Wettbewerb - Beurteilungskriterien und Lösungsmöglichkeiten, Tübingen

Hoppmann, E. (1980a), Gleichgewicht und Evolution, in: Ansprachen und Vorträge auf der Festveranstaltung der Wirtschaftswissenschaftlichen Fakultät der JuliusMaximilians-Universität Würzburg zum 75. Geburtstag von Erich Carell am 23. Juni 1980 im Toscana-Saal der Residenz, Baden-Baden, S. 19-39

Hoppmann, E. (1980b), Wettbewerb und Wachstum in marktwirtschaftlichen Ordnungen, Korreferat zum Referat von E. Kaufer, in: Streißler, E., Watrin, C. (Hrsg.), Zur Theorie marktwirtschaftlicher Ordnungen, Tübingen, S. 240-248 
Hoppmann, E. (1981), Über Funktionsprinzipien und Funktionsbedingungen des Marktsystems, in: Wegehenkel, L. (Hrsg.), Marktwirtschaft und Umwelt, Tübingen, S. 219-235

Hoppmann, E. (1983), Marktbeherrschung und Preismissbrauch, Baden-Baden

Ihde, G. (1972), Logistik, Stuttgart

Ihde, G. (1999), Mikro- und Makrologistik, in: Weber, J., Baumgarten, H. (Hrsg.), Handbuch Logistik: Management von Material- und Warenflussprozessen, Stuttgart, S. 115-128

Ihde, G. (2001), Transport, Verkehr, Logistik: Gesamtwirtschaftliche Aspekte und einzelwirtschaftliche Handhabung, 3. Auflage, München

Illetschko, L. (1966), Transport-Betriebswirtschaftslehre, 2. Auflage, Wien

Isermann, H. (1994), Logistik im Unternehmen - eine Einführung, in: Isermann, H. (Hrsg.), Logistik, Landsberg L., S. 21-43

Isermann, H. (1998), Grundlagen eines systemorientierten Logistikmanagements, in: Isermann, H. (Hrsg.), Logistik: Gestaltung von Logistiksystemen, 2. Auflage, Landsberg L., S. 21-60

Isermann, H. (2002), Transportmärkte der Verkehrsträger, in: Arnold, D., Isermann, H., Kuhn, A., Tempelmeier, H. (Hrsg.), Handbuch Logistik, Berlin, S. D2-7 D2-8

Jacquemin, A. (1986), Industrieökonomik: Strategie und Effizienz des modernen Unternehmens, Frankfurt a. M.

Jaeger, G., Laudel, H. (2000), Transportmanagement: die Fachkunde des Güterverkehrs für Spedition, Handel und Industrie, 4. Auflage, Hamburg

Jammernegg, W., Trcka, M. (1999), Organisatorische Aspekte von Supply Chain Design und Management, in: Faller, P. (Hrsg.), Transportwirtschaft im Umbruch: Strukturwandel, Anpassungserfordernisse, Gestaltungsaufgaben, Wien, S. 209216

Jansen, H. (2004), Verfügungsrechte und Transaktionskosten, in: Wirtschaftswissenschaftliches Studium (WiSt), Jg. 33, Heft 10, S. 597-602

Jevons, W. (1888), The Theory of Political Economy, 3. Auflage, London (Macmillan and Co.) 
Kaldor, N. (1935), Market Imperfection and Excess Capacity, in: Economica, Jg. 2, S. 33-50

Kallfaß, H. (1997), Konzepte und Indikatoren zur Abgrenzung räumlicher Märkte in der europäischen Zusammenschlusskontrolle, in: Kruse, J., Stockmann, K., Vollmer, L. (Hrsg.), Wettbewerbspolitik im Spannungsfeld nationaler und internationaler Kartellrechtsordnungen, Baden-Baden, S. 111-130

Kantzenbach, E. (1967), Die Funktionsfähigkeit des Wettbewerbs, 2. Auflage, Göttingen

Kantzenbach, E. (1967/68), Das Konzept der optimalen Wettbewerbsintensität, in: Jahrbücher für Nationalökonomie und Statistik, Bd. 181, S. 193-241

Katz, M., Shapiro, C. (1985), Network Externalities, Competition, and Compatibility, in: The American Economic Review, Jg. 75, S. 424-440

Katz, M., Shapiro, C. (1986), Technology Adoption in the Presence of Network Externalities, in: Journal of Political Economy, Jg. 94, Heft 4, S. 822-841

Kaufer, E. (1967), Nochmals: Von der Preistheorie zur Wettbewerbstheorie, in: Ordo, Jg. 18, S. 95-114

Kaufer, E. (1980), Industrieökonomik, München

Kaufmann, L., Germer, T. (2001), Controlling Internationaler Supply Chains: Positionierung - Instrumente - Perspektiven, in: Arnold, U., Mayer, R., Urban, G. (Hrsg.), Supply Chain Management: Unternehmensübergreifende Prozesse Kollaboration - IT-Standards, Bonn, S. 177-192

Kaupp, M. (2002), Kapitel D 3.6: Logistiknetzwerke, in: Arnold, D., Isermann, H., Kuhn, A., Tempelmeier, H. (Hrsg.), Handbuch Logistik, Berlin, S. D3-34 - D341

Kerber, W. (2003), Wettbewerbspolitik, in: Bender, D., Berg, H., Cassel et al. (Hrsg.), Vahlens Kompendium der Wirtschaftstheorie und Wirtschaftspolitik, Bd. 2, 8. Auflage, München, S. 297-361

Kersten, W., Koch, J. (2007), Kapitel 2.1: Motive für das Outsourcing komplexer Logistikdienstleistungen, in: Stölzle, W., Weber, J., Hofmann, E., Wallenburg, C. (Hrsg.), Handbuch Kontraktlogistik - Management komplexer Logistikdienstleistungen, Weinheim, S. 115-132 
Kirsch, W., Bamberger, I., Gabele, E., Klein, H. K. (1973), Betriebswirtschaftliche Logistik: Systeme, Entscheidungen, Methoden, Wiesbaden

Klatt, S. (1975), Die Problematik einer Steuerung des Strukturwandels der Wirtschaft, in: Klatt, S., Willms, M. (Hrsg.), Strukturwandel und makroökonomische Steuerung, Berlin, S. 11-37

Klaus, P. (1999), Logistik als „Weltsicht“, in: Weber, J., Baumgarten, H. (Hrsg.), Handbuch Logistik: Management von Material- und Warenflussprozessen, Stuttgart, S. 15-32

Klaus, P. (2000a), Logistikmanagement, in: Klaus, P., Krieger, W. (Hrsg.), Gabler Lexikon Logistik, 2. Auflage, Wiesbaden, S. 335-340

Klaus, P. (2000b), Supply Chain Management, in: Klaus, P., Krieger, W. (Hrsg.), Gabler Lexikon Logistik, 2. Auflage, Wiesbaden, S. 449-456

Klaus, P. (2003), Die „TOP 100“ der Logistik: Marktgrößen, Marktsegmente und Marktführer in der Logistik-Dienstleistungswirtschaft - Deutschland und Europa, Bundesvereinigung Logistik e. V. (BVL) und Deutscher Verkehrs-Verlag (Hrsg.), 3. Auflage, Hamburg

Klaus, P. (2007), Kapitel 1.4: Markt für Kontraktlogistik - Volumen und Entwicklungen in Europa, in: Stölzle, W., Weber, J., Hofmann, E., Wallenburg, C. (Hrsg.), Handbuch Kontraktlogistik - Management komplexer Logistikdienstleistungen, Weinheim, S. 89-112

Klaus, P., Kille, C. (2006), Die TOP 100 der Logistik: Marktgrößen, Marktsegmente und Marktführer in der Logistikdienstleistungswirtschaft, Bundesvereinigung Logistik e. V. (BVL) und Deutsche Verkehrszeitung (DVZ) (Hrsg.), 4. Auflage, Hamburg

Klaus, P., Krieger, W. (2000), Logistik für die Managementpraxis: Die Herausforderung der Systematisierung oder „Wie den Pudding an die Wand nageln?“, in: Klaus, P., Krieger, W. (Hrsg.), Gabler Lexikon Logistik, 2. Auflage, Wiesbaden, S. XIII-XVIII

Klaus, P., Müller-Steinfahrt, U. (1997), Die „TOP 100“ der Logistik: eine GVB-Studie zu Marktsegmenten, Marktgrößen und Marktführern in der deutschen LogistikDienstleistungswirtschaft. Hrsg. von der Gesellschaft für Verkehrsbetriebswirtschaft und Logistik (GVB) e. V. (Nürnberg), Hamburg 
Klaus, P., Müller-Steinfahrt, U. (2000), Die „TOP 100“ der Logistik: eine Studie zu Marktgrößen, Marktsegmenten und Markführern in der LogistikDienstleistungswirtschaft. Hrsg. von der Gesellschaft für Verkehrsbetriebswirtschaft und Logistik (GVB) e. V. (Nürnberg), 2. Auflage, Hamburg

Kleeberg, L. (2000), Management von Transportnetzwerken: Ein modellgestützter Führungsansatz zur Planung und Steuerung zukunftsorientierter Gütertransportsysteme für Stück- und Kleinguttransporte im kombinierten Straßen/Schienengüterverkehr, Göttingen

Klodt, H. (2001), Die Neue Ökonomie: Aufbruch und Umbruch, in: Die Weltwirtschaft (2001), Heft 1, S. 78-98

Kloster, T. (2002), Gestaltung von Logistiksystemen auf Basis von Netzeffekten, Frankfurt a. M.

Knieps, G. (2001), Wettbewerbsökonomie: Regulierungstheorie, Industrieökonomie, Wettbewerbspolitik, Berlin

Knight, F. (1921), Risk, Uncertainty and Profit, New York

Knight, F. (1946), Immutable Law in Economics: Its Reality and Limitations, in: American Economic Review (Papers and Proceedings), Jg. 36, S. 93 ff.

Koch, W., Czogalla, C. (2004), Grundlagen der Wirtschaftspolitik, 2. Auflage, Stuttgart

Köberlein, C. (1997), Kompendium der Verkehrspolitik, München

Koldau, A. (2002), Auswirkungen neuer Informations- und Kommunikationstechnologien auf die Logistik, in: Stölzle, W., Gareis, K. (Hrsg.), Integrative Management- und Logistikkonzepte, Wiesbaden, S. 451-471

Kondratieff, N. (1926), Die langen Wellen der Konjunktur, in: Archiv für Sozialwissenschaft und Sozialpolitik, 56 Jg., Stuttgart, S. 573-609

Kortmann, W. (2002), Mikroökonomik - Anwendungsbezogene Grundlagen, 3. Auflage, Heidelberg

Kortmann, W. (2003), Eine neue Methode für systematische Markt-, Branchen- und Wettbewerbsanalysen, Berlin 
Kottmann, E. (2000), Die räumliche Abgrenzung des relevanten Marktes: Eine ökonomische Analyse unter Berücksichtigung der wettbewerbspolitischen Praxis in der europäischen Zusammenschlusskontrolle, Baden-Baden

Kotzab, H. (1999), Supply Chain Management: Ausprägung einer integrationsorientierten Logistikmanagementkonzeption, in: Faller, P. (Hrsg.), Transportwirtschaft im Umbruch: Strukturwandel, Anpassungserfordernisse, Gestaltungsaufgaben, Wien, S. 217-233

Krakowski, M. (1988), Theoretische Grundlagen der Regulierung, in: Krakowski, M. (Hrsg.), Regulierung in der Bundesrepublik Deutschland: Die Ausnahmebereiche des Gesetzes gegen Wettbewerbsbeschränkungen, Hamburg, S. 19-116

Kremer, S. (2000), Verkehrsreduzierung durch Speditionskooperationen und Vernetzungsstrategien: Raumbezug und Folgewirkungen, Aachen

Krieger, W. (2000), E-Business und Logistik, in: Klaus, P., Krieger, W. (Hrsg.), Gabler Lexikon Logistik, 2. Auflage, Wiesbaden, S. 100-102

Krüsselberg, H.-G. (1969), Marktwirtschaft und ökonomische Theorie, Freiburg

Kruse, J. (1985), Ökonomie der Monopolregulierung, Göttingen

Kruse, J. (1997), Vertikale Integration als Wettbewerbsproblem, in: Kruse, J., Stockmann, K., Vollmer, L. (Hrsg.), Wettbewerbspolitik im Spannungsfeld nationaler und internationaler Kartellrechtsordnungen, Baden-Baden, S. 247-270

Kruse, J., Berger, U. (1996), Skript Ordnungspolitik, 3. Auflage, Universität Hohenheim

Kruse, P. (2003), Mit den Märkten wachsen. Der Wandel vom KEP-Dienstleister zum Global Player der Logistik, in: Merkel, H., Bjelicic, B. (Hrsg.), Logistik und Verkehrswirtschaft im Wandel: Unternehmensübergreifende Versorgungsnetzwerke verändern die Wirtschaft, München, S.437-444

Kujath, H. (2003), Logistik und Raum - Neue regionale Netzwerke der Güterverteilung und Logistik, Institut für Regionalentwicklung und Strukturplanung

Kummer, S., Fuster, R. (1999), Auswirkungen des e-commerce auf Logistikdienstleister, in: Faller, P. (Hrsg.), Transportwirtschaft im Umbruch: Strukturwandel, Anpassungserfordernisse, Gestaltungsaufgaben, Wien, S. 381-400 
Laaser, C.-F. (1986), Reform der Verkehrsmärkte, in: Vaubel, R., Barbier, H. (Hrsg.), Handbuch Marktwirtschaft, Pfullingen, S. 328-333

Laaser, C.-F. (1991), Wettbewerb im Verkehrswesen: Chancen für eine Deregulierung in der Bundesrepublik, Tübingen

Laaser, C.-F., Soltwedel, R. (2001), Raumstruktur und New Economy - zur Bedeutung von E-commerce für die Arbeitsteilung im Raum, in: Die Weltwirtschaft (2001), Heft 2, S. 173-189

Lammich, K. (1994), Deutschland nach dem Tarifaufhebungsgesetz: Was bleibt übrig von der kontrollierten Verkehrsmarktordnung?, in: Internationales Verkehrswesen, Jg. 46, Heft 1+2, S. 20-24

Langerfeldt, M. (2002), Transaktionskostentheorie, in: Das Wirtschaftsstudium, Jg. 31, Heft 5, S. 653-655

Langfeldt, E. (1986), Wettbewerbsordnung, in: Vaubel, R., Barbier, H. (Hrsg.), Handbuch Marktwirtschaft, Pfullingen, S. 106-217

Laupper, U. (2005), Wertorientierte Netzwerksteuerung: neue Werttreiber für Unternehmen in Wertschöpfungsnetzen, Bern

Leibenstein, H. (1966), Allocative Efficiency vs. „X-Inefficiency“, in: The American Economic Review, Vol. 56, S. 392-415

Lieb, T., Lange, U. (2003), Strategien und Organisationsstrukturen global integrierter Logistikdienstleister, in: Merkel, H., Bjelicic, B. (Hrsg.), Logistik und Verkehrswirtschaft im Wandel: Unternehmensübergreifende Versorgungsnetzwerke verändern die Wirtschaft, München, S. 445-459

Lipsey, R., Lancaster, K. (1956), The General Theory of Second Best, in: Review of Economic Studies, Jg. 24, S. 11-32

Lösch, A. (1962), Die räumliche Ordnung der Wirtschaft, 3. Auflage, Stuttgart

Lüpschen, B. (2004), Kostendegressionspotenziale in Logistiksystemen, Arbeitsbericht Nr. 105 des Seminars für Allgemeine Betriebswirtschaftlehre, Betriebswirtschaftliche Planung und Logistik der Universität zu Köln, Köln

Machlup, F. (1958), Structure and Structural Change: Weaselwords and Jargon, in: Zeitschrift für Nationalökonomie, Bd. 18, S. 280-298

Maleri, R. (1991), Grundlagen der Dienstleistungsproduktion, 2. Auflage, Berlin 
Manner-Romberg, H. (2001), KEP-Markt - Mitten im Wandel, in: Logistik Heute, Jg.23, Heft 7-8, S. 34-35

Mantzavinos, C. (1994a), Wettbewerbstheorie, Berlin

Mantzavinos, C. (1994b), Positive und normative Wettbewerbstheorie: der Versuch einer Systematisierung, in: Ott, A. (Hrsg.), Probleme der unvollkommenen Konkurrenz, Tübingen, S. 65-74

Mason, E. S. (1939), Price and Production Policies of Large-scale Enterprise, in: The American Economic Review, Jg. 29, S. 61-74

Mason, E. S. (1949), The Current State of the Monopoly Problem in the United States, in: Harvard Law Review, Bd. 62, S. 1265-1285

Mason, E. S. (1959), Economic Concentration and the Monopoly Problem, 2. Auflage, Cambridge, MA

McNulty, P. J. (1967), A Note on the History of Perfect Competition, in: Journal of Political Economy, Jg. 75, S. 395-399

Meißner, W., Fassing, W. (1989), Wirtschaftsstruktur und Strukturpolitik, München

Melzer-Ridinger, R. (2007), Supply Chain Management, München

Ménard, C., Shirley, M. (2005), Introduction, in: Ménard, C., Shirley, M. (Hrsg.), Handbook of New Institutional Economics, Berlin, S. 1-18

Meyer, A., Blümelhuber, C. (1994), Interdependenzen zwischen Absatz und Produktion in Dienstleistungsunternehmen und ihre Auswirkungen auf konzeptionelle Fragen des Absatzmarketing, in: Corsten, H., Hilke, W. (Hrsg.), Dienstleistungsproduktion, Schriften zur Unternehmensführung, Bd. 52, Wiesbaden, S. 5-41

Michaelis, E. (1985), Organisation unternehmerischer Aufgaben - Transaktionskosten als Beurteilungskriterium, Frankfurt a. M.

Mikus, B. (2003), Strategisches Logistikmanagement: Ein markt-, prozess- und ressourcenorientiertes Konzept, Göttingen

Milling, P., Dengel, H. (2003), Systemtheorie und Logistik, in: Merkel, H., Bjelicic, B. (Hrsg.), Logistik und Verkehrswirtschaft im Wandel: Unternehmensübergreifende Versorgungsnetzwerke verändern die Wirtschaft, Festschrift für Gösta B. Ihde, München, S. 133-148 
Möhlmann, E. (1984), Anforderungen optimaler Verkehrssysteme an die Verkehrspolitik, in: Seidenfus, H. (Hrsg.), Transportsysteme und Verkehrspolitik, Göttingen, S. 7-46

Monopolkommission (1982), Fortschritte bei der Konzentrationserfassung, Viertes Hauptgutachten, Baden-Baden

Monopolkommission (1984), Ökonomische Kriterien für die Rechtsanwendung, Fünftes Hauptgutachten, Baden-Baden

Monopolkommission (1986), Gesamtwirtschaftliche Chancen und Risiken wachsender Unternehmensgrößen, Sechstes Hauptgutachten, Baden-Baden

Monopolkommission (1990), Wettbewerbspolitik vor neuen Herausforderungen, Achtes Hauptgutachten, Baden-Baden

Monopolkommission (2007), Wettbewerbs- und Regulierungsversuche im Eisenbahnverkehr, Sondergutachten Nr. 48, Baden-Baden

Morgenstern, O. (1955), Note on the Formulation of the Theory of Logistics, in: Naval Research Logistics Quarterly, Jg. 5, S. 129-136

Müller-Steinfahrt, U. (2000), Logistik in Deutschland, in: Klaus, P., Krieger, W. (Hrsg.), Gabler Lexikon Logistik, 2. Auflage, Wiesbaden, S. 297-305

Nemoto, T., Visser, J., Yoshimoto, R. (2001), Impacts of Information and Communication Technology on Urban Logistics System, Joint OECD/ECMT Seminar Paris - 5./6. Juni 2001, URL http://wwwl.oecd.org/cem/online/ecom01/Nemoto.pdf, Zugriff am 4.7.2002

Neumann, C. W. (1982), Historische Entwicklung und heutiger Stand der Wettbewerbstheorie, Königstein/Ts.

OECD (Organisation for Economic Co-operation and Development) (2002), Transport Logistics: Shared Solutions to Common Challenges, Paris

Oettle, K. (1976), Verkehrsbetrieb und Verkehrsbetriebslehre, in: Grochla, E., Wittmann, W. (Hrsg.), Handwörterbuch der Betriebswirtschaft, 4. Auflage, Bd. 3, Stuttgart, Sp. 4150-4161

Ott, A. E. (1959), Marktform und Verhaltensweise, Stuttgart

Papandreou, A. (1949), Market Structure and Monopoly Power, in: The American Economic Review, Jg. 39, S. 883-897 
Pfohl, H.-C. (1974), Marketing-Logistik, in: Verlag Moderne Industrie (Hrsg.), Marketing Enzyklopädie, München, S. 577-593

Pfohl, H.-C. (1997), Logistik, in: Pfohl, H.-C. (Hrsg.), Betriebswirtschaftslehre der Mittel- und Kleinbetriebe: Größenspezifische Probleme und Möglichkeiten zu ihrer Lösung, 3. Auflage, Berlin, S. 255-286

Pfohl, H.-C. (2004a), Logistiksysteme: Betriebswirtschaftliche Grundlagen, 7. Auflage, Berlin

Pfohl, H.-C. (2004b), Grundlagen der Kooperation in logistischen Netzwerken, in: Pfohl, H.-C. (Hrsg.), Erfolgsfaktor Kooperation in der Logistik - Outsourcing, Beziehungsmanagement, Finanzielle Performance, Berlin, S. 1-36

Pfohl, H-.C. (2007), Kapitel 1.2: Kontraktlogistik als Gegenstand betriebswirtschaftlicher Theorien, in: Stölzle, W., Weber, J., Hofmann, E., Wallenburg, C. (Hrsg.), Handbuch Kontraktlogistik - Management komplexer Logistikdienstleistungen, Weinheim, S. 55-70

Pfohl, H.-C., Large, R. (1992), Gestaltung interorganisatorischer Logistiksysteme auf der Grundlage der Transaktionskostentheorie, in: Zeitschrift für Verkehrswissenschaft, 63 Jg., S.15-51

Picot, A. (1991), Ökonomische Theorien der Organisation - Ein Überblick über neuere Ansätze und deren betriebswirtschaftliches Anwendungspotential, in: Ordelheide, D., Rudolph, B., Büsselmann, E. (Hrsg.), Betriebswirtschaftslehre und ökonomische Theorie, Stuttgart, S. 143-170

Picot, A., Dietl, H. (1990), Transaktionskostentheorie, in: Wirtschaftswissenschaftliches Studium (WiSt), 19. Jg., S. 178-184

Picot, A., Neuburger, R. (2000), Prinzipien der Internet-Ökonomie, in: Wirtschaftsdienst, 80 Jg., Heft 10, S. 591-595

Picot, A., Reichwald, R., Wigand, R. (2003), Die grenzenlose Unternehmung, 5. Auflage, Wiesbaden

Pirath, C. (1934), Die Grundlagen der Verkehrswirtschaft, Berlin

Pirk, K.-T., Türks, M., Mayer, S. (2000), Leistungstiefenoptimierung in der Logistik, in: Klaus, P., Krieger, W. (Hrsg.), Gabler Lexikon Logistik, 2. Auflage, Wiesbaden, S. 270-276 
Poeche, J. (1970), Workable Competition als wettbewerbspolitisches Leitbild, in: Forschungsinstitut für Wirtschaftsverfassung und Wettbewerb (FIW) (Hrsg.), Das Konzept der „Workable Competition“ in der angelsächsischen Literatur, FIW-Dokumentation, Heft 1, Köln, S. 9-32

Powell, W. (1990), Neither Market nor Hierarchy: Network Forms of Organization, in: Research in Organizational Behaviour, Bd. 12, S. 295-336

Predöhl, A. (1964), Verkehrspolitik, 2. Auflage, Göttingen

Puf, P.-R. (1979), Wirtschaftlicher Wandel in der Bundesrepublik Deutschland, in: Seidenfus, H. (Hrsg.) Wirtschaftlicher Strukturwandel und Verkehr, Göttingen, S. $7-79$

Puls, U. (2003), Marktanalyse - Kein Land in Sicht, in: Logistik Heute, Jg. 25, Heft $7-$ 8, S. 20-21

Recktenwald, H. (1986), Verteilung der Einkommen und Vermögen, in: Vaubel, R., Barbier, H. (Hrsg.), Handbuch Marktwirtschaft, Pfullingen, S. 249-256

Rennings, K. (1992), Zur Relevanz der Transaktionskostentheorie für die Verkehrswirtschaft, in: Seidenfus, H. (Hrsg.), Make or Buy: Transaktionskostentheorie als Entscheidungshilfe für die Verkehrswirtschaft, Göttingen, S. 7-49

Richardson, G. (1972), The Organisation of Industry, in: The Economic Journal, Jg. 82, S. 883-896

Robinson, J. (1933), The Economics of Imperfect Competition, London

Rösler, O. (2003), Gestaltung von kooperativen Logistiknetzwerken: Bewertung unter ökonomischen und ökologischen Aspekten, Wiesbaden

Rümenapp, T. (2002), Strategische Konfigurationen von Logistikunternehmen: Ansätze zur konsistenten Ausrichtung in den Dimensionen Strategie, Struktur und Umwelt, Wiesbaden

Sachverständigenrat (2000), Jahresgutachten 2000/01 des Sachverständigenrates zur Begutachtung der gesamtwirtschaftlichen Entwicklung, Wiesbaden

Sax, E. (1918), Die Verkehrsmittel in Volks- und Staatswirtschaft, Bd. 1: Allgemeine Verkehrslehre, 2. Auflage, Berlin

SBA (Statistisches Bundesamt) (Hrsg. ) (2007a), Statistisches Jahrbuch 2007 für die Bundesrepublik Deutschland, Wiesbaden 
SBA (Statistisches Bundesamt) (Hrsg.) (2007b), Verkehr im Überblick, Jahr 2006, Fachserie 8, Reihe 1.2

Schechler, J. (2002), Sozialkapital und Netzwerkökonomik, Frankfurt a. M., Berlin, Bern

Scherer, F. M., Ross, D. (1990), Industrial Market Structure and Economic Performance, 3. Auflage, Boston

Scherrer, W. (1996), Lange Wellen, neue Technologien und Beschäftigung, in: Wirtschaftpolitische Blätter, 43 Jg., Heft 2, S. 132-141

Schmidt, F. (1998), Institutionelle Markteintrittsschranken, potentielle Konkurrenz und Unternehmensverhalten: ein Beitrag zur Endogenisierung der Marktstruktur, Berlin

Schmidt, I. (1999), Wettbewerbspolitik und Kartellrecht: eine Einführung, 6. Auflage, Stuttgart

Schmidt, I., Fritz, A. (1996), Pro und Contra Konzentrationsprivileg: die unterschiedlichen Wirkungen von Kartellen und Fusionen auf Wettbewerb und Effizienz, in: Kruse, J. (Hrsg.), Aktuelle Probleme der Wettbewerbs- und Wirtschaftspolitik, Baden-Baden, S. 119-134

Schmidt, I., Rittaler, J. (1987), Marktphasen und Wettbewerb, in: Wirtschaftswissenschaftliches Studium (WiSt), Jg. 16, Heft 12, S. 597-602

Schmidt, I., Röhrich, M. (1992), Zielkonflikte zwischen dem Erhalt kompetitiver Marktstrukturen und der Realisierung von Effizienzsteigerungen durch externes Unternehmenswachstum?, in: Wirtschaftswissenschaftliches Studium (WiSt), Jg. 21, Heft 4, S. 179-184

Schmidtchen, D. (1978), Wettbewerbspolitik als Aufgabe, Baden-Baden

Schmitt, A. (2003), E-Commerce heute: Scharlatanerie oder Quantensprung? Aktuelle Trends in der Logistik unter dem Einfluss von E-Commerce, in: Weber, J., Deepen, J. (Hrsg.), Erfolg durch Logistik - Erkenntnisse aktueller Forschung, Bern, S. 167-196

Schneider, C., Siebel, L. (2002), Marktveränderung - Wohin fährt der KEP-Zug?, in: Logistik Heute, Jg. 24, Heft 7-8, S. 60-61 
Schneider, V., Kenis, P. (1996), Verteilte Kontrolle: Institutionelle Steuerung in modernen Gesellschaften, in: Kenis, P., Schneider, V. (Hrsg.), Organisation und Netzwerk: Institutionelle Steuerung in Wirtschaft und Politik, Frankfurt/M., S. 943

Schüller, A. (1986), Die institutionellen Voraussetzungen einer marktwirtschaftlichen Ordnung, in: Vaubel, R., Barbier, H. (Hrsg.), Handbuch Marktwirtschaft, Pfullingen, S. 34-44

Schulze, P. (2003), Beschreibende Statistik, 5. Auflage, München

Schumann, J., Meyer, U., Ströbele, W. (1999), Grundzüge der mikroökonomischen Theorie, 7. Auflage, Berlin

Schumpeter, J. A. (1975), Kapitalismus, Sozialismus und Demokratie, 2. Auflage von 1950, München, 7. Kapitel: Der Prozess der schöpferischen Zerstörung, S. 134142, abgedruckt in: Herdzina, K. (Hrsg.), Wettbewerbstheorie, Köln, S. 118-123

Segerer, M., Benz, M. (2002), Logistikmarketing - Was der Markt wirklich will, in: Logistik Heute, Jg. 24, Heft 7-8, S. 24-25

Seidenfus, H. (1959), Verkehrsmärkte: Marktform, Marktbeziehung, Marktverhalten, Tübingen

Seidenfus, H. (1973), Systemtheoretische Grundlagen der Verkehrspolitik, in Seidenfus, H. (Hrsg.), Systemorientierte Verkehrspolitik, Göttingen, S. 7-32

Senger-Weiss, P., Mazur, V., Werle, O. (1999), EDI in der Transportlogistik ...die Erfolgsstory „WeissNet“, in: Faller, P. (Hrsg.), Transportwirtschaft im Umbruch: Strukturwandel, Anpassungserfordernisse, Gestaltungsaufgaben, Wien, S. 369380

Shapiro, C., Varian, H. (1999), Information Rules: A Strategic Guide to the Network Economy, Boston

Sibbel, R., Hartmann, F. (2005), Target Costing für Dienstleistungen (I), in: Das Wirtschaftsstudium, Jg. 34, Heft 1, S. 78-82

Siebert, H. (2000), The New Economy - What is really new?, Kiel Working Paper No. 1000 , Kiel

Simon, H. (1991), Organizations and Markets, in: Journal of Economic Perspectives, Jg. 5 (2), S. 25-44 
Slotta, G. (2001), Vom Speditionsunternehmen zum E-Logistiker, in: Baumgarten, H. (Hrsg.), Logistik im E-Zeitalter: Die Welt der globalen Logistiknetzwerke, Frankfurt a. M., S. 228-235

Smith, A. (1852), An Inquiry into the Nature and Causes of the Wealth of Nations, complete in one volume, London (T. Nelson and Sons, Paternoster Row)

Söllner, F. (2001), Die Geschichte des ökonomischen Denkens, 2. Auflage, Berlin

Sohmen, E. (1971), Wettbewerbskonzeptionen und Wettbewerbspolitik, in: Bickel, W. (Hrsg.), Verstehen und Gestalten der Wirtschaft, Tübingen, S. 99 ff.

Soltwedel, R., Busch, A., Groß, A., Laaser, C.-F. (1987), Zur staatlichen Marktregulierung in der Bundesrepublik, Kiel

Sosnick, S. (1958), A Critique of Concepts of Workable Competition, in: The Quarterly Journal of Economics, Bd. 72, S. 380-423

Sraffa, P. (1926), The Laws of Returns under Competitive Conditions, in: Economic Journal, Jg. 36, S. 535-550

Stabenau, H. (1994), Verkehrsbetriebslehre: betriebswirtschaftliche Grundlagen für eine langfristig orientierte Unternehmenspolitik in strukturell sich ändernden Verkehrsmärkten, 3. Auflage, Düsseldorf

Stabenau, H. (1999), Wohin entwickelt sich die Transportwirtschaft?, in: Faller, P. (Hrsg.), Transportwirtschaft im Umbruch: Strukturwandel, Anpassungserfordernisse, Gestaltungsaufgaben, Wien, S. 91-94

Stabenau, H. (2000), Entwicklung und Stand der Logistik, in: Klaus, P., Krieger, W. (Hrsg.), Gabler Lexikon Logistik, 2. Auflage, Wiesbaden, S. 127-132

Stabenau, H. (2003), Netzwerkmanagement logistischer Dienstleister, in: Merkel, H., Bjelicic, B. (Hrsg.), Logistik und Verkehrswirtschaft im Wandel: Unternehmensübergreifende Versorgungsnetzwerke verändern die Wirtschaft, München, S. 387-397

Stahl, D. (1994), Die Bedeutung des Informationsmanagements in strategischen Unternehmensnetzwerken der Speditions- und Transportbranche, in: Ewers, H.-J. (Hrsg.), Die Bedeutung von Informations- und Kommunikationstechnologien für den Verkehr, Göttingen, S. 131-189 
Stahl, D. (1995), Internationale Speditionsnetzwerke: eine theoretische und empirische Analyse im Lichte der Transaktionskostentheorie, Göttingen

Starbatty, J. (1986), Klassischer Liberalismus, in: Vaubel, R., Barbier, H. (Hrsg.), Handbuch Marktwirtschaft, Pfullingen, S. 82-89

Stein, A. (2000), Kontraktlogistik, in: Klaus, P., Krieger, W. (Hrsg.), Gabler Lexikon Logistik, 2. Auflage, Wiesbaden, S. 243-247

Stigler, G. (1957), Perfect Competition, Historically Contemplated, in: Journal of Political Economy, Jg. 65, S. 1-17

Stölzle, W. (2002), Logistikforschung - Entwicklungszüge und Integrationsperspektiven, in: Stölzle, W., Gareis, K. (Hrsg.), Integrative Management- und Logistikkonzepte, Wiesbaden, S. $511-527$

Straube, F. (2001), E-Business braucht E-Logistics, in: Baumgarten, H. (Hrsg.), Logistik im E-Zeitalter: Die Welt der globalen Logistiknetzwerke, Frankfurt a. M., S. 177-196

Straube, F., Butz, C. (2005), E-Logistik in Netzwerken, in: Das Wirtschaftsstudium, Jg. 34, Heft 5, S. 670-675

Streißler, E. (1982), Theorie der Wirtschaftsstruktur (Was ist Gegenstand der Strukturberichterstattung?), in: Gahlen, B. (Hrsg.), Strukturberichterstattung der Wirtschaftsforschungsinstitute: Analyse und Diskussion, Tübingen, S. 1-27

Strohm, A. (1988), Ökonomische Theorie der Unternehmensentstehung, Freiburg

Suntum, U. van (1993), Verkehrspolitik in der Marktwirtschaft, in: Aus Politik und Zeitgeschichte: Beilage zur Wochenzeitung Das Parlament, S. 3-13

Tapscott, D. (1996), Die digitale Revolution: Verheißungen einer vernetzten Welt die Folgen für Wirtschaft, Management und Gesellschaft, Wiesbaden

Teleroute (2008), Site: Was ist eine Frachtenbörse, Internetauftritt der Firma Teleroute Deutschland GmbH, URL http://www.teleroute.de/Deutschland/Deutsch/Home/ Produkte+Services/Was+ist+eine+Frachtenb\%c3\%b6rse/page.aspx/1923, Zugriff am 3.2.2008

TimoCom (2008a), Site: Die Frachtenbörse, Internetauftritt der Firma TimoCom Softund Hardware GmbH, URL http://www.timocom.de/sec/900100/index.cfm/ DYN/umenuaction,503101318510004/, Zugriff am 3.2.2008 
TimoCom (2008b), Site: Die Risikominderung, Internetauftritt der Firma TimoCom Soft- und Hardware GmbH, URL http://www.timocom.de/sec/900100/index.cfm/ DYN/umenuaction,503141300340100/, Zugriff am 3.2.2008

Tolksdorf, M. (1994), Dynamischer Wettbewerb: Einführung in die Grundlagen der deutschen und internationalen Wettbewerbspolitik, Wiesbaden

Tripp, C. (2003), Mittelstandskooperationen auf dem Prüfstand - Chancen und Risiken mittelständischer System-Stückgutkooperationen in Deutschland, eine Untersuchung der Fraunhofer ATL (Nürnberg) im Auftrag der Bayerischen Hypo- und Vereinsbank AG (München), aktualisierte Fassung, Nürnberg

Tripp, C. (2004), Mittelstand und Kontraktlogistik - Chancen und Risiken mittelständischer Logistikdienstleister in der Kontraktlogistik, eine Untersuchung der Fraunhofer ATL (Nürnberg) im Auftrag der Bayerischen Hypo- und Vereinsbank AG (München), Nürnberg

Frhr. v. Tucher, F., Wiezorek, H. (2000), Efficient Consumer Response (ECR), in: Klaus, P., Krieger, W. (Hrsg.), Gabler Lexikon Logistik, 2. Auflage, Wiesbaden, S. 104-109

Umbhauer, G. (1998), Introduction, in: The Economics of Networks, Interaction and Behaviours, Berlin, S. 1-13

Vogel, J. (1979), Implikationen des wirtschaftlichen Strukturwandels für die zukünftigen Aufgaben der Spedition, in: Seidenfus, H. (Hrsg.), Wirtschaftlicher Strukturwandel und Verkehr, Göttingen, S. 279-336

Voigt, F. (1973), Verkehr, Bd. 1, Die Theorie der Verkehrswirtschaft, Berlin

Vorgrimler, D. (2003), Wettbewerb auf stagnierenden Märkten, Wiesbaden

Voß, S., Domschke, W. (1999), Informationslogistik als integraler Bestandteil des Informationsmanagements in der Verkehrswirtschaft, in: Faller, P. (Hrsg.), Transportwirtschaft im Umbruch: Strukturwandel, Anpassungserfordernisse, Gestaltungsaufgaben, Wien, S. 329-340

Wacker-Theodorakopoulos C. (1988), Regulierung des Verkehrssektors, in: Krakowski, M. (Hrsg.), Regulierung in der Bundesrepublik Deutschland: Die Ausnahmebereiche des Gesetzes gegen Wettbewerbsbeschränkungen, Hamburg, S. 287346 
Wagner, K.-L. (2001), Flexible Unternehmensstrukturen: schnelle und effiziente Chancen-Realisierung mit FRAKT-n, München

Weber, J. (1999), Ursprünge, praktische Entwicklung und theoretische Einordnung der Logistik, in: Weber, J., Baumgarten, H. (Hrsg.), Handbuch Logistik: Management von Material- und Warenflussprozessen, Stuttgart, S. 3-14

Weber, J., Engelbrecht, C., Schmitt, A., Wallenburg, C. (2001), Auswirkungen des mobilen Internets auf die Logistik, in: Nicolai, A., Petersmann, T. (Hrsg.), Strategien im M-Commerce. Grundlagen, Management, Geschäftsmodelle, Stuttgart, S. $45-70$

Weber, J., Kummer, S. (1998), Logistikmanagement, 2. Auflage, Stuttgart

Weber, J., Schmitt, A., Engelbrecht, C., Knobloch, U., Wallenburg, C. (2002), ECommerce in der Logistik: Quantensprung oder business as usual?, Bern

Weber, J., Stölzle, W., Wallenburg, C., Hofmann, E. (2007), Kapitel 1.1: Einführung in das Management der Kontraktlogistik, in: Stölzle, W., Weber, J., Hofmann, E., Wallenburg, C. (Hrsg.), Handbuch Kontraktlogistik - Management komplexer Logistikdienstleistungen, Weinheim, S. 35-54

Weber, S.-M. (1999), Netzwerkartige Wertschöpfungssysteme: Informations- und Kommunikationssysteme im Beziehungsgeflecht Hersteller-Handel-Serviceanbieter, Wiesbaden

Wein, T. (2004), Deregulierungspolitik in Deutschland - Erfahrungen und Perspektiven, in: Fritsch, M. (Hrsg.), Marktdynamik und Innovation, Berlin, S. 131-148

Wendlandt, V., Böttiger, J.-M. (2007), Kooperationen von Logistikunternehmen Eine hypothesenbasierte Auswertung von Experteninterviews, Arbeitspapiere des Instituts für Genossenschaftswesen der Westfälischen Wilhelms-Universität Münster, Nr. 68, Münster

Willeke, R. (1995), 40 Jahre Verkehrswissenschaft und Verkehrspolitik, in: Zeitschrift für Verkehrswissenschaft, Jg. 66, Heft 3, S. 167-186

Williamson, O. E. (1975), Markets and Hierarchies: Analysis and Antitrust Implications, New York

Williamson, O. E. (1988), The Logic of Economic Organization, in: Journal of Law, Economics and Organization, Jg. 4 (1), S. 65-93 
Williamson, O. E. (1990), Die ökonomischen Institutionen des Kapitalismus. Unternehmen, Märkte, Kooperationen, Tübingen

Williamson, O. E. (1991), Vergleichende ökonomische Organisationstheorie: Die Analyse diskreter Strukturalternativen, in: Ordelheide, D., Rudolph, B., Büsselmann, E. (Hrsg.), Betriebswirtschaftslehre und ökonomische Theorie, Stuttgart, S. $13-49$

Wirtz, B. (2001), Electronic Business, 2. Auflage, Wiesbaden

Wirtz, B., Kleineicken, A. (2000), Geschäftsmodelltypologien im Internet, in: Wirtschaftswissenschaftliches Studium (WiSt), Jg. 29, Heft 11, S. 628-635

Woll, A. (2005), Marktbeherrschung im Zeitalter der Globalisierung, in: Das Wirtschaftsstudium, Jg. 34, Heft 10, S. 1274-1279

Young, A. (1928), Increasing Returns and Economic Progress, in: Economic Journal, Jg. 38, S. $527-540$

Zänker, K. (1997), Spedition, in: Bloech, J., Ihde, G. (Hrsg.), Vahlens großes Logistiklexikon, München, S. 970-971

Zentes, J., Janz, M. (2002), Kapitel D 3.5: Horizontale Kooperationen in der Distributionslogistik, in: Arnold, D., Isermann, H., Kuhn, A., Tempelmeier, H. (Hrsg.), Handbuch Logistik, Berlin, S. D3-31 - D3-34

Zentes, J., Morschett, D. (2003), Die Servicebausteine in der Logistik, in: Merkel, H., Bjelicic, B. (Hrsg.), Logistik und Verkehrswirtschaft im Wandel: Unternehmensübergreifende Versorgungsnetzwerke verändern die Wirtschaft, München, S.419436

Zerdick, A., Picot, A., Schrape, K., Atropé, A. Goldhammer, K., Lange, U., Vierkant, E., López-Escobar, E., Silverstone, R. (1999), Die Internet-Ökonomie: Strategien für die digitale Wirtschaft, Berlin

Zinn, H. (2002), Fourth Party Logistics - Mehr als nur ein Modebegriff?, in: Logistik Heute, Jg. 24, Heft 9, S. 36

Zöllner, W. A. (1990), Strategische Absatzmarktplanung: Kunden- und Wettbewerbsanalyse für Logistikunternehmen, Berlin 
Zohlnhöfer, W. (1976), Wettbewerbspolitik in der Demokratie, in: Gutzler, H., Herion, W., Kaiser, J. (Hrsg.), Wettbewerb im Wandel - Eberhard Günther zum 65. Geburtstag, Baden-Baden, S. 27-45 
Carsten Wander - 978-3-631-75390-3

Downloaded from PubFactory at 01/11/2019 05:34:40AM

via free access 


\section{HOHENHEIMER VOLKSWIRTSCHAFTLICHE SCHRIFTEN}

Band 1 Walter Deffaa: Anonymisierte Befragungen mit zufallsverschlüsselten Antworten. Die Randomized-Response-Technik (RRT). Methodische Grundlagen, Modelle und Anwendungen. 1982.

Band 2 Thomas Michael Baum: Staatsverschuldung und Stabilisierungspolitik in der Demokratie. Zur neoinstitutionalistischen Kritik der keynesianischen Fiskalpolitik. 1982.

Band 3 Klaus Schröter: Die wettbewerbspolitische Behandlung der leitungsgebundenen Energiewirtschaft. Dargestellt am Beispiel der Fernwärmewirtschaft der Bundesrepublik Deutschland. 1986.

Band 4 Hugo Mann: Theorie und Politik der Steuerreform in der Demokratie. 1987.

Band 5 Max Christoph Wewel: Intervallarithmetische Dependenzanalyse in der Ökonometrie. Ein konjekturaler Ansatz. 1987.

Band 6 Heinrich Pascher: Die U.S.-amerikanische Deregulation Policy im Luftverkehrs- und Bankenbereich. 1987.

Band 7 Harald Lob: Die Entwicklung der französischen Wettbewerbspolitik bis zur Verordnung $\mathrm{Nr} .86-1243$ vom 01. Dezember 1986. Eine exemplarische Untersuchung der Erfassung der Behinderungsstrategie auf der Grundlage des Konzepts eines wirksamen Wettbewerbs. 1988.

Band 8 Ulrich Kirschner: Die Erfassung der Nachfragemacht von Handelsunternehmen. Eine Analyse der ökonomischen Beurteilungskriterien und der wettbewerbsrechtlichen Instrumente im Bereich der Verhaltenskontrolle.1988.

Band 9 Friedhelm Herb: Marktwirtschaftliche Innovationspolitik. 1988.

Band 10 Claus Schnabel: Zur ökonomischen Analyse der Gewerkschaften in der Bundesrepublik Deutschland. Theoretische und empirische Untersuchungen von Mitgliederentwicklung, Verhalten und Einfluß auf wirtschaftliche Größen. 1989.

Band 11 Jan B. Rittaler: Industrial Concentration and the Chicago School of Antitrust Analysis. A Critical Evaluation on the Basis of Effective Competition. 1989.

Band 12 Thomas Märtz: Interessengruppen und Gruppeninteressen in der Demokratie. Zur Theorie des Rent-Seeking. 1990.

Band 13 Andreas Maurer: Statistische Verfahren zur Ermittlung von oligopolistischen Strukturen. 1990.

Band 14 Peter Mendler: Zur ökonomischen und politisch-institutionellen Analyse öffentlicher Kredithilfen. 1992.

Band 15 Heinrich J. Engelke: Die Interpretation der Rundfunkfreiheit des Grundgesetzes: Eine Analyse aus ökonomischer Sicht. 1992.

Band 16 Thomas Fischer: Staat, Recht und Verfassung im Denken von Walter Eucken. Zu den staats- und rechtstheoretischen Grundlagen einer wirtschaftsordnungspolitischen Konzeption. 1993.

Band 17 Stefan Elßer: Innovationswettbewerb. Determinanten und Unternehmensverhalten. 1993.

Band 18 Reinhard Scharff: Regionalpolitik und regionale Entwicklungspotentiale. Eine kritische Analyse. 1993.

Band 19 Karin Beckmann: Probleme der Regionalpolitik im Zuge der Vollendung des Europäischen Binnenmarktes. Eine ökonomische Analyse. 1995. 
Band 20 Bernd Nolte: Engpaßfaktoren der Innovation und Innovationsinfrastruktur. Eine theoretische und empirische Analyse für ländliche Wirtschaftsräume in Baden-Württemberg. 1996.

Band 21 Klaus-Rainer Brintzinger: Die Nationalökonomie an den Universitäten Freiburg, Heidelberg und Tübingen 1918 - 1945. Eine institutionenhistorische, vergleichende Studie der wirtschaftswissenschaftlichen Fakultäten und Abteilungen südwestdeutscher Universitäten. 1996.

Band 22 Steffen Binder: Die Idee der Konsumentensouveränität in der Wettbewerbstheorie. Teleokratische vs. nomokratische Auffassung. 1996.

Band 23 Alexander Burger: Deregulierungspotentiale in der Gesetzlichen Rentenversicherung. Reformnotwendigkeiten versus Reformmöglichkeiten. 1996.

Band 24 Burkhard Scherer: Regionale Entwicklungspolitik. Konzeption einer dezentralisierten und integrierten Regionalpolitik. 1997.

Band 25 Frauke Wolf: Lorenzkurvendisparität. Neuere Entwicklungen, Erweiterungen und Anwendungen. 1997.

Band 26 Hans Pitlik: Politische Ökonomie des Föderalismus. Föderative Kompetenzverteilung im Lichte der konstitutionellen Ökonomik. 1997.

Band 27 Stephan Seiter: Der Beitrag Nicholas Kaldors zur Neuen Wachstumstheorie. Eine vergleichende Studie vor dem Hintergrund der Debatte über den Verdoorn-Zusammenhang. 1997.

Band 28 André Schmidt: Ordnungspolitische Perspektiven der europäischen Integration im Spannungsfeld von Wettbewerbs- und Industriepolitik. 1998.

Band 29 Bernd Blessin: Innovations- und Umweltmanagement in kleinen und mittleren Unternehmen. Eine theoretische und empirische Analyse. 1998.

Band 30 Oliver Letzgus: Die Ökonomie internationalen Umweltschutzes. 1999.

Band 31 Claudia Hafner: Systemwettbewerb versus Harmonisierung in Europa. Am Beispiel des Arbeitsmarktes. 1999.

Band 32 Jürgen Kulle: Ökonomie der Musikindustrie. Eine Analyse der körperlichen und unkörperlichen Musikverwertung mit Hilfe von Tonträgern und Netzen. 1998.

Band 33 Michael Ganske: Intertemporale Aspekte von Staatsverschuldung und Außenhandel. 1999.

Band 34 Margit Ströbele: Die Deregulierungswirkungen der europäischen Integration. Das Beispiel der Sondermärkte. 1999.

Band 35 Marion Benesch: Devisenmarktinterventionen in Theorie und Praxis. Eine umfassende Analyse ihrer Zielsetzungen, Wirkungsweisen und wirtschaftspolitischen Bedeutung. 1999.

Band 36 Torsten Gruber: Unterschiedliche geldpolitische Transmissionsmechanismen und Stabilitätskulturen als mögliche Ursachen geldpolitischer Spannungen in der Europäischen Währungsunion. 2000.

Band 37 Bertram Melzig-Thiel: Arbeit in der Informationsgesellschaft. Chancen und Risiken neuer Informations- und Kommunikationstechnologien für die Beschäftigung. 2000.

Band 38 Annette Fritz: Die Entsorgungswirtschaft im Spannungsfeld zwischen Abfallpolitik und Kartellrecht. Eine industrieökonomische Branchenstudie. 2001.

Band 39 Harald Strotmann: Arbeitsplatzdynamik in der baden-württembergischen Industrie. Eine Analyse mit amtlichen Betriebspaneldaten. 2002. 
Band 40 Dietrich Benner: Qualitätsungewißheit bei Gütern mit Vertrauenseigenschaften. Entwicklung und Anwendung eines entscheidungstheoretisch fundierten Analyserahmens. 2002.

Band 41 Jürgen M. Schechler: Sozialkapital und Netzwerkökonomik. 2002.

Band 42 Kay-Uwe May: Haushaltskonsolidierung durch Ausgabekürzungen. Restriktionen und Strategien. 2002.

Band 43 Peter Kühnl: Der Wechselkurs als Zwischenziel der Geldpolitik im Aufholprozess. Die monetärkeynesianische Entwicklungsstrategie der Berliner Schule vor dem Hintergrund der makroökonomischen Entwicklung ausgewählter Länder Mittel- und Osteuropas. 2003.

Band 44 Steffen Wirth: Nichtparametrische Analyse von Bildungsertragsraten. Neuere Entwicklungen und Anwendungen. 2003.

Band 45 Bernhard Holwegler: Innovation, Diffusion und Beschäftigung. Die ökonomische Theorie der Technologiediffusion und ihr Beitrag zur Erklärung technologischer Arbeitslosigkeit. 2003.

Band 46 Guntram R. M. Hepperle: Zukunftsorientierte Industriepolitik. Möglichkeiten und Grenzen. 2004.

Band 47 Udo Vullhorst: Stabilisierungspolitik bei supranationaler Geldpolitik und nationaler Fiskalpolitik. Eine spieltheoretische Betrachung. 2004.

Band 48 Matthias Rösch: Die Bedeutung von Investivlöhnen und Gewinnbeteiligungen für Einkommensverteilung und Beschäftigung. 2004.

Band 49 Michael Bubik: Erfolgskriterien für Unternehmenszusammenschlüsse. Eine theoretische und exemplarische Analyse. 2005.

Band 50 Jörg Weltin: Internationale Unternehmensbesteuerung. Allokation der Besteuerungsrechte unter veränderten Rahmenbedingungen. 2005.

Band 51 Susanne Reichart: Zum Konvergenzprozess der mittel- und osteuropäischen EU-Beitrittsländer. 2005.

Band 52 Daniel Hartmann: Geldpolitik und Beschäftigung. Die geldpolitische Strategie der Federal Reserve: Vorbild oder Auslaufmodell? 2005.

Band 53 Marc Peter Radke: Explaining Financial Crises. A Cyclical Approach. 2005.

Band 54 Katja Hölsch: Umverteilungseffekte in Europa. Eine Analyse für ausgewählte Länder. 2006.

Band 55 Ulrike Lehr: Contingent Valuation Daten und Bayes'sche Verfahren. Ein Vorschlag zur Verbesserung von Umweltbewertung und Nutzentransfer. 2006.

Band 56 Jutta Maute: Hyperinflation, Currency Board, and Bust. The Case of Argentina. 2006.

Band 57 Michael Knittel: Geldpolitik und Stabilität des Bankensystems. Das Liquiditätsproblem aus Sicht der Theoriegeschichte und der gegenwärtigen Finanzmarktentwicklung. 2007.

Band 58 Oliver Frör: Rationality Concepts in Environmental Valuation. 2007.

Band 59 Jochen Gert Arend Wiegmann: Produktivitätsentwicklung in Deutschland. 2008.

Band 60 Nicola Meier: China - The New Developmental State? An Empirical Analysis of the Automotive Industry. 2009.

Band 61 Carsten H. Wander: Logistik und Wettbewerb. Zur Rolle logistischer (Re-)Organisation in einer wettbewerbsbasierten Marktwirtschaft. 2009.

www.peterlang.de 


\section{Nachhaltige Innovation in Produktion und Logistik}

Frankfurt am Main, Berlin, Bern, Bruxelles, New York, Oxford, Wien, 2007. 166 S., zahlr. Abb., Tab. und Graf.

Wertschöpfungsmanagement. Herausgegeben von Hans-Dietrich Haasis. Bd. 1 ISBN 978-3-631-55872-0 • br. $€ 36.90^{*}$

Innovation signalisiert neue Ideen und deren wirtschaftliche Umsetzung.

Nachhaltige Innovation orientiert sich an den Überlegungen zur Realisierung einer Nachhaltigen Entwicklung, insbesondere durch die Berücksichtigung von ökonomischen, ökologischen und sozialen Zielen bei der Entscheidungsfindung in Unternehmen. Nachhaltige Innovation in Produktion und Logistik fokussiert auf die betrieblichen und überbetrieblichen wertschöpfenden Unternehmensbereiche Produktion und Logistik. Hierzu sind in diesem Buch ausgewählte Beispiele zu Prozess- und Managementinnovationen zusammengestellt.

Aus dem Inhalt: Prozess- und Managementinnovationen in Produktion und Logistik - Supply Chain Simulation - Kreislaufwirtschaftslogistik - Intermodale Transportketten - Internationales Kooperationsmanagement · PPS-Systeme für dynamische Produktionsnetzwerke

Frankfurt am Main - Berlin - Bern - Bruxelles - New York - Oxford - Wien

Auslieferung: Verlag Peter Lang AG

Moosstr. 1, CH-2542 Pieterlen

Telefax 0041 (0) $32 / 3761727$

*inklusive der in Deutschland gültigen Mehrwertsteuer

Preisänderungen vorbehalten

Homepage http://www.peterlang.de 